\title{
TOXICOLOGICAL PROFILE FOR PYRETHRINS AND PYRETHROIDS
}

\author{
U.S. DEPARTMENT OF HEALTH AND HUMAN SERVICES \\ Public Health Service \\ Agency for Toxic Substances and Disease Registry
}

September 2003 


\section{DISCLAIMER}

The use of company or product name(s) is for identification only and does not imply endorsement by the Agency for Toxic Substances and Disease Registry. 


\section{UPDATE STATEMENT}

A Toxicological Profile for pyrethrins and pyrethroids, Draft for Public Comment was released in September, 2001. This edition supersedes any previously released draft or final profile.

Toxicological profiles are revised and republished as necessary, but no less than once every three years. For information regarding the update status of previously released profiles, contact ATSDR at:

Agency for Toxic Substances and Disease Registry Division of Toxicology/Toxicology Information Branch 1600 Clifton Road NE, Mailstop E-29

Atlanta, Georgia 30333 



\section{FOREWORD}

This toxicological profile is prepared in accordance with guidelines* developed by the Agency for Toxic Substances and Disease Registry (ATSDR) and the Environmental Protection Agency (EPA). The original guidelines were published in the Federal Register on April 17, 1987. Each profile will be revised and republished as necessary.

The ATSDR toxicological profile succinctly characterizes the toxicologic and adverse health effects information for the hazardous substance described therein. Each peer-reviewed profile identifies and reviews the key literature that describes a hazardous substance's toxicologic properties. Other pertinent literature is also presented, but is described in less detail than the key studies. The profile is not intended to be an exhaustive document; however, more comprehensive sources of specialty information are referenced.

The focus of the profiles is on health and toxicologic information; therefore, each toxicological profile begins with a public health statement that describes, in nontechnical language, a substance's relevant toxicological properties. Following the public health statement is information concerning levels of significant human exposure and, where known, significant health effects. The adequacy of information to determine a substance's health effects is described in a health effects summary. Data needs that are of significance to protection of public health are identified by ATSDR and EPA.

Each profile includes the following:

(A) The examination, summary, and interpretation of available toxicologic information and epidemiologic evaluations on a hazardous substance to ascertain the levels of significant human exposure for the substance and the associated acute, subacute, and chronic health effects;

(B) A determination of whether adequate information on the health effects of each substance is available or in the process of development to determine levels of exposure that present a significant risk to human health of acute, subacute, and chronic health effects; and

(C) Where appropriate, identification of toxicologic testing needed to identify the types or levels of exposure that may present significant risk of adverse health effects in humans.

The principal audiences for the toxicological profiles are health professionals at the Federal, State, and local levels; interested private sector organizations and groups; and members of the public.

This profile reflects ATSDR's assessment of all relevant toxicologic testing and information that has been peer-reviewed. Staff of the Centers for Disease Control and Prevention and other Federal scientists have also reviewed the profile. In addition, this profile has been peer-reviewed by a nongovernmental panel and was made available for public review. Final responsibility for the contents and views expressed in this toxicological profile resides with ATSDR.

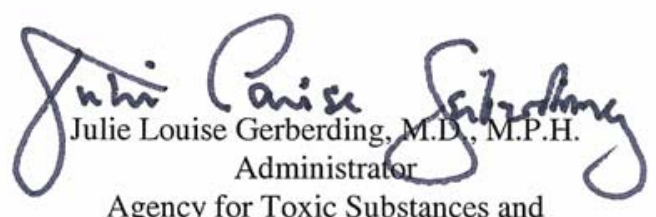

Agency for Toxic Substances and Disease Registry 


\section{*Legislative Background}

The toxicological profiles are developed in response to the Superfund Amendments and Reauthorization Act (SARA) of 1986 (Public Law 99-499) which amended the Comprehensive Environmental Response, Compensation, and Liability Act of 1980 (CERCLA or Superfund). This public law directed ATSDR to prepare toxicological profiles for hazardous substances most commonly found at facilities on the CERCLA National Priorities List and that pose the most significant potential threat to human health, as determined by ATSDR and the EPA. The availability of the revised priority list of 275 hazardous substances was announced in the Federal Register on October 25, 2001 (66 FR 54014). For prior versions of the list of substances, see Federal Register notices dated April 17, 1987 (52 FR 12866); October 20, 1988 (53 FR 41280); October 26, 1989 (54 FR 43619); October 17,1990 (55 FR 42067); October 17, 1991 (56 FR 52166); October 28, 1992 (57 FR 48801); February 28, 1994 (59 FR 9486); April 29, 1996 (61 FR 18744); November 17, 1997 (62 FR 61332); and October 21, 1999 (64 FR 56792). Section 104(i)(3) of CERCLA, as amended, directs the Administrator of ATSDR to prepare a toxicological profile for each substance on the list. 


\section{QUICK REFERENCE FOR HEALTH CARE PROVIDERS}

Toxicological Profiles are a unique compilation of toxicological information on a given hazardous substance. Each profile reflects a comprehensive and extensive evaluation, summary, and interpretation of available toxicologic and epidemiologic information on a substance. Health care providers treating patients potentially exposed to hazardous substances will find the following information helpful for fast answers to often-asked questions.

\section{Primary Chapters/Sections of Interest}

Chapter 1: Public Health Statement: The Public Health Statement can be a useful tool for educating patients about possible exposure to a hazardous substance. It explains a substance's relevant toxicologic properties in a nontechnical, question-and-answer format, and it includes a review of the general health effects observed following exposure.

Chapter 2: Relevance to Public Health: The Relevance to Public Health Section evaluates, interprets, and assesses the significance of toxicity data to human health.

Chapter 3: Health Effects: Specific health effects of a given hazardous compound are reported by type of health effect (death, systemic, immunologic, reproductive), by route of exposure, and by length of exposure (acute, intermediate, and chronic). In addition, both human and animal studies are reported in this section.

NOTE: Not all health effects reported in this section are necessarily observed in the clinical setting. Please refer to the Public Health Statement to identify general health effects observed following exposure.

Pediatrics: Four new sections have been added to each Toxicological Profile to address child health issues:

Section 1.6 How Can (Chemical X) Affect Children?

Section 1.7 How Can Families Reduce the Risk of Exposure to (Chemical X)?

Section 3.7 Children's Susceptibility

Section 6.6 Exposures of Children

Other Sections of Interest:

Section 3.8 Biomarkers of Exposure and Effect

Section 3.11 Methods for Reducing Toxic Effects

\section{ATSDR Information Center}

Phone: 1-888-42-ATSDR or (404) 498-0110 Fax: (404) 498-0093

E-mail: atsdric@cdc.gov Internet: http://www.atsdr.cdc.gov

The following additional material can be ordered through the ATSDR Information Center:

Case Studies in Environmental Medicine: Taking an Exposure History-The importance of taking an exposure history and how to conduct one are described, and an example of a thorough exposure history is provided. Other case studies of interest include Reproductive and Developmental Hazards; Skin Lesions and Environmental Exposures; Cholinesterase-Inhibiting Pesticide Toxicity; and numerous chemical-specific case studies. 
Managing Hazardous Materials Incidents is a three-volume set of recommendations for on-scene (prehospital) and hospital medical management of patients exposed during a hazardous materials incident. Volumes I and II are planning guides to assist first responders and hospital emergency department personnel in planning for incidents that involve hazardous materials. Volume IIIMedical Management Guidelines for Acute Chemical Exposures - is a guide for health care professionals treating patients exposed to hazardous materials.

Fact Sheets (ToxFAQs) provide answers to frequently asked questions about toxic substances.

\section{Other Agencies and Organizations}

The National Center for Environmental Health (NCEH) focuses on preventing or controlling disease, injury, and disability related to the interactions between people and their environment outside the workplace. Contact: NCEH, Mailstop F-29, 4770 Buford Highway, NE, Atlanta, GA 303413724 • Phone: 770-488-7000 • FAX: 770-488-7015.

The National Institute for Occupational Safety and Health (NIOSH) conducts research on occupational diseases and injuries, responds to requests for assistance by investigating problems of health and safety in the workplace, recommends standards to the Occupational Safety and Health Administration (OSHA) and the Mine Safety and Health Administration (MSHA), and trains professionals in occupational safety and health. Contact: NIOSH, 200 Independence Avenue, SW, Washington, DC 20201 • Phone: 800-356-4674 or NIOSH Technical Information Branch, Robert A. Taft Laboratory, Mailstop C-19, 4676 Columbia Parkway, Cincinnati, OH 45226-1998 - Phone: 800-35-NIOSH.

The National Institute of Environmental Health Sciences (NIEHS) is the principal federal agency for biomedical research on the effects of chemical, physical, and biologic environmental agents on human health and well-being. Contact: NIEHS, PO Box 12233, 104 T.W. Alexander Drive, Research Triangle Park, NC 27709 • Phone: 919-541-3212.

\section{Referrals}

The Association of Occupational and Environmental Clinics (AOEC) has developed a network of clinics in the United States to provide expertise in occupational and environmental issues. Contact: AOEC, 1010 Vermont Avenue, NW, \#513, Washington, DC 20005 • Phone: 202-347-4976• FAX: 202-347-4950 • e-mail: AOEC@,AOEC.ORG •Web Page: http://www.aoec.org/.

The American College of Occupational and Environmental Medicine (ACOEM) is an association of physicians and other health care providers specializing in the field of occupational and environmental medicine. Contact: ACOEM, 55 West Seegers Road, Arlington Heights, IL 60005 P Phone: 847-818-1800 • FAX: 847-818-9266. 


\section{CONTRIBUTORS}

\section{CHEMICAL MANAGER(S)/AUTHOR(S):}

G. Daniel Todd, Ph.D.

ATSDR, Division of Toxicology, Atlanta, GA

David Wohlers, Ph.D.

Mario Citra, Ph.D.

Syracuse Research Corporation, North Syracuse, NY

THE PROFILE HAS UNDERGONE THE FOLLOWING ATSDR INTERNAL REVIEWS:

1. Health Effects Review. The Health Effects Review Committee examines the health effects chapter of each profile for consistency and accuracy in interpreting health effects and classifying end points.

2. Minimal Risk Level Review. The Minimal Risk Level Workgroup considers issues relevant to substance-specific minimal risk levels (MRLs), reviews the health effects database of each profile, and makes recommendations for derivation of MRLs.

3. Data Needs Review. The Research Implementation Branch reviews data needs sections to assure consistency across profiles and adherence to instructions in the Guidance. 



\section{PEER REVIEW}

A peer review panel was assembled for pyrethrins and pyrethroids. The panel consisted of the following members:

1. Sam Kacew, Ph.D., Professor of Pharmacology, Department of Cellular \& Molecular Medicine, University of Ottawa, Ottawa, Ontario, Canada;

2. Harihara Mehendale, Ph.D., DABT, Professor and Kitty DeGree Endowed Chair in Toxicology, School of Pharmacy, The University of Louisiana at Monroe, Monroe, Louisiana; and

3. Stephen B. Tucker, M.D., Clinical Professor of Dermatology, The University of Texas-Houston Medical School, The Woodlands, Texas.

These experts collectively have knowledge of pyrethrins and pyrethroids physical and chemical properties, toxicokinetics, key health end points, mechanisms of action, human and animal exposure, and quantification of risk to humans. All reviewers were selected in conformity with the conditions for peer review specified in Section 104(I)(13) of the Comprehensive Environmental Response, Compensation, and Liability Act, as amended.

Scientists from the Agency for Toxic Substances and Disease Registry (ATSDR) have reviewed the peer reviewers' comments and determined which comments will be included in the profile. A listing of the peer reviewers' comments not incorporated in the profile, with a brief explanation of the rationale for their exclusion, exists as part of the administrative record for this compound. A list of databases reviewed and a list of unpublished documents cited are also included in the administrative record.

The citation of the peer review panel should not be understood to imply its approval of the profile's final content. The responsibility for the content of this profile lies with the ATSDR. 



\section{CONTENTS}

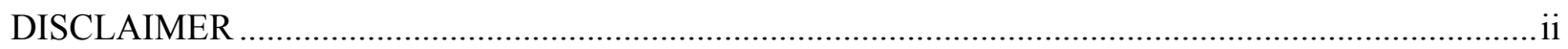

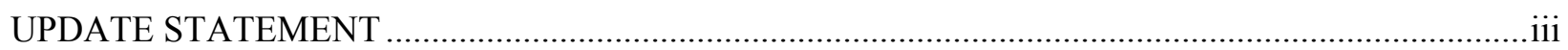

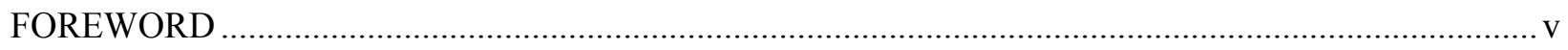

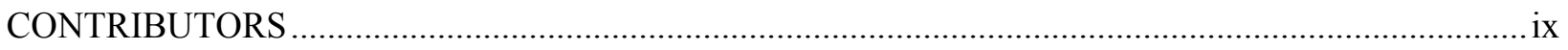

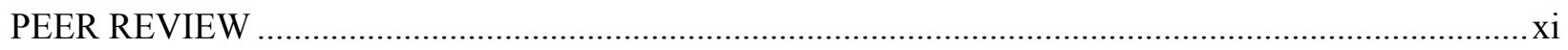

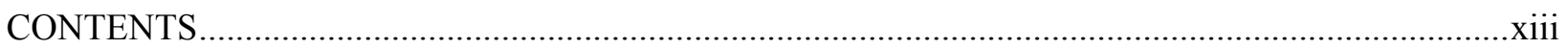

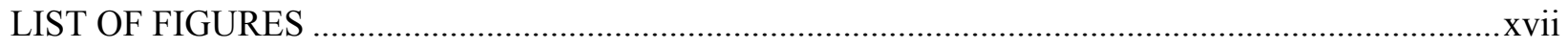

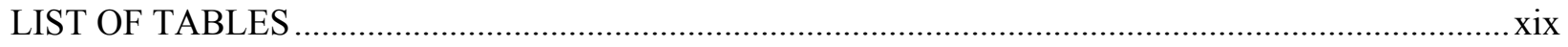

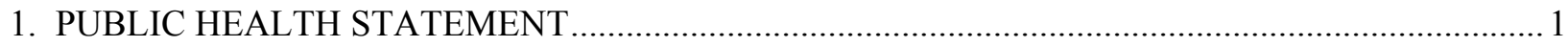

$1.1 \quad$ WHAT ARE PYRETHRINS AND PYRETHROIDS? ..................................................... 1

1.2 WHAT HAPPENS TO PYRETHRINS AND PYRETHROIDS WHEN THEY ENTER

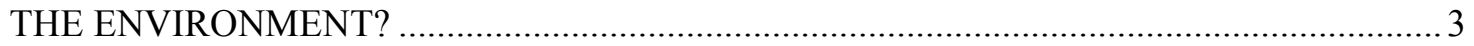

1.3 HOW MIGHT I BE EXPOSED TO PYRETHRINS AND PYRETHROIDS? ........................ 4

1.4 HOW CAN PYRETHRINS AND PYRETHROIDS ENTER AND LEAVE MY BODY? ....... 4

1.5 HOW CAN PYRETHRINS AND PYRETHROIDS AFFECT MY HEALTH?.......................5

1.6 HOW CAN PYRETHRINS AND PYRETHROIDS AFFECT CHILDREN? .......................... 6

1.7 HOW CAN FAMILIES REDUCE THE RISK OF EXPOSURE TO PYRETHRINS

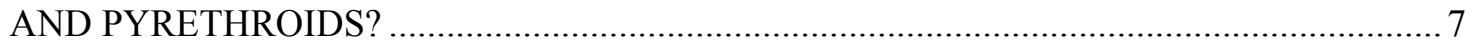

1.8 IS THERE A MEDICAL TEST TO DETERMINE WHETHER I HAVE BEEN EXPOSED

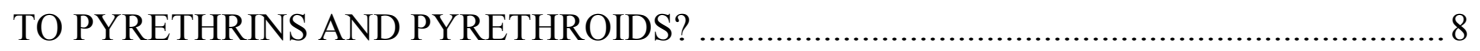

1.9 WHAT RECOMMENDATIONS HAS THE FEDERAL GOVERNMENT MADE TO

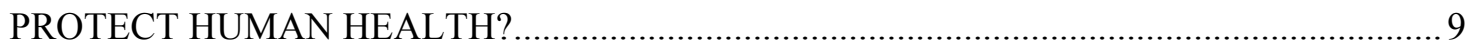

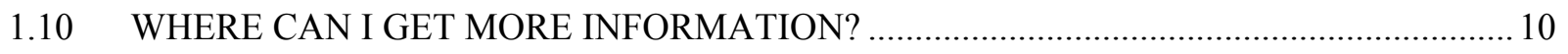

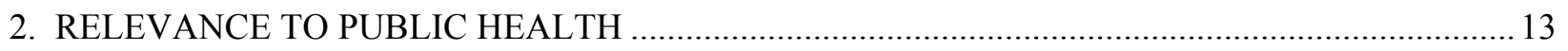

2.1 BACKGROUND AND ENVIRONMENTAL EXPOSURES TO PYRETHRINS AND

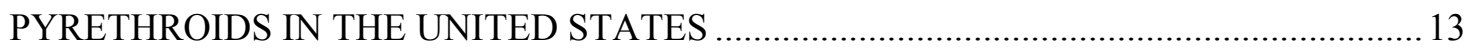

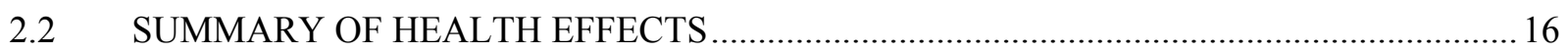

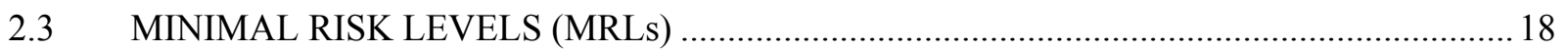

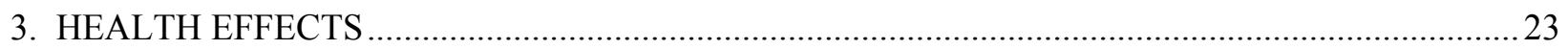

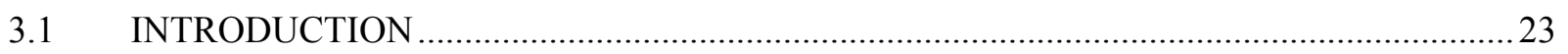

3.2 DISCUSSION OF HEALTH EFFECTS BY ROUTE OF EXPOSURE .............................23

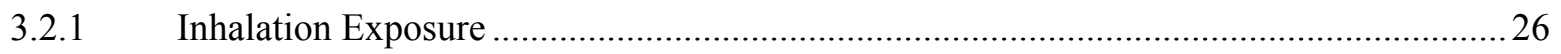

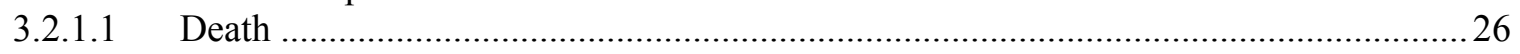

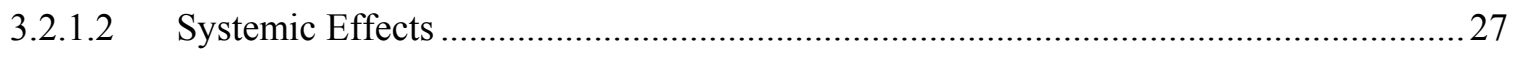

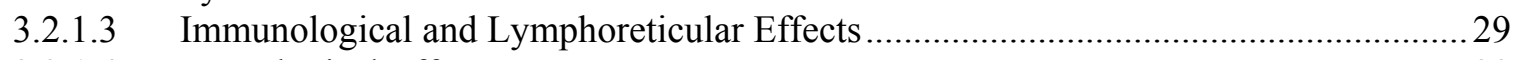

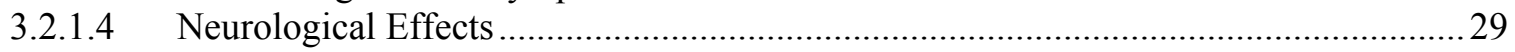

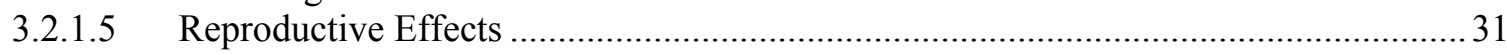


3.2.1.6 Developmental Effects .................................................................................... 31

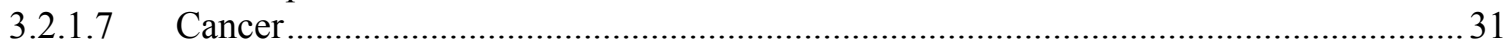

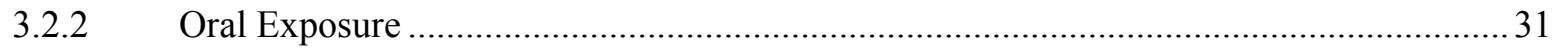

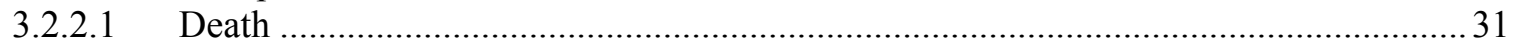

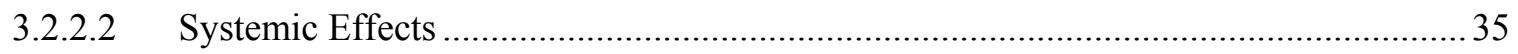

3.2.2.3 Immunological and Lymphoreticular Effects.............................................................5 57

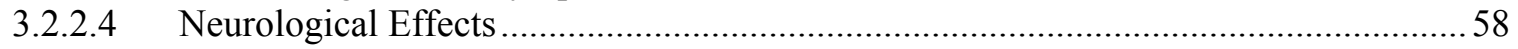

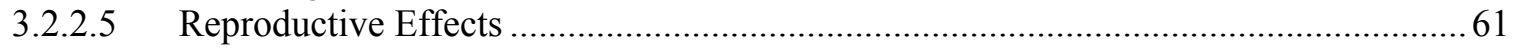

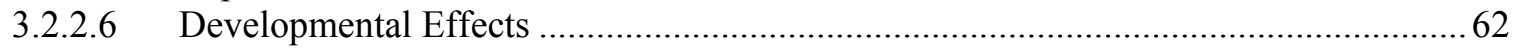

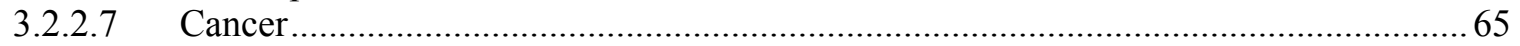

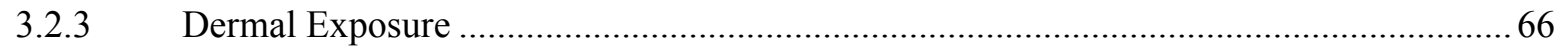

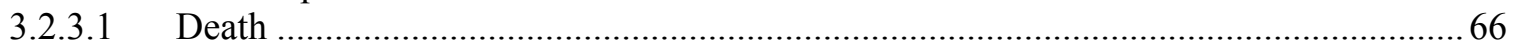

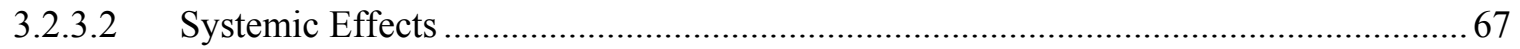

3.2.3.3 Immunological and Lymphoreticular Effects...............................................................6 68

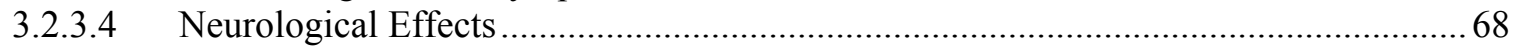

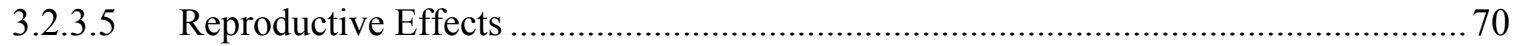

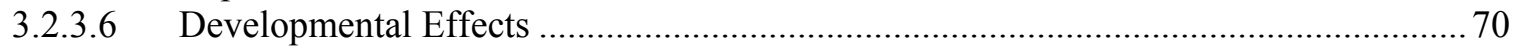

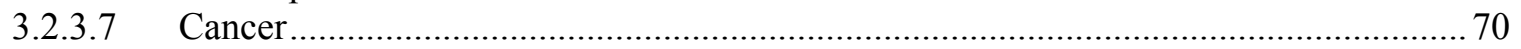

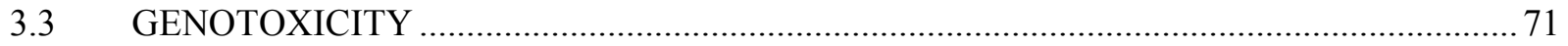

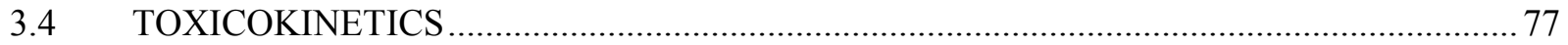

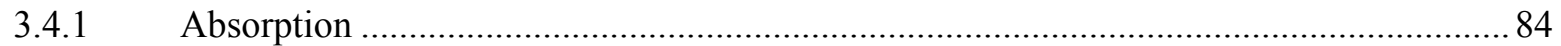

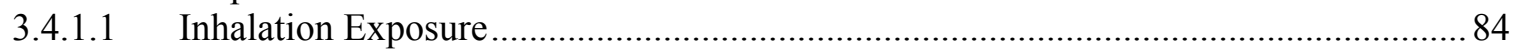

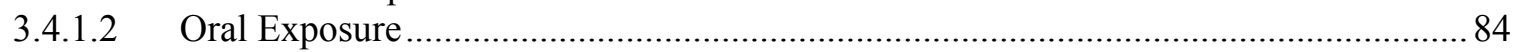

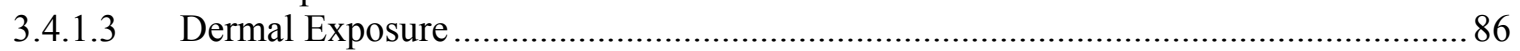

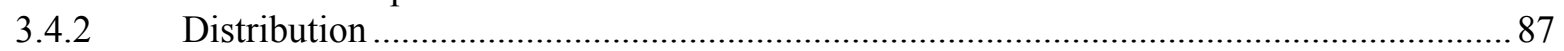

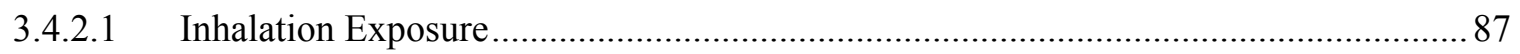

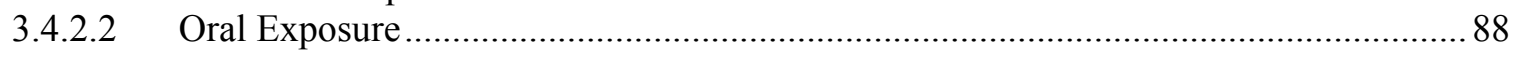

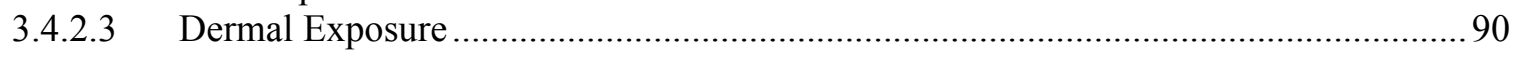

3.4.2.4 Other Routes of Exposure ………………………………………………....... 90

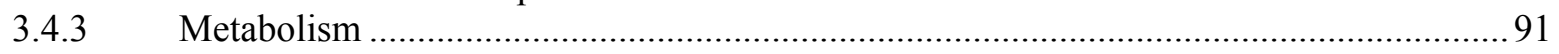

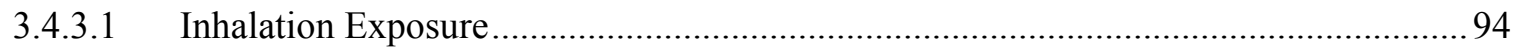

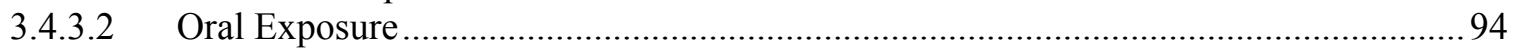

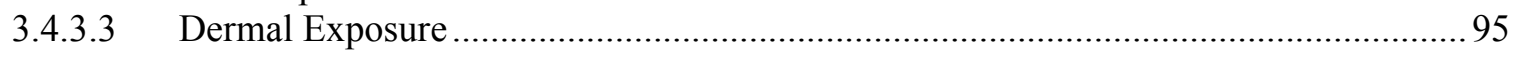

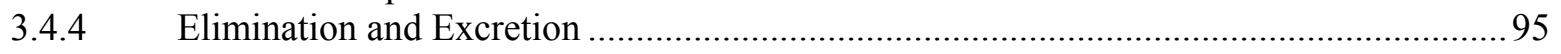

3.4.4.1 Inhalation Exposure ..............................................................................................95

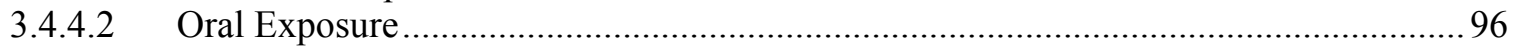

3.4.4.3 Dermal Exposure _...………………………………………………………... 98

3.4.4.4 Other Routes of Exposure ………………………………………………….... 99

3.4.5 Physiologically Based Pharmacokinetic (PBPK)/Pharmacodynamic (PD) Models ......... 99

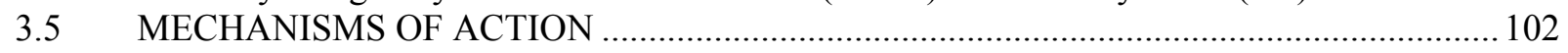

3.5.1 Pharmacokinetic Mechanisms …………………………………………………….... 102

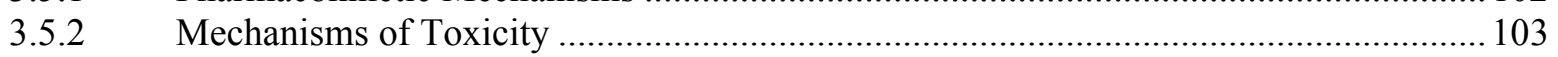

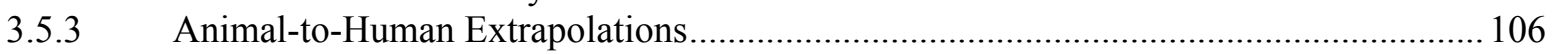

3.6 TOXICITIES MEDIATED THROUGH THE NEUROENDOCRINE AXIS …………...........106

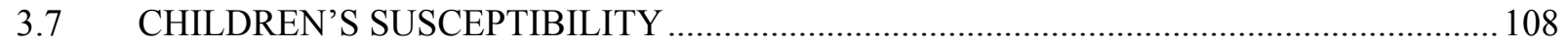

$3.8 \quad$ BIOMARKERS OF EXPOSURE AND EFFECT …………………………………......112

3.8.1 Biomarkers Used to Identify or Quantify Exposure to Pyrethrins and Pyrethroids........113

3.8.2 Biomarkers Used to Characterize Effects Caused by Pyrethrins and Pyrethroids ........... 113

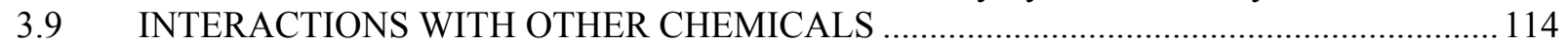

3.10 POPULATIONS THAT ARE UNUSUALLY SUSCEPTIBLE ...........................................115

3.11 METHODS FOR REDUCING TOXIC EFFECTS...........................................................116 


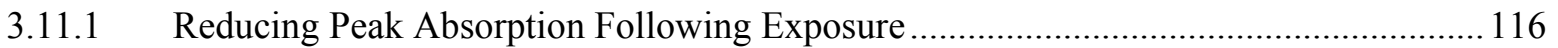

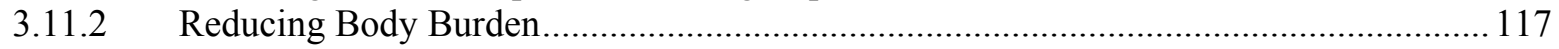

3.11.3 Interfering with the Mechanism of Action for Toxic Effects ..................................... 117

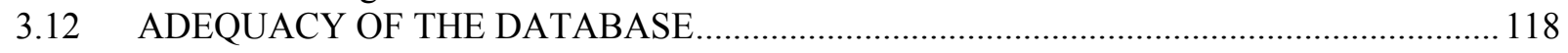

3.12.1 Existing Information on Health Effects of Pyrethrins and Pyrethroids ........................ 118

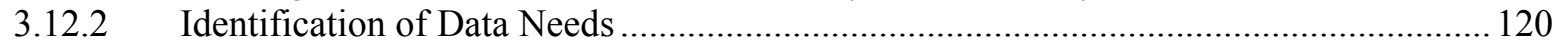

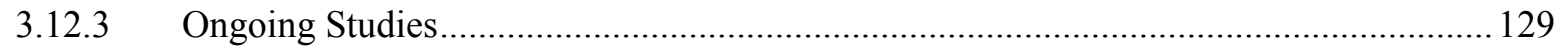

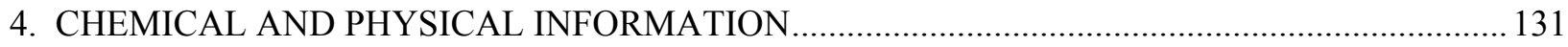

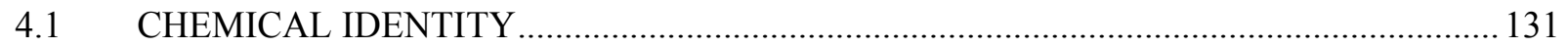

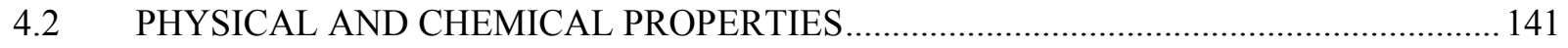

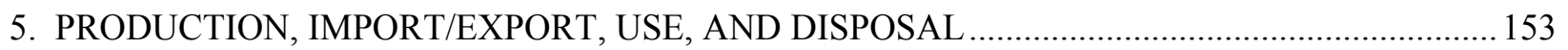

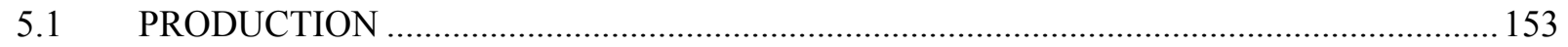

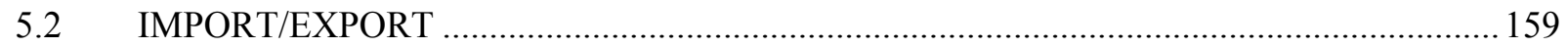

5.3 USE

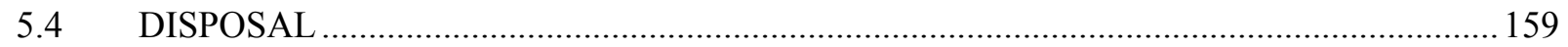

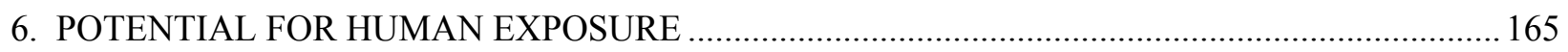

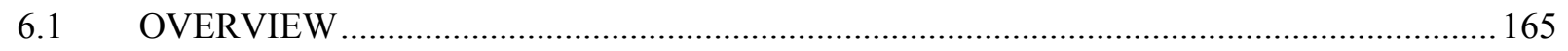

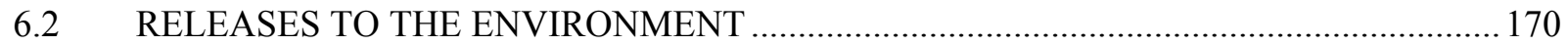

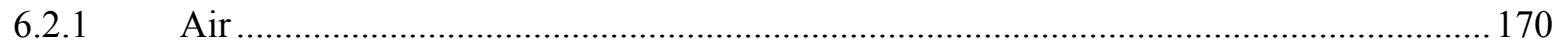

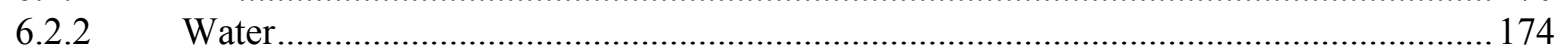

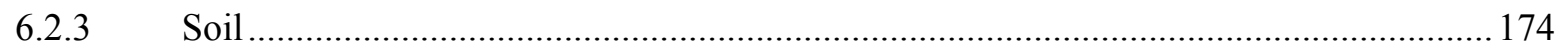

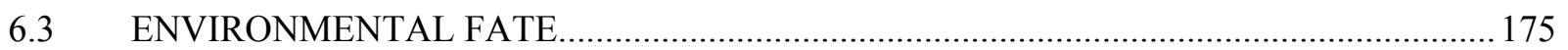

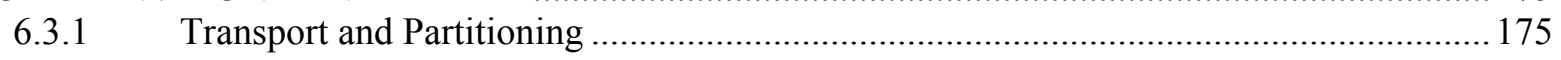

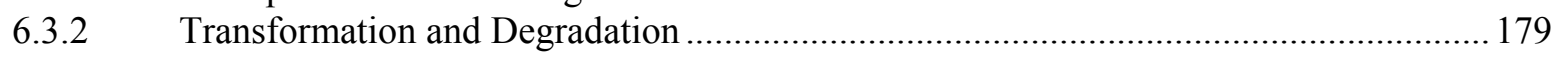

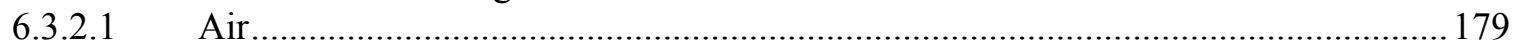

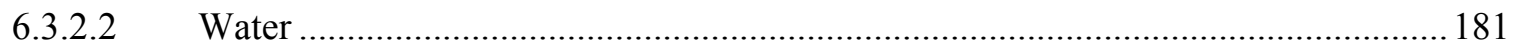

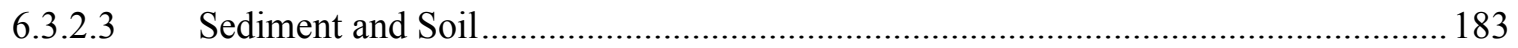

6.4 LEVELS MONITORED OR ESTIMATED IN THE ENVIRONMENT ............................ 185

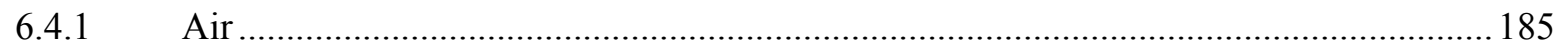

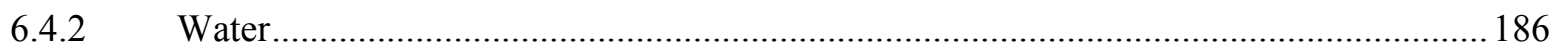

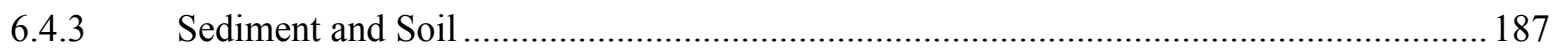

Other Environmental Media .................................................................................... 188

6.5 GENERAL POPULATION AND OCCUPATIONAL EXPOSURE ................................. 194

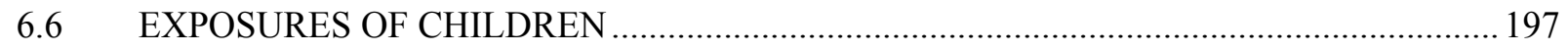

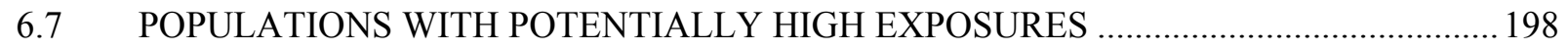

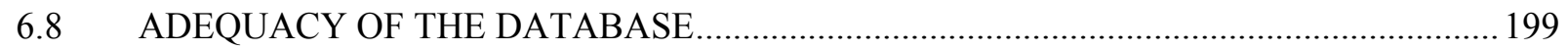

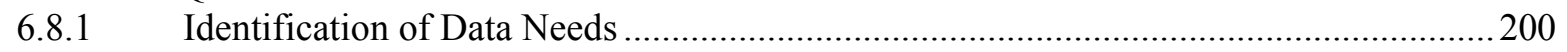

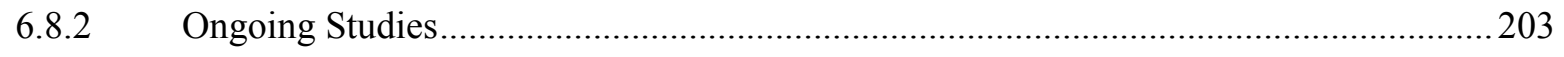

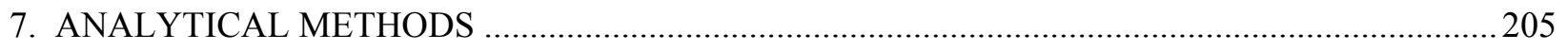

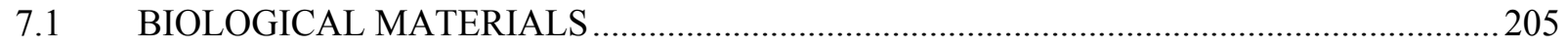

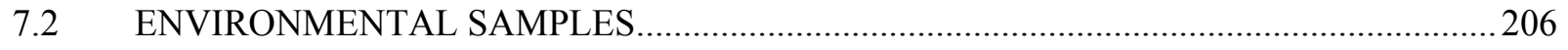

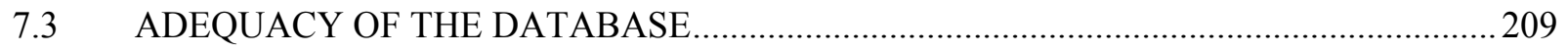

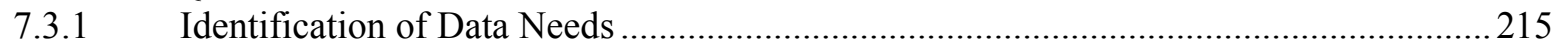

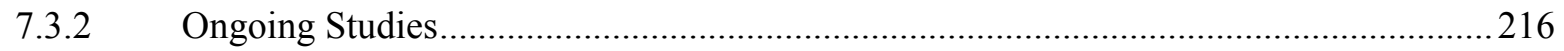

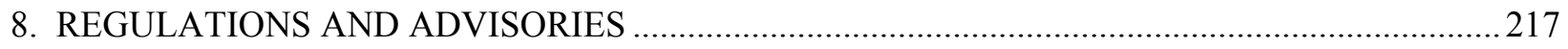




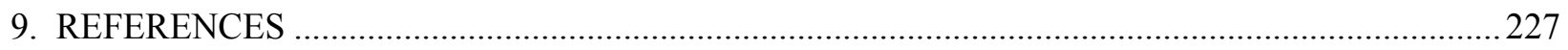

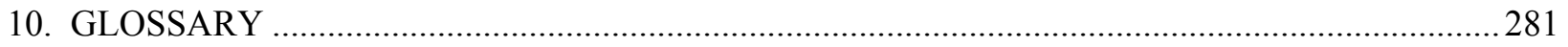

APPENDIX A. ATSDR MINIMAL RISK LEVELS AND WORKSHEETS .......................................

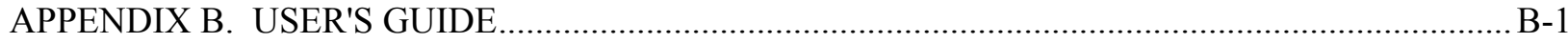

APPENDIX C. ACRONYMS, ABBREVIATIONS, AND SYMBOLS ….......................................... 


\section{LIST OF FIGURES}

3-1. Levels of Significant Exposure to Pyrethroids - Inhalation........................................................ 33

3-2. Levels of Significant Exposure to Pyrethroids - Oral ....................................................................... 51

3-3. Metabolic Diagram for Deltamethrin, Permethrin, and Cypermethrin............................................ 93

3-4. Conceptual Representation of a Physiologically Based Pharmacokinetic (PBPK) Model for a

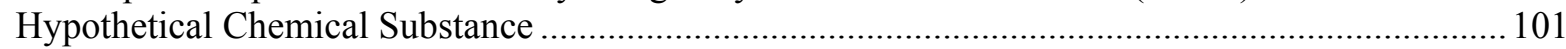

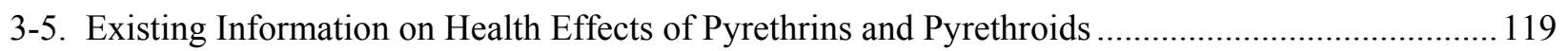

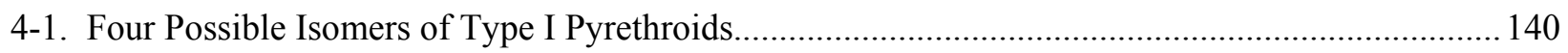

4-2. Illustration of the S Conformer about the Alpha Carbon for the Type II Pyrethroid Cyhalothrin ... 152

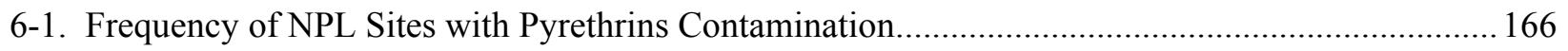

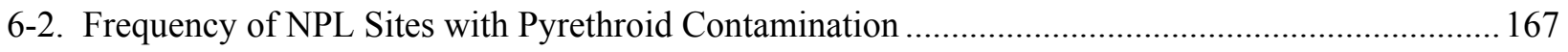




\section{LIST OF TABLES}

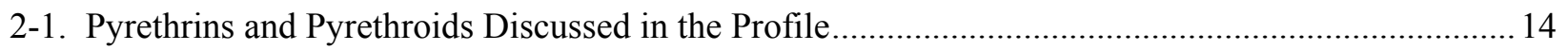

3-1. Levels of Significant Exposure to Pyrethrins and Pyrethroids - Inhalation..................................... 32

3-2. Levels of Significant Exposure to Pyrethrins and Pyrethroids - Oral........................................... 36

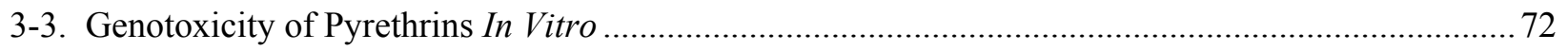

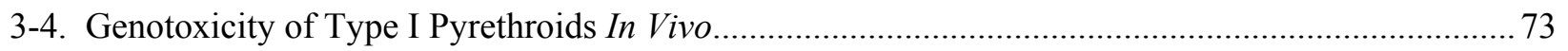

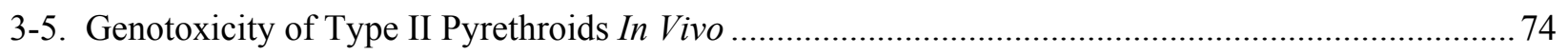

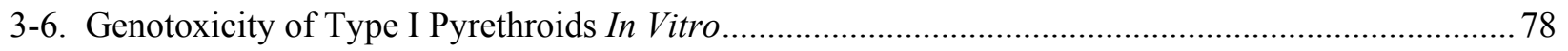

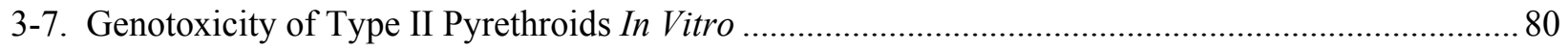

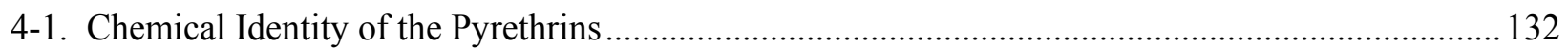

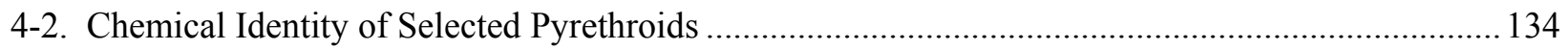

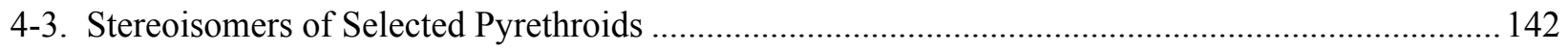

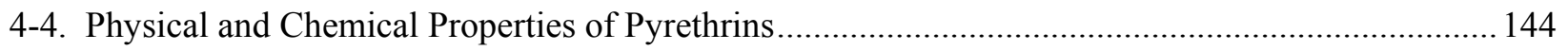

4-5. Physical and Chemical Properties of Selected Pyrethroids ........................................................ 146

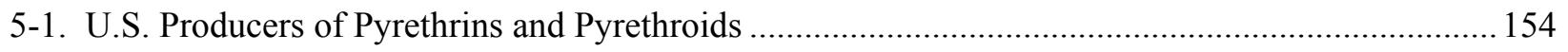

5-2. Facilities that Produce, Process, or Use Pyrethroids ….......................................................... 155

5-3. Acid and Alcohol Feedstocks in the Pyrethroids Synthesis ...................................................... 156

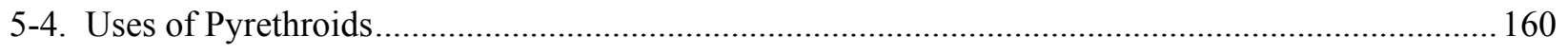

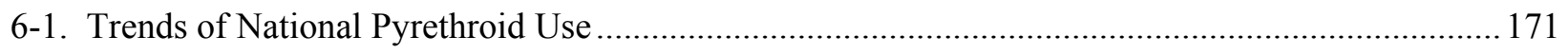

6-2. Releases to the Environment from Facilities that Produce, Process, or Use Pyrethroids ................. 172

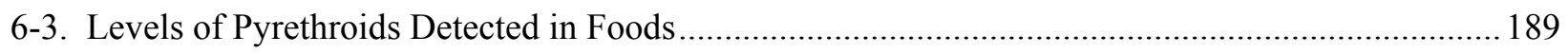

6-4. Average Daily Intake (AVDI, ng/kg/day) of Permethrin in Eight Population Groups.................... 195

7-1. Analytical Methods for Determining Pyrethrins and Pyrethroids in Biological Materials.............. 207

7-2. Analytical Methods for Determining Pyrethrins and Pyrethroids in Environmental Samples .........210 
8-1. Regulations and Guidelines Applicable to Pyrethrins and Pyrethroids .........................................218

8-2. Tolerances for Residues Applicable to Pyrethrins and Pyrethroids (ppm) ...................................222 


\section{PUBLIC HEALTH STATEMENT}

This public health statement tells you about pyrethrins and pyrethroids and the effects of exposure.

The Environmental Protection Agency (EPA) identifies the most serious hazardous waste sites in the nation. These sites make up the National Priorities List (NPL) and are the sites targeted for long-term federal cleanup activities. Pyrethrins and pyrethroids have been found in at least 5 and 2 of the 1,636 current or former NPL sites, respectively. However, the total number of NPL sites evaluated for these substances is not known. As more sites are evaluated, the sites at which pyrethrins and pyrethroids are found may increase. This information is important because exposure to these substances may harm you and because these sites may be sources of exposure.

When a substance is released from a large area, such as an industrial plant, or from a container, such as a drum or bottle, it enters the environment. This release does not always lead to exposure. You are exposed to a substance only when you come in contact with it. You may be exposed by breathing, eating, or drinking the substance, or by skin contact.

If you are exposed to pyrethrins and pyrethroids, many factors determine whether you'll be harmed. These factors include the dose (how much), the duration (how long), and how you come in contact with them. You must also consider the other chemicals you're exposed to and your age, sex, diet, family traits, lifestyle, and state of health.

\subsection{WHAT ARE PYRETHRINS AND PYRETHROIDS?}

Pyrethrum is a naturally occurring mixture of chemicals found in certain chrysanthemum flowers. Pyrethrum was first recognized as having insecticidal properties around 1800 in Asia and was used to kill ticks and various insects such as fleas and mosquitos. Six individual chemicals have active insecticidal properties in the pyrethrum extract, and these compounds are called pyrethrins. Pyrethrum looks like a tan-colored dust as ground flowers or a syrupy liquid 
as the crude extract. Pyrethrins are only slightly soluble in water, but they dissolve in organic solvents like alcohol, chlorinated hydrocarbons, and kerosene. Pyrethrins are often used in household insecticides and products to control insects on pets or livestock. Pyrethrins break down quickly in the environment, especially when exposed to natural sunlight.

Pyrethroids are manufactured chemicals that are very similar in structure to the pyrethrins, but are often more toxic to insects, as well as to mammals, and last longer in the environment than pyrethrins. More than 1,000 synthetic pyrethroids have been developed, but less than a dozen of them are currently used in the United States. Pyrethrins and pyrethroids are often combined commercially with other chemicals called synergists, which enhance the insecticidal activity of the pyrethrins and pyrethroids. The synergists prevent some enzymes from breaking down the pyrethrins and pyrethroids, thus increasing their toxicity.

Most commercial pyrethroids are not one single molecule; rather, they are several molecules with the same chemical formula that have their atoms joined together in the same sequence, but have a different arrangement of the atoms in space. Such compounds are called stereoisomers. If the stereoisomers are not mirror images of one another, they are called diastereomers and have different physical properties like boiling point, melting point, and solubility. If they are nonsuperimposable mirror images of each other, they are called enantiomers and properties like boiling point, melting point, and solubility are identical. However, both diastereomers and enantiomers can have different insecticidal properties and different toxicities. Some pyrethroids are composed of as many as eight different stereoisomers.

Technical-grade (concentrated) pyrethrins and pyrethroids are usually mixed with carriers or solvents to produce a commercial-grade formulated product. The formulated product contains many inert ingredients that can increase the toxicity of the product when compared to the technical-grade material. By law, the active ingredient must be identified by name on the pesticide label and its percentage must be provided. Nonactive ingredients (sometimes called inert ingredients) do not need to be identified by name on a pesticide label, only the percentage of nonactive ingredients must be specified, so it is often difficult to determine what other chemicals are included in the final formulated product. 


\subsection{WHAT HAPPENS TO PYRETHRINS AND PYRETHROIDS WHEN THEY ENTER THE ENVIRONMENT?}

Pyrethrins and pyrethroids are primarily released to air because of their use as insecticides. Sometimes they are sprayed on crops from planes and helicopters or sprayed from the ground by trucks, tractors, or hand-held applicators. They are also used to control flying insects like mosquitos and flies on livestock and pets. These compounds are also in aerosol bombs and sprays that can be used indoors. Pyrethrins can be released naturally from chrysanthemum flowers, but these releases are small compared with the amounts used as commercial insecticides. Manufacturing facilities that produce these compounds can also release them to the environment during the production process.

In air, all six of the pyrethrins and many of the pyrethroids are broken down or degraded rapidly by sunlight or other compounds found in the atmosphere. Often, they last only 1 or 2 days before being degraded. Rain and snow help remove the pyrethroids from air that are not rapidly degraded. Since many of these compounds are extremely toxic to fish, they are usually not sprayed directly onto water, but they can enter lakes, ponds, rivers, and streams from rainfall or runoff from agricultural fields. These compounds bind strongly to dirt and usually are not very mobile in soil. Pyrethrins and pyrethroids are not easily taken up by the roots of plants and vegetation because they are strongly bound to the soil; however, they are often sprayed directly onto crops and plants so they may be found on leaves, fruits, and vegetables. Because these compounds adsorb so strongly to soil, pyrethrins and pyrethroids usually do not leach into groundwater, do not contaminate drinking water supplies, and volatilize from soil surfaces slowly. These compounds are eventually degraded by the microorganisms in soil and water. They can also be degraded by sunlight at the surfaces of water, soil, or plants. However, some of the more recently developed pyrethroids can persist in the environment for a few months before they are degraded.

For more information about the fate and movement of pyrethrins and pyrethroids in the environment, see Chapter 6. 


\subsection{HOW MIGHT I BE EXPOSED TO PYRETHRINS AND PYRETHROIDS?}

You can be exposed to pyrethrins and pyrethroids in several ways. Eating foods that are contaminated with these compounds is the most likely way. You can also breathe in air that contains these compounds. This is especially possible soon after the insecticide has been sprayed. After spraying, these compounds can also come in contact with your skin and you can be exposed by dermal contact. These compounds are contained in many household insecticides, pet sprays, and shampoos. Some pyrethroids are also used as lice treatments that are applied directly to the head and as mosquito repellents that can be applied to your clothes. A common treatment for scabies is the application of a pyrethroid to the affected skin surface excluding the scalp. The use of these products can lead to exposure.

The average daily intake of permethrin (the most frequently used pyrethroid in the United States) for a 70 kilogram adult male is estimated as about 3.2 micrograms per day ( 1 microgram equals $1 / 1,000,000$ of a gram). This value is about 1,000 times less than the acceptable daily intake (ADI) of permethrin derived by the United Nations' Food and Agriculture Organization (FAO) and the World Health Organization (WHO).

\subsection{HOW CAN PYRETHRINS AND PYRETHROIDS ENTER AND LEAVE MY BODY?}

Pyrethrins and pyrethroids usually enter the body when people eat foods contaminated by these chemicals. They may also enter your body by breathing air that contains these compounds or through dermal exposure when you use commercially available insecticides that contain pyrethrins and pyrethroids. These chemicals are absorbed by the body when you eat contaminated foods and breathe contaminated air, but they are not as easily absorbed through the skin when you touch contaminated soil, vegetation, or insecticides containing these compounds. Some insect repellents that are applied to the skin contain pyrethrins or pyrethroids in addition to another chemical called DEET, which may allow the pyrethrins or pyrethroids to enter your body 
more easily. Pyrethrins and pyrethroids can enter your body if you swallow drinking water contaminated with these compounds, but since pyrethrins and pyrethroids are rarely found in drinking water, this will be a minor exposure route. Accidental exposures to pyrethrins or pyrethroids may also occur if these pesticides are improperly used.

Pyrethrins and pyrethroids that enter the body leave quickly, mainly in the urine, but also in feces and breath. These compounds are also quickly broken down by the body into other chemicals called metabolites. The concentration of these chemicals in the urine increases as the amount of the exposure goes up. If exposure levels are very high or if exposure occurs over a long time, then pyrethrins and pyrethroids can build up in fatty tissue and remain in the body for a little longer. Certain types of pyrethroids can also be retained for longer periods of time in the skin and hair.

Chapter 3 contains more information on how pyrethrins and pyrethroids enter and leave the human body.

\subsection{HOW CAN PYRETHRINS AND PYRETHROIDS AFFECT MY HEALTH?}

Pyrethrins and pyrethroids interfere with the way that the nerves and brain function. If you get a large amount of pyrethrins or pyrethroids on your skin, you may get feelings of numbness, itching, burning, stinging, tingling, or warmth that could last for a few hours. You are not likely to be exposed to amounts of pyrethrins or pyrethroids by breathing air, eating food, or touching anything that would cause enough pyrethrins or pyrethroids to enter your body and cause other problems. But if very large amounts of these chemicals were to enter your body, you might experience dizziness, headache, and nausea that might last for several hours. Larger amounts might cause muscle twitching, reduced energy, and changes in awareness. Even larger amounts could cause convulsions and loss of consciousness that could last for several days. Allergic reactions have been seen in a few individuals who used products that contain pyrethrins or pyrethroids. There is no evidence that pyrethrins or pyrethroids cause birth defects in humans or affect the ability of humans to produce children. There is evidence from animal studies that 
pyrethrins and pyrethroids might be capable of causing cancer in people, but the evidence comes from animals that ate very large amounts of pyrethrins or pyrethroids for a lifetime.

To protect the public from the harmful effects of toxic chemicals and to find ways to treat people who have been harmed, scientists use many tests.

One way to see if a chemical will hurt people is to learn how the chemical is absorbed, used, and released by the body; for some chemicals, animal testing may be necessary. Animal testing may also be used to identify health effects such as cancer or birth defects. Without laboratory animals, scientists would lose a basic method to get information needed to make wise decisions to protect public health. Scientists have the responsibility to treat research animals with care and compassion. Laws today protect the welfare of research animals, and scientists must comply with strict animal care guidelines.

Animal studies show effects of pyrethrins and pyrethroids similar to those seen in people exposed to very high amounts of these chemicals. In addition, exposure to pyrethrins or pyrethroids might affect the ability of some animals to reproduce and may also cause cancer.

\subsection{HOW CAN PYRETHRINS AND PYRETHROIDS AFFECT CHILDREN?}

This section discusses potential health effects from exposures during the period from conception to maturity at 18 years of age in humans.

Children exposed to large amounts of pyrethrins or pyrethroids would be expected to be affected in the same manner as adults. If children were to get a large amount of pyrethrins or pyrethroids on their skin, they might get feelings of numbness, itching, burning, tingling, or warmth that could last for a few hours. If very large amounts of these chemicals were to enter a child's body, the child might experience dizziness, headache, and nausea that might last for several hours. Even larger amounts could cause muscle twitches, tremors, convulsions, and loss of consciousness that could last up to several days. 
Pyrethroids might be able to penetrate the skin of infants and young children more easily than the skin of adults. Infants and young children are more easily dehydrated than adults through exercise, flue, colds, and the conditions that contribute to fluid loss. Therefore, pyrethroids that penetrate the skin may become more concentrated in internal tissues of the young.

There is no evidence in humans that pyrethrins or pyrethroids cause birth defects. Some young animals showed signs of possible damage to the body's defense system that fights infection after their mothers were exposed to pyrethroids while their babies were developing in the womb. There is some indication that the developing brain of some very young animals could be affected by pyrethroids.

\subsection{HOW CAN FAMILIES REDUCE THE RISK OF EXPOSURE TO PYRETHRINS AND PYRETHROIDS?}

If your doctor finds that you have been exposed to significant amounts of pyrethrins or pyrethroids, ask whether your children might also be exposed. Your doctor might need to ask your state health department to investigate.

Pyrethrins and pyrethroids are effective insecticides that are often used in household sprays, aerosol bombs, insect repellents, pet shampoos, and lice treatments. Using products containing these compounds will expose you to these chemicals. If you decide to use these products, carefully follow the instructions on how to apply them properly and how long to wait before reentering the treated area. Do not apply more than the recommended amount. Pesticides and household chemicals should be stored out of reach of young children to prevent accidental poisoning. Always store pesticides in their original labeled containers; never store pesticides in containers that young children would find attractive, such as old soda bottles. If you feel sick after a pesticide has been used in your home, call the local poison control center or see a doctor. Keep your poison control center's number next to the phone. If a close neighbor or someone living nearby is applying pyrethrins or pyrethroids, you may want to remain indoors with your children and pets in order to avoid being accidentally exposed to these chemicals. Certain pyrethroids, such as permethrin, phenothrin, and resmethrin, are sprayed to control mosquitos 
during the spring and summer. Remaining indoors and closing your windows while your neighborhood is being sprayed will lessen your exposure.

Since these compounds frequently are used on crops, they are often detected in fruits and vegetables. Make sure you wash fruits and vegetables thoroughly before eating them. Trim the fat from meat and poultry because pesticides often concentrate in fat. These compounds are often detected in soils, especially in agricultural areas. Some children eat a lot of dirt. You should discourage your children from eating dirt. Make sure they wash their hands frequently and before eating. Discourage your children from putting their hands in their mouths or any other hand-to-mouth activity.

\subsection{IS THERE A MEDICAL TEST TO DETERMINE WHETHER I HAVE BEEN EXPOSED TO PYRETHRINS AND PYRETHROIDS?}

Methods exist that can detect pyrethrins and pyrethroids in blood and urine. Because these compounds are broken down in the body quickly, there are also ways to measure the metabolites of these chemicals in human blood and urine. These methods are not available in a doctor's office because special equipment is required. However, a sample taken in a doctor's office can be shipped to a special medical laboratory, if necessary. These laboratories are usually located at research universities or affiliated with government agencies such as the Centers for Disease Control and Prevention (CDC). Your doctor may need to contact the county health department for a list of laboratories that can perform these tests. Because pyrethrins and pyrethroids break down in the body rapidly, these methods are useful only if exposure has occurred within the last few days. At this time, these methods can tell only if you have been exposed to pyrethrins or pyrethroids and cannot tell if you will have any adverse health effects. Methods also exist that can measure the concentration of pyrethrins and pyrethroids in air, water, soil, and foods.

For pesticide emergencies, the National Pesticide Information Center (NPIC) (formerly called the National Pesticide Telecommunications Network [NPTN]) located at Oregon State University, is also available. The NPIC (telephone number: 1-800-858-7378 for the general 
public and 1-800-858-7377 for medical profession/government agencies) provides information about pesticides to anyone in the United States.

Chapter 7 contains more information regarding the measurement of pyrethrins and pyrethroids in humans and environmental samples.

\subsection{WHAT RECOMMENDATIONS HAS THE FEDERAL GOVERNMENT MADE TO PROTECT HUMAN HEALTH?}

The federal government develops regulations and recommendations to protect public health. Regulations can be enforced by law. Federal agencies that develop regulations for toxic substances include the Environmental Protection Agency (EPA), the Occupational Safety and Health Administration (OSHA), and the Food and Drug Administration (FDA).

Recommendations provide valuable guidelines to protect public health but cannot be enforced by law. Federal organizations that develop recommendations for toxic substances include the Agency for Toxic Substances and Disease Registry (ATSDR) and the National Institute for Occupational Safety and Health (NIOSH).

Regulations and recommendations can be expressed in not-to-exceed levels in air, water, soil, or food that are usually based on levels that affect animals; then they are adjusted to help protect people. Sometimes these not-to-exceed levels differ among federal organizations because of different exposure times (an 8-hour workday or a 24-hour day), the use of different animal studies, or other factors.

Recommendations and regulations are also periodically updated as more information becomes available. For the most current information, check with the federal agency or organization that provides it. Some regulations and recommendations for pyrethrins and pyrethroids include the following:

The WHO has recommended that the level of permethrin in drinking water not exceed 20 micrograms per liter $(\mu \mathrm{g} / \mathrm{L})$. OSHA regulates the level of pyrethrins in workplace air. The 
occupational exposure limits for an 8-hour workday, 40-hour workweek are $5 \mathrm{mg}$ per cubic meter $\left(\mathrm{mg} / \mathrm{m}^{3}\right)$. The EPA has recommended daily oral exposure limits for 10 different pyrethroids. These limits range from 0.005 to $0.05 \mathrm{mg} / \mathrm{kg} / \mathrm{day}$.

In September of 1997, the EPA issued a request to pesticide formulators to voluntarily change the term "inert ingredients" to "other ingredients" on pesticide labels because the general public often believed that inert ingredients meant harmless ingredients. Since federal law does not define inert ingredients on the basis of toxicity or hazard to humans, it should not be assumed that all inert ingredients are nontoxic. The EPA publishes a list of all inert ingredients used in currently registered pesticides, but it does not specify which ingredients are contained in any specific formulated product.

For more information on regulations and guidelines, see Chapter 8.

\subsection{WHERE CAN I GET MORE INFORMATION?}

If you have any more questions or concerns, please contact your community or state health or environmental quality department, or contact ATSDR at the address and phone number below.

ATSDR can also tell you the location of occupational and environmental health clinics. These clinics specialize in recognizing, evaluating, and treating illnesses resulting from exposure to hazardous substances.

Toxicological profiles are also available on-line at www.atsdr.cdc.gov and on CD-ROM. You may request a copy of the ATSDR ToxProfiles CD-ROM by calling the information and technical assistance toll-free number at 1-888-42ATSDR (1-888-422-8737), by email at atsdric@cdc.gov, or by writing at: 


\author{
Agency for Toxic Substances and Disease Registry \\ Division of Toxicology \\ 1600 Clifton Road NE \\ Mailstop E-29 \\ Atlanta, GA 30333 \\ Fax: 1-404-498-0093
}

For-profit organizations may request a copy of final profiles from the following:

National Technical Information Service (NTIS)

5285 Port Royal Road

Springfield, VA 22161

Phone: 1-800-553-6847 or 1-703-605-6000

Web site: http://www.ntis.gov/ 



\section{RELEVANCE TO PUBLIC HEALTH}

\subsection{BACKGROUND AND ENVIRONMENTAL EXPOSURES TO PYRETHRINS AND PYRETHROIDS IN THE UNITED STATES}

Pyrethrum is the natural extract that occurs in the flowers of Chrysanthemum cinerariaefolium and Chrysanthemum cineum. Pyrethrum has long been recognized as possessing insecticidal properties; over the years, first the chemical extracts of pyrethrum, and then more recently, the specific synthetic chemical analogs have been produced. The six active insecticidal compounds of pyrethrum are called pyrethrins. The six individual pyrethrins are pyrethrin I, pyrethrin II, cinerin I, cinerin II, jasmolin I, and jasmolin II. The pyrethroids are synthetic analogs and derivatives of the original pyrethrins and represent a diverse group of over 1,000 powerful insecticides. Although they are based on the chemical structure and biological activity of the pyrethrins, the development of synthetic pyrethroids has involved extensive chemical modifications that make these compounds more toxic and less degradable in the environment. A list of the pyrethrins and some of the more common pyrethroids is presented in Table 2-1. While many pyrethroids have been developed, only about a dozen or so are frequently used in the United States. The individual pyrethroids are typically grouped into two general classes, called Type I and Type II, based on a combination of toxicological and physical properties, which is further described in Chapters 3 and 4. Also, the individual pyrethroid substances, due to a complex chemical structure, are often composed of two, four, or eight isomers, and their commercially manufactured products routinely contain a mixture of these various isomers. Thus, the production of individual pyrethroids with slightly varying isomeric ratios can often be the reason for the differences in the reported toxicities of the same compound. See Chapter 4 for the structures and explanation of the isomerism, as well as more information on the chemical and physical properties of the pyrethrins and pyrethroids.

Both groups, the pyrethrins and the pyrethroids, are very important insecticides because of their rapid paralysis of flying insects, relatively low mammalian toxicity, and rapid rate of degradation in the environment. They are typically used as insecticides for both home and commercial use. Also, the pyrethrins and pyrethroids are often formulated with compounds such as piperonyl butoxide, piperonyl sulfoxide, and sesamex, which act as synergists to increase the effectiveness of the insecticide. Currently, the products containing small amounts of pyrethroids for uses around the home are still classified as general use pesticides; however, emulsified or granular concentrate formulations that are applied to fields were classified as restricted use pesticides by EPA in 1995. Formulated commercial pyrethroid products 
Table 2-1. Pyrethrins and Pyrethroids Discussed in the Profile ${ }^{a}$

\begin{tabular}{lll}
\hline Pyrethrins & Type I pyrethroids & Type II pyrethroid \\
\hline $\begin{array}{l}\text { Constituents of } \\
\text { natural pyrethrum } \\
\text { extract }\end{array}$ & $\begin{array}{l}\text { Derivatives of pyrethrins that } \\
\text { do not include a cyano group } \\
\text { and may elicit tremors }\end{array}$ & $\begin{array}{l}\text { Derivatives of pyrethrins that include a } \\
\text { cyano group and may elicit sinuous } \\
\text { writhing (choreoathetosis) and salivation }\end{array}$ \\
\hline Pyrethrin I & Allethrin & Cyfluthrin \\
Pyrethrin II & Bifenthrin & Cyhalothrin \\
Cinerin I & Permethrin & Cypermethrin \\
Cinerin II & Phenothrin(Bio) & Deltamethrin \\
Jasmolin I & Resmethrin & Fenvalerate \\
Jasmolin II & Tefluthrin & Fenpropathrin \\
& Tetramethrin & Flucythrinate \\
& & Flumethrin \\
& & Fluvalinate \\
& & Tralomethrin \\
\hline
\end{tabular}

${ }^{\mathrm{a}}$ Type I and Type II pyrethroids are described in more detail in Section 3.5.2, Mechanisms of Toxicity. 
(like most pesticides), also contain a high percentage of other (sometimes referred to as "inert") ingredients, many of which may be potentially toxic. Federal law only requires that the percentage of "inert" ingredients be defined and does not require the actual chemicals that make up the "inert" ingredients to be identified on a pesticide label.

Pyrethrins and pyrethroids are released to the environment due to their use as insecticides. They can be applied to crops from aerial and ground-based sprayers or applied indoors from commercially available sprays or aerosol bombs. These compounds are readily degraded in the atmosphere by natural sunlight and usually do not persist for more than several days to a few weeks. Certain pyrethroids such as permethrin and cyhalothrin, where the isobutenyl group attached to the cyclopropane moiety has been altered, are slightly more stable to sunlight than other pyrethroids. Air concentrations are usually in the $\mu \mathrm{g} / \mathrm{m}^{3}$ range (both indoors and outdoors) after spraying, but diminish over time as these compounds are degraded or removed by wet and dry deposition. In soils, pyrethrins and pyrethroids are not very mobile and usually do not leach into groundwater, unless a large spill has occurred. These compounds are biodegraded in soil and water and can also undergo hydrolysis under alkaline conditions. Since these compounds adsorb strongly to soils, they are not taken up substantially by the roots of vascular plants. These compounds bioconcentrate in aquatic organisms and are extremely toxic to fish.

The general population is primarily exposed to pyrethrins and pyrethroids from the ingestion of foods, particularly vegetables and fruits. Exposure due to inhalation of ambient air is also possible after these compounds have been used. Pyrethrins and pyrethroids are also employed in a variety of pet shampoos, lice treatments, household insecticide sprays, and aerosol bombs that can be used in or around the home, and the use of these products can lead to both dermal and inhalation exposure. Occupational exposure to agricultural workers who apply these compounds onto crops can be substantial, with dermal exposure considered the most important pathway (see Section 6.5).

The average daily intake (AVDI) of permethrin for eight different age/sex groups has been estimated from market basket surveys conducted by the Food and Drug Administration (FDA). Based upon market basket surveys conducted from 1986 to 1991, the AVDI of permethrin ranges from about 36 to $71 \mathrm{ng} / \mathrm{kg} /$ day (see Table 6-4). Since permethrin is the most frequently used pyrethroid in the United States, the data from these surveys may represent a reasonable first approximation for the average total intake of all the pyrethroids. 


\subsection{SUMMARY OF HEALTH EFFECTS}

Pyrethrins and pyrethroids are used extensively as effective insecticides, but pose relatively little hazard to mammals (including humans) by natural routes of exposure at levels likely to be encountered in the environment or resulting from the normal use of pyrethrin- or pyrethroid-containing substances. Signs and symptoms of acute toxicity vary according to the type of pyrethroid to which one may be exposed. However, almost all systemic effects are related to the action of pyrethrins and pyrethroids on the nervous system. These chemicals exert their profound effect by prolonging the open phase of the sodium channel gates when a nerve cell is excited. In rodents, effects such as tremors are induced if the open state is prolonged for brief periods; effects such as sinuous writhing (choreoathetosis) and salivation occur if the open state is prolonged for longer periods. Neurological signs typically result from acute toxicity. Lowlevel chronic exposures to pyrethrins and pyrethroids usually do not cause neurological signs in mammals, largely due to rapid metabolism and elimination. However, direct skin contact may cause temporary paresthesia (abnormal cutaneous sensations such as tingling, burning, stinging, numbness, and itching) that is limited to the area of contact. Available animal data do not indicate that pyrethrins or pyrethroids significantly affect end points other than the nervous system, although changes in liver weight and metabolism of chemicals have sometimes been used as an index of adverse effect levels for pyrethroids. Results of a few recent animal studies suggest that neurodevelopmental, reproductive, and immunological effects may result following exposure to some pyrethroids at levels below those that induce overt signs of neurotoxicity. Available data indicate that pyrethrins may be a carcinogenic concern to humans. No human data are available regarding the potential for pyrethroids to cross the placental barrier and enter a developing fetus. Limited animal data indicate that transfer of pyrethroids

across the placenta to the fetus may occur. Although pyrethroids have not been identified in human breast milk, very low levels of pyrethroids ( $<1 \%$ of an orally administered dose) are excreted into milk of lactating animals.

Neurological Effects. Pyrethrins and pyrethroids act principally on the sodium channels of nerve cells in exerting their toxic effects. Two different types of pyrethroids are recognized, based on differences in basic structure (the presence or absence of a cyano group in the alpha position) and the symptoms of poisoning in laboratory rodents. Type I pyrethroids do not include a cyano group; their effects typically include rapid onset of aggressive behavior and increased sensitivity to external stimuli, followed by fine tremor, prostration with coarse whole body tremor, elevated body temperature, coma, and death. The term T-syndrome (from tremor) has been applied to Type I responses. Clinical signs of neurotoxicity in animals exposed to pyrethrins are similar to those of Type I pyrethroids. Type II 
pyrethroids include a cyano group; their effects are usually characterized by pawing and burrowing behavior, followed by profuse salivation, increased startle response, abnormal hindlimb movements, and coarse whole body tremors that progress to sinuous writhing (choreoathetosis). Clonic seizures may be observed prior to death. Body temperature usually is not increased, but may decrease. The term CS-syndrome (from choreoathetosis and salivation) has been applied to Type II responses. In general, the distinction between Type I and Type II pyrethroids is clear. However, two of the cyano-pyrethroids, fenpropathrin and cyphenothrin, have been shown to trigger responses intermediate to those of $\mathrm{T}$ - and CS-syndrome, characterized by both tremors and salivation. These neurological responses to pyrethroid poisoning are typically of acute duration. There is no evidence to indicate that long-term, low-level exposure of adults to pyrethroids might result in more severe neurological effects.

Whereas distinctive signs of these neurotoxic symptoms (T- and CS-syndrome) occur in humans diagnosed with mild to severe pyrethroid poisoning, levels high enough to trigger these symptoms are not likely to occur under most exposure scenarios. Pyrethroids (particularly Type II pyrethroids containing the cyano group) frequently induce paresthesia among individuals occupationally exposed via unprotected areas of the skin. This effect is often observed at exposure levels far below those in which other clinical signs of neurotoxicity might be expected to occur. Pyrethroid-induced parasthesia typically peaks within 3-6 hours following dermal exposure and resolves within 12-24 hours. Some animal studies indicate that exposure to pyrethroids may result in other less overt signs of neurotoxicity, such as changes in startle and avoidance responses, altered levels of spontaneous motor activity, and changes in operant conditioned responses, which may occur at levels below those eliciting typical T- or CS-syndrome.

Cancer. Increased incidences of thyroid follicular cell tumors were reported in male and female rats administered pyrethrins (57.57\% pyrethrum extract) in the diet for 2 years. The female rats also exhibited increased incidences of hepatocellular adenomas and combined adenomas and/or carcinomas. In a review of this rat carcinogenicity study, the Cancer Assessment Review Committee for pyrethrins attributed the increased incidences of thyroid and liver tumors to pyrethrum treatment and classified pyrethrins as "likely to be a human carcinogen by the oral route."

Developmental Effects. Standard developmental studies have not elucidated typical signs of developmental toxicity in animals exposed to pyrethrins or pyrethroids.

Eriksson and coworkers reported alterations in brain muscarinic receptor density and increased spontaneous activity in mice that had received oral (gavage) doses of pyrethroids during critical stages of 
neonatal neurological development; however, limitations in study design and lack of success in duplicating the results render the studies of questionable value for the purpose of risk assessment. In utero exposure of rats resulted in cellular changes indicative of compromised immunological function.

Reproductive Effects. Standard reproductive toxicity studies, including some that were performed for three successive generations, did not indicate that pyrethrins or pyrethroids might be of particular concern to reproductive success. However, a few recent studies have indicated that relatively low-level, intermediate-duration oral exposure of adult male laboratory animals to some Type II pyrethroids may result in damage to reproductive organs, abnormal sperm characteristics, reduced plasma testosterone levels, and reduced fertility.

\subsection{MINIMAL RISK LEVELS (MRLS)}

\section{Inhalation MRLs}

No inhalation MRLs were derived for pyrethrins or pyrethroids for inhalation exposure since adequate data were not available for this route of exposure.

\section{Oral MRLs}

No oral MRLs were derived for pyrethrins since adequate data were not available. Oral MRLs were derived for selected pyrethroids, based on cleared reviews (Data Evaluation Records, DERs) of studies submitted to EPA by the pesticide industry and a study published in the open literature (McDaniel and Moser 1993. The DERs were used because the associated primary studies were not available to ATSDR for independent assessment. The MRLs were developed for specific technical-grade pyrethroids and may not be applied to a different composition of that pyrethroid or for a different pyrethroid. For example, the intermediate-duration oral MRL of $0.2 \mathrm{mg} / \mathrm{kg} /$ day that was derived for permethrin accounts for oral exposure to technical-grade permethrin (95.3\% purity; isomeric ratio 50/50 cis/trans; corn oil vehicle). Isomeric ratio, administration vehicle, purity of the compound, and formulation of a pyrethroidcontaining pesticide must all be taken into account when assessing the risk of exposure. 


\section{Acute-duration Oral MRLs}

- $\quad$ An MRL of $0.3 \mathrm{mg} / \mathrm{kg} /$ day has been derived for acute-duration oral exposure (14 days or less) to permethrin ( $95 \%$ purity; $50 / 50$ cis/trans).

This MRL is based on a no-observed-adverse-effect level (NOAEL) of $25 \mathrm{mg} / \mathrm{kg}$ for neurological impairment in rats (McDaniel and Moser 1993). An uncertainty factor of 100 was used (10 for animal to human extrapolation and 10 to account for intrahuman variation). Groups of Long-Evans rats (8/sex/dose) were administered permethrin (95\% purity; 50/50 cis/trans; in corn oil vehicle) in single gavage doses of $0,25,75$, or $150 \mathrm{mg} / \mathrm{kg}$. Selected rats from each dose group were subjected to functional observational battery (FOB) and motor activity assessment at 2 and 4 hours following dosing. A lowestobserved-adverse-effect level (LOAEL) of $75 \mathrm{mg} / \mathrm{kg}$ was identified for neurological impairment that included increased excitability and aggressiveness, abnormal motor movement, and decreased grip strength and motor activity.

- $\quad$ An MRL of $0.02 \mathrm{mg} / \mathrm{kg} /$ day has been derived for acute-duration oral exposure (14 days or less) to cypermethrin ( $97 \%$ purity; $50 / 50$ cis/trans).

This MRL is based on a lowest-observed-adverse-effect level (LOAEL) of $20 \mathrm{mg} / \mathrm{kg}$ for neurological impairment in rats (McDaniel and Moser 1993). An uncertainty factor of 1,000 was used (10 for lack of a NOAEL, 10 for animal to human extrapolation, and 10 to account for intrahuman variation). Groups of Long-Evans rats (8/sex/dose) were administered cypermethrin (97\% purity; $50 / 50$ cis/trans; in corn oil vehicle) in single gavage doses of $0,20,60$, or $120 \mathrm{mg} / \mathrm{kg}$. Selected rats from each dose group were subjected to functional observational battery (FOB) and motor activity assessment at 2 and 4 hours following dosing. LOAEL of $20 \mathrm{mg} / \mathrm{kg}$ was identified for neurological impairment that statistically significantly altered gait and decreased motor activity. A NOAEL was not established.

- An MRL of $0.01 \mathrm{mg} / \mathrm{kg} /$ day has been derived for acute-duration oral exposure (14 days or less) to cyhalothrin.

This MRL is based on a NOAEL of $1 \mathrm{mg} / \mathrm{kg}$ /day for gastrointestinal effects (diarrhea) in dogs (EPA 1981). An uncertainty factor of 100 was used (10 for animal to human extrapolation and 10 to account for intrahuman variation). Groups of 4-5-month-old male and female beagle dogs (6/sex/dose) were administered cyhalothrin (in corn oil vehicle) in gelatin capsules at doses of $0,1.0,2.5$, or $10.0 \mathrm{mg} / \mathrm{kg} / \mathrm{day}$ for 26 weeks. The dosing volume was $0.1 \mathrm{~mL} / \mathrm{kg}$ body weight. A dose-related increase in diarrhea was observed as early as the first week of treatment, and persisted throughout the study $(7,26$, and $39 \%$ 
greater incidences of diarrhea in low-, mid-, and high-dose dogs, respectively, relative to controls). The $7 \%$ increased incidence of diarrhea at the $1.0 \mathrm{mg} / \mathrm{kg} /$ day dose level may not be a clear indication of an adverse treatment-related effect. However, the $26 \%$ increased incidence of diarrhea at $2.5 \mathrm{mg} / \mathrm{kg} / \mathrm{day}$ is considered to represent a definitive adverse effect. Thus, the $2.5 \mathrm{mg} / \mathrm{kg} /$ day dose level is considered a LOAEL for gastrointestinal effects. A detailed description of the test substance was not provided in the study. The acute-duration oral MRL is based on the assumption that the test substance consisted of technical-grade cyhalothrin with a purity of approximately $90 \%$.

\section{Intermediate-duration Oral MRLs}

- $\quad$ An MRL of $0.2 \mathrm{mg} / \mathrm{kg} /$ day has been derived for intermediate-duration oral exposure (15364 days) to permethrin (technical grade, approximately 95\% assumed purity; 50/50 cis/trans).

This MRL is based on a NOAEL of $15.5 \mathrm{mg} / \mathrm{kg} /$ day for neurological impairment in rats (EPA 1994b). An uncertainty factor of 100 was used (10 for animal to human extrapolation and 10 to account for intrahuman variation). Groups of Sprague-Dawley rats (10/sex/dose) were administered permethrin (technical grade; 50/50 cis/trans) in the diet for 13 weeks at concentrations of $0,250,1,500$, or 2,500 ppm (respective time-weighted average doses of $0,15.5,91.5$, or $150.4 \mathrm{mg} / \mathrm{kg} /$ day for males and $0,18.7$, 111.4 , or $189.7 \mathrm{mg} / \mathrm{kg} /$ day for females). Hindlimb splay was observed as early as days 38 and 18 in some 1,500 -ppm males and females, respectively. Other signs of neurotoxicity in the 1,500-ppm rats first appeared between treatment days 35 and 68. Signs of neurotoxicity appeared earlier and were more prevalent in rats of the 2,500-ppm treatment group. There were no signs of neurotoxicity in rats of the 250 -ppm treatment group. This study identified a LOAEL of 1,500 ppm $(91.5$ and $111.4 \mathrm{mg} / \mathrm{kg} / \mathrm{day}$ in males and females, respectively) for neurotoxicity.

- $\quad$ An MRL of $0.01 \mathrm{mg} / \mathrm{kg} /$ day has been derived for intermediate-duration oral exposure (15364 days) to cyhalothrin.

This MRL is based on a NOAEL of $1 \mathrm{mg} / \mathrm{kg}$ /day for gastrointestinal effects (diarrhea) in dogs (EPA 1981). An uncertainty factor of 100 was used (10 for animal to human extrapolation and 10 to account for intrahuman variation). Groups of 4-5-month-old male and female beagle dogs (6/sex/dose) were administered cyhalothrin (in corn oil vehicle) in gelatin capsules at doses of $0,1.0,2.5$, or $10.0 \mathrm{mg} / \mathrm{kg} / \mathrm{day}$ for 26 weeks. The dosing volume was $0.1 \mathrm{~mL} / \mathrm{kg}$ body weight. A dose-related increase in diarrhea was observed throughout the study (7, 26, and 39\% greater incidences of diarrhea in low-, mid-, and high-dose dogs, respectively, relative to controls). The $7 \%$ increased incidence of diarrhea at the $1.0 \mathrm{mg} / \mathrm{kg} / \mathrm{day}$ dose level may not be a clear indication of an adverse treatment-related effect. However, the $26 \%$ 
increased incidence of diarrhea at $2.5 \mathrm{mg} / \mathrm{kg} /$ day is considered to represent a definitive adverse effect. Thus, the $2.5 \mathrm{mg} / \mathrm{kg} /$ day dose level is considered a LOAEL for gastrointestinal effects. A detailed description of the test substance was not provided in the study. The intermediate-duration oral MRL is based on the assumption that the test substance consisted of technical-grade cyhalothrin with a purity of approximately $90 \%$.

\section{Chronic-duration Oral MRLs}

No clinical signs of neurotoxicity were observed in rats administered permethrin ( $93.9 \%$ purity; $40 / 60 \mathrm{cis} /$ trans ratio) in the diet for two years at concentrations up to 1,000 ppm (Ishmael and Litchfield 1994). This study was not used as the basis of a chronic-duration oral MRL because the concentrations of permethrin in the diet were not adjusted for decreased food consumption as the rats aged. However, during the second year of treatment, when the rats consumed considerably less food per kilogram of body weight, the permethrin doses were approximately $40 \mathrm{mg} / \mathrm{kg} /$ day for male and female rats. Thus, a NOAEL of at least $40 \mathrm{mg} / \mathrm{kg} /$ day was identified in this study. For this reason, the intermediate-duration oral MRL of $0.2 \mathrm{mg} / \mathrm{kg} /$ day that was based on a NOAEL of $15.5 \mathrm{mg} / \mathrm{kg} / \mathrm{day}$ should be protective for chronic-duration oral exposure to permethrin with a purity approaching $95 \%$ and approximately equal amounts of cis and trans isomers.

An average daily intake (AVDI) of 36-71 ng/kg/day has been estimated for permethrin (see Table 6-4), the most frequently used pyrethroid in the United States (see Table 6-1). The acute- and intermediateduration oral MRLs of $0.2 \mathrm{mg} / \mathrm{kg} / \mathrm{day}$ should be protective of acute- and intermediate-duration oral exposure to permethrin, with the exception of accidental or intentional ingestion of permethrin in amounts several orders of magnitude greater than those experienced during the normal consumption of food or drinking water containing permethrin residues. 



\section{HEALTH EFFECTS}

\section{$3.1 \quad$ INTRODUCTION}

The primary purpose of this chapter is to provide public health officials, physicians, toxicologists, and other interested individuals and groups with an overall perspective on the toxicology of pyrethrins and pyrethroids. It contains descriptions and evaluations of toxicological studies and epidemiological investigations and provides conclusions, where possible, on the relevance of toxicity and toxicokinetic data to public health.

A glossary and list of acronyms, abbreviations, and symbols can be found at the end of this profile.

\subsection{DISCUSSION OF HEALTH EFFECTS BY ROUTE OF EXPOSURE}

To help public health professionals and others address the needs of persons living or working near hazardous waste sites, the information in this section is organized first by route of exposure (inhalation, oral, and dermal) and then by health effect (death, systemic, immunological, neurological, reproductive, developmental, genotoxic, and carcinogenic effects). These data are discussed in terms of three exposure periods: acute (14 days or less), intermediate (15-364 days), and chronic (365 days or more).

Levels of significant exposure for each route and duration are presented in tables and illustrated in figures. The points in the figures showing no-observed-adverse-effect levels (NOAELs) or lowestobserved-adverse-effect levels (LOAELs) reflect the actual doses (levels of exposure) used in the studies. LOAELs have been classified into "less serious" or "serious" effects. "Serious" effects are those that evoke failure in a biological system and can lead to morbidity or mortality (e.g., acute respiratory distress or death). "Less serious" effects are those that are not expected to cause significant dysfunction or death, or those whose significance to the organism is not entirely clear. ATSDR acknowledges that a considerable amount of judgment may be required in establishing whether an end point should be classified as a NOAEL, "less serious" LOAEL, or "serious" LOAEL, and that in some cases, there will be insufficient data to decide whether the effect is indicative of significant dysfunction. However, the Agency has established guidelines and policies that are used to classify these end points. ATSDR believes that there is sufficient merit in this approach to warrant an attempt at distinguishing between 
"less serious" and "serious" effects. The distinction between "less serious" effects and "serious" effects is considered to be important because it helps the users of the profiles to identify levels of exposure at which major health effects start to appear. LOAELs or NOAELs should also help in determining whether or not the effects vary with dose and/or duration, and place into perspective the possible significance of these effects to human health.

The significance of the exposure levels shown in the Levels of Significant Exposure (LSE) tables and figures may differ depending on the user's perspective. Public health officials and others concerned with appropriate actions to take at hazardous waste sites may want information on levels of exposure associated with more subtle effects in humans or animals (LOAELs) or exposure levels below which no adverse effects (NOAELs) have been observed. Estimates of levels posing minimal risk to humans (Minimal Risk Levels or MRLs) may be of interest to health professionals and citizens alike.

Levels of exposure associated with carcinogenic effects (Cancer Effect Levels, CELs) of pyrethrins and pyrethroids are indicated in Table 3-2 and Figure 3-2.

Estimates of exposure levels posing minimal risk to humans (Minimal Risk Levels or MRLs) have been made for pyrethrins and pyrethroids. An MRL is defined as an estimate of daily human exposure to a substance that is likely to be without an appreciable risk of adverse effects (noncarcinogenic) over a specified duration of exposure. MRLs are derived when reliable and sufficient data exist to identify the target organ(s) of effect or the most sensitive health effect(s) for a specific duration within a given route of exposure. MRLs are based on noncancerous health effects only and do not consider carcinogenic effects. MRLs can be derived for acute, intermediate, and chronic duration exposures for inhalation and oral routes. Appropriate methodology does not exist to develop MRLs for dermal exposure.

Although methods have been established to derive these levels (Barnes and Dourson 1988; EPA 1990), uncertainties are associated with these techniques. Furthermore, ATSDR acknowledges additional uncertainties inherent in the application of the procedures to derive less than lifetime MRLs. As an example, acute inhalation MRLs may not be protective for health effects that are delayed in development or are acquired following repeated acute insults, such as hypersensitivity reactions, asthma, or chronic bronchitis. As these kinds of health effects data become available and methods to assess levels of significant human exposure improve, these MRLs will be revised. 
A User's Guide has been provided at the end of this profile (see Appendix B). This guide should aid in the interpretation of the tables and figures for Levels of Significant Exposure and the MRLs.

Pyrethrum, the natural extract of the flowers of Chrysanthemum cinerariaefolium and Chrysanthemum cocineum, contains six active insecticidal compounds called pyrethrins. Pyrethroids are synthetic analogs and derivatives of pyrethrins and represent a diverse group of over 1,000 powerful insecticides (MuellerBeilschmidt 1990). Although they are based on the chemical structure and biological activity of the pyrethrins, the development of synthetic pyrethroids has involved extensive chemical modifications that make these compounds more toxic and less degradable in the environment. The pyrethrins and some of the more common pyrethroids are listed in Table 2-1. Pyrethrins and pyrethroids pose relatively little hazard to mammals (including humans) by common routes of exposure at levels likely to be encountered in the environment or resulting from the normal use of pyrethrin- or pyrethroid-containing substances.

Two different types of pyrethroids are recognized, based on differences in basic structure (the presence or absence of a cyano group) and the symptoms of poisoning in laboratory rodents (Coats 1990; Verschoyle and Aldridge 1980). In general, Type I pyrethroids do not include a cyano group, and clinical signs of Type I pyrethroid-induced toxicity include whole body tremors. Type II pyrethroids include a cyano group and are characterized by their elicitation of salivation and sinuous writhing (choreoathetosis).

Toxicity among the various pyrethroids varies greatly, as is evidenced by the wide range in $\mathrm{LD}_{50}$ values (concentrations or doses that result in 50\% mortality in exposed laboratory animals). These differences are dependent on a number of factors including specific pyrethroid, ratios of stereo and optical isomers within a given pyrethroid formulation, and vehicle. Acute oral $\mathrm{LD}_{50}$ values are generally lower in Type II than Type I pyrethroids, indicating a greater degree of toxicity for Type II pyrethroids. In the case of tetramethrin, like all other Type I pyrethroids, isomers of the $1 \mathrm{R}$ conformation are considerably more toxic than those of the $1 \mathrm{~S}$ conformation. The $1 \mathrm{~S}$ isomer can also inhibit toxicity by competitive inhibition at a number of stereospecific pyrethroid binding sites, thus preventing binding of the more toxic $1 \mathrm{R}$ isomer (Narahashi 1986). Furthermore, it has been observed that the cis isomers possess greater mammalian toxicity than the trans isomers. For Type II pyrethroids, the $\mathrm{S}$ conformation at the alpha carbon adjacent to the cyano group is considerably more toxic than the R conformation. Consult Chapter 4 for additional information regarding the structural properties of Type I and Type II pyrethroids.

Neurological signs are typically the result of acute toxicity and do not appear to be significantly amplified following repeated low-level exposures. This may be a result of rapid metabolism and elimination of 
pyrethrins and pyrethroids by mammals. Available animal data indicate that the nervous system is the primary target of pyrethrin- or pyrethroid-induced toxicity. However, changes in liver weight and liver metabolism of chemicals have sometimes been used as an index of adverse effect levels for pyrethroids. In addition, a few recent studies indicate the potential for adverse neurodevelopmental, reproductive, and immunological effects at exposure levels below those expected to result in overt signs of neurotoxicity. Available data indicate that pyrethrins may be a carcinogenic concern to humans.

Based on the wide range of differences in levels of animal toxicity to pyrethrins and various pyrethroids, factors related to chemical properties and exposure scenarios of a given pyrethroid must be taken into account when assessing health risk. Human exposure to pesticides such as pyrethrins and pyrethroids often involves simultaneous exposure to other chemicals, which may range from impurities in a technical grade of a particular pyrethrin- or pyrethroid-containing product to dispersal agents, wetting agents, solubility agents, and additional pesticides in a given end-formulated product.

\subsubsection{Inhalation Exposure}

\subsubsection{Death}

Two case reports were located in which death was associated with allergic reactions to dog shampoo products containing pyrethrins (Wax and Hoffman 1994). An 11-year-old girl, who had been diagnosed with asthma at 6 years of age, was asymptomatic when she began to wash her dog with a shampoo containing $0.2 \%$ pyrethrin. Within 10 minutes, the subject suffered a severe acute asthmatic attack and died $<3$ hours later, despite medical treatment (Wagner 2000). This girl had experienced a mild increase in asthmatic symptoms when she had used the same shampoo 2 years earlier. A 37-year-old female, who had a 10-year history of mild asthma that did not require chronic medication, developed severe shortness of breath 5 minutes after beginning to wash her dog with a shampoo containing $0.06 \%$ pyrethrin (Wax and Hoffman 1994). The subject quickly went into cardiopulmonary arrest and died a short time later, despite efforts to revive her. Postmortem examination revealed pulmonary findings consistent with reactive airway responses. The relative contributions of inhalation and dermal exposure routes were not addressed in these reports. No other reports were located regarding death in humans following inhalation exposure to pyrethrins or pyrethroids.

Information regarding death in animals following inhalation exposure to pyrethrins or pyrethroids is mainly derived from studies designed to assess lethal toxicity in animals following airborne exposure to 
pyrethrins or pyrethroids for durations of 2-4 hours. In rats exposed to pyrethrum extract, an estimated airborne concentration in which death could be expected in $50 \%$ of the exposed animals $\left(\mathrm{LC}_{50}\right)$ was $3,400 \mathrm{mg} / \mathrm{m}^{3}$ (Schoenig 1995). Most synthetic pyrethroids are more toxic than natural pyrethrins (the active neurotoxic components of pyrethrum extract). Results from studies of rats exposed to synthetic pyrethroids indicate $\mathrm{LC}_{50}$ values ranging from approximately 23 to $1,000 \mathrm{mg} / \mathrm{m}^{3}$ (Curry and Bennett 1985; Flucke and Thyssen 1980; Hext 1987; Kavlock et al. 1979; Pauluhn and Thyssen 1982). No specific patterns could be discerned regarding the relatively wide range of $\mathrm{LC}_{50}$ values among the various pyrethroids for which inhalation data were available. One series of studies assessed acute inhalation lethality of several Type I pyrethroids (Miyamoto 1976). In most cases, lethality was not observed following exposure to airborne pyrethroid concentrations ranging from 685 to $2,500 \mathrm{mg} / \mathrm{m}^{3}$. In some cases, higher concentrations could not be attained. The only report of death was in rats and mice exposed to a mixture of (+)-allethronyl (+)-trans allethrin for 3 hours. LC $_{50}$ values were 1,600 and 2,720 mg/m for rats and mice, respectively, but minimum concentrations in which death was noted were not presented in the report. Miyamoto (1976) also assessed the toxicity of several Type I pyrethroids in rats and mice repeatedly exposed (2-4 hours/day, 5 days/week for 4 weeks) to atmospheres containing pyrethroid concentrations ranging from 6.1 to $210 \mathrm{mg} / \mathrm{m}^{3}$. Although clinical signs of toxicity were noted at concentrations of $61.3 \mathrm{mg} / \mathrm{m}^{3}$ (allethrin) and $200 \mathrm{mg} / \mathrm{m}^{3}$ (furamethrin), no exposure-related deaths occurred during the study period.

\subsubsection{Systemic Effects}

No reports were located in which cardiovascular, gastrointestinal, musculoskeletal, renal, endocrine, dermal, or ocular effects were associated with inhalation exposure of humans or animals to pyrethrins or pyrethroids. Systemic effects related to occupational exposure are generally associated with dermal exposure to pyrethrins or pyrethroids, and are therefore presented in Section 3.2.3.2.

Respiratory Effects. Limited information was available regarding respiratory effects in humans following inhalation exposure to pyrethrins or pyrethroids. Hypersensitivity pneumonitis, characterized by pleuritic chest pain, nonproductive cough, and shortness of breath, was diagnosed in a 24 -year-old woman following repeated indoor use of a pyrethrum-based insecticide (Carlson and Villaveces 1977). A pulmonary challenge test to the insecticide resulted in an itchy and runny nose within 2 minutes following initiation of exposure, but no cough or shortness of breath. Subsequent skin tests resulted in immediate skin reactions and allergic pulmonary responses to pyrethrum, but not to other ingredients in the 
insecticide. Signs of respiratory irritation, such as shortness of breath, cough, and congestion, were reported among five office workers, commencing upon entry into a building that had been treated for termites 2 days previously with a cypermethrin formulation that contained xylene-based aromatic petroleum solvents, trimethylbenzene, and paraffinic oils (Lessenger 1992). Symptoms worsened after the air-conditioning system was activated in an attempt to clear the air. It was determined that a portion of the insecticide had been injected into ventilation ducts. The possible influence of inert ingredients was not evaluated. Among 12 workers who sprayed lambda-cyhalothrin indoors, daily interviews following spraying on each of 6 consecutive days revealed 11 complaints of nasal irritation and 6 complaints of throat irritation (Moretto 1991). Coughing, dyspnea, increased nasal secretions, and sneezing were reported by plant nursery workers who used pyrethroids for treating conifer seedlings (Kolmodin-Hedman et al. 1982). Sniffles and sneezes were noted in subjects exposed to deltamethrin and fenvalerate while packaging the insecticides (He et al. 1988).

Signs of respiratory irritation were reported in laboratory animals acutely exposed to aerosols of pyrethroids at lethal or near-lethal airborne concentrations (Curry and Bennett 1985; Flucke and Thyssen 1980; Hext 1987; Pauluhn and Thyssen 1982). Intermediate-duration (90-day) repeated exposures of rats to mean analytical pyrethrin concentrations $\geq 30 \mathrm{mg} / \mathrm{m}^{3}$ resulted in clinical and microscopic evidence of respiratory irritation; a no-effect level was $11 \mathrm{mg} / \mathrm{m}^{3}$ (Schoenig 1995). More detailed information regarding respiratory effects was not available in the report.

Hematological Effects. In studies available for review, no information was located regarding hematological effects in humans following inhalation exposure to pyrethrins or pyrethroids. Available information regarding adverse hematological effects in animals is limited to a single account in which anemia was indicated in rats repeatedly exposed to pyrethrins at mean analytical airborne concentrations $\geq 30 \mathrm{mg} / \mathrm{m}^{3}$ for 90 days (Schoenig 1995). More detailed information regarding hematological effects was not available in the report.

Hepatic Effects. In studies available for review, no information was located regarding hepatic effects in humans following inhalation exposure to pyrethrins or pyrethroids. Available information regarding hepatic effects in animals is limited to a single account in which increased liver weights were reported in rats repeatedly exposed to pyrethrins at a mean analytical airborne concentration of $356 \mathrm{mg} / \mathrm{m}^{3}$ for 90 days (Schoenig 1995). 
Body Weight Effects. No information was located regarding body weight effects in humans following inhalation exposure to pyrethrins or pyrethroids. Available information regarding body weight effects in animals is limited. Decreased body weight gains were reported in rats repeatedly exposed to pyrethrins at mean analytical airborne concentrations $\geq 100 \mathrm{mg} / \mathrm{m}^{3}$ for 90 days (Schoenig 1995).

\subsubsection{Immunological and Lymphoreticular Effects}

Hypersensitivity pneumonitis, characterized by pleuritic chest pain, nonproductive cough, and shortness of breath, was diagnosed in a 24-year-old woman who was hospitalized for 2 weeks following repeated indoor use of a pyrethrum-based insecticide (Carlson and Villaveces 1977). In this patient, levels of antibodies IgG, IgM, and IgE were all elevated. Symptomatic treatment was employed, and a week after discharge, a pulmonary challenge test to the insecticide resulted in an itchy and runny nose within 2 minutes following initiation of exposure, but no cough or shortness of breath. Subsequent skin tests resulted in immediate skin reactions and allergic pulmonary response to pyrethrum, but not to other ingredients in the insecticide. In a review of literature pertaining to pyrethrum (Moore 1975), it was noted that many individuals who were sensitive to ragweed were also sensitive to pyrethrum, but that the sensitization effect arose mainly from a volatile oil contained in the pyrethrum extract, not from the pyrethrins. On the other hand, pyrethrins were implicated in two cases of severe asthmatic reactions to exposure to dog shampoo products containing pyrethrins (Wagner 2000; Wax and Hoffman 1994). A 45-year-old female animal keeper, who was suspected to be suffering from pesticide intoxication, indicated that she had been exposed to pyrethroid insecticides over a period of 13 years (Mitsche et al. 2000). Upon skin (scratch) testing, dose-dependent allergic responses (wheals and flares) were elicited from the Type I pyrethroids, S-bioallethrin and permethrin.

No animal studies were located in which inhalation exposure to pyrethrins or pyrethroids could be associated with immunological or lymphoreticular effects.

\subsubsection{Neurological Effects}

Shortness of breath, nausea, headache, and irritability were experienced by five office workers upon entering their work area 2 days after it had been sprayed with cypermethrin in an effort to eliminate termites (Lessenger 1992). The symptoms were exacerbated when the air-conditioning system was 
activated to ventilate the area, but levels of cypermethrin in the air were not measured. Signs of neurotoxicity have been associated with acute occupational (inhalation and dermal) exposure to various pyrethroids during outdoor or indoor spraying (Chen et al. 1991; He et al. 1991; Moretto 1991; Shujie et al. 1988; Zhang et al. 1991). In a cross-sectional survey on the prevalence of acute pyrethroid poisoning of cotton workers conducted in China in 1987 and 1988 (Chen et al. 1991), approximately 27\% (696 of 2,588 ) of the workers who sprayed pure pyrethroids reported having experienced symptoms such as abnormal facial sensations (paresthesia), dizziness, headache, nausea, loss of appetite, blurred vision, and tightness of the chest. Eight of these workers were diagnosed with mild acute pyrethroid poisoning, characterized in part by listlessness and muscular fasciculations. He et al. (1991) reported increased peripheral nerve excitability in cotton workers following 3 days of exposure to deltamethrin during spraying. Nerve excitability was assessed by presenting two sequential electrical stimuli of equal intensity and duration to the median nerve area of the wrist and recording the median nerve activity at the lateral side of the elbow. Following deltamethrin exposure, median nerve conduction measurements revealed a significant increase in the supernormal period, defined as a period after recovery of normal excitability (from a given action potential) during which an action potential induced by a second stimulus is higher in amplitude than the first action potential. In some of these studies, air concentrations of pyrethroids in the breathing zone of the sprayers were measured and ranged from approximately 0.005 to $2.0 \mu \mathrm{g} / \mathrm{m}^{3}$. However, one study reported air concentrations as high as $24 \mu \mathrm{g} / \mathrm{m}^{3}$ (Shujie et al. 1988). Among sprayers, dermal contact was considered to be the major source of exposure, although some of the sprayers also reported symptoms of nasal and laryngeal irritation (Moretto 1991). Facial paresthesia, dizziness, fatigue, miliary red facial papules, and sniffles and sneezes were noted in subjects exposed to deltamethrin and fenvalerate while packaging the insecticides (He et al. 1988). Air sampling indicated pyrethroid levels in the range of $0.005-0.055 \mathrm{mg} / \mathrm{m}^{3}$, but dermal contact was also evident, and may have been the basis for increased signs of toxicity during summer months.

In studies of acute lethality associated with inhalation exposure to pyrethrins or pyrethroids, neurological effects were observed at or near lethal exposure levels. However, most studies do not include doseresponse data for exposure levels much lower than those resulting in death. Tremors were observed in rats acutely exposed to pyrethrins at mean analytical airborne concentrations $\geq 2,100 \mathrm{mg} / \mathrm{m}^{3}$, but not at a concentration of $690 \mathrm{mg} / \mathrm{m}^{3}$ (Schoenig 1995). Acute exposure of rats to aerosols of a 13\% formulation of cyhalothrin, at analytical concentrations ranging from 3.6 to $68 \mathrm{mg} / \mathrm{m}^{3}$, resulted in dose-related increasing severity of neurological signs, ranging from temporary lethargy, abnormal posture, and salivation at the lowest concentration, to convulsions and death within 15 minutes postexposure at the highest concentration (Curry and Bennett 1985). Disturbed posture and abnormal motor activity were observed 
in rats exposed to aerosols of cyfluthrin for 4 hours at an analytical concentration of $17 \mathrm{mg} / \mathrm{m}^{3}$, the lowest level presented. A concentration of $735 \mathrm{mg} / \mathrm{m}^{3}$, which was lethal to many of the rats, caused severe behavioral disturbances in surviving rats that continued for 3 days postexposure (Pauluhn and Thyssen 1982). A group of female rats exhibited no signs of toxicity in response to acute exposure to cyfluthrin at an analytical concentration of $44 \mathrm{mg} / \mathrm{m}^{3}$ (Flucke and Thyssen 1980). Both male and female rats, similarly exposed to a concentration of $57 \mathrm{mg}$ cyfluthrin $/ \mathrm{m}^{3}$, showed signs of restlessness and altered gait. Labored breathing, hyperactivity, and tremors were reported in rats repeatedly exposed (6 hours/day, 5 days/week for 90 days) to pyrethrins at a mean airborne concentration of $356 \mathrm{mg} / \mathrm{m}^{3}$ (Schoenig 1995). Repeated 6-hour inhalation exposures to atmospheres containing cyfluthrin concentrations of $10.5 \mathrm{mg} / \mathrm{m}^{3}$ or higher resulted in dose-related unspecified clinical signs of behavioral disorders (Flucke and Thyssen 1980; Thyssen 1980). Occasional salivation was observed in rats repeatedly exposed to atmospheres of cypermethrin at a concentration of $50 \mathrm{mg} / \mathrm{m}^{3}$; a concentration of $250 \mathrm{mg} / \mathrm{m}^{3}$ resulted in additional signs of neurotoxicity that included decreased activity, lacrymation, head and paw flicking, and tip toe gait (EPA 1996).

The highest NOAEL values and all LOAEL values from each reliable study for neurological effects in each species and duration category are recorded in Table 3-1 and plotted in Figure 3-1.

No reports were located regarding the following health effects in humans or animals following inhalation exposure to pyrethrins or pyrethroids:

\subsubsection{Reproductive Effects}

\subsubsection{Developmental Effects}

\subsubsection{Cancer}

\subsubsection{Oral Exposure}

\subsubsection{Death}

Among 573 cases of acute pyrethroid poisoning reported in China between 1983 and 1988, 344 cases with accidental poisoning were considered to have been largely due to ingestion of pyrethroids (He et al. 1989). Four deaths were reported; two of these were related to occupational exposure. Peter et al. (1996) 
Table 3-1 Levels of Significant Exposure to Pyrethrins And Pyrethroids - Inhalation

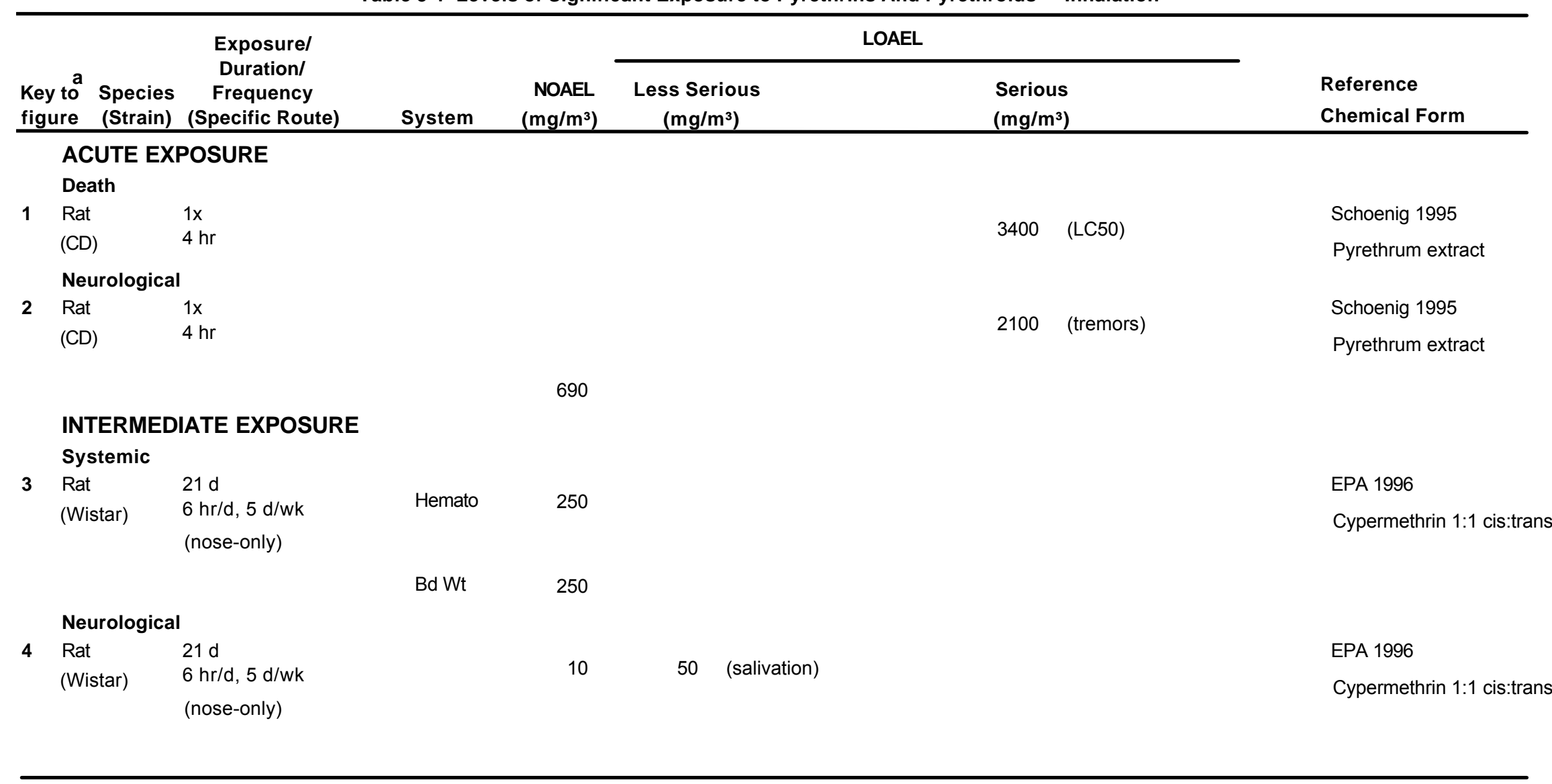

a The number corresponds to entries in Figure 3-1.

$\mathrm{Bd} \mathrm{Wt}=$ body weight; $\mathrm{d}=\operatorname{day}(\mathrm{s}) ;$ Hemato = hematological; $\mathrm{hr}=$ hour(s); LC50 = lethal concentration, $50 \%$ kill; $\mathrm{x}=$ time(s); wk = week(s) 
Figure 3-1. Levels of Significant Exposure to Pyrethrins and Pyrethroids - inhalation Acute ( $\leq 14$ days) Intermediate (15-364 days)

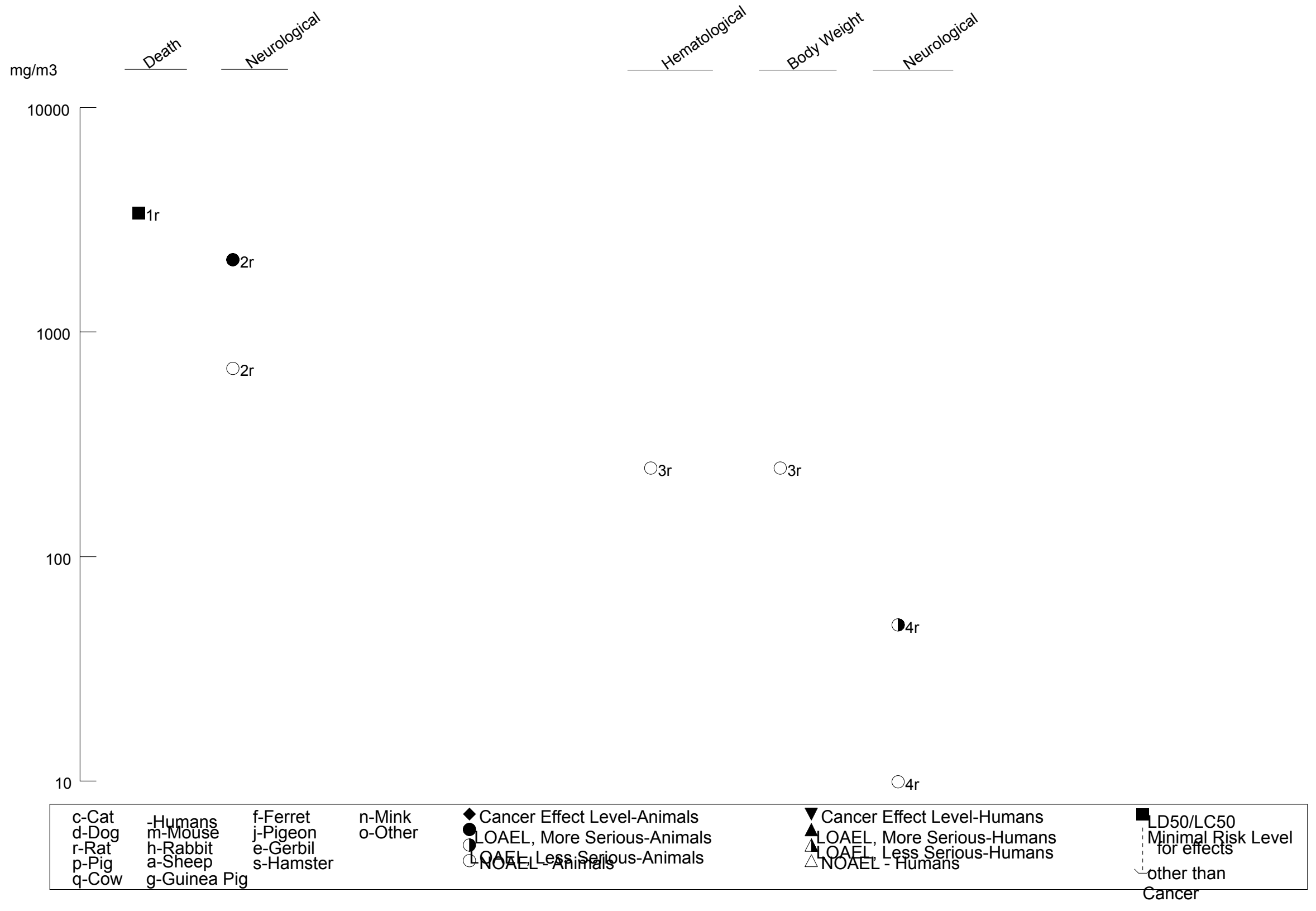


reported the death of a 30-year-old male approximately 2 days after he had consumed about $30 \mathrm{~mL}$ of deltamethrin. In another case, an adult male rapidly developed convulsions, became comatose, and died shortly after having accidentally ingested an unknown amount of $10 \%$ cypermethrin (Poulos et al. 1982). No other information was located regarding death in humans following oral exposure to pyrethrins or pyrethroids.

Animal studies associate mortality with relatively high oral exposure to pyrethrins and pyrethroids. Acute oral $\mathrm{LD}_{50}$ values for total pyrethrins from undiluted pyrethrum extract were 2,370 and $1,030 \mathrm{mg} / \mathrm{kg}$ in male and female rats, respectively (Schoenig 1995). Acute oral $\mathrm{LD}_{50}$ values for pyrethroids in rats range from approximately 18 to $>5,000 \mathrm{mg} / \mathrm{kg}$ (Casida et al. 1983; Metcalf 1995; Valentine 1990). The wide range in $\mathrm{LD}_{50}$ values is dependent on a number of factors including specific pyrethroid, ratios of stereo and optical isomers within a given pyrethroid formulation, and vehicle. For example, an acute oral $\mathrm{LD}_{50}$ value of $3,801 \mathrm{mg} / \mathrm{kg}$ was reported for rats receiving a gavage dose of permethrin ( $45 / 55 \mathrm{cis} / \mathrm{trans})$ neat, whereas the $\mathrm{LD}_{50}$ value was $584 \mathrm{mg} / \mathrm{kg}$ when the dose was administered in corn oil vehicle (DOD 1977). Acute oral $\mathrm{LD}_{50}$ values are generally lower in Type II than Type I pyrethroids, indicating a greater degree of toxicity for Type II pyrethroids. Pyrethroid-induced mortality appears to be influenced by ambient temperature. Acute oral $\mathrm{LD}_{50}$ values for cismethrin in female rats increased from $157 \mathrm{mg} / \mathrm{kg}$ at $4{ }^{\circ} \mathrm{C}$ to $197 \mathrm{mg} / \mathrm{kg}$ at $20^{\circ} \mathrm{C}$ and $>1,000 \mathrm{mg} / \mathrm{kg}$ at $30^{\circ} \mathrm{C}$ (White et al. 1976). In a 4-week oral study, mortality was observed in rats after 3-5 days of daily oral administration of cyfluthrin at a dose level of $80 \mathrm{mg} / \mathrm{kg} / \mathrm{day}$ (Flucke and Schilde 1980). In mice, repeated administration of fenvalerate, at a dose level of $80 \mathrm{mg} / \mathrm{kg} / \mathrm{day}$, also resulted in mortality that was considered to be compound related (Cabral and Galendo 1990). In 90-day oral studies, compound-related death was noted in rats and mice given diets containing pyrethrins at concentrations $\geq 10,000 \mathrm{ppm}$ ( 800 and $1,900 \mathrm{mg} / \mathrm{kg} /$ day for rats and mice, respectively) (Schoenig 1995). Compound-related mortality was also reported in pregnant rats and rabbits repeatedly administered oral doses of pyrethrins (in $0.5 \%$ methyl cellulose) $\geq 150$ and $600 \mathrm{mg} / \mathrm{kg} / \mathrm{day}$, respectively (Schoenig 1995). Three of four dogs died during an 8-week oral study in which pyrethrins were administered in the diet at a concentration of 6,000 ppm (approximate dose of $100 \mathrm{mg} / \mathrm{kg} / \mathrm{day}$ ) (Schoenig 1995). One of six dogs, administered $1,000 \mathrm{ppm}$ of fenvalerate in the diet (approximate dose of $80 \mathrm{mg} / \mathrm{kg} /$ day), was euthanized in extremis during week 24 after exhibiting signs of extreme neurotoxicity (Parker et al. 1984b). One of six dogs, given daily oral doses of cyhalothrin at $3.5 \mathrm{mg} / \mathrm{kg}$, was killed during week 46 of a 52-week oral dosing study, due to persistent pyrethroid-induced convulsions (Hext et al. 1986). Mortality was also observed during a 90-day oral exposure to permethrin in the diets of rats (DOD 1977). All 10 male and female rats in the projected $850 \mathrm{mg} / \mathrm{kg} /$ day exposure groups died during the study; actual doses were 505 and $870 \mathrm{mg} / \mathrm{kg} /$ day in males and females, respectively. Mortality was 
not significantly increased in rats or mice administered permethrin in the diet at concentrations resulting in estimated daily doses of up to $104 \mathrm{mg} / \mathrm{kg} /$ day for 2 years in rats or $350 \mathrm{mg} / \mathrm{kg} /$ day for 98 weeks in mice (Ishmael and Litchfield 1988).

Selected oral $\mathrm{LD}_{50}$ values for some pyrethroids are recorded in Table 3-2 and plotted in Figure 3-2.

\subsubsection{Systemic Effects}

The highest NOAEL values and all LOAEL values from each reliable study for each systemic effect in each species and duration category are recorded in Table 3-2 and plotted in Figure 3-2.

No reports were located regarding respiratory, cardiovascular, musculoskeletal, dermal, or ocular effects following oral exposure of humans or animals to pyrethrins or pyrethroids.

Gastrointestinal Effects. Information regarding gastrointestinal effects following oral exposure is mainly limited to clinical signs following exposure to pyrethroids. Symptoms such as epigastric pain, nausea, vomiting, and diarrhea have been reported in human subjects who consumed relatively large quantities of pyrethroids (Gotoh et al. 1998; He et al. 1989). Diarrhea was reported in dogs ingesting pyrethroids in the diet at dose levels as low as $1-6 \mathrm{mg} / \mathrm{kg} /$ day for treatment periods ranging from 13 weeks to 1 year (EPA 1981; IRIS 2003a, 2003b, 2003c). Gastritis and mucosal erosion and ulceration were observed in male mice fed esfenvalerate in the diet for 90 days at a concentration resulting in a mean dose of $106 \mathrm{mg} / \mathrm{kg} /$ day (EPA 1991a).

Hematological Effects. Information regarding hematological effects following oral exposure is limited. Leukocytosis was observed in $15 \%$ of 235 human cases of pyrethroid poisoning in which blood tests were performed (He et al. 1989). In most animal studies that examined hematological end points, no significant alterations were observed. However, Shakoori et al. (1992a) reported significantly decreased red blood cell count, hemoglobin content, and mean corpuscular hemoglobin, as well as increased white blood cell count in rabbits following daily oral administration of fenvalerate at a dose level of $10 \mathrm{mg} / \mathrm{kg}$ for 7 days. Schoenig (1995) reported evidence of anemia in surviving dogs that were fed pyrethrins in the diet for 8 weeks at a concentration resulting in a dose level of approximately $100 \mathrm{mg} / \mathrm{kg} / \mathrm{day}$. Decreases in red blood cell counts, hemoglobin, and hematocrit were observed in male and female mice fed esfenvalerate in the diet for 90 days at a concentration resulting in mean doses of 106 and $113 \mathrm{mg} / \mathrm{kg} / \mathrm{day}$, 
Table 3-2 Levels of Significant Exposure to Pyrethrins And Pyrethroids - Oral

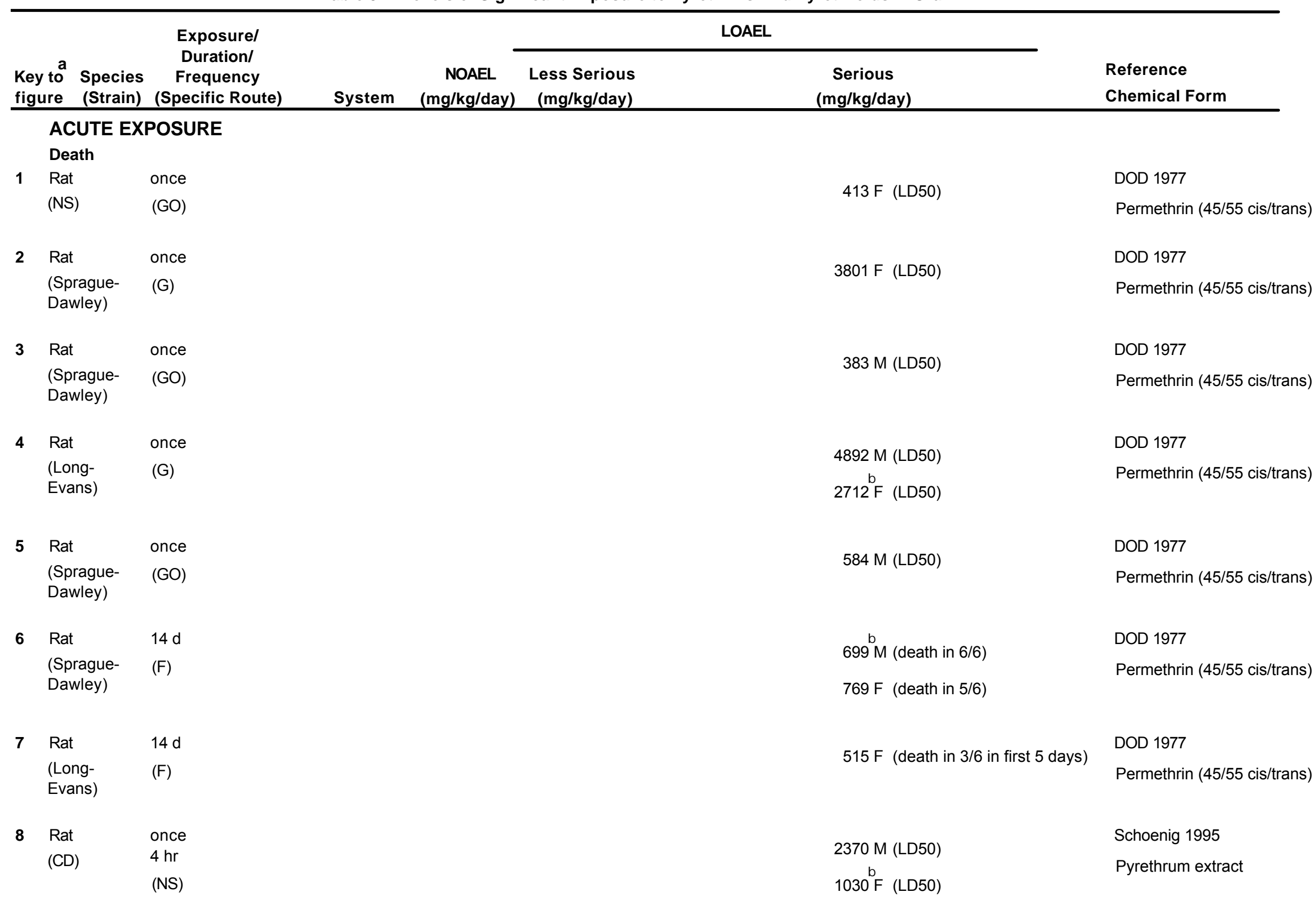


Table 3-2 Levels of Significant Exposure to Pyrethrins And Pyrethroids - Oral

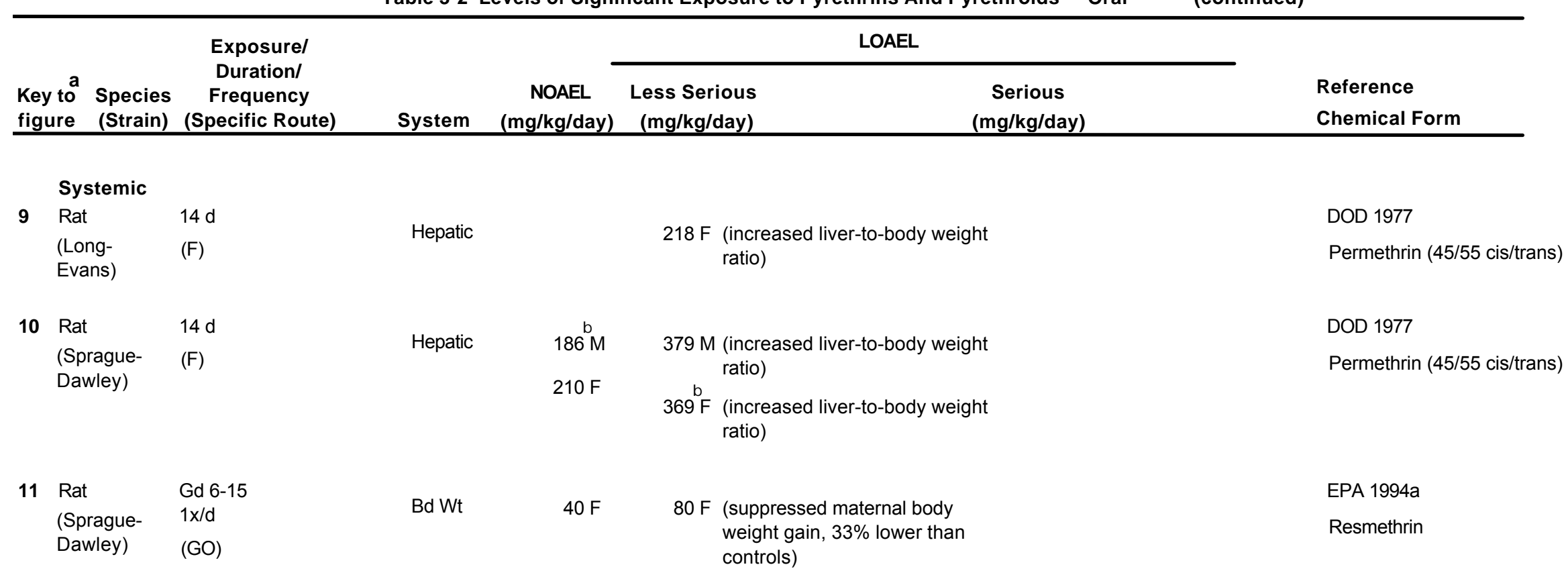




\begin{tabular}{|c|c|c|c|c|c|c|c|}
\hline \multirow{2}{*}{$\begin{array}{l}\text { Key to } \\
\text { figure }\end{array}$} & \multirow[b]{2}{*}{$\begin{array}{l}\text { Species } \\
\text { (Strain) }\end{array}$} & \multirow{2}{*}{$\begin{array}{c}\text { Exposure/ } \\
\text { Duration/ } \\
\text { Frequency } \\
\text { (Specific Route) } \\
\end{array}$} & \multirow[b]{2}{*}{ System } & \multirow[b]{2}{*}{$\begin{array}{c}\text { NOAEL } \\
(\mathrm{mg} / \mathrm{kg} / \text { day })\end{array}$} & \multicolumn{2}{|c|}{ LOAEL } & \multirow[b]{2}{*}{$\begin{array}{l}\text { Reference } \\
\text { Chemical Form }\end{array}$} \\
\hline & & & & & $\begin{array}{l}\text { Less Serious } \\
\text { (mg/kg/day) }\end{array}$ & $\begin{array}{c}\text { Serious } \\
\text { (mg/kg/day) }\end{array}$ & \\
\hline \multicolumn{8}{|c|}{ Neurological } \\
\hline \multirow[t]{3}{*}{12} & Rat & $14 \mathrm{~d}$ & \multicolumn{2}{|r|}{$186^{b} \mathrm{M}$} & & \multirow{2}{*}{$379 \mathrm{M}$ (muscle tremors) } & DOD 1977 \\
\hline & (Sprague- & $(F)$ & & & & & Permethrin (45/55 cis/trans) \\
\hline & & & & $210 \mathrm{~F}$ & & $369 \mathrm{~F}$ (muscle tremors) & \\
\hline \multirow[t]{3}{*}{13} & Rat & $14 \mathrm{~d}$ & \multirow{2}{*}{\multicolumn{2}{|c|}{$92 \mathrm{~b}$}} & & \multirow{2}{*}{$185^{\mathrm{b}} \mathrm{M}$ (muscle tremors) } & DOD 1977 \\
\hline & (Long- & $(\mathrm{F})$ & & & & & Permethrin (45/55 cis/trans) \\
\hline & Evans) & & & $114 \mathrm{~F}$ & & $218 \mathrm{~F}$ (muscle tremors) & \\
\hline \multirow[t]{3}{*}{14} & Rat & Gd 6-15 & \multirow{3}{*}{\multicolumn{2}{|c|}{$75 \mathrm{~F}$}} & & & EPA 1988c \\
\hline & (CD) & $1 \times / d$ & & & & & Pyrethrum extract \\
\hline & & $(\mathrm{G})$ & & & & & \\
\hline \multirow[t]{3}{*}{15} & Rat & Gd 6-15 & \multirow{3}{*}{\multicolumn{2}{|c|}{$37.5 \mathrm{~F}$}} & & \multirow{3}{*}{$75 \mathrm{~F}$ (transient tremors $2 / 5$ dams) } & EPA 1988c \\
\hline & (CD) & $1 \mathrm{x} / \mathrm{d}$ & & & & & Pyrethrum extract \\
\hline & & $(\mathrm{G})$ & & & & & \\
\hline \multirow[t]{3}{*}{16} & Rat & Gd 7-16 & \multirow{3}{*}{\multicolumn{2}{|c|}{150}} & & & EPA 1991b \\
\hline & (Wistar) & $1 \mathrm{X} / \mathrm{d}$ & & & & & Permethrin (40/60 cis/trans) \\
\hline & & (GO) & & & & & \\
\hline \multirow[t]{3}{*}{17} & Rat & Gd 7-16 & \multirow{3}{*}{\multicolumn{2}{|c|}{$50 \mathrm{~F}$}} & & \multirow{3}{*}{$\begin{array}{l}150 \mathrm{~F} \text { (tremors, head flicking, } \\
\text { piloerection) }\end{array}$} & EPA 1991b \\
\hline & (Wistar) & $1 \mathrm{X} / \mathrm{d}$ & & & & & Permethrin (40/60 cis/trans) \\
\hline & & (GO) & & & & & \\
\hline \multirow[t]{2}{*}{18} & Rat & once & \multirow{2}{*}{\multicolumn{2}{|c|}{5}} & & (tremorc calivation atayia) & EPA 1992b \\
\hline & $\begin{array}{l}\text { (Sprague- } \\
\text { Dawley) }\end{array}$ & (GO) & & & & zo (tientiots, sainvation, ataxia) & Esfenvalerate \\
\hline \multirow[t]{3}{*}{19} & \multirow{3}{*}{$\begin{array}{l}\text { Rat } \\
\text { (Sprague- } \\
\text { Dawley) }\end{array}$} & Gd 6-15 & \multirow{3}{*}{\multicolumn{2}{|c|}{$80 \mathrm{~F}$}} & & & EPA 1994a \\
\hline & & $\begin{array}{l}1 \mathrm{x} / \mathrm{d} \\
(\mathrm{GO})\end{array}$ & & & & & Resmethrin \\
\hline & & & & & & & \\
\hline
\end{tabular}


Table 3-2 Levels of Significant Exposure to Pyrethrins And Pyrethroids - Oral

\begin{tabular}{|c|c|c|c|c|c|c|c|}
\hline \multirow[b]{2}{*}{$\begin{array}{l}\text { Key to } \\
\text { figure }\end{array}$} & \multirow[b]{2}{*}{$\begin{array}{c}\text { Species } \\
\text { (Strain) }\end{array}$} & \multirow{2}{*}{$\begin{array}{c}\text { Exposure/ } \\
\text { Duration/ } \\
\text { Frequency } \\
\text { (Specific Route) }\end{array}$} & \multirow[b]{2}{*}{ System } & \multirow[b]{2}{*}{$\begin{array}{c}\text { NOAEL } \\
\text { (mg/kg/day) }\end{array}$} & \multicolumn{2}{|c|}{ LOAEL } & \multirow[b]{2}{*}{$\begin{array}{l}\text { Reference } \\
\text { Chemical Form }\end{array}$} \\
\hline & & & & & $\begin{array}{r}\text { Less Serious } \\
\text { (mg/kg/day) }\end{array}$ & $\begin{array}{c}\text { Serious } \\
\text { (mg/kg/day) }\end{array}$ & \\
\hline
\end{tabular}

20 Rat

(Long-

once

21 Rat

once

(Long-

Evans)

(GO)

22 Rat

(CD)

23 Rabbit

(New

Zealand)
Gd 7-19

$1 \mathrm{x} / \mathrm{d}$

(G)
$25^{\mathrm{C}}$

$20^{d} \quad$ (altered gait, decreased activity)

$710 \mathrm{M}$

$320^{\mathrm{b}} \mathrm{F}$

$100 \mathrm{~F}$ (salivation, head arching labored breathing in $1 / 16$ does)
75 (abnormal motor movements, decreased grip strength)

McDaniel and Moser 1993

Permethrin 50:50 cis:trans

McDaniel and Moser 1993

Cypermethrin 50:50 cis:trans

Schoenig 1995

Pyrethrum extract

EPA $1988 c$

Pyrethrum extract 
Table 3-2 Levels of Significant Exposure to Pyrethrins And Pyrethroids - Oral

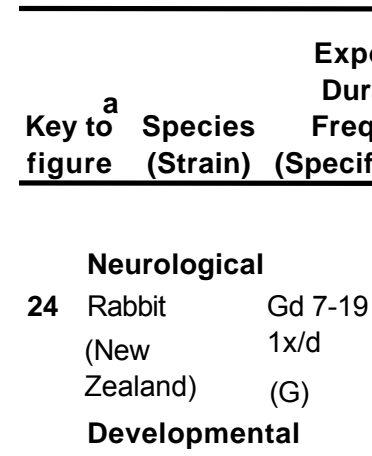

25 Rat (CD)

Gd 6-15

G)

26 Rat

Gd 6-15

(CD) $\quad 1 \times / d$

(G)

27 Rat (Wistar)

$\mathrm{X} / \mathrm{d}$

(GO)

28 Rat

(Beagle) $\quad 1 \mathrm{x} / \mathrm{d}$

(GO)

29 Rabbit

Gd 7-19

(New

$1 \mathrm{x} / \mathrm{d}$

Zealand)

(G)

\section{INTERMEDIATE EXPOSURE}

Death

30 Rat

(Sprague-

$90 d$

Dawley) LOAEL

LOAEL
Less Serious

Serious

Reference

Chemical Form

(mg/kg/day)

$300 \mathrm{~F}$ (tremors in $1 / 5$ does, $11 \%$ weight loss)

EPA 1988c

Pyrethrum extract

EPA 1988c

Pyrethrum extract

EPA 1988c

Pyrethrum extract

EPA 1991b

Permethrin (40/60 cis/trans)

EPA 1994a

Resmethrin

of skeletal variations, delayed ossification)

\section{EPA 1988c}

Pyrethrum extract

$505^{b} \mathrm{M}$ (death in $\left.10 / 10\right)$

$870 \mathrm{~F}$ (death in 10/10)

DOD 1977

Permethrin (45/55 cis/trans) 
Table 3-2 Levels of Significant Exposure to Pyrethrins And Pyrethroids - Oral

\begin{tabular}{|c|c|c|c|c|c|c|}
\hline & \multirow[b]{2}{*}{$\begin{array}{ll}\text { a } & \text { Species } \\
\text { te } & \text { (Strain) } \\
\end{array}$} & \multirow{2}{*}{$\begin{array}{c}\text { Exposure/ } \\
\text { Duration/ } \\
\text { Frequency } \\
\text { (Specific Route) } \\
\end{array}$} & \multirow[b]{2}{*}{ System } & \multirow[b]{2}{*}{$\begin{array}{c}\text { NOAEL } \\
(\mathrm{mg} / \mathrm{kg} / \text { day }) \\
\end{array}$} & LOAEL & \multirow[b]{2}{*}{$\begin{array}{l}\text { Reference } \\
\text { Chemical Form }\end{array}$} \\
\hline $\begin{array}{l}\text { Key to } \\
\text { figure }\end{array}$ & & & & & $\begin{array}{l}\text { Less Serious } \\
\text { (mg/kg/day) }\end{array}$ & \\
\hline & \multicolumn{2}{|l|}{ Systemic } & & & & \\
\hline \multirow[t]{3}{*}{31} & \multirow{3}{*}{$\begin{array}{l}\text { Rat } \\
\text { (Sprague- } \\
\text { Dawley) }\end{array}$} & \multirow{3}{*}{$\begin{array}{l}90 \mathrm{~d} \\
(\mathrm{~F})\end{array}$} & \multirow{3}{*}{ Hepatic } & \multirow{2}{*}{$73.6^{\mathrm{b}} \mathrm{M}$} & \multirow{2}{*}{$\begin{array}{l}243.5 \mathrm{~b} \mathrm{M} \text { (increased liver-to-body weight } \\
\text { ratio) }\end{array}$} & \multirow{3}{*}{$\begin{array}{l}\text { DOD } 1977 \\
\text { Permethrin (45/55 cis/trans) }\end{array}$} \\
\hline & & & & & & \\
\hline & & & & 0. & $\begin{array}{l}250.7 \mathrm{~F} \text { (increased liver-to-body weight } \\
\text { ratio) }\end{array}$ & \\
\hline \multirow[t]{2}{*}{32} & \multirow{2}{*}{$\begin{array}{l}\text { Rat } \\
\text { (Wistar) }\end{array}$} & $28 \mathrm{~d}$ & \multirow{2}{*}{$B d W t$} & \multirow{2}{*}{$1 \mathrm{~F}$} & & EPA 1985a \\
\hline & & $(F)$ & & & & Cyhalothrin \\
\hline \multirow[t]{3}{*}{33} & \multirow{3}{*}{$\begin{array}{l}\text { Rat } \\
\text { (Wistar) }\end{array}$} & $90 \mathrm{~d}$ & \multirow{2}{*}{ Ocular } & \multirow{2}{*}{$21.2 \mathrm{M}$} & & EPA 1985b \\
\hline & & $(F)$ & & & & Cyhalothrin \\
\hline & & & $\mathrm{Bd} W \mathrm{t}$ & $5.4 \mathrm{M}$ & $\begin{array}{l}21.2 \mathrm{M} \text { (depressed body weight, } \\
10-16 \%)\end{array}$ & \\
\hline \multirow[t]{2}{*}{34} & \multirow{2}{*}{$\begin{array}{l}\text { Rat } \\
(\mathrm{CD})\end{array}$} & Gd 6-15 & \multirow{2}{*}{$\mathrm{Bd} W \mathrm{t}$} & \multirow{2}{*}{$15 \mathrm{~F}$} & & EPA 1986a \\
\hline & & $\begin{array}{l}1 \mathrm{x} / \mathrm{d} \\
(\mathrm{GO})\end{array}$ & & & & Cyhalothrin \\
\hline
\end{tabular}


Table 3-2 Levels of Significant Exposure to Pyrethrins And Pyrethroids - Oral

\begin{tabular}{|c|c|c|c|c|c|c|}
\hline \multirow[b]{2}{*}{$\begin{array}{l}\text { Key t } \\
\text { figur }\end{array}$} & \multirow[b]{2}{*}{$\begin{array}{ll}\text { a } & \text { Species } \\
\text { : } & \text { (Strain) } \\
\end{array}$} & \multirow{2}{*}{$\begin{array}{c}\text { Exposure/ } \\
\text { Duration/ } \\
\text { Frequency } \\
\text { (Specific Route) }\end{array}$} & \multirow[b]{2}{*}{ System } & \multirow[b]{2}{*}{$\begin{array}{c}\text { NOAEL } \\
(\mathrm{mg} / \mathrm{kg} / \text { day })\end{array}$} & LOAEL & \multirow[b]{2}{*}{$\begin{array}{l}\text { Reference } \\
\text { Chemical Form }\end{array}$} \\
\hline & & & & & $\begin{array}{l}\text { Less Serious } \\
(\mathrm{mg} / \mathrm{kg} / \text { day })\end{array}$ & \\
\hline \multirow{4}{*}{35} & \multicolumn{2}{|l|}{ Systemic } & & \multirow{3}{*}{$9.2^{\mathrm{b}} \mathrm{M}$} & & \\
\hline & \multirow{3}{*}{$\begin{array}{l}\text { Rat } \\
\text { (Wistar) }\end{array}$} & \multirow[t]{3}{*}{ continuous } & \multirow{3}{*}{$\mathrm{Bd} W \mathrm{t}$} & & & \multirow{3}{*}{$\begin{array}{l}\text { EPA 1986b } \\
\text { Cyhalothrin }\end{array}$} \\
\hline & & & & & & \\
\hline & & & & $10.3 \mathrm{~F}$ & & \\
\hline \multirow[t]{3}{*}{36} & \multirow{3}{*}{$\begin{array}{l}\text { Rat } \\
\text { (Sprague- } \\
\text { Dawley) }\end{array}$} & \multirow{3}{*}{$\begin{array}{l}13 w k \\
(F)\end{array}$} & \multirow{3}{*}{$\mathrm{Bd} W \mathrm{t}$} & \multirow{2}{*}{$150.35^{\mathrm{b}} \mathrm{M}$} & & \multirow{3}{*}{$\begin{array}{l}\text { EPA 1994b } \\
\text { Permethrin 50:50 cis:trans }\end{array}$} \\
\hline & & & & & & \\
\hline & & & & $189.66 \mathrm{~F}$ & & \\
\hline \multirow[t]{9}{*}{37} & \multirow{9}{*}{$\begin{array}{l}\text { Mouse } \\
\text { (B6C3F1) }\end{array}$} & \multirow{9}{*}{$\begin{array}{l}90 \mathrm{~d} \\
(\mathrm{~F})\end{array}$} & \multirow{3}{*}{ Gastro } & \multirow{3}{*}{$\begin{array}{l}30.5^{\mathrm{b}} \mathrm{M} \\
113 \mathrm{~F}\end{array}$} & \multirow{3}{*}{$\begin{array}{c}106 \mathrm{M} \text { (mucosal erosion and } \\
\text { ulceration, gastritis) }\end{array}$} & \multirow{9}{*}{$\begin{array}{l}\text { EPA 1991a } \\
\text { Esfenvalerate }\end{array}$} \\
\hline & & & & & & \\
\hline & & & & & & \\
\hline & & & \multirow[t]{2}{*}{ Hemato } & $30.5^{\mathrm{b}} \mathrm{M}$ & \multirow{2}{*}{$\begin{array}{l}106 \mathrm{~b} \text { (decreased RBCs, hemoglobin, } \\
\text { hematocrit) } \\
113 \mathrm{~F} \text { (decreased RBCs, hemoglobin, } \\
\text { hematocrit) }\end{array}$} & \\
\hline & & & & $36.8 \mathrm{~F}$ & & \\
\hline & & & \multirow[t]{2}{*}{ Dermal } & \multirow{2}{*}{$\begin{array}{l}30.5 \mathrm{~b} \\
36.8 \mathrm{~F}\end{array}$} & $\begin{array}{c}106 \mathrm{~b} \text { M (dermatitis, hyperkeratosis, } \\
\text { ulceration) }\end{array}$ & \\
\hline & & & & & $\begin{array}{l}113 \mathrm{~F} \text { (dermatitis, hyperkeratosis, } \\
\text { ulceration) }\end{array}$ & \\
\hline & & & \multirow[t]{2}{*}{$\mathrm{Bd} W \mathrm{t}$} & \multirow{2}{*}{$\begin{array}{l}30.5 \mathrm{~b} \mathrm{M} \\
36.8 \mathrm{~F}\end{array}$} & $\begin{array}{l}106 \mathrm{~b} \text { M (50\% suppressed body weight } \\
\text { gain) }\end{array}$ & \\
\hline & & & & & $\begin{array}{l}113 \mathrm{~F} \text { (35\% suppressed body weight } \\
\text { gain) }\end{array}$ & \\
\hline 38 & Dog & $26 w k$ & Gastro & $1^{e}$ & 2.5 (diarrhea) & EPA 1981 \\
\hline & (Beagle) & $\begin{array}{l}1 \mathrm{x} / \mathrm{d} \\
(C)\end{array}$ & & & 2.0 (niantiea) & \\
\hline & & & Ocular & 10 & & \\
\hline
\end{tabular}




\begin{tabular}{|c|c|c|c|c|c|c|c|}
\hline \multirow[b]{2}{*}{$\begin{array}{l}\text { Key to } \\
\text { figure }\end{array}$} & \multirow[b]{2}{*}{$\begin{array}{l}\text { Species } \\
\text { (Strain) }\end{array}$} & \multirow{2}{*}{$\begin{array}{c}\text { Exposure/ } \\
\text { Duration/ } \\
\text { Frequency } \\
\text { (Specific Route) } \\
\end{array}$} & \multirow[b]{2}{*}{ System } & \multirow[b]{2}{*}{$\begin{array}{c}\text { NOAEL } \\
\text { (mg/kg/day) }\end{array}$} & \multicolumn{2}{|c|}{ LOAEL } & \multirow[b]{2}{*}{$\begin{array}{l}\text { Reference } \\
\text { Chemical Form }\end{array}$} \\
\hline & & & & & $\begin{array}{l}\text { Less Serious } \\
\text { (mg/kg/day) }\end{array}$ & $\begin{array}{c}\text { Serious } \\
\text { (mg/kg/day) }\end{array}$ & \\
\hline
\end{tabular}

Bd Wt $\quad 10$

Neurological

39 Rat >120d

(CD) continuous

$(\mathrm{F})$

40 Rat 2 gen

(CD) continuous

$(\mathrm{F})$

41 Rat

(Sprague-

Dawley)

$13 w k$

(F)

42 Mouse

(B6C3F1)

$90 \mathrm{~d}$

(F)

43 Dog 26 wk

(Beagle) $\quad 1 x / d$

(C)
27 (hypersensitivity to sound)

$15.49^{\mathrm{f}} \mathrm{M}$

$18.66 \mathrm{~F}$

$30.5^{\mathrm{b}} \mathrm{M}$

$36.8 \mathrm{~F}$
EPA 1992c

Cypermethrin

EPA 1994a

Resmethrin

EPA 1994b

Permethrin 50:50 cis:trans hindlimb splay)

111.37 F (tremors, staggered gait, hindlimb splay)

$106^{\mathrm{b}} \mathrm{M}$ (tremors, staggered gait, hindlimb splay)

EPA 1991a

Esfenvalerate

$113 \mathrm{~F}$ (multiple signs including tremors, convulsions, abnormal gait)

10 (muscle tremors

EPA 1981 incoordination)

Cyhalothrin 


\begin{tabular}{|c|c|c|c|c|c|c|c|}
\hline \multirow[b]{2}{*}{$\begin{array}{l}\text { Key to } \\
\text { figure }\end{array}$} & \multirow[b]{2}{*}{$\begin{array}{l}\text { Species } \\
\text { (Strain) }\end{array}$} & \multirow{2}{*}{$\begin{array}{l}\text { Exposure/ } \\
\text { Duration/ } \\
\text { Frequency } \\
\text { (Specific Route) }\end{array}$} & \multirow[b]{2}{*}{ System } & \multirow[b]{2}{*}{$\begin{array}{c}\text { NOAEL } \\
\text { (mg/kg/day) }\end{array}$} & \multicolumn{2}{|c|}{ LOAEL } & \multirow[b]{2}{*}{$\begin{array}{l}\text { Reference } \\
\text { Chemical Form }\end{array}$} \\
\hline & & & & & $\begin{array}{l}\text { Less Serious } \\
\text { (mg/kg/day) }\end{array}$ & $\begin{array}{c}\text { Serious } \\
\text { (mg/kg/day) }\end{array}$ & \\
\hline
\end{tabular}

\section{Reproductive}

44 Rat 65

(albino) $\quad 1 x / d$

(GW)

45 Rat (Wistar)

continuous

$9.2^{\mathrm{b}} \mathrm{M}$

$10.3 \mathrm{~F}$

46 Rat

continuous

(CD) (F)

47 Rat 2 gen

(CD) continuous

$(\mathrm{F})$

Developmental

48 Rat Gd 6-15

(CD) $\quad 1 \times / d$

(GO)

49 Rat 2 gen

(CD) continuous

$(\mathrm{F})$

50 Rat Gd 4-21

(Wistar) Ld 1-21

$1 \mathrm{x} /$ day

(GO)

51 Rat Gd 4-21

(Wistar) Ld 1-21

$1 \mathrm{x} / \mathrm{day}$

(GO)
$1 \mathrm{M}(50 \%$ reduction in successful impregnation)

Abd El-Aziz et al. 1994

Deltamethrin

EPA 1986b

Cyhalothrin

EPA 1992c

Cypermethrin

EPA 1994a

Resmethrin

EPA 1986a

Cyhalothrin

EPA 1994a

Resmethrin

Malaviya et al. 1993

Fenvalerate

Malaviya et al. 1993

Cypermethrin
15 (increased levels of dopamine and muscarinic receptors in striatal membrane) and muscarinic receptors in

striatal membrane) 
Table 3-2 Levels of Significant Exposure to Pyrethrins And Pyrethroids - Oral

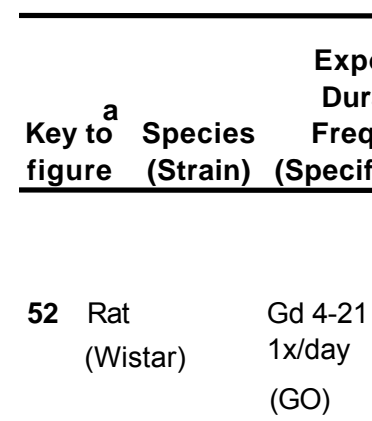

53 Rat (Wistar)

Gd 4-21

$\mathrm{x} /$ day

(GO)
LOAEL

NOAEL Less Serious Serious

(mg/kg/day)

15 (increased levels of muscarinic

receptors in striatal membrane)

10 (decreased levels of dopamine receptors in striatal membrane)
Reference

Chemical Form

Malaviya et al. 1993

Cypermethrin

Malaviya et al. 1993

Fenvalerate 
Table 3-2 Levels of Significant Exposure to Pyrethrins And Pyrethroids - Oral

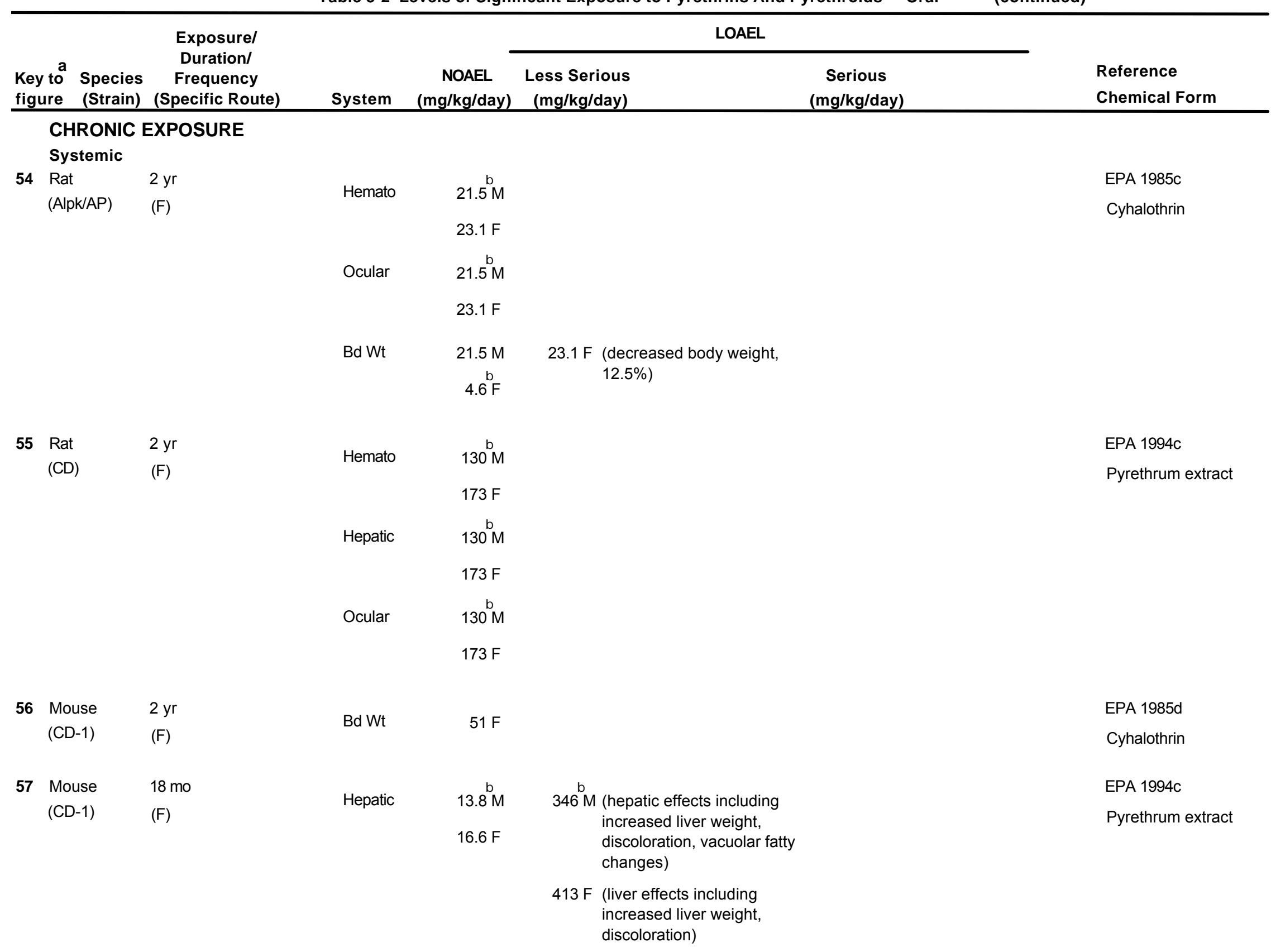


Table 3-2 Levels of Significant Exposure to Pyrethrins And Pyrethroids - Oral

\begin{tabular}{|c|c|c|c|c|c|c|c|}
\hline \multirow[b]{2}{*}{$\begin{array}{l}\text { Key to } \\
\text { figure }\end{array}$} & \multirow[b]{2}{*}{$\begin{array}{c}\text { Species } \\
\text { (Strain) }\end{array}$} & \multirow{2}{*}{$\begin{array}{l}\text { Exposure/ } \\
\text { Duration/ } \\
\text { Frequency } \\
\text { (Specific Route) }\end{array}$} & \multirow[b]{2}{*}{ System } & \multirow[b]{2}{*}{$\begin{array}{c}\text { NOAEL } \\
\text { (mg/kg/day) }\end{array}$} & \multicolumn{2}{|c|}{ LOAEL } & \multirow[b]{2}{*}{$\begin{array}{l}\text { Reference } \\
\text { Chemical Form }\end{array}$} \\
\hline & & & & & $\begin{array}{r}\text { Less Serious } \\
\text { (mg/kg/day) }\end{array}$ & $\begin{array}{c}\text { Serious } \\
\text { (mg/kg/day) }\end{array}$ & \\
\hline
\end{tabular}

$\quad 686^{\mathrm{b}} \mathrm{M}$
$834 \mathrm{~F}$

58 Mouse $85 \mathrm{wk}$

$(\mathrm{CD}-1) \quad(\mathrm{F})$

$\begin{array}{lr}\text { Cardio } & \begin{array}{r}137.9^{\mathrm{b}} \mathrm{M} \\ 165.8 \mathrm{~F}\end{array} \\ & \begin{array}{l}137.9^{\mathrm{b}} \mathrm{M} \\ \text { Gastro }\end{array} \\ & 165.8 \mathrm{~F} \\ & 137.9^{\mathrm{b}} \mathrm{M} \\ \text { Hepatic } & 165.8 \mathrm{~F} \\ & 137.9 \mathrm{~b} \mathrm{M} \\ \text { Renal } & 165.8 \mathrm{~F} \\ & 137.9^{\mathrm{b}} \mathrm{M} \\ & 165.8 \mathrm{~F}\end{array}$

EPA 1994d

Resmethrin 


\begin{tabular}{|c|c|c|c|c|c|c|c|}
\hline \multirow[b]{2}{*}{$\begin{array}{l}\text { Key } t \\
\text { figur }\end{array}$} & \multirow[b]{2}{*}{$\begin{array}{ll}\text { a } & \text { Species } \\
\text { o } & \text { Specin) } \\
\text { e } & \text { (Strain } \\
\end{array}$} & \multirow{2}{*}{$\begin{array}{c}\text { Exposure/ } \\
\text { Duration/ } \\
\text { Frequency } \\
\text { (Specific Route) }\end{array}$} & \multirow[b]{2}{*}{ System } & \multirow[b]{2}{*}{$\begin{array}{c}\text { NOAEL } \\
(\mathrm{mg} / \mathrm{kg} / \mathrm{day})\end{array}$} & \multicolumn{2}{|c|}{ LOAEL } & \multirow[b]{2}{*}{$\begin{array}{l}\text { Reference } \\
\text { Chemical Form }\end{array}$} \\
\hline & & & & & $\begin{array}{r}\text { Less Serious } \\
\text { (mg/kg/day) }\end{array}$ & $\begin{array}{c}\text { Serious } \\
\text { (mg/kg/day) }\end{array}$ & \\
\hline \multicolumn{8}{|c|}{ Neurological } \\
\hline \multirow[t]{3}{*}{59} & Rat & $2 \mathrm{yr}$ & & $\stackrel{b}{b}$ & & & EPA 1994c \\
\hline & (CD) & $(F)$ & & $100 \mathrm{in}$ & & & Pyrethrum extract \\
\hline & & & & $173 \mathrm{~F}$ & & & \\
\hline \multirow[t]{3}{*}{60} & Rat & $2 \mathrm{yr}$ & & $\stackrel{b}{b}$ & & $1872^{\mathrm{b}} \mathrm{M}$ (sliaht whole hodv tremors & Ishmael and Litchfield 1988 \\
\hline & (Wistar) & $(F)$ & & & & during first 2 weeks) & Permethrin (40/60 cis/trans) \\
\hline & & & & $40.2 \mathrm{~F}$ & & $\begin{array}{c}200.1 \mathrm{~F} \text { (slight whole body tremors } \\
\text { during first } 2 \text { weeks) }\end{array}$ & \\
\hline \multirow[t]{3}{*}{61} & Rat & $104 \mathrm{wk}$ & & $\stackrel{b}{b}$ & & & Parker et al. 1984a \\
\hline & (Sprague- & $(\mathrm{F})$ & & $10 \mathrm{TVI}$ & & incoordination) & Fenvalerate \\
\hline & & & & $20 \mathrm{~F}$ & & & \\
\hline \multirow[t]{2}{*}{62} & Mouse & $2 \mathrm{yr}$ & & $57.6 \mathrm{M}$ & & & EPA 1985d \\
\hline & (CD-1) & $(\mathrm{F})$ & & b & & & Cyhalothrin \\
\hline \multirow[t]{3}{*}{63} & Mouse & $18 \mathrm{mo}$ & & $\stackrel{b}{b}$ & & & EPA 1994c \\
\hline & $(C D-1)$ & $(F)$ & & & & & Pyrethrum extract \\
\hline & & & & $834 \mathrm{~F}$ & & & \\
\hline \multirow[t]{3}{*}{64} & Mouse & $85 w k$ & & $1379^{\mathrm{b}} \mathrm{M}$ & & & EPA 1994d \\
\hline & $(\mathrm{CD}-1)$ & $(F)$ & & IVI & & & Resmethrin \\
\hline & & & & $165.8 \mathrm{~F}$ & & & \\
\hline \multirow[t]{2}{*}{65} & Mouse & $2 \mathrm{yr}$ & & $295.1^{\mathrm{b}} \mathrm{M}$ & & & Ishmael and Litchfield 1988 \\
\hline & (Swiss) & $(F)$ & & $348.1 \mathrm{~F}$ & & & Permethrin (40/60 cis/trans) \\
\hline
\end{tabular}


Table 3-2 Levels of Significant Exposure to Pyrethrins And Pyrethroids - Oral

\begin{tabular}{|c|c|c|c|c|c|c|c|}
\hline \multirow[b]{2}{*}{$\begin{array}{l}\text { Key to } \\
\text { figure }\end{array}$} & \multirow[b]{2}{*}{$\begin{array}{c}\text { Species } \\
\text { (Strain) }\end{array}$} & \multirow{2}{*}{$\begin{array}{c}\text { Exposure/ } \\
\text { Duration/ } \\
\text { Frequency } \\
\text { (Specific Route) }\end{array}$} & \multirow[b]{2}{*}{ System } & \multirow[b]{2}{*}{$\begin{array}{c}\text { NOAEL } \\
\text { (mg/kg/day) }\end{array}$} & \multicolumn{2}{|c|}{ LOAEL } & \multirow[b]{2}{*}{$\begin{array}{l}\text { Reference } \\
\text { Chemical Form }\end{array}$} \\
\hline & & & & & $\begin{array}{r}\text { Less Serious } \\
\text { (mg/kg/day) }\end{array}$ & $\begin{array}{c}\text { Serious } \\
\text { (mg/kg/day) }\end{array}$ & \\
\hline
\end{tabular}

66 Dog $1 \mathrm{yr}$

(Beagle) (C)

67 Dog

(Beagle)

$1 \mathrm{yr}$

8 Dog

(Beagle)

$52 \mathrm{wk}$

$1 \mathrm{x} / \mathrm{d}$

(GO)

69 Dog

(Beagle)
100
1000 (tremors, incoordinated gait, convulsions, excessive salivation)

\begin{tabular}{lll} 
& EPA 1987 \\
& Esfenvalerate \\
& Hext et al. 1986 \\
& Cyhalothrin \\
\hline (muscle tremors, ataxia) & $\begin{array}{l}\text { (tremors, gait abnormalities, } \\
\text { incoordination, disorientation, } \\
\text { hypersensitivity to sound) }\end{array}$ & Cypermethrin \\
\hline
\end{tabular}

EPA 1983

Permethrin (40/60 cis/trans)

ersensitivity to sound) 


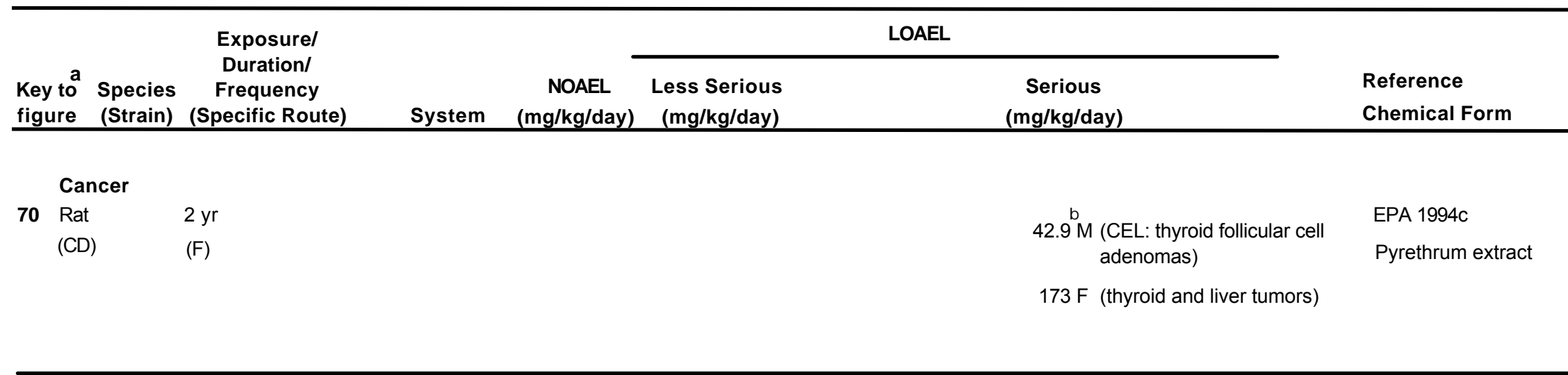

a The number corresponds to entries in Figure 3-2.

b Differences in levels of health effects and cancer effects between males and females are not indicated in Figure 3-2. Where such differences exist, only the levels of effects for the most sensitive gender are presented.

c Used to derive an acute-duration oral minimal risk level (MRL) of $0.3 \mathrm{mg} / \mathrm{kg} /$ day for permethrin ( $95 \%$ purity; $50 / 50$ cis/trans). The MRL was derived by dividing the NOAEL of 25 $\mathrm{mg} / \mathrm{kg} /$ day by an uncertainty factor of 100 (10 for animal to human extrapolation and 10 for intrahuman variation).

d Used to derive an acute-duration oral minimal risk level (MRL) of $0.02 \mathrm{mg} / \mathrm{kg} / \mathrm{day}$ for cypermethrin ( $97 \%$ purity, 50/50 cis/trans, in corn oil vehicle). The MRL was derived by dividing the LOAEL of $20 \mathrm{mg} / \mathrm{kg} /$ day by an uncertainty factor of 1000 (10 for the use of a LOAEL, 10 for animal to human extrapolation and 10 for intrahuman variation).

e Used to derive both an acute- and intermediate-duration oral minimal risk level (MRL) of $0.01 \mathrm{mg} / \mathrm{kg} /$ day for cyhalothrin. The MRL was derived by dividing the NOAEL of 1 $\mathrm{mg} / \mathrm{kg} /$ day by an uncertainty factor of 100 (10 for animal to human extrapolation and 10 for intrahuman variation).

$\mathrm{f}$ Used to derive an intermediate-duration oral minimal risk level (MRL) of $0.2 \mathrm{mg} / \mathrm{kg} / \mathrm{day}$ for permethrin. The MRL was derived by dividing the NOAEL of $15.5 \mathrm{mg} / \mathrm{kg} / \mathrm{day}$ by an uncertainty factor of 100 (10 for animal to human extrapolation and 10 for intrahuman variation).

$\mathrm{B}=$ both; $\mathrm{Bd} \mathrm{Wt}=$ body weight; $(\mathrm{C})$ = capsule; cardio = cardiovascular; $\mathrm{d}=\mathrm{day}(\mathrm{s}) ;(\mathrm{F})=$ feed; $\mathrm{F}=$ female; $(\mathrm{G})=$ gavage; gastro = gastrointestinal; gen = generation; Gd = gestation day; $(\mathrm{GO})$ = gavage in oil; $(\mathrm{GW})$ = gavage in water; hemato = hematological; $\mathrm{hr}=$ hour(s); Ld = lactation day; LD50 = lethal dose, $50 \%$ kill; $\mathrm{LOAEL}=$

lowest-observed-adverse-effect level; $\mathrm{M}=$ male; $\mathrm{mg} / \mathrm{kg} /$ day = milligram per kilogram per day; $\mathrm{mo}=$ month(s); NOAEL = no-observed-adverse-effect level; (NS) = not specified; ppd = post-parturition day; $w k=$ week(s); $x=$ time; $y r=$ year(s) 
Figure 3-2. Levels of Significant Exposure to Pyrethrins and Pyrethroids - Oral Acute ( $\leq 14$ days) 
Figure 3-2. Levels of Significant Exposure to Pyrethrins and Pyrethroids - Oral (Continued)

Intermediate (15-364 days)
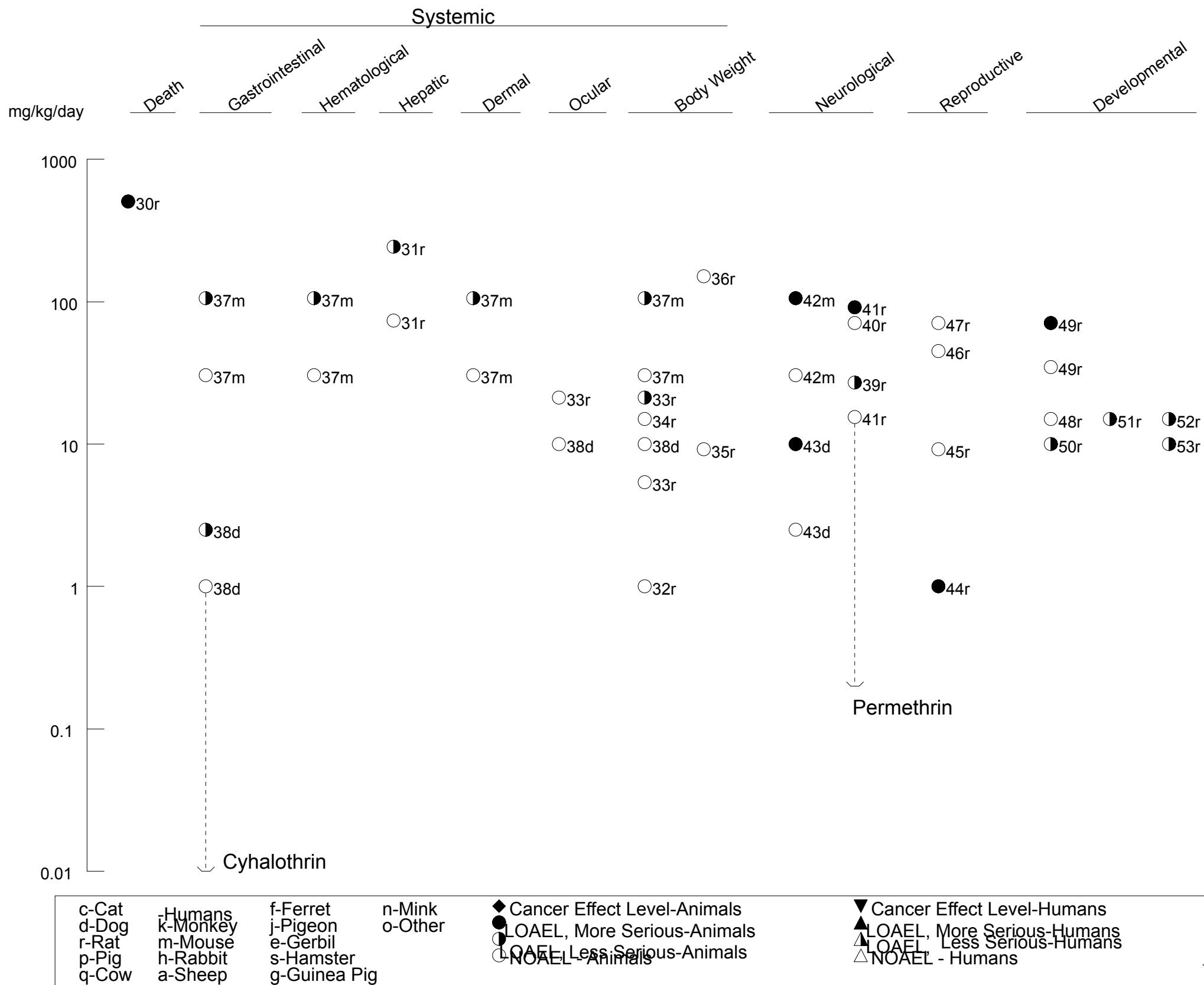

LD50/LC50

Mipimatedisk Level other than

Cancer 
Figure 3-2. Levels of Significant Exposure to Pyrethrins and Pyrethroids - Oral (Continued)

Chronic ( $\geq 365$ days)

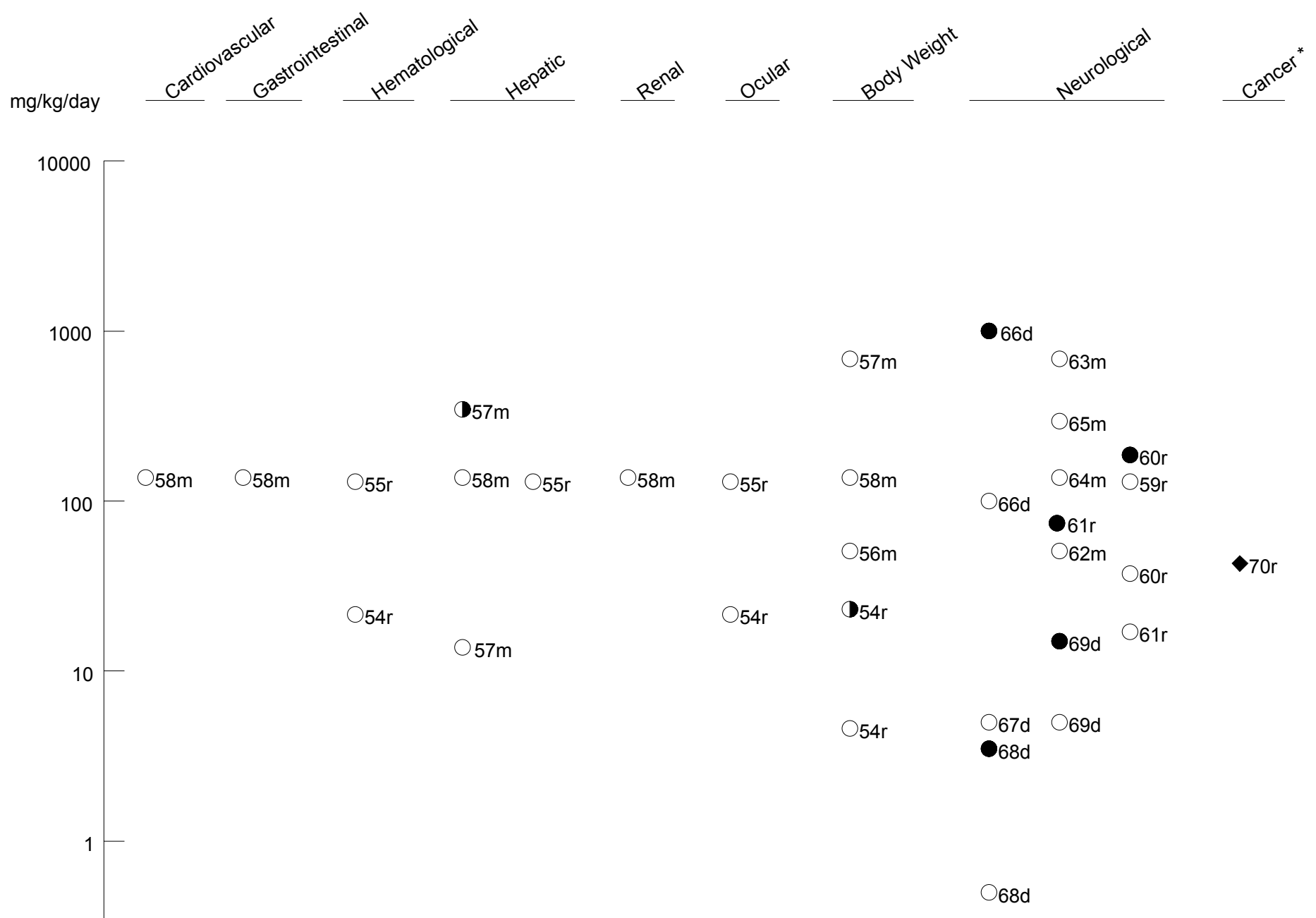

*Doses represent the lowest dose tested per study that produced a tumorigenic response and do not imply the existence of a threshold for the cancer endpoint.

01

\begin{tabular}{|c|c|c|c|c|c|c|}
\hline $\begin{array}{l}\text { c-Cat } \\
\text { d-Dog } \\
\text { r-Rat } \\
\text { p-Pig } \\
\text { q-Cow }\end{array}$ & $\begin{array}{l}\text { k-Mymans } \\
\text { m-Monkey } \\
\text { m-Mouse } \\
\text { h-Rabbit } \\
\text { a-Sheep }\end{array}$ & $\begin{array}{l}\text { f-Ferret } \\
\text { j-Pigeon } \\
\text { e-Gerbil } \\
\text { s-Hamster } \\
\text { g-Guinea Pig }\end{array}$ & $\begin{array}{l}\text { n-Mink } \\
\text { o-Other }\end{array}$ & 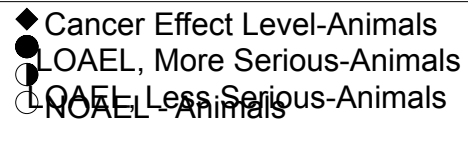 & $\begin{array}{l}\nabla \text { Cancer Effect Level-Humans } \\
\text { ALAEL, More Serious-Humans } \\
\text { LOAEL, Less Serious-Humans } \\
\text { NOAEL - Humans }\end{array}$ & $\begin{array}{l}\text { LD50/LC50 } \\
\text { Minimal Risk Level } \\
\text { for effects } \\
\text { 'other than }\end{array}$ \\
\hline
\end{tabular}


respectively (EPA 1991a). In a 6-month feeding study in dogs, decreased red blood cell counts and decreased hematocrit and hemoglobin were observed at a dietary concentration of fenpropathrin that resulted in a dose level of approximately $20 \mathrm{mg} / \mathrm{kg}$ /day (Parker et al. 1984b). Hematology and blood chemistry data from rats and mice, administered permethrin in the diet at concentrations resulting in estimated doses of up to $104 \mathrm{mg} / \mathrm{kg} /$ day for 2 years (rats) or $350 \mathrm{mg} / \mathrm{kg} /$ day for 98 weeks (mice), did not indicate significant treatment-related hematological effects (Ishmael and Litchfield 1988). Hematological effects were not seen in male or female rats fed cyhalothrin or pyrethrum extract in the diet for 2 years at concentrations resulting in cyhalothrin doses of 21.5 and $23.1 \mathrm{mg} / \mathrm{kg} /$ day (males and females, respectively) or total pyrethrin doses of 130 and $173 \mathrm{mg} / \mathrm{kg} /$ day (males and females, respectively) (EPA 1985c, 1994c).

In a number of oral animal studies that were performed for the pesticide industry and evaluated by the EPA, statistically significant hematological effects were attributed to adaptive responses rather than pyrethroid-induced hematotoxicity per se. However, treatment-related anemia was reported in mice treated for 90 days with esfenvalerate in the food, which resulted in doses of approximately 106$113 \mathrm{mg} / \mathrm{kg} /$ day (EPA 1991a).

Hepatic Effects. No studies were located regarding hepatic effects in humans following oral exposure to pyrethrins or pyrethroids. Some animal studies indicated increased liver weights, congestion, hepatocellular hypertrophy, and other microscopic signs of liver changes in laboratory animals during intermediate- and chronic-duration oral exposure to pyrethrins or pyrethroids, particularly at dose levels also resulting in clinical signs of neurotoxicity (Hext et al. 1986; IRIS 2003d, 2003e; Ishmael and Litchfield 1988; Parker et al. 1984a, 1984b; Schoenig 1995). Increased liver enzyme activity has also been observed in some animal studies (EPA 1985a, 1985b, 1994c; Schoenig 1995). These hepatic effects may reflect, at least in part, an adaptive response similar to that seen following exposure to many other xenobiotics (Ishmael and Litchfield 1988; Okuno et al. 1986a). Increased liver weight and liver discoloration were noted in mice fed pyrethrum extract in the diet for 18 months at concentrations resulting in doses of total pyrethrins of approximately 346 and $413 \mathrm{mg} / \mathrm{kg} /$ day in males and females, respectively. The male mice also exhibited vacuolar fatty liver changes (EPA 1994c).

Renal Effects. No studies were located regarding renal effects in humans following oral exposure to pyrethrins or pyrethroids. Available information regarding renal effects in animals is limited to a report of decreased kidney weights and tubular degeneration in rats consuming pyrethrins (from pyrethrum extract) in the diet at concentrations resulting in dose levels $\geq 320 \mathrm{mg} / \mathrm{kg} / \mathrm{day}$ for 90 days (Schoenig 
1995), and a report of a small decrease in kidney weight in male rats receiving permethrin in the diet at concentrations resulting in estimated daily doses of $19.4-91.5 \mathrm{mg} / \mathrm{kg}$ for 2 years (Ishmael and Litchfield 1988). However, the magnitude and statistical significance of these renal changes were not presented in these reports. In a 2-year feeding study reported by Sumitomo Chemical America, Inc., and summarized in IRIS (2003c), increased absolute and relative kidney weights were observed in male (but not female) rats fed fenpropathrin (in corn oil) at a dietary concentration of $600 \mathrm{ppm}$ (calculated daily doses of 22.8 and $23.98 \mathrm{mg} / \mathrm{kg}$ for males and females, respectively).

Endocrine Effects. No studies were located regarding endocrine effects in humans following oral exposure to pyrethrins or pyrethroids. Limited data were available regarding endocrine effects in animals following oral exposure to pyrethroids. Serum levels of the thyroid hormones $\mathrm{T}_{3}$ and $\mathrm{T}_{4}$ were significantly decreased in mice administered fenvalerate at a dose level of $120 \mathrm{mg} / \mathrm{kg} /$ day for 15 days (Maiti and Kar 1998). Akhtar et al. (1996) reported similar effects in rats administered bifenthrin or lambda-cyhalothrin at daily oral dose levels of $0.5 \mathrm{mg} / \mathrm{rat}$ (approximately $0.75 \mathrm{mg} / \mathrm{kg} /$ day) and $0.2 \mathrm{mg} / \mathrm{rat}$ (approximately $2 \mathrm{mg} / \mathrm{kg} /$ day), respectively, for 21 days. Lambda-cyhalothrin treated rats also exhibited a significantly decreased serum $T_{3} / T_{4}$ ratio, relative to controls. In addition, both bifenthrin and lambdacyhalothrin treatment resulted in significantly increased serum TSH levels, compared with control rats. The studies of Maiti and Kar (1998) and Akhtar et al. (1996) did not include dose-response information, nor were thyroid tissues examined. However, these studies indicate that pyrethroids may exert a direct or indirect influence on the thyroid. Pyrethroid-induced decreased plasma testosterone may also serve as an indication of potential for pyrethroid-mediated endocrine effects. Significantly reduced plasma testosterone levels were noted as early as day 14 in groups of male rats administered deltamethrin in oral doses of 1 or $2 \mathrm{mg} / \mathrm{kg}$ for 65 days, and remained lower than controls throughout 21 days of posttreatment observation (Abd El-Aziz et al. 1994). El-Khalek et al. (1999) observed significant decreases in plasma testosterone levels in rats administered cypermethrin in oral doses of 3.8 or $7.7 \mathrm{mg} / \mathrm{kg} / \mathrm{day}$ for 65 days, also demonstrating that this effect lasted throughout 30 days of posttreatment observation. In a 2-year feeding study reported by Sumitomo Chemical America, Inc., and summarized in IRIS (2003c), absolute and relative pituitary weights were nearly doubled in male rats fed fenpropathrin (in corn oil) at a dietary concentration of $600 \mathrm{ppm}$ (calculated daily dose of $22.8 \mathrm{mg} / \mathrm{kg}$ ). Female rats of the $600 \mathrm{ppm}$ group (calculated daily dose of $23.98 \mathrm{mg} / \mathrm{kg}$ ) exhibited decreased absolute and relative ovary weights.

Body Weight Effects. No studies were located regarding body weight effects in humans following oral exposure to pyrethrins or pyrethroids. Reduced body weights or body weight gains were reported in some studies of laboratory animals administered pyrethrins (from pyrethrum extract) for intermediate or 
chronic durations. For instance, decreased body weight gain and food consumption were observed in rats administered 3,000-20,000 ppm (total pyrethrins; approximately 320-1,600 mg/kg/day) in the diet for 90 days. Decreased body weight and food consumption were noted in dogs administered total pyrethrins at $6,000 \mathrm{ppm}$ (approximately $100 \mathrm{mg} / \mathrm{kg} /$ day) in the diet for 8 weeks. Decreased body weight was also reported in rats administered total pyrethrins at 3,000 ppm (approximately $250 \mathrm{mg} / \mathrm{kg} /$ day) in the diet for 104 weeks. Weight loss was observed in rabbit does administered $600 \mathrm{mg}$ total pyrethrins/kg/day on gestation days 7-19. In a 2-generation reproductive toxicity study involving dietary exposure, decreased body weights and food consumption were observed in $\mathrm{F}_{1}$ parental rats that had been exposed to pyrethrins during fetal and neonatal development, as well as premating, mating, and gestation. The reports of Schoenig (1995) did not include more detailed descriptions of body weight effects at dose levels that also resulted in clinical signs of neurotoxicity (Ishmael and Litchfield 1988; Parker et al. 1984a; Schoenig 1995).

The EPA (IRIS 2003c) reviewed a report by Sumitomo Chemical America, Inc. in which slightly reduced weight gain was noted in dogs administered fenpropathrin in the diet at dose levels $\geq 500 \mathrm{ppm}$ (12.5 mg/kg/day) for 3 months. Ishmael and Litchfield (1988) reported initial decreases in body weight gain in rats and mice administered permethrin at 2,500 ppm in the diet for 2 years (rats) or a lifetime (mice), in the absence of apparent changes in food consumption. Estimated daily doses of permethrin were 91.5 and $103.8 \mathrm{mg} / \mathrm{kg} /$ day for male and female rats, respectively, and 295.1 and $348.1 \mathrm{mg} / \mathrm{kg} /$ day for male and female mice, respectively, based on body weight and food consumption values presented. The decreased body weight gain was seen only during the first 6 weeks of treatment in rats and sporadically during the first 52 weeks of treatment in mice. Parker et al. (1984a) observed significant decreases in mean body weight gain among rats fed fenvalerate at 1,000 ppm in the diet (approximate doses of 70 and $80 \mathrm{mg} / \mathrm{kg}$ /day for males and females, respectively) from week 16 (males) and week 44 (females) through week 104. No treatment-related changes in food consumption were observed, and no treatment-related significant changes in body weight were seen in groups receiving $\leq 250 \mathrm{ppm}$ of fenvalerate in the diet, relative to controls. Suppressed body weight gain was seen in male and female mice ingesting daily doses of esfenvalerate of 106 and $113 \mathrm{mg} / \mathrm{kg}$, respectively, for 90 days (EPA 1991a). Female rats, administered cyhalothrin in the diet at a concentration resulting in a dose level of $23.1 \mathrm{mg} / \mathrm{kg} /$ day for 2 years, exhibited body weights that were $12.5 \%$ lower than controls (EPA 1985c). 


\subsubsection{Immunological and Lymphoreticular Effects}

No reports were located in which immunological or lymphoreticular effects in humans could be specifically associated with oral exposure to pyrethrins or pyrethroids. See Section 3.2.1.3 for information regarding immunological effects in humans following exposures to pyrethrins or pyrethroids that were likely mixed (inhalation, dermal, and possibly oral).

Information on immunotoxicity of selected pyrethroids is available from oral studies in rats, mice, and rabbits repeatedly administered pyrethroids at doses low enough that clinical signs of neurotoxicity were not observed (Blaylock et al. 1995; Demian 1998; Demian and El-Sayed 1993; Dési et al. 1986; Lukowicz-Ratajczak and Krechniak 1992). Dési et al. (1986) conducted a series of studies in rats and rabbits. In rats, a single oral dose of cypermethrin at $125 \mathrm{mg} / \mathrm{kg}$ resulted in statistically significant changes, which included suppression of the humoral immune response, decreases in rosette-forming lymphocytes and ratio of lymphocytes to leukocytes, and decreased relative spleen weight. Although doses of cypermethrin at $6.25,12.5$, or $25 \mathrm{mg} / \mathrm{kg}$ /day for 6 or 12 weeks did not result in significant changes in relative spleen weight, a significantly reduced humoral immune response was observed at the $25 \mathrm{mg} / \mathrm{kg} /$ day dose level, and both the 12.5 and $25 \mathrm{mg} / \mathrm{kg} /$ day levels resulted in significant decreases in rosette-forming lymphocytes. Dose-dependent significant suppression of the humoral immune response in rabbits was observed by the end of week 1 of a study in which cypermethrin was administered orally to rabbits 5 days/week for 6 weeks at levels of 75,150 , or $300 \mathrm{mg} / \mathrm{kg} /$ day.

Lukowicz-Ratajczak and Krechniak (1992) administered deltamethrin to female mice in oral doses of $6 \mathrm{mg} / \mathrm{kg} /$ day for 84 days or $15 \mathrm{mg} / \mathrm{kg} /$ day for 14 days. Treatment at both dose levels resulted in significant immunosuppression of the humoral immune response and a significant decrease in enzyme activity in lymphocytes isolated from the lymph nodes and spleen. These effects occurred earlier in the treatment period in high-dose mice. Other signs of immunotoxicity included decreased numbers of splenic plaque-forming cells, decreased percentages of rosette-forming lymphocytes in lymph nodes and spleen, depressed cell-mediated immune response that was expressed as decreased swelling of the foot pad in response to deltramethrin exposure of mice previously immunized with sheep red blood cells, and decreased interleukin-1 activity.

Demian and coworkers (Demian 1998; Demian and El-Sayed 1993) demonstrated dose-related deltamethrin-induced suppression of the humoral immune response, decreased numbers of splenic plaqueforming cells and rosette-forming lymphocytes, decreased total serum protein (as well as alpha-1-, 
alpha-2-, and gamma-globulins), and increased serum albumin content in male mice. Doses used by Demian and coworkers were described as being 0.1 and 0.2 of the oral $\mathrm{LD}_{50}$ value, but this value was not identified in the reports.

Blaylock et al. (1995) assessed the immunotoxic potential of permethrin by examining immune responses of splenocytes from female mice that had been administered permethrin at $0-0.4 \mathrm{mg} / \mathrm{kg} / \mathrm{day}(0-1 \%$ of the oral $\mathrm{LD}_{50}$ value) for 10 days. At the highest dose tested $(0.4 \mathrm{mg} / \mathrm{kg} /$ day $)$, significantly reduced mixed lymphocyte responses, T-lymphocyte cytotoxic activity, and natural killer cell activity were observed in the absence of significant treatment-related changes in spleen weights. The toxicological significance of these findings is uncertain because the mice were not assessed for compromised immune function.

Severe leukopenia was observed in male rats orally administered cypermethrin at $40 \mathrm{mg} / \mathrm{kg} / \mathrm{day}$ for 90 days (Varshneya et al. 1992). A delayed type skin hypersensitivity test, performed on day 61 (following intradermal injection of tuberculin on day 60), revealed 24 and $27 \%$ decreases in reactivity in the 20 and $40 \mathrm{mg} / \mathrm{kg} /$ day dose groups, respectively. Examination of organ weights revealed a significant decrease in relative spleen weight within the high-dose group. However, no definite treatment-induced effect was noticed in the humoral immune response. Madsen et al. (1996) reported increased numbers of antibody forming cells in the spleen and enhanced natural killer cell activity in rats administered deltamethrin at oral dose levels of 5 or $10 \mathrm{mg} / \mathrm{kg} /$ day for 28 days. See Section 3.2.2.6 for information regarding immunological effects in rats exposed via their mothers during gestation.

The highest NOAEL values and all LOAEL values from each reliable study for immunological and lymphoreticular effects in each species and duration category are recorded in Table 3-2 and plotted in Figure 3-2.

\subsubsection{Neurological Effects}

In cases of accidental or intentional ingestion of relatively large quantities of solutions containing pyrethroids, neurotoxic signs such as headache, muscular fasciculations, convulsions, and coma have been reported (Gotoh et al. 1998; He et al. 1989; Peter et al. 1996).

Numerous investigators have reported signs of neurotoxicity in laboratory animals administered lethal and sublethal oral doses of pyrethrins and pyrethroids. Two different types of pyrethroids are recognized, 
based on symptoms of poisoning and chemical structure (Coats 1990; Verschoyle and Aldridge 1980). Chapter 4 contains information regarding chemical properties of Type I and Type II pyrethroids. Type I pyrethroids induce neurological signs that include aggressive behavior and increased sensitivity to external stimuli, fine tremor, prostration with coarse whole body tremor, elevated body temperature, and coma. Pyrethrins induce neurological effects similar to those induced by Type I pyrethroids (Mbaria et al. 1993; Schoenig 1995). Effects induced by Type II pyrethroids include pawing and burrowing behavior, profuse salivation, increased startle response, abnormal hindlimb movements, and coarse whole body tremor that progresses to sinuous writhing (choreoathetosis). The presence of a cyano group within Type II pyrethroids also distinguishes this group from Type I pyrethroids. However, fenpropathrin and cyphenothrin, which are considered to be Type II pyrethroids by the presence of a cyano group, induce intermediate neurological responses characterized by both tremors (typical of Type I pyrethroids) and salivation (typical of Type II pyrethroids) (Miyamoto et al. 1995; Wright et al. 1988).

Acute oral dosing with Type I or Type II pyrethroids results in typical clinical signs of neurotoxicity within minutes to hours, with symptoms subsiding within several hours to a few days (EPA 1992b; Eriksson and Nordberg 1990; Hudson et al. 1986; Parker et al. 1983, 1984a, 1984b, 1985; Ray and Cremer 1979; Southwood 1984). Refer to Section 3.5.2 for a detailed discussion of mechanisms of toxicity associated with exposure to Type I and Type II pyrethroids. Several investigators reported typical signs of Type I or Type II pyrethroid poisoning in laboratory animals during repeated oral administration of pyrethrins or pyrethroids (from 2 days to 2 years), but there were few indications that repeated or continuous exposure might result in cumulative neurological effects (Cabral and Galendo 1990; DOD 1977; EPA 1983, 1988c, 1991a, 1991b, 1994b; Flucke and Schilde 1980; Hext et al. 1986; IRIS 2003a, 2003b, 2003c; Ishmael and Litchfield 1988; Mohan et al. 1998; Parker et al. 1984a, 1984b; Schoenig 1995). For example, Ishmael and Litchfield (1988) administered permethrin in the diet of rats and mice for 2 years and a lifetime (up to 98 weeks), respectively. Male and female rats were administered permethrin at concentrations that resulted in daily doses of $19.4,37.5$, and $91.5 \mathrm{mg} / \mathrm{kg} / \mathrm{day}$ and 19.1, 40.2, and $103.8 \mathrm{mg} / \mathrm{kg} / \mathrm{day}$, respectively. Estimated doses to male and female mice were 28.7, 124.2 , and $295.1 \mathrm{mg} / \mathrm{kg} / \mathrm{day}$ and 42.8, 135.8, and $348.1 \mathrm{mg} / \mathrm{kg} / \mathrm{day}$, respectively. During the first 2 weeks of treatment, high-dose male and female rats exhibited slight whole body tremors, hypersensitivity to noise and other disturbances, and piloerection. These findings were not seen at lower dose levels. None of the groups of mice exhibited clinical signs of treatment-related neurotoxicity. Histological and ultrastructural examination of sciatic nerves at interim (52 weeks in rats, 26 and 52 weeks in mice) and terminal kills revealed no signs of permethrin-induced abnormalities. In a cancer bioassay, Cabral and Galendo (1990) administered fenvalerate (in arachis oil vehicle) to mice via gavage at 0,40 , or 
$80 \mathrm{mg} / \mathrm{kg} /$ day for 2 years. Reported noncancer effects were limited, but included observation of choreoathetosis and salivation in high-dose female mice. Parker et al. (1984a) fed fenvalerate to rats at dietary concentrations ranging from 1 to $1,000 \mathrm{ppm}(0.07-70 \mathrm{mg} / \mathrm{kg} / \mathrm{day}$ in males and $0.08-80 \mathrm{mg} / \mathrm{kg} / \mathrm{day}$ in females) for 2 years. Five of 50 high-dose male rats exhibited clinical signs of neurotoxicity (abnormal gait, ataxia, muscular incoordination) during weeks 3 and 4 . There was no report of clinical signs of neurotoxicity in other treatment groups.

Crofton et al. (1995) demonstrated the significance of vehicle in the expression of neurological effects in rats given single oral doses of deltamethrin. The lowest doses at which at least $50 \%$ of the exposed animals exhibited decreased motor activity $\left(\mathrm{ED}_{50}\right)$ ranged from $5.1 \mathrm{mg} / \mathrm{kg}$ for deltamethrin in corn oil to $>1,000 \mathrm{mg} / \mathrm{kg}$ for deltamethrin in methyl cellulose.

Some investigators have assessed other aspects of neurotoxicity in animals administered oral doses of pyrethroids, often at doses much lower than those resulting in typical clinical signs. For example, Crofton and Reiter (1988) observed significant decreases in motor activity of rats following administration of a Type I pyrethroid (permethrin) at $200 \mathrm{mg} / \mathrm{kg}$ and Type II pyrethroids (cyfluthrin at $12.5 \mathrm{mg} / \mathrm{kg}$, fenvalerate at $30 \mathrm{mg} / \mathrm{kg}$, flucythrinate at $2.5 \mathrm{mg} / \mathrm{kg}$, cypermethrin at $30 \mathrm{mg} / \mathrm{kg}$, fluvalinate at $15 \mathrm{mg} / \mathrm{kg}$, and a pyrethroid identified as RU26607 at $3 \mathrm{mg} / \mathrm{kg}$ ). Crofton and Reiter (1988) also found that some of the pyrethroids tested affected the acoustic startle response by altering the amplitude or latency. In another rat study, a Type I pyrethroid (NAK 1901) enhanced the acoustic startle response amplitude in a dose-dependent manner, whereas a Type II pyrethroid (cypermethrin) had no effect on amplitude or latency, even at a dose level that elicited clinical signs (Hijzen et al. 1988). Hypersensitivity to sound was noted in some rats administered cypermethrin in the diet at a concentration resulting in daily intakes of $27 \mathrm{mg} / \mathrm{kg}$ for 83 days (EPA 1992c). Reduced locomotion and rearing frequency were observed in rats administered fenvalerate at single oral doses of $10 \mathrm{mg} / \mathrm{kg}$ (Spinosa et al. 1999). No treatment-related effects were seen in passive avoidance. Husain et al. (1991) observed pronounced treatment-related changes in brain levels of the neurotransmitters noradrenaline and dopamine, as well as their acid metabolites, following oral administration of fenvalerate at doses of $5-20 \mathrm{mg} / \mathrm{kg} / \mathrm{day}$ for 21 days. The changes did not appear to be either dose-related or region specific, although the brain regions most affected appeared to be those that contribute most significantly to motor function and aggression. Significant increases were noted in grouped total activity and individual nonambulatory (but not ambulatory) activity of male mice observed for 4 hours following single oral administration of permethrin at $50 \mathrm{mg} / \mathrm{kg}$ or fenvalerate at $30 \mathrm{mg} / \mathrm{kg}$ (Mitchell et al. 1988). These effects were observed in the absence of typical clinical signs of pyrethroid-induced neurotoxicity. In another set of behavioral paradigms in 
mice, fenvalerate, administered in single oral doses of $15-45 \mathrm{mg} / \mathrm{kg}$ (as little as $1 / 24$ of the $\mathrm{LD}_{50}$ value), resulted in significantly increased startle response latency and decreased ambulation and rearing in open field (Mandhane and Chopde 1997). Dose-related increased immobility in tail-suspension test and attenuated haloperidol-induced catalepsy were also observed. Axonal damage was observed in peripheral nerves of laboratory animals that had been administered pyrethroids in oral doses sufficient to induce clinical signs of neurotoxicity; the damage resolved upon cessation of treatment (Calore et al. 2000; Parker et al. 1985; Rose and Dewar 1983). Although the typical primary Type I and Type II clinical responses to pyrethroid poisoning can be explained by the action of Type I and Type II pyrethroids on sodium channels, the basis for these other pyrethroid-associated neurological changes is not presently known (see Section 3.5.2 for a discussion of mechanisms of toxicity).

The highest NOAEL values and all LOAEL values from each reliable study for neurological effects in each species and duration category are recorded in Table 3-2 and plotted in Figure 3-2.

\subsubsection{Reproductive Effects}

No reports were located regarding reproductive effects in humans following oral exposure to pyrethrins or pyrethroids.

No signs of exposure-related adverse effects on reproductive parameters, including male or female fertility indices, litter size, and numbers of viable and stillborn pups, were observed in a 2-generation reproductive study of rats administered pyrethrins (from pyrethrum extract) in the diet at concentrations up to 3,000 ppm (resulting in an average daily dose of approximately $240 \mathrm{mg} / \mathrm{kg}$ ) (Schoenig 1995). No signs of reproductive toxicity were observed in a 3-generation reproductive toxicity study of fenpropathrin administered in the diet at concentrations up to $250 \mathrm{ppm}$ (resulting in an average daily dose of approximately $25 \mathrm{mg} / \mathrm{kg}$ ) (Hend et al. 1979). In another 3-generation reproductive toxicity study, rats were administered cyfluthrin in the diet at concentrations of 50,150, or $450 \mathrm{ppm}$ (resulting in average daily doses of $4,11-14$, or 35-40 mg/kg/day, respectively, in males and 5.5, 14-16, or $46-50 \mathrm{mg} / \mathrm{kg} / \mathrm{day}$, respectively, in females) (Loeser and Eiben 1983). Treatment-related reduced viability, decreased lactation, and decreased birth weight or weight gain were observed in some generations at concentrations $\geq 150$ ppm. 
Some investigators have reported adverse effects in male reprodutive organs following intermediateduration oral exposure to pyrethroids at dose levels below those eliciting clinical signs of neurotoxicity. Abd El-Aziz et al. (1994) reported that male rats, administered deltamethrin in oral doses as low as $1 \mathrm{mg} / \mathrm{kg}$ /day (the lowest level tested) for 65 days, exhibited significantly lower weights of testicles, seminal vesicles, and prostate gland than vehicle controls. Sperm analysis of treated rats revealed significantly reduced sperm cell concentration, live cell percentage, and motility index, and a significantly higher percentage of total sperm abnormalities, relative to controls. Plasma testosterone levels were significantly reduced as early as 14 days following the beginning of treatment, remaining significantly lower 21 days after treatment ceased. Male fertility was tested at the end of treatment and 60 days posttreatment. At both time points, the percentage of successful matings to untreated female rats was $50 \%$ that of controls.

Similarly, oral administration of cypermethrin to male rats at 3.8 and $7.7 \mathrm{mg} / \mathrm{kg} / \mathrm{day}$ (El-Khalek et al. 1999 ) and fenvalerate at 20 or $100 \mathrm{mg} / \mathrm{kg} /$ day (Hassan et al. 1993) for 65 days resulted in reduced male reproductive organ weights and significantly altered sperm characteristics. Hassan et al. (1993) also found reduced percentages of pregnancies in untreated female rats that were mated with fenvaleratetreated males, while El-Khalek et al. (1999) observed significant decreases in plasma testosterone levels in cypermethrin-treated rats.

The highest NOAEL values and all LOAEL values from each reliable study for reproductive effects in each species and duration category are recorded in Table 3-2 and plotted in Figure 3-2.

\subsubsection{Developmental Effects}

No reports were located regarding developmental effects in humans following oral exposure to pyrethrins or pyrethroids.

Standard tests for developmental effects in animals following oral exposure to pyrethrins or pyrethroids provide little indication that pyrethrins or pyrethroids might pose a significant developmental toxicity concern. However, more focused testing has revealed some persistent neurotoxic effects in animals exposed in utero and or via lactation. 
Oral administration of pyrethrins (from pyrethrum extract) to female rats on gestation days 6-15 at doses in the range of 5-600 $\mathrm{mg}$ (total pyrethrins) $/ \mathrm{kg} /$ day did not cause apparent developmental effects, even at doses in which maternal toxicity was observed (Schoenig 1995). However, high postimplantation loss was noted when pregnant rabbits were administered total pyrethrins at $600 \mathrm{mg} / \mathrm{kg} /$ day on gestation days 7-19 (Schoenig 1995). This dose level resulted in serious maternal toxicity (tremors, convulsions, and death). The World Health Organization (WHO 2001) reviewed the database for various pyrethroids and published a number of Environmental Health Criteria documents in which animal developmental toxicity studies (mostly unpublished or proprietary information from chemical organizations) provided little indication that pyrethroids might pose a developmental toxicity concern. The EPA evaluated a number of studies that included developmental toxicity end points, which are briefly summarized in documents in which reference doses (RfDs) were derived for selected Type I and Type II pyrethroids (IRIS 2003f). Cleared reviews (Data Evaluation Records) of some of the original studies, submitted to EPA as confidential business information, are available to the public. Most of the studies do not indicate that pyrethroids are of biologically significant developmental toxicity concern. However, decreased pup survival was noted in rats following parental exposure to resmethrin in the diet at a concentration resulting in a dose level of $70.8 \mathrm{mg} / \mathrm{kg} /$ day prior to mating and throughout gestation and lactation (EPA 1994a). Gavage administration of resmethrin ( $80 \mathrm{mg} / \mathrm{kg} /$ day $)$ to other rats during gestation days 6-15 resulted in slightly increased incidences of skeletal variations and delayed ossification (EPA 1994a). No serious signs of fetotoxicity or teratogenicity were observed in fetuses of rats administered deltamethrin at doses of $1,2.5$, or $5 \mathrm{mg} / \mathrm{kg}$ /day during gestation days 6 through 15 , although the highest dose level resulted in the death of 4/20 treated dams (Bhaumik and Gupta 1990). Oral administration of cypermethrin to pregnant rats at 2, 4, or $8 \mathrm{mg} / \mathrm{kg} /$ day on gestation days 6-15 resulted in neither maternal toxicity nor significant incidences of fetotoxicity or teratogenicity (Gupta 1990). Abdel-Khalik et al. (1993) reported significant dose-dependent postimplantation loss and retarded growth in fetuses of rat dams administered deltamethrin at oral dose levels of $1,2.5$, or $5 \mathrm{mg} / \mathrm{kg} /$ day on gestation days 6-15. However, since treatment-related significantly increased placental weight was noted at all dose levels, the investigators considered the developmental effects to have resulted, at least in part, from compromised placental tissues in treated dams. Kavlock et al. (1979) found no significant treatment-related signs of fetotoxicity or teratogenicity in fetuses of rat or mouse dams administered deltamethrin during major stages of organogenesis at dose levels up to and including those eliciting overt signs of maternal toxicity (up to 12 and $5 \mathrm{mg} / \mathrm{kg} /$ day in rat and mouse dams, respectively). In addition, deltamethrin administration to rat dams from gestation day 7 through lactation day 15 , at daily oral doses of $2.5 \mathrm{or} 5.0 \mathrm{mg} / \mathrm{kg}$, resulted in no sign of adverse effects in 6-week-old female offspring that were subjected to open field 
measurements of activity and exploration, although a dose-related depression in growth was observed during the period of lactation.

Eriksson and coworkers (Ahlbom et al. 1994; Eriksson and Fredriksson 1991; Eriksson and Nordberg 1990; Talts et al. 1998a) reported altered locomotory behavior and changes in muscarinic acetylcholine (MACh) receptor density in the cerebral cortex of adult mice that had been exposed to bioallethrin or deltamethrin at oral gavage dose levels in the range of 0.21 to $0.7 \mathrm{mg} / \mathrm{kg} /$ day during neonatal stages of development (post partum days 6-10). No significant differences were observed in locomotion of 17-day-old mice, relative to controls. However, when examined at 4 months of age, both bioallethrinand deltamethrin-treated mice exhibited significantly increased spontaneous locomotor behavior (Eriksson and Fredriksson 1991). In contrast to the findings in the $0.21-0.7 \mathrm{mg} / \mathrm{kg}$ dose groups, mice administered $42 \mathrm{mg}$ bioallethrin/kg daily exhibited significant decreases in locomotion and total activity counts and no significant differences in densities of MACh receptor density. Underlying mechanisms responsible for the differences observed in low-dose groups $(0.21-0.7 \mathrm{mg} / \mathrm{kg})$ and mice in the $42 \mathrm{mg} / \mathrm{kg}$ dose group, a level approaching that which would be expected to result in overt clinical signs of neurotoxicity, could not be explained. Other investigators (Ray et al. 2002; Tsuji et al. 2002) were unable to duplicate the results of Eriksson and coworkers.

Malaviya et al. (1993) observed significant increases in the levels of dopamine and muscarinic receptors of striatal membrane in rat pups that had been exposed to fenvalerate or cypermethrin in utero. In this study, pregnant dams were administered $10 \mathrm{mg}$ fenvalerate/kg or $15 \mathrm{mg}$ cypermethrin $/ \mathrm{kg}$ on gestation days 5 through 21 . These effects were more pronounced in pups that continued to be exposed via their mothers throughout 3 weeks of postpartum lactation. Other significant treatment-related effects in the brain included increased acetylcholinesterase activity and decreased activities of monoamine oxidase and $\mathrm{Na}^{+}$- and $\mathrm{K}^{+}$-ATPase from gestational exposure to fenvalerate, decreases in monoamine oxidase and acetylcholinesterase during lactation in fenvalerate-exposed pups, and decreases in acetylcholinesterase and $\mathrm{Na}^{+}$- and $\mathrm{K}^{+}$-ATPase during lactation in cypermethrin-exposed pups. The toxicological relevance of increased brain acetylcholinesterase activity is uncertain because cholinesterase levels are naturally highly variable.

Moniz et al. (1990) demonstrated pyrethroid-induced disruption of avoidance learning (significantly decreased latency in avoidance to the dark area of a maze) in 97- and 104-day-old adult rats that had nursed from mothers exposed to cyhalothrin in the drinking water throughout the entire period of lactation 
at a level resulting in an estimated maternal cyhalothrin dose of $27 \mathrm{mg} / \mathrm{kg} /$ day. During the exposure period, no indication of neurotoxicity was seen in motor activity of dams or nursing pups.

Santoni and coworkers reported treatment-related increases in natural killer (NK) cell and antibodydependent cytotoxic activity, impaired thymocyte function, and increased and decreased numbers of $\mathrm{T}$ cells in peripheral blood and spleen, respectively, in rats after their mothers had been orally administered cypermethrin during gestation at $50 \mathrm{mg} / \mathrm{kg} /$ day, a dose schedule that did not result in clinical signs of maternal toxicity (Santoni et al. 1997, 1998, 1999). In one phase of these studies, marked and long-lasting increases were noted in plasma adrenaline and noradrenaline concentrations of offspring (from treated dams) that were tested up to 90 days postpartum (Santoni et al. 1999). The toxicological significance of these results is uncertain.

The highest NOAEL values and all LOAEL values from each reliable study for developmental effects in each species and duration category are recorded in Table 3-2 and plotted in Figure 3-2.

\subsubsection{Cancer}

No reports were located regarding cancer in humans following oral exposure to pyrethrins or pyrethroids.

Results of cancer bioassays in laboratory animals are mixed. Pyrethrum extract was not oncogenic in mice following dietary administration at total pyrethrin concentrations of up to 5,000 ppm (approximately $850 \mathrm{mg} / \mathrm{kg} /$ day) for 18 months (EPA 1994c; Schoenig 1995). However, increased incidences of thyroid follicular cell tumors were reported in male rats administered pyrethrum extract in the diet at total pyrethrin concentrations of 1,000 ppm (approximately $42.9 \mathrm{mg} / \mathrm{kg} /$ day) and in both male and female rats receiving approximately $173 \mathrm{mg} / \mathrm{kg} /$ day (EPA 1994c; Schoenig 1995). The 3,000-ppm (173 mg/kg/day) group of female rats also exhibited increased incidences of hepatocellular adenomas and combined adenomas and/or carcinomas. In a review of this rat carcinogenicity study, the Cancer Assessment Review Committee for pyrethrins (EPA 1999) attributed the increased incidences of thyroid and liver tumors to pyrethrum treatment and classified pyrethrins as "likely to be a human carcinogen by the oral route."

Cancer bioassays of selected synthetic pyrethroids have also produced mixed results. Ishmael and Litchfield (1988) administered permethrin (40/60 cis/trans) in the diet to rats at concentrations of 500, 
1,000 , or 2,500 ppm for 2 years and to mice at concentrations of 250, 1,000, or 2,500 ppm for a lifetime. The estimated daily doses in high-dose rats were 91.5 and $103.8 \mathrm{mg} / \mathrm{kg} /$ day for males and females, respectively, based on body weight and food consumption values presented. Estimated doses to the highdose mice were 295.1 and $348.1 \mathrm{mg} / \mathrm{kg} /$ day for males and females, respectively. There was no evidence for a carcinogenic effect in treated rats. The high-dose male (but not female) mice exhibited statistically significant elevated incidences of benign lung tumors (17/70 high-dose males versus 11/70 in controls). Cancer bioassays that employed a 25/75 (cis/trans) mixture of permethrin isomers at dietary concentrations resulting in permethrin doses of up to $250 \mathrm{mg} / \mathrm{kg} /$ day in both rats and mice revealed no evidence of carcinogenicity in rats and statistically significantly elevated incidences of benign lung tumors in female, but not male, mice (15/74 high-dose females versus 3/96 in controls).

The World Health Organization (WHO 2001) reviewed the database for various pyrethroids and published a number of Environmental Health Criteria documents in which animal cancer bioassays (mostly proprietary information from chemical organizations) provided little indication that pyrethroids should be considered carcinogens. No indications of a carcinogenic effect were observed in other cancer bioassays of fenvalerate-treated rats (Parker et al. 1984a) and mice (Cabral and Galendo 1990; Parker et al. 1983).

The Cancer Effect Levels are recorded in Table 3-2 and plotted in Figure 3-2.

\subsubsection{Dermal Exposure}

\subsubsection{Death}

Two case reports were located in which death was associated with allergic reactions to dog shampoo products containing pyrethrins (Wagner 2000; Wax and Hoffman 1994). The relative contributions of inhalation and dermal exposure routes were not addressed. No other reports were located regarding death in humans following dermal exposure to pyrethrins or pyrethroids.

Several studies designed to assess the lethality of pyrethrins and pyrethroids could not establish dermal $\mathrm{LD}_{50}$ values (exposure level resulting in death of $50 \%$ of the dosed animals), even when administered the highest concentrations possible for given pyrethrin- or pyrethroid-containing substances (see Kavlock et al. 1979; Litchfield 1985; Schoenig 1995). However, El-Elaimy (1986) observed 100\% mortality within 4 days among male rats exposed by daily dermal applications of cyfluthrin that resulted in daily doses of 
1,845 or 2,460 mg cyfluthrin/kg/day. Rats receiving daily doses of 615 or $1,250 \mathrm{mg} / \mathrm{kg} /$ day survived a 7-day treatment period. Death was noted in 2/10 male mice within 48 hours following dermal application of $1,800 \mathrm{mg}$ fenvalerate $/ \mathrm{kg}$ (Mitchell et al. 1988). Acute dermal $\mathrm{LD}_{50}$ values for laboratory animals, listed by a secondary source (Metcalf 1995) for several pyrethroids, were considered to be $>5,000 \mathrm{mg} / \mathrm{kg}$, but dermal $\mathrm{LD}_{50}$ values for tefluthrin, cyhalothrin, and cyfluthrin were in the range of $148-696 \mathrm{mg} / \mathrm{kg}$. However, primary sources for these values were not listed and could not be verified. Deaths in domestic cats have been associated with erroneous exposure to concentrated (45-65\%) permethrin products designed to be used as flea treatment for dogs (Meyer 1999). The increased sensitivity of the cat to concentrated permethrin may be the result of less efficient hepatic glucuronidation (Whittem 1995), a second step in the metabolism of pyrethroids in mammalian systems. No other information was located regarding death in animals following dermal exposure to pyrethrins or pyrethroids.

\subsubsection{Systemic Effects}

No reliable reports were located regarding respiratory, cardiovascular, gastrointestinal, hematological, musculoskeletal, hepatic, renal, endocrine, or body weight effects in humans or animals following dermal exposure to pyrethrins or pyrethroids.

Dermal Effects. Slight skin irritation was observed in workers in plants producing pyrethrum extract to be used as insecticide powders in an early study by McCord et al. (1921). Paresthesia (an abnormal cutaneous sensation sometimes described as tingling, burning, stinging, numbness, and/or itching) has been reported in individuals occupationally exposed to pyrethroids that contact the skin; however, paresthesia is generally considered to be a neurological effect, not a dermal effect (see Section 3.2.3.4). Reports were not located in which dermal exposure to pyrethrins or pyrethroids could be associated with other dermal effects in humans.

Animal studies indicate that dermal exposure to pyrethrins or pyrethroids may result in slight dermal irritation, but they do not elicit strongly positive responses in standard dermal sensitization tests (see, for example, DOD 1977; Litchfield 1985; Schoenig 1995).

Ocular Effects. No reliable reports were located regarding ocular effects in humans following dermal exposure to pyrethrins or pyrethroids. Some workers reported irritation of the eyes after dipping conifer seedlings into solutions containing fenvalerate or permethrin (Kolmodin-Hedman et al. 1982); however, control groups were not included in the survey. 
Animal studies indicate that pyrethrins and pyrethroids may cause mild ocular irritation upon contact with the eye (see, for example, DOD 1977; Litchfield 1985; Schoenig 1995).

\subsubsection{Immunological and Lymphoreticular Effects}

A single case report was located in which a 47-year-old farmer developed a hypersensitive response that included a widespread dermal rash after dipping sheep in a solution, the active component of which was flumethrin (Box and Lee 1996). The relative contributions of dermal and inhalation exposure were not indicated in the report. See Section 3.2.1.3 for information regarding immunological effects in humans following exposures to pyrethrins or pyrethroids that were likely mixed (inhalation, dermal, and possibly oral).

No reports were located regarding immunological effects in animals following dermal exposure to pyrethrins or pyrethroids.

\subsubsection{Neurological Effects}

Paresthesia (an abnormal cutaneous sensation sometimes described as tingling, burning, stinging, numbness, and itching) has been widely reported among individuals occupationally exposed to pyrethroids (Flannigan and Tucker 1985; Flannigan et al. 1985b; Knox et al. 1984; LeQuesne and Maxwell 1980; Tucker and Flannigan 1983; see also Vijverberg and van den Bercken 1990 for a summary of available information on occupationally-induced paresthesia). This effect is considered to be the result of a direct effect on intracutaneous nerve endings following dermal exposure to pyrethroids (LeQuesne and Maxwell 1980; Wilks 2000). In a double-blind study of volunteers exposed to fenvalerate via application to the earlobe $\left(0.081 \mathrm{mg} / \mathrm{cm}^{2}\right)$, the onset of cutaneous sensations occurred at 1 hour postapplication, peaked at 3-6 hours, and lasted approximately 24 hours (Knox et al. 1984). Sensations included numbness, itching, burning, tingling, and warmth. A similar time-course for paresthesia was noted among agricultural workers exposed during or shortly following the spraying of fenvalerate on field crops (Tucker and Flannigan 1983). Type I (permethrin) and Type II (cypermethrin, fenvalerate, and flucythrinate) pyrethroids have been shown to induce differing severity in paresthesia responses in volunteers exposed on separate days to each pyrethroid in doses of $0.13 \mathrm{mg} / \mathrm{cm}^{2}$ (Flannigan and Tucker 1985). The mildest responses were elicited by permethrin. Both cypermethrin and fenvalerate induced 
significantly more severe responses than those of permethrin. Responses to cypermethrin were significantly more severe than those induced by the other three pyrethroids (see Section 3.5.2 for a discussion of mechanisms responsible for differences in toxicity among various pyrethroids).

Signs of mild acute pyrethroid poisoning include dizziness, headache, and nausea, in addition to paresthesia. These signs have been associated with acute occupational (inhalation and dermal) exposure to various pyrethroids during outdoor or indoor spraying (Chen et al. 1991; Moretto 1991; Shujie et al. 1988; Zhang et al. 1991). Based on measurements of pyrethroids deposited on gauze pads during spraying, estimates of dermal deposits on exposed skin ranged from 0.013 to $0.347 \mu \mathrm{g} / \mathrm{cm}^{2}$ (Chen et al. 1991) and from $<0.01$ to $141.61 \mu \mathrm{g} / \mathrm{cm}^{2}$ (Zhang et al. 1991). Although dermal exposure was considered to be the major source of exposure, inhalation exposure was also likely. Facial paresthesia, dizziness, fatigue, miliary red facial papules, and sniffles and sneezes were noted in subjects exposed to deltamethrin and fenvalerate while packaging the insecticides (He et al. 1988). Both inhalation and dermal exposures were likely, although increased toxicity during summer months was indication that dermal exposure may have been increased when greater areas of skin were exposed due to warmer weather. He et al. (1991) reported increased peripheral nerve excitability in individuals following 3 days of exposure to deltamethrin during spraying, in the absence of other clinical signs of acute pyrethroid poisoning. Higher levels of exposure to pyrethroids result in additional clinical signs such as listlessness, muscular fasciculations, and mild disturbance of consciousness, indicative of moderate acute pyrethroid poisoning (Chen et al. 1991; He et al. 1989). Even higher exposure levels may result in convulsive attacks and coma (severe acute pyrethroid poisoning), effects that may last for several weeks (He et al. 1989).

Limited information was available regarding neurological effects in animals following dermal exposure to pyrethrins or pyrethroids. El-Elaimy (1986) observed signs of pyrethroid poisoning (chewing, licking, and salivation) in groups of rats receiving daily dermal applications of cyfluthrin for up to 7 days. In this study, dose levels were $0,615,1,250,1,845$, and 2,460 mg cyfluthrin/kg/day. Pawing, whole body tremors, and choreoathetosis were noted at the two highest dose levels, which were also lethal. The description of the findings did not indicate whether clinical signs of neurotoxicity were seen at all dose levels. Significant increases were noted in grouped total activity and individual nonambulatory (but not ambulatory) activity of male mice observed for 4 hours following single dermal applications of $300 \mathrm{mg}$ permethrin $/ \mathrm{kg}$ or $\geq 600 \mathrm{mg}$ fenvalerate/kg (Mitchell et al. 1988). These effects were observed in the absence of typical clinical signs of pyrethroid-induced neurotoxicity. Guinea pigs responded to dermal applications of permethrin or fenvalerate by licking, rubbing, scratching, or biting the area of application 
(Cagen et al. 1984). These behavioral responses were indicative of paresthesia (considered to result from a direct action of pyrethroids on sensory nerve endings), since these responses were elicited in the absence of visible signs of dermal irritation.

\subsubsection{Reproductive Effects}

No reports were located regarding reproductive effects in humans or animals following dermal exposure to pyrethrins or pyrethroids.

\subsubsection{Developmental Effects}

No reports were located regarding developmental effects in humans following dermal exposure to pyrethrins or pyrethroids.

Available information regarding developmental effects in animals is limited to a single study in which $1 \mathrm{~mL}$ of a $0.018 \%$ solution of cyhalothrin was applied daily to the skin of pregnant rats throughout gestation (Gomes et al. 1991a). Assuming a mature dam body weight of $0.32 \mathrm{~kg}$ (EPA 1988a), the initial dermal dose to the dams was approximately $56 \mathrm{mg} / \mathrm{kg} / \mathrm{day}$. A control group was similarly treated with vehicle only. Relative to controls, treated pups exhibited delays in development of fur, ear and eye opening, and testes descent into the scrotum. At weaning and 90 days of age, the frequency of spontaneous locomotion and active avoidance responses did not differ significantly among treated and control groups of offspring. However, when tested as adults for motivational responses, the total number of head-dips in a hole-board test (an index of motivational state) was decreased in offspring of treated dams, relative to control offspring.

\subsubsection{Cancer}

No reports were located regarding cancer in humans or animals following dermal exposure to pyrethrins or pyrethroids. 


\subsection{GENOTOXICITY}

Limited information regarding the genotoxicity of natural pyrethrins was located in the studies available for review. As shown in Table 3-3, natural pyrethrins, tested in the standard Ames test in various Salmonella strains and in Escherichia coli with or without metabolic activation gave negative results (Moriya et al. 1983).

Much more information has been generated regarding the genotoxic properties of both Type I and Type II pyrethroids. For example, administration of the Type I pyrethroids cismethrin (31 or $40 \mathrm{mg} / \mathrm{kg}$ ) or bioresmethrin $(1,000 \mathrm{mg} / \mathrm{kg})$ to female Sprague-Dawley rats by gavage significantly increased the percentage of micronuclei in bone marrow (Hoellinger et al. 1987). In male and female CD-1 mice, intraperitoneal administration of a single dose of permethrin at up to $275 \mathrm{mg} / \mathrm{kg}$ failed to increase the percentage of micronuclei in bone marrow (Chruścielska and Kalhorn 1999). In a 28-day study in male Wistar rats, daily administration of permethrin $(12.6,50.3$, or $125.7 \mathrm{mg} / \mathrm{kg}$ ) by gavage significantly increased the number of chromosome aberrations in a dose-related manner (Institóris et al. 1999b). A commercial formulation of permethrin fed to the larva of Drosophila was mutagenic in the sex-linked recessive lethal mutation assay in Drosophila, affecting the DNA of both spermatogonia and spermatocytes (Kale et al. 1995). In contrast, in a study by Gupta et al. (1990), treating adult males resulted in no significant differences in frequencies of spontaneous mutations. The genotoxicity of Type I pyrethroids in vivo is summarized in Table 3-4.

Several Type II pyrethroids have been tested for genotoxicity in mammalian systems (mostly to rats and mice) following oral, parenteral, or dermal administration of the compounds (Table 3-5). Tests conducted with cypermethrin showed that doses $\geq 30 \mathrm{mg} / \mathrm{kg}$ administered intraperitoneally significantly increased the incidence of chromosomal aberrations and micronuclei in bone marrow and the percent of sperm with head abnormalities (Bhunya and Pati 1988). A dose of $50 \mathrm{mg} / \mathrm{kg}$ by gavage, but not dermally, also induced chromosomal aberrations in bone marrow (Bhunya and Pati 1988). Of the three assays used by these investigators, the sperm abnormality test was found to be the most sensitive and the micronucleus test was determined to be the least sensitive. Chromosomal aberrations in mouse bone marrow and spleen cells have also been observed in other studies with higher doses of cypermethrin (Amer et al. 1993). Increased incidences of sister chromatid exchanges were also reported by Amer et al. (1993) in mouse bone marrow after an intraperitoneal dose of $180 \mathrm{mg}$ cypermethrin/ $\mathrm{kg}$ and by Chauhan et al. (1997) after a gavage dose of $32 \mathrm{mg}$ cypermethrin $/ \mathrm{kg}$, but not $21.1 \mathrm{mg}$ cypermethrin $/ \mathrm{kg}$. Experiments conducted with cypermethrin-dosed rats showed increased chromosomal aberrations in bone marrow after administration 
3. HEALTH EFFECTS

\section{Table 3-3. Genotoxicity of Pyrethrins In Vitro}

\begin{tabular}{llllll}
\hline $\begin{array}{l}\text { Species (test system) } \\
\text { Prokaryotic organisms: }\end{array}$ & Chemical & End point & $\begin{array}{l}\text { With } \\
\text { activation }\end{array}$ & $\begin{array}{l}\text { Without } \\
\text { activation }\end{array}$ & Reference \\
$\begin{array}{l}\text { Salmonella typhimurium } \\
\text { (TA100, TA98, TA1535, }\end{array}$ & Pyrethrins & Gene mutation & - & - & Moriya et al. 1983 \\
$\begin{array}{l}\text { TA1537, TA1538) } \\
\begin{array}{l}\text { Escherichia coli (WP2 hor) } \\
\text { Pyrethrins }\end{array}\end{array}$ & Gene mutation & - & - & Moriya et al. 1983 \\
\hline
\end{tabular}

$-=$ negative result 
3. HEALTH EFFECTS

Table 3-4. Genotoxicity of Type I Pyrethroids In Vivo

\begin{tabular}{|c|c|c|c|c|}
\hline $\begin{array}{l}\text { Species } \\
\text { (test system) }\end{array}$ & Chemical & End point & Results & Reference \\
\hline \multicolumn{5}{|l|}{ Eukaryotic organisms: } \\
\hline Drosophila & Permethrin & $\begin{array}{l}\text { Sex linked } \\
\text { recessive lethal }\end{array}$ & + & Kale et al. 1995 \\
\hline Drosophila & Permethrin & $\begin{array}{l}\text { Sex linked } \\
\text { recessive lethal }\end{array}$ & - & Gupta et al. 1990 \\
\hline \multicolumn{5}{|l|}{ Mammalian cells: } \\
\hline Rat bone marrow & Bioresmethrin & Micronuclei & + & Hoellinger et al. 1987 \\
\hline Rat bone marrow & Cismethrin & Micronuclei & + & Hoellinger et al. 1987 \\
\hline Rat bone marrow & Permethrin & $\begin{array}{l}\text { Chromosomal } \\
\text { aberrations }\end{array}$ & + & Institóris et al. 1999b \\
\hline Rat bone marrow & Permethrin & Micronuclei & + & Hoellinger et al. 1987 \\
\hline Mouse bone marrow & Permethrin & Micronuclei & - & Chruścielska and Kalhorn 1999 \\
\hline
\end{tabular}

- = negative result; $+=$ positive result 
Table 3-5. Genotoxicity of Type II Pyrethroids In Vivo

\begin{tabular}{|c|c|c|c|c|}
\hline Species (test system) & Chemical & End point & Results & Reference \\
\hline \multicolumn{5}{|l|}{ Eukaryotic organisms: } \\
\hline Drosophila & Cypermethrin & Sex-linked recessive lethal & \pm & $\begin{array}{l}\text { Batiste-Alentorn et al. } \\
1986\end{array}$ \\
\hline Drosophila & Cypermethrin & Sex-chromosome loss & - & $\begin{array}{l}\text { Batiste-Alentorn et al. } \\
1986\end{array}$ \\
\hline Drosophila & Cypermethrin & Non-disjunction & - & $\begin{array}{l}\text { Batiste-Alentorn et al. } \\
1986\end{array}$ \\
\hline Drosophila & $\begin{array}{l}\text { Supercyper- } \\
\text { methrin }\end{array}$ & Sex-linked recessive lethal & - & Miadoková et al. 1992 \\
\hline Drosophila & $\begin{array}{l}\text { Supercyper- } \\
\text { methrin }\end{array}$ & $\begin{array}{l}\text { Sex-chromosome loss, } \\
\text { non-disjunction, frequency } \\
\text { of deletion }\end{array}$ & - & Miadoková et al. 1992 \\
\hline \multicolumn{5}{|l|}{ Mammalian systems: } \\
\hline Rat bone marrow & Cypermethrin & Chromosomal aberrations & + & Institóris et al. 1999b \\
\hline Rat bone marrow & Cypermethrin & Chromosomal aberrations & - & Nehéz et al. 2000 \\
\hline Mouse bone marrow & Cypermethrin & Chromosomal aberrations &,+- & Bhunya and Pati 1988 \\
\hline Mouse bone marrow & Cypermethrin & Chromosomal aberrations & + & Amer et al. 1993 \\
\hline Mouse spleen cells & Cypermethrin & Chromosomal aberrations & + & Amer et al. 1993 \\
\hline Mouse bone marrow & Cypermethrin & Sister chromatid exchange & + & Chauhan et al. 1997 \\
\hline Mouse bone marrow & Cypermethrin & Sister chromatid exchange & + & Amer et al. 1993 \\
\hline Rat bone marrow & Cypermethrin & Micronuclei & - & Hoellinger et al. 1987 \\
\hline Mouse bone marrow & Cypermethrin & Micronuclei & + & Bhunya and Pati 1988 \\
\hline Mouse sperm & Cypermethrin & Cellular abnormalities & + & Bhunya and Pati 1988 \\
\hline Rat bone marrow & Deltamethrin & Chromosomal aberrations & + & Agarwal et al. 1994 \\
\hline Mouse bone marrow & Deltamethrin & Chromosomal aberrations & + & Bhunya and Pati 1990 \\
\hline Mouse bone marrow & Deltamethrin & Chromosomal aberrations & - & $\begin{array}{l}\text { Poláková and Vargová } \\
1983\end{array}$ \\
\hline Mouse bone marrow & Deltamethrin & Sister chromatid exchange & + & Chauhan et al. 1997 \\
\hline Rat bone marrow & Deltamethrin & Micronuclei & + & Agarwal et al. 1994 \\
\hline Rat bone marrow & Deltamethrin & Micronuclei & - & Hoellinger et al. 1987 \\
\hline Mouse bone marrow & Deltamethrin & Micronuclei & + & Bhunya and Pati 1990 \\
\hline Mouse bone marrow & Deltamethrin & Micronuclei & + & Gandhi et al. 1995 \\
\hline Rat testes & Deltamethrin & DNA fragmentation & + & El-Gohary et al. 1999 \\
\hline Mouse sperm & Deltamethrin & Cellular abnormalities & + & Bhunya and Pati 1990 \\
\hline Mouse & Deltamethrin & Dominant lethal mutations & - & $\begin{array}{l}\text { Shukla and Taneja } \\
2000\end{array}$ \\
\hline
\end{tabular}


3. HEALTH EFFECTS

Table 3-5. Genotoxicity of Type II Pyrethroids In Vivo

\begin{tabular}{lllcl}
\hline Species (test system) & Chemical & End point & Results & Reference \\
\hline Rat bone marrow & $\begin{array}{l}\text { Fenpropathrin } \\
\text { (Meothrin) }\end{array}$ & Micronuclei & + & Oraby 1997 \\
Mouse bone marrow & Fenpropathrin & Micronuclei & - & Ryu et al. 1996 \\
Rat bone marrow & Fenvalerate & Chromosomal aberrations & + & Chatterjee et al. 1982 \\
Mouse bone marrow & Fenvalerate & Chromosomal aberrations & + & Ghosh et al. 1992 \\
Mouse bone marrow & Fenvalerate & Chromosomal aberrations & + & Pati and Bhunya 1989 \\
Mouse sperm & Fenvalerate & Cellular abnormalities & + & Pati and Bhunya 1989 \\
Mouse bone marrow & Flumethrin & Chromosomal aberrations &,+- & Nakano et al. 1996 \\
Mouse bone marrow & Flumethrin & Micronuclei &,+- & Nakano et al. 1996 \\
\hline
\end{tabular}

- = negative result; $+=$ positive result; $\pm=$ weak positive result;,$+-=$ both positive and negative results; DNA = deoxyribonucleic acid 
at $22.2 \mathrm{mg} / \mathrm{kg} /$ day for 28 days, but not at $11.1 \mathrm{mg} / \mathrm{kg} /$ day (Institóris et al. 1999b). However, Nehéz et al. (2000), also in a 4-week gavage study, did not find increases in chromosomal aberrations in bone marrow from rats treated with up to $22 \mathrm{mg}$ cypermethrin $/ \mathrm{kg} /$ day. No significantly increased incidences of micronuclei were observed in rat bone marrow following acute treatment by gavage with $15 \mathrm{mg}$ cypermethrin/kg (Hoellinger et al. 1987).

Studies of deltamethrin-dosed mice showed increased chromosomal aberrations and micronuclei in bone marrow cells as well as sperm abnormalities following acute intraperitoneal treatment with $\geq 10 \mathrm{mg} / \mathrm{kg}$ (Bhunya and Pati 1990). Increased sister chromatid exchanges were detected after a single $20 \mathrm{mg} / \mathrm{kg}$ dose, but not after doses of $13.2 \mathrm{mg} / \mathrm{kg}$ or lower (Chauhan et al. 1997). No statistically significant increase in dominant lethal mutation rate was seen in mice treated orally with $0.36,0.72$, or $1.08 \mathrm{mg}$ deltamethrin/kg (Shukla and Taneja 2000). In rats, acute intraperitoneal administration of deltamethrin at $\geq 5.6 \mathrm{mg} / \mathrm{kg}$ induced micronuclei in bone marrow cells (Agarwal et al. 1994), but gavage administration of up to $20 \mathrm{mg} / \mathrm{kg}$ did not (Hoellinger et al. 1987). This is consistent with other experiments conducted by Agarwal et al. (1994) in which intraperitoneal and subcutaneous administration of deltamethrin $(\geq 11.2 \mathrm{mg} / \mathrm{kg}$ ) proved to be more efficient routes for inducing chromosomal aberrations than gavage. Deltamethrin also was shown to induce DNA fragmentation in sections of rat testes following intraperitoneal administration of $1 \mathrm{mg} / \mathrm{kg} /$ day (only level tested) for 21 days (El-Gohary et al. 1999).

In mice dosed intraperitoneally, fenvalerate induced chromosomal aberrations in bone marrow cells at $\geq 32.5 \mathrm{mg} / \mathrm{kg}$ (Ghosh et al. 1992; Pati and Bhunya 1989), micronuclei at $150 \mathrm{mg} / \mathrm{kg}$, and sperm abnormalities at $100 \mathrm{mg} / \mathrm{kg}$ (Pati and Bhunya 1989). Fenvalerate also induced chromosomal aberrations in rat bone marrow cells following gavage dosing at $\geq 50 \mathrm{mg} / \mathrm{kg} /$ day for 21 days (Chatterjee et al. 1982). Studies conducted with flumethrin in mice showed induction of chromosomal aberrations in bone marrow cells after a single dermal application of $5,325 \mathrm{mg} / \mathrm{kg}$ to a shaved area or a single intraperitoneal injection of $2,083 \mathrm{mg} / \mathrm{kg}$, but not after repeated intraperitoneal injections of $128 \mathrm{mg} / \mathrm{kg}$ (Nakano et al. 1996). In contrast, micronuclei frequency was not significantly affected after a single dermal dose of 5,325 mg/kg, but was increased after repeated intraperitoneal doses of $128 \mathrm{mg} / \mathrm{kg}$ (Nakano et al. 1996). Additional studies found no significant change in chromosomal aberrations in mouse bone marrow following a single gavage administration of deltamethrin by gavage at up to $6.8 \mathrm{mg} / \mathrm{kg}$ (Poláková and Vargová 1983) or of micronuclei after an intraperitoneal dose of up to $105 \mathrm{mg}$ fenpropathrin/kg (Ryu et al. 1996). However, 14 daily doses of fenpropathrin by gavage at $\geq 0.074 \mathrm{mg} / \mathrm{kg} /$ day increased the frequency of micronuclei in rat bone marrow (Oraby 1997); a dose of $0.0074 \mathrm{mg} / \mathrm{kg} /$ day was without significant effect. 
A limited number of studies of Type II pyrethroids in Drosophila show mostly nonmutagenic results under the experimental conditions of the tests. Batiste-Alentorn et al. (1986) showed a significant increase in the frequency of sex-linked recessive lethal mutations after adult ingestion or larval feeding of cypermethrin. However, there were no significant increases in the frequency of sex-chromosome loss or nondisjunction. Similar negative results were reported by Miadoková et al. (1992).

Many in vitro studies have also been conducted on both Type I and Type II pyrethroids (Tables 3-6 and 3-7). Many papers investigated gene mutations in various Salmonella strains both with and without metabolic activation and, for the most part, the results did not indicate a mutagenic response. In yeast, results were inconsistent, although there was some evidence of mutations of mitochondrial DNA, particularly when commercial formulations were tested, but not when only the active ingredient was tested (Chruścielska et al. 1999).

In vitro experiments in mammalian cells show a greater percentage of mutagenic effects than the bacteria and yeast studies (Tables 3-6 and 3-7). Investigations of human, pig, and cattle lymphocytes, Chinese and Syrian hamster cells, and mouse spleen cells were positive for several genetic end points. Chromosomal aberrations, sister chromatid exchange, increased micronuclei, DNA damage, C-mitosis induction, and other damage were all observed. However, as with the bacteria studies, no consistent pattern was seen that could relate genotoxicity to the presence or absence of metabolic activation of the pyrethroids by liver cells or enzymes.

\subsection{TOXICOKINETICS}

Pyrethroids have been classified into two major categories, Type I or Type II, based on distinct toxicological mechanisms (see Section 3.5.2 for details regarding the classification of pyrethroids). Although synthetic pyrethroids are all derivatives of the natural pyrethrins, they exhibit a wide structural diversity and some differences in their toxicokinetics. The differences are most apparent in the metabolism of individual pyrethroid compounds (see Section 3.4.3). Thus, while generalizations are made in the profile regarding the toxicokinetics of the major pyrethroid classes and the basis for these generalizations is provided, the reader is cautioned about applying these generalizations too strictly to specific pyrethroid compounds, even within a class. Relevant literature regarding the toxicokinetics of specific pyrethroid compounds is cited where appropriate to this review, and the reader is encouraged to pursue such literature if information is needed regarding specific pyrethroid compounds. 
Table 3-6. Genotoxicity of Type I Pyrethroids In Vitro

\begin{tabular}{|c|c|c|c|c|c|}
\hline Species (test system) & Chemical & End point & $\begin{array}{l}\text { With } \\
\text { activation }\end{array}$ & $\begin{array}{l}\text { Without } \\
\text { activation }\end{array}$ & Reference \\
\hline \multicolumn{6}{|l|}{ Prokaryotic organisms: } \\
\hline $\begin{array}{l}\text { Escherichia coli } \\
\text { (WP2 her) }\end{array}$ & Allethrin & Gene mutation & & $--^{a}$ & Moriya et al. 1983 \\
\hline $\begin{array}{l}\text { Salmonella typhimurium } \\
\text { (TA98, JK1) }\end{array}$ & Allethrin & Gene mutation & & $-{ }^{\mathrm{b}}$ & Hour et al. 1998 \\
\hline $\begin{array}{l}\text { S. typhimurium } \\
\text { (JK3, JK947) }\end{array}$ & Allethrin & Gene mutation & & $++^{b}$ & Hour et al. 1998 \\
\hline $\begin{array}{l}\text { S. typhimurium } \\
\text { (TA98, TA1535, TA1537, } \\
\text { TA1538) }\end{array}$ & Allethrin & Gene mutation & & $-^{a}$ & Moriya et al. 1983 \\
\hline S. typhimurium (TA100) & Allethrin & Gene mutation & + & + & Moriya et al. 1983 \\
\hline $\begin{array}{l}\text { S. typhimurium } \\
\text { (TA97, TA100, TA104) }\end{array}$ & Allethrin & Gene mutation & + & - & $\begin{array}{l}\text { Herrera and } \\
\text { Laborda } 1988\end{array}$ \\
\hline $\begin{array}{l}\text { S. typhimurium } \\
\text { (TA98, TA1535, TA1538, } \\
\text { TA1537) }\end{array}$ & Allethrin & Gene mutation & - & - & $\begin{array}{l}\text { Herrera and } \\
\text { Laborda } 1988\end{array}$ \\
\hline $\begin{array}{l}\text { S. typhimurium } \\
\text { (TA98, TA100) }\end{array}$ & Bioresmethrin & Gene mutation & - & - & Pluijmen et al. 1984 \\
\hline $\begin{array}{l}\text { S. typhimurium } \\
\text { (TA98, T100) }\end{array}$ & Cismethrin & Gene mutation & - & - & Pluijmen et al. 1984 \\
\hline E. coli (WP2 her) & Permethrin & Gene mutation & & $-{ }^{\mathrm{a}}$ & Moriya et al. 1983 \\
\hline $\begin{array}{l}\text { S. typhimurium } \\
\text { (TA98, TA100) }\end{array}$ & Permethrin & Gene mutation & - & - & Pluijmen et al. 1984 \\
\hline $\begin{array}{l}\text { S. typhimurium } \\
\text { (TA98, TA100, TA1535, } \\
\text { TA1537, TA1538) }\end{array}$ & Permethrin & Gene mutation & & $-^{a}$ & Moriya et al. 1983 \\
\hline $\begin{array}{l}\text { S. typhimurium } \\
\text { (TA98, TA100) }\end{array}$ & Permethrin & Gene mutation & - & & Bartsch et al. 1980 \\
\hline $\begin{array}{l}\text { S. typhimurium } \\
\text { (TA97, TA98, TA100, } \\
\text { TA104, TA1535, TA1537, } \\
\text { TA1538) }\end{array}$ & Permethrin & Gene mutation & - & - & $\begin{array}{l}\text { Herrera and } \\
\text { Laborda } 1988\end{array}$ \\
\hline $\begin{array}{l}\text { S. typhimurium } \\
\text { (TA98, TA100) }\end{array}$ & Resmethrin & Gene mutation & - & - & Pluijmen et al. 1984 \\
\hline $\begin{array}{l}\text { S. typhimurium } \\
\text { (TA97, TA98, TA100, } \\
\text { TA104, TA1535, TA1537, } \\
\text { TA1538) }\end{array}$ & Resmethrin & Gene mutation & - & - & $\begin{array}{l}\text { Herrera and } \\
\text { Laborda } 1988\end{array}$ \\
\hline \multicolumn{6}{|l|}{ Eukaryotic organisms: } \\
\hline Yeast (Strain $\mathrm{A}$ and $\mathrm{HB}$ ) & $\begin{array}{l}\text { Ambush } \\
\text { 25EC } \\
\text { (Permethrin) }\end{array}$ & $\begin{array}{l}\text { Mitochondrial } \\
\text { mutation }\end{array}$ & & + & $\begin{array}{l}\text { Chruścielska et al. } \\
1999\end{array}$ \\
\hline
\end{tabular}


3. HEALTH EFFECTS

Table 3-6. Genotoxicity of Type I Pyrethroids In Vitro

\begin{tabular}{|c|c|c|c|c|c|}
\hline Species (test system) & Chemical & End point & $\begin{array}{l}\text { With } \\
\text { activation }\end{array}$ & $\begin{array}{l}\text { Without } \\
\text { activation }\end{array}$ & Reference \\
\hline Yeast (Strain A and HB) & Permethrin & $\begin{array}{l}\text { Mitochondrial } \\
\text { mutation }\end{array}$ & & - & $\begin{array}{l}\text { Chruścielska et al. } \\
1999\end{array}$ \\
\hline \multicolumn{6}{|l|}{ Mammalian cells: } \\
\hline $\begin{array}{l}\text { Chinese hamster ovary } \\
\text { cells }\end{array}$ & Bioresmethrin & Gene mutation & & - & Pluijmen et al. 1984 \\
\hline $\begin{array}{l}\text { Chinese hamster ovary } \\
\text { cells }\end{array}$ & Cismethrin & Gene mutation & & - & Pluijmen et al. 1984 \\
\hline $\begin{array}{l}\text { Chinese hamster ovary } \\
\text { cells }\end{array}$ & Permethrin & $\begin{array}{l}\text { Chromosomal } \\
\text { aberrations }\end{array}$ & & + & $\begin{array}{l}\text { Barrueco et al. } \\
1994\end{array}$ \\
\hline Human lymphocytes & Permethrin & $\begin{array}{l}\text { Chromosomal } \\
\text { aberrations }\end{array}$ & - & + & $\begin{array}{l}\text { Barrueco et al. } \\
1992\end{array}$ \\
\hline Human lymphocytes & Permethrin & $\begin{array}{l}\text { Chromosomal } \\
\text { aberrations }\end{array}$ & & + & $\begin{array}{l}\text { Barrueco et al. } \\
1994\end{array}$ \\
\hline Human lymphocytes & Permethrin & $\begin{array}{l}\text { Sister } \\
\text { chromatid } \\
\text { exchange }\end{array}$ & \pm & \pm & $\begin{array}{l}\text { Barrueco et al. } \\
1992\end{array}$ \\
\hline Human lymphocytes & Permethrin & Micronuclei & & + & $\begin{array}{l}\text { Barrueco et al. } \\
1992\end{array}$ \\
\hline Human lymphocytes & Permethrin & Micronuclei & & - & $\begin{array}{l}\text { Surrallés et al. } \\
1995\end{array}$ \\
\hline Human whole blood & Permethrin & Micronuclei & & - & $\begin{array}{l}\text { Surrallés et al. } \\
1995\end{array}$ \\
\hline $\begin{array}{l}\text { Chinese hamster ovary } \\
\text { cells }\end{array}$ & Permethrin & Gene mutation & & - & Pluijmen et al. 1984 \\
\hline $\begin{array}{l}\text { Chinese hamster ovary } \\
\text { cells }\end{array}$ & Resmethrin & Gene mutation & & - & Pluijmen et al. 1984 \\
\hline
\end{tabular}

${ }^{\mathrm{a}}$ Not clear whether tests were performed with or without activation.

${ }^{\mathrm{b}}$ Tests assumed to be performed without activation because use of activation was not discussed in the study.

$-=$ negative result; $+=$ positive result; $\pm=$ weak positive result 
Table 3-7. Genotoxicity of Type II Pyrethroids In Vitro

\begin{tabular}{|c|c|c|c|c|c|}
\hline $\begin{array}{l}\text { Species } \\
\text { (test system) }\end{array}$ & Chemical & End point & $\begin{array}{l}\text { With } \\
\text { activation }\end{array}$ & $\begin{array}{l}\text { Without } \\
\text { activation }\end{array}$ & Reference \\
\hline \multicolumn{6}{|l|}{ Prokaryotic organisms: } \\
\hline $\begin{array}{l}\text { Salmonella } \\
\text { typhimurium } \\
(\mathrm{TA} 98,100)\end{array}$ & Cypermethrin & Gene mutation & - & - & Pluijmen et al. 1984 \\
\hline $\begin{array}{l}\text { S. typhimurium } \\
\text { (TA98) }\end{array}$ & Deltamethrin & Gene mutation & - & & Bartsch et al. 1980 \\
\hline $\begin{array}{l}\text { S. typhimurium } \\
\text { (TA100) }\end{array}$ & Deltamethrin & Gene mutation & - & + & Bartsch et al. 1980 \\
\hline $\begin{array}{l}\text { S. typhimurium } \\
\text { (TA98, TA100) }\end{array}$ & Deltamethrin & Gene mutation & - & - & Pluijmen et al. 1984 \\
\hline $\begin{array}{l}\text { S. typhimurium } \\
\text { (TA98, TA100, } \\
\text { TA1535, TA1537) }\end{array}$ & Fenpropathrin & Gene mutation & - & - & Ryu et al. 1996 \\
\hline $\begin{array}{l}\text { S. typhimurium } \\
\text { (TA98, TA100) }\end{array}$ & Fenvalerate & Gene mutation & - & - & Pluijmen et al. 1984 \\
\hline $\begin{array}{l}\text { S. typhimurium } \\
\text { (TA97, TA98, TA100, } \\
\text { TA1535, TA1538) }\end{array}$ & $\begin{array}{l}\text { Supercyper- } \\
\text { methrin }\end{array}$ & Gene mutation & - & - & $\begin{array}{l}\text { Miadoková et al. } \\
1991\end{array}$ \\
\hline \multicolumn{6}{|l|}{ Eukaryotic organisms: } \\
\hline $\begin{array}{l}\text { Yeast } \\
\text { (Strains } A \text { and HB) }\end{array}$ & Cypermethrin & $\begin{array}{l}\text { Mitochondrial } \\
\text { mutation }\end{array}$ & & - & $\begin{array}{l}\text { Chruścielska et al. } \\
1999\end{array}$ \\
\hline $\begin{array}{l}\text { Yeast } \\
\text { (Strains } A \text { and } H B \text { ) }\end{array}$ & $\begin{array}{l}\text { Fastac 10EC } \\
\text { (10\% alpha- } \\
\text { cypermethrin) }\end{array}$ & $\begin{array}{l}\text { Mitochondrial } \\
\text { mutation }\end{array}$ & & \pm & $\begin{array}{l}\text { Chruścielska et al. } \\
1999\end{array}$ \\
\hline $\begin{array}{l}\text { Yeast } \\
\text { (Strains } A \text { and } H B \text { ) }\end{array}$ & Deltamethrin & $\begin{array}{l}\text { Mitochondrial } \\
\text { mutation }\end{array}$ & & - & $\begin{array}{l}\text { Chruścielska et al. } \\
1999\end{array}$ \\
\hline $\begin{array}{l}\text { Yeast } \\
\text { (Strains } A \text { and } H B \text { ) }\end{array}$ & $\begin{array}{l}\text { Decis } 2.5 \mathrm{EC} \\
(2.5 \% \text { delta- } \\
\text { methrin) }\end{array}$ & $\begin{array}{l}\text { Mitochondrial } \\
\text { mutation }\end{array}$ & & + & $\begin{array}{l}\text { Chruścielska et al. } \\
1999\end{array}$ \\
\hline $\begin{array}{l}\text { Yeast } \\
\text { (Strains A and HB) }\end{array}$ & $\begin{array}{l}\text { Karate 025EC } \\
\text { ( } 25 \mathrm{~g} / \mathrm{L} \text { lambda- } \\
\text { cyhalothrin) }\end{array}$ & $\begin{array}{l}\text { Mitochondrial } \\
\text { mutation }\end{array}$ & & + & $\begin{array}{l}\text { Chruścielska et al. } \\
1999\end{array}$ \\
\hline Yeast Strain D7 & $\begin{array}{l}\text { Supercyper- } \\
\text { methrin }\end{array}$ & $\begin{array}{l}\text { Mitotic cross- } \\
\text { over }\end{array}$ & & \pm or - & Vlčková 1991 \\
\hline Yeast Strain D7 & $\begin{array}{l}\text { Supercyper- } \\
\text { methrin }\end{array}$ & $\begin{array}{l}\text { Conversion at } \\
\text { the tryptophan } \\
\text { locus }\end{array}$ & & \pm or - & Vlčková 1991 \\
\hline Yeast Strain D7 & $\begin{array}{l}\text { Supercyper- } \\
\text { methrin }\end{array}$ & $\begin{array}{l}\text { Conversion at } \\
\text { the tryptophan } \\
\text { locus }\end{array}$ & & + & $\begin{array}{l}\text { Miadoková et al. } \\
1992\end{array}$ \\
\hline Yeast Strain D7 & $\begin{array}{l}\text { Supercyper- } \\
\text { methrin }\end{array}$ & $\begin{array}{l}\text { Gene reversion } \\
\text { mutations }\end{array}$ & & + & Vlčková 1991 \\
\hline Yeast Strain D7 & $\begin{array}{l}\text { Supercyper- } \\
\text { methrin }\end{array}$ & $\begin{array}{l}\text { Point mutations } \\
\text { at isoleucine } \\
\text { locus }\end{array}$ & & + & $\begin{array}{l}\text { Miadoková et al. } \\
1992\end{array}$ \\
\hline
\end{tabular}


Table 3-7. Genotoxicity of Type II Pyrethroids In Vitro

\begin{tabular}{|c|c|c|c|c|c|}
\hline $\begin{array}{l}\text { Species } \\
\text { (test system) }\end{array}$ & Chemical & End point & $\begin{array}{l}\text { With } \\
\text { activation }\end{array}$ & $\begin{array}{l}\text { Without } \\
\text { activation }\end{array}$ & Reference \\
\hline \multicolumn{6}{|l|}{ Mammalian systems: } \\
\hline Human lymphocytes & Cypermethrin & $\begin{array}{l}\text { Sister } \\
\text { chromatid } \\
\text { exchange }\end{array}$ & & - & Puig et al. 1989 \\
\hline Human lymphocytes & Cypermethrin & Micronuclei & & \pm & Surrallés et al. 1995 \\
\hline Human whole blood & Cypermethrin & Micronuclei & & \pm & Surrallés et al. 1995 \\
\hline Mouse spleen cells & Cypermethrin & $\begin{array}{l}\text { Chromosomal } \\
\text { aberrations }\end{array}$ & & + & Amer et al. 1993 \\
\hline Mouse spleen cells & Cypermethrin & $\begin{array}{l}\text { Sister } \\
\text { chromatid } \\
\text { exchange }\end{array}$ & & + & Amer et al. 1993 \\
\hline $\begin{array}{l}\text { Chinese hamster } \\
\text { ovary cells }\end{array}$ & Cypermethrin & Gene mutation & & - & Pluijmen et al. 1984 \\
\hline Human lymphocytes & Deltamethrin & $\begin{array}{l}\text { Sister } \\
\text { chromatid } \\
\text { exchange }\end{array}$ & & \pm & Dolara et al. 1992 \\
\hline Human lymphocytes & Deltamethrin & $\begin{array}{l}\text { Sister } \\
\text { chromatid } \\
\text { exchange }\end{array}$ & - & - & Villarini et al. 1998 \\
\hline Human lymphocytes & Deltamethrin & Micronuclei & & \pm & Surrallés et al. 1995 \\
\hline Human lymphocytes & Deltamethrin & Micronuclei & - & - & Villarini et al. 1998 \\
\hline Human lymphocytes & Deltamethrin & DNA damage & + & \pm & Villarini et al. 1998 \\
\hline Human whole blood & Deltamethrin & Micronuclei & & \pm & Surrallés et al. 1995 \\
\hline $\begin{array}{l}\text { Chinese hamster } \\
\text { ovary cells }\end{array}$ & Deltamethrin & Gene mutation & & - & Pluijmen et al. 1984 \\
\hline $\begin{array}{l}\text { Chinese hamster } \\
\text { lung fibroblasts }\end{array}$ & Fenpropathrin & $\begin{array}{l}\text { Chromosomal } \\
\text { aberrations }\end{array}$ & - & - & Ryu et al. 1996 \\
\hline Human lymphocytes & Fenpropathrin & Micronuclei & & \pm & Surrallés et al. 1995 \\
\hline Human whole blood & Fenpropathrin & Micronuclei & & \pm & Surrallés et al. 1995 \\
\hline Human lymphocytes & Fenvalerate & $\begin{array}{l}\text { Chromosomal } \\
\text { aberrations }\end{array}$ & & + & Puig et al. 1989 \\
\hline $\begin{array}{l}\text { Chinese hamster } \\
\text { ovary cells }\end{array}$ & Fenvalerate & $\begin{array}{l}\text { Chromosomal } \\
\text { aberrations }\end{array}$ & + & - & Caballo et al. 1992 \\
\hline $\begin{array}{l}\text { Chinese hamster } \\
\text { ovary cells }\end{array}$ & Fenvalerate & $\begin{array}{l}\text { Sister } \\
\text { chromatid } \\
\text { exchange }\end{array}$ & + & + & Caballo et al. 1992 \\
\hline Human lymphocytes & Fenvalerate & Micronuclei & & - & Surrallés et al. 1995 \\
\hline
\end{tabular}


3. HEALTH EFFECTS

Table 3-7. Genotoxicity of Type II Pyrethroids In Vitro

\begin{tabular}{|c|c|c|c|c|c|}
\hline $\begin{array}{l}\text { Species } \\
\text { (test system) }\end{array}$ & Chemical & End point & $\begin{array}{l}\text { With } \\
\text { activation }\end{array}$ & $\begin{array}{l}\text { Without } \\
\text { activation }\end{array}$ & Reference \\
\hline Human whole blood & Fenvalerate & Micronuclei & & - & Surrallés et al. 1995 \\
\hline Human lymphocytes & Fenvalerate & $\begin{array}{l}\text { C-mitosis } \\
\text { induction }\end{array}$ & & + & $\begin{array}{l}\text { Carbonell et al. } \\
1989\end{array}$ \\
\hline $\begin{array}{l}\text { Chinese hamster } \\
\text { ovary cells }\end{array}$ & Fenvalerate & Gene mutation & & - & Pluijmen et al. 1984 \\
\hline Pig lymphocytes & Supermethrin & $\begin{array}{l}\text { Chromosomal } \\
\text { aberrations }\end{array}$ & & + & $\begin{array}{l}\text { Dianovský and } \\
\text { Šiviková } 1997\end{array}$ \\
\hline Cattle lymphocytes & Supermethrin & $\begin{array}{l}\text { Chromosomal } \\
\text { aberrations }\end{array}$ & & + & $\begin{array}{l}\text { Dianovský and } \\
\text { Šiviková } 1997\end{array}$ \\
\hline Pig lymphocytes & Supermethrin & $\begin{array}{l}\text { Sister } \\
\text { chromatid } \\
\text { exchange }\end{array}$ & & - & $\begin{array}{l}\text { Dianovský and } \\
\text { Šiviková } 1997\end{array}$ \\
\hline Cattle lymphocytes & Supermethrin & $\begin{array}{l}\text { Sister } \\
\text { chromatid } \\
\text { exchange }\end{array}$ & & \pm & $\begin{array}{l}\text { Dianovský and } \\
\text { Šiviková } 1997\end{array}$ \\
\hline $\begin{array}{l}\text { Syrian hamster } \\
\text { embryo cells }\end{array}$ & $\begin{array}{l}\text { Supercyper- } \\
\text { methrin }\end{array}$ & $\begin{array}{l}\text { Morphological } \\
\text { transformation }\end{array}$ & & + & $\begin{array}{l}\text { Slameňová et al. } \\
1992\end{array}$ \\
\hline $\begin{array}{l}\text { BHK21 (baby } \\
\text { hamster kidney cells) }\end{array}$ & $\begin{array}{l}\text { Supercyper- } \\
\text { methrin }\end{array}$ & $\begin{array}{l}\text { Anchorage } \\
\text { independent } \\
\text { growth }\end{array}$ & + & + & $\begin{array}{l}\text { Slameňová et al. } \\
1992\end{array}$ \\
\hline
\end{tabular}

- = negative result; $+=$ positive result; $\pm=$ weak positive result; DNA $=$ deoxyribonucleic acid 
Results of studies of volunteers and laboratory animals indicate that Type I and Type II pyrethroid compounds are absorbed from the gastrointestinal tract following oral exposure. Absorption is incomplete, with minimum estimates for absorption between 40 and $60 \%$ of an orally or intragastrically administered dose. However, first-pass metabolism may contribute significantly to under-estimation of the absorption of pyrethroids. Pyrethroids are rapidly absorbed in humans following inhalation exposure, but no estimates are available regarding how much of an inhaled dose is absorbed. Only small amounts ( $<2 \%$ of the applied dose) of pyrethroids are absorbed following dermal exposure, and the rate of absorption from this route is much slower than by the oral or inhaled routes. Pyrethroids may be stored in skin and then slowly released into the systemic circulation. Distribution of pyrethroids has not been well studied in humans; most of the available information is based on the results of studies in animals. Following absorption, pyrethroids are widely and rapidly distributed to most tissues, particularly to tissues with a high lipid content, and are concentrated in central and peripheral nervous tissues. Although there is little information on the metabolism of pyrethroids in humans, metabolism of pyrethroids has been extensively studied in animal models. The major metabolic pathways for pyrethroids are hydrolysis of the central ester bond, oxidative attacks at several sites, and conjugation reactions, to produce a complex array of primary and secondary water-soluble metabolites that undergo urinary excretion. Information on the specific enzymes involved in the metabolism of pyrethroid compounds is limited, but it appears to involve nonspecific microsomal carboxyesterases and microsomal mixed function oxidases, which are located in nearly all tissue types, with particularly high activities in the liver. Since microsomal enzymes play an important role in the metabolism of pyrethroids, it is expected that many tissue types are potentially capable of rapidly metabolizing these compounds. Elimination and excretion of pyrethroids in humans have not been extensively studied. Elimination appears to follow first-order kinetics, with elimination half-times in humans ranging from 6.4 to 16.5 hours, depending upon the specific pyrethroid and the exposure route studied. For most pyrethroids, elimination is nearly complete within 5 days of exposure, although certain isomers can persist in the body for a longer period of time. Pyrethroids have been shown to undergo urinary and fecal excretion in humans, but other routes of excretion, such as exhalation of volatile products, have not been studied. In animals, Type I and Type II pyrethroids undergo urinary, fecal, and biliary excretion, with urinary and fecal excretion as the primary routes; small quantities are also excreted in milk. Pyrethroids do not appear to be excreted as parent compounds via expired air of animals. 


\subsubsection{Absorption}

Pyrethrins and pyrethroids are used to control insects in agricultural, commercial, and houshold environments. Since aerial application is the typical method by which pyrethrin- and pyrethroidcontaining substances are dispersed, the use of such substances may result in combinations of inhalation, oral, and dermal exposure.

\subsubsection{Inhalation Exposure}

Several studies demonstrate absorption of Type I and Type II pyrethroids following occupational exposure through identification of pyrethroid metabolites in urine (Aprea et al. 1997; Chester et al. 1987, 1992; Kühn et al. 1999; Leng et al. 1996, 1997b). In some cases, plasma levels of pyrethroids were below the limits of detection (5 $\mathrm{g} / \mathrm{L}$ ) (Leng et al. 1997a, 1997b). Absorption of cyfluthrin in workers was confirmed by measurement of plasma cyfluthrin levels, although estimates of total exposure levels of cyfluthrin in these workers were not available (Leng and Lewalter 1999). It appears that pyrethroids are rapidly absorbed following inhalation, based on the appearance of urinary metabolites within 30 minutes of exposure (Leng et al. 1997a). In this study, an increase in the amount of urinary metabolites correlated with increasing exposure levels, indicating that absorption by the inhalation route is not capacity-limited, at least over the range of exposures studied $\left(10-160 \mathrm{mg} / \mathrm{m}^{3}\right)$. However, occupational exposure of humans to pyrethroids may include inhalation, oral, and/or dermal routes. Studies providing estimates for total absorption of pyrethroids following inhalation or occupational exposure were not identified.

No information was located regarding absorption of pyrethroids following inhalation exposure in animals.

\subsubsection{Oral Exposure}

Available information regarding oral exposure of humans indicates that both Type I and Type II pyrethroids are absorbed from the gastrointestinal tract. A 59-year-old male attempted suicide by drinking approximately $600 \mathrm{~mL}$ of $20 \%$ permethrin emulsion (143 grams) (Gotoh et al. 1998). The emulsion contained a mix of cis and trans isomers (43.5\% cis and 56.5\% trans). Maximal plasma concentrations of permethrin occurred 3-4 hours after ingestion. Both isomers were detected in plasma, indicating that both cis and trans isomers of permethrin are absorbed following oral administration. It is not possible to determine the fraction of the administered dose that was absorbed in this patient. Oral 
exposure of a single volunteer demonstrated absorption of cyfluthrin by measurement of cyfluthrin metabolites in the urine, with an estimated minimum oral absorption of $40 \%$, based on recovery of urinary cyfluthrin metabolites (Leng et al. 1997b). Similar results were observed in male volunteers exposed to cypermethrin, with absorption estimates ranging from 36 to $63 \%$ of the administered dose (Eadsforth and Baldwin 1983; Eadsforth et al. 1988; Woollen et al. 1992). Estimates of absorption following oral exposure to pyrethroids may be low, however, since they are based on the appearance of metabolites in the urine and do not consider other routes of excretion, such as biliary excretion.

Observations in humans are supported by the results of animal studies. In several mammalian species, absorption of Type I pyrethroids following oral administration has been demonstrated by the presence of pyrethroid compounds in plasma, urine, and milk (Anadón et al. 1991b; Elliott et al. 1976; Gaughan et al. 1977, 1978; Hunt and Gilbert 1977; Ohsawa and Casida 1980; Tomigahara et al. 1994a, 1994b; Ueda et al. 1975a, 1975b). Following oral administration of a single dose of permethrin to rats, peak plasma levels of permethrin occurred 3-4 hours after ingestion, with an estimated total absorption of approximately $60 \%$ of the administered dose (Anadón et al. 1991b). In cows administered resmethrin orally, $43 \%$ of the administered dose was excreted in the urine as resmethrin metabolites, indicating a minimum absorption of $43 \%$ of the administered dose (Ridlen et al. 1984). Absorption of several Type II pyrethroids following oral administration has been demonstrated by the presence of pyrethroid compounds in plasma, urine, and milk (Anadón et al. 1996; Quistad and Selim 1983; Quistad et al. 1982, 1983). In Rhesus monkeys exposed to oral doses of ${ }^{14} \mathrm{C}$-fluvalinate, peak plasma levels were observed $2-$ 3 hours after administration, with $37 \%$ of the administered dose eliminated in the urine as metabolites (Quistad and Selim 1983). Khan et al. $(1986,1990)$ demonstrated that ${ }^{14} \mathrm{C}$-labeled deltamethrin was absorbed by rats following the ingestion of plant material containing bound residues of the pyrethroid.

Differences in the rate and extent of absorption in young versus older rats were demonstrated in one study of rats administered ${ }^{14} \mathrm{C}$-fluvalinate by gavage (Quistad et al. 1983). In younger rats (7 weeks old), peak plasma levels of ${ }^{14} \mathrm{C}$ occurred at 7 hours, compared to 14 hours in older rats. However, lower plasma ${ }^{14} \mathrm{C}$ levels were observed in younger compared to older rats; thus, it is not clear whether fractional absorption was lower or higher in the younger rats. No information was located that could serve as a basis for predicting the effects of age on absorption of pyrethroids from the human gastrointestinal tract.

No information was located regarding possible sex-related differences in absorption of ingested pyrethroids in humans or animals. 


\subsubsection{Dermal Exposure}

Limited information is available regarding absorption of Type I or Type II pyrethroids following dermal exposure in humans. Following dermal application of permethrin to patients for treatment of scabies, the estimated absorption of permethrin was $0.5 \%$ of the applied dose, based upon the urinary excretion of permethrin metabolites (van der Rhee et al. 1989). Urinary excretion of metabolites persisted for 710 days following a single dermal application, suggesting that pyrethroids may be stored in skin and slowly released into the systemic circulation. A study using an in vitro preparation of human skin indicated that only a small fraction (approximately $0.7 \%$ ) of a topically applied dose of permethrin fully penetrated the skin after a single 48-hour exposure, with small amounts of permethrin identified in the epidermal and dermal layers (Franz et al. 1996). Two studies evaluated the absorption of cypermethrin following dermal application of a single dose to volunteers (Eadsforth et al. 1988; Woollen et al. 1992). Based upon the recovery of urinary metabolites of cypermethrin, it was estimated that $0.3-1.8 \%$ of the applied dose was absorbed. Peak urinary excretion of metabolites was observed between 14 and 36 hours after application. This is in contrast to observations following oral exposure of cypermethrin in humans in which the urinary excretion rate of metabolites was highest during the first 24 hours after dosing (Woollen et al. 1992).

Limited animal data are available regarding absorption of Type I or Type II pyrethroids following dermal exposure. Results of one study in rats are consistent with findings in humans; approximately $0.7 \%$ of a dermal application of fluvalinate was absorbed (Quistad et al. 1983). A single study indicates that fenvalerate is absorbed more quickly following dermal exposure to goats compared with other mammalian species, with peak plasma concentrations reached 2 hours after dosing (Mandal et al. 1996). The total percutaneous absorption of fenvalerate was not determined in that study. Percutaneous absorption of permethrin was demonstrated in guinea pigs in vivo following a single dermal application (Franz et al. 1996). In this study, absorption was found to be 20 -fold greater than that measured in a preparation of human skin. The percutaneous absorption of permethrin in rats, as measured by recovery of ${ }^{14} \mathrm{C}$ in urine and feces, was estimated to be $46 \%$ of the applied dose (Shah et al. 1987). This finding is not consistent with lower estimates from other studies in humans and animals and may be attributed to lack of restraint of the animals, allowing for oral exposure from licking of the application site. However, insufficient information is provided in the report to confirm this possibility. In this same study, there was no difference in the absorption of young (33 days) versus adult rats exposed to a single dermal application of permethrin. 
No additional information was located regarding sex- or age-related differences in absorption of pyrethroids following dermal exposure in humans or animals. There is no obvious structural basis for predicting substantial differences in the percutaneous absorption of Type I and Type II compounds in humans.

\subsubsection{Distribution}

No information is available regarding the distribution of Type I and Type II pyrethroid compounds or pyrethroid metabolites in humans, except for information regarding the distribution of pyrethroids and pyrethroid metabolites into excretory compartments. Given the lipophilic nature of pyrethroids, it is expected that, in humans, they are widely distributed and undergo rapid distribution to tissues with a high lipid content, including fat and central and peripheral nervous tissues. Based upon observations of central and peripheral nervous system toxicity in humans exposed to pyrethroid compounds, it is apparent that distribution of pyrethroids to these tissues occurs (Aldridge 1990; Casida et al. 1983; Vijverberg and van den Bercken 1990). Since pyrethroid metabolites are less lipid soluble than the parent compounds, it is expected that distribution of metabolites to central and peripheral nervous tissues would be decreased compared to that of the parent compounds. Studies in several mammalian species confirm that pyrethroids are widely and rapidly distributed to many tissues, including liver and kidney, and are concentrated in central and peripheral nervous tissues. In pregnant and lactating animals, pyrethroids are distributed into milk. Although animal studies of placental transfer of pyrethroids indicate that pyrethroids do not cross the placenta in substantial amounts or accumulate in the fetus (Kaneko et al. 1984b; Quistad et al. 1982; Shiba et al. 1990), other animal studies indicate that in utero exposure to pyrethroids may result in persistent effects on neurotransmitters (Malaviya et al. 1993; Santoni et al. 1999) and on the immune system (Santoni et al. 1997, 1998, 1999). Interpretation of results obtained from many of the distribution studies in animals is limited by the study design; the distribution of pyrethroids was typically evaluated in tissues collected from animals after most of the chemical had been excreted from the body (1-8 days after treatment with the last dose).

\subsubsection{Inhalation Exposure}

No information was located regarding the distribution of pyrethroids in humans or animals following inhalation exposure. 


\subsubsection{Oral Exposure}

Limited information is available on the distribution of Type I or Type II pyrethroids in humans following oral exposure, and most of the available information describes the distribution of pyrethroids and pyrethroid metabolites into excretory compartments (reviewed in Section 3.4.3.2). Based on the results of a study in which plasma permethrin concentrations were measured in an adult male who ingested permethrin in a suicide attempt, permethrin appears to follow a two-compartment model, with distribution half-times for the trans and cis compounds of 5.08 and 4.82 hours, respectively (Gotoh at el. 1998). One study that investigated the elimination of ${ }^{14} \mathrm{C}$-deltamethrin in volunteers following oral administration showed that small amounts of deltamethrin or its metabolites were distributed to saliva (Stockis et al. 1985). In this same study, evaluation of the distribution of ${ }^{14} \mathrm{C}$ in plasma indicated that approximately $25 \%$ of the plasma ${ }^{14} \mathrm{C}$ was associated with red blood cells.

In rats, permethrin was rapidly distributed to nervous tissues after administration of a single oral dose, with a distribution half-time of 4.85 hours (Anadón et al. 1991b). Plasma levels of permethrin exhibited a bi-phasic decline, which can be represented by a two-compartment model with a rapid distribution phase. Based on a large apparent volume of distribution, it appears that permethrin is distributed in both extracellular and intracellular fluids, indicating that pyrethroids can easily cross cell membranes. Permethrin concentrations in nervous tissue were higher than those measured in plasma, indicating that permethrin is concentrated in nerve tissue relative to plasma. Concentrations in nerve tissue were highest in the sciatic nerve, followed by (in decreasing order) hypothalamus, frontal cortex, hippocampus, caudate putamen, cerebellum, and medulla oblongata. Peak concentrations were observed to occur within 4 hours of dosing in both nerve tissue and plasma. Permethrin was also distributed to the liver, with peak concentrations observed within 4 hours of dosing. Concentrations of permethrin metabolites ( $m$-phenoxybenzyl alcohol and $m$-phenoxybenzoic acid) in nerve tissues were lower than those observed for the parent compound. Although it is not possible to determine if the permethrin metabolites entered the nerve tissue from blood or if permethrin was metabolized to its metabolites in nerve tissue, distribution of the more lipid soluble parent compounds into nerve tissue is considered more likely (Anadón et al. 1991a, 1991b). ${ }^{14}$ C-Permethrin or its metabolites are also rapidly distributed to the kidney following oral administration to rats, with levels of ${ }^{14} \mathrm{C}$ in the kidney peaking approximately 4 hours after dosing (Miyamoto et al. 1968). Studies in lactating cows indicate that very low levels of Type I pyrethroids (e.g., $<0.5 \%$ of the administered dose) are distributed into milk (Gaughan et al. 1978; Ridlen et al. 1984). Following oral exposure, permethrin or its metabolites have also been detected in fat of cows and rats up to12 days after dosing (Gaughan et al. 1977, 1978). 
Fluvalinate was widely distributed in rats following oral exposure to ${ }^{14} \mathrm{C}$-fluvalinate, based on detection of small amounts of ${ }^{14} \mathrm{C}$ in nearly all tissue types (Ruzo et al. 1978). However, interpretation of these results must be made with caution, since tissue levels of ${ }^{14} \mathrm{C}$ were measured in animals that had been sacrificed 8 days after oral dosing and nearly all of the ${ }^{14} \mathrm{C}$ had been eliminated from the body by that time. In rats, deltamethrin was rapidly distributed to nerve tissues after administration of a single oral dose, with a distribution half-time of 2.1 hours (Anadón et al. 1996). Plasma levels of deltamethrin exhibited a biphasic decline, which can be represented by a two-compartment model with a rapid distribution phase. Deltamethrin concentrations in nerve tissue were higher than those measured in plasma, indicating that deltamethrin is concentrated in nervous tissue relative to plasma. Concentrations in nerve tissue were highest in the hypothalamus, followed by (in decreasing order) hippocampus, cerebellum, frontal cortex, caudate putamen, and medulla oblongata, with peak concentrations occurring between 4 and 6 hours after oral administration. Similar distribution was observed for the 4-OH-metabolite of deltamethrin but, in general, the concentrations of metabolite measured in each tissue were less than those measured for the parent compound. It is not possible to determine if the metabolite entered the nervous tissue from blood or if deltamethrin was metabolized to the 4-OH-metabolite by nervous tissue. However, distribution of the more lipid soluble parent compounds into nerve tissue is considered more likely due to the lower lipid solubility of the metabolites (Anadón et al. 1996). Deltamethrin and its 4-OH metabolite were also detected in vas deferens and anococcygeus muscle at concentrations that were greater than plasma but less than those observed in nervous tissue (Anadón et al. 1996). Residual amounts of pyrethroids have been measured in fat several days after oral exposure to lambs and cows (Quistad et al. 1982; Wszolek et al. 1981a, 1981b). Studies in lactating cows indicate that Type II pyrethroids are rapidly distributed into milk after exposure to a single oral dose, but that only small amounts of the total dose are distributed to milk (0.4-0.9\% of the administered dose) (Quistad et al. 1982; Wszolek et al. 1980). Pyrethroids do not appear to cross the placenta in substantial amounts or accumulate in the fetus of animals, as evidenced by the results of dosing of pregnant rats and a single cow. Measurements of radioactivity in fetuses of rats administered radiolabeled pyrethroids indicated that $<0.004 \%$ of the administered dose of the Type I pyrethroid, tetramethrin, was recovered in the fetus (Kaneko et al. 1984b). Recovered activity from radiolabeled fenvalerate (a Type II pyrethroid) was $<0.07 \%$ (Shiba et al. 1990). Eight days after a pregnant cow was given a single dose of ${ }^{14} \mathrm{C}$-fluvalinate, only trace amounts of ${ }^{14} \mathrm{C}$ were detected in the fetus (Quistad et al. 1982).

The results of Anadón and coworkers (Anadón et al. 1991b, 1996) indicate that the Type II pyrethroid, fluvalinate, may be more rapidly distributed than permethrin, a Type I pyrethroid, following dermal 
exposure in rats. These apparent differences in distribution of permethrin and fluvalinate could be the result of chemical or toxicokinetic differences in these pyrethroids or Type I and Type II pyrethroids in general, although no data are presently available to confirm or refute this possibility.

No information was located regarding distribution within tissues of pyrethroid compounds following oral exposure of humans or animals. No information was located regarding sex- or age-related differences in distribution of Type I and Type II pyrethroids following oral exposure of humans or animals.

\subsubsection{Dermal Exposure}

No information is available regarding distribution of Type I or Type II pyrethroids in humans following dermal exposure, and available data from animal studies are limited. In guinea pigs exposed to dermally applied permethrin, the concentration of permethrin measured in brain tissue 24 hours after dosing was 7-fold higher than that of plasma (Franz et al. 1996). Residual tissue concentrations of fenvalerate, but not of its metabolites, were determined 4 days after administration of a single dermal dose to goats (Mandal et al. 1996). The highest concentration was observed in the adrenal gland, followed by (in decreasing order) biceps muscle, omental fat, liver, kidney, lung, and cerebrum. Interpretation of these data is hindered because at the time of fenvalerate tissue content measurement, the majority of the dose had been eliminated (only small amounts of fenvalerate remained in plasma at 3 days after dosing). No additional studies were located concerning distribution of Type I or Type II pyrethroids, and no information was available regarding age- or sex-related differences in distribution.

\subsubsection{Other Routes of Exposure}

No information was located regarding distribution of pyrethroids in humans following exposure by other routes.

Following intravenous administration in rats, Type I and Type II pyrethroids are rapidly and widely distributed to tissues and are concentrated in nervous tissue (Anadón et al. 1991b, 1996; Gray and Rickard 1982; Gray et al. 1980a; Silver and Dauterman 1989a). Plasma levels of parent compound exhibit a biphasic decline and fit a two-compartment model with rapid distribution phase (Anadón et al. 1991b, 1996). Distribution to the central nervous system is very rapid, with concentrations reaching peak levels 
within 5 minutes of administration (Gray et al. 1980a). Following intraperitoneal injection of rats with Type I pyrethroids, pyrethroids are rapidly distributed to the liver and are found to be associated with several subcellular fractions, including microsomes, indicating that pyrethroids are rapidly distributed to a detoxifying organ (Graillot and Hoellinger 1982). Results of these studies provide supportive evidence for the expectedly rapid and wide distribution of pyrethroids after absorption in humans.

No information was located regarding sex- or age-related differences in distribution of pyrethroids following parenteral exposure.

\subsubsection{Metabolism}

Extensive study of the metabolic pathways involved in the biotransformation of pyrethroids in humans has not been undertaken. Information on the metabolism of Type I and Type II pyrethroid compounds in humans is based upon identification of pyrethroid metabolites in urine and blood obtained in a small number of studies conducted under controlled conditions or following occupational exposures. In contrast, the metabolism of Type I and Type II pyrethroid compounds has been extensively studied in several mammalian animal models. Since the metabolites that have been identified in humans have also been identified in other mammalian species, it is unlikely that there are significant qualitative differences between humans and other mammals in the major metabolic pathways for pyrethroids, although some species differences do undoubtedly exist (Anadón et al. 1991b; Eadsforth and Baldwin 1983; Eadsforth et al. 1988; Elliott et al. 1976; Gaughan et al. 1977; Leng et al. 1997a, 1997b; Woollen et al. 1992). The following summary of pyrethroid metabolism is based on the results of extensive investigations of the metabolism of pyrethroids in mammalian models. It is presumed that these metabolic pathways pertain to human metabolism of pyrethroid compounds, although there may be important quantitative differences between species.

All synthetic pyrethroid compounds appear to be degraded by similar metabolic processes in mammals. Upon administration of pyrethroids to mammals, biotransformation takes place through hydrolysis of the central ester bond, oxidative attacks at several sites, and conjugation reactions to produce a complex array of primary and secondary water-soluble metabolites that undergo urinary and biliary excretion (Casida et al. 1983; Gray and Soderlund 1985; Leng et al. 1999a). It is widely accepted that metabolism results in the formation of compounds that have little or no demonstrable toxicity, although the formation of reactive or toxic intermediates cannot be ruled out, and it appears that cleavage of the ester bond results in substantial detoxification (Gray and Soderlund 1985; Hutson 1979). For halogenated pyrethroids (such as 
cyfluthrin, cypermethrin, and permethrin), rapid hydrolytic cleavage of the ester bond is followed by oxidation to yield carboxylic acid derivatives and phenoxybenzoic acid derivatives (Leng et al. 1997a, 1997b). These metabolites are, in general, excreted as alcohols, phenols, carboxylic acids, and their glycine, sulfate, glucuronide, or glucoside conjugates (Aprea et al. 1997; Casida et al. 1983). Metabolic pathways for permethrin, cypermethrin, and deltamethrin are shown in Figure 3-3. However, depending upon the type of pyrethroid compound, either oxidation or hydrolysis may predominate (Miyamoto 1976). The presence of the alpha-cyano group of the Type II pyrethroid compounds has been shown to decrease the rate of hydrolytic cleavage of the ester bond (Casida et al. 1983). Many of the trans enantiomers of pyrethroid compounds are metabolized mainly through hydrolytic cleavage of the ester linkage, with subsequent oxidation and/or conjugation of the component alcohol and acid moieties, whereas certain cis enantiomers are more resistant to hydrolytic attack and are degraded via oxidation at various sites of the molecule (Miyamoto 1976; Shono et al. 1979). For pyrethroids containing an alpha-cyanophenoxybenzyl substituent (Type II pyrethroids), cleavage of the ester bond results in the release of cyanide, which is rapidly converted mainly to thiocyanate (Casida et al. 1983; Gray and Soderlund 1985; Ohkawa et al. 1979). It does not appear that there is significant additional metabolic fragmentation of the acid and alcohol moieties, since metabolism studies with ${ }^{14} \mathrm{C}$-labeled pyrethroid compounds yield little or no detectable ${ }^{14} \mathrm{CO}_{2}$ (Ohkawa et al. 1979; Ruzo et al. 1978).

Information on the specific enzymes involved in the metabolism of pyrethroid compounds is limited. Metabolism appears to involve nonspecific microsomal carboxyesterases and microsomal mixed function oxidases, which are located in nearly all tissue types (Casida et al. 1983; Miyamoto 1976; Shono et al. 1979). Since microsomal enzymes play an important role in the metabolism of pyrethroids, it is expected that many tissue types are potentially capable of rapidly metabolizing these compounds, with a particularly important role for the liver. Pyrethroids are metabolized in blood in vitro (Gray and Rickard 1982). Metabolism of pyrethroids may also occur in the brain (Anadón et al. 1996; Ghiasuddin and Soderlund 1984), which may contribute to the detoxification of some pyrethroids in mammals (Ghiasuddin and Soderlund 1984).

Information on the effects of induction or inhibition of microsomal enzymes by other chemicals or drugs on the rate of metabolism of pyrethroid compounds in humans or animals was not identified.

No information was located regarding sex- or age-related differences in metabolism of pyrethroids following exposure in humans or animals. 
Figure 3-3. Metabolic Diagram for Deltamethrin, Permethrin, and Cypermethrin

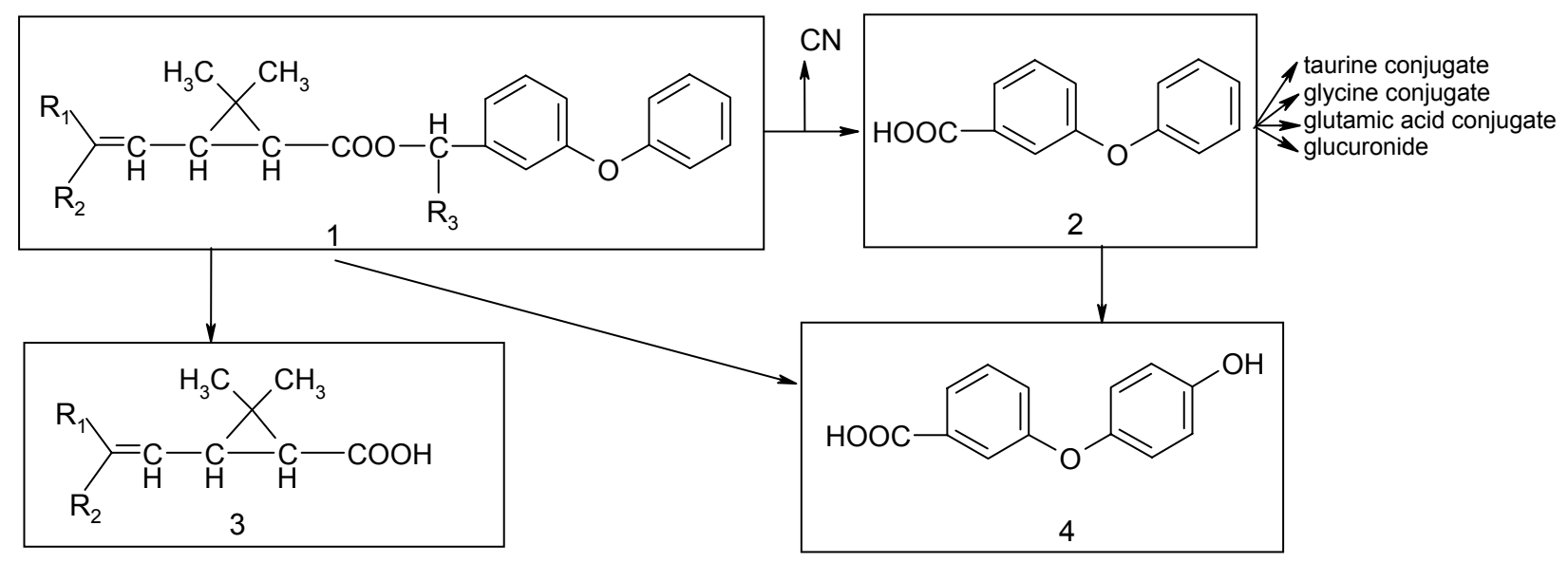

deltamethrin $\mathrm{R}_{1}=\mathrm{R}_{2}=\mathrm{Br} \mathrm{R}_{3}=\mathrm{CN}$

permethrin $\mathrm{R}_{1}=\mathrm{R}_{2}=\mathrm{Cl} \mathrm{R}_{3}=\mathrm{H}$

cypermethrin $\mathrm{R}_{1}=\mathrm{R}_{2}=\mathrm{Cl} \mathrm{R}_{3}=\mathrm{CN}$

$2\{3$-phenoxybenzoic acid (3-PBA)

$3\{$ 3-(2,2-dichlorovinyl)-2,2-dimethyl-cyclopropane carboxylic acid (DCVA)

$3\{$ 3-(2,2-dibromovinyl)-2,2-dimethy-cyclopropane carboxylic acid (DBVA)

4 \{ 3-(4-hydroxy)-phenoxybenzoic acid (4-OHPBA) 


\subsubsection{Inhalation Exposure}

The results of a single study of cyfluthrin in humans demonstrate that, when administered by the inhalation route, pyrethroids are rapidly metabolized, with metabolites appearing in the urine by 30 minutes after exposure (Leng et al. 1997a).

No studies were located regarding metabolism of pyrethroids following inhalation exposure to animals.

\subsubsection{Oral Exposure}

Given the important role of hepatic microsomal enzymes in the biotransformation of xenobiotics, accurate estimates of absorption following oral administration of pyrethroid compounds must take into account first-pass metabolism. Studies in humans indicate that the absorption of orally administered pyrethroids is incomplete; however, these studies do not provide evidence for first pass metabolism (Eadsforth and Baldwin 1983; Eadsforth et al. 1988; Woollen et al. 1992). Results of a study in isolated perfused rat liver are supportive for an important role for first-pass metabolism of pyrethroid compounds (Silver and Dauterman 1989b). In this study, the hepatic extraction ratios for both cis and trans isomers of tetramethrin were approximately 0.9 , and both the cis and trans isomers were rapidly metabolized by the liver. If the high in vitro extraction is indicative of in vivo, then first-pass extraction from the hepatic portal circulation and metabolism would be likely. Incomplete absorption of pyrethroids following oral exposure may also result from metabolism within the gastrointestinal tract or binding to poorly absorbed components of the ingesta. Results of studies in rats indicate that pyrethroid metabolites are produced within the gastrointestinal tract (Tomigahara et al. 1994b). Metabolites from permethrin were recovered in the feces following oral administration to rats, suggesting the possibility of metabolism in the gastrointestinal tract or fecal elimination of metabolites formed after absorption (Gaughan et al. 1977).

Although no information is available regarding sex-related differences in metabolism following oral administration of pyrethroids in humans, no differences in metabolism were observed in male and female rats orally exposed to pyrethroids (Quistad et al. 1983). 


\subsubsection{Dermal Exposure}

Little information is available regarding metabolism of pyrethroid compounds following dermal exposure. Following dermal application of permethrin to patients for treatment of scabies, permethrin metabolites were recovered from urine (van der Rhee et al. 1989). Results of a single study in volunteers comparing urinary metabolite profiles following oral and dermal exposure to cis- and trans-cypermethrin isomers demonstrated a difference in the urinary metabolite profiles following exposure by each route (Woollen et al. 1992). Following oral exposure, urine contained a higher proportion of trans-metabolites compared to that obtained following dermal exposure. These results could indicate differences in absorption or metabolism between these two routes of exposure.

No information was located regarding sex- or age-related differences in metabolism following dermal administration of pyrethroids to humans or animals.

\subsubsection{Elimination and Excretion}

\subsubsection{Inhalation Exposure}

The results of a single study examining urinary metabolites in humans following inhalation exposure to cyfluthrin indicate that elimination follows first-order kinetics, with $93 \%$ of the urinary elimination complete within 24 hours of exposure (Leng et al. 1997a). Elimination half-times for the cyfluthrin metabolites cis-/trans-3-(2,2-dichlorovinyl)-2,2-dimethylcyclopropane carboxylic acid (DCCA), 4-fluoro3-phenoxybenzoic acid (FPBA), and their isomers ranged from 5.3 to 6.9 hours. These elimination halftimes remained constant over a range of exposure levels, providing supportive evidence that pyrethroids exhibit first-order elimination kinetics. The amounts of cyfluthrin metabolites excreted in urine correlated with increasing exposure levels, demonstrating that urinary levels of pyrethroid metabolites may be a useful indicator of exposure level.

Several studies of occupational exposure of humans to pyrethroids were located; however, the exposures may have been by the inhalation, oral, or dermal routes, or a combination of these routes. Following occupational exposure to Type I and Type II pyrethroid compounds, excretion of pyrethroid metabolites in the urine occurs and is nearly complete within 4 days of exposure (Aprea et al. 1997; Chester et al. 
1987; Kühn et al. 1999). Based on elimination of cyfluthrin from plasma, the elimination half-time is estimated to be between 0.5 and 2 hours (Leng and Lewalter 1999). Based on elimination of metabolites into the urine, the elimination half-times are 5 hours for cyfluthrin and 8 hours for cypermethrin (Kühn et al. 1999). No information was provided in these studies regarding the amount of pyrethroid eliminated by nonurinary routes.

No information was located regarding sex- or age-related differences, or other factors, that might affect the elimination and excretion of pyrethroids following inhalation exposure of humans or animals.

\subsubsection{Oral Exposure}

Limited information is available regarding the elimination and excretion of Type I and Type II pyrethroid compounds following oral exposure in humans. The elimination half-time of cis-permethrin in plasma following ingestion of a mix of cis and trans isomers of permethrin in a suicide attempt was approximately 67 hours (Gotoh et al. 1998). Trans-permethrin was eliminated from the blood more quickly than the cis isomer and was undetectable in blood after 25 hours. However, an estimate of the plasma elimination half-time for the trans isomer was not reported. This patient was noted to have a history of chronic renal dysfunction, but no specific details were reported. Therefore, it is not possible to determine how this patient's renal status may have affected the elimination of permethrin from the plasma. In humans exposed to single oral doses of Type II pyrethroids, the elimination half-time based on the appearance of metabolites in the urine has been estimated to be between 6 and 13 hours (Leng et al. 1997b; Woollen et al. 1992). Approximately 35-50\% of the administered dose was excreted in the urine as metabolites during the first 5 days after dosing, with peak urinary excretion rates observed during the first 24 hours after dosing (Eadsforth and Baldwin 1983; Eadsforth et al. 1988; Leng et al. 1997b; Woollen et al. 1992). It is not possible to determine the percentage of the administered dose that was eliminated in the urine in these studies since only the urinary pyrethroid metabolites, and not total urinary pyrethroids (parent compound plus metabolites), were measured. Fecal elimination following oral dosing of Type II pyrethroids in humans has been confirmed based on the results of one study in humans, but neither the fraction of the administered dose excreted in feces nor the identity of the compounds excreted in feces were determined (Stockis et al. 1985).

Results of animal studies indicate that Type I and Type II pyrethroids are almost completely eliminated from the body within 4-12 days following oral exposure, with the majority of the dose eliminated within the first 12-48 hours (Anadón et al. 1996; Elliott et al. 1976; Gaughan et al. 1977; Hunt and Gilbert 1977; 
Lee et al. 1985; Quistad and Selim 1983; Quistad et al. 1982; Ridlen et al. 1984; Ruzo et al. 1978; Staiger and Quistad 1984; Wszolek et al. 1980). Type I and Type II pyrethroids exhibit first-order elimination kinetics. An estimate for the elimination half-time of permethrin in rats is approximately 8 hours (Anadón et al. 1991b). In oral studies, the plasma elimination half-time for fluvalinate in Rhesus monkeys was 2-3 hours, whereas, in rats, the elimination half-time of deltamethrin was 38.5 hours, although the time from administration to peak levels of the pyrethroids in both studies was similar (approximately 2-3 hours) (Anadón et al. 1996; Quistad and Selim 1983). It is not known if the differences in the elimination half-times observed in these studies are related to species differences, differences in dose, or differences in the elimination kinetics of the specific pyrethroid compounds.

In monkeys, cows, and rats, a large portion of the orally administered dose (43-56\%) is excreted in the urine (Quistad and Selim 1983; Quistad et al. 1982; Ridlen et al. 1984; Staiger and Quistad 1984), primarily as metabolites. In rats subject to oral exposure, almost all of the pyrethroids recovered in the urine are metabolites, with urine containing very little of the unchanged compound (Ueda et al. 1975b). In monkeys, cows, and rats, approximately $45-60 \%$ of the orally administered dose is excreted in the feces as a mix of parent compound and metabolites (Miyamoto et al. 1968; Quistad and Selim 1983; Quistad et al. 1982; Ridlen et al. 1984; Staiger and Quistad 1984; Ueda et al. 1975b). The urinary excretion route appears to be more important for trans-permethrin metabolites, while the fecal excretion route appears to be more important for cis-permethrin metabolites (Elliott et al. 1976; Hunt and Gilbert 1977).

Studies performed using cows, rats, and monkeys indicate that pyrethroids undergo biliary excretion, although estimates for the amount of biliary excretion were not available in these studies (Quistad and Selim 1983; Quistad et al. 1982, 1983). Based on the results of a study in isolated perfused rat liver, it appears that tetramethrin may undergo extensive biliary excretion (Silver and Dauterman 1989b). Studies in lactating cows and goats indicate that only very low levels of Type I pyrethroids are excreted $(<1 \%$ of the administered dose) in milk (Gaughan et al. 1978; Hunt and Gilbert 1977; Quistad et al. 1982; Ridlen et al. 1984; Wszolek et al. 1980). In one study, one pregnant cow was administered a single oral dose of ${ }^{14} \mathrm{C}$-fluvalinate and tissues were examined for radioactivity 8 days after dosing (Quistad et al. 1982). Analysis of the ${ }^{14} \mathrm{C}$ content of the fetus indicates minimal transfer of fluvalinate or its metabolites to the fetus (approximately $1 \times 10^{-5} \%$ of the administered dose). It does not appear that pyrethroids are excreted in significant amounts via expired air (Gaughan et al. 1977; Ohkawa et al. 1979; Ruzo et al. 1978; Ueda et al. 1975b). 
Apart from the finding that pyrethroids may be excreted in milk, no additional information was located regarding sex-related differences, and no information was located regarding age-related differences, which might affect the elimination and excretion of pyrethroids following oral exposure of humans or animals.

\subsubsection{Dermal Exposure}

Limited information is available regarding elimination and excretion of pyrethroids following dermal exposure in humans. Results of two studies in humans exposed to single dermal doses of cypermethrin indicate that a small fraction $(0.1-1.2 \%)$ of the administered dose is excreted in the urine as metabolites (Eadsforth et al. 1988; Woollen et al. 1992). Peak urinary excretion rates were observed between 12 and 36 hours after dosing (Woollen et al. 1992). Following dermal application of a single permethrin dose to patients for treatment of scabies, permethrin metabolites were excreted in urine, with urinary excretion persisting for 7 days after exposure (van der Rhee et al. 1989).

In rats exposed to single dermal doses of permethrin, $>90 \%$ of the absorbed dose was excreted in urine and feces, with a urine-to-fecal ratio of approximately 4:1 (Shah et al. 1987). While results of this study may provide evidence for fecal excretion following exposure by a nonoral route, it is possible that oral exposure occurred through licking of the application site if the animals were not properly restrained. In this study, no differences were noted in urinary excretion between young and adult rats. No other studies were located in which age-related differences in elimination and excretion of pyrethroids or their metabolites were assessed following dermal exposure. Following dermal exposure of rats to ${ }^{14} \mathrm{C}$-fluvalinate, 0.7 and $0.8 \%$ of the administered radioactivity was excreted in the urine and feces, respectively (Quistad et al. 1983). In this study, one group of animals was not restrained and the animals were able to lick the application site, which may have resulted in oral exposure and higher urinary and fecal excretion of ${ }^{14} \mathrm{C}$.

No information was located regarding sex-related differences, or other factors, that might affect the elimination and excretion of pyrethroids following dermal exposure in humans or animals. 


\subsubsection{Other Routes of Exposure}

No information was located regarding the elimination and excretion of Type I or Type II pyrethroids in humans following parenteral exposure. In rats administered a mix of cis- and trans-tetramethrin intravenously, the elimination half-time for the cis isomer was less (72 minutes) than that observed for the trans isomer (125 minutes) (Silver and Dauterman 1989a). Following intravenous administration to the rats, tetramethrin metabolites were recovered from both urine and, to a lesser extent, feces, providing evidence for biliary excretion. No unmetabolized tetramethrin was recovered in the urine. Only a small amount of the parent cis isomer was identified in the feces. Fecal excretion appears to be the major excretory pathway for the cis isomer, whereas urinary excretion appears to be the major excretory route for the trans isomer. Thus, biliary elimination appears to be more important for the cis isomer than for the trans isomer. In rats administered deltamethrin and its metabolite (4-OH-deltamethrin) intravenously, elimination half-times were 33 and 25 hours, respectively. In another phase of this study involving gavage administration, similar elimination rates were observed (Anadón et al. 1996).

No information was located regarding age- or sex-related differences that might affect the excretion and elimination of pyrethroids following parenteral exposure in humans or animals.

\subsubsection{Physiologically Based Pharmacokinetic (PBPK)/Pharmacodynamic (PD) Models}

Physiologically based pharmacokinetic (PBPK) models use mathematical descriptions of the uptake and disposition of chemical substances to quantitatively describe the relationships among critical biological processes (Krishnan et al. 1994). PBPK models are also called biologically based tissue dosimetry models. PBPK models are increasingly used in risk assessments, primarily to predict the concentration of potentially toxic moieties of a chemical that will be delivered to any given target tissue following various combinations of route, dose level, and test species (Clewell and Andersen 1985). Physiologically based pharmacodynamic (PBPD) models use mathematical descriptions of the dose-response function to quantitatively describe the relationship between target tissue dose and toxic end points.

PBPK/PD models refine our understanding of complex quantitative dose behaviors by helping to delineate and characterize the relationships between: (1) the external/exposure concentration and target tissue dose of the toxic moiety, and (2) the target tissue dose and observed responses (Andersen et al. 1987; Andersen and Krishnan 1994). These models are biologically and mechanistically based and can 
be used to extrapolate the pharmacokinetic behavior of chemical substances from high to low dose, from route to route, between species, and between subpopulations within a species. The biological basis of PBPK models results in more meaningful extrapolations than those generated with the more conventional use of uncertainty factors.

The PBPK model for a chemical substance is developed in four interconnected steps: (1) model representation, (2) model parametrization, (3) model simulation, and (4) model validation (Krishnan and Andersen 1994). In the early 1990s, validated PBPK models were developed for a number of toxicologically important chemical substances, both volatile and nonvolatile (Krishnan and Andersen 1994; Leung 1993). PBPK models for a particular substance require estimates of the chemical substancespecific physicochemical parameters, and species-specific physiological and biological parameters. The numerical estimates of these model parameters are incorporated within a set of differential and algebraic equations that describe the pharmacokinetic processes. Solving these differential and algebraic equations provides the predictions of tissue dose. Computers then provide process simulations based on these solutions.

The structure and mathematical expressions used in PBPK models significantly simplify the true complexities of biological systems. If the uptake and disposition of the chemical substance(s) is adequately described, however, this simplification is desirable because data are often unavailable for many biological processes. A simplified scheme reduces the magnitude of cumulative uncertainty. The adequacy of the model is, therefore, of great importance, and model validation is essential to the use of PBPK models in risk assessment.

PBPK models improve the pharmacokinetic extrapolations used in risk assessments that identify the maximal (i.e., the safe) levels for human exposure to chemical substances (Andersen and Krishnan 1994). PBPK models provide a scientifically sound means to predict the target tissue dose of chemicals in humans who are exposed to environmental levels (for example, levels that might occur at hazardous waste sites) based on the results of studies where doses were higher or were administered in different species. Figure 3-4 shows a conceptualized representation of a PBPK model.

No PBPK models for exposure to pyrethroid compounds were identified. Thorough study of the toxicokinetic profiles of Type I and Type II pyrethroids in humans or experimental animals has not been undertaken. Empirical models for exposure to Type I (permethrin) and Type II (deltamethrin) pyrethroids have been developed based upon the results of two studies in rats (Anadón et al. 1991b, 1996). The 
Figure 3-4. Conceptual Representation of a Physiologically Based

Pharmacokinetic (PBPK) Model for a Hypothetical Chemical Substance

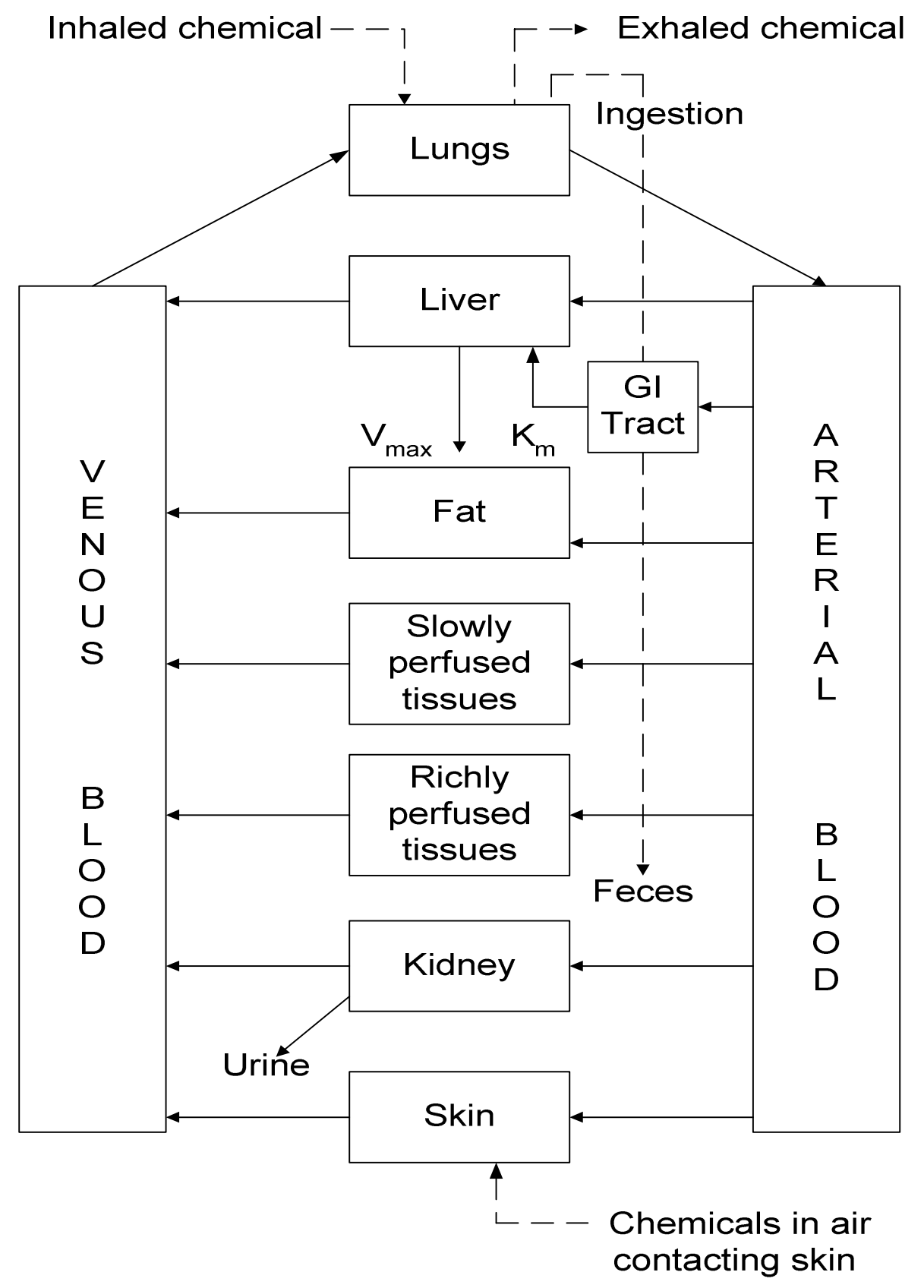

Source: adapted from Krishnan et al. 1994

Note: This is a conceptual representation of a physiologically based pharmacokinetic (PBPK) model for a hypothetical chemical substance. The chemical substance is shown to be absorbed via the skin, by inhalation, or by ingestion, metabolized in the liver, and excreted in the urine or by exhalation. 
empirical models developed from these toxicokinetic studies yielded similar results for both compounds, indicating that the biodisposition of Type I and Type II compounds is similar. Pyrethroids are rapidly absorbed following oral exposure. Following oral and intravenous exposure, permethrin and deltamethrin plasma kinetics are described by a two-compartment model with a relatively rapid distribution phase, followed by a slower elimination phase. Following intravenous administration, the distribution and elimination half-times were 0.46 and 8.67 hours for permethrin, respectively, and 1.39 and 33.0 hours for deltamethrin, respectively. Under these experimental conditions, permethrin was eliminated more rapidly than deltamethrin.

\subsection{MECHANISMS OF ACTION}

\subsubsection{Pharmacokinetic Mechanisms}

Absorption. No information was located regarding the mechanism of absorption of pyrethroids from the gastrointestinal tract. Since pyrethroids are lipophilic compounds, it is presumed that they cross intestinal cells and pass into the circulation by diffusion across lipid membranes. No information was identified on the location of absorption of pyrethroids within the gastrointestinal tract. However, it is presumed that most of the absorption takes place in the intestines due to the large exposed surface area. Although no information was located regarding the mechanism of absorption through the skin or across alveolar membranes, it is presumed that pyrethroids cross these barriers by diffusion across lipid membranes.

Distribution. No information was located regarding the transport of pyrethroid compounds in blood. Pyrethroids are distributed to nearly all tissues and are concentrated in tissues with high lipid contents, such as fat and nerve tissue (Anadón et al. 1991b, 1996). It is likely that the pattern of concentration in lipid-rich tissues is due to the high lipid solubility of pyrethroid compounds. Since metabolism of pyrethroids results in products that are more water-soluble than the parent compounds, it is likely that the metabolites are less able to cross the blood-brain barrier, unless there are facilitated mechanisms for transport of pyrethroid metabolites that have not yet been characterized.

Metabolism. Upon administration of pyrethroids to mammals, biotransformation takes place through hydrolysis of the central ester bond, oxidative attacks at several sites, and conjugation reactions to produce a complex array of primary and secondary water-soluble metabolites that undergo urinary excretion (Casida et al. 1983; Gray and Soderlund 1985; Leng et al. 1999a, 1999b). It is well accepted 
that these metabolites have little or no demonstrable toxicity, although the formation of reactive or toxic intermediates cannot be ruled out, and it appears that cleavage of the ester bond results in detoxification (Gray and Soderlund 1985). For halogenated pyrethroids (such as cyfluthrin, cypermethrin, and permethrin), rapid hydrolytic cleavage of the ester bond is followed by oxidation to yield carboxylic acid derivatives and phenoxybenzoic acid derivatives (Leng et al. 1997a, 1997b). These metabolites are then generally metabolized further and form conjugated products with compounds such as glycine, sulfate, and glucuronic acid (Aprea et al. 1997; Casida et al. 1983). Information on the specific enzymes involved in metabolism of pyrethroid compounds is limited. Metabolism appears to involve nonspecific microsomal carboxyesterases and microsomal mixed function oxidases, which are located in nearly all tissue types.

Excretion. No information was located regarding the specific mechanisms of excretion of pyrethroid compounds. However, metabolism of pyrethroids results in products that are water soluble and, therefore, are more readily eliminated from the body by renal and biliary excretion. No information is available regarding the mechanisms of excretion of pyrethroids and pyrethroid metabolites by the kidney, but it is expected that pyrethroids and their metabolites are eliminated, at least in part, by glomerular filtration since their molecular size is not restrictive for passage though the glomerular membrane. However, there is no information on the extent to which these compounds bind to plasma proteins, which might restrict their glomerular filtration. No information was located regarding mechanisms of excretion for the biliary or salivary routes of elimination. No information was located regarding mechanisms involved in the passage of pyrethroids into milk, although excretion into milk most likely occurs via lipid diffusion across membranes with retention in milk fat.

\subsubsection{Mechanisms of Toxicity}

The primary site of action for pyrethrins and pyrethroids is the sodium channel of nerve cells, as is also the case for DDT and its analogs (for reviews, see Cassida et al. 1983; Coats 1990; Narahashi 1985; Sattelle and Yamamoto 1988; Soderlund 1995; Soderlund et al. 2002; Valentine 1990; Vijverberg and van den Bercken 1990). Using a variety of methods, including voltage clamp and patch clamp techniques, it has been shown that pyrethrins and pyrethroids slow the closing of sodium channel gates following an initial influx of sodium during the depolarizing phase of an action potential, which results in a prolonged sodium tail current (Narahashi 1986; Vijverberg and Van den Bercken 1982). Two different types of pyrethroids are recognized, based on differences in basic structure (the presence or absence of a cyano group in the alpha position), and the symptoms of poisoning (Coats 1990; Verschoyle and Aldridge 1980). Type I pyrethroids do not include a cyano group; their effects in rodents typically include rapid 
onset of aggressive behavior and increased sensitivity to external stimuli, followed by fine tremor, prostration with coarse whole body tremor, elevated body temperature, coma, and death. The term T-syndrome (from tremor) has been applied to Type I responses. Type II pyrethroids include a cyano group; their effects in rodents are usually characterized by pawing and burrowing behavior, followed by profuse salivation, increased startle response, abnormal hindlimb movements, and coarse whole body tremor that progresses to sinuous writhing (choreoathetosis). Clonic seizures may be observed prior to death. Body temperature is not increased, but may decrease. The term CS-syndrome (from choreoathetosis and salivation) has been applied to Type II responses. Two of the cyano-pyrethroids, fenpropathrin and cyphenothrin, have been shown to trigger responses intermediate to those of T-syndrome and CS-syndrome, characterized by both tremors and salivation (Miyamoto et al. 1995; Wright et al. 1988). Mechanisms underlying this intermediate response type have not been elucidated. Occupational exposure to pyrethroids (particularly Type II pyrethroids containing the cyano group) frequently leads to paresthesia (abnormal cutaneous sensations such as tingling, burning, numbness, and itching). This response is considered to be the result of the direct action of pyrethroids on sensory nerve endings (LeQuesne and Maxwell 1980; Wilks 2000), causing repetitive firing in these fibers (Vijverberg and van den Bercken 1990).

Marked differences exist in the duration of action on the sodium channel gate, particularly between Type I and Type II pyrethroids. These differences may account for the differences observed in toxic effects elicited in laboratory animals. Measurements of sodium tail currents in frog nerve fibers treated with Type I pyrethroids measure approximately 6-150 milliseconds in duration, whereas those generated from Type II pyrethroids last much longer (290 milliseconds to as long as several seconds) (Narahashi 1986; Vijverberg et al. 1986). The shorter-duration sodium tail current generated by Type I pyrethroids results in an elevated after potential that may cause repetitive discharges. The longer-duration sodium tail current generated by Type II pyrethroids may result in summation of after potentials, which can cause gradual depolarization of the nerve and frequency-dependent suppression of action potentials. For both Type I and Type II pyrethroids, the magnitude of effect on sodium influx is strongly dependent on temperature, increasing markedly with cooling (Narahashi 1971, 1976; Vijverberg et al. 1983). The action of pyrethroids on as little as $0.6 \%$ of the sodium channel gates results in repetitive after-discharges that could lead to neurotoxic symptoms in animals (Narahashi 1996; Song and Narahashi 1996).

Pyrethroids appear to bind to the membrane lipid phase in the immediate vicinity of the sodium channel, thus modifying the channel kinetics. Results of radioligand binding assays indicate that the actions of DDT and pyrethroids on the sodium channel are site-specific, functionally distinct from, but allosterically 
coupled to, sites 2, 3, and 5 of the 5 known neurotoxin-binding domains of the sodium channel (Lombet et al. 1988). Pyrethroids do not appear to influence sodium channel properties such as cation selectivity and cation binding (Yamamoto et al. 1986).

Stereochemistry dictates the degree of toxicity that will be expressed by a given pyrethroid formulation or mixture. In the case of tetramethrin, like all other Type I pyrethroids, the $1 \mathrm{R}$ conformation is considerably more toxic than the $1 \mathrm{~S}$ conformation. The $1 \mathrm{~S}$ isomer can also inhibit toxicity by competitive inhibition at number of stereospecific pyrethroid binding sites, thus preventing binding of the more toxic 1R isomer (Narahashi 1986). Furthermore, it has been observed that the cis isomers possess greater mammalian toxicity than the trans isomers. For these reasons, recent formulations of tetramethrin (d-tetramethrin) contain predominantly the $1 \mathrm{R}$ cis and $1 \mathrm{R}$ trans isomers in a ratio of 20:80 (Tomlin 1997).

Type II pyrethroids have been shown to inhibit specific binding at or near the picrotoxin site of $\mathrm{GABA}_{\mathrm{A}}$ receptors in mouse brain (Crofton et al. 1987; Lawrence and Casida 1983), specifically inhibiting GABAdependent chloride flux (Bloomquist et al. 1986). However, taken together, the results of a number of studies that investigated the actions of pyrethrins and pyrethroids on ligand-gated ion channels indicate a limited role for the $\mathrm{GABA}_{\mathrm{A}}$ receptor in pyrethroid-induced neurotoxicity (Bloomquist 1993).

Recently, Forshaw et al. (2000) demonstrated that voltage-gated chloride channels may play a role in Type II, but not Type I, pyrethroid poisoning. Their patch test experiments showed that ivermectin and pentobarbitone significantly increased open chloride channel probability in mouse neuroblastoma cells. When rats were pretreated with ivermectin or pentobarbitone and subsequently administered the Type II pyrethroid deltamethrin, comparatively reduced severity of neurotoxic effects was observed. This was an indication that these chemicals effectively antagonized Type II pyrethroid poisoning. Changes in neurotoxic effects were not observed when the Type I pyrethroid, cismethrin, was used.

Other pyrethroid-induced effects include altered concentrations of catecholamines, blood glucose, and lactate, and marked changes in cerebral blood flow. However, these effects may be secondary effects arising from neural dysfunction resulting from the action of pyrethroids on the sodium and chloride channels. 


\subsubsection{Animal-to-Human Extrapolations}

Limited information is available regarding the specific mechanisms involved in the toxicokinetics of pyrethroids in either humans or animals. Therefore, it is difficult to assess how the toxicokinetic data obtained from studies in laboratory animals may differ from that obtained in humans. It is presumed that the toxicokinetic mechanisms involved are generally similar in all mammalian species, although quantitative interspecies differences most certainly exist. Absorption and distribution of pyrethroids appear to be largely determined by the lipid-soluble nature of these compounds. Therefore, it is expected that the absorption and distribution of pyrethroids in humans will be similar to that observed in other mammalian species. In both humans and animals, pyrethroids appear to be metabolized by nonspecific microsomal carboxyesterases and microsomal mixed function oxidases, which are located in nearly all tissue types and are common to all mammalian species. Since the metabolites that have been identified in humans have also been identified in other mammalian species, it is unlikely that there are significant qualitative differences between humans and most animal species for the major metabolic pathways for pyrethroids (Anadón et al. 1991b; Eadsforth and Baldwin 1983; Eadsforth et al. 1988; Elliott et al. 1976; Gaughan et al. 1977; Leng et al. 1997b; Woollen et al. 1992). The cat appears to be an exception, exhibiting increased sensitivity to the toxic actions of pyrethroids. This increased sensitivity may be the result of less efficient hepatic glucuronidation in the cat (Whittem 1995), a second step in the metabolism of pyrethroids in mammalian systems. Pyrethroids and their metabolites are excreted primarily in the urine and feces, and it is likely that mechanisms involved are the same in all mammalian species. If interspecies differences exist in sodium channel kinetics, such differences could increase the uncertainty related to interspecies extrapolation.

\subsection{TOXICITIES MEDIATED THROUGH THE NEUROENDOCRINE AXIS}

Recently, attention has focused on the potential hazardous effects of certain chemicals on the endocrine system because of the ability of these chemicals to mimic or block endogenous hormones. Chemicals with this type of activity are most commonly referred to as endocrine disruptors. However, appropriate terminology to describe such effects remains controversial. The terminology endocrine disruptors, initially used by Colborn and Clement (1992), was also used in 1996 when Congress mandated the Environmental Protection Agency (EPA) to develop a screening program for “...certain substances [which] may have an effect produced by a naturally occurring estrogen, or other such endocrine effect[s]...”. To meet this mandate, EPA convened a panel called the Endocrine Disruptors Screening and Testing Advisory Committee (EDSTAC), which in 1998 completed its deliberations and made 


\section{HEALTH EFFECTS}

recommendations to EPA concerning endocrine disruptors. In 1999, the National Academy of Sciences released a report that referred to these same types of chemicals as hormonally active agents. The terminology endocrine modulators has also been used to convey the fact that effects caused by such chemicals may not necessarily be adverse. Many scientists agree that chemicals with the ability to disrupt or modulate the endocrine system are a potential threat to the health of humans, aquatic animals, and wildlife. However, others think that endocrine-active chemicals do not pose a significant health risk, particularly in view of the fact that hormone mimics exist in the natural environment. Examples of natural hormone mimics are the isoflavinoid phytoestrogens (Adlercreutz 1995; Livingston 1978; Mayr et al. 1992). These chemicals are derived from plants and are similar in structure and action to endogenous estrogen. Although the public health significance and descriptive terminology of substances capable of affecting the endocrine system remains controversial, scientists agree that these chemicals may affect the synthesis, secretion, transport, binding, action, or elimination of natural hormones in the body responsible for maintaining homeostasis, reproduction, development, and/or behavior (EPA 1997). Stated differently, such compounds may cause toxicities that are mediated through the neuroendocrine axis. As a result, these chemicals may play a role in altering, for example, metabolic, sexual, immune, and neurobehavioral function. Such chemicals are also thought to be involved in inducing breast, testicular, and prostate cancers, as well as endometriosis (Berger 1994; Giwercman et al. 1993; Hoel et al. 1992).

The potential for pyrethroids to act as endocrine disruptors has been investigated in a limited number of studies in vitro (Eil and Nisula 1990; Garey and Wolff 1998; Go et al. 1999). Using Ishikawa Var-I human endometrial cancer cell line and the T47D human breast cancer cell line, cell lines that produce phosphatase as an indicator of hormonal activity, Garey and Wolff (1998) demonstrated that fenvalerate and phenothrin induced significant estrogenicity at concentrations of $10 \mu \mathrm{M}$. Similar tests performed using d-trans-allethrin and permethrin did not result in apparent estrogenicity. None of the four pyrethroids showed significant estrogen antagonist activity or acted as progestins, but fenvalerate and d-trans-allethrin significantly antagonized the action of progesterone in T47D cells. Go et al. (1999) found that micromolar concentrations of phenothrin or fenvalerate induced pS2 expression in the MCF-7 human breast cell carcinoma cell line by 5 -fold, indicating that these pyrethroids may induce estrogenic activity. The fact that phenothrin-induced $\mathrm{pS} 2$ expression was suppressed by antiestrogen co-treatment is a further indication that phenothrin may affect endocrine function. Other pyrethroids (fenvalerate, permethrin, and cypermethrin) were also found to induce pS2 expression (Chen et al. 2002). Several pyrethroids have been shown to interact with androgen binding sites in dispersed intact human genital skin fibroblasts, with varying degrees of potency, but at levels comparable to those resulting in the same order of binding observed using cimetidine, a known inhibitor of androgen receptor binding (Eil and 
Nisula 1990). Pyrethrins and bioallethrin were found to displace $\left[{ }^{3} \mathrm{H}\right]$ testosterone from sex hormone binding globulin in human plasma, at inhibitory levels up to 50\% (Eil and Nisula 1990).

Data regarding potential for pyrethrins and pyrethroids to act as endocrine disruptors in vivo include findings of reduced reproductive organ weights, significantly altered sperm characteristics, and reduced plasma testosterone levels in male rats administered oral doses of pyrethroids for up to 65 days (Abd El-Aziz et al. 1994; Abd El-Khalek et al. 1999; Hassan et al. 1993). However, there was no evidence of androgenicity or estrogenicity following repeated oral gavage exposure of castrated male rats (5-day Hershberger assay) and ovariectomized female rats (3-day uterotrophic assay) to esfenvalerate, fenvalerate, or permethrin at doses high enough to elicit classical clinical signs of neurotoxicity (Kunimatsu et al. 2002).

\subsection{CHILDREN'S SUSCEPTIBILITY}

This section discusses potential health effects from exposures during the period from conception to maturity at 18 years of age in humans, when all biological systems will have fully developed. Potential effects on offspring resulting from exposures of parental germ cells are considered, as well as any indirect effects on the fetus and neonate resulting from maternal exposure during gestation and lactation. Relevant animal and in vitro models are also discussed.

Children are not small adults. They differ from adults in their exposures and may differ in their susceptibility to hazardous chemicals. Children's unique physiology and behavior can influence the extent of their exposure. Exposures of children are discussed in Section 6.6 Exposures of Children.

Children sometimes differ from adults in their susceptibility to hazardous chemicals, but whether there is a difference depends on the chemical (Guzelian et al. 1992; NRC 1993). Children may be more or less susceptible than adults to health effects, and the relationship may change with developmental age (Guzelian et al. 1992; NRC 1993). Vulnerability often depends on developmental stage. There are critical periods of structural and functional development during both prenatal and postnatal life and a particular structure or function will be most sensitive to disruption during its critical period(s). Damage may not be evident until a later stage of development. There are often differences in pharmacokinetics and metabolism between children and adults. For example, absorption may be different in neonates because of the immaturity of their gastrointestinal tract and their larger skin surface area in proportion to 
body weight (Morselli et al. 1980; NRC 1993); the gastrointestinal absorption of lead is greatest in infants and young children (Ziegler et al. 1978). Distribution of xenobiotics may be different; for example, infants have a larger proportion of their bodies as extracellular water and their brains and livers are proportionately larger (Altman and Dittmer 1974; Fomon 1966; Fomon et al. 1982; Owen and Brozek 1966; Widdowson and Dickerson 1964). The infant also has an immature blood-brain barrier (Adinolfi 1985; Johanson 1980) and probably an immature blood-testis barrier (Setchell and Waites 1975). Many xenobiotic metabolizing enzymes have distinctive developmental patterns. At various stages of growth and development, levels of particular enzymes may be higher or lower than those of adults, and sometimes unique enzymes may exist at particular developmental stages (Komori et al. 1990; Leeder and Kearns 1997; NRC 1993; Vieira et al. 1996). Whether differences in xenobiotic metabolism make the child more or less susceptible also depends on whether the relevant enzymes are involved in activation of the parent compound to its toxic form or in detoxification. There may also be differences in excretion, particularly in newborns who all have a low glomerular filtration rate and have not developed efficient tubular secretion and resorption capacities (Altman and Dittmer 1974; NRC 1993; West et al. 1948). Children and adults may differ in their capacity to repair damage from chemical insults. Children also have a longer remaining lifetime in which to express damage from chemicals; this potential is particularly relevant to cancer.

Certain characteristics of the developing human may increase exposure or susceptibility, whereas others may decrease susceptibility to the same chemical. For example, although infants breathe more air per kilogram of body weight than adults breathe, this difference might be somewhat counterbalanced by their alveoli being less developed, which results in a disproportionately smaller surface area for alveolar absorption (NRC 1993).

Differences between children and adults regarding the toxicokinetics of pyrethroid compounds have not been investigated in humans, and there is insufficient information from studies conducted in immature laboratory animals to allow for prediction of particular sensitivities in children. However, based on what is known about the toxicokinetics of pyrethroid compounds, some general areas of concern for exposure of children to pyrethroids can be identified.

Limited information is available regarding the ability of pyrethroid compounds to cross the placenta and be distributed to the fetus. Measurements of radioactivity in fetuses of rats administered radiolabeled pyrethroids indicated that $<0.004 \%$ of the administered dose of the Type I pyrethroid, tetramethrin, was recovered in the fetus (Kaneko et al. 1984b). Recovered activity from radiolabeled fenvalerate (a Type II 
pyrethroid) was $<0.07 \%$ (Shiba et al. 1990). Eight days after a pregnant cow was given a single dose of

${ }^{14} \mathrm{C}$-fluvalinate, only trace amounts (approximately $1 \times 10^{-5} \%$ of the administered dose) of ${ }^{14} \mathrm{C}$ were detected in the fetus (Quistad et al. 1982). However, given the fact that exposure of rat fetuses to pyrethroids via their mothers resulted in persistent alterations in brain neurotransmitter numbers (Malaviya et al. 1993), it would appear that concentrations that reached the fetal brain were sufficient to cause a consistent effect.

Pyrethroids are eliminated from the body primarily by metabolism and subsequent excretion of metabolites via the urine and feces. Hepatic metabolism of pyrethroids is of critical importance for the detoxification and, ultimately, the excretion of these compounds. Although biotransformation reactions are catalyzed largely by microsomal enzymes, and enzymatic activity is involved in conjugation reactions, the specific enzymes involved in pyrethroid metabolism have not been identified. The ability of children to detoxify pyrethroid compounds through metabolic pathways may be different from that of adults (Komori et al. 1990; Leeder and Kearns 1997; NRC 1993; Vieira et al. 1996). Using lethality as an indicator of toxicity in a study designed to assess age-related susceptibility to pyrethroids, Sheets et al. (1994) found that adult rats were approximately 16 and 7 times less sensitive to orally administered deltamethrin than 11- and 21-day-old rats, respectively. Cantalamessa (1993) administered acute oral doses of permethrin or cypermethrin to 8-, 16-, and 21-day-old rats, as well as adult rats. For both permethrin and cypermethrin, acute oral $\mathrm{LD}_{50}$ values increased with increasing age, indicating greater sensitivity in younger rats. No significant changes in $\mathrm{LD}_{50}$ values were seen in young rats pretreated with either tri-o-tolyl phosphate (TOTP, an esterase inhibitor) or piperonyl butoxide (PB, a monooxygenase inhibitor). However, TOTP pretreatment in adult rats resulted in a significant increase in pyrethroidinduced lethality. Increased lethality in adult rats pretreated with PB did not reach the level of statistical significance. These results suggest the possibility that increased susceptibility of young animals to pyrethroid poisoning may be related to less efficient enzyme production than in adult animals. If children have a decreased metabolic capacity compared to adults, altered distribution and excretion of pyrethroids could result. However, age-related differences in responses of animals to near-lethal doses of pyrethroids do not provide a firm basis for human risk assessment.

Since pyrethroid metabolites are water-soluble compounds, it is likely that their ability to cross the bloodbrain barrier is limited. In children, a decrease in the production of these polar metabolites could result in an increased distribution of unmetabolized pyrethroids to the central nervous system. There also could be an increase in the distribution of pyrethroids to the central nervous system due to immature development of the blood-brain barrier. Very little unmetabolized pyrethroid is excreted in the urine, most likely 
because pyrethroid compounds are very lipid soluble and, if filtered by the glomerulus, are likely to undergo extensive renal reabsorption via lipid diffusion. If the metabolism of pyrethroids is decreased in children, a decrease in the renal excretion of pyrethroids may occur. Since specific details on the mechanisms of the renal handling of pyrethroids are not known, it is unclear how immature renal functions may affect the excretion of pyrethroids and pyrethroid metabolites in newborns and young children.

Exposure to pyrethroids through ingestion of breast milk in nursing infants has not been investigated in humans. However, only very low levels of pyrethroids ( $<1 \%$ of the orally administered dose) are excreted into milk of lactating cows and goats, which would suggest that exposures in human by this route may be similarly low (Gaughan et al. 1978; Hunt and Gilbert 1977; Quistad et al.1982; Ridlen et al. 1984; Wszolek et al. 1980). The relatively low transfers of lipophilic pyrethroids to milk presumably reflects competing pathways of elimination, including relatively rapid and extensive metabolism to more water-soluble metabolites and excretion in urine and feces.

Pyrethroids do not appear to impair gross morphological development in animals. Some investigators have suggested that repeated oral exposure of neonatal mice to selected pyrethroids may result in altered locomotor behavior and changes in brain neurotransmitter receptor densities as adults (Ahlbom et al. 1994; Eriksson and Fredriksson 1991; Talts et al. 1998a). However, limitations in study design and the inability to duplicate the results (Ray et al. 2002) render the findings of Eriksson and coworkers of questionable toxicological significance.

Children may be more likely to be exposed to pyrethroids than adults. Behavioral patterns of children can result in higher rates of ingestion of soil and dust, which may contain pyrethroid compounds following spraying. Examples of activities that tend to promote soil and dust ingestion preferentially in children include playing and crawling on the ground and floor, hand-to-mouth activity, mouthing of objects, and indiscriminate eating of food items on the ground or floor. Pyrethroids are also used in shampoos and creams for treatment of patients with lice and scabies. Hand-to-mouth behavior may increase the risk of exposure in children under these conditions of use. 
3. HEALTH EFFECTS

\subsection{BIOMARKERS OF EXPOSURE AND EFFECT}

Biomarkers are broadly defined as indicators signaling events in biologic systems or samples. They have been classified as markers of exposure, markers of effect, and markers of susceptibility (NAS/NRC 1989).

Due to a nascent understanding of the use and interpretation of biomarkers, implementation of biomarkers as tools of exposure in the general population is very limited. A biomarker of exposure is a xenobiotic substance or its metabolite(s) or the product of an interaction between a xenobiotic agent and some target molecule(s) or cell(s) that is measured within a compartment of an organism (NAS/NRC 1989). The preferred biomarkers of exposure are generally the substance itself or substance-specific metabolites in readily obtainable body fluid(s), or excreta. However, several factors can confound the use and interpretation of biomarkers of exposure. The body burden of a substance may be the result of exposures from more than one source. The substance being measured may be a metabolite of another xenobiotic substance (e.g., high urinary levels of phenol can result from exposure to several different aromatic compounds). Depending on the properties of the substance (e.g., biologic half-life) and environmental conditions (e.g., duration and route of exposure), the substance and all of its metabolites may have left the body by the time samples can be taken. It may be difficult to identify individuals exposed to hazardous substances that are commonly found in body tissues and fluids (e.g., essential mineral nutrients such as copper, zinc, and selenium). Biomarkers of exposure to pyrethrins and pyrethroids are discussed in Section 3.8.1.

Biomarkers of effect are defined as any measurable biochemical, physiologic, or other alteration within an organism that, depending on magnitude, can be recognized as an established or potential health impairment or disease (NAS/NRC 1989). This definition encompasses biochemical or cellular signals of tissue dysfunction (e.g., increased liver enzyme activity or pathologic changes in female genital epithelial cells), as well as physiologic signs of dysfunction such as increased blood pressure or decreased lung capacity. Note that these markers are not often substance specific. They also may not be directly adverse, but can indicate potential health impairment (e.g., DNA adducts). Biomarkers of effects caused by pyrethrins and pyrethroids are discussed in Section 3.8.2.

A biomarker of susceptibility is an indicator of an inherent or acquired limitation of an organism's ability to respond to the challenge of exposure to a specific xenobiotic substance. It can be an intrinsic genetic or other characteristic or a preexisting disease that results in an increase in absorbed dose, a decrease in the 
biologically effective dose, or a target tissue response. If biomarkers of susceptibility exist, they are discussed in Section 3.10 "Populations That Are Unusually Susceptible."

\subsubsection{Biomarkers Used to Identify or Quantify Exposure to Pyrethrins and Pyrethroids}

Measurement of urinary metabolites of pyrethroids may serve as biomarkers of exposure. In several studies in humans exposed to pyrethroids occupationally, the presence of pyrethroid metabolites in urine has been used to confirm exposure (Aprea et al. 1997; Kühn et al. 1999; Leng et al. 1996, 1997a, 1997b). Chemically, synthetic pyrethroids are esters of chrysanthemic acid and specific alcohols, such as 3-phenoxybenzyl alcohol. Hydrolytic cleavage of the ester bond in vivo yields chrysanthemic acid derivatives and 3-phenoxybenzoic (3-PBA) (Aprea et al. 1997; Kühn et al. 1999; Leng et al. 1997a, 1997b). The specific pyrethroid metabolites found in urine vary depending upon the parent compound, which may have some modifications to the chrysanthemic acid moiety (Kühn et al. 1999). Results of a single study in humans following inhalation exposure to cyfluthrin indicate that the amounts of cyfluthrin metabolites excreted in urine correlate with increasing exposure levels (Leng et al. 1997a). Thus, urinary levels of pyrethroid metabolites may be a useful indicator of exposure level; however, at this time, there is insufficient information to allow for correlation of the amount of metabolites measured in the urine to the body burden of pyrethroids or to the level of exposure to pyrethroids.

\subsubsection{Biomarkers Used to Characterize Effects Caused by Pyrethrins and Pyrethroids}

Paresthesia (an abnormal cutaneous sensation sometimes described as tingling, burning, stinging, numbness, and itching) has been widely reported among individuals occupationally exposed to pyrethroids (see Vijverberg and van den Bercken 1990 for a summary of available information on occupationally-induced paresthesia). Other symptoms associated with occupational exposure to pyrethroids include dizziness, headache, nausea, loss of appetite, blurred vision, and tightness of the chest. Mild acute pyrethroid poisoning is characterized in part by listlessness and muscular fasciculations. Increased peripheral nerve excitability was measured in cotton workers following 3 days of exposure to deltamethrin during spraying. Whereas paresthesia may be a biomarker of effect for humans occupationally exposed to pyrethroids, other reported symptoms are not specifically indicative of pyrethrin or pyrethroid poisoning. 


\subsection{INTERACTIONS WITH OTHER CHEMICALS}

Pyrethroids are eliminated through biotransformation reactions that are catalyzed by microsomal enzymes, although the specific enzymes involved have not been identified. Results from studies of laboratory animals show that inhibition of hydrolytic reactions and of oxidative metabolism increases the toxicity of pyrethroids, while induction of microsomal oxidases decreases the toxicity of pyrethroids (Hutson 1979). Therefore, it appears that chemicals or drugs capable of inducing or inhibiting the enzymes involved in pyrethroid biotransformation reactions can alter the metabolism of pyrethroids. Since the metabolites of pyrethroids are more water soluble than the parent compounds, they are less likely to cross the blood-brain barrier and are more easily excreted by the kidney and liver than the parent compounds. Thus, alterations in the metabolism of pyrethroids through inhibition or induction of microsomal enzymes could alter the distribution and excretion of pyrethroids. For example, piperonyl butoxide, a common insecticide synergist, inhibits microsomal enzymes and potentiates the toxic effects of pyrethrins and pyrethroids to mammals.

Limited evidence exists to suggest that some Gulf War veterans with chronic, nonspecific symptoms may be experiencing neurological dysfunction due to low-level exposures to mixtures of anti-cholinesterase agents, insect repellents, and pyrethroids that might have additive or synergistic effects (Haley and Kurt 1997; Haley et al. 1997a, 1997b). To test this hypothesis, McCain et al. (1997) administered rats oral doses of a short-acting anti-cholinesterase agent (pyridostigmine bromide), an insect repellent (DEET), and permethrin, alone or in combination, and found that combined exposure resulted in a higher degree of lethality than that which would be expected from additive lethal values obtained for each chemical separately. Abu-Qare and Abou-Donia (2001a) demonstrated that co-administration of DEET and permethrin to the skin of rats resulted in significantly increased release of brain mitochondrial cytochrome c, whereas no significant effect was seen following applications of either chemical alone. The effects of combined exposure may be the result of synergistic effects that are expressed following absorption since results of an in situ assay of mouse skin revealed that DEET appeared to inhibit the dermal absorption of permethrin (Baynes et al. 1997). Synergistic effects could potentially occur in workers who spray a variety of pesticides, although no data were available to indicate such effects.

Another indication of an adverse toxic interaction between pyrethroids and other chemicals is the finding of significantly increased chromosomal aberrations in bone marrow cells of rats orally administered repeated doses of cypermethrin and lead, in combination (Nehéz et al. 2000). This effect was significant 
when compared with both control animals and those administered cypermethrin or lead separately, and appeared to be greater than an additive effect.

See Section 3.11.3 for information regarding chemicals used to reduce the toxic effects of pyrethrins and pyrethroids.

\subsection{POPULATIONS THAT ARE UNUSUALLY SUSCEPTIBLE}

A susceptible population will exhibit a different or enhanced response to pyrethrins or pyrethroids than will most persons exposed to the same level of pyrethrins or pyrethroids in the environment. Reasons may include genetic makeup, age, health and nutritional status, and exposure to other toxic substances (e.g., cigarette smoke). These parameters result in reduced detoxification or excretion of pyrethrins or pyrethroids, or compromised function of organs affected by pyrethrins or pyrethroids. Populations who are at greater risk due to their unusually high exposure to pyrethrins or pyrethroids are discussed in Section 6.7, Populations With Potentially High Exposures.

Pyrethroids are eliminated from the body primarily by metabolism and subsequent excretion of metabolites into the urine. Individuals with impaired liver function that results in decreased ability to metabolize pyrethrins or pyrethroids are likely to have increased susceptibility to the toxic effects of pyrethrins or pyrethroids. Since urine and bile are the major excretory routes for pyrethrin and pyrethroid metabolites, kidney and/or liver disease are likely to delay elimination of metabolites from the body. However, no studies were located in which metabolites of pyrethrins or pyrethroids were shown to exert toxic effects in humans or animals. Young animals may be more susceptible during stages when enzymes responsible for metabolizing absorbed pyrethroids are not fully developed (Cantalamessa 1993) or during critical stages of neonatal brain development (Ahlbom et al. 1994; Eriksson and Fredriksson 1991; Talts et al. 1998a). A predisposition for asthma may contribute to pyrethrin- or pyrethroid-induced respiratory effects. Allergic reactions have been observed in a few individuals following exposure to products that contain pyrethrins or pyrethroids. However, such responses may be due, at least in part, to "inert ingredients" in such products. 


\subsection{METHODS FOR REDUCING TOXIC EFFECTS}

This section will describe clinical practice and research concerning methods for reducing toxic effects of exposure to pyrethrins or pyrethroids. However, because some of the treatments discussed may be experimental and unproven, this section should not be used as a guide for treatment of exposures to pyrethrins. When specific exposures have occurred, poison control centers and medical toxicologists should be consulted for medical advice. The following texts provide specific information about treatment following exposures to pyrethrins:

Ellenhorn MJ, Schonwald S, Ordog G, et al., eds. 1997. Medical toxicology: Diagnosis and treatment of human poisoning. $2^{\text {nd }}$ edition. Baltimore: Williams \& Wilkins, 1626-1627.

Goldfrank LR, Flomenbaum NE, Lewin NA, et al., eds. 1998. Goldfrank's toxicologic emergencies. $6^{\text {th }}$ edition. Stamford: Appleton \& Lange, 1455-1456.

Haddad LM, Shannon MW, Winchester JF, eds. 1998. Clinical management of poisoning and drug overdose. $3^{\text {rd }}$ edition. Philadelphia: W.B. Saunders, 482-483.

\subsubsection{Reducing Peak Absorption Following Exposure}

Inhalation Exposure. There is little information regarding the degree of absorption following inhalation exposure to pyrethrins or pyrethroids, although it is presumed that absorption will occur via diffusion across lipid membranes. However, there is no known effective way to reduce absorption following inhalation exposure to pyrethrins or pyrethroids.

Oral Exposure. Pyrethrins and pyrethroids are rapidly absorbed following oral exposure and it is presumed that absorption occurs across the intestinal mucosa via diffusion. There is, however, very little information available regarding the rate or extent of absorption following oral administration in humans. Use of lavage and activated charcoal would likely result in reduced absorption following oral exposure, and charcoal may aid in removing compounds undergoing enterohepatic recirculation. It is also presumed that some absorption could occur in the mouth and stomach and, therefore, mouth rinsing may modestly contribute to decreasing absorption following oral exposure. 
Dermal Exposure. Pyrethrins and pyrethroids are not well absorbed following dermal exposure, but limited absorption through the skin does occur. Washing of the skin with soap and water would reduce dermal absorption. If the eyes are affected, proper rinsing procedures should be followed.

No information was located regarding the effectiveness of various methods intended to reduce peak absorption of pyrethrins or pyrethroids following exposure.

\subsubsection{Reducing Body Burden}

No information was located regarding the effectiveness of various methods intended to reduce pyrethrin or pyrethroid body burden following absorption.

Pyrethrins and pyrethroids are substantially detoxified through biotransformation reactions catalyzed by microsomal enzymes, although the specific enzymes involved have not been identified. It is anticipated that the body burden would be reduced more quickly if these enzymes are induced; however, until the specific enzymes involved are identified, it is not possible to specify protocols to reduce the body burden of pyrethrins or pyrethroids through induction of microsomal enzymes. Metabolites of pyrethrins and pyrethroids are excreted in urine and bile, but no specific information is available regarding the renal or hepatic handling of these metabolites. Increased fluid consumption, which increases the rate of urine production and excretion, may help to decrease the body burden of pyrethroid metabolites since they are water soluble and excreted in the urine. Activated charcoal might aid in removing pyrethrins or pyrethroids undergoing enterohepatic circulation. However, since pyrethrins and pyrethroids are rapidly metabolized by mammalian detoxification systems, such methods for reducing body burden might not effectively shorten the time during which pyrethrins and pyrethroids exert their toxic effects.

\subsubsection{Interfering with the Mechanism of Action for Toxic Effects}

No information was located regarding effective methods for interfering with the mechanism of action for pyrethrin- or pyrethroid-induced toxic effects. Anticonvulsant drugs have varying degrees of therapeutic efficacy in various animal species treated with a variety of pyrethroids, and may not be regarded as specific antidotes for pyrethroid poisoning in general (Vijverberg and van den Bercken 1990). Muscle relaxants such as mephenesin and methocarbamol may be more effective counters to pyrethroid poisoning, but appear to be more effective against Type II than Type I pyrethroids (Bradbury et al. 1981; 
Hiromori et al. 1986). Atropine appears to be effective in reducing pyrethroid-induced effects such as salivation and choreoathetosis in animals (Ray and Cremer 1979). Agents such as ivermectin and pentobarbitone, which act as agonists at chloride channels, have been shown to reduce salivation and choreoathetosis, respectively, in animals (Forshaw and Ray 1997). Dermal applications of Vitamin E and local anesthetic creams have effectively reduced symptoms of paresthesia following dermal exposure to pyrethroids (Flannigan et al. 1985b; Malley et al. 1985; Tucker et al. 1984).

\subsection{ADEQUACY OF THE DATABASE}

Section 104(i)(5) of CERCLA, as amended, directs the Administrator of ATSDR (in consultation with the Administrator of EPA and agencies and programs of the Public Health Service) to assess whether adequate information on the health effects of pyrethrins and pyrethroids is available. Where adequate information is not available, ATSDR, in conjunction with the National Toxicology Program (NTP), is required to assure the initiation of a program of research designed to determine the health effects (and techniques for developing methods to determine such health effects) of pyrethrins and pyrethroids.

The following categories of possible data needs have been identified by a joint team of scientists from ATSDR, NTP, and EPA. They are defined as substance-specific informational needs that if met would reduce the uncertainties of human health assessment. This definition should not be interpreted to mean that all data needs discussed in this section must be filled. In the future, the identified data needs will be evaluated and prioritized, and a substance-specific research agenda will be proposed.

\subsubsection{Existing Information on Health Effects of Pyrethrins and Pyrethroids}

The existing data on health effects of inhalation, oral, and dermal exposure of humans and animals to pyrethrins and pyrethroids are summarized in Figure 3-5. The purpose of this figure is to illustrate the existing information concerning the health effects of pyrethrins and pyrethroids. Each dot in the figure indicates that one or more studies provide information associated with that particular effect. The dot does not necessarily imply anything about the quality of the study or studies, nor should missing information in this figure be interpreted as a "data need". A data need, as defined in ATSDR's Decision Guide for Identifying Substance-Specific Data Needs Related to Toxicological Profiles (Agency for Toxic Substances and Disease Registry 1989), is substance-specific information necessary to conduct 
Figure 3-5. Existing Information on Health Effects of Pyrethrins and Pyrethroids

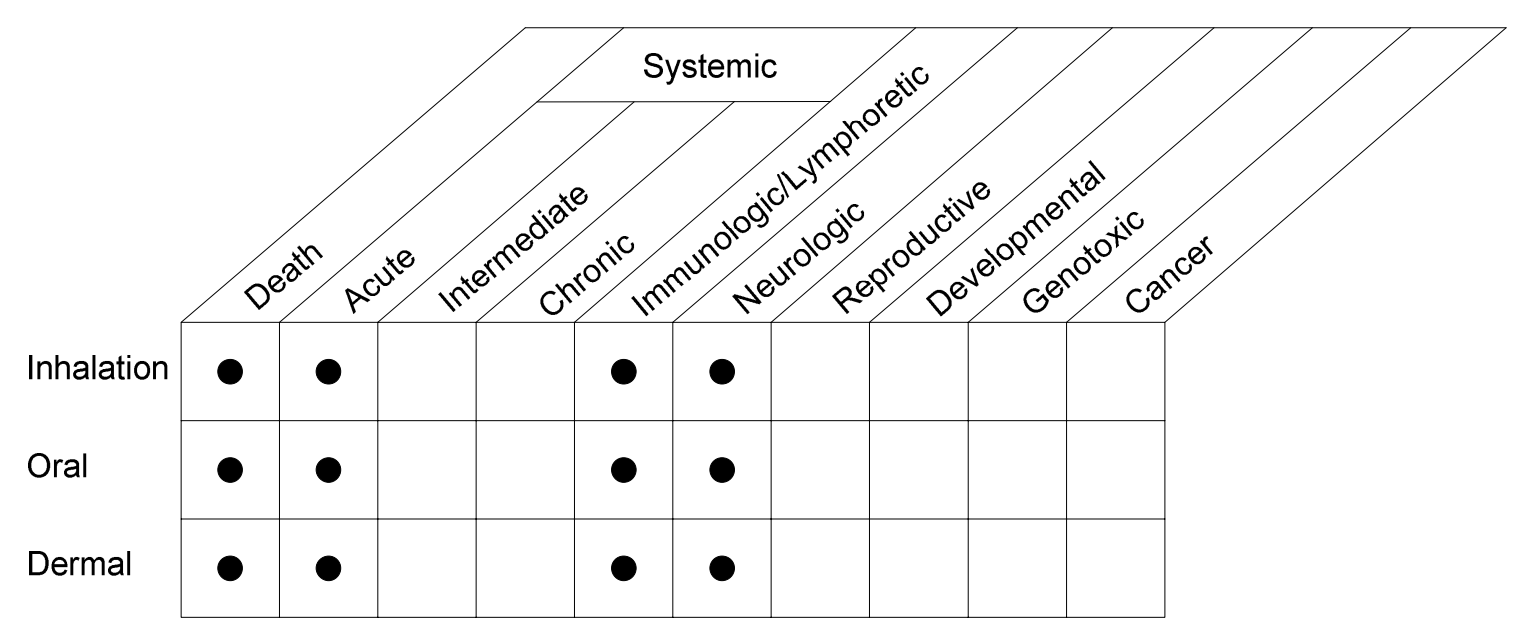

Human

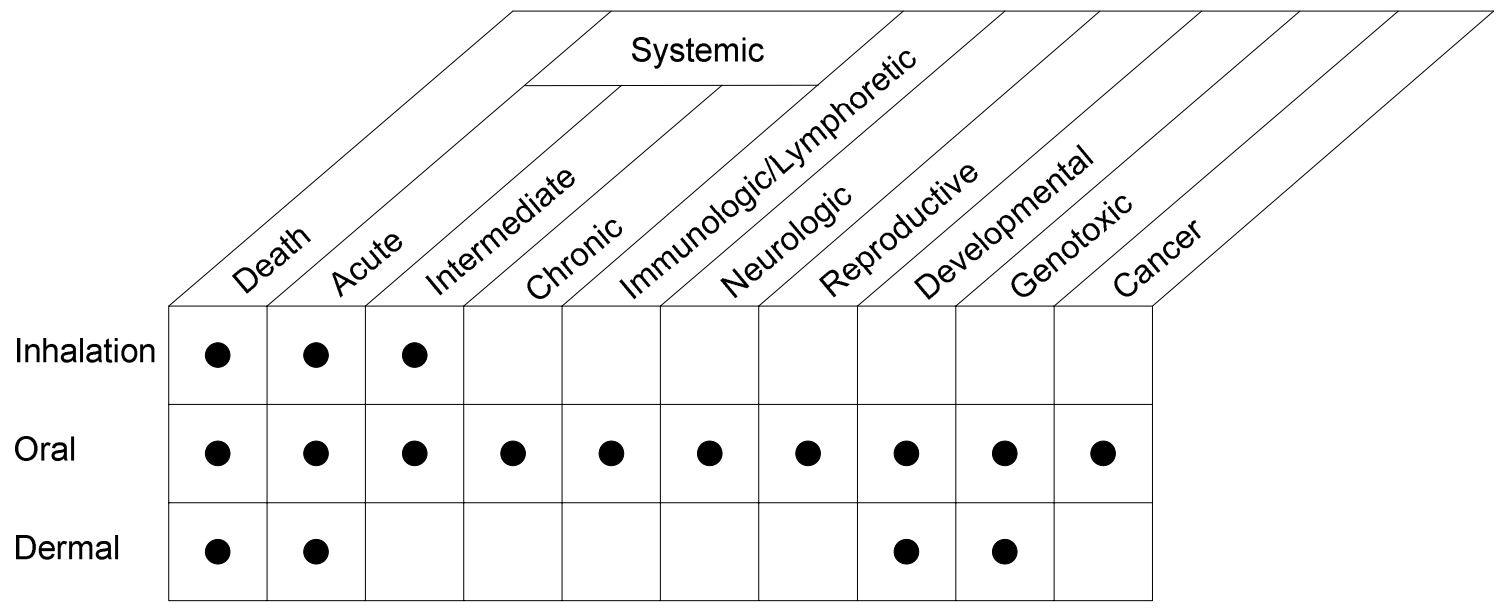

Animal

Existing Studies 
comprehensive public health assessments. Generally, ATSDR defines a data gap more broadly as any substance-specific information missing from the scientific literature.

Available data regarding health effects in humans exposed to pyrethrins or pyrethroids largely concern occupational exposure during crop applications in which exposure was considered to have occurred primarily via dermal contact, although inhalation exposure could not be ruled out. Therefore, Figure 3-5 indicates that information exists for both inhalation and dermal exposure routes. A number of human cases involved intentional ingestion of pyrethroids. Both inhalation and dermal exposures were likely in the few reported cases of reactive airway responses. Some occupational exposures were considered to have been of intermediate or chronic duration due to repeated exposures ranging from weeks to years. However, observed health effects following repeated exposure to pyrethrins or pyrethroids were similar to those that characterize acute pyrethroid poisoning.

The database for health effects following oral exposure to pyrethrins or pyrethroids in experimental animals is substantial. However, as can be seen in Figure 3-5, information regarding health effects following inhalation or dermal exposure is more limited. The nervous system appears to be the predominant target of pyrethrin- and pyrethroid-induced toxicity. Genotoxicity data on pyrethrins and pyrethroids are available from studies in vivo and in vitro; results of genotoxicity tests are predominantly negative. Pyrethrum extract (containing $57.7 \%$ pyrethrins) may induce cancer in laboratory animals as evidenced by increased incidences of liver and thyroid tumors in rats exposed orally for a lifetime. Based on currently available animal cancer bioassays, synthetic pyrethroids do not appear to pose a particular carcinogenicity concern.

\subsubsection{Identification of Data Needs}

Acute-Duration Exposure. Reports in which inhalation could be considered to be a significant route of exposure to pyrethrins or pyrethroids are mainly available from studies of workers involved in the manufacture or use of the chemicals (Chen et al. 1991; Flannigan and Tucker 1985; Flannigan et al. 1985b; He et al. 1988, 1989, 1991; Knox et al. 1984; Kolmodin-Hedman et al. 1982; LeQuesne and Maxwell 1980; Moretto 1991; Shujie et al. 1988; Tucker and Flannigan 1983; Zhang et al. 1991). Limitations associated with these reports include lack of quantitative exposure data, lack of data on duration of exposure, and the possibility of multiple routes of exposure (i.e., dermal as well as inhalation). Dermal exposure was considered to have been the principal exposure route among individuals involved 
with spraying pyrethroids. A limited report in which inhalation exposure was considered to be the primary exposure route did not include exposure levels (Lessenger 1992). Limited animal inhalation toxicity data are available for pyrethrins and pyrethroids (Curry and Bennett 1985; Flucke and Thyssen 1980; Hext 1987; Kavlock et al. 1979; Miyamoto 1976; Pauluhn and Thyssen 1982; Schoenig 1995), but these studies mainly concerned lethality or used exposure levels at which serious neurological effects were elicited. Due to the limited nature of the human and animal data, an acute inhalation MRL could not be derived. Additional peer-reviewed animal studies designed to examine the effects of acute inhalation exposure to pyrethrins and pyrethroids would strengthen the database of currently available information.

The nervous system is the major target of pyrethrin- and pyrethroid-induced toxicity. Numerous reports describe clinical signs of neurotoxicity in humans (Gotoh et al. 1998; He et al. 1989; Peter et al. 1996) and laboratory animals (Eriksson and Nordberg 1990; Hudson et al. 1986; Parker et al. 1983, 1984a, 1984b, 1985; Ray and Cremer 1979; Southwood 1984) following acute oral exposure to relatively high doses of pyrethrins or pyrethroids. One research group (Eriksson and coworkers) has reported neurological effects in adult mice that had been administered acute oral doses of pyrethroids during critical stages of neonatal brain growth (postpartum days 10-16) at exposure levels much lower than those eliciting the classical clinical signs of neurotoxicity (Ahlbom et al. 1994; Eriksson and Fredriksson 1991; Eriksson and Nordberg 1990; Talts et al. 1998a). Another group of investigators (Ray et al. 2002) duplicated the study design of Eriksson and coworkers, but did not observe a toxicologically significant neurological effect. Additional studies designed to assess developmental neurotoxic effects at relatively low levels of oral exposure to pyrethrins and pyrethroids could serve to support or refute the findings of Eriksson and coworkers.

Paresthesia (an abnormal cutaneous sensation sometimes described as tingling, burning, stinging, numbness, and itching) has been widely reported by individuals occupationally exposed to pyrethroids (Flannigan and Tucker 1985; Flannigan et al. 1985b; Knox et al. 1984; LeQuesne and Maxwell 1980; Tucker and Flannigan 1983). Higher levels of exposure to various pyrethroids have resulted in mild acute pyrethroid poisoning that included dizziness, headache, and nausea (Chen et al. 1991; Moretto 1991; Shujie et al. 1988; Zhang et al. 1991). However, human studies typically involved the potential for multiple exposure routes and exposure levels were not quantified. Limited available peer-reviewed animal data indicate neurotoxicity following acute dermal exposure to pyrethroids (El-Elaimy 1986; Meyer 1999; Mitchell et al. 1988). Analysis of results of acute dermal toxicity testing by the pesticide industry might preclude the need for additional animal studies. 
Acute-duration inhalation MRLs were not derived for pyrethrins or pyrethroids due to the limited available information concerning health effects following inhalation exposure to pyrethrins or pyrethroids. Acute-duration oral MRLs were derived for permethrin, cypermethrin, and cyhalothrin. As information becomes available for additional pyrethroids, acute-duration oral MRLs can be derived for them as well.

Intermediate-Duration Exposure. Available reports of toxicoses in humans occupationally exposed to pyrethrins or pyrethroids include multiple exposure routes (dermal, inhalation, and possibly oral) and lack quantitative exposure data. Oral data and limited inhalation data were available for laboratory animals repeatedly exposed to pyrethrins or pyrethroids (Cabral and Galendo 1990; DOD 1977; Flucke and Schilde 1980; Hext et al. 1986; IRIS 2003a, 2003b, 2003c; Ishmael and Litchfield 1988; Miyamoto 1976; Mohan et al. 1998; Parker et al. 1984a, 1984b; Schoenig 1995), but there were few indications that repeated or continuous exposure result in cumulative neurological effects in animals exposed as adults. Intermediate-duration inhalation MRLs were not derived for pyrethrins or pyrethroids due to the limited available information concerning health effects following inhalation exposure to pyrethrins or pyrethroids. Intermediate-duration oral MRLs were derived for permethrin and cyhalothrin. As information becomes available for additional pyrethroids, intermediate-duration oral MRLs can be derived for them as well.

Chronic-Duration Exposure and Cancer. Available reports of toxicity in humans occupationally exposed to pyrethrins or pyrethroids include multiple exposure routes (dermal, inhalation, and possibly oral) and lack quantitative exposure data. Oral data were available for laboratory animals chronically exposed to pyrethrins or pyrethroids (Cabral and Galendo 1990; Hext et al. 1986; IRIS 2003a, 2003b, 2003c; Ishmael and Litchfield 1988; Parker et al. 1984a; Schoenig 1995), but there were no indications that repeated or continuous exposure might result in cumulative neurological effects. Chronic-duration inhalation MRLs were not derived for pyrethrins or pyrethroids due to the limited available information concerning health effects following inhalation exposure to pyrethrins or pyrethroids. Chronic-duration oral MRLs were not derived for pyrethrins or pyrethroids, due to inadequate data.

Available cancer bioassays of animals administered pyrethrins or selected pyrethroids orally provide equivocal evidence of a carcinogenic effect (Cabral and Galendo 1990; EPA 1994c; Ishmael and Litchfield 1988; Miyamoto 1976; Parker et al. 1983, 1984a; Schoenig 1995). Additional information from the pesticide industry should be reviewed in the process of assessing the need for additional studies. 
Genotoxicity. No information was located regarding the genotoxicity of pyrethrins or pyrethroids in humans. Limited information indicated that pyrethrins were not mutagenic in bacterial test systems in vitro (see Table 3-3). Type I and Type II pyrethroids generally tested negative for mutagenicity in prokaryotic test systems, but some positive results were obtained for mutation in yeast cells exposed to selected Type I and Type II pyrethroids (see Tables 3-6 and 3-7). Tests in mammalian systems, both in vivo and in vitro, indicated that Type I and Type II pyrethroids had the potential to induce chromosomal damage (see Tables 3-6 and 3-7).

Reproductive Toxicity. No information was located regarding pyrethrin- or pyrethroid-induced reproductive toxicity in humans. Reproductive toxicity was not observed in rats administered oral doses of pyrethrins in the diet at concentrations resulting in average daily doses of $240 \mathrm{mg} / \mathrm{kg}$ for 2 generations (Schoenig 1995). One 3-generation study found no evidence for reproductive toxicity from fenpropathrin at an oral dose level of $25 \mathrm{mg} / \mathrm{kg} /$ day (Hend et al. 1979). However, Abd El-Aziz et al. (1994) reported significantly reduced fertility in male rats following intermediate-duration oral exposure to deltamethrin at a dose level of $1 \mathrm{mg} / \mathrm{kg} /$ day. Additional reproductive toxicity studies could be designed to support or refute these results.

Developmental Toxicity. No information was located regarding pyrethrin- or pyrethroid-induced developmental toxicity in humans. Most available developmental toxicity studies in animals do not indicate that pyrethrins or pyrethroids might be considered to be developmental toxicity hazards. The World Health Organization (WHO 2001), and EPA (IRIS 2003f) reviewed a number of unpublished or proprietary developmental toxicity studies performed for various chemical organizations. The summaries of WHO (2001) and EPA (IRIS 2003f) indicate that classical developmental effects are not elicited following exposure to pyrethroids.

Recent studies by Eriksson and coworkers suggest that exposure to pyrethroids during neonatal stages of development when the brain is rapidly growing, may result in adverse neurological effects (changes in MACh receptor density in the cerebral cortex and increased spontaneous locomotor behavior) that are not apparent until adulthood (Ahlbom et al. 1994; Eriksson and Fredriksson 1991; Eriksson and Nordberg 1990; Talts et al. 1998a). However, limitations in study design and lack of success in duplicating the results (Ray et al. 2002; Tsuji et al. 2002) render the studies of Eriksson and coworkers of questionable value for the purpose of risk assessment. Additional studies should be designed to support or refute the findings of Eriksson and coworkers. 
Immunotoxicity. A few cases of hypersensitive responses in humans exposed to pyrethrins and pyrethroids have been documented in available literature (Box and Lee 1996; Carlson and Villaveces 1977; Wagner 2000; Wax and Hoffman 1994). Available information regarding immunotoxicity in animals was limited to oral studies in which administration of selected pyrethroids resulted in immunotoxic effects such as suppression of the humoral immune response, alterations in lymphocytes, leukopenia, altered natural killer cell activity, and decreased spleen weight (Blaylock et al. 1995; Demian 1998; Demian and El-Sayed 1993; Dési et al. 1986; Lukowicz-Ratajczak and Krechniak 1992; Varshneya et al. 1992). No adequate studies are available in humans to assess the immunotoxic potential of pyrethrins or pyrethroids. Studies measuring specific immunologic parameters in occupationally exposed populations might provide useful information. However, inherent variation among human subjects would necessitate very large sample sizes. Animal studies designed to investigate the mechanism for pyrethroidinduced immunotoxicity might help to identify special populations at risk for such effects.

Neurotoxicity. Abundant human data show that exposure to large amounts of pyrethroids, either by accidental or intentional ingestion or by dermal and inhalation exposure during unprotected handling or spraying of pyrethroids, may result in clinical signs of neurotoxicity (Chen et al. 1991; Flannigan and Tucker 1985; Flannigan et al. 1985b; Gotoh et al. 1998; He et al. 1989, 1991; Knox et al. 1984; LeQuesne and Maxwell 1980; Moretto 1991; Peter et al. 1996; Shujie et al. 1988; Tucker and Flannigan 1983; Zhang et al. 1991). Exposure of laboratory rodents to selected Type I and Type II pyrethroids has been shown to trigger typical signs of Type I (aggressive behavior and increased sensitivity to external stimuli, fine tremor, prostration with coarse whole body tremor, elevated body temperature, and coma) and Type II (pawing and burrowing behavior, profuse salivation, increased startle response, abnormal hindlimb movements, and choreoathetosis) pyrethroid poisoning. Although the majority of animal studies reporting neurotoxic effects employed oral exposure (EPA 1988c, 1991a, 1991b, 1992b, 1992c, 1994b; Eriksson and Nordberg 1990; Hudson et al. 1986; McDaniel and Moser 1993; Parker et al. 1983, 1984a, 1984b, 1985; Ray and Cremer 1979; Southwood 1984), these effects were also elicited following inhalation and dermal exposure (Curry and Bennett 1985; El-Elaimy 1986; Pauluhn and Thyssen 1982; Schoenig 1995). Several investigators reported typical signs of Type I or Type II pyrethroid poisoning in laboratory rodents during repeated oral administration of pyrethrins or pyrethroids (from 2 days to 2 years), but there were few indications that repeated or continuous exposure might result in cumulative neurological effects (Cabral and Galendo 1990; DOD 1977; Flucke and Schilde 1980; Hext et al. 1986; IRIS 2003a, 2003b, 2003c; Ishmael and Litchfield 1988; Mohan et al. 1998; Parker et al. 1984a, 1984b; Schoenig 1995). Some investigators have reported signs of neurotoxicity such as altered locomotor 
activity, altered acoustic startle response, decreased active avoidance response, and changes in brain neurotransmitter concentrations at pyrethroid exposure levels below those eliciting clinical signs of Type I or Type II pyrethroid poisoning (Crofton and Reiter 1988; Hijzen et al. 1988; Husain et al. 1991; Mandhane and Chopde 1997; Mitchell et al. 1988; Moniz et al. 1994; Spinosa et al. 1999). Additional studies of the neurotoxicity of pyrethrins and pyrethroids should assess sensory function in humans and sensitivity of unique populations such as farm workers, children of farm workers, the elderly, and veterans of the Gulf War.

Epidemiological and Human Dosimetry Studies. Available information regarding the health effects of pyrethrins and pyrethroids in humans mainly concerns reports of neurological effects following accidental or intentional ingestion or during unprotected handling or spraying (Chen et al. 1991; Flannigan and Tucker 1985; Flannigan et al. 1985b; Gotoh et al. 1998; He et al. 1989, 1991; Knox et al. 1984; LeQuesne and Maxwell 1980; Moretto 1991; Peter et al. 1996; Shujie et al. 1988; Tucker and Flannigan 1983; Zhang et al. 1991). Occupational exposure to pyrethrins and pyrethroids may be confounded by differences in specific formulations and by concurrent exposures to other pesticides. Pesticide applicators, farm workers, individuals involved in production of pyrethrins or pyrethroids, and individuals exposed in recently sprayed homes or offices might serve as a focus for well-designed epidemiological studies for further assessment of neurological effects of pyrethrins and pyrethroids, as well as assessment of other potential adverse effects, such as immunotoxicity. Studies of dosimetry would be useful in future epidemiological studies.

\section{Biomarkers of Exposure and Effect.}

Exposure. Measurement of urinary metabolites of pyrethroids can serve as useful markers of exposure (Aprea et al. 1997; Kühn et al. 1999; Leng et al. 1996, 1997a, 1997b). However, there is insufficient information from studies in humans or animals to allow for correlation of the amounts of metabolites measured in the urine to the body burden of pyrethroids or to the level of exposure to pyrethroids. Additional information regarding the relationship of urinary pyrethroid metabolite levels to pyrethroid body burden and to exposure levels could improve the ability to monitor worker's exposure to pyrethroids. Also, residues of pyrethrins and pyrethroids and their metabolites should be determined in blood of humans (antemortem) and in blood, digestive tract contents, liver, kidney, and brain of animals and accidently exposed or suicide victims (postmortem). Without detailed knowledge regarding the appearance and disappearance of parent compounds and metabolites over the course of a toxicosis, confirmed diagnoses will remain elusive to impossible. 
Effect. Biomarkers of effect for pyrethrins and pyrethriods include typical neurotoxic signs of acute pyrethroid poisoning (Coats 1990; Verschoyle and Aldridge 1980). Although these clinical signs are distinctive, they are not totally unique to pyrethrin or pyrethroid poisoning.

Absorption, Distribution, Metabolism, and Excretion. The absorption, distribution, metabolism, and excretion of pyrethrins or pyrethroids following exposure by any route are not well characterized in humans. While many studies have investigated these processes for pyrethroids in various laboratory animals, in general, toxicokinetics of these compounds are not well defined. No PBPK models of pyrethrins or pyrethroids have been reported. Information to support the development of a PBPK model for pyrethrins or pyrethroids has not been systematically compiled and is currently insufficient to support such models (e.g., mechanisms and kinetic constants and variables of metabolism, tissue partition coefficients). Such models would be useful for predicting body burdens and, if combined with doseresponse models, for predicting health effects of pyrethrins and pyrethroids associated with known or projected exposures.

Absorption. Although results of studies in humans and laboratory animals demonstrate that pyrethroids are absorbed following exposure by the inhaled, oral, and dermal routes, further studies would be helpful for quantifying the absorption and time-course of absorption by each exposure route. It has been proposed that pyrethroids are stored in the skin following dermal exposure and are slowly released into the systemic circulation (Eadsforth et al. 1988; Woollen et al. 1992). Given the importance of the dermal route in occupational exposure to pyrethroids, additional information regarding the time-course of absorption following dermal exposure would be helpful. Little information is available concerning roles such factors as diet, age, sex, or other chemicals and drugs might play in the absorption of pyrethroids by any route in humans and animals. Further studies are needed to examine these factors and define potential differences in absorption over a range of pyrethrins and pyrethroids.

Distribution. The distribution of pyrethrins and pyrethroids in humans and animals has not been well studied. From the results of studies in laboratory animals, it is concluded that pyrethroids are rapidly and widely distributed and are concentrated in central and peripheral nerve tissues (Anadón et al. 1991a, 1991b, 1996; Gray and Rickard 1982; Gray et al. 1980). Additional investigations on distribution would provide a further understanding of the extent of distribution of pyrethroids to nervous system tissues (a principal target of pyrethroid toxicity) and to define the time-course for distribution and tissue retention, particularly in tissues that are targets for toxicity. Extremely limited information is available regarding 
distribution of pyrethroids to the fetus and into breast milk. Additional studies are needed to assess the potential risks of exposure in utero and via breast milk. Additional studies also may be warranted to identify factors that may alter distribution of pyrethroids and to define potential differences in distribution with respect to age and sex.

Metabolism. The metabolism of pyrethrins and pyrethroids in humans has not been well defined. Although the metabolism of pyrethroids has been extensively studied in laboratory animals, the specific enzymes responsible for the biotransformation of pyrethroids have not been identified. Further research identifying these enzymes would allow the evaluation of many potential factors, such as age, sex, and other chemicals and drugs, that could alter the metabolism of pyrethroids. This is of particular importance since metabolism of pyrethroids is generally accepted as the primary detoxifying mechanism in mammals (Gray and Soderlund 1985; Hutson 1979).

Elimination and Excretion. The elimination and excretion of pyrethrins and pyrethroids in humans have not been well defined and information is limited to studies investigating the elimination of pyrethroids from the plasma and excretion of pyrethroids into the urine. Additional information on nonurinary excretory routes and information to quantify excretion by each route in humans would be helpful for predicting routes and elimination kinetics in humans. Based on the limited information available in humans, it is not possible to predict precisely how long pyrethroids will remain in the body following exposure by various routes. Further study on the elimination kinetics of a range of pyrethroids by each route of exposure would be helpful for developing predictive models in humans. There is little information available regarding the mechanisms of excretion in either humans or animals. Further study on these mechanisms would allow assessment of the many potential factors, such as age, sex, and other chemicals and drugs, that could alter the elimination and excretion of pyrethroids.

Comparative Toxicokinetics. Insufficient information is available regarding comparative toxicokinetics of pyrethrins or pyrethroids in humans and laboratory animals. Further investigations on potential differences in humans and animals may help to determine appropriate species and strains of animals to use in predicting the toxicokinetics of pyrethroids in humans. Evaluation of mechanisms, character, and extent of human variability in the disposition of pyrethroids is also warranted.

Methods for Reducing Toxic Effects. Other than general guidelines of washing the skin with soap and water following dermal exposure and use of gastric lavage and activated charcoal following oral exposure, little additional information is available regarding methods for reducing absorption of 
pyrethroids. Additional studies on factors that could affect the absorption and metabolism of pyrethroids, such as diet and concomitant exposure to other chemicals and drugs, would be helpful in understanding the impact of these factors on risks from occupational exposures.

Children's Susceptibility. Neurotoxic effects have been well characterized in humans exposed to pyrethrins and pyrethroids. Information mainly derives from individuals occupationally exposed during spraying. No reports on exposed children were found, but it is reasonable to assume that children would exhibit signs and symptoms similar to those in adults under similar exposure conditions. No information was located regarding developmental toxicity in humans exposed to pyrethrins or pyrethroids. Studies in animals have suggested that neonatal exposure to pyrethroids may result in neurological effects first observed in adulthood (Ahlbom et al. 1994; Eriksson and Fredriksson 1991; Eriksson and Nordberg 1990; Talts et al. 1998a). These results could not be confirmed by independent investigators (Ray et al. 2002).

No human data were located regarding age-related differences in the pharmacokinetics of pyrethrins or pyrethroids. Limited animal data suggest that young animals may be more susceptible to pyrethroid poisoning, possibly due to less efficient production of enzymes responsible for detoxification (Cantalamessa 1993).

Extremely limited data suggest that pyrethroids may be minimally transferred across the placenta to the fetus (Quistad et al. 1982). Very low levels of pyrethroids have been measured in the milk of lactating cows and goats (Gaughan et al. 1978; Hunt and Gilbert 1977; Quistad et al.1982; Ridlen et al. 1984; Wszolek et al. 1980).

No data were located regarding pediatric-specific methods to reduce peak absorption of pyrethrins or pyrethroids following exposure, to reduce body burdens, or to interfere with mechanisms of action. Based on available information, it is reasonable to assume that methods recommended for treating adults will also be applicable to children.

Child health data needs relating to exposure are discussed in 6.8.1 Identification of Data Needs: Exposures of Children. 


\subsubsection{Ongoing Studies}

The Federal Research In Progress database (FEDRIP 2003) lists an ongoing study in which Dr. B. Wilson, from the University of California, Davis, California has proposed the development of biomarkers of exposure and effect for organophosphorus and pyrethroid insecticidal sprays. Two studies were located in the Computer Retrieval of Information in Scientific Projects database (CRISP 2003). Dr. S. Holladay, from Virginia Polytechnic Institute and State University, Blacksburg, Virginia, is investigating the immunotoxicity of permethrin. Dr. D. Soderlund, from Cornell University, Ithaca, New York, is investigating specific mechanisms of action of pyrethroids in vertebrate systems. Dr. T. Narahashi, from Northwestern University, Chicago, Illinois, is investigating differential actions of Type II pyrethroids on sodium channels. 



\section{CHEMICAL AND PHYSICAL INFORMATION}

\subsection{CHEMICAL IDENTITY}

The naturally-occurring pyrethrins, extracted from chrysanthemum flowers, are esters of chrysanthemic acid (Pyrethrin I, Cinerin I, and Jasmolin I) and esters of pyrethric acid (Pyrethrin II, Cinerin II, and Jasmolin II). In the United States, the pyrethrum extract is standardized as $45-55 \% \mathrm{w} / \mathrm{w}$ total pyrethrins. The typical proportion of Pyrethrins I to II is $0.2: 2.8$, while the ratio of pyrethrins:cinerins:jasmolins is 71:21:7 (Tomlin 1997). Information regarding the chemical identity of the pyrethrins is presented in Table 4-1.

Pyrethroids are synthetic esters derived from the naturally-occurring pyrethrins. One exception to the axiom that all pyrethroids are esters of carboxylic acids is noteworthy. There is a group of oxime ethers that exhibits insecticidal activity similar in nature to the pyrethrins and pyrethroid esters (Davies 1985). Little data exist regarding these compounds, and no commercial products have been produced. Commercially available pyrethroids include allethrin, bifenthrin, bioresmethrin, cyfluthrin, cyhalothrin, cypermethrin, deltamethrin, esfenvalerate (fenvalerate), flucythrinate, flumethrin, fluvalinate, fenpropathrin, permethrin, phenothrin, resmethrin, tefluthrin, tetramethrin, and tralomethrin. Information regarding the chemical identity of pyrethroids is shown in Table 4-2.

With the exception of deltamethrin, pyrethroids are a complex mixture of isomers rather than one single pure compound. For pyrethroids possessing the cyclopropane moiety, isomerism about the cyclopropane ring greatly influences the toxicity of these insecticides. The presence of two chiral centers in the ring results in two pairs of diastereomers. The diastereomers and their nonsuperimposable mirror images (enantiomers) are illustrated in Figure 4-1. In this figure, the C-1 position of the ring is assigned to the carbon atom bonded to the ester moiety. It is also customary to designate the stereochemistry at the C-3 position as simply cis or trans relative to the ester group bonded to $\mathrm{C}-1$ rather than assigning its absolute configuration. The $1 \mathrm{R}$ conformations about the cyclopropane ring are considerably more toxic than the $1 \mathrm{~S}$ isomers. Both the cis and trans isomers show insecticidal activity, but have differing mammalian toxicities, with the cis isomers being more potent (Ray 1991). Pyrethroids that contain a cyano substituent at the alcohol moiety (Type II pyrethroids) demonstrate differing toxicity based upon the optical isomerism of the alpha carbon. It has been demonstrated that the $\mathrm{S}$ conformation about the alpha carbon is considerably more toxic towards insects when compared to the R conformation (Dorman and 
Table 4-1. Chemical Identity of the Pyrethrins

\begin{tabular}{|c|c|c|c|}
\hline Characteristic & Pyrethrin I & Cinerin I & Jasmolin I \\
\hline Synonym(s) & $\begin{array}{l}\text { (Z)-(S)-2-methyl-4-oxo- } \\
\text { 3-(penta-2,4- } \\
\text { dienyl)cyclo pent-2- } \\
\text { enyl (1R)-trans-2,2- } \\
\text { dimethyl-3-(2-methyl } \\
\text { prop-1-enyl)cyclo- } \\
\text { propanecarboxylate }\end{array}$ & $\begin{array}{l}\text { (Z)-(S)-3-(but-2-enyl)- } \\
\text { 2-methyl-4- } \\
\text { oxocyclopent-2-enyl } \\
\text { (1R)-trans-2,2-di } \\
\text { methyl-3-(2-methyl } \\
\text { prop-1-enyl)cyclo- } \\
\text { propanecarboxylate }\end{array}$ & $\begin{array}{l}\text { (Z)-(S)-2-methyl-4-oxo- } \\
\text { 3-(pent-2- } \\
\text { enyl)cyclopent-2-enyl } \\
\text { (1R)-trans-2,2-di- } \\
\text { methyl-3-(2- } \\
\text { methylprop-1-enyl)- } \\
\text { cyclopro- } \\
\text { panecarboxylate }\end{array}$ \\
\hline Ratio of isomers & Pure isomer & Pure isomer & Pure isomer \\
\hline $\begin{array}{l}\text { Registered trade name(s) } \\
\text { Chemical formula }\end{array}$ & $\begin{array}{l}\text { Alfadex, Evergreen, } \\
\text { ExciteR, Milon, Pycon, } \\
\text { Pyrocide, Pyronyl } \\
\mathrm{C}_{21} \mathrm{H}_{28} \mathrm{O}_{3}\end{array}$ & $\begin{array}{l}\text { Alfadex, Evergreen, } \\
\text { ExciteR, Milon, Pycon, } \\
\text { Pyrocide, Pyronyl } \\
\mathrm{C}_{20} \mathrm{H}_{28} \mathrm{O}_{3}\end{array}$ & $\begin{array}{l}\text { Alfadex, Evergreen, } \\
\text { ExciteR, Milon, Pycon, } \\
\text { Pyrocide, Pyronyl } \\
\mathrm{C}_{21} \mathrm{H}_{30} \mathrm{O}_{3}\end{array}$ \\
\hline \multicolumn{4}{|l|}{ Chemical structure } \\
\hline \multicolumn{4}{|l|}{ Identification numbers: } \\
\hline CAS registry & $121-21-1$ & $25402-06-6$ & $4466-14-2$ \\
\hline NIOSH RTECS ${ }^{c}$ & GZ1725000 & GZ1540000 & No data \\
\hline EPA hazardous wasted & No data & No data & No data \\
\hline OHM/TADS & No data & No data & No data \\
\hline DOT/UN/NA/IMCO shipping & No data & No data & 6302 \\
\hline $\operatorname{HSDB}^{\mathrm{d}}$ & 6302 & 6837 & No data \\
\hline $\mathrm{NCl}$ & No data & No data & No data \\
\hline
\end{tabular}




\section{Table 4-1. Chemical Identity of the Pyrethrins}

\begin{tabular}{|c|c|c|c|}
\hline Characteristic & Pyrethrin II & Cinerin II & Jasmolin II \\
\hline Synonym(s) $^{b}$ & $\begin{array}{l}\text { (Z)-(S)-2-methyl-4- } \\
\text { oxo-3-(penta-2,4- } \\
\text { dienyl)cyclo pent-2- } \\
\text { enyl (E)-(1R)-trans-3- } \\
\text { (2-methoxy carbon } \\
\text { ylprop-1-enyl)-2,2- } \\
\text { dimethylcyclopropane- } \\
\text { carboxylate }\end{array}$ & $\begin{array}{l}\text { (Z)-(S)-3-(but-2-enyl)-2- } \\
\text { methyl-4-oxocyclopent-2- } \\
\text { enyl (E)-(1R)-trans-3-(2- } \\
\text { methoxycarbonylprop-1- } \\
\text { enyl)-2,2-dimethyl } \\
\text { cyclopropanecarboxylate }\end{array}$ & $\begin{array}{l}\text { (Z)-(S)-2-methyl-4-oxo- } \\
\text { 3-(pent-2- } \\
\text { enyl)cyclopent-2-enyl } \\
\text { (E)-(1R)-trans-3-(2- } \\
\text { methoxycarbonylprop-1- } \\
\text { enyl)-2,2-dimethylcyclo- } \\
\text { propanecarboxylate }\end{array}$ \\
\hline Ratio of isomers & Pure isomer & Pure isomer & Pure isomer \\
\hline $\begin{array}{l}\text { Registered trade name(s) } \\
\text { Chemical formula }\end{array}$ & $\begin{array}{l}\text { Alfadex, Evergreen, } \\
\text { ExciteR, Milon, Pycon, } \\
\text { Pyrocide, Pyronyl } \\
\mathrm{C}_{22} \mathrm{H}_{28} \mathrm{O}_{5}\end{array}$ & $\begin{array}{l}\text { Alfadex, Evergreen, } \\
\text { ExciteR, Milon, Pycon, } \\
\text { Pyrocide, Pyronyl } \\
\mathrm{C}_{21} \mathrm{H}_{28} \mathrm{O}_{5}\end{array}$ & $\begin{array}{l}\text { Alfadex, Evergreen, } \\
\text { ExciteR, Milon, Pycon, } \\
\text { Pyrocide, Pyronyl } \\
\mathrm{C}_{22} \mathrm{H}_{30} \mathrm{O}_{3}\end{array}$ \\
\hline \multicolumn{4}{|l|}{ Chemical structure } \\
\hline \multicolumn{4}{|l|}{ Identification numbers: } \\
\hline CAS registry & $121-29-9$ & $121-20-0$ & $1172-63-0$ \\
\hline NIOSH RTECS ${ }^{c}$ & GZ0700000 & No data & No data \\
\hline EPA hazardous wasted & No data & No data & No data \\
\hline $\mathrm{OHM} / \mathrm{TADS}$ & No data & No data & No data \\
\hline DOT/UN/NA/IMCO shipping & No data & No data & No data \\
\hline $\mathrm{HSDB}^{\mathrm{d}}$ & 6303 & 6838 & No data \\
\hline $\mathrm{NCl}$ & No data & No data & No data \\
\hline
\end{tabular}

${ }^{a}$ All information obtained from Tomlin, 1997 except where noted.

${ }^{\mathrm{b}}$ Chemical names used are those currently indexed by the Chemical Abstracts Service.

${ }^{\mathrm{c}} \mathrm{NIOSH} 1987$

${ }^{\mathrm{d}} \mathrm{HSDB} 2001$

e WHO 2001

CAS = Chemical Abstracts Services; DOT/UN/NA/IMCO $=$ Department of Transportation/United Nations/North America/International Maritime Dangerous Goods Code; EPA = Environmental Protection Agency; HSDB = Hazardous Substances Data Bank; NCI = National Cancer Institute; NIOSH = National Institute for Occupational Safety and Health; $\mathrm{OHM} / \mathrm{TADS}=\mathrm{Oil}$ and Hazardous Materials/Technical Assistance Data System; RTECS =Registry of Toxic Effects of Chemical Substances 
Table 4-2. Chemical Identity of Selected Pyrethroids ${ }^{a}$

\begin{tabular}{|c|c|c|c|}
\hline Characteristic & Allethrin & Bifenthrin & Bioresmethrin \\
\hline Synonym(s) & $\begin{array}{l}\text { 2-methyl-4-oxo-3-(2- } \\
\text { propenyl)-2-cyclopenten- } \\
\text { 1-yl 2,2-dimethyl-3-(2- } \\
\text { methyl-1- } \\
\text { propenyl)cycloprane- } \\
\text { carboxylate }\end{array}$ & $\begin{array}{l}\text { (2-methyl[1,1'-biphenyl]- } \\
\text { 3-yl)methyl 3-(2-chloro- } \\
\text { 3,3,3-trifluoro-1- } \\
\text { propenyl)-2,2- } \\
\text { dimethylcyclopropane- } \\
\text { carboxylate }\end{array}$ & $\begin{array}{l}\text { (1R-trans)-[5- } \\
\text { phenylmethyl)-3- } \\
\text { furanyl]mehtyl 2,2- } \\
\text { dimethyl-3-(2-methyl-1- } \\
\text { propenyl)cyclopropane- } \\
\text { carboxylate }\end{array}$ \\
\hline Ratio of isomers & $\begin{array}{l}\geq 95 \%(1 \mathrm{R}) \text {-isomers } \\
\geq 75 \% \text { trans-isomers }\end{array}$ & $\geq 97 \%$ cis-isomer & $\geq 90 \%$ (1R)-trans-isomer \\
\hline Registered trade name(s) & $\begin{array}{l}\text { Pyresin, Pynamin Forte, } \\
\text { Exthrin }\end{array}$ & Talstar & Isathrine \\
\hline Chemical formula & $\mathrm{C}_{19} \mathrm{H}_{26} \mathrm{O}_{3}$ & $\mathrm{C}_{23} \mathrm{H}_{22} \mathrm{ClF}_{3} \mathrm{O}_{2}$ & $\mathrm{C}_{22} \mathrm{H}_{26} \mathrm{O}_{3}$ \\
\hline \multicolumn{4}{|l|}{ Chemical structure } \\
\hline \multicolumn{4}{|l|}{ Identification numbers: } \\
\hline CAS registry & $584-79-2$ & $82657-04-3$ & 28434-01-7 \\
\hline NIOSH RTECS ${ }^{c}$ & GZ1925000 & GZ1227800 & GZ1227800 \\
\hline EPA hazardous waste & No data & No data & No data \\
\hline OHM/TADS & No data & No data & No data \\
\hline DOT/UN/NA/IMCO shipping & $\begin{array}{l}\text { NA2902, NA2588, } \\
\text { UN2588, UN2902, } \\
\text { UN2903, UN3201, } \\
\text { IMO3.2, IMO6.1 }\end{array}$ & No data & No data \\
\hline $\mathrm{HSDB}^{\mathrm{d}}$ & 1511 & 6568 & 6568 \\
\hline $\mathrm{NCl}$ & No data & No data & No data \\
\hline
\end{tabular}




\section{Table 4-2. Chemical Identity of Selected Pyrethroids ${ }^{a}$}

\begin{tabular}{|c|c|c|c|}
\hline Characteristic & Cyfluthrin & Cyhalothrin & Cypermethrin \\
\hline Synonym(s) & $\begin{array}{l}\text { Cyano(4-fluoro-3-phen- } \\
\text { oxyphenyl)methyl 3-(2,2- } \\
\text { dichloroethenyl)-2,2- } \\
\text { dimethylcyclopropane- } \\
\text { carboxylate }\end{array}$ & $\begin{array}{l}\text { [1 } \alpha, 3 \alpha(Z)]-( \pm)-C y a n o-(3- \\
\text { phenoxyphenyl)methyl } \\
\text { 3-(2-chloro-3,3,3- } \\
\text { trifluoro-1-propenyl)2,2- } \\
\text { dimethyl- } \\
\text { cyclopropanecarboxylate }\end{array}$ & $\begin{array}{l}\text { Cyano(3-phenoxyphenyl } \\
\text { )methyl 3-(2,2-dichloro } \\
\text { ethenyl)-2,2-dimethyl- } \\
\text { cyclopropanecarboxylate }\end{array}$ \\
\hline Ratio of isomers & $\begin{array}{l}\text { Unstated } \\
\text { stereochemistry }\end{array}$ & $\geq 95 \%$ cis-isomers & $\begin{array}{l}\text { Unstated } \\
\text { stereochemistry }\end{array}$ \\
\hline Registered trade name(s) & $\begin{array}{l}\text { Baythroid, Baygon } \\
\text { aerosol, Solfac }^{\mathrm{b}}\end{array}$ & Cyhalon, Grenade & $\begin{array}{l}\text { Arrivo, Cymbush, } \\
\text { Cymperator, Cynoff, } \\
\text { Ripcord, Basathrin, } \\
\text { Demar, Grand, Starcyp }\end{array}$ \\
\hline Chemical formula & $\mathrm{C}_{22} \mathrm{H}_{18} \mathrm{Cl}_{2} \mathrm{FNO}_{3}$ & $\mathrm{C}_{23} \mathrm{H}_{19} \mathrm{ClF}_{3} \mathrm{NO}_{3}$ & $\mathrm{C}_{22} \mathrm{H}_{19} \mathrm{Br}_{2} \mathrm{NO}_{3}$ \\
\hline \multicolumn{4}{|l|}{ Chemical structure } \\
\hline \multicolumn{4}{|l|}{ Identification numbers: } \\
\hline CAS registry & $68359-37-5$ & $68085-85-8$ & $52315-07-8$ \\
\hline NIOSH RTECS ${ }^{c}$ & GZ1253000 & GZ122770 & GZ1250000 \\
\hline EPA hazardous waste & No data & No data & No data \\
\hline $\mathrm{OHM} / \mathrm{TADS}$ & No data & No data & No data \\
\hline DOT/UN/NA/IMCO shipping & No data & No data & No data \\
\hline $\mathrm{HSDB}^{\mathrm{d}}$ & 6599 & 6791 & 6600 \\
\hline $\mathrm{NCl}$ & No data & No data & No data \\
\hline
\end{tabular}




\section{Table 4-2. Chemical Identity of Selected Pyrethroids ${ }^{a}$}

\begin{tabular}{|c|c|c|c|}
\hline Characteristic & Deltamethrin & Esfenvalerate & Fenpropathrin \\
\hline$\overline{\text { Synonym(s) }}{ }^{b}$ & $\begin{array}{l}\left.\left.\text { [1R-[1 } \alpha\left(\mathrm{S}^{*}\right), 3 \alpha\right]\right]-C y a n o \\
\text { (3-phenoxy- } \\
\text { phenyl)methyl 3-(2,2- } \\
\text { dibromo ethenyl)-2,2- } \\
\text { dimethylcyclopropane- } \\
\text { carboxylate, } \\
\text { decamethrin }\end{array}$ & $\begin{array}{l}\left\{S-R^{*}, R^{*}\right]-C y a n o(3- \\
\text { phenoxyphenyl)methyl } \\
\text { 4-chloro-2-(1-methyl- } \\
\text { ethyl)benzeneacetate, } \\
\text { fenvalerate }\end{array}$ & $\begin{array}{l}\text { Cyano(3-phenoxy- } \\
\text { phenyl)methyl 2,2,3,3- } \\
\text { tetramethyl- } \\
\text { cyclopropane- } \\
\text { carboxylate(racemate) } \\
\text { fenpropanate } \\
\text { (unspecified) }\end{array}$ \\
\hline Ratio of isomers & $\geq 98 \%$ single isomer & $\geq 75 \%(\mathrm{~S}, \mathrm{~S})$-isomers & $\begin{array}{l}\text { Unstated } \\
\text { stereochemistry }\end{array}$ \\
\hline Registered trade name(s) & $\begin{array}{l}\text { Butox, Decis, K-Othrin, } \\
\text { Kordon, Sadethrin }^{b}\end{array}$ & $\begin{array}{l}\text { Sumi-alfa, Sumi-alpha, } \\
\text { Asana (esfenvalerate), } \\
\text { Pydrin, Ectrin,Sumicidin, } \\
\text { Arfen, Dufen, Fenval } \\
\text { (fenvalerate) }\end{array}$ & $\begin{array}{l}\text { Danitol, Herald, } \\
\text { Meothrin, Rody, Digital }\end{array}$ \\
\hline Chemical formula & $\mathrm{C}_{22} \mathrm{H}_{19} \mathrm{Br}_{2} \mathrm{NO}_{3}$ & $\mathrm{C}_{25} \mathrm{H}_{22} \mathrm{CINO}_{3}$ & $\mathrm{C}_{22} \mathrm{H}_{23} \mathrm{NO}_{3}$ \\
\hline \multicolumn{4}{|l|}{ Chemical structure } \\
\hline \multicolumn{4}{|l|}{ Identification numbers: } \\
\hline CAS registry & $52918-63-5$ & $\begin{array}{l}66230-04-4,51630-58-1 \\
\text { (fenvalerate) }\end{array}$ & $\begin{array}{l}\text { 64257-84-7 (racemic), } \\
39515-41-8 \\
\text { (stereochemistry) }\end{array}$ \\
\hline NIOSH RTECS ${ }^{c}$ & $\begin{array}{l}\text { GZ1233000, } \\
\text { GZ1232000 }\end{array}$ & $\begin{array}{l}\text { CY1576367, } \\
\text { CY1576350 }\end{array}$ & $\begin{array}{l}\text { GZ2090500, } \\
\text { GZ2090000 }\end{array}$ \\
\hline EPA hazardous waste & No data & CY1576350 & No data \\
\hline OHM/TADS & No data & No data & No data \\
\hline DOT/UN/NA/IMCO shipping & No data & No data & No data \\
\hline $\mathrm{HSDB}^{\mathrm{d}}$ & 6604 & 6625,6640 & 6636 \\
\hline $\mathrm{NCl}$ & No data & No data & No data \\
\hline
\end{tabular}


Table 4-2. Chemical Identity of Selected Pyrethroids ${ }^{a}$

\begin{tabular}{|c|c|c|c|}
\hline Characteristic & Flucythrinate & Flumethrin & Fluvalinate \\
\hline Synonym(s) $^{b}$ & $\begin{array}{l}\text { Cyano(3-phenoxy- } \\
\text { phenyl)methyl 4- } \\
\text { (difluoromethoxy)- } \alpha-(1- \\
\text { methylethyl)benzene- } \\
\text { acetate }\end{array}$ & $\begin{array}{l}\alpha \text {-Cyano-4-fluoro-3- } \\
\text { phenoxybenzyl 3-(ß,4- } \\
\text { dichlorostyryl)-2,2- } \\
\text { dimethylcyclopropane- } \\
\text { carboxylate }\end{array}$ & $\begin{array}{l}\text { Cyano(3-phenoxy- } \\
\text { phenyl)methyl N-N-[2- } \\
\text { chloro-4-(trifluoro- } \\
\text { methyphenyl)-DL- } \\
\text { valinate, D-valinate }\end{array}$ \\
\hline Ratio of isomers & No data & $\begin{array}{l}\text { Unstated } \\
\text { stereochemistry }\end{array}$ & $\begin{array}{l}\text { Tau-fluvalinate is a } 1: 1 \\
\text { mixture of }(R) \text {-a-cyano, } \\
2-(R) \text { and }(S) \text {-a- cyano, } \\
2-(R) \text { diasteriomers }\end{array}$ \\
\hline Registered trade name(s) & $\begin{array}{l}\text { Cybolt, Cythrin, Pay-off, } \\
\text { Fluent }\end{array}$ & Bayticol, Bayvarol & Klartan, Mavrik \\
\hline Chemical formula & $\mathrm{C}_{26} \mathrm{H}_{23} \mathrm{~F}_{2} \mathrm{NO}_{4}$ & $\mathrm{C}_{28} \mathrm{H}_{22} \mathrm{Cl}_{2} \mathrm{FNO}_{3}$ & $\mathrm{C}_{26} \mathrm{H}_{22} \mathrm{ClF}_{3} \mathrm{~N}_{2} \mathrm{O}_{3}$ \\
\hline \multicolumn{4}{|l|}{ Chemical structure } \\
\hline \multicolumn{4}{|l|}{ Identification numbers: } \\
\hline CAS registry & $70124-77-5$ & $69770-45-2$ & $\begin{array}{l}69409-94-5, \\
102851-06-9 \text { (tau- } \\
\text { fluvalinate) }\end{array}$ \\
\hline NIOSH RTECS ${ }^{c}$ & CY1578620 & No data & YV9397100 \\
\hline EPA hazardous waste & No data & No data & No data \\
\hline OHM/TADS & No data & No data & No data \\
\hline DOT/UN/NA/IMCO shipping & No data & No data & No data \\
\hline $\mathrm{HSDB}^{\mathrm{d}}$ & 6647 & No data & 6659 \\
\hline $\mathrm{NCl}$ & No data & No data & No data \\
\hline
\end{tabular}




\section{Table 4-2. Chemical Identity of Selected Pyrethroids ${ }^{a}$}

\begin{tabular}{|c|c|c|c|}
\hline Characteristic & Permethrin & Phenothrin & Resmethrin \\
\hline Synonym(s) $^{b}$ & $\begin{array}{l}\text { (3- } \\
\text { Phenoxyphenyl)methyl3- } \\
\text { (2,2-dichloroehenyl)-2,2- } \\
\text { dimethylcyclopropane- } \\
\text { carboxylate }\end{array}$ & $\begin{array}{l}\text { (3- } \\
\text { Phenoxyphenyl)methyl- } \\
\text { 2,2-dimethyl-3-(2- } \\
\text { methyl-1-propenyl)- } \\
\text { cyclopropanecarboxylate }\end{array}$ & $\begin{array}{l}\text { [5-Phenylmethyl)-3- } \\
\text { furanyl]mehtyl 2,2- } \\
\text { dimethyl-3-(2-methyl-1- } \\
\text { propenyl)cyclopropane- } \\
\text { carboxylate }\end{array}$ \\
\hline Ratio of isomers & $\begin{array}{l}(1 \mathrm{R}, \text { trans }):(1 \mathrm{R}, \mathrm{cis}):(1 \mathrm{~S}, \\
\text { trans):(1S, cis })=3: 2: 3: 2^{\mathrm{e}}\end{array}$ & Mixed isomers & $\begin{array}{l}20-30 \%(1 \mathrm{RS}) \text {-cis- } \\
\text { isomers } \\
80-70 \%(1(\mathrm{RS}) \text {-trans- } \\
\text { isomers) }\end{array}$ \\
\hline Registered trade name(s) & $\begin{array}{l}\text { Ambush, Assithrin, } \\
\text { Cliper, Coopex, Corsair, } \\
\text { Dragnet, Dragon, Kafil, } \\
\text { Eksmin, Perkill, Pounce }\end{array}$ & Sumithrin & Synthrin, Chrysron \\
\hline Chemical formula & $\mathrm{C}_{21} \mathrm{H}_{20} \mathrm{Cl}_{2} \mathrm{O}_{3}$ & $\mathrm{C}_{23} \mathrm{H}_{26} \mathrm{O}_{3}$ & $\mathrm{C}_{22} \mathrm{H}_{26} \mathrm{O}_{3}$ \\
\hline \multicolumn{4}{|l|}{ Chemical structure } \\
\hline \multicolumn{4}{|l|}{ Identification numbers: } \\
\hline CAS registry & $52645-53-1$ & $26002-80-2$ & $10453-86-8$ \\
\hline NIOSH RTECS ${ }^{c}$ & GZ1255000 & GZ1975000 & GZ1310000 \\
\hline EPA hazardous wasted & No data & No data & No data \\
\hline OHM/TADS & No data & No data & No data \\
\hline DOT/UN/NA/IMCO shipping & No data & No data & No data \\
\hline $\mathrm{HSDB}^{\mathrm{d}}$ & 6740 & 3922 & 6790 \\
\hline $\mathrm{NCl}$ & No data & No data & No data \\
\hline
\end{tabular}




\section{Table 4-2. Chemical Identity of Selected Pyrethroids ${ }^{a}$}

\begin{tabular}{|c|c|c|c|}
\hline Characteristic & Tefluthrin & Tetramethrin & Tralomethrin \\
\hline$\overline{\text { Synonym(s) }}{ }^{b}$ & $\begin{array}{l}\text { [1 } \alpha, 3 \alpha(Z)]-( \pm)-(2,3,5,6- \\
\text { Tetrafluoro-4- } \\
\text { methylphenyl)methyl 3- } \\
\text { (2-chloro-3,3,3-trifluoro- } \\
\text { 1propenyl)-2,2-dimethyl- } \\
\text { cyclopropanecarboxylate }\end{array}$ & $\begin{array}{l}\text { (1,3,4,5,6,7-Hexahydro- } \\
\text { 1,3-dioxo-2H-isoindol-2- } \\
\text { yl)methyl 2,2-dimethyl-3- } \\
\text { (2-methyl-1-propenyl)- } \\
\text { cyclopropanecarboxylate }\end{array}$ & $\begin{array}{l}\text { Cyano(3-phenoxyphenyl)- } \\
\text { methyl 2,2-dimethyl-3- } \\
\text { (1,2,2,2-tetrabromoethyl)- } \\
\text { cyclopropanecarboxylate }\end{array}$ \\
\hline Ratio of isomers & Mixture of isomers & 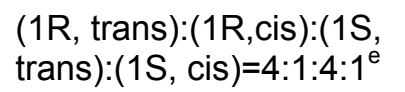 & Unstated stereochemistry \\
\hline Registered trade name(s) & Force, Fireban & Neo-Pynamin, Duracide & $\begin{array}{l}\text { Saga, Scout, Tralox, } \\
\text { Tracker, Tralate }\end{array}$ \\
\hline Chemical formula & $\mathrm{C}_{17} \mathrm{H}_{14} \mathrm{ClF}_{7} \mathrm{O}_{2}$ & $\mathrm{C}_{19} \mathrm{H}_{25} \mathrm{NO}_{4}$ & $\mathrm{C}_{22} \mathrm{H}_{19} \mathrm{Br}_{4} \mathrm{NO}_{3}$ \\
\hline \multicolumn{4}{|l|}{ Chemical structure } \\
\hline \multicolumn{4}{|l|}{ Identification numbers: } \\
\hline CAS registry & $79538-32-2$ & $7696-12-0$ & $66841-25-6$ \\
\hline NIOSH RTECS ${ }^{c}$ & GZ1227850 & GX1730000 & GZ2009500 \\
\hline EPA hazardous waste & No data & No data & No data \\
\hline $\mathrm{OHM} / \mathrm{TADS}$ & No data & No data & No data \\
\hline DOT/UN/NA/IMCO shipping & No data & No data & No data \\
\hline $\mathrm{HSDB}^{\mathrm{d}}$ & No data & 6738 & 6604 \\
\hline $\mathrm{NCl}$ & No data & No data & No data \\
\hline
\end{tabular}

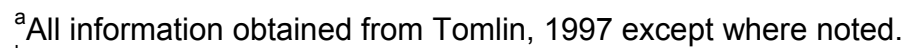

${ }^{\mathrm{b}}$ Chemical names used are those currently indexed by the Chemical Abstracts Service.

${ }^{\mathrm{C}} \mathrm{NIOSH} 1987$

${ }^{\mathrm{d}} \mathrm{HSDB} 2001$

e WHO 2001

CAS = Chemical Abstracts Services; DOT/UN/NA/IMCO = Department of Transportation/United Nations/North America/International Maritime Dangerous Goods Code; EPA = Environmental Protection Agency; HSDB = Hazardous Substances Data Bank; $\mathrm{NCI}=$ National Cancer Institute; $\mathrm{NIOSH}=$ National Institute for Occupational Safety and Health; $\mathrm{OHM} / \mathrm{TADS}=$ Oil and Hazardous Materials/Technical Assistance Data System; RTECS =Registry of Toxic Effects of Chemical Substances 
Figure 4-1. Four Possible Isomers of Type I Pyrethroids

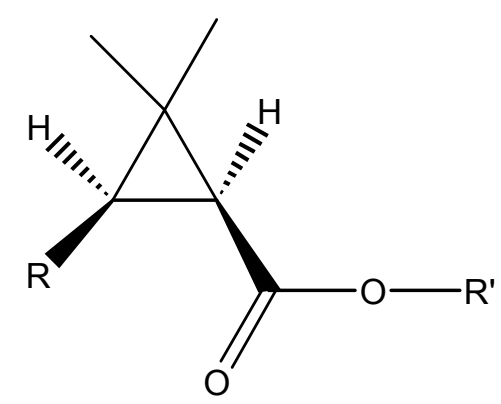

1S cis configuration

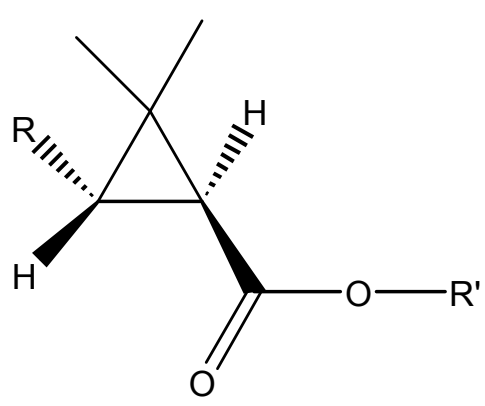

1S trans configuration

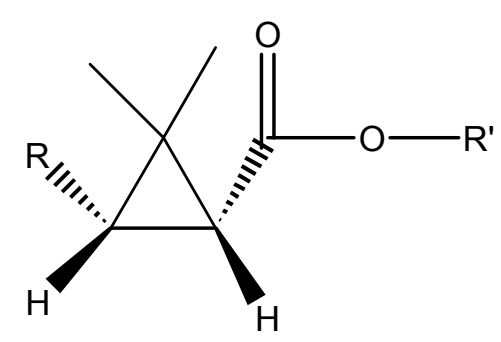

1R cis configuration

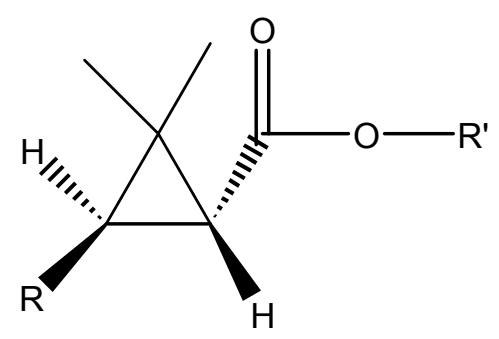

1R trans configuration 
Beasley 1991). Figure 4-2 illustrates the S conformation of the type II pyrethroid cyhalothrin about the alpha carbon. Pyrethroids such as cyfluthrin, cypermethrin, and cyhalothrin possess three chiral centers, and thus consist of eight possible isomers. The production of pyrethroids with differing isomeric ratios is one reason for the wide variation in reported toxicities of these compounds. For example, cypermethrin is formulated as four different insecticides (alpha-, beta-, theta- and zeta-cypermethrin) depending upon the ratio of the different isomers; and each of these products has different toxicologic properties. The complex compositions of several important pyrethroids are illustrated in Table 4-3.

\subsection{PHYSICAL AND CHEMICAL PROPERTIES}

Information regarding the physical and chemical properties of the pyrethrins and selected pyrethroids are located in Tables 4-4 and 4-5, respectively. Generally, pyrethrins and pyrethroids have low vapor pressures, low Henry's law constants, and large octanol/water coefficients $\left(\mathrm{K}_{\mathrm{ow}}\right)$, and are not very soluble in water. Aside from their interaction with polarized light, enantiomers possess identical physical properties (e.g., boiling point, melting point, solubility, etc.). Diastereomers have different physical properties however, and changes in the geometrical isomeric composition can lead to different values in the properties reported for the pyrethroids listed in Table 4-5. 


\section{Table 4-3. Stereoisomers of Selected Pyrethroids ${ }^{a}$}

\begin{tabular}{lll}
\hline Pyrethroid & Different products & Isomer composition \\
\hline Cypermethrin & alpha-cypermethrin & Racemic mixture comprised of: \\
& (S)-alpha-cyano-3-phenoxybenzyl-(1R)-cis-3-(2,2- \\
& dichlorovinyl)-2,2-dimethylcyclopropanecarboxylate \\
& and (R)-alpha-cyano-3-phenoxybenzyl-(1S)-cis-3-(2,2- \\
& dichlorovinyl)-2,2-dimethylcyclopropanecarboxylate \\
& Mixture comprised of two enantiomeric pairs in a 2:3 \\
& ratio: \\
& (S)-alpha-cyano-3-phenoxybenzyl-(1R)-cis-3-(2,2- \\
& dichlorovinyl)-2,2-dimethylcyclopropanecarboxylate \\
& and (R)-alpha-cyano-3-phenoxybenzyl-(1S)-cis-3-(2,2- \\
& dichlorovinyl)-2,2-dimethylcyclopropanecarboxylate \\
& with (S)-alpha-cyano-3-phenoxybenzyl-(1R)-trans-3- \\
& (2,2-dichlorovinyl)-2,2-dimethylcyclopropane- \\
& carboxylate and (R)-alpha-cyano-3-phenoxybenzyl- \\
& (1S)-trans-3-(2,2-dichlorovinyl)-2,2-dimethylcyclo- \\
& propanecarboxylate \\
& Racemic mixture comprised of: \\
& (S)-alpha-cyano-3-phenoxybenzyl-(1R)-trans-3-(2,2- \\
& dichlorovinyl)-2,2-dimethylcyclopropanecarboxylate \\
& and (R)-alpha-cyano-3-phenoxybenzyl-(1S)-trans-3- \\
& (2,2-dichlorovinyl)-2,2-dimethylcyclopropane- \\
& carboxylate \\
& Mixture of the stereoisomers: \\
& (S)-alpha-cyano-3- \\
& phenoxybenzyl(1RS,3RS;1RS,3SR)-3-(2,2- \\
& dichlorovinyl)-2,2-dimethylcyclopropanecarboxylate \\
& where the ratio of the (S); (1RS,3RS) isomeric pair to \\
& the (S);(1RS,3SR) isomeric pair lies in the range of \\
& $45-55$ to 55-45. \\
&
\end{tabular}


4. CHEMICAL AND PHYSICAL INFORMATION

\section{Table 4-3. Stereoisomers of Selected Pyrethroids ${ }^{a}$}

\begin{tabular}{|c|c|c|}
\hline Pyrethroid & Different products & Isomer composition \\
\hline \multirow[t]{7}{*}{ Cyfluthrin } & cyfluthrin & $\begin{array}{l}\text { Comprised of a mixture of the } 4 \text { diastereomeric pairs } \\
\text { of enantiomers: }\end{array}$ \\
\hline & & $\begin{array}{l}\mathrm{I}=(\mathrm{R}) \text {-alpha-cyano-4-fluoro-3-phenoxybenzyl-(1R)- } \\
\text { cis -3-(2,2-dichlorovinyl)-2,2-dimethylcyclopropane- } \\
\text { carboxylate + (S)-alpha, (1S)-cis }\end{array}$ \\
\hline & & $\begin{array}{l}\text { II = (S)-alpha-cyano-4-fluoro-3-phenoxybenzyl-(1R)- } \\
\text { cis -3-(2,2-dichlorovinyl)-2,2-dimethylcyclopropane- } \\
\text { carboxylate }+(\mathrm{R}) \text {-alpha, }(1 \mathrm{~S}) \text {-cis }\end{array}$ \\
\hline & & $\begin{array}{l}\mathrm{III}=(\mathrm{R}) \text {-alpha-cyano-4-fluoro-3-phenoxybenzyl-(1R)- } \\
\text { trans -3-(2,2-dichlorovinyl)-2,2-dimethylcyclopropane- } \\
\text { carboxylate + (S)-alpha, (1S)-trans }\end{array}$ \\
\hline & & $\begin{array}{l}\text { IV }=(\mathrm{S}) \text {-alpha-cyano-4-fluoro-3-phenoxybenzyl-(1R)- } \\
\text { trans -3-(2,2-dichlorovinyl)-2,2-dimethylcyclopropane- } \\
\text { carboxylate }+(\mathrm{R}) \text {-alpha, (1S)-trans }\end{array}$ \\
\hline & & $\begin{array}{l}\text { The technical grade product consists of } 23-26 \% \text { I, } 16- \\
19 \% \text { II, } 33-36 \% \text { III and } 22-25 \% \text { IV. }\end{array}$ \\
\hline & beta-cyfluthrin & Mixture of II and IV in a 1:2 ratio. \\
\hline \multirow[t]{2}{*}{ Cyhalothrin } & cyhalothrin & $\begin{array}{l}\text { (RS)-alpha-cyano-3-phenoxybenzyl (Z) (1RS)-cis-3- } \\
\text { (2-chloro-3,3,3-trifluoropropenyl)-2,2-dimethylcyclo- } \\
\text { propanecarboxylate }\end{array}$ \\
\hline & lambda-cyhalothrin & $\begin{array}{l}\text { Racemic mixture comprised of: } \\
\text { (S)-alpha-cyano-3-phenoxybenzyl (Z) (1R)-cis-3-(2- } \\
\text { chloro-3,3,3-trifluoropropenyl)-2,2-dimethylcyclo- } \\
\text { propanecarboxylate and (R)-alpha-cyano-3- } \\
\text { phenoxybenzyl (Z) (1S)-cis-3-(2-chloro-3,3,3- } \\
\text { trifluoropropenyl)-2,2-dimethylcyclopropane- } \\
\text { carboxylate }\end{array}$ \\
\hline
\end{tabular}

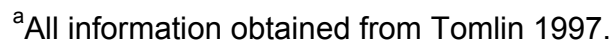


4. CHEMICAL AND PHYSICAL INFORMATION

Table 4-4. Physical and Chemical Properties of Pyrethrins ${ }^{a}$

\begin{tabular}{|c|c|c|c|}
\hline Property & Pyrethrin I & Cinerin I & Jasmolin I \\
\hline Molecular weight & 328.5 & 316.4 & 330.5 \\
\hline Color & No data & No data & No data \\
\hline Physical state & Viscous liquid $^{\mathrm{b}}$ & No data & No data \\
\hline Melting point, ${ }^{\circ} \mathrm{C}$ & No data & No data & No data \\
\hline Boiling point, ${ }^{\circ} \mathrm{C}$ & $\begin{array}{l}146-150 \text { at } 0.0005 \mathrm{~mm}^{\mathrm{Hg}} \\
\mathrm{Hg}, 170 \text { at } 0.1 \mathrm{~mm} \mathrm{Hg}\end{array}$ & $\begin{array}{l}136-138 \text { at } 0.008 \mathrm{~mm} \\
\mathrm{Hg}^{\mathrm{d}}\end{array}$ & No data \\
\hline Density, $\mathrm{g} / \mathrm{cm}^{3}$ at $25{ }^{\circ} \mathrm{C}$ & $1.51\left(18^{\circ} \mathrm{C}\right)$ & No data & No data \\
\hline Odor & No data & No data & No data \\
\hline \multicolumn{4}{|l|}{ Odor threshold: } \\
\hline $\begin{array}{l}\text { Water } \\
\text { Air }\end{array}$ & $\begin{array}{l}\text { No data } \\
\text { No data }\end{array}$ & $\begin{array}{l}\text { No data } \\
\text { No data }\end{array}$ & $\begin{array}{l}\text { No data } \\
\text { No data }\end{array}$ \\
\hline \multicolumn{4}{|l|}{ Solubility: } \\
\hline $\begin{array}{l}\text { Water, mg/L } \\
\text { Organic solvent(s) }\end{array}$ & $\begin{array}{l}0.2 \\
\text { Soluble }\end{array}$ & $\begin{array}{l}\text { Insoluble } \\
\text { Soluble }\end{array}$ & $\begin{array}{l}0.03^{i} \\
\text { No data }\end{array}$ \\
\hline \multicolumn{4}{|l|}{ Partition coefficients: } \\
\hline $\log \mathrm{K}_{\mathrm{ow}}$ & 5.9 & $5.93^{\mathrm{i}}$ & $6.42^{\mathrm{i}}$ \\
\hline $\begin{array}{l}\text { Vapor pressure, } \mathrm{mm} \\
\mathrm{Hg} \text { at } 25^{\circ} \mathrm{C}\end{array}$ & $2.03 \times 10^{-5}$ & $1.1 \times 10^{-6 i}$ & $4.8 \times 10^{-7 i}$ \\
\hline $\begin{array}{l}\text { Henry's Law constant, } \\
\text { atm- } \mathrm{m}^{3} / \mathrm{mol} \text { at } 25^{\circ} \mathrm{C}\end{array}$ & $7.7 \times 10^{-7 i}$ & $9.6 \times 10^{-7 i}$ & $1.3 \times 10^{-6 i}$ \\
\hline $\begin{array}{l}\text { Autoignition } \\
\text { temperature }\end{array}$ & No data & No data & No data \\
\hline $\begin{array}{l}\text { Flashpoint, }{ }^{\circ} \mathrm{C} \\
\text { (Pensky-Martens } \\
\text { closed cup) }\end{array}$ & No data & No data & No data \\
\hline Flammability limits, ${ }^{\circ} \mathrm{C}$ & No data & No data & No data \\
\hline \multicolumn{4}{|l|}{ Conversion factors } \\
\hline $\operatorname{Air}\left(25^{\circ} \mathrm{C} 1\right)^{\mathrm{e}}$ & $1 \mathrm{mg} / \mathrm{m}^{3}=0.074 \mathrm{ppm}$ & $1 \mathrm{mg} / \mathrm{m}^{3}=0.077 \mathrm{ppm}$ & $1 \mathrm{mg} / \mathrm{m}^{3}=0.074 \mathrm{ppm}$ \\
\hline Explosive limits & No data & No data & No data \\
\hline
\end{tabular}


Table 4-4. Physical and Chemical Properties of Pyrethrins ${ }^{a}$

\begin{tabular}{|c|c|c|c|}
\hline Property & Pyrethrin II & Cinerin II & Jasmolin II \\
\hline Molecular weight & 372.5 & 360.4 & 357.7 \\
\hline Color & No data & No data & No data \\
\hline Physical state & Viscous liquid $^{b}$ & Viscous oil $^{b}$ & No data \\
\hline Melting point, ${ }^{\circ} \mathrm{C}$ & No data & No data & No data \\
\hline Boiling point, ${ }^{\circ} \mathrm{C}$ & $\begin{array}{l}192-193 \text { at } 0.007 \mathrm{~mm} \mathrm{Hg} \\
200 \text { at } 0.1 \mathrm{~mm} \mathrm{Hg}^{\mathrm{c}}\end{array}$ & $\begin{array}{l}182-184 \text { at } 0.001 \mathrm{~mm} \\
\mathrm{Hg}\end{array}$ & No data \\
\hline Density, $\mathrm{g} / \mathrm{cm}^{3}$ at $25^{\circ} \mathrm{C}$ & No data & No data & No data \\
\hline Odor & No data & No data & No data \\
\hline \multicolumn{4}{|l|}{ Odor threshold: } \\
\hline $\begin{array}{l}\text { Water } \\
\text { Air }\end{array}$ & $\begin{array}{l}\text { No data } \\
\text { No data }\end{array}$ & $\begin{array}{l}\text { No data } \\
\text { No data }\end{array}$ & $\begin{array}{l}\text { No data } \\
\text { No data }\end{array}$ \\
\hline \multicolumn{4}{|l|}{ Solubility: } \\
\hline $\begin{array}{l}\text { Water, mg/L } \\
\text { Organic solvent(s) }\end{array}$ & $\begin{array}{l}9.0 \\
\text { Soluble }\end{array}$ & $\begin{array}{l}\text { Insoluble } \\
\text { Soluble }\end{array}$ & $\begin{array}{l}0.09^{i} \\
\text { No data }\end{array}$ \\
\hline \multicolumn{4}{|l|}{ Partition coefficients: } \\
\hline $\log \mathrm{K}_{\mathrm{ow}}$ & 4.3 & $4.98^{\mathrm{i}}$ & $5.47^{\mathrm{i}}$ \\
\hline $\begin{array}{l}\text { Vapor pressure, } \mathrm{mm} \mathrm{Hg} \\
\text { at } 25^{\circ} \mathrm{C}\end{array}$ & $3.98 \times 10^{-7}$ & $4.6 \times 10^{-7 i}$ & $1.9 \times 10^{-7 i}$ \\
\hline $\begin{array}{l}\text { Henry's Law constant, } \\
\text { atm- } \mathrm{m}^{3} / \mathrm{mol} \text { at } 25^{\circ} \mathrm{C}\end{array}$ & $7.4 \times 10^{-10 i}$ & $9.2 \times 10^{-10 \mathrm{i}}$ & $1.2 \times 10^{-9 i}$ \\
\hline $\begin{array}{l}\text { Autoignition } \\
\text { temperature }\end{array}$ & No data & No data & No data \\
\hline $\begin{array}{l}\text { Flashpoint, }{ }^{\circ} \mathrm{C} \text { (Pensky- } \\
\text { Martens closed cup) }\end{array}$ & No data & No data & No data \\
\hline Flammability limits, ${ }^{\circ} \mathrm{C}$ & No data & No data & No data \\
\hline \multicolumn{4}{|l|}{ Conversion factors } \\
\hline $\operatorname{Air}\left(25^{\circ} \mathrm{C} 1\right)^{\mathrm{e}}$ & $1 \mathrm{mg} / \mathrm{m}^{3}=0.066 \mathrm{ppm}$ & $1 \mathrm{mg} / \mathrm{m}^{3}=0.068 \mathrm{ppm}$ & $1 \mathrm{mg} / \mathrm{m}^{3}=0.065 \mathrm{ppm}$ \\
\hline Explosive limits & No data & No data & No data \\
\hline
\end{tabular}

\footnotetext{
${ }^{a}$ All information obtained from HSDB 2001 except where noted

${ }^{\mathrm{b}}$ Technical grade

${ }^{\mathrm{c}}$ Tomlin 1997

dBudavari 1996

${ }^{9}$ USDA 2001a

${ }^{\mathrm{e}}$ These air conversion factors were calculated by using the average molecular weight and ideal gas law.

'Milne 1995

${ }^{\mathrm{h}}$ Howard and Meylan 1997

'Estimated value from EPIWIN (Syracuse Research Corporation)
} 
Table 4-5. Physical and Chemical Properties of Selected Pyrethroids ${ }^{a}$

\begin{tabular}{|c|c|c|c|}
\hline Property & Allethrin & Bifenthrin & Bioresmethrin $^{b}$ \\
\hline Molecular weight & 302.4 & 422.9 & 338.4 \\
\hline Color & Pale yellow ${ }^{b, c}$ & Light brown ${ }^{c}$ & Yellow to brown ${ }^{c}$ \\
\hline Physical state & Viscous liquid & Viscous oil & Viscous liquid $^{\mathrm{C}}$ \\
\hline Melting point, ${ }^{\circ} \mathrm{C}$ & $\sim 4$ & $68-70$ & $71.5-83^{d}$ \\
\hline Boiling point, ${ }^{\circ} \mathrm{C}$ & 281.5 & No data & Dec. $>180$ \\
\hline Density, $\mathrm{g} / \mathrm{cm}^{3}$ at $25^{\circ} \mathrm{C}$ & $1.01\left(25^{\circ} \mathrm{C}\right)$ & $1.212\left(25^{\circ} \mathrm{C}\right)$ & $1.050\left(20^{\circ} \mathrm{C}\right)$ \\
\hline Odor & No data & No data & No data \\
\hline $\begin{array}{l}\text { Odor threshold: } \\
\text { Water } \\
\text { Air } \\
\text { Solubility: }\end{array}$ & $\begin{array}{l}\text { No data } \\
\text { No data }\end{array}$ & $\begin{array}{l}\text { No data } \\
\text { No data }\end{array}$ & $\begin{array}{l}\text { No data } \\
\text { No data }\end{array}$ \\
\hline $\begin{array}{l}\text { Water, } \mathrm{mg} / \mathrm{L} \\
\text { Organic solvent(s) }\end{array}$ & $\begin{array}{l}4.6\left(25^{\circ} \mathrm{C}\right) \\
\text { Soluble }\end{array}$ & $\begin{array}{l}0.1 \\
\text { Soluble }\end{array}$ & $\begin{array}{l}<0.3\left(25^{\circ} \mathrm{C}\right) \\
\text { Soluble }\end{array}$ \\
\hline $\begin{array}{l}\text { Partition coefficients: } \\
\text { Log } \mathrm{K}_{\mathrm{ow}} \\
\text { Vapor pressure, } \mathrm{mm} \mathrm{Hg} \text { at } 25^{\circ} \mathrm{C}\end{array}$ & $\begin{array}{l}4.8 \\
1.2 \times 10^{-6}\left(21^{\circ} \mathrm{C}\right)\end{array}$ & $\begin{array}{l}6^{\mathrm{e}} \\
1.8 \times 10^{-4 d}\end{array}$ & $\begin{array}{l}>4.7 \\
1.4 \times 10^{-8}\end{array}$ \\
\hline $\begin{array}{l}\text { Henry's Law constant, atm- } \\
\mathrm{m}^{3} / \mathrm{mol} \text { at } 25^{\circ} \mathrm{C} \\
\text { Autoignition temperature }\end{array}$ & $\begin{array}{l}6.1 \times 10^{-7 i} \\
\text { No data }\end{array}$ & $\begin{array}{l}<1.0 \times 10^{-3 d} \\
\text { No data }\end{array}$ & $\begin{array}{l}1.3 \times 10^{-7 f} \\
\text { No data }\end{array}$ \\
\hline $\begin{array}{l}\text { Flashpoint, }{ }^{\circ} \mathrm{C} \text { (Pensky-Martens } \\
\text { closed cup) }\end{array}$ & $87^{b}$ & $165^{b}$ & $92^{b}$ \\
\hline Flammability limits & No data & No data & No data \\
\hline $\begin{array}{l}\text { Conversion factors } \\
\text { Air }\left(25^{\circ} \mathrm{C} 1\right)^{\mathrm{g}} \\
\text { Explosive limits }\end{array}$ & $\begin{array}{l}1 \mathrm{mg} / \mathrm{m}^{3}=0.081 \mathrm{ppm} \\
\text { No data }\end{array}$ & $\begin{array}{l}1 \mathrm{mg} / \mathrm{m}^{3}=0.058 \mathrm{ppm} \\
\text { No data }\end{array}$ & $\begin{array}{l}1 \mathrm{mg} / \mathrm{m}^{3}=0.072 \mathrm{ppm} \\
\text { No data }\end{array}$ \\
\hline
\end{tabular}




\section{Table 4-5. Physical and Chemical Properties of Selected Pyrethroids ${ }^{a}$}

\begin{tabular}{|c|c|c|c|}
\hline Property & Cyfluthrin & Cyhalothrin & Cypermethrin \\
\hline Molecular weight $^{c}$ & 453.3 & 449.9 & 416.3 \\
\hline Color & Yellowish brown ${ }^{c}$ & Yellow-brown ${ }^{c}$ & Yellow brown $n^{b, c}$ \\
\hline Physical state & Oil $(A)$ & Viscous liquid $^{c}$ & Viscous semi-solid ${ }^{b, c}$ \\
\hline Melting point, ${ }^{\circ} \mathrm{C}$ & $60(A)$ & $49.2^{g}$ & 80.5 \\
\hline Boiling point, ${ }^{\circ} \mathrm{C}$ & No data & $187-190$ & No data \\
\hline Density, $\mathrm{g} / \mathrm{cm}^{3}$ at $25^{\circ} \mathrm{C}$ & No data & 1.25 & 1.25 \\
\hline Odor & Aromatic & Mild & Odorless \\
\hline \multicolumn{4}{|l|}{ Odor threshold: } \\
\hline Water & No data & No data & No data \\
\hline Air & No data & No data & No data \\
\hline \multicolumn{4}{|l|}{ Solubility: } \\
\hline Water, mg/L & $0.002\left(20^{\circ} \mathrm{C}\right)^{g}$ & $0.003\left(20^{\circ} \mathrm{C}\right)$ & $0.004\left(20^{\circ} \mathrm{C}\right)$ \\
\hline Organic solvent(s) & Soluble & Soluble & Soluble \\
\hline \\
\hline $\begin{array}{l}\log \mathrm{K}_{\mathrm{ow}} \\
\text { Vapor pressure, } \mathrm{mm} \mathrm{Hg} \text { at } 25^{\circ} \mathrm{C}\end{array}$ & $\begin{array}{l}5.94 \\
2.03 \times 10^{-9 d}\end{array}$ & $\begin{array}{l}6.9 \\
1.5 \times 10^{-9}\left(20{ }^{\circ} \mathrm{C}\right)^{d}\end{array}$ & $\begin{array}{l}6.6 \\
3.07 \times 10^{-9}\left(20^{\circ} \mathrm{C}\right)\end{array}$ \\
\hline $\begin{array}{l}\text { Henry's Law constant, atm- } \\
\mathrm{m}^{3} / \mathrm{mol} \text { at } 25{ }^{\circ} \mathrm{C}\end{array}$ & $9.5 \times 10^{-7 h}$ & $1.8 \times 10^{-7 d}$ & $4.2 \times 10^{-7 d}$ \\
\hline Autoignition temperature & No data & No data & No data \\
\hline $\begin{array}{l}\text { Flashpoint, }{ }^{\circ} \mathrm{C} \text { (Pensky-Martens } \\
\text { closed cup) }\end{array}$ & $107^{\mathrm{b}}$ & $>100^{b}$ & No data \\
\hline Flammability limits, ${ }^{\circ} \mathrm{C}$ & No data & No data & No data \\
\hline \multicolumn{4}{|l|}{ Conversion factors } \\
\hline Explosive limits & $\begin{array}{l}1 \mathrm{mg} / \mathrm{m}=0.054 \mathrm{ppm} \\
\text { No data }\end{array}$ & $\begin{array}{l}1 \mathrm{mg} / \mathrm{m}=0.054 \mathrm{ppm} \\
\text { No data }\end{array}$ & $\begin{array}{l}1 \mathrm{mg} / \mathrm{m}=0.059 \mathrm{ppm} \\
\text { No data }\end{array}$ \\
\hline
\end{tabular}


4. CHEMICAL AND PHYSICAL INFORMATION

Table 4-5. Physical and Chemical Properties of Selected Pyrethroids ${ }^{a}$

\begin{tabular}{|c|c|c|c|}
\hline Property & Deltamethrin & Esfenvalerate & Fenpropathrin \\
\hline Molecular weight $^{\mathrm{C}}$ & 505.2 & 419.9 & 349.4 \\
\hline Color & Colorless & Colorless & Yellow brown ${ }^{c}$ \\
\hline Physical state & Crystals & Crystals & Solid $^{\mathrm{C}}$ \\
\hline Melting point, ${ }^{\circ} \mathrm{C}$ & $101-102$ & $59-60.2$ & $45-50$ \\
\hline Boiling point, ${ }^{\circ} \mathrm{C}$ & No data & $151-167$ & No data \\
\hline Density, $\mathrm{g} / \mathrm{cm}^{3}$ at $25^{\circ} \mathrm{C}$ & $0.55^{b}$ & 1.175 & $1.15\left(25^{\circ} \mathrm{C}\right)$ \\
\hline Odor & Odorless & No data & No data \\
\hline $\begin{array}{l}\text { Odor threshold: } \\
\text { Water } \\
\text { Air }\end{array}$ & $\begin{array}{l}\text { No data } \\
\text { No data }\end{array}$ & $\begin{array}{l}\text { No data } \\
\text { No data }\end{array}$ & $\begin{array}{l}\text { No data } \\
\text { No data }\end{array}$ \\
\hline $\begin{array}{l}\text { Solubility: } \\
\text { Water, mg/L } \\
\text { Organic solvent(s) }\end{array}$ & $\begin{array}{l}<0.002 \\
\text { Soluble }\end{array}$ & $\begin{array}{l}0.0002\left(25^{\circ} \mathrm{C}\right) \\
\text { Soluble }\end{array}$ & $\begin{array}{l}0.014\left(25^{\circ} \mathrm{C}\right)^{\mathrm{d}} \\
\text { Soluble }\end{array}$ \\
\hline $\begin{array}{l}\text { Partition coefficients: } \\
\text { Log } \mathrm{K}_{\text {ow }} \\
\text { Vapor pressure, } \mathrm{mm} \mathrm{Hg} \text { at } 25^{\circ} \mathrm{C}\end{array}$ & $\begin{array}{l}6.1 \\
1.5 \times 10^{-8}\end{array}$ & $\begin{array}{l}4.0 \\
1.5 \times 10^{-9}\end{array}$ & $\begin{array}{l}6.0\left(20^{\circ} \mathrm{C}\right) \\
5.5 \times 10^{-6}\left(20^{\circ} \mathrm{C}\right)\end{array}$ \\
\hline $\begin{array}{l}\text { Henry's Law constant, atm- } \\
\mathrm{m}^{3} / \mathrm{mol} \text { at } 25^{\circ} \mathrm{C} \\
\text { Autoignition temperature }\end{array}$ & $\begin{array}{l}1.2 \times 10^{-4} \\
\text { No data }\end{array}$ & $\begin{array}{l}4.1 \times 10^{-7 d} \\
\text { No data }\end{array}$ & $\begin{array}{l}1.8 \times 10^{-4 g} \\
\text { No data }\end{array}$ \\
\hline $\begin{array}{l}\text { Flashpoint, }{ }^{\circ} \mathrm{C} \text { (Pensky-Martens } \\
\text { closed cup) }\end{array}$ & No data & $256^{\mathrm{b}}$ & No data \\
\hline Flammability limits, ${ }^{\circ} \mathrm{C}$ & No data & No data & No data \\
\hline $\begin{array}{l}\text { Conversion factors } \\
\text { Air }\left(25^{\circ} \mathrm{C} 1\right)^{\mathrm{g}} \\
\text { Explosive limits }\end{array}$ & $\begin{array}{l}1 \mathrm{mg} / \mathrm{m}^{3}=0.048 \mathrm{ppm} \\
\text { No data }\end{array}$ & $\begin{array}{l}1 \mathrm{mg} / \mathrm{m}^{3}=0.058 \mathrm{ppm} \\
\text { No data }\end{array}$ & $\begin{array}{l}1 \mathrm{mg} / \mathrm{m}^{3}=0.070 \mathrm{ppm} \\
\text { No data }\end{array}$ \\
\hline
\end{tabular}


4. CHEMICAL AND PHYSICAL INFORMATION

Table 4-5. Physical and Chemical Properties of Selected Pyrethroids ${ }^{a}$

\begin{tabular}{|c|c|c|c|}
\hline Property & Flucythrinate & Flumethrin $^{b}$ & Fluvalinate \\
\hline Molecular weight $^{\mathrm{C}}$ & 451.5 & 510.4 & 502.9 \\
\hline Color & Dark amber ${ }^{b, c}$ & Yellowish $^{c}$ & Yellow-amber ${ }^{c}$ \\
\hline Physical state & Viscous liquid ${ }^{\mathrm{C}}$ & Viscous oil ${ }^{c}$ & Viscous liquid $^{c}$ \\
\hline Melting point, ${ }^{\circ} \mathrm{C}$ & No data & No data & No data \\
\hline Boiling point, ${ }^{\circ} \mathrm{C}$ & 108 at $0.35 \mathrm{~mm} \mathrm{Hg}$ & $>250$ & $\begin{array}{l}>450 \\
164 \text { at } 0.07 \mathrm{~mm} \mathrm{Ha}^{\mathrm{b}}\end{array}$ \\
\hline Density, $\mathrm{g} / \mathrm{cm}^{3}$ at $25^{\circ} \mathrm{C}$ & $1.189\left(22^{\circ} \mathrm{C}\right)$ & No data & 1.29 \\
\hline Odor & No data & No data & No data \\
\hline $\begin{array}{l}\text { Odor threshold: } \\
\text { Water } \\
\text { Air }\end{array}$ & $\begin{array}{l}\text { No data } \\
\text { No data }\end{array}$ & $\begin{array}{l}\text { No data } \\
\text { No data }\end{array}$ & $\begin{array}{l}\text { No data } \\
\text { No data }\end{array}$ \\
\hline $\begin{array}{l}\text { Solubility: } \\
\text { Water, mg/L } \\
\text { Organic solvent(s) }\end{array}$ & $\begin{array}{l}0.5\left(21^{\circ} \mathrm{C}\right) \\
\text { Soluble }\end{array}$ & $\begin{array}{l}9.7 \times 10^{-5 f} \\
\text { No data }\end{array}$ & $\begin{array}{l}0.002 \\
\text { Soluble }\end{array}$ \\
\hline $\begin{array}{l}\text { Partition coefficients: } \\
\text { Log } \mathrm{K}_{\mathrm{ow}} \\
\text { Vapor pressure, } \mathrm{mm} \mathrm{Hg} \text { at } 25^{\circ} \mathrm{C}\end{array}$ & $\begin{array}{l}4.7^{d} \\
8.5 \times 10^{-9 d}\end{array}$ & $\begin{array}{l}7.65^{\mathrm{i}} \\
3.9 \times 10^{-9 f}\end{array}$ & $\begin{array}{l}4.26^{g} \\
5.7 \times 10^{-7 d}\end{array}$ \\
\hline $\begin{array}{l}\text { Henry's Law constant, atm- } \\
\mathrm{m}^{3} / \mathrm{mol} \text { at } 25^{\circ} \mathrm{C}\end{array}$ & $8.47 \times 10^{-8 d}$ & $4.2 \times 10^{-8 f}$ & $3.05 \times 10^{-5 d}$ \\
\hline Autoignition temperature & No data & No data & No data \\
\hline $\begin{array}{l}\text { Flashpoint, }{ }^{\circ} \mathrm{C} \text { (Pensky-Martens } \\
\text { closed cup) }\end{array}$ & No data & No data & $90^{c}$ \\
\hline Flammability limits, ${ }^{\circ} \mathrm{C}$ & No data & No data & No data \\
\hline $\begin{array}{l}\text { Conversion factors } \\
\text { Air }\left(25^{\circ} \mathrm{C} 1\right)^{\mathrm{e}} \\
\text { Explosive limits }\end{array}$ & $\begin{array}{l}1 \mathrm{mg} / \mathrm{m}^{3}=0.054 \mathrm{ppm} \\
\text { No data }\end{array}$ & $\begin{array}{l}1 \mathrm{mg} / \mathrm{m}^{3}=0.048 \mathrm{ppm} \\
\text { No data }\end{array}$ & $\begin{array}{l}1 \mathrm{mg} / \mathrm{m}^{3}=0.049 \mathrm{ppm} \\
\text { No data }\end{array}$ \\
\hline
\end{tabular}




\section{Table 4-5. Physical and Chemical Properties of Selected Pyrethroids ${ }^{a}$}

\begin{tabular}{|c|c|c|c|}
\hline Property & Permethrin & Phenothrin & Resmethrin \\
\hline Molecular weight $^{c}$ & 391.3 & 350.5 & 338.4 \\
\hline Color & Colorless to yellow ${ }^{c}$ & Colorless & Colorless \\
\hline Physical state & $\begin{array}{l}\text { Crystals to viscous } \\
\text { liquid }^{c}\end{array}$ & Liquid & Crystals \\
\hline Melting point, ${ }^{\circ} \mathrm{C}$ & $34-35$ & No data & 56.5 \\
\hline Boiling point, ${ }^{\circ} \mathrm{C}$ & 220 at $0.05 \mathrm{~mm} \mathrm{Hg}^{f}$ & $>290$ & Dec. at $>180{ }^{\circ} \mathrm{C}$ \\
\hline Density, $\mathrm{g} / \mathrm{cm}^{3}$ at $25^{\circ} \mathrm{C}$ & $1.19-1.27\left(20^{\circ} \mathrm{C}\right)$ & 1.061 & $0.96-0.97\left(20^{\circ} \mathrm{C}\right)$ \\
\hline Odor & No data & No data & Chrysanthemate \\
\hline \multicolumn{4}{|l|}{ Odor threshold: } \\
\hline Water & No data & No data & No data \\
\hline Air & No data & No data & No data \\
\hline \multicolumn{4}{|l|}{ Solubility: } \\
\hline Water, mg/L & $0.006\left(20^{\circ} \mathrm{C}\right)$ & $2.0\left(30^{\circ} \mathrm{C}\right)$ & $0.037\left(25^{\circ} \mathrm{C}\right)^{\mathrm{b}}$ \\
\hline Organic solvent(s) & Soluble & Soluble & Soluble \\
\hline \multicolumn{4}{|l|}{ Partition coefficients: } \\
\hline Log $K_{o w}$ & 6.5 & $7.54^{f}$ & 5.43 \\
\hline $\begin{array}{l}\text { Vapor pressure, } \mathrm{mm} \mathrm{Hg} \\
\text { at } 25^{\circ} \mathrm{C}\end{array}$ & $2.2 \times 10^{-8}$ & $1.4 \times 10^{-7 b}$ & $1.13 \times 10^{-8 i}$ \\
\hline $\begin{array}{l}\text { Henry's Law constant, } \\
\text { atm- } \mathrm{m}^{3} / \mathrm{mol} \text { at } 25{ }^{\circ} \mathrm{C}\end{array}$ & $1.9 \times 10^{-6 d}$ & $1.4 \times 10^{-6 f}$ & $<8.9 \times 10^{7 d}$ \\
\hline $\begin{array}{l}\text { Autoignition } \\
\text { temperature }\end{array}$ & No data & No data & No data \\
\hline $\begin{array}{l}\text { Flashpoint, }{ }^{\circ} \mathrm{C} \text { (Pensky- } \\
\text { Martens closed cup) }\end{array}$ & $>100^{b}$ & $107^{b}$ & $129^{b}$ \\
\hline Flammability limits, ${ }^{\circ} \mathrm{C}$ & No data & No data & No data \\
\hline $\begin{array}{l}\text { Conversion factors } \\
\text { Air }\left(25^{\circ} \mathrm{C} 1\right)^{\mathrm{e}} \\
\text { Explosive limits }\end{array}$ & $\begin{array}{l}1 \mathrm{mg} / \mathrm{m}^{3}=0.062 \mathrm{ppm} \\
\text { No data }\end{array}$ & $\begin{array}{l}1 \mathrm{mg} / \mathrm{m}^{3}=0.070 \mathrm{ppm} \\
\text { No data }\end{array}$ & $\begin{array}{l}1 \mathrm{mg} / \mathrm{m}^{3}=0.072 \mathrm{ppm} \\
\text { No data }\end{array}$ \\
\hline
\end{tabular}




\section{Table 4-5. Physical and Chemical Properties of Selected Pyrethroids ${ }^{a}$}

\begin{tabular}{|c|c|c|c|}
\hline Property & Tefluthrin $^{b}$ & Tetramethrin & Tralomethrin \\
\hline Molecular weight & 418.7 & 331.4 & 665.0 \\
\hline Color & Colorless & Colorless & Yellow orange \\
\hline Physical state & Solid & Crystals & Resinoid \\
\hline Melting point, ${ }^{\circ} \mathrm{C}$ & 44.6 & $65-80$ & $138-148$ \\
\hline Boiling point, ${ }^{\circ} \mathrm{C}$ & 153 at $1 \mathrm{~mm} \mathrm{Hg}$ & $180-190$ & No data \\
\hline Density, $\mathrm{g} / \mathrm{cm}^{3}$ at $25^{\circ} \mathrm{C}$ & 1.48 & $1.1\left(20^{\circ} \mathrm{C}\right)$ & $1.70\left(20{ }^{\circ} \mathrm{C}\right)$ \\
\hline Odor & No data & No data & No data \\
\hline \multicolumn{4}{|l|}{ Odor threshold: } \\
\hline Water & No data & No data & No data \\
\hline Air & No data & No data & No data \\
\hline \multicolumn{4}{|l|}{ Solubility: } \\
\hline Water, mg/L & $0.002\left(20^{\circ} \mathrm{C}\right)$ & $1.83^{b}$ & 0.08 \\
\hline Organic solvent(s) & Soluble & Soluble & Soluble \\
\hline \multicolumn{4}{|l|}{ Partition coefficients: } \\
\hline $\begin{array}{l}\text { Log } \mathrm{K}_{\mathrm{ow}} \\
\text { Vapor pressure, } \mathrm{mm} \mathrm{Hg} \\
\text { at } 25^{\circ} \mathrm{C}\end{array}$ & $\begin{array}{l}6.5 \\
6.0 \times 10^{-5}\end{array}$ & $\begin{array}{l}4.6^{\mathrm{c}} \\
7.1 \times 10^{-6 \mathrm{~b}}\end{array}$ & $\begin{array}{l}7.6^{f} \\
3.6 \times 10^{-11}\end{array}$ \\
\hline $\begin{array}{l}\text { Henry's Law constant, } \\
\text { atm- } \mathrm{m}^{3} / \mathrm{mol} \text { at } 25^{\circ} \mathrm{C}\end{array}$ & $4.6 \times 10^{-4 f}$ & $8.3 \times 10^{-9 f}$ & $3.9 \times 10^{-15 d}$ \\
\hline $\begin{array}{l}\text { Autoignition } \\
\text { temperature }\end{array}$ & No data & No data & No data \\
\hline $\begin{array}{c}\text { Flashpoint, }{ }^{\circ} \mathrm{C} \text { (Pensky- } \\
\text { Martens open cup) }\end{array}$ & 124 & No data & No data \\
\hline Flammability limits, ${ }^{\circ} \mathrm{C}$ & No data & No data & No data \\
\hline $\begin{array}{l}\text { Conversion factors } \\
\text { Air }\left(25^{\circ} \mathrm{C} 1\right)^{g} \\
\text { Explosive limits }\end{array}$ & $\begin{array}{l}1 \mathrm{mg} / \mathrm{m}^{3}=0.058 \mathrm{ppm} \\
\text { No data }\end{array}$ & $\begin{array}{l}1 \mathrm{mg} / \mathrm{m}^{3}=0.074 \mathrm{ppm} \\
\text { No data }\end{array}$ & $\begin{array}{l}1 \mathrm{mg} / \mathrm{m}^{3}=0.074 \mathrm{ppm} \\
\text { No data }\end{array}$ \\
\hline
\end{tabular}

${ }^{a}$ All information obtained from HSDB 2001 except where noted

${ }^{\mathrm{b}}$ Tomlin 1997

${ }^{\mathrm{c}}$ Technical grade

dUSDA 2001a

e Milne 1995

${ }^{f}$ Estimated value from EPIWIN (Syracuse Research Corporation)

${ }^{9}$ These air conversion factors were calculated by using the average molecular weight and ideal gas law

hudavari 1996

iHoward and Meylan 1997 
4. CHEMICAL AND PHYSICAL INFORMATION

Figure 4-2. Illustration of the S Conformer about the Alpha Carbon for the Type II Pyrethroid Cyhalothrin

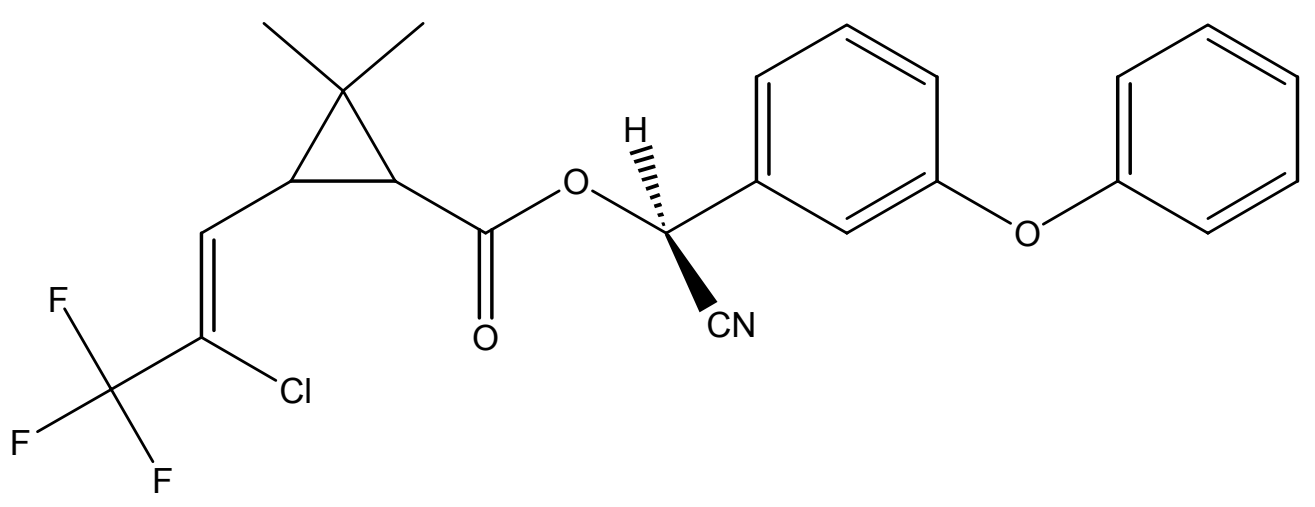




\section{PRODUCTION, IMPORT/EXPORT, USE, AND DISPOSAL}

\subsection{PRODUCTION}

Information regarding the manufacturers of various pyrethrins and pyrethroids in the United States is given in Table 5-1 (SRI 2000). Table 5-2 lists the number of facilities in each state that produce, process, or import pyrethrins and pyrethroids for commercial use. The intended use and the range of maximum amounts of these substances that are stored on site are also included. The data listed in these tables are derived from the Toxics Release Inventory (TRI99 2001). Only certain types of facilities were required to report, and this is not an exhaustive list. The only pyrethroids that are on the list are allethrin, bifenthrin, cyfluthrin, cyhalothrin, fenpropathrin, fluvalinate, permethrin, phenothrin, resmethrin, and tetramethrin (TRI99 2001). Furthermore, data have only been reported for bifenthrin, cyfluthrin, permethrin, resmethrin, and tetramethrin. No data regarding the production volumes are available.

Naturally-occurring pyrethrins are produced by certain species of chrysanthemum plants (Chrysanthemum cinerariaefolium and Chrysanthemum cineum). Either the flowers are dried and powdered or the oils within the flowers are extracted with solvents such as petroleum ether, acetone, or acetic acid (Metcalf 1995). Synthetic pyrethroids are manufactured by the esterification of an appropriate acid with an appropriate alcohol (Table 5-3).

Technical-grade (concentrated) pyrethroids are usually formulated for use in commercial products. The formulated product may contain up to $99 \%$ inert ("secret") ingredients that improve storing, application handling, or effectiveness. The EPA publishes a complete list of all inert ingredients found in pesticide products registered in the United States, and categorizes them along the following four classes: (1) inert ingredients of toxicological concern; (2) potentially toxic inert ingredients; (3) inert ingredients of unknown toxicity; and (4) inerts of minimal concern (EPA 2003). Even though the EPA publishes a list of all inert ingredients used in currently registered pesticides, it does not specify which ingredients are contained in any specific formulated product, and federal law does not require the pesticide label to identity the inert ingredients unless they are categorized as class one inert ingredients. A common formulation used in pyrethrin and pyrethroid products is an emulsifiable concentrate (EC). The primary inert ingredients in a pesticide product formulated as an EC are an emulsifier and a petroleum solvent, such as kerosene. Other popular formulations are aerosol dispenser (AE), wettable powder (WP), dustable powder (DP), and water dispersible granules (WG) (Tomlin 1997). 
5. PRODUCTION, IMPORT/EXPORT, USE, AND DISPOSAL

Table 5-1. U.S. Producers of Pyrethrins and Pyrethroids

\begin{tabular}{lll}
\hline Pyrethroid & Producer & Production site \\
\hline Bifenthrin & FMC Corporation & Baltimore, Maryland \\
Cyfluthrin & Bayer Corporation & Kansas City, Missouri; Shawnee, Kansas \\
Cypermethrin & Astra Zeneca & Cold Creek, Alabama \\
& FMC Corporation & Baltimore, Maryland \\
Esfenvalerate & Du Pont & Axis, Alabama \\
Fluvalinate & BASF Corporation & Beaumont, Texas \\
Permethrin & Astra Zeneca & Cold Creek, Alabama \\
& FMC Corporation & Baltimore, Maryland \\
Pyrethrins (Pyrethrum) & McLaughlin Gormley King & Chaska, Minnesota \\
& SureCo Incorporated & Fort Valley, Georgia \\
\hline
\end{tabular}

Source: SRI 2000 


\section{Table 5-2. Facilities that Produce, Process, or Use Pyrethroids}

\begin{tabular}{|c|c|c|c|c|}
\hline State $^{a}$ & $\begin{array}{l}\text { Number of } \\
\text { facilities }\end{array}$ & $\begin{array}{l}\text { Minimum amount } \\
\text { on site in pounds }\end{array}$ & $\begin{array}{l}\text { Maximum amount } \\
\text { on site in pounds }\end{array}$ & Activities and uses ${ }^{\circ}$ \\
\hline \multicolumn{5}{|c|}{ Bifenthrin } \\
\hline $\mathrm{FL}$ & 1 & 100,000 & 999,999 & 8 \\
\hline IL & 1 & 10,000 & 99,999 & 8 \\
\hline $\mathrm{TX}$ & 1 & 10,000 & 99,999 & $2,3,8$ \\
\hline \multicolumn{5}{|c|}{ Cyfluthrin } \\
\hline MO & 1 & 100,000 & 999,999 & 8 \\
\hline $\mathrm{TX}$ & 1 & 10,000 & 99,999 & 8 \\
\hline \multicolumn{5}{|c|}{ Permethrin } \\
\hline$A L$ & 1 & 100,000 & 999,999 & 1,4 \\
\hline AR & 1 & 10,000 & 99,999 & 8 \\
\hline $\mathrm{FL}$ & 1 & $1,000,000$ & $9,999,999$ & 8 \\
\hline GA & 1 & 100,000 & 999,999 & 8 \\
\hline IL & 1 & 10,000 & 99,999 & 8 \\
\hline LA & 1 & 1,000 & 9,999 & 8 \\
\hline MD & 1 & $1,000,000$ & $9,999,999$ & 1,4 \\
\hline NJ & 1 & 1,000 & 9,999 & 8 \\
\hline $\mathrm{TN}$ & 1 & 10,000 & 99,999 & 8 \\
\hline $\mathrm{TX}$ & 2 & 10,000 & 99,999 & $2,3,8,10$ \\
\hline WI & 1 & 10,000 & 99,999 & 8 \\
\hline \multicolumn{5}{|c|}{ Resmethrin } \\
\hline $\mathrm{TX}$ & 1 & 10,000 & 99,999 & 8 \\
\hline \multicolumn{5}{|c|}{ Tetramethrin } \\
\hline WI & 1 & 10,000 & 99,999 & 8 \\
\hline
\end{tabular}

${ }^{\text {ap }}$ ost office state abbreviations used

${ }^{\mathrm{b}}$ Amounts on site reported by facilities in each state

${ }^{\mathrm{c}}$ Activities/Uses:
1. Produce
6. Impurity
2. Import
7. Reactant
10. Repackaging
3. Onsite use/processing
8. Formulation Component
11. Chemical Processing Aid
4. Sale/Distribution
9. Article Component
12. Manufacturing Aid
5. Byproduct
13. Ancillary/Other Uses

Source: TRI99 2001 
5. PRODUCTION, IMPORT/EXPORT, USE, AND DISPOSAL

Table 5-3. Acid and Alcohol Feedstocks in the Pyrethroids Synthesis

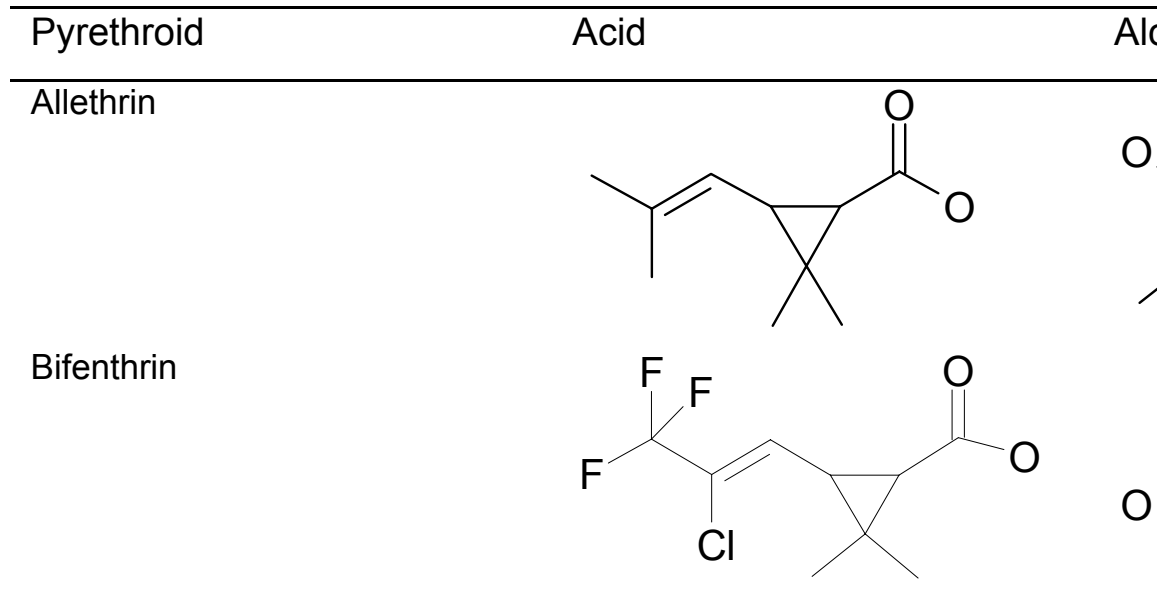

Bioresmethrin<smiles>CC(C)=CC1C(C(=O)O)C1(C)C</smiles><smiles>OCc1coc(Cc2ccccc2)c1</smiles>

Cyfluthrin<smiles>CC1(C)C(C=C(Cl)Cl)C1C(=O)O</smiles><smiles>N#CC(O)c1ccc(F)c(Oc2ccccc2)c1</smiles>

Cyhalothrin<smiles>CC(C)(C/C=C(\Cl)C(F)(F)F)CC(O)Cl</smiles><smiles>O=CO</smiles>

Cypermethrin<smiles>CC1(C)C(C=C(Br)Br)C1C(=O)O</smiles><smiles>N#CC(O)c1cccc(Oc2ccccc2)c1</smiles> 
Table 5-3. Acid and Alcohol Feedstocks in the Pyrethroids Synthesis

Esfenvalerate

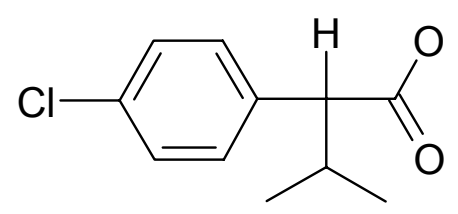<smiles>N#CC(O)c1cccc(Oc2ccccc2)c1</smiles>

Fenproparthrin

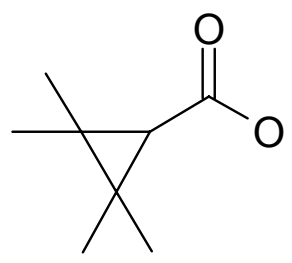<smiles>N#CC(O)c1cccc(Oc2ccccc2)c1</smiles>

Flucythrinate
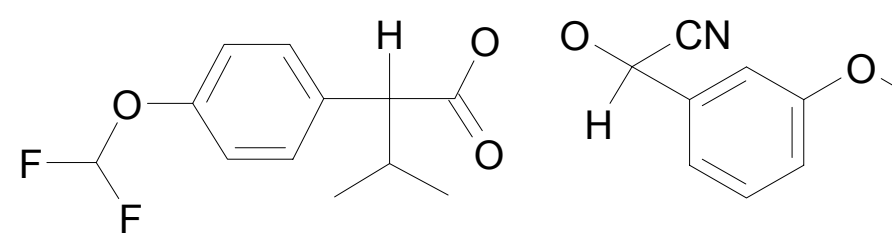

Flumethrin<smiles>CC1(C)C(C=Cc2ccc(Cl)cc2)C1C(=O)O</smiles><smiles>N#CC(O)c1ccc(F)c(Oc2ccccc2)c1</smiles>

Fluvalinate

$\mathrm{F}_{3} \mathrm{C}$<smiles>CC(C)C(O)C(N)=O</smiles>

Permethrin<smiles>CC1(C)C(C=C(Cl)Cl)C1C(=O)O</smiles><smiles>OCc1cccc(Oc2ccccc2)c1</smiles> 
Table 5-3. Acid and Alcohol Feedstocks in the Pyrethroids Synthesis

Phenothrin

Resmethrin<smiles>CC(C)=CC1C(C(=O)O)C1(C)C</smiles>

Tefluthrin

Tralomethrin<smiles>CC1(C)C(C(=O)O)C1C(Br)Br</smiles>

Tetramethrin<smiles>CC(C)=CC1C(C(=O)O)C1(C)C</smiles>

O

O<smiles>OCc1cccc(Oc2ccccc2)c1</smiles><smiles>CC1(C)C(C=C(Cl)C(F)(F)F)C1C(=O)O</smiles>

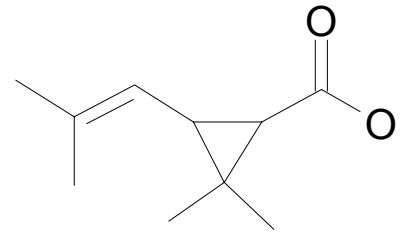<smiles>OCc1coc(Cc2ccccc2)c1</smiles><smiles>Cc1c(F)c(F)c(C(O)C#N)c(F)c1F</smiles><smiles>N#CC(O)c1cccc(Oc2ccccc2)c1</smiles>

$\mathrm{O}$<smiles>C1CCC2=C(C1)CNC2</smiles> 


\section{$5.2 \quad$ IMPORT/EXPORT}

No data regarding the import or export volumes of pyrethrins and pyrethroids are available.

\subsection{USE}

Naturally-occurring pyrethrins were first used around 1800 in the Transcaucasus region of Asia to control human lice, mosquitoes, cockroaches, beetles, and flies. Pyrethroids are broad-spectrum insecticides, effective against a wide range of flying, crawling, chewing, and sucking insects of the orders Coleoptera, Diptera, Hemiptera (Homoptera and Heteroptera), Hymenoptera, Lepidoptera, Orthoptera, and Thysanoptera. They are used as household insecticides, as grain protectants, and to control pests on edible products just prior to harvest (Metcalf 1989). They are used in a variety of locations including residential, public, and commercial buildings, animal houses, warehouses, fields, and green houses. They are also extensively used in the field of veterinary medicine (Davies 1985).

All concentrated formulations of pyrethroids were classified as restricted use pesticides by the EPA in 1995 (EPA 2000a). This classification restricts a pesticide to be used only by a certified applicator, or under the direct supervision of a certified applicator. Detailed information regarding the amounts applied and use of individual pyrethroids is provided in Table 5-4. The data shown in Table 5-4 were developed from state-wide estimates of pesticide use rates on cropland and do not include pesticide applications to noncropland areas (i.e., home use, greenhouse use, etc.).

\subsection{DISPOSAL}

All pyrethrins and pyrethroids as well as piperonyl butoxide are listed as toxic substances under Section 313 of the Emergency Planning and Community Right to Know Act (EPCRA) under Title III of the Superfund Amendments and Reauthorization Act (SARA) (EPA 1995). Disposal of wastes containing these compounds is controlled by a number of federal regulations (see Chapter 8). According to the TRI, in 1999, an estimated 1,239 pounds of permethrin were transferred off-site, presumably for disposal (TRI99 2001). No other pyrethroids or pyrethrins were reported as having off-site transfers in 1999 (TRI99 2001). 
Table 5-4. Uses of Pyrethroids

\begin{tabular}{|c|c|c|c|c|}
\hline Pyrethroid & $\begin{array}{l}\text { Amount }^{a} \\
\text { (pounds) }\end{array}$ & Insects $^{b, c, d}$ & Crops $^{b, c, d}$ & $\begin{array}{l}\text { Other locations } \\
\text { and applications }{ }^{\mathrm{b}, \mathrm{c}}\end{array}$ \\
\hline Allethrin & NA & $\begin{array}{l}\text { Flies, mosquitoes, } \\
\text { ants }\end{array}$ & $\mathrm{N} / \mathrm{A}$ & $\begin{array}{l}\text { Residential, public } \\
\text { health, animal } \\
\text { houses, topical } \\
\text { application in pet } \\
\text { sprays and } \\
\text { shampoos }\end{array}$ \\
\hline Bifenthrin & 114,377 & $\begin{array}{l}\text { Beetles, weevils, } \\
\text { houseflies, } \\
\text { mosquitoes, lice, } \\
\text { bedbugs, aphids, } \\
\text { moths, cockroaches, } \\
\text { locusts }\end{array}$ & $\begin{array}{l}\text { Alfalfa hay, beans, } \\
\text { cantaloupes, cereals, corn, } \\
\text { cotton, field and grass seed, } \\
\text { hops, melons, oilseed rape, } \\
\text { potatoes, peas, raspberries, } \\
\text { watermelons, squash }\end{array}$ & NA \\
\hline Bioresmethrin & NA & $\begin{array}{l}\text { Houseflies, } \\
\text { mosquitoes, } \\
\text { cockroaches }\end{array}$ & NA & $\begin{array}{l}\text { Household, public } \\
\text { health, animal } \\
\text { houses }\end{array}$ \\
\hline Cyfluthrin & 151,422 & $\begin{array}{l}\text { Aphids, cabbage } \\
\text { stem flea beetle, } \\
\text { cockroaches house } \\
\text { flies, mosquitoes, } \\
\text { rape winter stem } \\
\text { weevil }\end{array}$ & $\begin{array}{l}\text { Alfalfa, cereals, cotton, citrus, } \\
\text { deciduous fruit, ground nuts, } \\
\text { maize, oilseed rape, pears, } \\
\text { potatoes, rice, sugar beet, } \\
\text { sugarcane, tobacco, } \\
\text { vegetables }\end{array}$ & Green houses \\
\hline Cyhalothrin & NA & $\begin{array}{l}\text { Bedbugs, beetles, } \\
\text { houseflies, ked, lice, } \\
\text { mosquitoes, moths, } \\
\text { weevils }\end{array}$ & N/A & $\begin{array}{l}\text { Public health, animal } \\
\text { houses, inert } \\
\text { surfaces }\end{array}$ \\
\hline Cypermethrin & 215,066 & $\begin{array}{l}\text { Cockroaches, flies, } \\
\text { mosquitoes, moths }\end{array}$ & $\begin{array}{l}\text { Cotton, lettuce, onions, pears, } \\
\text { peaches, pecans, sugar beets }\end{array}$ & $\begin{array}{l}\text { Residential and } \\
\text { commercial } \\
\text { buildings, animal } \\
\text { houses }\end{array}$ \\
\hline Deltamethrin & NA & $\begin{array}{l}\text { Aphids, beetles, boll- } \\
\text { worm, bud-worm, } \\
\text { caterpillars, cicadas, } \\
\text { codling moths, tortrix } \\
\text { moths, weevils, } \\
\text { whitefly, winter } \\
\text { moths }\end{array}$ & $\begin{array}{l}\text { Alfalfa, beet, cereals, coffee, } \\
\text { cotton, figs, fruits, hops, maize, } \\
\text { oilseed rape, olives, oil palms, } \\
\text { potatoes, rice, soybeans, } \\
\text { sunflowers, tea, tobacco, } \\
\text { vegetables }\end{array}$ & $\begin{array}{l}\text { Forests, households, } \\
\text { animal houses, } \\
\text { stored products }\end{array}$ \\
\hline Esfenvalerate & 215,919 & Beetles, moths & $\begin{array}{l}\text { Cabbage, corn, cotton, fruit } \\
\text { trees, grains, groundnuts, } \\
\text { maize, pecan, potatoes, } \\
\text { sorghum, soybeans, sugar } \\
\text { cane, sunflowers, sweet corn, } \\
\text { tomatoes, vegetables, wheats }\end{array}$ & $\begin{array}{l}\text { Ornamentals, non- } \\
\text { crop land }\end{array}$ \\
\hline
\end{tabular}


Table 5-4. Uses of Pyrethroids

\begin{tabular}{|c|c|c|c|c|}
\hline Pyrethroid & $\begin{array}{l}\text { Amount }^{\mathrm{a}} \\
\text { (pounds) }\end{array}$ & Insects ${ }^{b, c, d}$ & Crops $^{b, c, d}$ & $\begin{array}{l}\text { Other locations } \\
\text { and applications }{ }^{\mathrm{b}, \mathrm{c}}\end{array}$ \\
\hline Fenproparthrin & 146,707 & $\begin{array}{l}\text { Aphids, armyworms, } \\
\text { bollworms, bud- } \\
\text { worms, cabbage } \\
\text { looper, cabbage- } \\
\text { worms, cutworms, } \\
\text { diamondback moth, } \\
\text { fruit moths, leaf- } \\
\text { miners, leafrollers, } \\
\text { leaf-worms, } \\
\text { lepidopterous larvae, } \\
\text { mites, mosquito, } \\
\text { psyllas, stem-borers, } \\
\text { ticks, tortrixies, } \\
\text { tuber-worms, } \\
\text { whiteflies }\end{array}$ & $\begin{array}{l}\text { Cotton, citrus, fruits, pome, } \\
\text { tomatoes, vegetables, vines }\end{array}$ & $\begin{array}{l}\text { Glasshouse, } \\
\text { ornamental trees }\end{array}$ \\
\hline Flucythrinate & NA & $\begin{array}{l}\text { Boll-worms, leaf- } \\
\text { worms, sucking } \\
\text { insects, whiteflies, } \\
\text { beetles }\end{array}$ & $\begin{array}{l}\text { Cotton, vines, strawberries, } \\
\text { citrus fruit, bananas, } \\
\text { pineapples, olives, coffee, } \\
\text { cocoa, hops, vegetables, } \\
\text { soybeans, cereals, maize, } \\
\text { alfalfa, sugarbeet, sunflowers, } \\
\text { tobacco }\end{array}$ & NA \\
\hline Flumethrin & NA & $\begin{array}{l}\text { Lice, ticks, psoroptic, } \\
\text { chorioptic and } \\
\text { sarcoptic munge }\end{array}$ & NA & NA \\
\hline Fenvalerate & 61,582 & $\begin{array}{l}\text { Beetles, } \\
\text { cockroaches, flies, } \\
\text { locusts, mosquitos, } \\
\text { moths }\end{array}$ & $\begin{array}{l}\text { Alfalfa hay, apples, beet, } \\
\text { cereals, cotton, corn, } \\
\text { cucurbita, fruit, green beans, } \\
\text { groundnuts, hops, maize, nuts, } \\
\text { oilseed rape, olives, potatoes, } \\
\text { sorghum, soybeans, squash, } \\
\text { sugarcane, sunflower, } \\
\text { vegetables, vines, tobacco }\end{array}$ & $\begin{array}{l}\text { Ornamentals, } \\
\text { forestry, non-crop } \\
\text { land }\end{array}$ \\
\hline Fluvalinate & NA & $\begin{array}{l}\text { Aphids, leaf- } \\
\text { hoppers, moths, } \\
\text { spider mites, thrips, } \\
\text { white-flies }\end{array}$ & $\begin{array}{l}\text { Apples, cereals, cotton, pears, } \\
\text { peaches, tobacco, vegetables, } \\
\text { vines }\end{array}$ & $\begin{array}{l}\text { Outdoor and indoor } \\
\text { ornamentals, turf }\end{array}$ \\
\hline Permethrin & $1,055,097$ & $\begin{array}{l}\text { Ants, beetle, boll- } \\
\text { worm, bud-worm, } \\
\text { fleas, flies, lice, } \\
\text { moths, mosquitos, } \\
\text { termites, weevils }\end{array}$ & $\begin{array}{l}\text { Alfalfa hay, corn, cotton, } \\
\text { grains, lettuce, onion, } \\
\text { peaches, potatoes, sweet } \\
\text { corn, tomatoes, wheat }\end{array}$ & $\begin{array}{l}\text { Home gardens, } \\
\text { green houses, pet } \\
\text { sprays, and } \\
\text { shampoos }\end{array}$ \\
\hline Phenotrhin & NA & $\begin{array}{l}\text { Ants, bedbugs, } \\
\text { cockroaches, fleas, } \\
\text { houseflies, lice, } \\
\text { mosquitoes, ticks }\end{array}$ & NA & $\begin{array}{l}\text { Public buildings, } \\
\text { stored grain, pet } \\
\text { sprays, and } \\
\text { shampoos }\end{array}$ \\
\hline Resmethrin & NA & $\begin{array}{l}\text { Flying and crawling } \\
\text { insects, mosquitoes } \\
\text { houseflies, german } \\
\text { cockroaches }\end{array}$ & NA & $\begin{array}{l}\text { Homes, } \\
\text { greenhouses, indoor } \\
\text { landscapes, } \\
\text { mushroom houses, } \\
\text { industrial sites }\end{array}$ \\
\hline
\end{tabular}


5. PRODUCTION, IMPORT/EXPORT, USE, AND DISPOSAL

Table 5-4. Uses of Pyrethroids

\begin{tabular}{|c|c|c|c|c|}
\hline Pyrethroid & $\begin{array}{l}\text { Amount }^{\mathrm{a}} \\
\text { (pounds) }\end{array}$ & Insects ${ }^{b, c, d}$ & Crops $^{b, c, d}$ & $\begin{array}{l}\text { Other locations } \\
\text { and applications }\end{array}$ \\
\hline Tefluthrin & 423,973 & $\begin{array}{l}\text { Beetles, houseflies, } \\
\text { mosquitoes moths, } \\
\text { weevils }\end{array}$ & $\begin{array}{l}\text { Corn, maize, sugar beet, } \\
\text { sweet corn }\end{array}$ & $\overline{N A}$ \\
\hline Tetramethrin & NA & $\begin{array}{l}\text { Flies, cockroaches, } \\
\text { mosquitoes, wasps }\end{array}$ & NA & $\begin{array}{l}\text { Public health, home } \\
\text { and garden use }\end{array}$ \\
\hline Tralomethrin & 53,331 & $\begin{array}{l}\text { Aphids, beetles, } \\
\text { cockroaches, moths, } \\
\text { weevils }\end{array}$ & $\begin{array}{l}\text { Cereals, coffee, cotton, fruit, } \\
\text { maize, oilseed rape, rice, } \\
\text { soybeans, tobacco, vegetables }\end{array}$ & $\begin{array}{l}\text { Wood protection, } \\
\text { homes, public } \\
\text { health, stored grain, } \\
\text { animal houses }\end{array}$ \\
\hline
\end{tabular}

aUSGS 2001

${ }^{\mathrm{b}} \mathrm{HSDB} 2001$

${ }^{c}$ Metcalf 1995

${ }^{\mathrm{d}}$ Tomlin 1997

$\mathrm{N} / \mathrm{A}=$ not available 
5. PRODUCTION, IMPORT/EXPORT, USE, AND DISPOSAL

The EPA Office of Pesticide Programs has detailed labels for the use, storage, and disposal of all pesticides, including registered products containing pyrethrins and pyrethroids. All pesticide products are required to bear instructions for the storage and disposal of the pesticides and the pesticide containers. Storage and disposal instructions cover the appropriate storage of the pesticide product; disposal of any unused pesticide product or any rinse liquids resulting from cleaning of pesticide application equipment; and the disposal of the pesticide container. State and local regulations may be stricter than the federal requirements listed on the label. 



\section{POTENTIAL FOR HUMAN EXPOSURE}

\subsection{OVERVIEW}

Pyrethrins and pyrethroids have been identified in at least 5 and 2 of the 1,636 hazardous waste sites, respectively, that have been proposed for inclusion on the EPA National Priorities List (NPL) (HazDat 2003). However, the number of sites evaluated for pyrethrins and pyrethroids is not known. The frequency of these sites can be seen in Figure 6-1 and 6-2, respectively. All of these sites are located within the United States.

Pyrethrum is the natural extract derived from the flowers of Chrysanthemum cinerariaefolium and Chrysanthemum cineum (Metcalf 1995). Pyrethrum has long been recognized as possessing insecticidal properties, and the manufacture of flea and louse powders employing this extract began in Asia around 1800. The six active insecticidal compounds of pyrethrum are called pyrethrins. The individual pyrethrins are pyrethrin I, pyrethrin II, cinerin I, cinerin II, jasmolin I, and jasmolin II. These compounds are esters of two carboxylic acids (chrysanthemic acid and pyrethric acid) and three cyclopentenolones (pyrethrolone, cinerolone, and jasmolone). See Chapter 4 for the structures as well as the chemical and physical properties of these compounds. Synthetic pyrethroids are a diverse class of over 1,000 powerful insecticides that are structurally similar to the pyrethrins (Mueller-Beilschmidt 1990). Although they are based on the chemical structure and biological activity of the pyrethrins, the development of synthetic pyrethroids has involved extensive chemical modifications that make these compounds more toxic and less degradable in the environment. Products containing small amounts of pyrethroids for uses around the home are still classified as general use pesticides; however, emulsified or granular concentrate formulations that are applied to fields were classified as restricted use pesticides by the EPA in 1995 (EPA 2000a). The restricted use classification restricts a pesticide to be used only by a certified applicator, or under the direct supervision of a certified applicator. Although many pyrethroids have been developed, less than a dozen are used with any frequency in the United States, with permethrin being the most commonly employed pyrethroid.

Pyrethrins and pyrethroids are released to the environment primarily as a result of their use as insecticides. These compounds are very important insecticides because of their rapid paralysis of flying insects, relatively low mammalian toxicity, and rapid rate of degradation in the environment. Often, 
6. POTENTIAL FOR HUMAN EXPOSURE

Figure 6-1. Frequency of NPL Sites with Pyrethrins Contamination

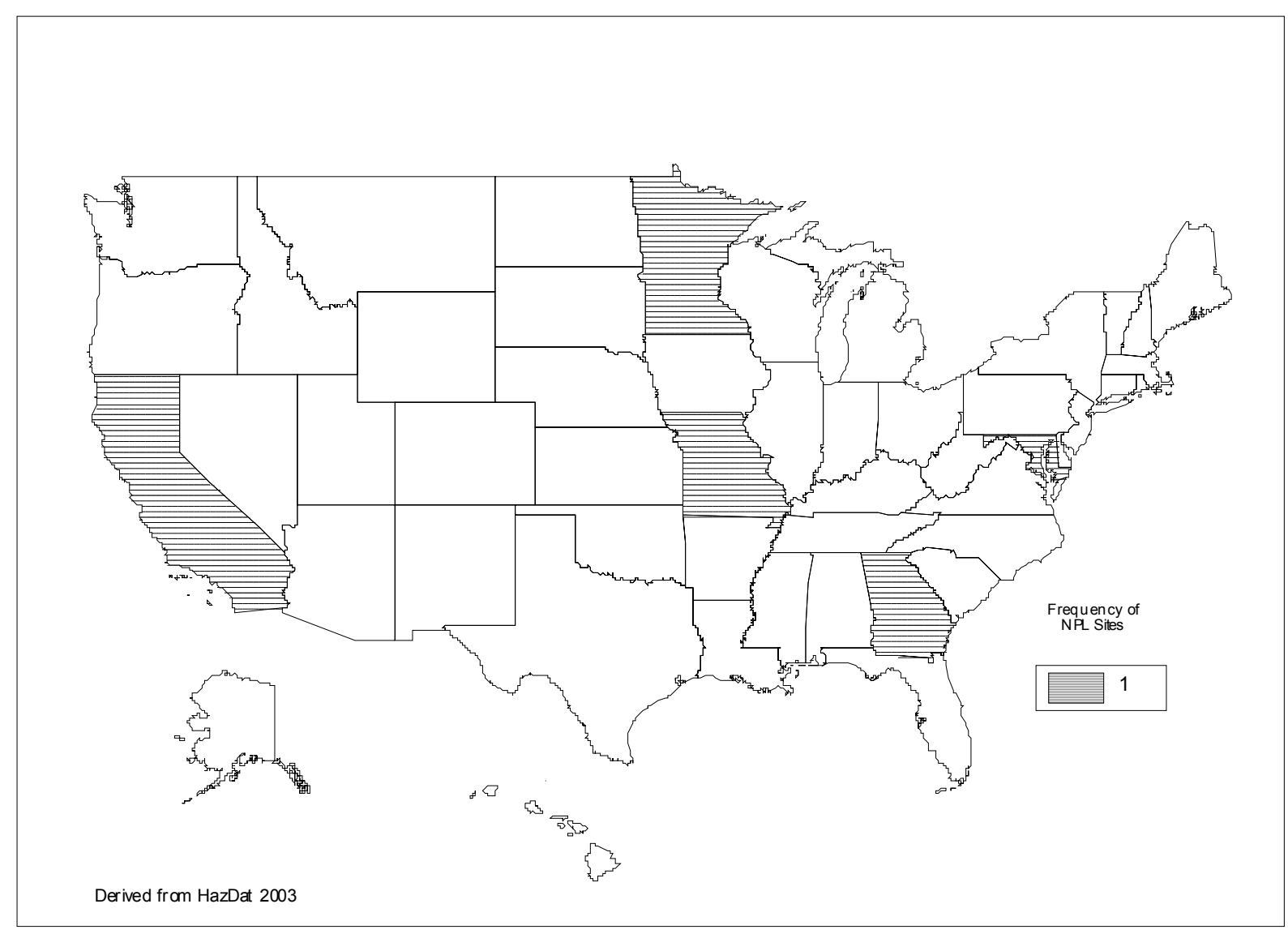


6. POTENTIAL FOR HUMAN EXPOSURE

Figure 6-2. Frequency of NPL Sites with Pyrethroid Contamination

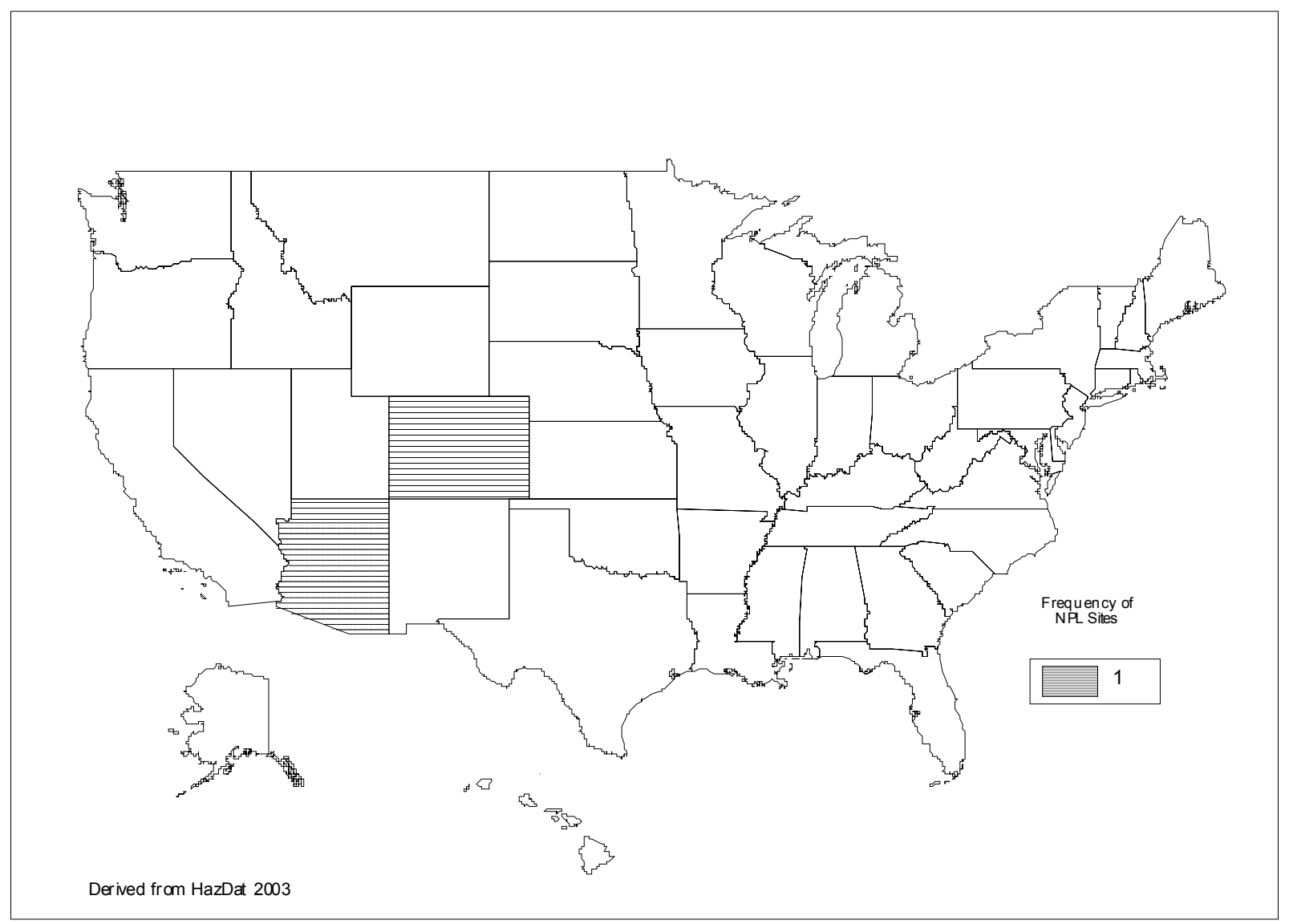


pyrethrins and pyrethroids are formulated with compounds such as piperonyl butoxide, piperonyl sulfoxide, and sesamex, which act as synergists to increase the effectiveness of the insecticide.

Pyrethrins are rapidly detoxified by enzymes of insects, and often, the paralyzed insect may survive and recover neurological function before mortality. The synergists are relatively nontoxic by themselves, but prevent the insect from detoxifying the active insecticide, thus increasing their effectiveness. At sufficient levels, the synergists may also increase the toxicity of pyrethrins and some pyrethroids in mammals. Pyrethrins are largely used indoors against flying insects in sprays, pet shampoos, and aerosol bombs, which contain about $0.04-0.25 \%$ of active ingredient and about $5-10$ times this amount of piperonyl butoxide or other synergists to attenuate detoxification (Metcalf 1989). They also can be employed in multi-purpose insecticides for use on livestock, grains, fruits, and vegetables. Since the pyrethrins are not very stable when exposed to sunlight, their outdoor use on crops has diminished as relatively light-stable pyrethroids have been developed. The different pyrethroids are used in many ways to control a wide variety of insects on crops, pets, and livestock. The toxicity of the pyrethroids is influenced by the isomeric properties of the compound. For pyrethroids possessing the cyclopropane moiety, the trans isomers tend to be rapidly eliminated by mammals and possess less toxicity than the cis isomers. For example, the oral $\mathrm{LD}_{50}$ (rats) of $1 \mathrm{R}$ cis resmethrin is about $168 \mathrm{mg} / \mathrm{kg}$, but the value for the $1 \mathrm{R}$ trans isomer is $>8,000 \mathrm{mg} / \mathrm{kg}$ (Dorman and Beasley 1991). Pyrethroids that contain the alpha-S-cyano phenoxybenzyl alcohol moiety demonstrate considerably greater toxicity when compared to the $\mathrm{R}$ configuration (Dorman and Beasley 1991). The enhanced insecticidal activity of esfenvalerate over fenvalerate is one example of this (Tomlin 1997). Esfenvalerate has become the preferred compound in the United States because it requires lower application rates than fenvalerate and is thus a more powerful insecticide. Esfenvalerate contains a much higher percentage of the alpha-S-cyano phenoxybenzyl alcohol isomer than fenvalerate. For most of the pyrethroids discussed, the approximate isomeric ratios of the technical-grade products have been reported by Tomlin (1997).

Technical-grade (concentrated) pyrethrins and pyrethroids are usually formulated (mixed with carriers and solvents) for use in commercial products, and the toxicity of the formulated commercial product is not necessarily identical to the toxicity of the pure material. Inert ingredients and contaminants in pyrethroid formulations often contain suspected carcinogens or chemicals that depress the central nervous system (Mueller-Beilschmidt 1990). The EPA publishes a complete list of all inert ingredients found in pesticide products registered in the United States, and categorizes them along the following four classes: (1) inert ingredients of toxicological concern; (2) potentially toxic inert ingredients; (3) inert ingredients of unknown toxicity; and (4) inerts of minimal concern (EPA 2003). Under federal law, inert ingredients 
are not required to be disclosed on pesticides labels unless they contain a class one inert ingredient. Even though the EPA publishes a list of all inert ingredients used in currently registered pesticides, it does not specify the identity or quantity of inert ingredients that are used in a specific formulation.

The most important route of exposure to pyrethrins and pyrethroids for the general population is through the ingestion of foods, especially vegetables and fruits that have been sprayed with these insecticides. Farmers, pesticide applicators, and persons using these insecticides on a regular basis may also receive additional exposure through inhalation and dermal contact. Many of these compounds are employed in household products such as pet shampoos, household sprays, mosquito repellents, and lice treatments, and the general population can be exposed to these compounds through these uses.

The natural pyrethrins and many pyrethroids are rapidly degraded in the environment via photolysis, hydrolysis, and biodegradation. The environmental persistence times of many of these compounds are in the range of 1-2 days. The least persistent pyrethroids are allethrin, phenothrin, resmethrin, and tetramethrin. Structural modifications have made certain pyrethroids such as permethrin, cypermethrin, cyfluthrin, cyhalothrin, deltamethrin, fenvalerate, tefluthrin, and tralomethrin more persistent. For this reason, these compounds are utilized more often outdoors on crops than the relatively light-unstable pyrethroids and pyrethrins. Pyrethrins and pyrethroids are extremely toxic to fish and environmentally beneficial insects such as bees. In field situations, the hazard to bees is often lessened because bees are repelled by pyrethroids, which reduces their contact with plant surfaces that have recently been sprayed and decreases the chance of receiving a lethal dose. The natural pyrethrins and several pyrethroids are relatively nontoxic to mammals, but some pyrethroids such as deltamethrin, flucythrinate, cyhalothrin, permethrin, and tefluthrin have demonstrated considerable toxicity (Metcalf 1995). For example, flea applications containing a high concentration of permethrin made for use on dogs have often been associated with the accidental poisoning of cats when improperly used.

In soils, these compounds adsorb strongly and do not leach appreciably into groundwater. These compounds are not considerably taken up by the roots of vascular plants; however, they are deposited upon the leafy region of vegetation following spraying. In general, most of these compounds have relatively low vapor pressures and Henry's law constants, and as a result, volatilization from soil and water surfaces occurs slowly. Volatilization from foliage and household surfaces such as glass windows or floors occurs more rapidly since these compounds do not adhere to these surfaces as strongly in comparison to soils. 


\subsection{RELEASES TO THE ENVIRONMENT}

Pyrethrum is found naturally in the environment as a constituent of Chrysanthemum cinerariaefolium and Chrysanthemum cineum (Metcalf 1995). However, the majority of releases of pyrethrins and pyrethroids are due to their use as insecticides. The estimated amounts of bifenthrin, cyfluthrin, cyhalothrin, cypermethrin, deltamethrin, esfenvalerate, fenpropathrin, fenvalerate, permethrin, tefluthrin, and tralomethrin applied to crops in the United States in 1992 and 1997 are summarized in Table 6-1 (Gianessi and Silvers 2000). No data were identified for any other pyrethroid or any of the pyrethrins. Similar findings have been reported by the United States Geological Survey (USGS) 1992 Census of Agriculture (USGS 2001) (See Table 5-4).

\subsubsection{Air}

Releases to the air represent the most important emission pathway of pyrethrins and pyrethroids. Most applications of these insecticides involve aerial or ground spraying of crops or other vegetation, as well as the use of aerosol bombs and sprays indoors.

Manufacturing facilities may also release pyrethrins and pyrethroids during their production. A list of chemicals has been compiled for which releases are required to be reported to the EPA for the SARA Section 313 Toxics Release Inventory (TRI) (EPA 1995). The only pyrethroids that are on the list are allethrin, bifenthrin, cyfluthrin, cyhalothrin, fenpropathrin, fluvalinate, permethrin, phenothrin, resmethrin, and tetramethrin (TRI99 2001). Furthermore, data have only been reported for bifenthrin, cyfluthrin, permethrin, resmethrin, and tetramethrin. According to the TRI (Table 6-2), an estimated total of 546 pounds of bifenthrin, 16 pounds of cyfluthrin, 2,593 pounds of permethrin, 22 pounds of resmethrin, and 10,080 pounds of tetramethrin were discharged to air from manufacturing and processing facilities in the United States in 1999 (TRI99 2001). The TRI data should be used with caution since only certain types of facilities are required to report. This is not an exhaustive list.

Pyrethrins or pyrethroids were not detected in air at the 1,636 NPL hazardous waste sites (HazDat 2003). 

6. POTENTIAL FOR HUMAN EXPOSURE

Table 6-1. Trends of National Pyrethroid Use

\begin{tabular}{|c|c|c|c|}
\hline Pyrethroid & $\begin{array}{l}\text { Amounts applied } \\
\text { (pounds) } 1992\end{array}$ & $\begin{array}{l}\text { Amounts applied } \\
\text { (pounds) } 1997\end{array}$ & Percent change \\
\hline Bifenthrin & 116,716 & 110,246 & -5 \\
\hline Cyfluthrin & 124,360 & 177,782 & +43 \\
\hline lambda Cyhalothrin & 205,329 & 321,284 & +57 \\
\hline Cypermethrin & 228,082 & 187,991 & -18 \\
\hline Deltamethrin & 0 & 27,045 & \\
\hline Esfenvalerate & 331,522 & 228,885 & -31 \\
\hline Fenpropathrin & 66,368 & 31,839 & -49 \\
\hline Fenvalerate & 66,281 & 0 & -100 \\
\hline Permethrin & $1,068,598$ & $1,066,056$ & -1 \\
\hline Tefluthrin & 238,429 & 576,865 & +142 \\
\hline Tralomethrin & 60,105 & 23,767 & -60 \\
\hline
\end{tabular}

Source: Gianessi and Silvers 2000 


\section{Table 6-2. Releases to the Environment from Facilities that Produce, Process, or} Use Pyrethroids

\begin{tabular}{|c|c|c|c|c|c|c|c|c|}
\hline \multirow[b]{2}{*}{ State $^{b}$} & \multirow[b]{2}{*}{$\begin{array}{l}\text { Number of } \\
\text { facilities }\end{array}$} & \multicolumn{6}{|c|}{ Reported amounts released in pounds per year ${ }^{a}$} & \multirow[b]{2}{*}{$\begin{array}{l}\text { Total on- } \\
\text { and } \\
\text { off-site } \\
\text { release }\end{array}$} \\
\hline & & $\mathrm{Air}^{\mathrm{C}}$ & Water & $\begin{array}{l}\text { Underground } \\
\text { injection }\end{array}$ & Land & $\begin{array}{l}\text { Total on- } \\
\text { site } \\
\text { release }\end{array}$ & $\begin{array}{l}\text { Total off- } \\
\text { site } \\
\text { release }\end{array}$ & \\
\hline \multicolumn{9}{|c|}{ Bifenthrin } \\
\hline FL & 1 & 36 & 0 & No data & No data & 36 & No data & 36 \\
\hline IL & 1 & 10 & No data & No data & No data & 10 & No data & 10 \\
\hline MD & 1 & No data & No data & No data & No data & No data & No data & No data \\
\hline NY & 1 & No data & No data & No data & No data & No data & No data & No data \\
\hline $\mathrm{TX}$ & 1 & 500 & No data & No data & No data & 500 & No data & 500 \\
\hline Total & 5 & 546 & 0 & 0 & 0 & 546 & 0 & 546 \\
\hline \multicolumn{9}{|c|}{ Cyfluthrin } \\
\hline MD & 1 & No data & No data & No data & No data & No data & No data & No data \\
\hline MO & 1 & 11 & 72 & No data & No data & 83 & No data & 83 \\
\hline $\mathrm{NJ}$ & 1 & No data & No data & No data & No data & No data & No data & No data \\
\hline $\mathrm{TX}$ & 2 & 5 & No data & No data & No data & 5 & No data & 5 \\
\hline Total & 5 & 16 & 72 & 0 & 0 & 88 & 0 & 88 \\
\hline \multicolumn{9}{|c|}{ Permethrin } \\
\hline$A L$ & 1 & 497 & 0 & No data & No data & 497 & 4 & 501 \\
\hline AR & 2 & 500 & No data & No data & No data & 500 & 1,235 & 1,735 \\
\hline$A Z$ & 1 & No data & No data & No data & No data & No data & No data & No data \\
\hline $\mathrm{FL}$ & 1 & 193 & 0 & No data & No data & 193 & No data & 193 \\
\hline GA & 2 & 1 & No data & No data & No data & 1 & No data & 1 \\
\hline IL & 2 & 10 & No data & No data & No data & 10 & No data & 10 \\
\hline LA & 2 & 10 & No data & No data & 31,000 & 31,010 & No data & 31,010 \\
\hline MD & 1 & 10 & 0 & No data & No data & 10 & No data & 10 \\
\hline MN & 1 & No data & No data & No data & No data & No data & No data & No data \\
\hline MO & 2 & No data & No data & No data & No data & No data & No data & No data \\
\hline $\mathrm{NJ}$ & 1 & No data & No data & No data & No data & No data & No data & No data \\
\hline $\mathrm{TN}$ & 1 & 751 & No data & No data & No data & 751 & No data & 751 \\
\hline $\mathrm{TX}$ & 4 & 621 & No data & No data & No data & 621 & No data & 621 \\
\hline WI & 1 & 0 & No data & No data & No data & 0 & No data & 0 \\
\hline
\end{tabular}




\section{Table 6-2. Releases to the Environment from Facilities that Produce, Process, or Use Pyrethroids}

\begin{tabular}{|c|c|c|c|c|c|c|c|c|}
\hline \multirow[b]{2}{*}{ State $^{b}$} & \multirow[b]{2}{*}{$\begin{array}{l}\text { Number of } \\
\text { facilities }\end{array}$} & \multicolumn{6}{|c|}{ Reported amounts released in pounds per year ${ }^{a}$} & \multirow[b]{2}{*}{$\begin{array}{l}\text { Total on } \\
\text { and } \\
\text { off-site } \\
\text { release }\end{array}$} \\
\hline & & $\mathrm{Air}^{\mathrm{C}}$ & Water & $\begin{array}{l}\text { Underground } \\
\text { injection }\end{array}$ & Land & $\begin{array}{l}\text { Total on- } \\
\text { site } \\
\text { release }^{d}\end{array}$ & $\begin{array}{l}\text { Total off- } \\
\text { site } \\
\text { release }\end{array}$ & \\
\hline Total & 22 & 2,593 & 0 & 0 & 31,000 & 33,593 & 1,239 & 34,832 \\
\hline
\end{tabular}

Resmethrin

$\begin{array}{rllllllll}\text { GA } & 1 & \text { No data } & \text { No data } & \text { No data } & \text { No data } & \text { No data } & \text { No data } & \text { No data } \\ \text { MO } & 1 & \text { No data } & \text { No data } & \text { No data } & \text { No data } & \text { No data } & \text { No data } & \text { No data } \\ \text { TX } & 1 & 22 & \text { No data } & \text { No data } & \text { No data } & 22 & \text { No data } & 22 \\ \text { Total } & 3 & 22 & 0 & 0 & 0 & 22 & 0 & 22\end{array}$

Tetramethrin

\begin{tabular}{cclllllll} 
IN & 1 & 10,080 & No data & No data & No data & 10,080 & No data & 10,080 \\
MN & 1 & No data & No data & No data & No data & No data & No data & No data \\
MO & 1 & No data & No data & No data & No data & No data & No data & No data \\
WI & 1 & 0 & No data & No data & No data & 0 & No data & 0 \\
Total & 4 & 10,080 & 0 & 0 & 0 & 10,080 & 0 & 10,080 \\
\hline $\begin{array}{l}\text { Grand } \\
\text { Total }\end{array}$ & 39 & 13,257 & 72 & 0 & 31,000 & 44,329 & 1,239 & 45,568 \\
\hline
\end{tabular}

${ }^{a}$ Data in TRI are maximum amounts released by each facility.

${ }^{\mathrm{b}}$ Post office state abbreviations are used.

${ }^{\mathrm{c}}$ The sum of fugitive and stack releases are included in releases to air by a given facility.

${ }^{\mathrm{d}}$ The sum of all releases of the chemical to air, land, water, and underground injection wells.

e Total amount of chemical transferred off-site, including to publicly owned treatment works (POTW).

Source: TRI99 2001 


\subsubsection{Water}

Direct releases to water are expected to be low for pyrethrins and pyrethroids because these compounds are primarily applied aerially or from ground-based sprayers directly to crops and vegetation. Spray drift following the application of these compounds, however, may contaminate nearby waters. Pyrethroids such as resmethrin, phenothrin, and permethrin, which are often used in mosquito control, are prohibited from being applied to open water or within 100 feet of lakes, rivers, and streams due to their high toxicity to fish (EPA 2000b).

Runoff water from fields or waste water from manufacturing facilities may contain pyrethrins and pyrethroids. For example, pyrethrin I and II were detected in runoff water following the application of a multi-purpose insecticide containing pyrethrins to a field in Franklin County, Kentucky (Antonious et al. 1997). Leachate collected near a pesticide manufacturing plant in Barcelona, Spain contained cypermethrin at concentrations exceeding 5-10 ppm (Rivera et al. 1985). Fenvalerate was detected in runoff water from an agricultural region in the Nicolet River Basin of Quebec, Canada at an average concentration of $0.05 \mu \mathrm{g} / \mathrm{L}$ in June of 1989 (Caux et al. 1996).

According to the TRI, an estimated total of 72 pounds of cyfluthrin (Table 6-2) was discharged to water from manufacturing and processing facilities in the United States in 1999 (TRI99 2001). The data listed in the TRI should be used with caution since only certain types of facilities are required to report. This is not an exhaustive list.

Pyrethrins or pyrethroids were not detected in groundwater or surface water at the 1,636 NPL hazardous waste sites (HazDat 2003).

\subsubsection{Soil}

Releases of pyrethrins and pyrethroids to soils typically result from deposition following aerial or boom spraying of crops or vegetation. Improper disposal also may account for some sources in soil.

According to the TRI, 31,000 pounds of permethrin were discharged to land from manufacturing and processing facilities in the United States in 1999 (TRI99 2001). The data listed in the TRI should be used with caution since only certain types of facilities are required to report. This is not an exhaustive list. 
Pyrethrins were detected in soil collected at two of the NPL hazardous waste sites where it was detected in some environmental media (HazDat 2003). Pyrethroids were not detected in soil at the 1,636 NPL hazardous waste sites.

\subsection{ENVIRONMENTAL FATE}

\subsubsection{Transport and Partitioning}

Spray drift following the application of any pesticide is an important source of environmental contamination and is responsible for much of the aerial transport of these compounds. Spray drift is simply the movement of the applied insecticide outside the intended target area by mass transport or diffusion. The characteristics of spray drift are influenced largely by meteorologic conditions and the method of application. Wind velocity is the dominant environmental factor that affects spray drift. Droplet size, height of flight, aircraft speed, and boom length are the dominant spraying and equipment factors that affect spray drift. Application parameters can be optimized, but they are different for different insecticides (e.g., some insecticides are more effective with large droplets and/or high spray rates and others are more effective with small droplets and/or low spray rates). In an aerial deposition study of deltamethrin involving spray application from an airplane, peak deposition to the ground was $0.5-1.2 \mathrm{ng} / \mathrm{cm}^{2}$ (Johnstone et al. 1987). A site $4 \mathrm{~km}$ away from the spray zone received ground depositions as high as $0.2 \mathrm{ng} / \mathrm{cm}^{2}$, although most areas outside the spray zone received insignificant deposition. During application of insecticides to an apple orchard in Massachusetts approximately 1 acre in size, fenvalerate was detected downwind of the spray zone ( 75 feet away) at a maximum concentration of $1.28 \mu \mathrm{g} / \mathrm{m}^{3}$ (Clark et al. 1991). Within 2 hours, the level had been reduced to $0.03 \mu \mathrm{g} / \mathrm{m}^{3}$.

Based on the vapor pressure of the pyrethrins and pyrethroids (Tables 4-4 and 4-5, respectively), these compounds are expected to exist in both vapor and particulate phases in the ambient atmosphere. Vapor phase pyrethrins and pyrethroids are rapidly degraded in the atmosphere by direct photolysis and reaction with oxidants found in air such as photochemically-produced hydroxyl radicals, ozone, and nitrate radicals. Particulate phase compounds are slower to degrade, however, and can travel long distances before being removed from the air by wet and dry deposition. The concentrations of 13 different pesticides in the atmosphere and rainfall were studied in an area of eastern France in 1992 (Millet et al. 1997). Fenpropathrin was detected in the vapor phase at concentrations ranging from 0.03 to $2.7 \mathrm{ng} / \mathrm{mL}$ and in the particulate-phase at concentrations of 0.03-4 ng/mL (Millet et al. 1997). 
Pyrethrins and pyrethroids are strongly adsorbed to soil surfaces and are not considered very mobile. A wide range of $\mathrm{K}_{\mathrm{oc}}$ values has been reported by different authors, but most of these values indicate a high degree of adsorption and little leaching potential. The $\mathrm{K}_{\mathrm{oc}}$ values for the pyrethrins were estimated to range from 700 (cinerin II) to 27,200 (pyrethrin I) (Crosby 1995). Adsorption data are available for several pyrethroids from the U.S. Department of Agriculture Pesticide Database (USDA 2001a). The Koc values for permethrin range from 10,471 to 86,000 . The $\mathrm{K}_{\mathrm{oc}}$ values in silt loam, sandy loam, sediment, and sand were $19,340,20,865,44,070$, and 60,870 , respectively. The $K_{o c}$ values of cypermethrin in loamy sand (pH 5.4, 2.1\% organic matter), sandy loam ( $\mathrm{pH} 6.5,3.4 \%$ organic matter), silt loam (pH 5.6, $2.0 \%$ organic matter), loamy sand ( $\mathrm{pH} 4.7,15.6 \%$ organic matter), and loam ( $\mathrm{pH} 7.1,5.2 \%$ organic matter) were 160,$000 ; 84,000 ; 22,000 ; 34,000$; and 5,800, respectively (USDA 2001a). The $\mathrm{K}_{\mathrm{oc}}$ values were 3,700 to $64,125,1,000$ to 12,000 , and 5,000 to 340,000 for cyfluthrin, fenvalerate, and fenpropathrin, respectively. The movement of deltamethrin, cypermethrin, permethrin, and their degradation products were studied in clay and loamy sands (Kaufman et al. 1981). Deltamethrin, permethrin (both cis and trans isomers) and cypermethrin (both cis and trans isomers), were considered immobile in all soils tested. The degradation products studied, cis, trans 3-(2,3-dichloroethenyl)2,2-dimethylcyclopropanecarboxylate; 3-phenoxybenzyl alcohol; and 3-phenoxybenzoic acid showed some level of mobility.

Volatilization from water and soil is expected to occur slowly for many of the pyrethroids since these compounds generally have low vapor pressures and Henry's law constants (Table 4-5). When released to water, partitioning to suspended solids and sediment occurs rapidly. These compounds adsorb strongly to suspended solids and sediment in the water column, and this process significantly attenuates volatilization. Laboratory studies indicated that $>95 \%$ of an initially applied amount of permethrin was adsorbed onto lake sediment and only $7-9 \%$ of the adsorbed complex could be desorbed from the sediment following four successive rinses with distilled water (Sharom and Solomon 1981). Compounds with relatively large Henry's law constants, such as deltamethrin, volatilize more readily from water surfaces than other pyrethroids. Muir et al. (1985) determined that after deltamethrin was applied to ponds, approximately $6 \%$ volatilized over the course of a 2 -day incubation period. However, the major partitioning process was adsorption to suspended solids and sediment. Maguire et al. (1989) observed that deltamethrin applied to a pond in Canada was rapidly dissipated by photolysis, hydrolysis, and volatilization. Laboratory studies using sterilized pond water showed that volatilization losses increased if the deltamethrin was sprayed directly onto the surface of the water rather than injecting the solution into the subsurface water. Volatilization losses from foliage may be considerably greater than 
volatilization from soils because pyrethrins and pyrethroids do not adsorb as strongly to the leafy component of vegetation as to soils (Boehncke et al. 1990). Laboratory and field tests were conducted to evaluate volatilization losses of deltamethrin sprayed on plant and soil surfaces (Boehncke et al. 1990). Under the summer time conditions of the field tests, mean evaporative losses from lettuce, kohlrabi, green beans, and summer wheat ranged from 12 to 71\% over a 24-hour period, while evaporative losses from soil were approximately $24 \%$ in 24 hours. Since pyrethrin I, cinerin I, and jasmolin I have larger Henry's law constants than the corresponding esters (pyrethrin II, cinerin II, and jasmolin II), they are expected to volatilize from moist soils and water more rapidly. The estimated volatilization half-lives of pyrethrin I, cinerin I, and jasmolin I from soil range from 1.8 to 2.7 days, while the half-life values for pyrethrin II, cinerin II, and jasmolin II range from 36.8 to 97 days (Crosby 1995). Pyrethrins and pyrethroids are often used indoors in sprays or aerosol bombs, and the volatilization rates from glass or floor surfaces may be significantly faster than from soils since these compounds are not likely to adsorb as strongly to these surfaces.

Pyrethrins and pyrethroids can bioconcentrate in aquatic organisms and are extremely toxic to fish. The bioconcentration factor $(\mathrm{BCF})$ of permethrin, fenvalerate, deltamethrin, and cypermethrin in rainbow trout (Oncorhynchus mykiss) and sheepshead minnow (Cyprinodon variegatus) were approximately 450-600, 180-600, 100-1,200 and 120-400, respectively (Haitzer et al. 1998). The BCF values varied considerably as the amount of dissolved organic matter in the water column was changed (Haitzer et al. 1998). The steady-state BCF values of fenvalerate and permethrin in eastern oysters (Crassostrea virginica) were measured as 4,700 and 1,900, respectively, over a 28-day incubation period (Schimmel et al. 1983). In pesticide-free water, the contaminated oysters depurated permethrin and fenvalerate to nondetectable levels in 1 week. Insect BCF values after 6 hours of exposure to sublethal permethrin concentrations were $18,30,7,4$, and 24 for black fly, caddisfly, damsefly, water scavenger, and mayfly, respectively (Tang and Siegfried 1996). Using a static test system and a 3-day incubation period, the BCF value for cypermethrin in golden ide fish (Leuciscus idus melanotus) was measured as 420 (Freitag et al. 1985). In a series of field tests designed to simulate the environmental fate of tralomethrin and deltamethrin due to spray drift and field runoff, fathead minnows were exposed to different levels of these pyrethroids (Erstfeld 1999). Over the course of a 7-day incubation period, the minnows were analyzed and BCF values of 219 and 315 were calculated for days 4 and 7, respectively, for the tralomethrin spray drift pond microcosms. The BCF values were 185 and 143 for days 4 and 7, respectively, for the tralomethrin runoff water microcosms. The BCF values were 260 and 185 for days 4 and 7, respectively, for the deltamethrin spray drift pond microcosms and the BCF values were 169 and 166 for days 4 and 7, respectively, for the deltamethrin runoff water microcosms. 
Little data exist regarding the uptake and transport of pyrethrins and pyrethroids by plant material. Since many of these compounds are rapidly degraded in the environment, this transport mechanism may not be an important environmental fate process other than the initial settling of these compounds on the canopy following deposition. The aerial surface of a plant, including foliage, is covered by a cuticle, which serves as a barrier to water loss and to prevent penetration of applied chemicals or environmental pollutants (Paterson et al. 1990). Once deposited on the surface, a chemical may be degraded, bind to the cuticle, or diffuse into the plant through the stomata. Parihar and Gupta (1998) demonstrated that fenvalerate applied to the surface of pigeon pea (Cajanus cajan) in India under field conditions was rapidly degraded and did not accumulate significantly in the plants. The fenvalerate residues were below detection limits at 15 and 20 days postapplication for two different application rates. These compounds can also be taken up from the soil by the roots of the plant. Since pyrethrins and pyrethroids adsorb strongly to soils, their uptake from roots and transport within plants is expected to be limited. Lettuce, beets, and wheat planted in soil 30,120 , and 365 days after treatment of $\left[{ }^{14} \mathrm{C}\right]$-fenvalerate were shown to accumulate very little ${ }^{14} \mathrm{C}$ when harvested at maturity (Lee 1985). Furthermore, it was demonstrated that very little downward movement of the radiolabeled fenvalerate occurred in the soils and that little, if any, fenvalerate or its degradation products are taken up by the roots of these plants. Chemicals may enter aquatic plants in solution directly from the water. Erstfeld (1999) demonstrated that aquatic plants accumulate deltamethrin and tralomethrin from the water column, in a series of pond and runoff water microcosms. Following application of tralomethrin, the BCF values in macrophytes were 18,200 and 8,290 in pond and water runoff microcosms, respectively, at 7 days postapplication (Erstfeld 1999). This observation is consistent with the data of Muir et al. (1985) that observed deltamethrin residues in aquatic plants at concentrations ranging from 253 to $1,021 \mathrm{ng} / \mathrm{g} 24$ hours after application of $1.8-2.5 \mu \mathrm{g} / \mathrm{L}$ deltamethrin solution to a pond. Similarly, permethrin applied to the surface of a fast-flowing stream was taken up by aquatic plants (Sundaram 1991). Following application of $1.658 \mathrm{~g}$ of permethrin to the stream surface, permethrin concentrations in aquatic plants located $280 \mathrm{~m}$ from the application site ranged from $6.78 \mathrm{ng} / \mathrm{g}$ (420 minutes postapplication) to $17.6 \mathrm{ng} / \mathrm{g}$ (60 minutes postapplication). It was concluded that the permethrin was largely absorbed in foliar waxes in the water arum and was slowly desorbed and lost by hydrolytic or microbial degradation. 


\subsubsection{Transformation and Degradation}

Many studies use first-order kinetics to model the dissipation of pesticides in the environment because a half-life for the chemical can be defined. The half-life represents the calculated time for loss of the first $50 \%$ of the substance. However, in many cases, the time required for the loss of the remaining substance may be substantially longer, and the rate of disappearance may decline further as time progresses. This is often the case for the disappearance of pesticides in soils. For simplicity, the term half-life in this document is used to indicate the estimated time for the initial disappearance of $50 \%$ of the compound and does not necessarily imply that first-order kinetics were observed throughout the experiment unless otherwise noted.

\subsubsection{Air}

Pyrethrins and pyrethroids in the ambient atmosphere are degraded rapidly through reaction with atmospheric oxidants or by direct photolysis. Based upon rate constants for the reaction with hydroxyl radicals and ozone molecules derived from a structure estimation method (Meylan and Howard 1993), the atmospheric half-lives of the pyrethrins are on the order of several minutes to a few hours (HSDB 2001). These compounds are also rapidly degraded by direct photolysis. Chen and Casida (1969) observed that thin films of pyrethrin I applied to glass plates underwent $90 \%$ photodecomposition within 0.2 hours, while a dark control underwent very little loss.

Pyrethroids where the isobutenyl group attached to the cyclopropane moiety has been altered are more stable to sunlight than the early pyrethroids like allethrin or resmethrin. For this reason, pyrethroids such as permethrin, deltamethrin, cyhalothrin, cyfluthrin, and cypermethrin are more frequently applied outdoors to crops in comparison to the rapidly degraded pyrethroids like resmethrin and allethrin. When exposed to daylight as a thin film indoors near a window, phenothrin decomposed with a half-life of about 6 days, whereas about $60 \%$ of applied permethrin remained undecomposed after 20 days (WHO 1990c). Thus, the replacement of the isobutenyl group with the dichlorovinyl substituent significantly enhanced the photostability of permethrin in comparison to phenothrin (WHO 1990c). The photodegradation halflife of permethrin on thin films exposed to light at 295-305 nm was in the range of 5-7 days, while the half-lives for deltamethrin and cis cypermethrin were 6 and 7.5 days, respectively (Chen et al. 1984). Cypermethrin exposed to ultraviolet (UV) light $>290 \mathrm{~nm}$, underwent $30.2 \%$ photomineralization over a 
17-hour irradiation period (Freitag et al. 1985). The photodegradation half-life of tetramethrin on glass films exposed to a sunlamp was approximately 1 hour, with nearly $100 \%$ photodecomposition observed after 15 hours of illumination (Chen and Casida 1969). Allethrin applied to glass films was degraded approximately $90 \%$ in 8 hours when irradiated with UV light, but some of the loss was attributed to volatilization (Chen and Casida 1969). Aqueous suspensions of allethrin underwent approximately $11.1 \%$ photodecomposition after only 15 minutes of exposure to sunlight (Ivie and Casida 1971b). It was also observed that the addition of chloroplasts to the suspensions photosensitized the photolysis and increased degradation rates in sunlight, suggesting that photodegradation on crops is a very rapid process. The photolysis half-life of resmethrin films on glass plates ranged from about 20 to 90 minutes when exposed to forenoon and midday sunlight conditions (Samsonov and Makarov 1996). The fastest rates were observed during midday sunlight and in the presence of the sensitizer methylene blue. Resmethrin also underwent direct photolysis when aerosols were irradiated with sunlight. Photodecomposition products of resmethrin included chrysanthemic acid, phenylacetic acid, benzyl alcohol, benzaldehyde, benzoic acid, and various chrysanthemates (Ueda et al. 1974). Cyhalothrin was reported as being stable to light, with $<10 \%$ photodecomposition after 20 months while stored under sunlight conditions (Tomlin 1997). However, on soil surfaces and in aqueous solutions at $\mathrm{pH} 5$, cyhalothrin was degraded upon exposure to sunlight with a reported half-life of about 30 days (WHO 1990a).

Compounds, such as nitroanilines, that absorb light in the environmental UV spectrum have been shown to photostabilize pyrethrins and pyrethroids (Dureja et al. 1984). Following irradiation at $360 \mathrm{~nm}$ for 18 hours, the percent recoveries of pyrethrins, allethrin, kadethrin, resmethrin, tetramethrin, phenothrin, and fenpropathrin on silica gel plates were 1, 2, 0, 7, 2, 29, and 28\%, respectively (Dureja et al. 1984). Following the addition of the herbicide trifluralin, the amounts recovered after irradiation were: pyrethrins, 54\%; allethrin, 78\%; kadethrin, 47\%; resmethrin, 85\%; tetramethrin, 77\%; phenothrin, 66\%; and fenpropathrin, 83\% (Dureja et al. 1984). Pyrethroids with halogenated acid moieties were also protected from photodecomposition due to the addition of trifluralin. Following irradiation at $360 \mathrm{~nm}$ for 32 hours on silica gel plates, the percent recoveries of permethrin, cypermethrin, deltamethrin, and fenvalerate were $32,19,25$, and $23 \%$, respectively. With the addition of trifluralin, the percent recoveries increased to $65 \%$ for permethrin, $83 \%$ for cypermethrin, $57 \%$ for deltamethrin, and $90 \%$ for fenvalerate (Dureja et al. 1984). Deltamethrin-impregnated cotton strips were degraded upon irradiation with UV light at differing rates, depending upon the color of the fabric and whether or not a UV absorber was added to the impregnating solution (Hussain and Perschke 1991). When white cotton fabric treated with deltamethrin alone was irradiated for 24 hours, nearly 100\% photodegradation was observed. However, deltamethrin applied to blue and black fabric was degraded approximately 44.9 and $37.5 \%$, respectively, 
over a 24-hour irradiation period (Hussain and Perschke 1991). Addition of the UV absorber 2,4-dihydroxybenzophenone also decreased the amount of degradation following exposure to UV light.

\subsubsection{Water}

Since pyrethrins and pyrethroids undergo photolysis in the atmosphere, they are also degraded by this mechanism in sunlit surface waters. Photosensitizing agents found in natural waters such as fulvic and humic acids increase the rate of photolysis. The photolysis half-life of permethrin in seawater exposed to outdoor light was determined to be 14 days and the half-life of fenvalerate was measured as 8 days (Schimmel et al. 1983). Little change in concentration was observed when each pyrethroid was incubated in dark constant temperature controls. Photolysis half-lives of 27.1 and 19.6 hours were determined for respective cis and trans isomers of permethrin, respectively, in $800 \mathrm{~mL}$ of pond water exposed to sunlight (Rawn et al. 1982). The photodegradation half-life of cypermethrin in a distilled water solution ranged from 2.6 to 3.6 days and the half-lives in river and seawater were in the range of 0.6-1.0 days when exposed to sunlight (Takahashi et al. 1985a). The cis isomers underwent photodegradation at greater rates than the trans isomers. The photodegradation half-life of deltamethrin in distilled water was 1-2 days, while the half-life in river water was longer, yet still $<5$ days when solutions were exposed to sunlight (Maguire 1990). The photolysis half-lives of fenpropathrin in distilled water, distilled water with humic acid, river water, and seawater were 13.5, 6, 2.7, and 1.6 weeks, respectively, when exposed to sunlight (Takahashi et al. 1985c).

These compounds also undergo hydrolysis in the environment at varying rates depending upon $\mathrm{pH}$ and temperature. Generally, hydrolysis is only an important environmental fate process under alkaline conditions and at temperatures of $20{ }^{\circ} \mathrm{C}$ or greater. The hydrolysis half-life of cyfluthrin is about 231 days at $\mathrm{pH} 7$, but about 2 days at $\mathrm{pH} 8$ (USDA 2001a). At pH 5 and $\mathrm{pH} 7$, permethrin is stable towards abiotic hydrolysis, but at $\mathrm{pH} 9$, the abiotic hydrolysis half-life is about 50 days (USDA 2001a). The aqueous hydrolysis half-lives of cypermethrin in sterile water-ethanol (99:1) phosphate buffers at $25{ }^{\circ} \mathrm{C}$ were determined to be $99,69,63$, and 50 weeks at $\mathrm{pH}$ values of $4.5,6$, 7, and 8 , respectively (Chapman and Cole 1982). The half-lives of an $8 \mathrm{ppb}$ solution of fluvalinate at $25{ }^{\circ} \mathrm{C}$ were $48,22.5$, and

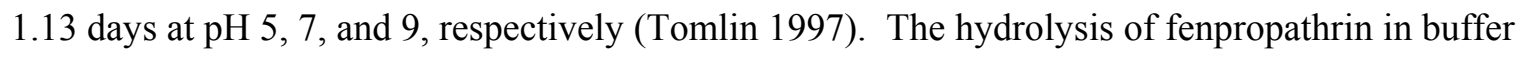
solution was studied under various $\mathrm{pH}$ and temperature conditions (Takahashi et al. 1985b). At $25{ }^{\circ} \mathrm{C}$, the hydrolysis half-lives of fenpropathrin were approximately 2.2 years and 8 days at $\mathrm{pH} 7$ and 9 , 
respectively (Takahashi et al. 1985b). At $40{ }^{\circ} \mathrm{C}$, the half-lives were about 80 days and 19 hours at $\mathrm{pH} 7$ and 9, respectively (Takahashi et al. 1985b).

Pyrethroids are readily degraded by environmental microorganisms. The half-life of permethrin in a sediment/seawater solution was $<2.5$ days, but under sterile conditions, there was no significant change in the permethrin concentration over a 4-week incubation period, suggesting that biodegradation was responsible for the loss under nonsterile conditions (Schimmel et al. 1983). The half-life of fenvalerate in the sediment/seawater solution was 27-42 days under nonsterile conditions and little loss was noted under sterilized conditions (Schimmel et al. 1983). Pond and runoff water microcosms were constructed to simulate the fate and persistence of tralomethrin and deltamethrin under field conditions following spray drift over a 7-day study period (Erstfeld 1999). The degradation profiles of tralomethrin in water showed rapid conversion to deltamethrin with a calculated half-life of about 6.8 hours. The resulting deltamethrin was further degraded to decamethrinic acid with a half-life of about 81 hours. In sediment, tralomethrin was rapidly converted to deltamethrin. Two experiments were conducted to evaluate the persistence of fenvalerate in seawater and seawater/sediment microcosms under different conditions (Cotham and Bidleman 1989). The half-lives of fenvalerate in unsterilized seawater at pH 8 and 8.05 were 17 and 14 days, respectively. The half-lives of fenvalerate in heat sterilized seawater at $\mathrm{pH} 8$ and 8.05 were 41 and 33 days, respectively (Cotham and Bidleman 1989). Bioresmethrin, cypermethrin, deltamethrin, permethrin, fenvalerate, and Nuerelle DX 50 (50 grams cypermethrin and 500 grams chlorpyriphos mixture) were degraded at different rates in a model ecosystem consisting of polluted river water and sediment under aerobic conditions (Lutnicka et al. 1999). The temperature of the ecosystem was $15-19{ }^{\circ} \mathrm{C}$ and the $\mathrm{pH}$ was 7.7. The ranges of half-lives in the model ecosystem were: bioresmethrin, 1.2-4.6 days; cypermethrin, 4.7-30.8 days; deltamethrin, 0.5-0.8 days; permethrin, 1.1-3.6 days; fenvalerate, 3.5-4.4 days; and cypermethrin in the Nuerelle DX 50 mixture, 11.6-30.4 days (Lutnicka et al. 1999). It was also noted that the degradation rates of the pyrethroids followed first-order kinetics, and that only fenvalerate and cypermethrin residues remained at detectable levels 56 days postapplication.

No data exist regarding the degradation of pyrethrins in water. Based upon degradation studies of structurally similar esters and the degradation rates of the pyrethroids, it has been concluded that pyrethrins should degrade rapidly in water (Crosby 1995). 


\subsubsection{Sediment and Soil}

Laboratory and field studies suggest that pyrethroids are degraded faster in soils than many of the longlasting organochlorine, organophosphorus, and carbamate pesticides. Fenvalerate and deltamethrin appear to be the most persistent compounds in commercial use, especially in soils containing a high clay content or a large percentage of organic matter.

Chapman et al. (1981) studied the persistence of permethrin, cypermethrin, deltamethrin, fenpropathrin, and fenvalerate in sterile and nonsterile soils in order to assess the importance of biodegradation versus abiotic transformation mechanisms. After initial application of $1 \mathrm{ppm}$ of each pyrethroid in a mineral soil, the percentages of pesticide recovered after an 8-week incubation period were: fenpropathrin, $2 \%$; permethrin, $6 \%$; cypermethrin, $4 \%$; fenvalerate, $12 \%$; and deltamethrin, $52 \%$. Over $90 \%$ of each pyrethroid was recovered from heat sterilized soils, suggesting that biodegradation plays a crucial role in the disappearance of these compounds. Similar results were obtained in a richly organic soil, although the amounts degraded were lower over the 8-week incubation period. In the organic soil, the percent recoveries after 8 weeks were as follows: fenpropathrin, $8 \%$; permethrin, 16\%; cypermethrin, 16\%; fenvalerate, 58\%; and deltamethrin, 74\%. The USDA Pesticide Database lists half-lives in the range of 88-287 days for fenvalerate, 56-63 days for cyfluthrin, 4-40 days for permethrin, and 6-60 days for cypermethrin in aerobic soils (USDA 2001a). In a biodegradation study using deltamethrin as the sole carbon source and pure bacterial isolates from soil as inoculum, $35.7-44.4 \%$ of the initially applied deltamethrin metabolized in 1 week and 59.7-72.5\% was degraded in 2 weeks (Khan et al. 1988). In the absence of bacterial isolates, only $3-10 \%$ of the deltamethrin was degraded. Deltamethrin was applied to a sandy loam from Alberta, Canada at an initial fortification level of $17.5 \mathrm{~g} / \mathrm{ha}$ (42.5 ppb) and studied under indoor laboratory conditions and field conditions over a 52-week incubation period (Hill 1983). The half-life of deltamethrin under the field conditions was 6.8 weeks, and approximately $5-7 \%$ of the applied deltamethrin remained after 52 weeks. The half-life of the deltamethrin in the indoor experiments was 4.8 weeks and the differences in persistence between the field and laboratory experiments were attributed to climate effects. In both cases, the degradation was exponential and the decay could be reasonably fit to first-order kinetic equations (Hill 1983). It was noted that in the field experiments, the rate of degradation was slowed during the winter months. The anaerobic degradation of cyfluthrin in heavy clay soils was studied under laboratory conditions for a period of 140 days at different moisture levels and organic matter content (Smith et al. 1995). The percentages of cyfluthrin recovered in an unamended soil after $31,73,115$, and 140 days were $50.8,27.9,14.8$, and $15 \%$, respectively. The percentages of cyfluthrin recovered in a soil amended with organic matter from cotton plant residue were 
$35.2,20.9,14.4$, and $9.4 \%$, respectively, over the same incubation periods. The disappearance of cyfluthrin was not significantly affected by the moisture content of the soils (Smith et al. 1995). The halflives of fluvalinate and flucythrinate in agricultural soil were 6.8-8.0 days and 9.4-11.9 days, respectively, depending upon the application rate (Agnihotri and Jain 1987). It was observed that the rate of disappearance followed first-order kinetics, and that after 40 days, neither insecticide remained at detectable levels in the soil (Agnihotri and Jain 1987). The half-lives of fenvalerate in a tidal marsh sediment ecosystem, with sediment obtained from the Chesapeake Bay, were calculated as 6.3 days (0.2 ppm initial concentration) and 8.8 days (1 ppm initial concentration) (Caplan et al. 1984). It was not possible to determine the exact mechanism of degradation (hydrolysis, biodegradation, or photolysis) since no dark or sterile controls were run; however, biodegradation and hydrolysis were the most likely routes since the fenvalerate was initially incorporated into the sediment, shielding it from substantial sunlight. The half-life of fenvalerate in a sediment/seawater (obtained from Charleston, South Carolina) system at pH 7.3-7.7 was 12 days (Cotham and Bidleman 1989). The half-life of fenvalerate applied to sandy loam and silty clay loam soils at an initial concentration of 5 ppm was approximately 75-80 days under indoor laboratory conditions (Lee 1985). The half-life under outdoor conditions was approximately 60 days (Lee 1985).

Since light is attenuated as a function of depth from the soil surface, photolysis of pyrethrins and pyrethroids is only an important environmental fate process at the surface of the soil. The photodegradation of cypermethrin was studied by exposing various soil surface applications to sunlight for 7-10 days (Takahashi et al. 1985a). The half-lives on soil surfaces exposed to sunlight ranged from 0.6 to 1.9 days, while half-lives on non-illuminated soils were $>7$ days. The photodegradation products resulting from exposure of cypermethrin to sunlight included various carbanoyl and hydroxy derivatives, a variety of benzoic acid derivatives, several lactone derivatives, and several aliphatic carboxylic acid derivatives (Takahashi et al. 1985a). The photodegradation of esfenvalerate on thin films of soil, clay, and humic material was studied (Katagi 1991). Half-lives ranged from about 8 to 100 days with reaction at the cyano group and ether cleavage in the alcohol moiety responsible for the photodegradation on the surfaces tested. The shortest photolysis half-lives were observed when esfenvalerate was incorporated into the clay thin films. The half-life of fenpropathrin on the surface of a sterilized sandy loam was 3-4 days following irradiation with natural sunlight (Dureja 1990). After 15 days, it was observed that only about $12 \%$ of the original amount remained (Dureja 1990).

A mid-summer field study in Alberta, Canada was performed to determine the persistence of deltamethrin on crops and litter in order to establish a minimum time interval between treatment of pastures and 
grazing by cattle (Hill and Johnson 1987). The average half-life of deltamethrin applied to two pastures to control grasshoppers was 5.8 days on the forage and 17 days on the litter (Hill and Johnson 1987). The authors attributed the rapid initial loss of deltamethrin to surface processes including volatilization and photolysis, but the remainder of the loss occurred by degradation through metabolic and chemical processes. The longer half-life of deltamethrin on the litter reflects a lower initial loss of the chemical through surface processes (volatilization and photolysis) due to the litter being more sheltered.

No data exist regarding the degradation rates of pyrethrins in soil. Based upon hydrolysis and biodegradation studies of structurally similar esters and the relatively rapid degradation rates of the pyrethroids, it has been concluded that pyrethrins should degrade rapidly in soil (Crosby 1995).

\subsection{LEVELS MONITORED OR ESTIMATED IN THE ENVIRONMENT}

Pyrethrins and pyrethroids have been detected at low levels in ambient air, indoor air samples, surface water, groundwater, and drinking water. These compounds have also been detected in soils, sediment, various foods, and animals. Quantitative concentration information is presented in the following sections.

\subsubsection{Air}

Pyrethrins and pyrethroids are used in both indoor and outdoor settings to control insects; therefore, these compounds are frequently detected in the air of homes and buildings after their use. During a study of pesticide use in Florida, permethrin was qualitatively identified in the porch or patio of two out of eight homes in Jacksonville, during August of 1985 (Lewis et al. 1988). During a study of pesticide occurrence in indoor air of New Jersey households, permethrin was detected at concentrations of 2,550 ng/g (cis) and $3,850 \mathrm{ng} / \mathrm{g}$ (trans) in household dust immediately following its application as an aerosol flea treatment (Roinestad et al. 1993). The concentrations decreased to $550 \mathrm{ng} / \mathrm{g}$ (cis) and $675 \mathrm{ng} / \mathrm{g}$ (trans) 8 weeks postapplication. Permethrin, resmethrin, and cypermethrin were detected in the ambient air of commercial pest control buildings in North Carolina at concentration ranges of 0.03-2.34, 0.31-14.10, and $0.02-11.66 \mu \mathrm{g} / \mathrm{m}^{3}$, respectively (Wright et al. 1996). The concentrations of cypermethrin detected in the air of vacant dormitory rooms following its application for cockroach control were 18.2, 8.5, 3.0, 7.1, $4.4,0.6$, and $0.3 \mu \mathrm{g} / \mathrm{m}^{3}$ at $0,7,28,42,56,70$, and 84 days postapplication, respectively (Wright et al. 1993). The concentration in untreated rooms adjacent to the sprayed rooms ranged from $0.1 \mu \mathrm{g} / \mathrm{m}^{3}$ (84 days postapplication) to $6.4 \mu \mathrm{g} / \mathrm{m}^{3}$ (immediately following application). The indoor air concentration 
of allethrin in a public community college cafeteria after bi-monthly applications ranged from $0.2 \mathrm{ng} / \mathrm{m}^{3}$ (13 days after application) to $48 \mathrm{ng} / \mathrm{m}^{3}$ (0.1 days after application) (Eitzer 1991). The maximum airborne residue of fenpropathrin in greenhouse air after application was $0.28 \mu \mathrm{g} / \mathrm{m}^{3}$ (Siebers and Mattusch 1996).

The mean and maximum concentrations of vapor-phase fenpropathrin in air collected at Colmar, France between 1991 and 1993 were 0.5 and $2.7 \mathrm{ng} / \mathrm{mL}$, respectively (Millet et al. 1997), while the mean and maximum concentrations of particulate-phase fenpropathrin in air were 0.6 and $4 \mathrm{ng} / \mathrm{mL}$, respectively (Millet et al. 1997). The concentrations of permethrin and cypermethrin in airborne particulate matter in areas of Saudi Arabia with heavy insecticide use were $1.84-30.70$ and $0.28-3.61 \mu \mathrm{g} / \mathrm{m}^{3}$, respectively (Badawy 1998).

\subsubsection{Water}

Permethrin was detected in 24 of 12,253 ambient surface water samples in the United States at an average concentration of $0.0137 \mu \mathrm{g} / \mathrm{L}$ (EPA 2000c). Permethrin was detected 6 hours postapplication at concentrations of 0.017 and $0.018 \mu \mathrm{g} / \mathrm{L}$ in 2 of 6 samples from a slow-moving creek approximately 60 meters from a potato field where permethrin was applied via aerial spraying (Frank et al. 1991). Concentrations as high as $0.28 \mu \mathrm{g} / \mathrm{L}$ were observed 10 minutes postapplication, but decreased rapidly. In 1996, the average permethrin concentration in surface waters from agricultural areas in Thailand was $2.81 \mu \mathrm{g} / \mathrm{L}$ (Thapinta and Hudak 2000). The deposition of cypermethrin on the surface of three streams adjacent to vineyards in France that were sprayed (via mistblowers) with cypermethrin were in the range of $0.04-0.45 \mathrm{mg} / \mathrm{m}^{2}$ and cypermethrin concentrations in subsurface water of the streams were in the range of $0.4-1.7 \mu \mathrm{g} / \mathrm{L}$ soon after spraying, but decreased to $<0.1 \mu \mathrm{g} / \mathrm{L}$ within a period of about 5 hours (Crossland et al. 1982).

Since pyrethrins and pyrethroids adsorb strongly to soils, they are not often detected at elevated concentrations in groundwater and drinking water. In an EPA compilation of monitoring studies of pesticides in groundwater from 1971 to 1991, fenvalerate was detected in 5 out of 345 wells at concentrations of $0.01-0.28 \mu \mathrm{g} / \mathrm{L}$ and permethrin was detected in 4 out of 1,097 wells at concentrations of 0.01-1.25 $\mu \mathrm{g} / \mathrm{L}$ (EPA 1992). Cypermethrin was not detected in 311 wells sampled, tralomethrin was not detected in 188 wells sampled, and pyrethrins were not detected in 144 wells sampled (EPA 1992). As part of the National Drinking Water Contaminant Occurrence Database, permethrin was detected in 3 of 73 ambient spring water samples at an average concentration of $0.0133 \mu \mathrm{g} / \mathrm{L}$ and in 3 of 5,728 ambient 
groundwater samples at an average concentration of $0.011 \mu \mathrm{g} / \mathrm{L}$ (EPA 2000c). Permethrin was not detected in 94 wells analyzed in a 1992 USGS study of pesticides in near-surface aquifers in the Midwest (Kolpin et al. 1995). In the 1993-1995 USGS survey of pesticides in shallow groundwater throughout the United States, permethrin was detected in 2 out of 1,034 sites at a maximum concentration of $0.007 \mu \mathrm{g} / \mathrm{L}$ (Kolpin et al. 1998).

\subsubsection{Sediment and Soil}

Pyrethrins and pyrethroids are detected in agricultural soils or sediment from lakes, rivers, and streams that may have been contaminated from spray drift or runoff water. Following the application of a multipurpose insecticide containing pyrethrins on a field in Franklin County Kentucky, the concentrations of pyrethrin I and II decreased in the soil as a function of time. After 1 hour, 1, 4, 8, 12, 18, 24, and 30 days, the concentrations of pyrethrin I were $9,5.1,3.9,2.1,0.9,1.3,0.3$, and $0.8 \mu \mathrm{g} / \mathrm{kg}$, respectively (Antonious et al. 1997). The concentrations of pyrethrin II over the same time frame were 900, 140, 103, 23, 1, 1, 1, and $1 \mu \mathrm{g} / \mathrm{kg}$. The average concentration of permethrin in soils collected from 48 agrochemical facilities located throughout the state of Illinois was $190 \mu \mathrm{g} / \mathrm{kg}$, with a range of concentrations from 11 to $4.22 \times 10^{5} \mu \mathrm{g} / \mathrm{kg}$ (Krapac et al. 1995). During 1996-1997, concentrations of permethrin in soil samples from cultivated areas in Thailand ranged from 62.41 to $1,178.40 \mu \mathrm{g} / \mathrm{kg}$ (Thapinta and Hudak 2000). Fenvalerate was detected in soil samples of two fields near the Nicolet River Basin in Quebec, Canada at concentrations of 20 and $8 \mu \mathrm{g} / \mathrm{kg}$ (0-5 cm depth) and 2 and $5 \mu \mathrm{g} / \mathrm{kg}(25-30 \mathrm{~cm} \mathrm{depth})$ (Caux et al. 1996). Permethrin was detected in the soil of two potato farms in Canada at concentrations ranging from 110 to $380 \mu \mathrm{g} / \mathrm{kg}$ at 6 hours after application via aerial spraying (Frank et al. 1991). The concentrations decreased to $6-220 \mu \mathrm{g} / \mathrm{kg}$ at 6 days postapplication and $8-15 \mu \mathrm{g} / \mathrm{kg}$ at 30 days postapplication (Frank et al. 1991).

Permethrin was detected in three of six sediment samples at concentrations of $18.1-21.1 \mu \mathrm{g} / \mathrm{kg}$ from a creek approximately 60 meters from a potato field where permethrin was applied via aerial spraying (Frank et al. 1991). At 30 days postapplication, permethrin was detected in only one of six samples at a concentration of $10 \mu \mathrm{g} / \mathrm{kg}$ (Frank et al. 1991). Sediment samples from an industrialized area of the Meltham Catchment in England contained permethrin at concentrations of 0.26-309.5 $\mu \mathrm{g} / \mathrm{kg}$ and cyfluthrin at concentrations of $0.086-5.8 \mu \mathrm{g} / \mathrm{kg}$ (Yasin et al. 1996). Deltamethrin was detected in sediment samples of the Vemmenhog Catchment in Sweden at an average concentration of $20 \mu \mathrm{g} / \mathrm{kg}$ (Kreuger et al. 1999). 


\subsubsection{Other Environmental Media}

According to the 1999 Food and Drug Administration (FDA) Pesticide Monitoring Program, permethrin was identified in 54 out of 1,040 food composites analyzed (FDA 2001). No range of levels was reported. Fenvalerate and fluvalinate were also qualitatively identified in food products, but no percentage of occurrence or concentrations were listed. Permethrin was also identified in 10 out of 78 baby foods at concentrations of $0.6-60 \mu \mathrm{g} / \mathrm{kg}$ and fenvalerate was identified in 1 out of 78 baby foods at a concentration of $5 \mu \mathrm{g} / \mathrm{kg}$ (FDA 2001). Resmethrin has been identified, but not quantified, in corn, cornmeal, flour, and wheat (Simonaitis and Cail 1975). An FDA analysis of 320 food groups conducted from 1991 to 1999 determined that pyrethroids were present at varying levels in several foods. The results of this study pertaining to pyrethroids are summarized in Table 6-3 (FDA 2000c).

Cypermethrin was detected in the milk from cows wearing ear tags impregnated with cypermethrin to control horn flies and other insects (Braun et al. 1985). Over a 21-day period, 60 milk samples were obtained from 10 cows. Only 11 out of 60 butterfat samples contained cypermethrin above the detection limit of $4 \mu \mathrm{g} / \mathrm{kg}$. The range of concentrations in the butterfat of these 11 samples was $4.0-9.6 \mu \mathrm{g} / \mathrm{kg}$ (Braun et al. 1985). Flumethrin, deltamethrin, cypermethrin, and cyhalothrin were detected in the milk of 10 dairy cows after single dermal applications at recommended doses (Bissacot and Vassilieff 1997a). The highest mean concentration for flumethrin was observed 28 days postapplication, while the highest mean concentrations for cypermethrin and cyhalothrin were observed 1 day postapplication. The highest mean concentration of deltamethrin in the milk was observed 7 days postapplication.

Fenvalerate residues were detected in a variety of nontarget vertebrate and invertebrate species after application onto a cotton field to control bollworm and tobacco budworm (Bennet et al. 1983). Terrestrial invertebrates contained the lowest levels, while the highest residue concentrations were found in fish and insects. Fenvalerate levels in ppm were as follows: house mouse, 0.01; dickcissel, 0.02; ribbon snake, 0.12; toad, 0.02; golden shiner, 0.47; mosquitofish, 0.32; snail, 0.53; and ground beetle, 0.55 (Bennett et al. 1983). 
Table 6-3. Levels of Pyrethroids Detected in Foods

\begin{tabular}{|c|c|c|c|c|c|}
\hline Pyrethroid & Food item & $\mathrm{n}$ & $\begin{array}{l}\text { Mean } \\
(\mathrm{ppm})\end{array}$ & $\begin{array}{l}\text { Minimum } \\
\text { (ppm) }\end{array}$ & $\begin{array}{l}\text { Maximum } \\
(\mathrm{ppm})\end{array}$ \\
\hline Bifenthrin & Raw strawberries & 3 & 0.0487 & 0.0040 & 0.084 \\
\hline Cyfluthrin & Green peppers & 1 & 0.002 & 0.002 & 0.002 \\
\hline Cyfluthrin & Raw raddish & 1 & 0.013 & 0.013 & 0.013 \\
\hline Cyfluthrin & Beef chow mein & 1 & 0.004 & 0.004 & 0.004 \\
\hline lambda cyhalothrin & Tomato sauce & 1 & 0.003 & 0.003 & 0.003 \\
\hline lambda cyhalothrin & Green peppers & 1 & 0.01 & 0.01 & 0.01 \\
\hline lambda cyhalothrin & Stuffed peppers & 1 & 0.002 & 0.002 & 0.002 \\
\hline Cypermethrin & Broccoli & 1 & 0.0013 & 0.0013 & 0.0013 \\
\hline Cypermethrin & Collards & 7 & 0.442 & 0.052 & 1.247 \\
\hline Cypermethrin & Iceberg lettuce & 2 & 0.0185 & 0.013 & 0.024 \\
\hline Esfenvalerate & Collards & 4 & 0.0535 & 0.021 & 0.099 \\
\hline Esfenvalerate & Raw tomatoes & 5 & 0.0146 & 0.005 & 0.02 \\
\hline Esfenvalerate & Green peppers & 4 & 0.015 & 0.009 & 0.024 \\
\hline Esfenvalerate & Catsup & 1 & 0.002 & 0.002 & 0.002 \\
\hline Esfenvalerate & Strained peaches/junior & 2 & 0.0065 & 0.005 & 0.008 \\
\hline Esfenvalerate & Fruit dessert/junior & 2 & 0.0025 & 0.002 & 0.003 \\
\hline Esfenvalerate & Raw apricot & 1 & 0.06 & 0.06 & 0.06 \\
\hline Esfenvalerate & Mushrooms & 1 & 0.019 & 0.019 & 0.019 \\
\hline Esfenvalerate & Stuffed peppers & 3 & 0.005 & 0.003 & 0.007 \\
\hline Fenvalerate & Raw apricot & 2 & 0.03 & 0.024 & 0.036 \\
\hline Fenvalerate & Strained peaches/junior & 1 & 0.011 & 0.011 & 0.011 \\
\hline Fenvalerate & Red grapes & 1 & 0.006 & 0.006 & 0.006 \\
\hline Fenvalerate & Raw cherries & 1 & 0.11 & 0.11 & 0.11 \\
\hline Fenvalerate & Collards & 12 & 0.1188 & 0.015 & 0.373 \\
\hline Fenvalerate & Raw tomatoes & 4 & 0.0418 & 0.004 & 0.134 \\
\hline Fenvalerate & Green beans & 2 & 0.017 & 0.015 & 0.019 \\
\hline Fenvalerate & Okra & 1 & 0.032 & 0.032 & 0.032 \\
\hline Fenvalerate & Stuffed peppers & 1 & 0.004 & 0.004 & 0.004 \\
\hline Fenvalerate & Tacos & 1 & 0.002 & 0.002 & 0.002 \\
\hline
\end{tabular}


Table 6-3. Levels of Pyrethroids Detected in Foods

\begin{tabular}{|c|c|c|c|c|c|}
\hline Pyrethroid & Food item & $\mathrm{n}$ & $\begin{array}{l}\text { Mean } \\
(\mathrm{ppm})\end{array}$ & $\begin{array}{l}\text { Minimum } \\
\text { (ppm) }\end{array}$ & $\begin{array}{l}\text { Maximum } \\
(\mathrm{ppm})\end{array}$ \\
\hline Permethrin (cis) & Baked ham & 1 & 0.001 & 0.001 & 0.001 \\
\hline Permethrin (trans) & Baked ham & 1 & 0.001 & 0.001 & 0.001 \\
\hline Permethrin (cis) & Fried eggs & 1 & 0.001 & 0.001 & 0.001 \\
\hline Permethrin (trans) & Fried eggs & 1 & 0.0006 & 0.0006 & 0.0006 \\
\hline Permethrin (cis) & Dry roasted peanuts & 1 & 0.006 & 0.006 & 0.006 \\
\hline Permethrin (trans) & Dry roasted peanuts & 1 & 0.009 & 0.009 & 0.009 \\
\hline Permethrin (cis) & Popcorn & 1 & 0.007 & 0.007 & 0.007 \\
\hline Permethrin (trans) & Popcorn & 1 & 0.007 & 0.007 & 0.007 \\
\hline Permethrin (cis) & Rye bread & 2 & 0.0099 & 0.0008 & 0.019 \\
\hline Permethrin (trans) & Rye bread & 2 & 0.0109 & 0.0007 & 0.021 \\
\hline Permethrin (cis) & Raw peaches & 3 & 0.0107 & 0.006 & 0.018 \\
\hline Permethrin (trans) & Raw peaches & 3 & 0.014 & 0.006 & 0.027 \\
\hline Permethrin (cis) & Raw cantaloupe & 2 & 0.045 & 0.004 & 0.005 \\
\hline Permethrin (cis) & Raw cherries & 1 & 0.022 & 0.022 & 0.022 \\
\hline Permethrin (trans) & Raw cherries & 1 & 0.022 & 0.022 & 0.022 \\
\hline Permethrin (cis) & Dried prunes & 1 & 0.002 & 0.002 & 0.002 \\
\hline Permethrin (trans) & Dried prunes & 1 & 0.002 & 0.002 & 0.002 \\
\hline Permethrin (cis) & Spinach & 22 & 0.6283 & 0.003 & 2.31 \\
\hline Permethrin (trans) & Spinach & 22 & 0.6803 & 0.002 & 2.74 \\
\hline Permethrin (cis) & Collards & 22 & 0.3331 & 0.002 & 1.33 \\
\hline Permethrin (trans) & Collards & 22 & 0.285 & 0.002 & 0.853 \\
\hline Permethrin (cis) & Iceberg lettuce & 5 & 0.0104 & 0.0009 & 0.036 \\
\hline Permethrin (trans) & Iceberg lettuce & 5 & 0.009 & 0.0009 & 0.034 \\
\hline Permethrin (cis) & Canned sauerkraut & 1 & 0.0004 & 0.0004 & 0.0004 \\
\hline Permethrin (trans) & Canned sauerkraut & 1 & 0.0005 & 0.0005 & 0.0005 \\
\hline Permethrin (cis) & Broccoli & 10 & 0.0047 & 0.001 & 0.014 \\
\hline Permethrin (trans) & Broccoli & 10 & 0.0037 & 0.0007 & 0.009 \\
\hline Permethrin (cis) & Raw celery & 22 & 0.0113 & 0.001 & 0.031 \\
\hline Permethrin (trans) & Raw celery & 22 & 0.0093 & 0.001 & 0.023 \\
\hline
\end{tabular}


Table 6-3. Levels of Pyrethroids Detected in Foods

\begin{tabular}{|c|c|c|c|c|c|}
\hline Pyrethroid & Food item & $\mathrm{n}$ & $\begin{array}{l}\text { Mean } \\
(\mathrm{ppm})\end{array}$ & $\begin{array}{l}\text { Minimum } \\
(\mathrm{ppm})\end{array}$ & $\begin{array}{l}\text { Maximum } \\
(\mathrm{ppm})\end{array}$ \\
\hline Permethrin (cis) & Asparagus & 2 & 0.0862 & 0.0003 & 0.172 \\
\hline Permethrin (trans) & Asparagus & 2 & 0.1087 & 0.0003 & 0.217 \\
\hline Permethrin (cis) & Cauliflower & 1 & 0.004 & 0.004 & 0.004 \\
\hline Permethrin (trans) & Cauliflower & 1 & 0.002 & 0.002 & 0.002 \\
\hline Permethrin (cis) & Raw tomato & 16 & 0.0072 & 0.0006 & 0.015 \\
\hline Permethrin (trans) & Raw tomato & 16 & 0.0072 & 0.0005 & 0.015 \\
\hline Permethrin (cis) & Green beans & 1 & 0.005 & 0.005 & 0.005 \\
\hline Permethrin (trans) & Green beans & 1 & 0.003 & 0.003 & 0.003 \\
\hline Permethrin (cis) & Green pepper & 11 & 0.0332 & 0.005 & 0.081 \\
\hline Permethrin (trans) & Green pepper & 11 & 0.0411 & 0.006 & 0.079 \\
\hline Permethrin (cis) & Raw raddish & 1 & 0.001 & 0.001 & 0.001 \\
\hline Permethrin (trans) & Raw raddish & 1 & 0.0005 & 0.0005 & 0.0005 \\
\hline Permethrin (cis) & Meatloaf & 1 & 0.0006 & 0.0005 & 0.0006 \\
\hline Permethrin (trans) & Meatloaf & 1 & 0.0006 & 0.0005 & 0.0006 \\
\hline Permethrin (cis) & Butter & 1 & 0.002 & 0.002 & 0.002 \\
\hline Permethrin (trans) & Butter & 1 & 0.003 & 0.003 & 0.003 \\
\hline Permethrin (cis) & Half \& Half cream & 1 & 0.0003 & 0.0003 & 0.0003 \\
\hline Permethrin (trans) & Half \& Half cream & 1 & 0.0005 & 0.0005 & 0.0005 \\
\hline Permethrin (cis) & Catsup & 1 & 0.0009 & 0.0009 & 0.0009 \\
\hline Permethrin (trans) & Catsup & 1 & 0.0007 & 0.0007 & 0.0007 \\
\hline Permethrin (cis) & Pumpkin pie & 7 & 0.0024 & 0.0006 & 0.006 \\
\hline Permethrin (trans) & Pumpkin pie & 7 & 0.0031 & 0.001 & 0.008 \\
\hline Permethrin (cis) & Chicken & 1 & 0.001 & 0.001 & 0.001 \\
\hline Permethrin (trans) & Chicken & 1 & 0.0008 & 0.0008 & 0.0008 \\
\hline Permethrin (cis) & Vegetables and chicken & 1 & 0.001 & 0.001 & 0.001 \\
\hline Permethrin (trans) & Vegetables and chicken & 1 & 0.001 & 0.001 & 0.001 \\
\hline Permethrin (cis) & $\begin{array}{l}\text { Strained green } \\
\text { beans/junior }\end{array}$ & 2 & 0.0035 & 0.002 & 0.005 \\
\hline Permethrin (trans) & $\begin{array}{l}\text { Strained green } \\
\text { beans/junior }\end{array}$ & 2 & 0.0035 & 0.002 & 0.005 \\
\hline Permethrin (cis) & Creamed spinach/junior & 8 & 0.0372 & 0.0006 & 0.138 \\
\hline
\end{tabular}


Table 6-3. Levels of Pyrethroids Detected in Foods

\begin{tabular}{|c|c|c|c|c|c|}
\hline Pyrethroid & Food item & $\mathrm{n}$ & $\begin{array}{l}\text { Mean } \\
(\mathrm{ppm})\end{array}$ & $\begin{array}{l}\text { Minimum } \\
(\mathrm{ppm})\end{array}$ & $\begin{array}{l}\text { Maximum } \\
(\mathrm{ppm})\end{array}$ \\
\hline Permethrin (trans) & Creamed spinach/junior & 8 & 0.0338 & 0.0004 & 0.12 \\
\hline Permethrin (cis) & Strained peaches/junior & 14 & 0.0185 & 0.0006 & 0.078 \\
\hline Permethrin (trans) & Strained peaches/junior & 14 & 0.022 & 0.0007 & 0.099 \\
\hline Permethrin (cis) & Strained pears/junior & 3 & 0.0013 & 0.0008 & 0.002 \\
\hline Permethrin (trans) & Strained pears/junior & 3 & 0.0009 & 0.0008 & 0.001 \\
\hline Permethrin (cis) & Fruit dessert/junior & 17 & 0.0045 & 0.0009 & 0.013 \\
\hline Permethrin (trans) & Fruit dessert/junior & 17 & 0.0057 & 0.0006 & 0.019 \\
\hline Permethrin (cis) & Veal cutlet & 1 & 0.002 & 0.002 & 0.002 \\
\hline Permethrin (trans) & Veal cutlet & 1 & 0.002 & 0.002 & 0.002 \\
\hline Permethrin (cis) & Wheat bread & 1 & 0.0009 & 0.0009 & 0.0009 \\
\hline Permethrin (trans) & Wheat bread & 1 & 0.0009 & 0.0009 & 0.0009 \\
\hline Permethrin (cis) & Canned peaches & 1 & 0.0004 & 0.0004 & 0.0004 \\
\hline Permethrin (trans) & Canned peaches & 1 & 0.0005 & 0.0005 & 0.0005 \\
\hline Permethrin (cis) & Canned tomatoes & 3 & 0.0015 & 0.0004 & 0.002 \\
\hline Permethrin (trans) & Canned tomatoes & 3 & 0.0016 & 0.0007 & 0.002 \\
\hline Permethrin (cis) & Brussel sprouts & 12 & 0.0154 & 0.0004 & 0.127 \\
\hline Permethrin (trans) & Brussel sprouts & 12 & 0.0124 & 0.0003 & 0.1 \\
\hline Permethrin (cis) & Mushrooms & 6 & 0.0285 & 0.0003 & 0.159 \\
\hline Permethrin (trans) & Mushrooms & 6 & 0.0221 & 0.0002 & 0.125 \\
\hline Permethrin (cis) & Turnips & 1 & 0.001 & 0.001 & 0.001 \\
\hline Permethrin (trans) & Turnips & 1 & 0.001 & 0.001 & 0.001 \\
\hline Permethrin (cis) & Okra & 1 & 0.002 & 0.002 & 0.002 \\
\hline Permethrin (trans) & Okra & 1 & 0.002 & 0.002 & 0.002 \\
\hline Permethrin (cis) & Beef stroganoff & 1 & 0.018 & 0.018 & 0.018 \\
\hline Permethrin (trans) & Beef stroganoff & 1 & 0.01 & 0.01 & 0.01 \\
\hline Permethrin (cis) & Stuffed peppers & 9 & 0.0138 & 0.0005 & 0.074 \\
\hline Permethrin (trans) & Stuffed peppers & 9 & 0.0171 & 0.0007 & 0.093 \\
\hline Permethrin (cis) & Tuna casserole & 6 & 0.0014 & 0.0008 & 0.002 \\
\hline Permethrin (trans) & Tuna caracole & 6 & 0.0012 & 0.0005 & 0.003 \\
\hline
\end{tabular}


Table 6-3. Levels of Pyrethroids Detected in Foods

\begin{tabular}{llcccc}
\hline Pyrethroid & Food item & $\mathrm{n}$ & $\begin{array}{l}\text { Mean } \\
(\mathrm{ppm})\end{array}$ & $\begin{array}{c}\text { Minimum } \\
(\mathrm{ppm})\end{array}$ & $\begin{array}{l}\text { Maximum } \\
(\mathrm{ppm})\end{array}$ \\
\hline Permethrin (cis) & $\begin{array}{l}\text { Quarter pound } \\
\text { cheeseburger }\end{array}$ & 1 & 0.005 & 0.005 & 0.005 \\
$\begin{array}{l}\text { Quarter pound } \\
\text { cheeseburger }\end{array}$ & 1 & 0.001 & 0.001 & 0.001 \\
Permethrin (trans) & 3 & 0.0015 & 0.0004 & 0.003 \\
Permethrin (trans) & Tacos & 3 & 0.0018 & 0.0005 & 0.004 \\
Permethrin (cis) & Pizza & 2 & 0.0006 & 0.0004 & 0.0007 \\
Permethrin (trans) & Pizza & 2 & 0.0006 & 0.0003 & 0.0008 \\
Permethrin (cis) & Beef chow mein & 6 & 0.0016 & 0.0006 & 0.003 \\
Permethrin (trans) & Beef chow mein & 6 & 0.001 & 0.0006 & 0.002 \\
Permethrin (cis) & $\begin{array}{l}\text { Split peas with } \\
\text { vegetables and ham }\end{array}$ & 1 & 0.0008 & 0.0008 & 0.0008 \\
Permethrin (trans) & $\begin{array}{l}\text { Split peas with } \\
\text { vegetables and ham }\end{array}$ & 1 & 0.0009 & 0.0009 & 0.0009 \\
Permethrin (cis) & $\begin{array}{l}\text { Strained squash/junior } \\
\text { Strained squash/junior }\end{array}$ & 2 & 0.0009 & 0.0008 & 0.0009 \\
Permethrin (trans) & 2 & 0.0009 & 0.0008 & 0.0009 \\
\hline
\end{tabular}

$\mathrm{n}=$ number of detections

Source: FDA $2000^{\circ}$ 


\subsection{GENERAL POPULATION AND OCCUPATIONAL EXPOSURE}

The general population is exposed to pyrethrins and pyrethroids primarily from food sources, especially fruits and vegetables. The average daily intake (AVDI) of permethrin per unit of body weight (ng/kgbody weight-per day) in eight population groups was estimated using the FDA's monitoring program for chemical contaminants in the U.S. food supply. The data were obtained from the FDA Total Diet Studies conducted in 1982-1984 (Gunderson 1988), 1984-1986 (Gunderson 1995a), and 1986-1991 (Gunderson 1995b) and are summarized in Table 6-4. These data can be compared to the United Nations' Food and Agriculture Organization (FAO) and the World Health Organization (WHO) acceptable daily intake (ADI) value for technical-grade permethrin of 50,000 ng/kg-body weight per day (Gunderson 1995b). The ADI of a chemical is defined as the maximum daily intake, which, during a lifetime, appears to be without appreciable risk. These values can be used to derive a rough estimate for the AVDI for all pyrethrins and pyrethroids because permethrin is the pyrethroid found most often in foods (see Table 6-3).

Many household products used to control insects, such as aerosol bombs, spray insecticides, and pet shampoos, contain pyrethrins and pyrethroids, and therefore, dermal and inhalation exposures are possible. Because of the low mobility of these compounds in soil surfaces, pyrethrins and pyrethroids are rarely detected at elevated levels in drinking water or groundwater, with the exception of shallow wells near agricultural areas.

Occupational exposure to pyrethrins and pyrethroids will occur by inhalation and dermal contact with these compounds at workplaces where they are produced or used. The National Institute of Occupational Safety and Health (NIOSH) has conducted National Occupational Exposure Surveys (NOES) for pyrethrum and selected pyrethroids (NIOSH 1989). The NOES data do not include farm workers who are likely to be exposed to these compounds. Therefore, the estimated occupational exposures reported are likely to be greatly underestimated. Furthermore, these surveys were conducted prior to the development of many of the more recent pyrethroids and no current surveys exist. NIOSH (NOES 1981-1983) has statistically estimated that 11,296 total workers (1,537 of these are females) are exposed to pyrethrum in the United States (NIOSH 1989). Similarly, NIOSH has statistically estimated that 9,244 workers (1,758 of these are female) are potentially exposed to tetramethrin in the United States, and 27,596 workers $(3,998$ of these are female) are potentially exposed to resmethrin in the United States (NIOSH 1989). The NOES database does not contain information on the frequency, level, or duration of 

6. POTENTIAL FOR HUMAN EXPOSURE

Table 6-4. Average Daily Intake (AVDI, ng/kg/day) of Permethrin in Eight Population Groups

\begin{tabular}{|c|c|c|c|c|c|c|c|c|}
\hline Date & $\begin{array}{l}\text { Infants } \\
(6-11 \\
\text { months })\end{array}$ & $\begin{array}{l}\text { Toddlers } \\
\text { ( } 2 \text { years) }\end{array}$ & $\begin{array}{l}\text { 14-16- } \\
\text { year-old } \\
\text { females }\end{array}$ & $\begin{array}{l}\text { 14-16- } \\
\text { year-old } \\
\text { males }\end{array}$ & $\begin{array}{l}25-30- \\
\text { year-old } \\
\text { females }\end{array}$ & $\begin{array}{l}25-30- \\
\text { year-old } \\
\text { males }\end{array}$ & $\begin{array}{l}\text { 60-65- } \\
\text { year-old } \\
\text { females }\end{array}$ & $\begin{array}{l}60-65- \\
\text { year-old } \\
\text { males }\end{array}$ \\
\hline $\begin{array}{l}1982- \\
1984^{a}\end{array}$ & 1.2 & 5.6 & 3.3 & 3.0 & 5.0 & 4.1 & 6.5 & 5.4 \\
\hline $\begin{array}{l}1984- \\
1986^{b}\end{array}$ & 89 & 25 & 10.7 & 14.9 & 15.1 & 13.7 & 24.2 & 22.4 \\
\hline $\begin{array}{l}1986- \\
1991^{\mathrm{C}}\end{array}$ & 46.5 & 70.7 & 35.7 & 41.5 & 56.5 & 46.0 & 58.6 & 59.2 \\
\hline
\end{tabular}

${ }^{\mathrm{a} G u n d e r s o n} 1988$

${ }^{\mathrm{b}}$ Gunderson 1995a

${ }^{\mathrm{c} G u n d e r s o n ~ 1995 b}$ 
the exposure of workers to any of the chemicals listed therein. They are surveys that only provide estimates of workers potentially exposed to the chemicals.

The concentration of 3-phenoxybenzoic acid (3-PBA), a urinary metabolite of permethrin, was measured in the urine of an agricultural worker in Japan exposed to this pyrethroid during its application to cabbage plants (Asakawa et al. 1996). The concentration of 3-PBA was $2.9 \mathrm{ng} / \mathrm{mL}$ (6 hours postapplication), $5.1 \mathrm{ng} / \mathrm{mL}$ (the morning after application), and $1.4 \mathrm{ng} / \mathrm{mL}$ (3 days postapplication) (Asakawa et al. 1996). Even though the worker was covered by protective clothing, it was determined that permethrin permeated the worker's clothing and led to significant dermal exposure, particularly on the arms and legs (Asakawa et al. 1996). In a study of 50 Chinese workers applying deltamethrin and fenvalerate onto cotton fields, it was determined that dermal exposure represented the main route of exposure for the workers. Inhalation exposure rates were determined to be on the order of $\mu \mathrm{g} /$ hour, while dermal exposure was on the order of $\mathrm{mg} /$ hour (Zhang et al. 1991). Dermal exposure to deltamethrin for a pilot applying the insecticide on crops while flying an ultra-light aircraft was estimated as $10.8 \mu \mathrm{g} /$ hour (Yoshida et al. 1990). A groundbased flagman on duty during the aerial spraying received an estimated dermal exposure of $25.4 \mu \mathrm{g} / \mathrm{hour}$ and dermal exposure to workers manually spraying deltamethrin was 2,800-65,400 $\mu \mathrm{g}$ /hour (Yoshida et al. 1990). The 1,000-fold exposure difference between hand-held applicators and aerial applicators was due, in part, to work practices of the workers. Dermal exposures on different regions of the bodies of 6 pesticide applicators who sprayed cypermethrin in tea plantations in China were measured (Wan 1990). Exposures (in $\mu \mathrm{g} / 100 \mathrm{~cm}^{2}$ ) were as follows: face: 0.06-0.72; chest: 0.11-2.06; abdomen: 0.09-2.68; thigh: 0.41-17.3; and ankle: 0.15-32.6. Total dermal exposures based upon spray amounts were $186-1,140 \mathrm{mg} / \mathrm{kg}$ for nonhand areas and $46.1 \mathrm{mg} / \mathrm{kg}$ for hands only (Wan 1990). Dermal exposure to permethrin was shown to be far greater than inhalation exposure for two applicators involved in the spraying of this pyrethroid onto tomatoes in greenhouses (Adamis et al. 1985). The estimated respiratory exposure rate for these workers was $0.004 \mathrm{mg} /$ hour and the dermal exposure rate was $3.8 \mathrm{mg}$ /hour (Adamis et al. 1985). However, based upon the findings of animal studies, the absorption of pyrethroids is likely to be higher via oral and inhalation pathways when compared to dermal absorption (Eadsforth et al. 1988; van der Rhee et al. 1989; Woollen et al. 1992). Estimates of pyrethroid absorption in humans following dermal application range from about 0.3 to $1.8 \%$ of the administered dose (see Section 3.4 ). 


\subsection{EXPOSURES OF CHILDREN}

This section focuses on exposures from conception to maturity at 18 years in humans. Differences from adults in susceptibility to hazardous substances are discussed in 3.7 Children's Susceptibility.

Children are not small adults. A child's exposure may differ from an adult's exposure in many ways. Children drink more fluids, eat more food, breathe more air per kilogram of body weight, and have a larger skin surface in proportion to their body volume. A child's diet often differs from that of adults. The developing human's source of nutrition changes with age: from placental nourishment to breast milk or formula to the diet of older children who eat more of certain types of foods than adults. A child's behavior and lifestyle also influence exposure. Children crawl on the floor, put things in their mouths, sometimes eat inappropriate things (such as dirt or paint chips), and spend more time outdoors. Children also are closer to the ground, and they do not use the judgment of adults to avoid hazards (NRC 1993).

Children are exposed to pyrethrins and pyrethroids by similar routes that affect adults. Ingestion of foods is the most important exposure pathway for children. The AVDI of permethrin has been reported as $46.5 \mathrm{ng} / \mathrm{kg}$-body weight/day for 6-11-month-old infants and $70.7 \mathrm{ng} / \mathrm{kg}$-body weight/day for 2-year-old toddlers (Gunderson 1995b). No measurements have been made of these compounds in amniotic fluid, meconium, cord blood, neonatal blood, or any other tissues that may indicate prenatal exposure. No data have been reported on the levels of pyrethrins or pyrethroids in breast milk.

The tendency of young children to ingest soil, either intentionally through pica or unintentionally through hand-to-mouth activity, is well documented. These behavioral traits can result in ingestion of pyrethrins and pyrethroids present in soil and dust. Since these compounds are adsorbed strongly to soils, they may not be in a highly bioavailable form. Young children often play on the ground or on carpets and this will increase the likelihood of dermal exposure and inhalation of contaminated particles from soil, household dust and treated surfaces. The transfer of allethrin residues from a carpeted floor to human subjects wearing dosimeter clothing was studied (Ross et al. 1990). For gloves, socks, shirts, and tights of subjects performing standardized aerobic exercises, the transfer coefficient ranged from 2.8 to $34.3 \mu \mathrm{g}$ allethrin $/ \mathrm{cm}^{2}$ clothing for a period of up to 12.5 hours after applying allethrin (via foggers) to the carpet. The transfer rates decreased with time after application (Ross et al. 1990). Pyrethrins and pyrethroids are also frequently used in products such as pet shampoos or sprays, and since children often spend a great deal of time playing with pets, this can increase childhood exposure. Pyrethrins and certain pyrethroids have been employed in head lice treatment products, which are often used on children. Very little data 
were located regarding the concentrations of pyrethroids in milk and dairy samples. No pyrethroids were detected in any milk or dairy samples from the FDA Market Basket Surveys compiled from the 1991 to 1999 data (FDA 2000c). However, cypermethrin was detected in the milk from cows wearing ear tags impregnated with cypermethrin to control certain insects (Braun et al. 1985). Flumethrin, deltamethrin, cypermethrin, and cyhalothrin were detected in the milk of cows after single dermal applications (Bissacot and Vassilieff 1997a). Children may be exposed to pyrethrins and pyrethroids from the clothing of parents who work as pesticide applicators. Asakawa et al. (1996) documented that permethrin adhered to a worker's clothing and different parts of the body following the application of this insecticide onto a cabbage field. Similar findings were obtained for cotton sprayers using deltamethrin and fenvalerate (Zhang et al. 1991). Washing the affected clothing does not necessarily assure that all of the pyrethroids will be removed from the contaminated garments. Fabrics that simulated the clothing worn by workers applying cypermethrin insecticides were found to contain $1.7-2.3 \mu \mathrm{g} / \mathrm{cm}^{2}$ before laundering; after laundering, levels of $0.3-1.1 \mathrm{ng} / \mathrm{cm}^{2}$ remained in the fabric (Laughlin et al. 1991). A study was conducted to determine the ability of laundry practices used by farm families to remove pesticides from clothing (Rigakis et al. 1987). After one wash, 2-18\% of initial deltamethrin remained on fabrics, and after two washes, $1-10 \%$ of initial deltamethrin remained on fabrics (Rigakis et al. 1987). Pretreating the fabric with a prewash spot removal product especially formulated to assist in the removal of oily stains resulted in the lowest recoveries. Cotton strips were coated with deltamethrin and then rinsed in deionized water for 1 hour (Hussain and Perschke 1991). After four rinses, only $37.7 \%$ of the initial deltamethrin was removed from the cotton. Impregnating the cotton with various paraffin wax and oils (corn, linseed, silicone) before coating with deltamethrin resulted in even lower percentages removed when washed (9.9-29.2\% removal).

\subsection{POPULATIONS WITH POTENTIALLY HIGH EXPOSURES}

Aside from agricultural workers or insect control applicators, populations with potentially high exposures to pyrethrins or pyrethroids are small. Workers involved in the manufacturing and production of these insecticides are likely to be exposed to higher levels than the general population. Veterinarian professionals or pet groomers who frequently apply pyrethrin- and pyrethroid-containing shampoos or flea applications to animals may also be exposed to high levels of these compounds through dermal routes. Persons residing near farms or orchards may be subject to spray drift following application of these insecticides onto crops. Humans who use shampoos or sprays that contain pyrethrins or pyrethroids for their pets are likely to be exposed to higher levels of these compounds than persons without pets. 
Home gardeners who use pyrethroids and pyrethrins for insect control either in the garden or within the household itself may be exposed to high levels. Diet is also a key factor in relative human exposure level to pyrethrins and pyrethroids. As shown in Table 6-3, these compounds are frequently detected at varying levels in fruits and vegetables.

Permethrin is part of the United States Department Of Defense (DOD) Insect Repellent System and was issued in the Persian Gulf War to military personnel as a ready to use insect repellent for clothing application. It is also labeled for use on battle dress clothing and bed netting (Cecchine et al. 2000). Phenothrin was also used for spraying on bed netting and inside of aircrafts to prevent transport of insects. Due to an absence of sampling data and information about pesticide application rates, individual exposures were reconstructed by means of interviews with service personnel. The DOD reported that approximately 44 and $28 \%$ of all service personal in the Gulf used permethrin and phenothrin sprays, respectively, and that the guidelines for their recommended use were not always strictly adhered to (DOD 2001). This may have led to excessive exposures to these insecticides by some members of the military serving in the Persian Gulf.

\subsection{ADEQUACY OF THE DATABASE}

Section 104(i)(5) of CERCLA, as amended, directs the Administrator of ATSDR (in consultation with the Administrator of EPA and agencies and programs of the Public Health Service) to assess whether adequate information on the health effects of pyrethrins and pyrethroids are available. Where adequate information is not available, ATSDR, in conjunction with the National Toxicology Program (NTP), is required to assure the initiation of a program of research designed to determine the health effects (and techniques for developing methods to determine such health effects) of pyrethrins and pyrethroids.

The following categories of possible data needs have been identified by a joint team of scientists from ATSDR, NTP, and EPA. They are defined as substance-specific informational needs that if met would reduce the uncertainties of human health assessment. This definition should not be interpreted to mean that all data needs discussed in this section must be filled. In the future, the identified data needs will be evaluated and prioritized, and a substance-specific research agenda will be proposed. 


\subsubsection{Identification of Data Needs}

Physical and Chemical Properties. As illustrated in Tables 4-4 and 4-5, the relevant physical and chemical properties of pyrethrins and the pyrethroids that are used in the United States are not entirely known. There are several pyrethroids that have been developed, and adequate data may not be available for all of them (Mueller-Beilschmidt 1990). Furthermore, inert ingredients used in formulated pesticide products are usually not disclosed. This makes a thorough evaluation of the final commercial product challenging. Complete disclosure of all the ingredients used in a formulated product would aid in the evaluation of both physical and toxicological properties of the pesticide.

\section{Production, Import/Export, Use, Release, and Disposal. Knowledge of a chemical's}

production volume is important because it may correlate with environmental contamination and human exposure. If a chemical's production volume is high, then there is an increased probability of general population exposure via consumer products and environmental sources, such as air, drinking water, and food.

The TRI99 (2001), which became available in 2001, has been used in this profile. The only pyrethroids that are on the list are allethrin, bifenthrin, cyfluthrin, cyhalothrin, fenpropathrin, fluvalinate, permethrin, phenothrin, resmethrin, and tetramethrin (TRI99 2001). Furthermore, data have only been reported for bifenthrin, cyfluthrin, permethrin, resmethrin, and tetramethrin. More detailed site- and medium-specific (e.g., air, water, or soil) release data for more pyrethroids are necessary. According to the Emergency Planning and Community Right-to-Know Act of 1986, 42 U.S.C. Section 11023, industries are required to submit chemical release and off-site transfer information to the EPA. TRI, which contains this information for 1999, became available in 2001. This database will be updated yearly and should provide a list of industrial production facilities and emissions.

Environmental Fate. Information is available to permit assessment of the environmental fate and transport of the pyrethrins and pyrethroids in air (Chen and Casida 1969; Chen et al. 1984; HSDB 2001; Samsonov and Makarov 1996; Ueda et al. 1974), water (Maguire 1990; Rawn et al. 1982; Schimmel et al. 1983; USDA 2001a), and soil (Chapman et al. 1981; Hill 1983; Khan et al. 1988; Smith et al. 1995; USDA 2001a). Most of these compounds are rapidly degraded in the air by photolysis or through the reaction with oxidants such as hydroxyl radicals, ozone, or nitrate radicals found in the atmosphere. Many of the recently developed pyrethroids such as cyhalothrin are more stable towards sunlight than the early light sensitive pyrethroids like allethrin and resmethrin. Volatilization from water surfaces may be 
an important fate process for pyrethrins and pyrethroids with relatively large Henry's law constants, but adsorption to suspended solids and sediments will attenuate this process. Photolysis in sunlit surface waters has been demonstrated for several pyrethroids (Maguire 1990; Rawn et al. 1982; Schimmel et al. 1983). Hydrolysis is also an important environmental fate process in water or moist soil under alkaline conditions (Chapman and Cole 1982; USDA 2001a). Biodegradation occurs in water, soil, and sediment at varying rates (Cotham and Bidleman 1989; Hill 1983; Schimmel et al. 1983; Smith et al. 1995; USDA 2001a). Photolysis and volatilization of these compounds can occur on soil and plant surfaces (Hill and Johnson 1987; Takahashi et al. 1985a). These compounds are not expected to leach extensively since they have very little mobility in soils (USDA 2001a).

While it can be reasonably concluded that pyrethrins will biodegrade in the environment based upon their chemical structure, there are no specific biodegradation studies of the six pyrethrins. Furthermore, there are several synthetic pyrethroids for which experimental data regarding their biodegradation, bioconcentration, photolysis, adsorption, and hydrolysis are not available. Studies on these pyrethroids are warranted.

Bioavailability from Environmental Media. The bioavailability of pyrethrins and pyrethroids from contaminated air, water, soil, or plant material in the environment has not been adequately studied. ${ }^{14} \mathrm{C}$-labeled deltamethrin was used to treat wheat grains that were ultimately fed to rats (Khan et al. 1990). The ${ }^{14} \mathrm{C}$ residues were excreted in the urine and feces of the rats and trace amounts were also present in the lungs and kidneys, which suggests that the bound deltamethrin residues in the wheat were bioavailable (Khan et al. 1990). A similar experiment was performed using deltamethrin ${ }^{14} \mathrm{C}$ labeled at either the methyl or benzylic position applied to bean plants (Khan et al. 1986). Four days after feeding rats the contaminated material, $60 \%$ (methyl ${ }^{14} \mathrm{C}$ labeled) and $53 \%$ (benzylic ${ }^{14} \mathrm{C}$ labeled) of the dose was excreted in the feces, while $31 \%$ (methyl ${ }^{14} \mathrm{C}$ labeled) and $20 \%$ (benzylic ${ }^{14} \mathrm{C}$ labeled) of the dose was excreted in the urine. No radioactivity was detected in the liver, kidney, brain, or lung tissue of the sacrificed rats. Workers applying pyrethroids in the field have a much greater dermal exposure rate when compared to inhalation exposure (Adamis et al. 1985; Wan 1990; Yoshida et al. 1990; Zhang et al. 1991), but the percentage of pyrethroid absorbed dermally is less than oral and inhalation absorption (Eadsforth et al. 1988; van der Rhee et al. 1989; Woollen et al. 1992). Since these compounds adsorb strongly to soils, bioavailability from soil may be limited, but absorption and bioavailability studies of these compounds from soils are lacking. Studies are needed on the bioavailability of these compounds from actual environmental media and on differences in bioavailability for the various pyrethrins and pyrethroids. 
Food Chain Bioaccumulation. Bioconcentration occurs in aquatic organisms (Freitag et al. 1985; Haitzer et al. 1998; Schimmel et al. 1983). There is no evidence to indicate that bioaccumulation occurs in aquatic or terrestrial species, but studies are needed to determine if pyrethrins and pyrethroids bioaccumulate up the food chain.

Exposure Levels in Environmental Media. Atmospheric concentrations of pyrethrins or pyrethroids are usually on the order of $\mu \mathrm{g} / \mathrm{m}^{3}$ immediately after their application (Eitzer 1991; Siebers and Mattusch 1996), but the levels decrease with time because these compounds undergo rapid degradation in the atmosphere. These compounds are infrequently detected in groundwater and drinking water in the United States because of their strong adsorption to soils and relatively rapid rate of degradation. Pyrethrins and pyrethroids are found in soils following their application, but their levels decrease with time. The average concentration of permethrin in soils collected from 48 agrochemical facilities located throughout the state of Illinois was $190 \mu \mathrm{g} / \mathrm{kg}$ (Krapac et al. 1995). More data regarding the levels of pyrethrins and pyrethroids in water and soil surfaces are needed in order to produce better estimates of the potential for human exposure to these compounds. Foods, especially fruits and vegetables, have been shown to contain pyrethroids at varying levels (Table 6-3). Continued monitoring data of these compounds in foods are necessary since ingestion of food sources is the most likely route of widespread human exposure.

Exposure Levels in Humans. The general population is exposed to pyrethrins and pyrethroids primarily through the ingestion of food sources. The AVDI of permethrin, the most frequently used pyrethroid in the United States, has been estimated for eight different population groups (Gunderson 1988, 1995a, 1995b). Additional data regarding the AVDI for other pyrethroids and pyrethrins would be useful in assessing total exposure for the U.S. population. The use of household insecticides containing these compounds can also lead to dermal and inhalation exposure. Workers employed in the agricultural industry, veterinary industry, or pet grooming business may be occupationally exposed to high levels of these compounds. Dermal exposure has been shown to be greater than inhalation exposure for applicators involved in the spraying of pyrethroids (Adamis et al. 1985; Wan 1990), but dermal absorption appears to be lower than the amount absorbed from the other routes. While body burden studies were located for persons occupationally exposed (Asakawa et al. 1996; Wan 1990), body burden studies are needed for the general population of the United States. 
Exposures of Children. Estimates regarding the AVDI of permethrin for children are available (Gunderson 1988, 1995a, 1995b). Additional data regarding the AVDI for other pyrethroids and pyrethrins would be useful to assess childhood exposure more thoroughly. Body burden studies of children are also necessary. Since children may be exposed to these compounds from pica, bioavailability studies from soils would be useful for a wide array of pyrethrins and pyrethroids.

Child health data needs relating to susceptibility are discussed in 3.12.2 Identification of Data Needs: Children's Susceptibility.

Exposure Registries. No exposure registries for pyrethrins and pyrethroids were located. These substances are not currently among the compounds for which a subregistry has been established in the National Exposure Registry. The substances will be considered in the future when chemical selection is made for subregistries to be established. The information amassed in the National Exposure Registry facilitates epidemiological research needed to assess adverse health outcomes that may be related to exposure to pyrethrins and pyrethroids.

The development of a registry of exposures would provide a useful reference tool for monitoring exposure levels and frequencies over time. Such a registry would allow an assessment of the variations in exposure levels from various sources. Also it could be used to assess the effect of geographical, seasonal, or regulatory actions on the level of exposure from a certain source. These assessments, in turn, would provide a better understanding of the needs for research or data acquisition based on the current exposure levels.

\subsubsection{Ongoing Studies}

The Federal Research Programs In Progress (FEDRIP 2001), Current Research Information System (CRIS/USDA 2001), and Computer Retrieval of Information on Scientific Projects (CRISP 2001) databases indicate that several projects are ongoing that may fill some existing data gaps. Symbiotech Inc., located in Wallingford, Connecticut, is investigating a topical preparation of permethrin intended for use on humans as an insect repellent (FEDRIP 2001). Researchers at the University of Arkansas (Dr. Meisch and Dr. Bernhardt) are investigating the efficacy and environmental effects of various pyrethroids for mosquito control in riceland systems (CRIS/USDA 2001). Dr. Epstein from the University of 
California Davis, is developing software based on the California Department of Pesticide Regulation's Pesticide Use Reports to document trends in fungicide and insecticide use on grapes and almonds, respectively (CRIS/USDA 2001). Dr. Hammock from the University of California Davis is attempting to develop and validate single compound, as well as class selective immunoassays for urinary metabolites of hazardous compounds (including pyrethroids) for use as biomarkers of internal exposure to these compounds (CRISP 2001). 


\section{ANALYTICAL METHODS}

The purpose of this chapter is to describe the analytical methods that are available for detecting, measuring, and/or monitoring pyrethrins and pyrethroids, its metabolites, and other biomarkers of exposure and effect to pyrethrins and pyrethroids. The intent is not to provide an exhaustive list of analytical methods. Rather, the intention is to identify well-established methods that are used as the standard methods of analysis. Many of the analytical methods used for environmental samples are the methods approved by federal agencies and organizations such as EPA and the National Institute for Occupational Safety and Health (NIOSH). Other methods presented in this chapter are those that are approved by groups such as the Association of Official Analytical Chemists (AOAC) and the American Public Health Association (APHA). Additionally, analytical methods are included that modify previously used methods to obtain lower detection limits and/or to improve accuracy and precision.

\subsection{BIOLOGICAL MATERIALS}

Exposure to pyrethrins and pyrethroids is most commonly evaluated by the analysis of urine and blood using gas chromatography (GC) combined with electron capture detection (ECD), flame ionization detection (FID), or mass spectrometry (MS) and high performance liquid chromatography (HPLC) coupled with ultraviolet (UV) detector. Recovery is generally high, and sensitivity is in the parts per billion (ppb) range.

A simple and rapid method for the isolation of synthetic pyrethroids using a solid phase extraction method is described by Junting and Chichang (1991). A similar method that employs HPLC for analysis was used to quantify pyrethrins in plasma by Wintersteiger et al. (1994). This method eliminates timeconsuming repeated extractions with organic solvents and centrifugations without losing the efficiency of recovery.

Pyrethrins and pyrethroids are extensively metabolized by the cleavage of the ester linkage, oxidation, and conjugation. Metabolites formed are less lipophilic, and are rapidly and easily excreted in the urine. Exposure to pyrethrins and pyrethroids can be monitored by the detection of these excreted metabolites. Pyrethroids such as cyfluthrin, cyhalothrin, cypermethrin, deltamethrin, fenvalerate, phenothrin, and permethrin can be metabolized resulting in the formation of halosubstituted chrysanthemic and 
3-phenoxybenzoic acids (Angrer and Ritter 1997; Yao et al. 1992). The rapid metabolism of the pyrethroids makes it useful to monitor for pyrethroid metabolites in the urine of exposed individuals rather than monitoring the actual concentration of the pyrethroid itself in blood (Leng et al. 1999a). Also, it has been demonstrated that storing frozen urine samples for up to a year results in no further degradation of the metabolites (Leng et al. 1999a). In contrast, pyrethroids stored in plasma are susceptible to continued degradation (Leng et al. 1999a).

Methods for analyzing pyrethrins and pyrethroids as well as the metabolites in biological samples are shown in Table 7-1.

\subsection{ENVIRONMENTAL SAMPLES}

Concerns about contamination of environmental media, plants, and animals with pyrethrins have led to the need for more rapid, sensitive, and selective methods of analysis. As with biological samples, the most common methods of analysis are GC combined with ECD, FID, or flame photometric detection (FPD) and HPLC coupled with UV detector. Thermal conductivity detectors, thermionic detectors, and nitrogen phosphorus detectors have also been used in conjunction with GC.

Pyrethrins and pyrethroids are nonpolar compounds and nonsystemic in plants; thus, the extraction procedures in environmental samples are simpler than those used for organophosphate and carbamate insecticides. Generally, the samples are homogenized with a nonpolar solvent, such as hexane or benzene, or a binary solvent mixture, such as hexane-acetone, hexane-isopropanol, or light petroleumdiethyl ether. The pyrethrins and pyrethroids, along with a wide variety of other lipophilic substances are co-extracted during this procedure. The resulting solution is dried with anhydrous sodium sulfate. If there are too many co-extracted compounds, separation by liquid-liquid partition or column chromatography is performed. Samples with a low water content, such as tea, tobacco, and straw, are usually extracted with a binary solvent mixture, as are moist vegetables and fruits. Soil samples are first ground and filtered to remove large particles and stones, and then are extracted with acetone-hexane, methanol, acetone, or acetonitrile. Pyrethrins and pyrethroids are extracted from water samples with hexane, methylene chloride, or acetonitrile with subsequent drying with anhydrous sodium sulfate. 


\section{Table 7-1. Analytical Methods for Determining Pyrethrins and Pyrethroids in Biological Materials}

\begin{tabular}{|c|c|c|c|c|c|c|}
\hline $\begin{array}{l}\text { Sample } \\
\text { matrix }\end{array}$ & Analyte & Preparation method & $\begin{array}{l}\text { Analytical } \\
\text { method }\end{array}$ & $\begin{array}{l}\text { Sample } \\
\text { detection } \\
\text { limit }\end{array}$ & $\begin{array}{l}\text { Percent } \\
\text { recovery }\end{array}$ & Reference \\
\hline $\begin{array}{l}\text { Blood, } \\
\text { milk }\end{array}$ & $\begin{array}{l}\text { Deltamethrin, } \\
\text { cyhalothrin } \\
\text { cypermethrin, } \\
\text { flumethrin }\end{array}$ & $\begin{array}{l}\text { Acidify with } 1 \mathrm{~N} \mathrm{HCl} \text {; } \\
\text { extract twice with } \\
\mathrm{CH}_{3} \mathrm{CN} \text { and filter; } \\
\text { extract filtrate with } \\
\text { hexane and discard } \\
\text { the hexane phase; } \\
\text { remove } \mathrm{CH}_{3} \mathrm{CN} \text { under } \\
\text { a stream of } \mathrm{N}_{2} \text { and } \\
\text { heat to dryness; } \\
\text { cleanup on a silica gel } \\
\text { column; dissolve in } \\
\mathrm{CH}_{3} \mathrm{CN} \text { and filter } \\
\text { through a } 0.45 \mu \mathrm{m} \\
\text { pore cellulose filter }\end{array}$ & LC/UV & $1.0 \mu \mathrm{g} / \mathrm{kg}$ & $78-91$ & $\begin{array}{l}\text { Bissacot and } \\
\text { Vassilieff } \\
\text { 1997a, 1997b }\end{array}$ \\
\hline Plasma & Pyrethrins & $\begin{array}{l}\text { Dilute centrifuged } \\
\text { plasma with water; } \\
\text { cleanup on a solid } \\
\text { phase extraction } \\
\text { column; elute with } \\
\text { methanol }\end{array}$ & RPHPLC/UV & $0.167 \mathrm{mg} / \mathrm{L}$ & $70-72$ & $\begin{array}{l}\text { Wintersteiger } \\
\text { et al. } 1994\end{array}$ \\
\hline Plasma & $\begin{array}{l}\text { Cyfluthrin, } \\
\text { cypermethrin, } \\
\text { permethrin }\end{array}$ & $\begin{array}{l}\text { Precipitation of } \\
\text { proteins followed by } \\
\text { liquid-liquid extraction }\end{array}$ & GC/ECD & $5 \mu \mathrm{g} / \mathrm{L}$ & No data & $\begin{array}{l}\text { Leng et al. } \\
1999 a\end{array}$ \\
\hline $\begin{array}{l}\text { Plasma, } \\
\text { urine }\end{array}$ & $\begin{array}{l}\text { Fenopropathrin, } \\
\text { permethrin, } \\
\text { cypermethrin, } \\
\text { fenvalerate, } \\
\text { deltamethrin }\end{array}$ & $\begin{array}{l}\text { Mix samples with } 70 \% \\
\text { methanol; pour on to } \\
\text { Sep-Pak } \mathrm{C}_{18} \text { columns } \\
\text { pretreated with } \\
\text { chloroform, methanol, } \\
\text { methanol/water, and } \\
\text { water; wash with } \\
\text { water; elute with } \\
\text { chloroform; evaporate } \\
\text { to dryness under } \\
\text { stream of } \mathrm{N}_{2} \text {; } \\
\text { redissolve in ethanol }\end{array}$ & GC/FID & $2 \mathrm{mg} / \mathrm{L}$ & $\begin{array}{l}81-93 \\
90-102\end{array}$ & $\begin{array}{l}\text { Junting and } \\
\text { Chuichang } \\
1991\end{array}$ \\
\hline Urine & $\begin{array}{l}\text { Cis- and trans- } \\
\text { 3-(2,2-dichloro- } \\
\text { vinyl)- } \\
\text { 2,2-dimethyl- } \\
\text { cycloprane-1- } \\
\text { carboxylic acid; } \\
\text { 3-phenoxyben- } \\
\text { zoic acid; fluoro- } \\
\text { phenoxybenzoic } \\
\text { acid }\end{array}$ & $\begin{array}{l}\text { Liquid-liquid } \\
\text { extraction followed by } \\
\text { methylation of the free } \\
\text { acid metabolites }\end{array}$ & GC/MS & $0.5 \mu \mathrm{g} / \mathrm{L}$ & No data & $\begin{array}{l}\text { Leng et al. } \\
1999 \mathrm{~b}\end{array}$ \\
\hline
\end{tabular}




\section{Table 7-1. Analytical Methods for Determining Pyrethrins and Pyrethroids in Biological Materials}

\begin{tabular}{|c|c|c|c|c|c|c|}
\hline $\begin{array}{l}\text { Sample } \\
\text { matrix }\end{array}$ & Analyte & Preparation method & $\begin{array}{l}\text { Analytical } \\
\text { method }\end{array}$ & $\begin{array}{l}\text { Sample } \\
\text { detection } \\
\text { limit }\end{array}$ & $\begin{array}{l}\text { Percent } \\
\text { recovery }\end{array}$ & Reference \\
\hline Urine & $\begin{array}{l}\text { Cis- and trans- } \\
\text { 3-(2,2-dichloro- } \\
\text { vinyl)- } \\
\text { 2,2-dimethyl- } \\
\text { cycloprane- } \\
\text { 1-carboxylic } \\
\text { acid; cis-3- } \\
\text { (2,2-dibro- } \\
\text { movinyl)- } \\
\text { 2,2-dimethylcy- } \\
\text { cloprane-1-car- } \\
\text { boxylic acid; } \\
\text { 3-phenoxy- } \\
\text { benzoic acid; } \\
\text { 4-fluoro- } \\
\text { 3-phenoxy-ben- } \\
\text { zoic acid }\end{array}$ & $\begin{array}{l}\text { Acidify with } \mathrm{AcOH} ; \\
\text { add concentrated } \\
\mathrm{H}_{2} \mathrm{SO}_{4} \text {; heat at } 90{ }^{\circ} \mathrm{C} \\
\text { for } 1 \text { hour; cleanup on } \\
\mathrm{C}_{18} \text { column; elute with } \\
\text { methanol into a vial } \\
\text { containing concen- } \\
\text { trated } \mathrm{H}_{2} \mathrm{SO}_{4} \text {; } \\
\text { complete derivati- } \\
\text { zation on water bath } \\
\text { for } 1 \text { hour; extract with } \\
\text { hexane }\end{array}$ & GC/MS & $0.3-0.5 \mu \mathrm{g} / \mathrm{L}$ & $90-98$ & $\begin{array}{l}\text { Angerer and } \\
\text { Ritter } 1997\end{array}$ \\
\hline Urine & $\begin{array}{l}\text { Dibromovinyl- } \\
\text { dimethylcyclo- } \\
\text { propane car- } \\
\text { boxylic acid, } \\
\text { 3-phenoxy- } \\
\text { benzyl-hydroxy- } \\
\text { ethyl acetate, } \\
\text { 3-phenoxyben- } \\
\text { zoic acid }\end{array}$ & $\begin{array}{l}\text { Adjust pH of sample } \\
\text { to } 6.5 \text {; extract with } \\
\text { hexane; evaporate to } \\
\text { dryness; redissolve in } \\
\text { methanol }\end{array}$ & RPHPLC/UV & No data & 95 & $\begin{array}{l}\text { Yao et al. } \\
1992\end{array}$ \\
\hline Urine & $\begin{array}{l}\text { Deltamethrin, } \\
\text { fenvalerate }\end{array}$ & $\begin{array}{l}\text { Extract with hexane; } \\
\text { concentrate and } \\
\text { cleanup on Florisil } \\
\text { column; elute with } \\
\text { benzene; dry on } \\
\text { anhydrous } \mathrm{Na}_{2} \mathrm{SO}_{4} \\
\end{array}$ & GC/ECD & $0.2 \mu \mathrm{g} / \mathrm{L}$ & $92-95.3$ & $\begin{array}{l}\text { Yi-Qun et al. } \\
1994\end{array}$ \\
\hline
\end{tabular}

$\mathrm{AcOH}=$ acetic acid; $\mathrm{CH}_{3} \mathrm{CN}=$ acetonitrile; $\mathrm{ECD}=$ electron capture detector; $\mathrm{FID}=$ flame ionization detector; $\mathrm{GC}=$ gas chromatography; $\mathrm{HCl}=$ hydrochloric acid; $\mathrm{H}_{2} \mathrm{SO}_{4}=$ sulfuric acid; $\mathrm{LC}=$ liquid chromatography; $\mathrm{MS}=$ mass spectrometry; $\mathrm{N}_{2}=$ nitrogen; $\mathrm{Na}_{2} \mathrm{SO}_{4}=$ sodium sulfate; $\mathrm{RPHPLC}=$ reverse phase high performance liquid chromatography; UV = ultra-violet detection 
In the analysis of pyrethrins, the total residues of the six active compounds are often analyzed for, but in the analysis of pyrethroids, the individual compounds are usually quantified (Chen and Wang 1996). An extensive review of the chromatographic methods employed for the determination of pyrethrins and pyrethroids in foods, crops, and environmental media has been published (Chen and Wang 1996). Many pyrethroids such as bifenthrin, cyfluthrin, cyhalothrin, cypermethrin, deltamethrin, fenvalerate, and permethrin possess one or more halogenated atoms which are sensitive to ECD. Often, derivitization is used to create a sensitive group for pyrethroids that do not possess halogenated atoms (allethrin, resmethrin, phenothrin, and tetramethrin, for example), or to improve the sensitivity and peak tailing situations in some halogenated pyrethroids (Chen and Wang 1996). Consequently, GC/ECD is the most popular analytical approach for analyzing pyrethroids in environmental samples.

A detection limit of $0.1 \mu \mathrm{g} / \mathrm{m}^{3}$ and a mean recovery of $100.15 \%$ has been reported for the analysis of cypermethrin in air using GC/ECD (Pomorska 1999), while permethrin and resmethrin had detection limits in the $\mathrm{ng} / \mathrm{m}^{3}$ and very good recoveries with a GC/MS method (Roinestad et al. 1993). This is comparable to methods used for the determination of other pyrethroids in air using GC (EMMI 1997). The analysis of pyrethrins and pyrethroids in water is also accomplished through the use of GC and HPLC. Detection limits in the ppb ( $\mu \mathrm{g} / \mathrm{L})$ range have been achieved (EMMI 1997). A method for the analysis of selected pyrethroids in soils has been described by Alawi et al. (1990) that utilizes GC equipped with a nitrogen phosphorus detector (NPD).

Methods for analyzing pyrethrins in environmental samples are shown in Table 7-2.

\subsection{ADEQUACY OF THE DATABASE}

Section 104(i)(5) of CERCLA, as amended, directs the Administrator of ATSDR (in consultation with the Administrator of EPA and agencies and programs of the Public Health Service) to assess whether adequate information on the health effects of pyrethrins and pyrethroids are available. Where adequate information is not available, ATSDR, in conjunction with the National Toxicology Program (NTP), is required to assure the initiation of a program of research designed to determine the health effects (and techniques for developing methods to determine such health effects) of pyrethrins.

The following categories of possible data needs have been identified by a joint team of scientists from ATSDR, NTP, and EPA. They are defined as substance-specific informational needs that if met would 


\section{Table 7-2. Analytical Methods for Determining Pyrethrins and Pyrethroids in Environmental Samples}

\begin{tabular}{|c|c|c|c|c|c|c|}
\hline $\begin{array}{l}\text { Sample } \\
\text { matrix }\end{array}$ & Analyte & $\begin{array}{l}\text { Preparation } \\
\text { method }\end{array}$ & $\begin{array}{l}\text { Analytical } \\
\text { method }\end{array}$ & $\begin{array}{l}\text { Sample } \\
\text { detection } \\
\text { limit }\end{array}$ & $\begin{array}{l}\text { Percent } \\
\text { recovery }\end{array}$ & Reference \\
\hline$\overline{\text { Air }}$ & $\begin{array}{l}\text { Allethrin, } \\
\text { fenvalerate, } \\
\text { pyrethrin I, } \\
\text { resmethrin }\end{array}$ & $\begin{array}{l}\text { Air samples } \\
\text { collected on a } \\
\text { sorbent cartridge; } \\
\text { extract with } 5 \% \\
\text { diethyl ether in } \\
\text { hexane }\end{array}$ & $\begin{array}{l}\text { GC/ECD; } \\
\text { GC/NPD; } \\
\text { GC/FPD; } \\
\text { HPLC/UV }\end{array}$ & $0.1-50 \mu \mathrm{g} / \mathrm{m}^{3}$ & No data & $\begin{array}{l}\text { ASTM } \\
\text { D4861 } \\
\text { EMMI } 1997\end{array}$ \\
\hline Air & Cypermethrin & $\begin{array}{l}\text { Air samples } \\
\text { collected on a } \\
\text { sorbent cartridge; } \\
\text { extract with acetone }\end{array}$ & GC/ECD & $0.1 \mu \mathrm{g} / \mathrm{m}^{3}$ & $\begin{array}{l}100.15 \\
\text { (mean } \\
\text { recovery) }\end{array}$ & $\begin{array}{l}\text { Pomorska } \\
1999\end{array}$ \\
\hline Air & $\begin{array}{l}\text { Resmethrin, } \\
\text { permethrin }\end{array}$ & $\begin{array}{l}\text { Air samples } \\
\text { collected on filter } \\
\text { paper or Tenax } \\
\text { tubes; extract with } \\
\text { acetone }\end{array}$ & GC/MS & $\begin{array}{l}1 \mathrm{ng} / \mathrm{m}^{3} \\
\text { (permethrin); } \\
10 \mathrm{ng} / \mathrm{m}^{3} \\
\text { (resmethrin) }\end{array}$ & $\begin{array}{l}\text { 109.5-110.9 } \\
\text { (permethrin); } \\
84.6 \\
\text { (resmethrin) }\end{array}$ & $\begin{array}{l}\text { Roinestad } \\
\text { et al. } 1993\end{array}$ \\
\hline Air (dust) & $\begin{array}{l}\text { Resmethrin, } \\
\text { permethrin }\end{array}$ & $\begin{array}{l}\text { Dust samples are } \\
\text { homogenized in a } \\
\text { blender or food } \\
\text { processor; extract } \\
\text { with acetone }\end{array}$ & GC/MS & $\begin{array}{l}50 \mathrm{ng} / \mathrm{g} \\
\text { (permethrin); } \\
100 \mathrm{ng} / \mathrm{g} \\
\text { (resmethrin) }\end{array}$ & $\begin{array}{l}94.8-124.4 \\
\text { (permethrin); } \\
82.6 \\
\text { (resmethrin) }\end{array}$ & $\begin{array}{l}\text { Roinestad } \\
\text { et al. } 1993\end{array}$ \\
\hline Air & Pyrethrums & $\begin{array}{l}\text { Air samples } \\
\text { collected with } \\
\text { sampling pump } \\
\text { equipped with filter; } \\
\text { extract with } \mathrm{CH}_{3} \mathrm{CN}\end{array}$ & HPLC/UV & $0.020 \mathrm{mg} / \mathrm{m}^{3}$ & No data & $\begin{array}{l}\text { NIOSH } \\
5008 \text { EMMI } \\
1997\end{array}$ \\
\hline $\begin{array}{l}\text { Fats, oils, } \\
\text { milk, cheese, } \\
\text { fish }\end{array}$ & $\begin{array}{l}\text { Allethrin, } \\
\text { bifenthrin, } \\
\text { deltamethrin, } \\
\text { esfenvalerate, } \\
\text { fenvalerate, } \\
\text { permethrin, } \\
\text { tetramethrin, } \\
\text { tralomethrin }\end{array}$ & $\begin{array}{l}\text { Dissolve fat in } \\
\text { petroleum ether; } \\
\text { extract with } \mathrm{CH}_{3} \mathrm{CN} \text {; } \\
\text { dilute with water; } \\
\text { clean up on Florisil } \\
\text { column; extract with } \\
\text { petroleum } \\
\text { ether/ethyl ether }\end{array}$ & GC/ECD & No data & No data & $\begin{array}{l}\text { FDA 211.1; } \\
\text { FDA 231.1 } \\
\text { EMMI 1997 }\end{array}$ \\
\hline $\begin{array}{l}\text { Fatty and } \\
\text { non fatty } \\
\text { foods }\end{array}$ & $\begin{array}{l}\text { Allethrin, } \\
\text { bifenthrin, } \\
\text { cyfluthrin, } \\
\text { deltamethrin, } \\
\text { esfenvalerate, } \\
\text { fenpropathrin, } \\
\text { fenvalerate, } \\
\text { fluvalinate, } \\
\text { permethrin, } \\
\text { tetramethrin, } \\
\text { tralomethrin }\end{array}$ & $\begin{array}{l}\text { Dissolve fat in } \\
\text { petroleum ether; } \\
\text { extract with } \mathrm{CH}_{3} \mathrm{CN} \text {; } \\
\text { dilute with water; } \\
\text { cleanup on Florisil } \\
\text { column; elute with a } \\
\text { series of eluants-- } \\
\text { methylene chloride, } \\
\text { hexane, and } \mathrm{CH}_{3} \mathrm{CN}\end{array}$ & GLC/ECD & No data & No data & $\begin{array}{l}\text { FDA } 252 \\
\text { EMMI } 1997\end{array}$ \\
\hline
\end{tabular}




\section{Table 7-2. Analytical Methods for Determining Pyrethrins and Pyrethroids in Environmental Samples}

\begin{tabular}{|c|c|c|c|c|c|c|}
\hline $\begin{array}{l}\text { Sample } \\
\text { matrix }\end{array}$ & Analyte & $\begin{array}{l}\text { Preparation } \\
\text { method }\end{array}$ & $\begin{array}{l}\text { Analytical } \\
\text { method }\end{array}$ & $\begin{array}{l}\text { Sample } \\
\text { detection } \\
\text { limit }\end{array}$ & $\begin{array}{l}\text { Percent } \\
\text { recovery }\end{array}$ & Reference \\
\hline $\begin{array}{l}\text { Non-fatty } \\
\text { foods }\end{array}$ & $\begin{array}{l}\text { Allethrin, } \\
\text { bifenthrin, } \\
\text { cyfluthrin, } \\
\text { deltamethrin, } \\
\text { esfenvalerate, } \\
\text { fenpropathrin, } \\
\text { fenvalerate, } \\
\text { fluvalinate, } \\
\text { permethrin, } \\
\text { tetramethrin, } \\
\text { tralomethrin }\end{array}$ & $\begin{array}{l}\text { Extract with } \mathrm{CH}_{3} \mathrm{CN} \\
\text { or } \mathrm{CH}_{3} \mathrm{CN} / \text { water } \\
\text { mixture; dilute with } \\
\text { water; extract with } \\
\text { petroleum ether; } \\
\text { cleanup on Florisil } \\
\text { column; elute with } \\
\text { petroleum } \\
\text { ether/ethyl ether }\end{array}$ & GC/FPD & No data & No data & $\begin{array}{l}\text { FDA } 232.1 \\
\text { EMMI } 1997\end{array}$ \\
\hline $\begin{array}{l}\text { Non-fatty } \\
\text { food }\end{array}$ & $\begin{array}{l}\text { Bifenthrin, } \\
\text { cyfluthrin, } \\
\text { deltamethrin, } \\
\text { esfenvalerate, } \\
\text { fenvalerate, } \\
\text { flucythrinate, } \\
\text { fluvalinate, } \\
\text { permethrin }\end{array}$ & $\begin{array}{l}\text { Blend with acetone } \\
\text { and filter; extract } \\
\text { with petroleum ether } \\
\text { and methylene } \\
\text { chloride; concen- } \\
\text { trate to remove } \\
\text { methylene chloride }\end{array}$ & $\begin{array}{l}\text { GC/ECD; } \\
\text { GC/FPD }\end{array}$ & No data & No data & $\begin{array}{l}\text { FDA } 232.4 \\
\text { EMMI } 1997\end{array}$ \\
\hline $\begin{array}{l}\text { Non-fatty } \\
\text { food }\end{array}$ & $\begin{array}{l}\text { Deltamethrin, } \\
\text { fenpropathrin, } \\
\text { tralomethrin }\end{array}$ & $\begin{array}{l}\text { Blend with acetone } \\
\text { and filter; extract } \\
\text { with methylene } \\
\text { chloride; cleanup on } \\
\text { a column containing } \\
\text { charcoal, } \mathrm{MgO} \text {, and } \\
\text { Celite } 545 \text {; elute } \\
\text { with } \mathrm{CH}_{3} \mathrm{CN} \text { - } \\
\text { benzene }\end{array}$ & $\begin{array}{l}\text { GC/FPD; } \\
\text { GC/TSD }\end{array}$ & No data & No data & $\begin{array}{l}\text { FDA } 232.3 \\
\text { EMMI } 1997\end{array}$ \\
\hline $\begin{array}{l}\text { Fruits, } \\
\text { vegetables, } \\
\text { grains }\end{array}$ & $\begin{array}{l}\text { Bifenthrin, } \\
\text { cyhalothrin, } \\
\text { cypermethrin, } \\
\text { deltamethrin, } \\
\text { fenpropathrin, } \\
\text { fenvalerate, } \\
\text { fluvalinate, } \\
\text { permethrin }\end{array}$ & $\begin{array}{l}\text { Homogenize in } \\
\mathrm{CH}_{3} \mathrm{CN} \text { and filter; } \\
\text { extract with hexane; } \\
\text { wash with } 4 \% \mathrm{NaCl} \text {; } \\
\text { dry over anhydrous } \\
\mathrm{Na}_{2} \mathrm{SO}_{4} \text {; evaporate } \\
\text { to dryness; redis- } \\
\text { solve in hexane; } \\
\text { extract with } \mathrm{CH}_{3} \mathrm{CN} \text {; } \\
\text { evaporate to } \\
\text { dryness; redissolve } \\
\text { in hexane; cleanup } \\
\text { on Florisil column; } \\
\text { elute with a mixture } \\
\text { of petroleum ether } \\
\text { and ethyl ether. }\end{array}$ & GC/ECD & No data & $>70$ & $\begin{array}{l}\text { Pang et al. } \\
1997\end{array}$ \\
\hline
\end{tabular}




\section{Table 7-2. Analytical Methods for Determining Pyrethrins and Pyrethroids in Environmental Samples}

\begin{tabular}{|c|c|c|c|c|c|c|}
\hline $\begin{array}{l}\text { Sample } \\
\text { matrix }\end{array}$ & Analyte & $\begin{array}{l}\text { Preparation } \\
\text { method }\end{array}$ & $\begin{array}{l}\text { Analytical } \\
\text { method }\end{array}$ & $\begin{array}{l}\text { Sample } \\
\text { detection } \\
\text { limit }\end{array}$ & $\begin{array}{l}\text { Percent } \\
\text { recovery }\end{array}$ & Reference \\
\hline $\begin{array}{l}\text { Ground- } \\
\text { water, } \\
\text { drinking } \\
\text { water }\end{array}$ & Permethrin & $\begin{array}{l}\text { Extract with } \\
\text { methylene chloride; } \\
\text { dry over anhydrous } \\
\mathrm{Na}_{2} \mathrm{SO}_{4} \text {; concen- } \\
\text { trate; add methyl } \\
\text { tert-butyl ether }\end{array}$ & GC/ECD & $0.5 \mu \mathrm{g} / \mathrm{L}$ & No data & $\begin{array}{l}\text { EMSLC } 508 \\
\text { EMMI } 1997\end{array}$ \\
\hline $\begin{array}{l}\text { Waste water, } \\
\text { municipal } \\
\text { and } \\
\text { industrial }\end{array}$ & $\begin{array}{l}\text { Allethrin, } \\
\text { cyfluthrin, } \\
\text { fenvalerate, } \\
\text { phenothrin, } \\
\text { pyrethrins I, } \\
\text { pyrethrins II, } \\
\text { resmethrin, } \\
\text { tetramethrin }\end{array}$ & $\begin{array}{l}\text { Saturate sample } \\
\text { with } \mathrm{NaCl} \text {; extract } \\
\text { with } \mathrm{CH}_{3} \mathrm{CN} \text {; } \\
\text { concentrate extract }\end{array}$ & HPLC/UV & $2 \mu \mathrm{g} / \mathrm{L}$ & No data & $\begin{array}{l}\text { EAD } 1660 \\
\text { EMMI } 1997\end{array}$ \\
\hline $\begin{array}{l}\text { Waste water, } \\
\text { industrial }\end{array}$ & Resmethrin & $\begin{array}{l}\text { Extract with } \\
\text { methylene chloride; } \\
\text { dry over anhydrous } \\
\mathrm{Na}_{2} \mathrm{SO}_{4} ; \\
\text { concentrate }\end{array}$ & GC/FID & $36 \mu \mathrm{g} / \mathrm{L}$ & No data & $\begin{array}{l}\text { EMSLC } 616 \\
\text { EMMI } 1997\end{array}$ \\
\hline Soil & $\begin{array}{l}\text { Cypermethrin, } \\
\text { permethrin, } \\
\text { cyfluthrin, } \\
\text { fluvalinate, } \\
\text { deltamethrin }\end{array}$ & $\begin{array}{l}\text { Extract with acetone } \\
\text { saturated with } \\
\text { sodium chloride; dry } \\
\text { with } \mathrm{Na}_{2} \mathrm{SO}_{4}\end{array}$ & GC/NPD & $\begin{array}{l}0.004-0.012 \\
\mathrm{mg} / \mathrm{kg}\end{array}$ & 114 & $\begin{array}{l}\text { Alawi et al. } \\
1990\end{array}$ \\
\hline $\begin{array}{l}\text { Pet } \\
\text { shampoo }\end{array}$ & $\begin{array}{l}\text { Pyrethrins I, } \\
\text { pyrethrins II, } \\
\text { tetramethrin }\end{array}$ & $\begin{array}{l}\text { Dilute with water } \\
\text { and add Celite } 545 \text {; } \\
\text { add to a Celite } \\
\text { column; elute with } \\
\text { petroleum ether; } \\
\text { filter through } 0.5 \mu \mathrm{m} \\
\text { filter }\end{array}$ & $\begin{array}{l}\text { HPLC/UV } \\
\text { GC/FID }\end{array}$ & No data & No data & $\begin{array}{l}\text { EPA-B } \\
\text { EMMI } 1997\end{array}$ \\
\hline
\end{tabular}




\section{Table 7-2. Analytical Methods for Determining Pyrethrins and Pyrethroids in Environmental Samples}

\begin{tabular}{|c|c|c|c|c|c|c|}
\hline $\begin{array}{l}\text { Sample } \\
\text { matrix }\end{array}$ & Analyte & $\begin{array}{l}\text { Preparation } \\
\text { method }\end{array}$ & $\begin{array}{l}\text { Analytical } \\
\text { method }\end{array}$ & $\begin{array}{l}\text { Sample } \\
\text { detection } \\
\text { limit }\end{array}$ & $\begin{array}{l}\text { Percent } \\
\text { recovery }\end{array}$ & Reference \\
\hline $\begin{array}{l}\text { Pesticide } \\
\text { formulation }\end{array}$ & $\begin{array}{l}\text { Pyrethrins I, } \\
\text { pyrethrins II }\end{array}$ & $\begin{array}{l}\text { Extract with } \\
\text { petroleum ether; } \\
\text { filter; evaporate the } \\
\text { filtrate to }<1 \mathrm{~mL} ; \\
\text { add } 0.5 \mathrm{~N} \text { alcoholic } \\
\mathrm{NaOH} \text { and reflux } \\
\text { gently; concentrate; } \\
\text { add Filter-Cel and } \\
10 \% \mathrm{BaCl}_{2} \text { filter; } \\
\text { neutralize with } \\
\mathrm{H}_{2} \mathrm{SO}_{4} \text { using } \\
\text { phenolphthalein; } \\
\text { extract with } \\
\text { petroleum ether; } \\
\text { extract with } 0.1 \mathrm{~N} \\
\mathrm{NaOH} \text {; add Deniges } \\
\text { reagent and let } \\
\text { stand in darkness; } \\
\text { add alcohol and } \\
\text { precipitate } \mathrm{HgCl} \\
\text { with NaCl solution; } \\
\text { filter; add dilute } \mathrm{HCl} \text {; } \\
\text { add chloroform and } \\
\mathrm{ICl} \text { solution }\end{array}$ & Titration & No data & No data & $\begin{array}{l}\text { AOAC } \\
936.05 \\
\text { EMMI } 1997\end{array}$ \\
\hline $\begin{array}{l}\text { Pesticide } \\
\text { formulation }\end{array}$ & Permethrin & $\begin{array}{l}\text { Dissolve in methyl } \\
\text { isobutyl ketone }\end{array}$ & GC/FID & No data & No data & $\begin{array}{l}\text { AOAC } \\
986.03 \\
\text { EMMI } 1997\end{array}$ \\
\hline $\begin{array}{l}\text { Pesticide } \\
\text { formulation }\end{array}$ & Deltamethrin & $\begin{array}{l}\text { Dissolve (and } \\
\text { sonicate) in } \\
\text { isooctane-1,4- } \\
\text { dioxane; filter }\end{array}$ & HPLC/UV & No data & No data & $\begin{array}{l}\text { AOAC } \\
991.03 \\
\text { EMMI } 1997\end{array}$ \\
\hline $\begin{array}{l}\text { Pesticide } \\
\text { formulation }\end{array}$ & Allethrin & $\begin{array}{l}\text { Add ethylenedia- } \\
\text { mine; swirl; let } \\
\text { stand; wash with } \\
\text { pyridine; add } \\
\text { thymophthalein } \\
\text { indicator; titrate with } \\
0.1 \mathrm{~N} \mathrm{NaOMe}\end{array}$ & Titration & No data & No data & $\begin{array}{l}\text { AOAC } \\
953.05 \\
\text { EMMI } 1997\end{array}$ \\
\hline $\begin{array}{l}\text { Pesticide } \\
\text { formulation }\end{array}$ & Pyrethrums & $\begin{array}{l}\text { Dilute with acetone; } \\
\text { add dicyclohexyl } \\
\text { phthalate (internal } \\
\text { standard) }\end{array}$ & GC/FID & No data & No data & $\begin{array}{l}\text { AOAC } \\
982.02 \\
\text { EMMI } 1997\end{array}$ \\
\hline
\end{tabular}




\section{Table 7-2. Analytical Methods for Determining Pyrethrins and Pyrethroids in Environmental Samples}

\begin{tabular}{|c|c|c|c|c|c|c|}
\hline $\begin{array}{l}\text { Sample } \\
\text { matrix }\end{array}$ & Analyte & $\begin{array}{l}\text { Preparation } \\
\text { method }\end{array}$ & $\begin{array}{l}\text { Analytical } \\
\text { method }\end{array}$ & $\begin{array}{l}\text { Sample } \\
\text { detection } \\
\text { limit }\end{array}$ & $\begin{array}{l}\text { Percent } \\
\text { recovery }\end{array}$ & Reference \\
\hline $\begin{array}{l}\text { Pesticide } \\
\text { formulation }\end{array}$ & $\begin{array}{l}\text { Pyrethrins I, } \\
\text { pyrethrins II }\end{array}$ & $\begin{array}{l}\text { Add sample to a } \\
\text { column packed, } \\
\text { bottom to top, with } \\
\text { anhydrous } \mathrm{Na}_{2} \mathrm{SO}_{4} \text {, } \\
\text { Florisil, and } \\
\text { anhydrous } \mathrm{Na}_{2} \mathrm{SO}_{4} \text {; } \\
\text { wash with hexane; } \\
\text { elute with acetone; } \\
\text { evaporate to } \\
\text { dryness; dissolve } \\
\text { residue in carbon } \\
\text { disulfide; dry over } \\
\text { anhydrous } \mathrm{Na}_{2} \mathrm{SO}_{4}\end{array}$ & GC/FID & No data & No data & $\begin{array}{l}\text { EPA-B } \\
\text { EMMI } 1997\end{array}$ \\
\hline $\begin{array}{l}\text { Aerosol } \\
\text { formulation }\end{array}$ & Resmethrin & $\begin{array}{l}\text { Cool can in freezer } \\
\text { overnight; punch } \\
\text { holes in can to } \\
\text { relieve pressure; } \\
\text { open can and warm } \\
\text { to room tempera- } \\
\text { ture; remove } \\
\text { remaining volatiles } \\
\text { by placing in a } \\
\text { water bath; dissolve } \\
\text { residue in benzene }\end{array}$ & GC/TCD & No data & No data & $\begin{array}{l}\text { PMD-Res } \\
\text { EMMI } 1997\end{array}$ \\
\hline $\begin{array}{l}\text { Aerosol } \\
\text { formulation }\end{array}$ & Resmethrin & $\begin{array}{l}\text { Cool can in freezer } \\
\text { overnight; punch } \\
\text { holes in can to } \\
\text { relieve pressure; } \\
\text { open can and warm } \\
\text { to room tempera- } \\
\text { ture; remove } \\
\text { remaining volatiles } \\
\text { by placing in a } \\
\text { water bath; dissolve } \\
\text { residue in methanol }\end{array}$ & $\begin{array}{l}\text { RPHPLC/ } \\
\text { UV }\end{array}$ & No data & No data & $\begin{array}{l}\text { PMD-Res } \\
\text { EPA-B } \\
\text { EMMI } 1997\end{array}$ \\
\hline
\end{tabular}

$\mathrm{BaCl}=$ barium chloride; $\mathrm{CH}_{3} \mathrm{CN}=$ acetonitrile; $\mathrm{ECD}$ = electron capture detector; $\mathrm{FID}=$ flame ionization detector; $\mathrm{FPD}=$ flame photometric detector; $\mathrm{GC}=$ gas chromatography; $\mathrm{HCl}=$ hydrochloric acid; $\mathrm{HgCl}=$ mercuric chloride; $\mathrm{HPLC}=$ high performance liquid chromatography; $\mathrm{H}_{2} \mathrm{SO}_{4}$ = sulfuric acid; $\mathrm{ICl}$ =iodine monochloride; $\mathrm{MgO}$ = magnesium oxide; $\mathrm{NaCl}=$ sodium chloride; $\mathrm{NaOH}$ = sodium hydroxide; $\mathrm{NaOMe}=$ sodium methoxide; $\mathrm{Na}_{2} \mathrm{SO}_{4}=$ sodium sulfate; $\mathrm{NPD}=$ nitrogen phosphorus detector; RPHPLC = reverse phase high performance liquid chromatography; $\mathrm{TCD}=$ thermal conductivity detector; TSD = thermionic detector; UV = ultra-violet detection 
reduce the uncertainties of human health assessment. This definition should not be interpreted to mean that all data needs discussed in this section must be filled. In the future, the identified data needs will be evaluated and prioritized, and a substance-specific research agenda will be proposed.

\subsubsection{Identification of Data Needs}

\section{Methods for Determining Biomarkers of Exposure and Effect.}

Exposure. Methods for detecting and quantifying pyrethrins and pyrethroids in blood (Bissacot and Vassilief 1997a, 1997b), plasma (Junting and Chuichang 1991; Wintersteiger et al. 1994), and urine (Junting and Chuichang 1991; Yi-Qun et al. 1994) are available. Chromatographic techniques, such as GC and HPLC, were used to isolate pyrethrins and their degradation products. ECD, FID, UV, and MS were coupled with the separation techniques to detect these compounds. Sensitivity was high (blood: $1 \mu \mathrm{g} / \mathrm{kg}$; plasma: $2-0.17 \mu \mathrm{g} / \mathrm{kg}$; urine: $0.2-0.5 \mu \mathrm{g} / \mathrm{L}$ ). These methods can accurately detect pyrethrins at background concentrations in blood, plasma, and urine. Methods are available to characterize the metabolites of selected pyrethroids in urine (Angrer and Ritter 1997; Leng et al. 1999a; Yi-Qun et al. 1994). The sensitivity is high and the recovery is good. The existing methods for detecting the pyrethrins in biological samples seem to be adequate.

Effect. Other than the clinical signs of Type I and Type II pyrethroid poisoning discussed in Section 3.8.2, there are no known biomarkers of effect for pyrethrins and pyrethroids. It is important to note that while these effects are characteristic signs of pyrethroid poisoning, they are not exclusive to pyrethroid poisoning. In humans, pyrethroids are rapidly metabolized by esterase, mainly in the liver, and it may be possible to correlate carboxyesterase activity with pyrethroid induced adverse effects (Leng et al. 1999b). However, human plasma contains very little carboxyesterases and the liver is not accessible for routine measurements. As a parameter of carboxyesterase activity for Type II pyrethroids, the production of cyanic acid in human lymphocytes was measured (Leng et al. 1999b). Initial findings indicate that the determination of carboxyesterase activity in lymphocytes may potentially be used as a marker for individual susceptibility.

\section{Methods for Determining Parent Compounds and Degradation Products in Environmental}

Media. Methods are available to measure pyrethrins in air (EMMI 1997; Pomorska 1999), foods (EMMI 1997), water (EMMI 1997), waste water (EMMI 1997), soil (Alawi et al. 1990), and in formulations (methods by American Society for Testing Materials [ASTM], NIOSH, Food and Drug 
Administration [FDA], EPA, Environmental Measurements Laboratory Center [EMLC], Engineering and Analysis Division [EAD], and AOAC). Sensitivity and recovery are not mentioned for several of the methods.

\subsubsection{Ongoing Studies}

Z. Elrassi, of Oklahoma State University, is conducting research on the development of high performance capillary electrophoresis (HPCE) and capillary electrochromatography (CEC) methods for the rapid, sensitive, and efficient separation of pesticides and their metabolites (CRIS 2001). B.W. Blair, of the Canadian Food Inspection Agency, Food Inspection Directorate, Lab Services Division, is developing a rapid, simple, and inexpensive immunological assay technology for low molecular weight contaminants of significance in food safety testing, as a tool for monitoring contaminants in foods and other environmental media (CRIS 2001).

In a study sponsored by the National Institute of Environmental Health Sciences at University of California, Davis, research is being performed to develop and validate single compounds, as well as a class selective immunoassay for urinary metabolites of hazardous compounds such as pyrethroids for use as biomarkers of internal exposure to theses compounds (CRISP 2001). 


\section{REGULATIONS AND ADVISORIES}

Available information on international, national, and state regulations and standards of pyrethrins and pyrethroids is presented in Table 8-1. Information concerning tolerances for residues of pyrethrins and selected pyrethroids is presented in Table 8-2.

ATSDR has not derived acute-, intermediate-, or chronic-duration inhalation MRLs for pyrethrins or pyrethroids because adequate data were not available for this route of exposure.

ATSDR derived an acute-duration oral MRL of $0.3 \mathrm{mg} / \mathrm{kg} /$ day for permethrin, based on a NOAEL of $25 \mathrm{mg} / \mathrm{kg} /$ day for neurological impairment in rats. An uncertainty factor of 100 was used (10 for animal to human extrapolation and 10 to account for intrahuman variation) to derive the MRL.

ATSDR derived an acute-duration oral MRL of $0.02 \mathrm{mg} / \mathrm{kg} /$ day for cypermethrin (97\% purity; $50 / 50$ cis/trans), based on a LOAEL of $20 \mathrm{mg} / \mathrm{kg}$ for neurological impairment in rats (McDaniel and Moser 1993). An uncertainty factor of 1,000 was used (10 for lack of a NOAEL, 10 for animal to human extrapolation, and 10 to account for intrahuman variation) to derive the MRL.

ATSDR derived an acute-duration oral MRL of $0.01 \mathrm{mg} / \mathrm{kg} /$ day for cyhalothrin, based on a NOAEL of $1 \mathrm{mg} / \mathrm{kg}$ /day for gastrointestinal effects in dogs. An uncertainty factor of 100 was used (10 for animal to human extrapolation and 10 to account for intrahuman variation) to derive the MRL.

ATSDR derived an intermediate-duration oral MRL of $0.2 \mathrm{mg} / \mathrm{kg} /$ day for permethrin, based on a NOAEL of $15.5 \mathrm{mg} / \mathrm{kg} /$ day for neurological impairment in rats. An uncertainty factor of 100 was used (10 for animal to human extrapolation and 10 to account for intrahuman variation) to derive the MRL.

ATSDR derived an intermediate-duration oral MRL of $0.01 \mathrm{mg} / \mathrm{kg} /$ day for cyhalothrin, based on a NOAEL of $1 \mathrm{mg} / \mathrm{kg} /$ day for gastrointestinal effects in dogs. An uncertainty factor of 100 was used (10 for animal to human extrapolation and 10 to account for intrahuman variation) to derive the MRL. 
Table 8-1. Regulations and Guidelines Applicable to Pyrethrins and Pyrethroids

\begin{tabular}{|c|c|c|c|}
\hline Agency & Description & Information & References \\
\hline \multicolumn{4}{|c|}{ INTERNATIONAL } \\
\hline \multicolumn{4}{|l|}{ Guidelines: } \\
\hline IARC & $\begin{array}{l}\text { Carcinogenic classification } \\
\text { Deltamethrin } \\
\text { Fenvalerate } \\
\text { Permethrin }\end{array}$ & Group $3^{\mathrm{a}}$ & IARC 2001 \\
\hline WHO & $\begin{array}{l}\text { Drinking water guideline } \\
\text { Permethrin }\end{array}$ & $20 \mu \mathrm{g} / \mathrm{L}$ & WHO 2001 \\
\hline \multicolumn{4}{|l|}{ NATIONAL } \\
\hline \multicolumn{4}{|c|}{$\begin{array}{l}\text { Regulations and } \\
\text { Guidelines: }\end{array}$} \\
\hline \multicolumn{4}{|c|}{ a. Air } \\
\hline ACGIH & TLV-TWA-pyrethrum & $5 \mathrm{mg} / \mathrm{m}^{3}$ & ACGIH 2000 \\
\hline $\mathrm{NIOSH}$ & $\begin{array}{l}\text { REL (TWA)-pyrethrum } \\
\text { IDLH-pyrethrum }\end{array}$ & $\begin{array}{l}5 \mathrm{mg} / \mathrm{m}^{3} \\
5,000 \mathrm{mg} / \mathrm{m}^{3}\end{array}$ & NIOSH 2001 \\
\hline \multirow[t]{3}{*}{ OSHA } & $\begin{array}{l}\text { PEL (8-hour TWA)-pyrethrum } \\
\text { General industry (total dust) }\end{array}$ & $5 \mathrm{mg} / \mathrm{m}^{3}$ & $\begin{array}{l}\text { OSHA 2001a } \\
\text { 29CFR1910.1000 } \\
\text { Table Z-1 }\end{array}$ \\
\hline & $\begin{array}{l}\text { PEL (8-hour TWA)-pyrethrum } \\
\text { Construction industry (total } \\
\text { dust) }\end{array}$ & $5 \mathrm{mg} / \mathrm{m}^{3}$ & $\begin{array}{l}\text { OSHA 2001c } \\
\text { 29CFR1926.55 } \\
\text { Appendix A }\end{array}$ \\
\hline & $\begin{array}{l}\text { PEL (8-hour TWA)-pyrethrum } \\
\text { Shipyard industry (total } \\
\text { dust) }\end{array}$ & $5 \mathrm{mg} / \mathrm{m}^{3}$ & $\begin{array}{l}\text { OSHA 2001b } \\
\text { 29CFR1915.1000 } \\
\text { Table Z }\end{array}$ \\
\hline \multicolumn{4}{|l|}{ b. Water } \\
\hline \multirow[t]{3}{*}{ EPA } & $\begin{array}{l}\text { Water pollution; determination } \\
\text { of reportable quantity - pyrethrin }\end{array}$ & 1 pound & $\begin{array}{l}\text { EPA 2001c } \\
\text { 40CFR117.3 }\end{array}$ \\
\hline & $\begin{array}{l}\text { Water pollution; designation of } \\
\text { hazardous } \\
\text { substance-pyrethrin }\end{array}$ & & $\begin{array}{l}\text { EPA 2001a } \\
\text { 40CFR116.4 }\end{array}$ \\
\hline & $\begin{array}{l}\text { NPDES; toxic pollutants and } \\
\text { hazardous substances required } \\
\text { to be identified by existing } \\
\text { dischargers if expected to be } \\
\text { present-pyrethrins }\end{array}$ & & $\begin{array}{l}\text { EPA 2001d } \\
\text { 40CFR122 } \\
\text { Appendix D }\end{array}$ \\
\hline \multicolumn{4}{|l|}{ c. Food } \\
\hline FDA & $\begin{array}{l}\text { Pyrethrins in combination with } \\
\text { piperonyl butoxide may be } \\
\text { safely used for insect control on } \\
\text { bags intended for use in } \\
\text { contact with dried food }\end{array}$ & & $\begin{array}{l}\text { FDA 2000a } \\
\text { 21CFR178.3720 }\end{array}$ \\
\hline
\end{tabular}


Table 8-1. Regulations and Guidelines Applicable to Pyrethrins and Pyrethroids

\begin{tabular}{|c|c|c|c|}
\hline Agency & Description & Information & References \\
\hline \multicolumn{4}{|c|}{ NATIONAL (cont.) } \\
\hline USDA & $\begin{array}{l}\text { Labeling of treated seed with } \\
\text { pyrethrins-"don't use for food, } \\
\text { feed, or oil purposes" } \\
\text { Oat } \\
\text { Sorghum }\end{array}$ & $\begin{array}{l}1 \mathrm{ppm} \\
3 \mathrm{ppm}\end{array}$ & $\begin{array}{l}\text { USDA 2001b } \\
\text { 7CFR201.31a(d) }\end{array}$ \\
\hline \multicolumn{4}{|l|}{ d. Other } \\
\hline ACGIH & $\begin{array}{l}\text { Carcinogenicity classification } \\
\text {-pyrethrum }\end{array}$ & $\mathrm{A} 4^{\mathrm{b}}$ & ACGIH 2000 \\
\hline DOT & $\begin{array}{l}\text { Superfund-reportable quantity } \\
\text { Pyrethrins }\end{array}$ & 1 pound & $\begin{array}{l}\text { DOT } 2001 \\
\text { 49CFR172.101 } \\
\text { Appendix A }\end{array}$ \\
\hline EPA & $\begin{array}{l}\text { RfD (mg/kg/day) } \\
\text { Type I Pyrethroids } \\
\text { Biphenthrin } \\
\text { Permethrin } \\
\text { Resmethrin } \\
\text { Type II Pyrethroids } \\
\text { Baythroid/Cyfluthrin } \\
\text { Cyhalothrin/Karate } \\
\text { Cypermethrin } \\
\text { Danitol/Fenpropathrin } \\
\text { Fluvalinate } \\
\text { Pydrin/Fenvalerate } \\
\text { Tralomethrin }\end{array}$ & $\begin{array}{l}1.5 \times 10^{-2} \\
5.0 \times 10^{-2} \\
3.0 \times 10^{-2} \\
\\
2.5 \times 10^{-2} \\
5.0 \times 10^{-3} \\
1.0 \times 10^{-2} \\
2.5 \times 10^{-2} \\
1.0 \times 10^{-2} \\
2.5 \times 10^{-2} \\
7.5 \times 10^{-3}\end{array}$ & IRIS 2003e \\
\hline & $\begin{array}{l}\text { Superfund-reportable quantity } \\
\text { Pyrethrins }\end{array}$ & 1 pound & $\begin{array}{l}\text { EPA 2001b } \\
\text { 40CFR302.4 }\end{array}$ \\
\hline & $\begin{array}{l}\text { Toxic chemical release } \\
\text { reporting; Community Right-to- } \\
\text { Know-effective date } \\
\text { Fenvalerate } \\
\text { Permethrin }\end{array}$ & $\begin{array}{l}01 / 01 / 95 \\
01 / 01 / 95\end{array}$ & $\begin{array}{l}\text { EPA 2001e } \\
\text { 40CFR372.65 }\end{array}$ \\
\hline FDA & $\begin{array}{l}\text { New animal drug-for use in the } \\
\text { treatment of ear mites in dogs } \\
\text { and cats }\end{array}$ & $0.05 \%$ pyrethrins & $\begin{array}{l}\text { FDA 2000b } \\
21 C F R 524.2140\end{array}$ \\
\hline \multicolumn{4}{|l|}{ STATE } \\
\hline \multicolumn{4}{|l|}{$\begin{array}{l}\text { Regulations and } \\
\text { Guidelines: }\end{array}$} \\
\hline \multicolumn{4}{|l|}{ a. Air } \\
\hline Alaska & $\begin{array}{l}\text { Air contaminant standard } \\
\text { (TWA)-pyrethrum }\end{array}$ & $5 \mathrm{mg} / \mathrm{m}^{3}$ & BNA 2001 \\
\hline California & $\begin{array}{l}\text { Airborne contaminant } \\
\text {-pyrethrum }\end{array}$ & & BNA 2001 \\
\hline Connecticut & HAP_pyrethrum & & BNA 2001 \\
\hline Hawaii & $\begin{array}{l}\text { Air contaminant-pyrethrum } \\
\text { PEL } \\
\text { STEL }\end{array}$ & $\begin{array}{l}5 \mathrm{mg} / \mathrm{m}^{3} \\
10 \mathrm{mg} / \mathrm{m}^{3}\end{array}$ & BNA 2001 \\
\hline
\end{tabular}


Table 8-1. Regulations and Guidelines Applicable to Pyrethrins and Pyrethroids

\begin{tabular}{|c|c|c|c|}
\hline Agency & Description & Information & References \\
\hline \multicolumn{4}{|l|}{ STATE (cont.) } \\
\hline Idaho & $\begin{array}{l}\text { Toxic air pollutants-pyrethrum } \\
\text { OEL } \\
\text { EL } \\
\text { AAC }\end{array}$ & $\begin{array}{l}5 \mathrm{mg} / \mathrm{m}^{3} \\
3.33 \times 10^{-1} \text { pounds/hour } \\
0.25 \mathrm{mg} / \mathrm{m}^{3}\end{array}$ & BNA 2001 \\
\hline Kentucky & $\begin{array}{l}\text { Air quality-pyrethrum } \\
\text { TAL } \\
\text { Averaging time } \\
\text { Significant levels }\end{array}$ & $\begin{array}{l}20.0 \mathrm{mg} / \mathrm{m}^{3} \\
8 \text { hours } \\
1.276 \times 10^{-3} \text { pounds/hour }\end{array}$ & BNA 2001 \\
\hline \multirow[t]{2}{*}{ Michigan } & $\begin{array}{l}\text { Air contaminant-maximum } \\
\text { allowable concentrations } \\
\text { Pyrethrum }\end{array}$ & $5 \mathrm{mg} / \mathrm{m}^{3}$ & BNA 2001 \\
\hline & $\begin{array}{l}\text { Air contaminant (PEL-TWA) } \\
\text { Pyrethrum }\end{array}$ & $5 \mathrm{mg} / \mathrm{m}^{3}$ & BNA 2001 \\
\hline Montana & $\begin{array}{l}\text { Occupational air contaminant } \\
\text { (TLV) for pyrethrum }\end{array}$ & $5 \mathrm{mg} / \mathrm{m}^{3}$ & BNA 2001 \\
\hline New Hampshire & Toxic air pollutants-pyrethrum & $5 \mathrm{mg} / \mathrm{m}^{3}$ & BNA 2001 \\
\hline New Mexico & $\begin{array}{l}\text { Toxic air pollutants-pyrethrum } \\
\text { OEL } \\
\text { Emissions }\end{array}$ & $\begin{array}{l}5.05 \mathrm{mg} / \mathrm{m}^{3} \\
3.33 \times 10^{-1} \text { pounds/hour }\end{array}$ & BNA 2001 \\
\hline New York & $\begin{array}{l}\text { Air contaminant (TLV) } \\
\text { Pyrethrum }\end{array}$ & $5 \mathrm{mg} / \mathrm{m}^{3}$ & BNA 2001 \\
\hline Oregon & $\begin{array}{l}\text { Air contaminant (TLV) } \\
\text { Pyrethrum }\end{array}$ & $5 \mathrm{mg} / \mathrm{m}^{3}$ & BNA 2001 \\
\hline South Carolina & $\begin{array}{l}\text { Toxic air emissions-pyrethrum } \\
\text { Maximum allowable } \\
\text { concentration }\end{array}$ & $50 \mu \mathrm{g} / \mathrm{m}^{3}$ & BNA 2001 \\
\hline Washington & $\begin{array}{l}\text { Toxic air pollutants (ASIL } \\
\text { 24-hour average) for pyrethrum }\end{array}$ & $1.7 \mu \mathrm{g} / \mathrm{m}^{3}$ & BNA 2001 \\
\hline Wisconsin & $\begin{array}{r}\text { Emission limits-pyrethrum } \\
<25 \text { feet emission point } \\
>25 \text { feet emission point }\end{array}$ & $\begin{array}{l}4.176 \times 10^{-1} \text { pounds/hour } \\
1.7520 \text { pounds/hour }\end{array}$ & BNA 2001 \\
\hline \multicolumn{4}{|l|}{ b. Water } \\
\hline Arizona & $\begin{array}{l}\text { Drinking water guideline } \\
\text { Fenvalerate }\end{array}$ & $180 \mu \mathrm{g} / \mathrm{L}$ & HSDB 2001 \\
\hline Florida & $\begin{array}{l}\text { Drinking water guideline } \\
\text { Permethrin } \\
\text { Cypermethrin }\end{array}$ & $\begin{array}{l}350 \mu \mathrm{g} / \mathrm{L} \\
700 \mu \mathrm{g} / \mathrm{L}\end{array}$ & HSDB 2001 \\
\hline \multicolumn{3}{|l|}{ d. Other } & \\
\hline California & $\begin{array}{l}\text { Pesticide registration-active } \\
\text { ingredients } \\
\text { Fluvalinate } \\
\text { Permethrin } \\
\text { Pyrethrins } \\
\text { Resmethrin }\end{array}$ & & BNA 2001 \\
\hline
\end{tabular}


Table 8-1. Regulations and Guidelines Applicable to Pyrethrins and Pyrethroids

\begin{tabular}{|c|c|c|}
\hline Agency & Information & References \\
\hline \multicolumn{3}{|l|}{ STATE (cont.) } \\
\hline & $\begin{array}{l}\text { Hazardous substance } \\
\text { Pyrethrins } \\
\text { Pyrethrum }\end{array}$ & BNA 2001 \\
\hline Florida & $\begin{array}{l}\text { Toxic substances in the } \\
\text { workplace-pyrethrum }\end{array}$ & BNA 2001 \\
\hline Georgia & $\begin{array}{l}\text { Regulated substances and soil } \\
\text { concentrations that trigger } \\
\text { notification } \\
\text { Pyrethrin I } \\
\text { Pyrethrin II } \\
\text { Pyrethrins and Pyrethroids } \\
\text { Pyrethrum } \\
\text { Pyrethrum I }\end{array}$ & BNA 2001 \\
\hline \multirow[t]{2}{*}{ Massachusetts } & $\begin{array}{l}\text { Containers adequately labeled } \\
\text { pursuant to federal law } \\
\text { - pyrethrum }\end{array}$ & BNA 2001 \\
\hline & $\begin{array}{l}\text { Oil and hazardous material } \\
\text { Pyrethrin } 1 \\
\text { Pyrethrin } 2 \\
\text { Pyrethrins } \\
\text { Pyrethroids } \\
\text { Pyrethrum }\end{array}$ & BNA 2001 \\
\hline Minnesota & $\begin{array}{l}\text { Hazardous substance } \\
\text {-pyrethrum }\end{array}$ & BNA 2001 \\
\hline New Jersey & $\begin{array}{l}\text { Hazardous substance } \\
\text { Permethrin } \\
\text { Phenothrin } \\
\text { Pyrethrin I } \\
\text { Pyrethrin II } \\
\text { Pyrethrum } \\
\text { Resmethrin } \\
\text { Tetramethrin }\end{array}$ & BNA 2001 \\
\hline
\end{tabular}

${ }^{a}$ Group 3: not classifiable as to its carcinogenicity to humans

${ }^{\mathrm{b}} \mathrm{A} 4$ : not classifiable as a human carcinogen

AAC = acceptable ambient concentrations; $A C G I H=$ American Conference of Governmental Industrial Hygienists; ASIL = acceptable source impact levels; CFR = Code of Federal Regulations; DOT = Department of Transportation; EL = emissions levels; EPA = Environmental Protection Agency; FDA = Food and Drug Administration; HAP = hazardous air pollutant; HSDB = Hazardous Substances Data Bank; IARC = International Agency for Research on Cancer; IDLH = immediately dangerous to life and health; NIOSH = National Institute of Occupational Safety and Health; NPDES = National Pollutant Discharge Elimination System; OEL = occupational exposure limit; OSHA = Occupational Safety and Health Administration; PEL = permissible exposure limit; $\mathrm{REL}=$ recommended exposure limit; $\mathrm{RfD}=$ oral reference dose; STEL = short-term exposure limit;

$\mathrm{TAL}=$ threshold ambient limits; TLV = threshold limit value; TWA = time-weighted average; USDA = United States Department of Agriculture; $\mathrm{WHO}=$ World Health Organization 
8. REGULATIONS AND ADVISORIES

Table 8-2. Tolerances for Residues Applicable to Pyrethrins and Pyrethroids (ppm)

\begin{tabular}{|c|c|c|c|c|c|c|c|c|c|}
\hline & \multirow[b]{2}{*}{ Pyrethrin } & \multicolumn{2}{|c|}{$\begin{array}{l}\text { Type I } \\
\text { Pyrethroids }\end{array}$} & \multicolumn{6}{|c|}{ Type II Pyrethroids } \\
\hline & & Allethrin & $\begin{array}{l}\text { Per- } \\
\text { methrin }\end{array}$ & $\begin{array}{l}\text { Cyper- } \\
\text { methrin }\end{array}$ & $\begin{array}{l}\text { Delta- } \\
\text { methrin }\end{array}$ & $\begin{array}{l}\text { Fenprop- } \\
\text { athrin }\end{array}$ & $\begin{array}{l}\text { Fenval- } \\
\text { erate }\end{array}$ & $\begin{array}{l}\text { Fluvali- } \\
\text { nate }\end{array}$ & $\begin{array}{l}\text { Tralo- } \\
\text { methrin }\end{array}$ \\
\hline & $\begin{array}{l}\text { 40CFR } \\
180.128\end{array}$ & $\begin{array}{l}\text { 40CFR } \\
180.113\end{array}$ & $\begin{array}{l}\text { 40CFR } \\
180.378\end{array}$ & $\begin{array}{l}\text { 40CFR } \\
180.418\end{array}$ & $\begin{array}{l}\text { 40CFR } \\
180.435\end{array}$ & $\begin{array}{l}\text { 40CFR } \\
180.466\end{array}$ & $\begin{array}{l}\text { 40CFR } \\
180.379\end{array}$ & $\begin{array}{l}\text { 40CFR } \\
180.427\end{array}$ & $\begin{array}{l}\text { 40CFR } \\
180.422\end{array}$ \\
\hline Alfalfa, fresh & - & - & 25.0 & - & - & - & - & - & - \\
\hline Alfalfa, hay & - & - & 55.0 & - & - & - & - & - & - \\
\hline Almond hulls & - & - & 0.05 & - & - & - & 15.0 & - & - \\
\hline Almonds & 1.0 & - & 20.0 & - & - & - & 0.2 & - & - \\
\hline Apples & 1.0 & 4.0 & 0.05 & - & - & - & 2.0 & - & - \\
\hline Artichokes & - & - & 10.0 & - & - & - & 0.2 & - & - \\
\hline Asparagus & - & - & 1.0 & - & - & - & - & - & - \\
\hline Avocados & - & - & 1.0 & - & - & - & - & - & - \\
\hline Barley & 3.0 & 2.0 & - & - & - & - & - & - & - \\
\hline Beans & 1.0 & - & - & - & - & - & - & - & - \\
\hline Beans, dried & - & - & - & - & - & - & 0.25 & - & - \\
\hline Beans, snap & - & - & - & - & - & - & 2.0 & - & - \\
\hline $\begin{array}{l}\text { Birdseed } \\
\text { mixtures }\end{array}$ & 3.0 & - & - & - & - & - & - & - & - \\
\hline Blackberries & 1.0 & 4.0 & - & - & - & - & - & - & - \\
\hline Blueberries & 1.0 & 4.0 & - & - & - & - & 3.0 & - & - \\
\hline $\begin{array}{l}\text { Boysen- } \\
\text { berries }\end{array}$ & 1.0 & 4.0 & - & - & - & - & - & - & - \\
\hline $\begin{array}{l}\text { Brassica, } \\
\text { head and } \\
\text { stem }\end{array}$ & - & - & - & 2.0 & - & 3.0 & - & - & - \\
\hline $\begin{array}{l}\text { Brassica, } \\
\text { leafy }\end{array}$ & - & - & - & 14.0 & - & - & - & - & - \\
\hline Broccoli & - & - & 1.0 & - & - & - & 2.0 & - & 0.5 \\
\hline $\begin{array}{l}\text { Brussels } \\
\text { sprouts }\end{array}$ & - & - & 1.0 & - & - & - & - & - & - \\
\hline Buckwheat & 3.0 & - & - & - & - & - & - & - & - \\
\hline Cabbage & - & - & 6.0 & - & - & - & 10.0 & - & - \\
\hline Cranberries & - & - & - & - & - & - & 3.0 & - & - \\
\hline Cantaloupes & - & - & - & - & - & - & 1.0 & - & - \\
\hline Carrots & - & - & - & - & - & - & 0.5 & - & - \\
\hline Cattle, fat & 0.1 & - & 3.0 & 0.05 & - & 1.0 & 1.5 & 0.01 & - \\
\hline Cattle, meat & 0.1 & - & 0.25 & 0.05 & - & 0.1 & 1.5 & 0.01 & - \\
\hline $\begin{array}{l}\text { Cattle, meat } \\
\text { byproducts }\end{array}$ & 0.1 & - & 2.0 & 0.05 & - & 0.1 & 1.5 & 0.01 & - \\
\hline Cauliflower & - & - & 1.0 & - & - & - & 0.5 & - & - \\
\hline Celery & - & - & 5.0 & - & - & - & - & - & - \\
\hline Cherries & 1.0 & 4.0 & 3.0 & - & - & - & - & - & - \\
\hline Citrus, dried & - & - & - & - & - & 4.0 & - & - & - \\
\hline
\end{tabular}


8. REGULATIONS AND ADVISORIES

Table 8-2. Tolerances for Residues Applicable to Pyrethrins and Pyrethroids (ppm)

\begin{tabular}{|c|c|c|c|c|c|c|c|c|c|}
\hline & \multirow[b]{2}{*}{ Pyrethrin } & \multicolumn{2}{|c|}{$\begin{array}{l}\text { Type I } \\
\text { Pyrethroids }\end{array}$} & \multicolumn{6}{|c|}{ Type II Pyrethroids } \\
\hline & & Allethrin & $\begin{array}{l}\text { Per- } \\
\text { methrin }\end{array}$ & $\begin{array}{l}\text { Cyper- } \\
\text { methrin }\end{array}$ & $\begin{array}{l}\text { Delta- } \\
\text { methrin }\end{array}$ & $\begin{array}{l}\text { Fenprop- } \\
\text { athrin }\end{array}$ & $\begin{array}{l}\text { Fenval- } \\
\text { erate }\end{array}$ & $\begin{array}{l}\text { Fluvali- } \\
\text { nate }\end{array}$ & $\begin{array}{l}\text { Tralo- } \\
\text { methrin }\end{array}$ \\
\hline & $\begin{array}{l}\text { 40CFR } \\
180.128\end{array}$ & $\begin{array}{l}\text { 40CFR } \\
180.113\end{array}$ & $\begin{array}{l}\text { 40CFR } \\
180.378\end{array}$ & $\begin{array}{l}\text { 40CFR } \\
180.418\end{array}$ & $\begin{array}{l}\text { 40CFR } \\
180.435\end{array}$ & $\begin{array}{l}\text { 40CFR } \\
180.466\end{array}$ & $\begin{array}{l}\text { 40CFR } \\
180.379\end{array}$ & $\begin{array}{l}\text { 40CFR } \\
180.427\end{array}$ & $\begin{array}{l}\text { 40CFR } \\
180.422\end{array}$ \\
\hline \multicolumn{10}{|l|}{ pulp } \\
\hline Citrus, oil & - & - & - & - & - & 75.0 & - & - & - \\
\hline Cocoa beans & 1.0 & - & - & - & - & - & - & - & - \\
\hline Coffee & - & - & - & - & - & - & - & 0.01 & - \\
\hline Collards & - & - & 20.0 & - & - & - & 10.0 & - & - \\
\hline Copra & 1.0 & - & - & - & - & - & - & - & - \\
\hline Corn, fodder & - & - & 60.0 & - & - & - & 50.0 & - & - \\
\hline Corn, forage & - & - & 60.0 & - & - & - & 50.0 & - & - \\
\hline Corn, grain & - & 2.0 & 0.05 & - & - & - & 0.02 & - & - \\
\hline $\begin{array}{l}\text { Corn, } \\
\text { including } \\
\text { popcorn }\end{array}$ & 3.0 & - & - & - & - & - & - & - & - \\
\hline $\begin{array}{l}\text { Corn, sweet, } \\
\text { kernels and } \\
\text { cobs }\end{array}$ & - & - & 0.1 & - & - & - & 0.1 & - & - \\
\hline Cottonseed & 1.0 & - & 0.5 & 0.5 & 0.04 & 1.0 & 0.2 & 0.1 & 0.02 \\
\hline $\begin{array}{l}\text { Cottonseed, } \\
\text { hulls }\end{array}$ & - & - & - & - & - & - & - & 0.3 & - \\
\hline $\begin{array}{l}\text { Cottonseed } \\
\text { oil }\end{array}$ & - & - & - & - & 0.2 & 3.0 & - & 1.0 & 0.2 \\
\hline Crabapples & 1.0 & 4.0 & - & - & - & - & - & - & - \\
\hline Cucumbers & - & - & - & - & - & - & 0.5 & - & - \\
\hline Currants & 1.0 & 4.0 & - & - & - & - & 3.0 & - & - \\
\hline Dewberries & 1.0 & 4.0 & - & - & - & - & - & - & - \\
\hline Eggplant & - & - & 1.0 & - & - & - & 1.0 & - & - \\
\hline Eggs & 0.1 & - & 1.0 & - & - & 0.05 & - & 0.01 & - \\
\hline Elderberries & - & - & - & - & - & - & 3.0 & - & - \\
\hline $\begin{array}{l}\text { English } \\
\text { walnuts }\end{array}$ & - & - & - & - & - & - & 0.2 & - & - \\
\hline Figs & 1.0 & 4.0 & - & - & - & - & - & - & - \\
\hline Filberts & - & - & 0.05 & - & - & - & 0.2 & - & - \\
\hline Flaxseed & 1.0 & - & - & - & - & - & - & - & - \\
\hline $\begin{array}{l}\text { Fruits, citrus, } \\
\text { crop } \\
\text { group } 10\end{array}$ & - & - & - & - & - & 2.0 & - & - & - \\
\hline $\begin{array}{l}\text { Fruits, pome, } \\
\text { crop } \\
\text { group } 11\end{array}$ & - & - & - & - & - & 5.0 & - & - & - \\
\hline Garlic & - & - & 0.1 & - & - & - & - & - & - \\
\hline Goats, fat & 0.1 & - & 3.0 & 0.05 & - & 1.0 & 1.5 & 0.01 & - \\
\hline
\end{tabular}


8. REGULATIONS AND ADVISORIES

Table 8-2. Tolerances for Residues Applicable to Pyrethrins and Pyrethroids (ppm)

\begin{tabular}{|c|c|c|c|c|c|c|c|c|c|}
\hline & \multirow[b]{2}{*}{ Pyrethrin } & \multicolumn{2}{|c|}{$\begin{array}{l}\text { Type I } \\
\text { Pyrethroids }\end{array}$} & \multicolumn{6}{|c|}{ Type II Pyrethroids } \\
\hline & & Allethrin & $\begin{array}{l}\text { Per- } \\
\text { methrin }\end{array}$ & $\begin{array}{l}\text { Cyper- } \\
\text { methrin }\end{array}$ & $\begin{array}{l}\text { Delta- } \\
\text { methrin }\end{array}$ & $\begin{array}{l}\text { Fenprop- } \\
\text { athrin }\end{array}$ & $\begin{array}{l}\text { Fenval- } \\
\text { erate }\end{array}$ & $\begin{array}{l}\text { Fluvali- } \\
\text { nate }\end{array}$ & $\begin{array}{l}\text { Tralo- } \\
\text { methrin }\end{array}$ \\
\hline & $\begin{array}{l}\text { 40CFR } \\
180.128\end{array}$ & $\begin{array}{l}\text { 40CFR } \\
180.113\end{array}$ & $\begin{array}{l}\text { 40CFR } \\
180.378\end{array}$ & $\begin{array}{l}\text { 40CFR } \\
180.418\end{array}$ & $\begin{array}{l}\text { 40CFR } \\
180.435\end{array}$ & $\begin{array}{l}\text { 40CFR } \\
180.466\end{array}$ & $\begin{array}{l}\text { 40CFR } \\
180.379\end{array}$ & $\begin{array}{l}\text { 40CFR } \\
180.427\end{array}$ & $\begin{array}{l}\text { 40CFR } \\
180.422\end{array}$ \\
\hline Goats, meat & 0.1 & - & 0.25 & 0.05 & - & 0.1 & 1.5 & 0.01 & - \\
\hline $\begin{array}{l}\text { Goats, meat } \\
\text { byproducts }\end{array}$ & 0.1 & - & 2.0 & 0.05 & - & 0.1 & 1.5 & 0.01 & - \\
\hline $\begin{array}{l}\text { Goose- } \\
\text { berries }\end{array}$ & 1.0 & 4.0 & - & - & - & - & 3.0 & - & - \\
\hline $\begin{array}{l}\text { Grain, } \\
\text { sorghum }\end{array}$ & 1.0 & 2.0 & - & - & - & - & - & - & - \\
\hline Grapes & - & 4.0 & - & - & - & 5.0 & - & - & - \\
\hline $\begin{array}{l}\text { Grasses, } \\
\text { range }\end{array}$ & - & - & 15.0 & - & - & - & - & - & - \\
\hline Guavas & - & 4.0 & - & - & - & - & - & - & - \\
\hline Hogs, fat & 0.1 & - & 3.0 & 0.05 & - & 1.0 & 1.5 & 0.01 & - \\
\hline Hogs, meat & 0.1 & - & 0.25 & 0.05 & - & 0.1 & 1.5 & 0.01 & - \\
\hline $\begin{array}{l}\text { Hogs, meat } \\
\text { byproducts }\end{array}$ & 0.1 & - & 3.0 & 0.05 & - & 0.1 & 1.5 & 0.01 & - \\
\hline Honey & - & - & - & - & - & - & - & 0.05 & - \\
\hline $\begin{array}{l}\text { Honeydew } \\
\text { melons }\end{array}$ & - & - & - & - & - & - & 1.5 & - & - \\
\hline Horseradish & - & - & 1.0 & - & - & - & - & - & - \\
\hline Horses, fat & 0.1 & - & 3.0 & 0.05 & - & 1.0 & 1.5 & 0.01 & - \\
\hline Horses, meat & 0.1 & - & 0.25 & 0.05 & - & 0.1 & 1.5 & 0.01 & - \\
\hline $\begin{array}{l}\text { Horses, meat } \\
\text { byproducts }\end{array}$ & 0.1 & - & 2.0 & 0.05 & - & 0.1 & 1.5 & 0.01 & - \\
\hline $\begin{array}{l}\text { Huckle- } \\
\text { berries }\end{array}$ & - & 4.0 & - & - & - & - & 3.0 & - & - \\
\hline Kiwifruit & - & - & 2.0 & - & - & - & - & - & - \\
\hline $\begin{array}{l}\text { Leafy } \\
\text { vegetables, } \\
\text { except } \\
\text { Brassica }\end{array}$ & - & - & 20.0 & - & - & - & - & - & - \\
\hline $\begin{array}{l}\text { Lettuce, } \\
\text { head }\end{array}$ & - & - & 20.0 & 10.0 & - & - & - & - & 1.0 \\
\hline Lettuce, leaf & - & - & - & - & - & - & - & - & 3.0 \\
\hline Loganberries & 1.0 & 4.0 & - & - & - & - & - & - & - \\
\hline Mangoes & 1.0 & 4.0 & - & - & - & - & - & - & - \\
\hline Milk & - & - & - & 0.05 & - & - & 0.3 & 0.01 & - \\
\hline Milk, fat & 0.5 & - & 6.25 & - & - & 2.0 & 7.0 & - & - \\
\hline Milo & - & 2.0 & - & - & - & - & - & - & - \\
\hline Mushrooms & - & - & 6.0 & - & - & - & - & - & - \\
\hline Muskmelons & 1.0 & 4.0 & - & - & - & - & 1.0 & - & - \\
\hline
\end{tabular}


8. REGULATIONS AND ADVISORIES

Table 8-2. Tolerances for Residues Applicable to Pyrethrins and Pyrethroids (ppm)

\begin{tabular}{|c|c|c|c|c|c|c|c|c|c|}
\hline & \multirow[b]{2}{*}{ Pyrethrin } & \multicolumn{2}{|c|}{$\begin{array}{l}\text { Type I } \\
\text { Pyrethroids }\end{array}$} & \multicolumn{6}{|c|}{ Type II Pyrethroids } \\
\hline & & Allethrin & $\begin{array}{l}\text { Per- } \\
\text { methrin }\end{array}$ & $\begin{array}{l}\text { Cyper- } \\
\text { methrin }\end{array}$ & $\begin{array}{l}\text { Delta- } \\
\text { methrin }\end{array}$ & $\begin{array}{l}\text { Fenprop- } \\
\text { athrin }\end{array}$ & $\begin{array}{l}\text { Fenval- } \\
\text { erate }\end{array}$ & $\begin{array}{l}\text { Fluvali- } \\
\text { nate }\end{array}$ & $\begin{array}{l}\text { Tralo- } \\
\text { methrin }\end{array}$ \\
\hline & $\begin{array}{l}\text { 40CFR } \\
180.128\end{array}$ & $\begin{array}{l}\text { 40CFR } \\
180.113\end{array}$ & $\begin{array}{l}\text { 40CFR } \\
180.378\end{array}$ & $\begin{array}{l}\text { 40CFR } \\
180.418\end{array}$ & $\begin{array}{l}\text { 40CFR } \\
180.435\end{array}$ & $\begin{array}{l}\text { 40CFR } \\
180.466\end{array}$ & $\begin{array}{l}\text { 40CFR } \\
180.379\end{array}$ & $\begin{array}{l}\text { 40CFR } \\
180.427\end{array}$ & $\begin{array}{l}\text { 40CFR } \\
180.422\end{array}$ \\
\hline Oats & 1.0 & 2.0 & - & - & - & - & - & - & - \\
\hline Okra & - & - & - & - & - & - & 0.1 & - & - \\
\hline Onion, bulb & - & - & 0.1 & 0.10 & - & - & - & - & - \\
\hline $\begin{array}{l}\text { Onions, } \\
\text { green }\end{array}$ & - & - & - & 6.0 & - & - & - & - & - \\
\hline Oranges & 1.0 & 4.0 & - & - & - & - & - & - & - \\
\hline Papayas & - & - & 1.0 & - & - & - & - & - & - \\
\hline Peaches & 1.0 & 4.0 & 5.0 & - & - & - & - & - & - \\
\hline Peanut, hay & - & - & - & - & - & 20.0 & - & - & - \\
\hline $\begin{array}{l}\text { Peanut, } \\
\text { nutmeat }\end{array}$ & - & - & - & - & - & 0.01 & - & - & - \\
\hline Peanuts & - & - & - & - & - & - & 0.02 & - & - \\
\hline $\begin{array}{l}\text { Peanuts, } \\
\text { with shell } \\
\text { removed }\end{array}$ & 1.0 & - & - & - & - & - & - & - & - \\
\hline Pears & 1.0 & 4.0 & 3.0 & - & - & - & 2.0 & - & - \\
\hline Peas & 1.0 & - & - & - & - & - & 1.0 & - & - \\
\hline Peas, dried & - & - & - & - & - & - & 0.25 & - & - \\
\hline Pecans & - & - & - & 0.05 & - & - & 0.2 & - & - \\
\hline Peppers & - & - & - & - & - & - & 1.0 & - & - \\
\hline Peppers, bell & - & - & 1.0 & - & - & - & - & - & - \\
\hline Pineapples & 1.0 & 4.0 & - & - & - & - & - & - & - \\
\hline Pistachios & - & - & 0.1 & - & - & - & - & - & - \\
\hline Plums & 1.0 & 4.0 & - & - & - & - & - & - & - \\
\hline Potatoes & 0.05 & - & 0.05 & - & - & - & 0.02 & - & - \\
\hline Poultry, fat & 0.2 & - & 0.15 & - & - & 0.05 & - & 0.01 & - \\
\hline Poultry, meat & 0.2 & - & 0.05 & - & - & 0.05 & - & 0.01 & - \\
\hline $\begin{array}{l}\text { Poultry, meat } \\
\text { byproducts }\end{array}$ & 0.2 & - & 0.25 & - & - & 0.05 & - & 0.01 & - \\
\hline Pumpkins & - & - & - & - & - & - & 1.0 & - & - \\
\hline Radish, roots & - & - & - & - & - & - & 0.3 & - & - \\
\hline Radish, tops & - & - & - & - & - & - & 8.0 & - & - \\
\hline Raisins & - & - & - & - & - & 10.0 & - & - & - \\
\hline Raspberries & 1.0 & 4.0 & - & - & - & - & - & - & - \\
\hline Rice & 3.0 & - & - & - & - & - & - & - & - \\
\hline Rye & 3.0 & 2.0 & - & - & - & - & - & - & - \\
\hline Sheep, fat & 0.1 & - & 3.0 & 0.05 & - & 1.0 & .5 & 0.01 & - \\
\hline Sheep, meat & 0.1 & - & 0.25 & 0.05 & - & 0.1 & 1.5 & 0.01 & - \\
\hline
\end{tabular}


8. REGULATIONS AND ADVISORIES

Table 8-2. Tolerances for Residues Applicable to Pyrethrins and Pyrethroids (ppm)

\begin{tabular}{|c|c|c|c|c|c|c|c|c|c|}
\hline & \multirow[b]{2}{*}{ Pyrethrin } & \multicolumn{2}{|c|}{$\begin{array}{l}\text { Type I } \\
\text { Pyrethroids }\end{array}$} & \multicolumn{6}{|c|}{ Type II Pyrethroids } \\
\hline & & Allethrin & $\begin{array}{l}\text { Per- } \\
\text { methrin }\end{array}$ & $\begin{array}{l}\text { Cyper- } \\
\text { methrin }\end{array}$ & $\begin{array}{l}\text { Delta- } \\
\text { methrin }\end{array}$ & $\begin{array}{l}\text { Fenprop- } \\
\text { athrin }\end{array}$ & $\begin{array}{l}\text { Fenval- } \\
\text { erate }\end{array}$ & $\begin{array}{l}\text { Fluvali- } \\
\text { nate }\end{array}$ & $\begin{array}{l}\text { Tralo- } \\
\text { methrin }\end{array}$ \\
\hline & $\begin{array}{l}\text { 40CFR } \\
180.128\end{array}$ & $\begin{array}{l}\text { 40CFR } \\
180.113\end{array}$ & $\begin{array}{l}\text { 40CFR } \\
180.378\end{array}$ & $\begin{array}{l}\text { 40CFR } \\
180.418\end{array}$ & $\begin{array}{l}\text { 40CFR } \\
180.435\end{array}$ & $\begin{array}{l}\text { 40CFR } \\
180.466\end{array}$ & $\begin{array}{l}\text { 40CFR } \\
180.379\end{array}$ & $\begin{array}{l}\text { 40CFR } \\
180.427\end{array}$ & $\begin{array}{l}\text { 40CFR } \\
180.422\end{array}$ \\
\hline $\begin{array}{l}\text { Sheep, meat } \\
\text { byproducts }\end{array}$ & 0.1 & - & 2.0 & 0.05 & - & 0.1 & 1.5 & 0.01 & - \\
\hline Soybeans & - & - & - & - & - & - & 0.05 & - & 0.05 \\
\hline $\begin{array}{l}\text { Soybean } \\
\text { hulls }\end{array}$ & - & - & 0.05 & - & - & - & 1.0 & - & - \\
\hline Spinach & - & - & 20.0 & - & - & - & - & - & - \\
\hline $\begin{array}{l}\text { Squash/cucu } \\
\text { mber } \\
\text { subgroup }\end{array}$ & - & - & - & - & - & 0.5 & - & - & - \\
\hline Stone fruits & - & - & - & - & - & - & 10.0 & - & - \\
\hline Strawberry & - & - & - & - & - & 2.0 & - & - & - \\
\hline Sugarcane & - & - & - & - & - & - & 2.0 & - & - \\
\hline $\begin{array}{l}\text { Summer } \\
\text { squash }\end{array}$ & - & - & - & - & - & - & 0.5 & - & - \\
\hline $\begin{array}{l}\text { Sunflower } \\
\text { seed }\end{array}$ & - & - & - & - & - & - & 1.0 & - & 0.05 \\
\hline $\begin{array}{l}\text { Sweet } \\
\text { potatoes }\end{array}$ & 0.05 & - & - & - & - & - & - & - & - \\
\hline Tomatoes & 1.0 & 4.0 & 2.0 & - & 0.2 & 0.6 & 1.0 & - & - \\
\hline $\begin{array}{l}\text { Tomato } \\
\text { (product) } \\
\text { concentrated }\end{array}$ & - & - & - & - & 0.1 & - & - & - & - \\
\hline $\begin{array}{l}\text { Turnip } \\
\text { greens }\end{array}$ & - & - & 20.0 & - & - & - & - & - & - \\
\hline Turnip roots & - & - & 1.0 & - & - & - & 0.5 & - & - \\
\hline Turnip tops & - & - & - & - & - & - & 20.0 & - & - \\
\hline $\begin{array}{l}\text { Vegetables, } \\
\text { curcurbit }\end{array}$ & - & - & 3.0 & - & - & 0.5 & - & - & - \\
\hline Walnuts & 1.0 & - & 0.05 & - & - & - & - & - & - \\
\hline Watercress & - & - & 5.0 & - & - & - & - & - & - \\
\hline Watermelons & - & - & - & - & - & - & 1.0 & - & - \\
\hline Wheat & 3.0 & 2.0 & - & - & - & - & - & - & - \\
\hline $\begin{array}{l}\text { Winter } \\
\text { squash }\end{array}$ & - & - & - & - & - & - & 1.0 & - & - \\
\hline
\end{tabular}

Source: EPA $2001 f$ 


\section{REFERENCES}

*Abd El-Aziz MI, Sahlab AM, Abd El-Khalik M. 1994. Influence of diazinon and deltamethrine on reproductive organs and fertility of male rats. Dtsch Tieräerztl Wochenshr 101:213-248.

*Abd El-Khalek MM, Rahmy NA, Haleem HH. 1999. Effect of the pyrethroid insecticide cypermethrin on fertility in male rats. Vet Med J Giza 47(3):295-305.

Abd El-Raheem K, El-Elaimy I, El-Mossallamy N, et al. 1987. Biochemical responses to induced intoxication with insecticides: 1. Effect of acute and repeated administration of pyrethroid (ripcord). Proc Zool Soc AR Egypt 13:141-156.

*Abdel-Khalik MM, Hanafy MSM, Abdel-Aziz MI. 1993. Studies on the teratogenic effects of deltamethrin in rats. Dtsch Tieräerztl Wochenshr 100:129-168.

Abdel-Rahman A, Shetty AK, Abdou-Donia MB. 2001. Subchronic dermal application of N,N-diethyl m-toluamide (DEET) and permethrin to adult rats, alone or in combination, causes diffuse neuronal cell death and cytoskeletal abnormalities in the cerebral cortex and the hippocampus, and purkinje neuron loss in the cerebellum. Exp Neurol 172:153-171.

Abernathy CO, Ueda K, Engel JL, et al. 1973. Substrate-specificity and toxicological significance of pyrethroid-hydrolyzing esterases of mouse liver microsomes. Pestic Biochem Physiol 3:300-311.

Abou-Donia MB, Goldstein LB, Dechovsaia A, et al. 2001. Effects of daily dermal application of DEET and permethrin, alone and in combination, on sensorimotor performance, blood-brain barrier, and bloodtests barrier in rats. J Toxicol Environ Health 62:523-541.

Abou-Donia MB, Wilmarth KR, Jensen KF, et al. 1996. Neurotoxicity resulting from coexposure to pyridostigmine bromide, DEET, and permethrin: Implications of Gulf War chemical exposures. J Toxicol Environ Health 48:35-56.

*Abu-Qare AW, Abou-Donia MB. 2001a. Combined exposure to DEET (N,N-diethyl-m-toluamide) and permethrin-induced release of rat brain mitochondrial cytochrome c. J Toxicol Environ Health 63:243-252.

Abu-Qare AW, Abou-Donia MB. 2001b. DEET (N,N-diethyl-m-toluamide) alone and in combination with permethrin increased urinary excretion of $6 \beta$-hydroxycortisol in rats, a marker of hepatic CYP3A induction. J Toxicol Environ Health A 64:373-384.

Abu-Qare AW, Abou-Donia MB. 2003. Combined exposure to DEET (N,N-diethyl- $m$-toluamide) and permethrin: Pharmacokinetics and toxicological effects. J Toxicol Environ Health B 6:41-53.

*ACGIH. 2000. TLVs and BEIs: Threshold limit values for chemical substances and physical agents and biological exposure indices. Cincinnati, $\mathrm{OH}$ : American Conference of Governmental Industrial Hygienists.

\footnotetext{
* Cited in text
} 


\section{REFERENCES}

*Adamis Z, Antal A, Füzesi I, et al. 1985. Occupational exposure to organophosphorus insecticides and synthetic pyrethroid. Int Arch Occup Environ Health 56:299-305.

*Adinolfi M. 1985. The development of the human blood-CSF-brain barrier. Dev Med Child Neurol 27:532-537.

*Adlercreutz H. 1995. Phytoestrogens: Epidemiology and a possible role in cancer protection. Environ Health Perspect Suppl 103(7):103-112.

*Agarwal DK, Chauhan LKS, Gupta S, et al. 1994. Cytogenetic effects of deltamethrin on rat bone marrow. Mutat Res 311:133-138.

*Agency for Toxic Substances and Disease Registry. 1989. Decision guide for identifying substancespecific data needs related to toxicological profiles; Notice. Agency for Toxic Substances and Disease Registry. Federal Register 54 (174):37618-37634.

*Agnihotri NP, Jain HK. 1987. Persistence of flucythrinate and fluvalinate in soil, water and sediment. Pesticides 21(6):36-38.

Agnihotri NP, Jain HK, Gajbhiye VT, et al. 1989. Persistence of some synthetic pyrethroids and organophosphorus insecticides in soil, water and sediment part II. J Entomol Res 13(2):131-136.

*Ahlbom J, Fredriksson A, Eriksson P. 1994. Neonatal exposure to a Type-I pyrethroid (bioallethrin) induces dose-response changes in brain muscarinic receptors and behaviour in neonatal and adult mice. Brain Res 645:318-324.

Akhtar MH, Danis C, Trenholm D, et al. 1992. Deltamethrin residues in milk and tissues of lactating dairy cows. J Environ Sci Health B 27(3):235-253.

*Akhtar N, Kayani SA, Ahmad MM, et al. 1996. Insecticide-induced changes in secretory activity of the thyroid gland in rats. J Appl Toxicol 16(5):397-400.

*Alawi MA, Gharaibeh S, Al-Shureiki Y. 1990. Rueckstandsuntersuchungen auf fenitrothion und pyrethroide in wasser, boden und pflanzen nach der heuschreckenbekaempfung in Jordanien 1989. Chemosphere 20(3-4):443-447.

Aldana L, González de Mejía E, Craigmill A, et al. 1998. Cypermethrin increases apo A-1 and apo B mRNA but not hyperlipidemia in rats. Toxicol Lett 95:31-39.

Aldana L, Tsutsumi V, Craigmill A, et al. 2001. $\alpha$-Tocopherol modulates liver toxicity of the pyrethroid cypermethrin. Toxicol Lett 125:107-16.

Aldridge WN. 1980. Mode of action of pyrethroids in mammals: Summary of toxicity and histological, neurophysiological and biochemical studies at Carshalton. In: Mattieu J, ed. Pyrethroid insecticides: Chemistry and action. Romainville, France: Roussel Uclaf, 45-47.

*Aldridge WN. 1990. An assessment of the toxicological properties of pyrethroids and their neurotoxicity. Crit Rev Toxicol 21(2):89-104. 
Aldridge WN, Clothier B, Forshaw P, et al. 1978. The effect of DDT and pyrethroids cismethrin and decamethrin on the acetyl choline and cyclic nucleotide content of rat brain. Biochem Pharmacol 27:1703-1706.

Allen GJ, Sanders D. 1995. Calcineurin, a type 2B protein phosphatase, modulates the $\mathrm{Ca}^{2+}$-permeable slow vacuolar ion channel of stomatal guard cells. Plant Cell 7:1473-1483.

Altenkirch H, Hopmann D, Brockmeier B, et al. 1996. Neurological investigations in 23 cases of pyrethroid intoxication reported to the German Federal Health Office. Neurotoxicology 17:645-652.

*Altman PL, Dittmer DS. 1974. In: Biological handbooks: Biology data book. Vol. III. $2^{\text {nd }}$ ed. Bethesda, MD: Federation of American Societies for Experimental Biology, 1987-2008, 2041.

*Amer SM, Abd-El Samie Ibrahim A, El-Sherbeny KM. 1993. Induction of chromosomal aberrations and sister chromatid exchange in vivo and in vitro by the insecticide cypermethrin. J Appl Toxicol 13(5):341-345.

*Anadón A, Martinez-Larrañaga MR, Díaz MJ, et al. 1991a. Effect of deltamethrin on antipyrine pharmacokinetics and metabolism in rat. Arch Toxicol 65:156-159.

*Anadón A, Martinez-Larrañaga MR, Díaz MJ, et al. 1991b. Toxicokinetics of permethrin in the rat. Toxicol Appl Pharmacol 110:1-8.

Anadón A, Martinez-Larrañaga MR, Díaz MJ, et al. 1995. Effects of flumethrin on hepatic drugmetabolizing enzymes and antipyrine disposition in rats. Toxicol Appl Pharmacol 132:14-18.

*Anadón A, Martinez-Larrañaga MR, Fernandez-Cruz ML, et al. 1996. Toxicokinetics of deltamethrin and its 4'-HO-metabolite in the rat. Toxicol Appl Pharmacol 141:8-16.

*Andersen ME, Kirshnan K. 1994. Relating in vitro to in vivo exposures with physiologically based tissue dosimetry and tissue response models. In: Salem H, ed. Animal test alternatives: Refinement, reduction, and replacement. New York: Marcel Dekker, Inc., 9-25.

*Andersen ME, Clewell HJ III, Gargas et al ML. 1987. Physiologically based pharmacokinetics and the risk assessment process for methylene chloride. Toxicol Appl Pharmacol 87:185-205.

*Angerer J, Ritter A. 1997. Determination of metabolites of pyrethroids in human urine using solidphase extraction and gas chromatography-mass spectrometry. J Chromatogr B Biomed Appl 695:217226.

Angerer J, Butte W, Hoppe H, et al. 1999. Pyrethroid metabolites (cis-3-(2,2-dichlorovinyl)-2,2dimethylcyclopropane-1-carboxylic acid; trans-3-(2,2-dichlorovinyl)-2,2-dimethylcyclopropane-1carboxylic acid; cis-3-(2,2-dibromovinyl)-2,2-dimethylcyclopropane-1-carboxylic acid; 3phenoxybenzoic acid; 4-fluoro-3-phenoxybenzoic acid). Anal Hazard Subst Biol Mater 6:231-254.

*Antonious GF, Byers ME, Kerst WC. 1997. Residue levels of pyrethrins and piperonyl butoxide in soil and runoff water. J Environ Sci Health B 32(5):621-644.

Appel KE, Michalak H, Gericke S. 1994. [Health risks from pyrethroids? Data on their neurotoxicity, toxicokinetics and human health disorders.] Wiss Umwelt 2:95-108. (German). 


\section{REFERENCES}

*Aprea C, Stridori A, Sciarra G. 1997. Analytical method for the determination of urinary 3phenoxybenzoic acid in subjects occupationally exposed to pyrethroid insecticides. J Chromatogr B Biomed Appl 695:227-236.

Asakawa F, Jitsunari F, Miki K, et al. 1996. Agricultural worker exposure to and absorption of permethrin applied to cabbage. Bull Environ Contam Toxicol 56:42-49.

Aziz MH, Agrawal AK, Adhami VM, et al. 2001. Neurodevelopmental consequences of gestational exposure (GD14-GD20) to low dose deltamethrin in rats. Neurosci Lett 300:161-165.

*Badawy MI. 1998. Organic insecticides in airborne suspended particulates. Bull Environ Contam Toxicol 60:693-701.

Balbaa M, Abdelhamid EME, Bassiouny K. 1998. Enhancement of lysosomal enzymes by the pyrethroids, fenvalerate and trans-cypermethrin. Jpn J Toxicol Environ Health (Eisei Kagaku) 44(2):8391.

Bansal N, Sharma SK, Srivastava AK, et al. 1997. Histomorphological and biochemical studies in experimental fluvanilate toxicity in rabbits. Indian J Anim Sci 67(4):278-280.

*Barnes DG, Dourson M. 1988. Reference dose (RfD) description and use in health risk assessments. Regul Toxicol Pharmacol 8:471-486.

*Barrueco C, Herrera A, Caballo C, et al. 1992. Cytogenetic effects of permethrin in cultured human lymphocytes. Mutagenesis 7(6):433-437.

*Barrueco C, Herrera A, Caballo C, et al. 1994. Induction of structural chromosome aberrations in human lymphocyte cultures and CHO cells by permethrin. Teratog Carcinog Mutagen 14:31-38.

*Bartsch H, Malaveille C, Camus AM, et al. 1980. Validation and comparative studies on 180 chemicals with S. typhimurium strains and V79 Chinese hamster cells in the presence of various metabolizing systems. Mutat Res 76:1-50.

Bast GE, Taeschner D, Kampffmeyer HG. 1997. Permethrin absorption not detected in single-pass perfused rabbit ear, and absorption with oxidation of 3-phenoxybenzyl alcohol. Arch Toxicol 71:179186.

Bateman DN. 2000. Management of pyrethroid exposure. Clin Toxicol 38(2):107-109.

*Batiste-Alentorn M, Xamena N, Velázquez A, et al. 1986. Mutagenicity testing of the pyrethroid insecticide cypermethrin in drosophila. Mutagenesis 1(5):343-346.

*Baynes RE, Halling KB, Riviere JE. 1997. The influence of diethyl-m-toluamide (DEET) on the percutaneous absorption of permethrin and carbaryl. Toxicol Appl Pharmacol 144:332-339.

*Bennett RS, Klass EE, Coats JR, et al. 1983. Fenvalerate residues in nontarget organisms from treated cotton fields. Bull Environ Contam Toxicol 31:61-65.

*Berger GS. 1994. Epidemiology of endometriosis. In: Berger GS, ed. Endometriosis: Advanced management and surgical techniques. New York, NY: Springer-Verlag. 


\section{REFERENCES}

Bhatnagar R, Kataria M. 1997. Influence of permethrin on certain biochemical parameters in the rat brain. Med Sci Res 25:327-328.

*Bhaumik A, Gupta PK. 1990. Teratogenicity of decamethrin in rats. Indian Vet J 2:213-219.

*Bhunya SP, Pati PC. 1988. Genotoxic effects of a synthetic pyrethroid insecticide, cypermethrin, in mice in vivo. Toxicol Lett 41:223-230.

*Bhunya SP, Pati PC. 1990. Effect of deltamethrin, a synthetic pyrethroid, on the induction of chromosome aberrations, micronuclei and sperm abnormalities in mice. Mutagenesis 5(3):229-232.

Binka FN, Kubaje A, Adjuik M, et al. 1996. Impact of permethrin impregnated bednets on child mortality in Kassena-Nankana district, Ghana: a randomized controlled trial. Tropical Medicine and International Health 1(2):147-154.

*Bissacot DZ, Vassilieff I. 1997a. HPLC determination of flumethrin, deltamethrin, cypermethrin and cyhalothrin residues in the milk and blood of lactating dairy cows. J Anal Toxicol 21:397-402.

*Bissacot DZ, Vassilieff I. 1997b. Pyrethroid residues in milk and blood of dairy cows following single topical applications. Vet Hum Toxicol 39(1):6-8.

*Blaylock BL, Abdel-Nasser M, McCarty SM, et al. 1995. Suppression of cellular immune responses in Balb/c mice following oral exposure to permethrin. Bull Environ Contam Toxicol 54:768-774.

Bloom AS, Staatz CG, Dieringer T. 1983. Pyrethroid effects on operant responding and feeding. Neurobehav Toxicol Teratol 5:321-324.

*Bloomquist JR. 1993. Neuroreceptor mechanisms in pyrethroid mode of action and resistance. In: Roe RM, Kuhr RJ, eds. Reviews in pesticide toxicology. Raleigh, NC: Toxicology Communications Inc., 184-230.

*Bloomquist JR, Adams PM, Soderlund DM. 1986. Inhibition of $\gamma$-aminobutyric acid-stimulated chloride flux in mouse brain vesicles by polychlorocycloalkane and pyrethroid insecticides.

Neurotoxicology 7(3):11-20.

Blume H-P, Ahlsdorf B. 1993. Prediction of pesticide behavior in soil by means of simple field tests. Ecotoxicol Environ Saf 26:313-332.

BNA. 2001. Environment and Safety Library on the Web States and Territories. Bureau of National Affairs, Inc. Washington, D.C. http//www.esweb.bna.com/. May 25, 2001.

*Boehncke A, Siebers J, Nolting H-G. 1990. Investigations of the evaporation of selected pesticides from natural and model surfaces in field and laboratory. Chemosphere 21(9):1109-1124.

*Box SA, Lee MR. 1996. A systemic reaction following exposure to a pyrethroid insecticide. Hum Exp Toxicol 15:389-390.

*Bradbury JE, Forshaw PJ, Gray AJ, et al. 1983. The action of mephenesin and other agents on the effects produced by two neurotoxic pyrethroids in the intact and spinal rat. Neuropharmacology 22(7):907-914. 
Bradbury JE, Gray AJ, Forshaw P. 1981. Protection against pyrethroid toxicity in rats with mephenesin. Toxicol Appl Pharmacol 60:382-384.

Bradbury SP, Coats JR. 1982. Toxicity of fenvalerate to bobwhite quail (Colinus virginianus) including brain and liver residues associated with mortality. J Toxicol Environ Health 10:307-319.

Bradbury SP, Coats JR. 1989. Comparative toxicology of the pyrethroid insecticides. Rev of Environ Contam and Toxicol 108:133-177.

*Braun HE, Frank R, Miller LA. 1985. Residues of cypermethrin in milk from cows wearing impregnated ear tags. Bull Environ Contam Toxicol 35:61-64.

Briggs G. 1981. Adsorption of pesticides by some Australian soils. Aust J Soil Res 19:61-68.

Brodie ME, Aldridge WN. 1982. Elevated cerebellar cyclic GMP levels during the deltamethrin-induced motor syndrome. Neurobehav Toxicol Teratol 4:109-113.

Brown GB, Gaupp JE, Olsen RW. 1988. Pyrethroid insecticides: Stereospecific allosteric interaction with the batrachotoxinin-A benzoate binding site of mammalian voltage-sensitive sodium channels. Mol Pharmacol 34:54-59.

*Budavari S, O'Neil MJ, Smith A, et al. 1996. The Merck index: An encyclopedia of chemicals, drugs, and biologicals. $12^{\text {th }}$ ed. Whitehouse Station, NJ: Merck and Co., Inc.

Butler WH, Cohen SH, Squire RA. 1997. Mesenchymal tumors of the mouse urinary bladder with vascular and smooth muscle differentiation. Toxicol Pathol 25(3):268-274.

*Caballo C, Herrera A, Barrueco C, et al. 1992. Analysis of cytogenetic damage induces in CHO cells by the pyrethroid insecticide fenvalerate. Teratog Carcinog Mutagen 12:243-249.

*Cabral JRP, Galendo D. 1990. Carcinogenicity study of the pesticide fenvalerate in mice. Cancer Lett 49:13-18.

Cabral JRP, Galendo D, Laval M, et al. 1990. Carcinogenicity studies with deltamethrin in mice and rats. Cancer Lett 49:147-152.

*Cagen SZ, Malley LA, Parker CM, et al. 1984. Pyrethroid-mediated skin sensory stimulation characterized by a new behavioral paradigm. Toxicol Appl Pharmacol 76:270-279.

*Calore EE, Cavaliere MJ, Puga FR, et al. 2000. Histologic peripheral nerve changes in rats induced by deltamethrin. Ecotoxicol Environ Saf 47:82-86.

Campana MA, Panzeri AM, Moreno VJ, et al. 1999. Genotoxic evaluation of the pyrethroid $\lambda$ cyhalothrin using the micronucleus test in erythrocytes of the fish Cheirodon interruptus interruptus. Mutat Res 438:155-161.

*Cantalamessa F. 1993. Acute toxicity of two pyrethroids, permethrin, and cypermethrin in neonatal and adult rats. Arch Toxicol 67:510-513.

*Caplan JA, Isensee AR, Nelson JO. 1984. Fate and effects of $\left[{ }^{14} \mathrm{C}\right]$ fenvalerate in a tidal marsh sediment ecosystem model. J Agric Food Chem 32:166-171. 


\section{REFERENCES}

*Carbonell E, Puig M, Xamena N, et al. 1989. Mitotic arrest induced by fenvalerate in human lymphocyte cultures. Toxicol Lett 48:45-48.

Carlson GP, Schoenig GP. 1980. Induction of liver microsomal NADPH cytochrome $c$ reductase and cytochrome $P-450$ by some new synthetic pyrethroids. Toxicol Appl Pharmacol 52:507-512.

*Carlson JE, Villaveces JW. 1977. Hypersensitivity pneumonitis due to pyrethrum: Report of a case. JAMA 237(16):1718-1719.

Carlton M. 1977. Some effects of cismethrin on the rabbit nervous system. Pestic Sci 8:700-712.

Casida JE. 1980. Pyrethrum flowers and pyrethroid insecticides. Environ Health Perspect 34:189-202.

Casida JE, Quistad GB. 1995. Metabolism and synergism of pyrethrins. In: Casida JE, Quistad GB, eds. Pyrethrum flowers: Production, chemistry, toxicology, and uses. New York: Oxford University Press, 258-276.

Casida JE, Ruzo LO. 1980. Metabolic chemistry of pyrethroid insecticides. Pestic Sci 11:257-269.

*Casida JE, Gammon DW, Glickman AH, et al. 1983. Mechanisms of selective action of pyrethroid insecticides. Annu Rev Pharmacol Toxicol 23:413-438.

*Casida JE, Kimmel EC, Elliott M, et al. 1971. Oxidative metabolism of pyrethrins in mammals. Nature 230:326-327.

Casida JE, Ueda K, Gaughan LC, et al. 1976. Structure-biodegradability relationships in pyrethroid insecticides. Arch Environ Contam Toxicol 3:491-500.

Catinot R, Hoellinger H, Pfister A, et al. 1989a. Effects on rats of subacute intoxication with deltamethrin via an osmotic pump. Drug Chem Toxicol 12:173-196.

Catinot R, Hoellinger H, Sonnier M, et al. 1989b. In vitro covalent binding of the pyrethroids cismethrin, cypermethrin and deltamethrin to rat liver homogenate and microsomes. Arch Toxicol 63:214-220.

Catterall WA. 1992. Cellular and molecular biology of voltage-gated sodium channels. Physiol Rev 72(4):S15-S48.

*Caux P-Y, Bastien C, Crowe A. 1996. Fate impact of pesticides applied to potato cultures: The Nicolet River Basin. Ecotoxicol Environ Saf 33:175-185.

*Cecchine G, Golomb BA, Hilborne LH, et al. 2000. A review of the scientific literature as it pertains to Gulf War illnesses. Rand Publication Database.

http://www.rand.org/publications/MR/MR1018.8/MR1018.8.pdf/. April 5, 2001.

Chalmers AE, Miller TA, Olsen RW. 1987. Deltamethrin: A neurophysiological study of the sites of action. Pestic Biochem Physiol 27:36-41.

Chambers J. 1980. An introduction to the metabolism of pyrethroids. Residue Rev 73:101-124. 
Chang J-Y, Lin J-M. 1998. Aliphatic aldehydes and allethrin in mosquito-coil smoke. Chemosphere 36(3):617-624.

Chanh PH, Navarro-Delmasure C, Chanh A, et al. 1980. Toxicity and cardiovascular effects of decamethrin on anaesthetized dogs. IRCS J Med Sci 8:388-389.

Chanh P, Navarro-Delmasure C, Chanh APH, et al. 1981. Analgesic effects of decamethrin. IRCS J Med Sci 9:503-504.

Chanh PH, Navarro-Delmasure C, Pham Huu Chanh A, et al. 1984. Toxicological studies of deltamethrin. Int J Tissue React 6(2):127-133.

*Chapman RA, Cole CM. 1982. Observations on the influence of water and soil $\mathrm{pH}$ on the persistence of insecticides. J Environ Sci Health B17(5):487-504.

*Chapman RA, Tu CM, Harris CR, et al. 1981. Persistence of five pyrethroid insecticides in sterile and natural, mineral and organic soil. Bull Environ Contam Toxicol 26:513-519.

*Chatterjee KK, Talukder G, Sharma A. 1982. Effects of synthetic pyrethroids on mammalian chromosomes: I. Sumicidin. Mutat Res 105:101-106.

*Chauhan LKS, Agarwal DK, Sundararaman V. 1997. In vivo induction of sister chromatid exchange in mouse bone marrow following oral exposure to commercial formulations of alpha-cyano pyrethroids.

Toxicol Lett 93:153-157.

Chawla R. 1996. Acute oral toxicity studies with K-othrine (a synthetic pyrethroid insecticide) in Swiss albino mice. Uttar Pradesh J Zool 16(1):67-68.

Chawla R. 1997. Laboratory evaluation of k-othrine, a synthetic pyrethroid against Swiss albino mice. J Adv Zool 18(1):51-53.

Chen AW, Fink JM, Letinski DJ, et al. 1997. Residue of cypermethrin and its major acid metabolites in milk and tissues from dairy bovines treated with cypermethrin. J Agric Food Chem 45:4850-4855.

*Chen $\mathrm{H}$, Xiao J, Hu G, et al. 2002. Estrogenicity of organophosporus and pyrethroid pesticides. J Toxicol Environ Health A 65:1419-1435.

*Chen S, Zhang Z, He F, et al. 1991. An epidemiological study on occupational acute pyrethroid poisoning in cotton farmers. Br J Ind Med 48:77-81.

*Chen Y-L, Casida JE. 1969. Photodecomposition of pyrethrin I, phthalthrin, and dimethrin: Modification in the acid moiety. J Agric Food Chem 17(2):208-215.

*Chen Z-M, Wang Y-H. 1996. Chromatographic methods for the determination of pyrethrin and pyrethroid pesticide residues in crops, foods and environmental samples. J Chromatogr 754:367-395.

*Chen ZM, Zabik MJ, Leavitt RA. 1984. Comparative study of thin film photodegradative rates for 36 pesticides. Ind Eng Chem Prod Res Dev 23:5-11. 
*Chester G, Hatfield LD, Hart TB, et al. 1987. Worker exposure to, and absorption of, cypermethrin during aerial application of an "ultra low volume" formulation to cotton. Arch Environ Contam Toxicol 16:69-78.

*Chester G, Sabapathy NN, Woollen BH. 1992. Exposure and health assessment during application of lambda-cyhalothrin for malaria vector control in Pakistan. Bull WHO 70(5):615-619.

*Chruścielska K, Kalhorn D. 1999. Genotoxicity of pyrethroids: Part 2. Studies on mutagenic activity of commercial formulations in mouse micronucleus test. Pestycydy 4:47-50.

*Chruścielska K, Kalhorn D, Sitowska B. 1999. Genotoxicity of pyrethroids: Part 1. Studies on mutagenic activity of pyrethroids formulations and their active ingredients in Saccharomyces cerevisiae assay. Pestycydy 4:39-45.

Chugh Y, Sankaranarayanan A, Sharma PL. 1991. Effect of fenvalerate and endosulfan on behavioral despair and forced locomotor activity in albino mice. Asia Pac J Pharmacol 6:31-35.

*Clark JM, Marion JR, Tessier DM, et al. 1991. Airborne drift residues collected near apple orchard environments due to application of insecticide mixtures. Bull Environ Contam Toxicol 46:829-836.

*Clewell HJ III, Andersen ME. 1985. Risk assessment extrapolations and physiological modeling. Toxicol Ind Health 1:111-113.

*Coats JR. 1990. Mechanisms of toxic action and structure-activity relationships for organochlorine and synthetic pyrethroid insecticides. Environ Health Perspect 87:255-262.

Condés-Lara M, Graff G A, Vega-Riveroll L. 1999. Effects of cypermethrin on the electroencephalographic activity of the rat: A model of chemically induced seizures. Neurobehav Toxicol Teratol 21(3):293-298.

Cordon C. 1986. Gas chromatographic determination of flucythrinate synthetic pyrethroid residues in a range of crops. J Agric Food Chem 34:953-955.

*Cotham WE, Bidleman TF. 1989. Degradation of malathion, endosulfan, and fenvalerate in seawater and seawater/sediment microcosms. J Agric Food Chem 37:824-828.

Cremer JE, Seville MP. 1985. Changes in regional cerebral blood flow and glucose metabolism associated with symptoms of pyrethroid toxicity. Neurotoxicology 6(3):1-12.

*CRIS/USDA. 2001. CRIS Database. Current Research Information System. U.S. Department of Agriculture. April, 2001.

*CRISP. 2001. CRISP Database. Computer Retrieval of Information on Scientific Projects.

*CRISP. 2003. CRISP Database. Computer Retrieval of Information on Scientific Projects.

Crofton KM, Reiter LW. 1984. Effects of two pyrethroid insecticides on motor activity and the acoustic startle response in the rat. Toxicol Appl Pharmacol 75:318-328.

*Crofton KM, Reiter LW. 1988. The effects of Type I and II pyrethroids on motor activity and the acoustic startle response in the rat. Fundam Appl Toxicol 10:624-634. 


\section{REFERENCES}

*Crofton KM, Kehn LS, Gilbert ME. 1995. Vehicle and route dependent effects of a pyrethroid insecticide, deltamethrin, on motor function in the rat. Neurotoxicol Teratol 17(4):489-495.

*Crofton KM, Reiter LW, Mailman RB. 1987. Pyrethroid insecticides and radio ligand displacement for the gaba receptor chloride ionophore complex. Toxicol Lett 35:183-190.

*Crosby DG. 1995. Environmental fate of pyrethrins. In: Casida JE, Quistad GB, eds. Pyrethrum flowers. New York, NY: Oxford University Press, 194-213.

*Crossland NO, Shires SW, Bennett D. 1982. Aquatic toxicology of cypermethrin. III. Fate and biological effects of spray drift deposits in fresh water adjacent to agricultural land. Aquatic Toxicol 2:253-270.

Culliford SJ, Kozlowski RZ. 1999. Effects of pyrethroids on volume-sensitive chloride channels. Br J Pharmacol 126:28.

Culver CA, Malina JJ, Talvert RL. 1988. Probable anaphylactoid reaction to a pyrethrin pediculocide shampoo. Clin Pharm 7:846-849.

*Curry AM, Bennett IP. 1985. PP321: 4 Hour acute inhalation toxicity study in the rat of a 13\% EC formulation. Imperial Chemical Industries PLC. OTS0538576.

Dandliker WB, Hicks AN, Levison SA, et al. 1980. Effects of pesticides on the immune response. Environ Sci Technol 14(2):204-210.

Danielson TJ, Golsteyn LR, Elder JL. 1996. Pharmacokinetics of fenvalerate after intravenous administration to sheep. Pestic Sci 46:145-150.

Das AC, Mukherjee D. 1999. Influence of BHC and fenvalerate on mineralization and availability of some plant nutrients in soil. Bull Environ Contam Toxicol 62:371-376.

*Davies JH. 1985. The pyrethroids: An historical introduction. In: Leahey JP, ed. The pyrethroid insecticides. Philadelphia, PA: Taylor \& Francis, 1-41.

Davies MG, Kersey PJ. 1986. Contact allergy to yarrow and dandelion. Contact Dermatitis 14:256-257.

Day KE. 1991. Effects of dissolved organic carbon on accumulation and acute toxicity of fenvalerate, deltamethrin and cyhalothrin to Daphnia magna (Straus). Environ Toxicol Chem 10:91-101.

Dayal M, Parmar D, Dhawan A, et al. 1999. Induction of rat brain and liver cytochrome P450 1A1/1A2 and 2B1/2B2 isoenzymes by deltamethrin. Environ Toxicol Pharmacol 7:169-178.

de Boer F, van der Gugten j, Slangen JL, et al. 1988. Changes in plasma corticosterone and catecholamine contents induced by low doses of deltamethrin in rats. Toxicology 49:263-270.

De Cheke ME. 1989. Chemical analysis of water and wastewater inorganics. J Water Pollut Control Fed 61(6):727-755.

Dejonckheere W, Steurbaut W, Drieghe S, et al. 1996a. Monitoring of pesticide residues in fresh vegetables, fruits, and other selected food items in Belgium. J Assoc Off Anal Chem Int 79(1):97-110. 
Dejonckheere W, Steurbaut W, Drieghe S, et al. 1996b. Pesticide residue concentrations in the Belgian total diet, 1991-1993. J Assoc Off Anal Chem Int 79(2):520-528.

*Demian SR. 1998. Immunological alteration in mice exposed to deltamethrin insecticide: II. Defective humoral immune reactivity. J Med Res Inst 19(2):154-164.

*Demian SR, El-Sayed MH. 1993. Immunological alterations in mice exposed to deltamethrin insecticide I. Impairment of IL-1 \& IL-2 production. J Med Res Inst 19(2):154-164.

Demoute JP. 1989. A brief review of the environmental fate and metabolism of pyrethroids. Pestic Sci 27:375-385.

Deshmukh PB. 1992. Three-generation reproductive studies of a synthetic pyrethroid - cyhalothrin. Toxicol Lett 64/65:779-781.

Deshmukh PB, Patel SV, Banerjee RS. 1993. Effect of cyhalothrin on reproductive parameters in mice. Proc Acad Environ Biol 2(1):99-104.

*Dési I, Dobronyi I, Varga L. 1986. Immuno-, neuro-, and general toxicologic animal studies on a synthetic pyrethroid: Cypermethrin. Ecotoxicol Environ Saf 12:220-232.

Devaud LL, Szot P, Murray TF. 1986. PK 1195 antagonism of pyrethroid-induced proconvulsant activity. Eur J Pharmacol 120:269-273.

*Dianovský J, Šiviková K. 1997. Cytogenetic effect of supermethrin in pig and cattle peripheral lymphocytes. Acta Vet Brno 66:33-38.

Diel F, Detscher M, Borck H, et al. 1998a. Effects of permethrin on human basophils and lymphocytes in vitro. Inflamm Res 47:S11-S12.

Diel F, Detscher M, Schock B, et al. 1998b. In vitro effects of the pyrethroid S-bioallethrin on lymphocytes and basophils from atopic and nonatopic subjects. Allergy 53:1052-1059.

Diel F, Horr B, Borck H, et al. 1999. Pyrethroids and piperonyl-butoxide affect human T-lymphocytes in vitro. Toxicol Lett 107:65-74.

*DOD. 1977. Toxicological evaluation of 3-(phenoxyphenyl) methyl (+ or -)-cis, trans-3-(2,2dichloroethenyl)-2,2-dimethyl cyclopropanecarboxylate (permethrin), December 1975-April 1977. Department of the Army, Department of Defense. ADA047284.

*DOD. 2001. Environmental exposure report. U.S. Department of Defense. http://www.gulflink.osd.mil/pesto/pest_s04.htm. April 9, 2001.

Dogheim SM, Alla SAG, El-Marsafy AM. 1999. Monitoring pesticide residues in Egyptian fruits and vegetables in 1995. J Assoc Off Anal Chem Int 82(4):948-954.

*Dolara P, Salvadori M, Capobianco T, et al. 1992. Sister-chromatid exchanges in human lymphocytes induced by dimethoate, omethoate, deltamethrin, benomyl and their mixture. Mutat Res 283:113-118. 
*Dorman DC, Beasley VR. 1991. Neurotoxicology of pyrethrin and the pyrethroid insecticides. Vet Hum Toxicol 33(3):238-243.

Dorman DC, Buck WB, Trammel HL, et al. 1990. Fenvalerate/N,N-diethyl-m-toluamide (DEET) toxicosis in two cats. J Am Vet Med Assoc 196(1):100-102.

*DOT. 2001. Hazardous materials table, special provisions, hazardous materials communications, emergency response information, and training requirements. Department of Transportation. Code of Federal Regulations. 49 CFR 172. Appendix A. http://www.dot.gov/. April 19, 2001.

Dowling RH, Mack E, Small DM, et al. 1970. Effects of controlled interruption of the enterohepatic circulation of bile salts by biliary diversion and by ileal resection on bile salt secretion, synthesis, and pool size in the Rhesus monkey. J Clin Invest 49:232-342.

*Dureja P. 1990. Photodecomposition of pyrethroid insecticide fenpropathrin. Pesticides 1989:31-33.

*Dureja P, Casida JE, Ruzo LO. 1984. Dinitroanilines as photostabilizers for pyrethroids. J Agric Food Chem 32:246-250.

Dyck PJ, Shimono M, Schoening GP, et al. 1984. The evaluation of a new synthetic pyrethroid pesticide (permethrin) for neurotoxicity. J Environ Pathol Toxicol Oncol 5:109-117.

*Eadsforth CV, Baldwin MK. 1983. Human dose-excretion studies with the pyrethroid insecticide, cypermethrin. Xenobiotica 13(2):67-72.

*Eadsforth CV, Bragt PC, van Sittert NJ. 1988. Human dose-excretion studies with pyrethroid insecticides cypermethrin and alphacypermethrin: Relevance for biological monitoring. Xenobiotica 18(5):603-614.

Eells JT, Bandettini PA, Holman PA, et al. 1992. Pyrethroid insecticide-induced alterations in mammalian synaptic membrane potential. J Pharmacol Exp Ther 262(3):1173-1181.

Eells JT, Rasmussen JL, Bandettini PA, et al. 1993. Differences in the neuroexcitatory actions of pyrethroid insecticides and sodium channel-specific neurotoxins in rat and trout brain synaptosomes. Toxicol Appl Pharmacol 123:107-119.

*Eil C, Nisula BC. 1990. The binding properties of pyrethroids to human skin fibroblast androgen receptors and to sex hormone binding globulin. J Steroid Biochem 3(3-4):409-414.

*Eitzer BD. 1991. Cycling of indoor air concentrations of $d$-trans-allethrin following repeated pesticide applications. Bull Environ Contam Toxicol 47:406-412.

Eke KR. 1996. Pesticides in the aquatic environment in England and Wales. Pestic Outlook April:1521.

El-Ashmawy IM, Zakaria AD, Hemed SA, et al. 1993. Cytotoxic effects of the pyrethroid insecticide (Matox) with reference to its influence on the reproductive hormone. Vet Med J Giza 41(3):125-130.

Elbetieha A, Da'as SI, Khamas W, et al. 2001. Evaluation of the toxic potentials of cypermethrin pesticide on some reproductive and fertility parameters in the male rats. Arch Environ Contam Toxicol 41:522-528. 


\section{REFERENCES}

*El-Elaimy I. 1986. Biochemical disturbance in liver function and whole blood AChE due to repeated dermal application of baythroid to rat. Proc Zool Soc AR Egypt 10:51-60.

*El-Gohary M, Awara WM, Nassar S, et al. 1999. Deltamethrin-induced testicular apoptosis in rats: The protective effect of nitric oxide synthase inhibitor. Toxicology 132:1-8.

El-Khatib EN. 2001. Assessment of the mutagenic activity of alpha-cypermethrin: Detection of p53 mutation using SSCP analysis of polymerase chain reaction. Mutat Res 483:S73.

El-Khatib EN, Rokaya HA. 2001. Genotoxic effects of two pesticides and their mixtures: In vivo chromosomal aberrations and micronucleus assay in rat bone-marrow cells. [Abstract]. Toxciol Lett 123:123.

*Ellenhorn MJ, Schonwald S, Ordog G, et al. 1997. Medical toxicology: Diagnosis and treatment of human poisoning. 2nd ed. Baltimore: Williams \& Wilkins.

Elliott M, Janes NF, Kimmel EC, et al. 1972. Metabolic fate of pyrethrin I, pyrethrin II, and allethrin administered orally to rats. J Agric Food Chem 20(2):300-313.

*Elliott M, Janes NF, Pulman DA, et al. 1976. Radiosynthesis and metabolism in rats of the $R$ isomers of the insecticide permethrin. J Agric Food Chem 24(2):270-276.

El-Meligy S, El-Ashwah N, Gaffar N, et al. 1993. Effect of fenvalerate on liver, brain, and kidney sodium-potassium adenosine triphosphatase activity and serum electrolytes in rats. Egypt J Biochem 11(1):47-55.

El-Salkh BA. 1996. Ultrastructural changes of the liver of rat after polytrin treatment. al-Azhar Bull Sci 7(1):939-946.

El-Sebae AH, Salem MH, El-Assar MRS, et al. 1988. In vitro effect of profenofos, fenvalerate and dimilin on protein and RNA biosynthesis by rabbit liver and muscle tissues. J Environ Sci Health B23(5):439-451.

El-Sewedy SM, Mostafa MH, El-Bassiouni EA, et al. 1982a. Effect of fenvalerate on kynurenine metabolizing enzymes and acid ribonuclease of mouse liver. J Environ Sci Health B 17:571-579.

El-Sewedy SM, Zahran MA, Seidan MA, et al. 1982b. Effect and mechanism of action of methomyl and cypermethrin insecticides on kynurenine metabolizing enzymes of mouse liver. J Environ Sci Health B17(5):527-539.

*El-Shahawi FI. 1996. In vivo toxicological studies of the effect of pyrethroid insectide permethrin on female Wistar rats. Alex J Pharm Sci 10(1):71-76.

El-Tawil OS, Abdel-Rahman MS. 1997. Effect of cypermethrin on isolated male and female rat hepatocytes. J Toxicol Environ Health 52:461-474.

El-Tawil OS, Abdel-Rahman MS. 2001. The role of enzyme induction and inhibition on cypermethrin hepatotoxicity. Pharmacol Res 44(1):33-40. 


\section{REFERENCES}

El-Toukhy MA, Girgis RS. 1993. In vivo and in vitro studies on the effect of larvin and cypermethrin on adenosine triphosphatase activity of male rats. J Environ Sci Health B 28(5):599-619.

El-Toukhy MA, Ebiad SA, Hassan AA, et al. 1989. In vivo studies on the effect of some insecticides on the hepatic activities of L-tryptophan 2,3-dioxygenase and pyridoxal phosphokinase of male mice. $\mathrm{J}$ Environ Sci Health B 24(3):265-276.

*EMMI. 1997. EMMI Database. Environmental Monitoring Methods Index. U.S. Environmental Protection Agency.

Enan E, Matsumura F. 1993. Activation of phosphoinositide/protein kinase C pathway in rat brain tissue by pyrethroids. Biochem Pharmacol 45(3):703-710.

Enan E, Pinkerton KE, Peake J, et al. 1996. Deltamethrin-induced thymus atrophy in male Balb/c mice. Biochem Pharmacol 51(4):447-454.

*EPA. 1981. Data evaluation record: Cyhalothrin oral toxicity study in beagle dogs (repeated daily dosing for 26 weeks). U.S. Environmental Protection Agency. Office of Pesticide Programs. Tox review 005100 (excerpt).

*EPA. 1983. Memorandum: Review of a 1 year dosing study with the synthetic pyrethroid permethrin. U.S. Environmental Protection Agency. Office of Pesticides and Toxic Substances. Tox Review 003403.

*EPA. 1985a. Data evaluation record: Cyhalothrin: 28-day feeding study in the rat. U.S.

Environmental Protection Agency. Office of Pesticide Programs. Tox review 005100 (excerpt).

*EPA. 1985b. Data evaluation record: Cyhalothrin: 90-day feeding study in rats. U.S. Environmental Protection Agency. Office of Pesticide Programs. Tox review 005100 (excerpt).

*EPA. 1985c. Data evaluation record: Cyhalothrin: Chronic toxicity study in rats. U.S. Environmental Protection Agency. Office of Pesticide Programs. Tox review 005100 (excerpt).

*EPA. 1985d. Data evaluation record: Cyhalothrin: Chronic toxicity and oncogenicity feeding study in mice. U.S. Environmental Protection Agency. Office of Pesticide Programs. Tox review 005100 (excerpt).

*EPA. 1986a. Data evaluation record: Cyhalothrin: Teratogenicity study in rats. U.S. Environmental Protection Agency. Office of Pesticide Programs. Tox review 005100 (excerpt).

*EPA. 1986b. Data evaluation record: Cyhalothrin: Three-generation reproduction study in rats. U.S. Environmental Protection Agency. Office of Pesticide Programs. Tox review 005100 (excerpt).

*EPA. 1987. Memorandum: Esfenvalerate: ASANA (pydrin)- Submission of the range-finding study used to determine dosages for the 1-year dog study. U.S. Environmental Protection Agency. Office of Pesticides and Toxic Substances. Tox review 006524.

*EPA. 1988a. Recommendations for and documentation of biological values for use in risk assessment. Cincinnati, OH: U.S. Environmental Protection Agency. PB88-179874.

*EPA. 1988b. Reference physiological parameters in pharmacokinetic modeling. Washington, DC:

U.S. Environmental Protection Agency. PB88-196019. 
*EPA. 1988c. Memorandum: Pyrethrins: Submission of rat and rabbit teratology range finding studies in response to a prior request from Toxicology Branch. U.S. Environmental Protection Agency. Office of Pesticides and Toxic Substances. Tox review 006824.

*EPA. 1990. Interim methods for development of inhalation reference concentrations. Washington, DC: U.S. Environmental Protection Agency. Office of Health and Environmental Assessment, Office of Research and Development. Environmental Criteria and Assessment Office. EPA 600/8-90/066A.

*EPA. 1991a. Data evaluation record: Esfenvalerate: Subchronic oral toxicity (90-day) mouse. U.S. Environmental Protection Agency. Office of Pesticide Programs. Tox review 008967 (excerpt).

*EPA. 1991b. Memorandum: Permethrin: Review of rat and rabbit development toxicity studies (83-3) submitted in response to FIFRA 88 toxicity data requirements. U.S. Environmental Protection Agency. Office of Pesticides and Toxic Substances. Tox review 008344.

*EPA. 1992a. Another look: National survey of pesticides in drinking water wells: Phase II report. Office of Water. U.S. Environmental Protection Agency. Office of Pesticides and Toxic Substances, EPA 579/09-91-020.

*EPA. 1992b. Data evaluation record: Esfenvalerate: Comparative mammalian neurotoxicity- Rat 818 ss 1 dose- 2 weeks. U.S. Environmental Protection Agency. Office of Pesticide Programs. Tox review 00981 (excerpt).

*EPA. 1992c. Data evaluation report: Cypermethrin: Multi generation reproduction study-rats. U.S. Environmental Protection Agency. Office of Pesticide Programs. Tox review (excerpt) 009347.

*EPA. 1994a. Memorandum: Resmethrin: Evaluation of 2-generation reproduction study in rat and reevaluation of the following previously submitted studies: 3-generation reproduction study in rat, six month dog, rat. U.S. Environmental Protection Agency. Office of Pesticides and Toxic Substances. Tox review 011329.

*EPA. 1994b. Memorandum: Permethrin: Review of series 81-8ss and 82-7ss acute and subchronic neurotoxicity screen studies and a literature publication on the neurotoxicity and commentary on a special positive control study with acrylamide. U.S. Environmental Protection Agency. Office of Pesticides and Toxic Substances.

*EPA. 1994c. Memorandum. Pyrethrum extract: Review of rat chronic feeding/carcinogenicity study (IRDC 1990) and mouse carcinogenicity study (IRDC 1990). U.S. Environmental Protection Agency. Office of Pesticides and Toxic Substances. Tox Review 01079.

*EPA. 1994d. Memorandum: Resmethrin: Evaluation of new mouse dietary carcinogenicity study and reevaluation of previously submitted mouse carcinogenicity study on resmethrin (SBP 1:52). U.S.

Environmental Protection Agency. Office of Pesticides and Toxic Substances. Tox review 011067.

*EPA. 1995. Emergency planning and community Right-to-know Act. U.S. Environmental Protection Agency. http://www.epa.gov/region5/ debs/html/epcra.htm. April 19, 1995.

*EPA. 1996. Memorandum: Cypermethrin: Review of a series 82-4 subchronic inhalation toxicity study in rats and a series 83-3 developmental toxicity study in rabbits. U.S. Environmental Protection Agency. Office of Pesticides and Toxic Substances. Tox review 012056. 


\section{REFERENCES}

*EPA. 1999. Memorandum: Pyrethrins: Report of the cancer assessment review committee. U.S. Environmental Protection Agency. Office of Pesticides and Toxic Substances. Tox Review 013354.

*EPA. 2000a. Restricted use products (RUP) report: October 2000. U.S. Environmental Protection Agency. Office of Pesticide Programs. http://www.epa.gov/RestProd/rupoct00.htm. April 2, 2001.

*EPA. 2000b. Synthetic pyrethroids for mosquito control. U.S. Environmental Protection Agency. 735F-00-004. May 2000.

*EPA. 2000c. NCOD query results: New CCL ambient occurrence data. U.S. Environmental Protection Agency. National Drinking Water Contaminant Occurrence Database.

http://oaspub.epa.gov/ncod/rpt_new_ccl_ambient_pkg.run_report. April 26, 2001.

*EPA. 2001a. Designation of hazardous substances. U.S. Environmental Protection Agency. Code of Federal Regulations. 40 CFR 116.4. http://www.epa.gov/epacfr40/chapt-I.info/chi-toc.h. April 26, 2001.

*EPA. 2001b. Designation of hazardous substances. U.S. Environmental Protection Agency. Code of Federal Regulations. 40 CFR 302.4. http://www.epa.gov/epacfr40/chapt-I.info/chi-toc.htm. April 26, 2001.

*EPA. 2001c. Determination of reportable quantities for hazardous substances. U.S. Environmental Protection Agency. Code of Federal Regulations. 40 CFR 117.3.

http://www.epa.gov/docs/epacfr40/chapt-I.info/subc. April 26, 2001.

*EPA. 2001d. NPDES Permit application testing requirements. U.S. Environmental Protection Agency. Code of Federal Regulations. 40 CFR 122, Appendix D. http://www.epa.gov/epahome/cfr40.htm. April 19, 2001.

*EPA. 2001e. Toxic chemical release reporting: Community right-to-know. U.S. Environmental Protection Agency. Code of Federal Regulations. 40 CFR 372.65. http://www.epa.gov/epacfr40/chaptI.infor/chi-toc. April 26, 2001.

*EPA. 2001f. Pesticide programs. Tolerances and exemptions from tolerances for pesticide chemicals in food. U.S. Environmental Protection Agency. Code of Federal Regulations. 40 CFR Part 180. http://access.gpo.gov/nara/cfr/cfrhtml_00/Title_40/40cfr180_main_00.html. April 19, 2001.

*EPA. 2003. Lists of other (inert) pesticide ingredients. U.S. Environmental Protection Agency. Office of Pesticide Programs. http://www.epa.gov/opprd001/inerts/lists.html. March 27, 2003.

Eriksson P. 1991. DDT and pyrethroids-ecotoxicological considerations. Comp Biochem Physiol 100C(1-2):269-270.

Eriksson P. 1992. Neuroreceptor and behavioral effects of DDT and pyrethroids in immature and adult mammals. In: Isaacson RL, Jensen KF, eds. The vulnerable brain and environmental risks. New York, NY: Plenum Press, 235-251.

*Eriksson P, Fredriksson A. 1991. Neurotoxic effects of two different pyrethroids, bioallethrin and deltamethrin, on immature and adult mice: Changes in behavioral and muscarinic receptor variables. Toxicol Appl Pharmacol 108:78-85. 
*Eriksson P, Nordberg A. 1990. Effects of two pyrethroids, bioallethrin and deltamethrin, on subpopulations of muscarinic and nicotinic receptors in the neonatal mouse brain. Toxicol Appl Pharmacol 102:452-463.

Eriksson P, Talts U. 2000. Neonatal exposure to neurotoxic pesticides increases adult susceptibility: A review of current findings. Neurotoxicology 21:37-48.

Eriksson P, Ankarberg E, Viberg H, et al. 2001. Neonatal exposure to toxicants: Defined critical period: Altered adult susceptibility. Neurotoxicology 22(4):510.

*Eriksson P, Fredriksson A, Nordbery A. 1991. Neonatal exposure to pyrethroids and nicotine influence on the development of cholinergic receptor subtypes and behavior in young and adult mice. Neurotoxicology 12(1):133-134.

*Erstfeld KM. 1999. Environmental fate of synthetic pyrethroids during spray drift and field runoff treatments in aquatic microcosms. Chemosphere 39(10):1737-1769.

Essawy GS, El-Banna HA, Sobiihy HM, et al. 1994. Influence of lambda (synthetic pyrethroids) on fertility and blood parameters in male rats. Vet Med J Giza 42(1):71-75.

FDA. 1989. Residues in foods-1988. J Assoc Off Anal Chem 72(5):133A-152A.

FDA. 1990. Residues in foods: Monitoring programs. J Assoc Off Anal Chem 73(5):127A-146A.

FDA. 1991. Residues in foods. J Assoc Off Anal Chem 74(5):121A-141A.

*FDA. 2000a. Piperonyl butoxide and pyrethrins as components of bags. U.S. Food and Drug Administration. Code of Federal Regulations. 21 CFR 178.3730. http://www.access.gpo.gov/. September 6, 2000.

*FDA. 2000b. Squalane, pyrethrins and piperonyl butoxide. U.S. Food and Drug Administration. Code of Federal Regulations. 21 CFR 524.2140. http://www.access.gpo.gov/. September 6, 2000.

*FDA. 2000c. Food and Drug Administration: Total diet study. Summary of residues found ordered by food market baskets 91-3-99-1. U.S. Food and Drug Administration. September 6, 2000.

*FDA. 2001. Food and Drug Administration pesticide program: Residue monitoring. U.S. Food and Drug Administration. http://vm.cfsan.fda.gov/ acrobat/pes99rep.pdf. April 16, 2001.

*FEDRIP. 2001. Federal Research in Progress. April 2001.

*FEDRIP. 2003. Federal Research in Progress. April 2003.

Fernandez MC, Martinez-Larrañaga MR, Fernandez-Cruz ML, et al. 1997. Neurotoxicological effects and brain disposition of deltamethrin in rats. Methods Find Exp Clin Pharmacol 19(Suppl. A):113.

Ferone MR, Amorena M, De Liguoro M, et al. 1994. Toxicokinetics of fenvalerate in rat. Acta Toxicol Ther 15(4):221-227.

*Flannigan SA, Tucker SB. 1985. Variation in cutaneous sensation between synthetic pyrethroid insecticides. Contact Dermatitis 13:140-147. 


\section{REFERENCES}

Flannigan SA, Tucker SB, Key MM, et al. 1985a. Primary irritant contact dermatitis from synthetic pyrethroid insecticide exposure. Arch Toxicol 56:288-294.

*Flannigan SA, Tucker SB, Key MM, et al. 1985b. Synthetic pyrethroid insecticides: A dermatological evaluation. Br J Ind Med 42:363-372.

Flodström S, Wärngård L, Ljungquist S, et al. 1988. Inhibition of metabolic cooperation in vitro and enhancement of enzyme altered foci incidence in rat liver by the pyrethroid insecticide fenvalerate. Arch Toxicol 61:218-223.

*Flucke W, Schilde B. 1980. FCR 1272. Subacute oral toxicity study on rats. Institut fur Toxikologie. Report No. 9039.

*Flucke W, Thyssen J. 1980. Acute toxicity studies. Institut fur Toxikologie. OTS0543768.

*Fomon SJ. 1966. Body composition of the infant: Part I: The male "reference infant". In: Falkner F, ed. Human development. Philadelphia, PA: WB Saunders, 239-246.

*Fomon SJ, Haschke F, Ziegler EE, et al. 1982. Body composition of reference children from birth to age 10 years. Am J Clin Nutr 35:1169-1175.

Forshaw PJ, Bradbury JE. 1983. Pharmacological effects of pyrethroids on the cardiovascular system of the rat. Eur J Pharmacol 91:207-213.

Forshaw PJ, Ray DE. 1986. The effects of two pyrethroids, cismethrin and deltamethrin, on skeletal muscle and the trigeminal reflex system in the rat. Pestic Biochem Physiol 25:143-151.

Forshaw PJ, Ray DE. 1990. A novel action of deltamethrin on membrane resistance in mammalian skeletal muscle and non-myelinated nerve fibers. Neuropharmacology 29(1):75-82.

Forshaw PJ, Ray DE. 1993. Deltamethrin, but not cismethrin, inhibits a neuronal voltage-dependent chloride channel. Neurotoxicology 14(4):555.

*Forshaw PJ, Ray DE. 1997. Development of therapy for Type II pyrethroid insecticide poisoning. Hum Exp Toxicol 16:382.

*Forshaw PJ, Lister T, Ray DE. 2000. The role of voltage-gated chloride channels in Type II pyrethroid insecticide poisoning. Toxicol Appl Pharmacol 163:1-8.

Foulhoux P, Cotonat J, Leclerc M, et al. 1984. Treatment of deltamethrin acute intoxications. Neurotoxicology 5(4):77.

Frank R, Braun HE, Clegg BS, et al. 1990. Survey of farm wells for pesticides, Ontario, Canada, 19861987. Bull Environ Contam Toxicol 44:410-419.

Frank R, Braun HE, Miller LA, et al. 1984. Fenvalerate residues in milk following topical treatment to dairy cows. Pestic Sci 15:600-604.

Frank R, Braun HE, Ripley BD. 1987a. Residues of insecticides, fungicides, and herbicides on Ontariogrown vegetables, 1980-1985. J Assoc Off Anal Chem 70(6):1081-1086. 


\section{REFERENCES}

*Frank R, Johnson K, Braun HE, et al. 1991. Monitoring air, soil, stream and fish for aerial drift of permethrin. Environ Monit Assess 16:127-150.

Frank R, Ripley BD, Braun HE, et al. 1987b. Survey of farm wells for pesticides residues, Southern Ontario, Canada, 1981-1982, 1984. Arch Environ Contam Toxicol 16:1-8.

*Franz TJ, Lehman PA, Franz SF, et al. 1996. Comparative percutaneous absorption of lindane and permethrin. Arch Dermatol 132:901-905.

*Freitag D, Ballhorn L, Geyer H, et al. 1985. Environmental hazard profile of organic chemicals. Chemosphere 14(10):1589-1616.

Frenkel REP, Hong YJ, Shin DH. 1988. Misuse of eye drops due to interchanged caps. Arch Ophthalmol 106:16-17.

Fuortes L. 1999. Urticaria due to airborne permethrin exposure. Vet Hum Toxicol 41:92-93.

Gabbianelli R, Falcioni G, Nasuit C, et al. 2002. Cypermethrin-induced plasma membrane perturbation on erythrocytes from rats: reduction of fluidity in the hydrophobic core and in gltathione peroxidase activity. Toxicology 175(1-3):91-101.

Galceran MT, Santos FJ, Caixach J, et al. 1993. PCBs and chlorinated pesticides in shellfish of a deltaic environment. Chemosphere 27(7):1183-1200.

*Gandhi G, Chowdhury JB, Sareen PK, et al. 1995. Genotoxic effects of deltamethrin in the mouse bone marrow micronucleus assay. Mutat Res 346:203-206.

*Garey J, Wolff MS. 1998. Estrogenic and antiprogestagenic activities of pyrethroid insecticides. Biochem Biophys Res Commun 251:855-859.

Garg SK, Shah MA, Garg KM, et al. 1997. Biochemical and physiological alterations following short term exposure to fluvalinate—a synthetic pyrethroid. Indian J Pharmacol 29:250-254.

*Gaughan LC, Ackerman ME, Unai T, et al. 1978. Distribution and metabolism of trans- and cispermethrin in lactating Jersey cows. J Agric Food Chem 26(3):813-818.

*Gaughan LC, Unai T, Casida JE. 1977. Permethrin metabolism in rats. J Agric Food Chem 25(1):9-17.

*Geetha KY, Devi KR. 1992. Evaluation of cypermethrin for mutagenicity in somatic and germ cells of mice. Trends Life Sci 7(2):99-104.

George DA. 1985. Chemical contaminants monitoring. J Assoc Off Anal Chem 68(6):1160-1163.

*Ghiasuddin SM, Soderlund DM. 1984. Hydrolysis of pyrethroid insecticides by soluble mouse brain esterases. Toxicol Appl Pharmacol 74:390-396.

*Ghosh AK, Sharma A, Talukder G. 1992. Cytotoxic effects of Sumicidin, a Type II synthetic pyrethroid, on mice in vivo at 6, 12 and $24 \mathrm{~h}$ after exposure. Cytobios 71:85-91. 


\section{REFERENCES}

Ghosh TK. 1990. Biochemical changes induced by the insecticide fenvalerate in the male gonads of albino rat. Environ Ecol 8(1):63-67.

*Gianessi LP, Silvers CS. 2000. Trends in crop pesticide use: Comparing 1992 and 1997. Washington, DC: National Center for Food and Agricultural Policy.

Gilbert ME, Mack CM, Crofton KM. 1989. Pyrethroids and enhanced inhibition in the hippocampus of the rat. Brain Res 477:314-321.

Giri S, Sharma GD, Giri A, et al. 2002. Fenvalerate-induced chromosome aberrations and sister chromatid exchanges in the bone marrow cells of mice in vivo. Mutat Res 520:125-132.

*Giwercman A, Carlsen E, Keiding N, et al. 1993. Evidence for increasing incidence of abnormalities of the human testis: A review. Environ Health Perspect Suppl 101(2):65-71.

Glickman AH, Casida JE. 1982. Species and structural variations affecting pyrethroid neurotoxicity. Neurobehav Toxicol Teratol 4:793-799.

Glowa JR. 1986. Acute and sub-acute effects of deltamethrin and chlordimeform on schedule-controlled responding in the mouse. Neurobehav Toxicol Teratol 8:97-102.

*Go V, Garey J, Wolff MS, et al. 1999. Estrogenic potential of certain pyrethroid compounds in the MCF-7 human breast carcinoma cell line. Environ Health Perspect 107(3):173-177.

*Goldfrank LR, Flomenbaum NE, Lewin NA, et al. 1998. Goldfrank's toxicologic emergencies. 6th ed. Stamford, CT: Appleton \& Lange.

Gombe S, Ogada TA. 1988. Health of men on long term exposure to pyrethrins. E Afr Med J 65(11):734-742.

*Gomes M, Bernardi MM, Spinosa H. 1991a. Effects of prenatal pyrethroid insecticide exposure on the sexual development of rats. Vet Hum Toxicol 33(5):427-428.

Gomes M, Bernardi MM, Spinosa H. 1991b. Pyrethroid insecticides and pregnancy: Effect on physical and behavioral development of rats. Vet Hum Toxicol 33(4):315-317.

Goswami N, Chatterjee SK. 1993. Effect of cypermethrin on hematological variables of albino mice. Environ Ecol 11(3):653-655.

*Gotoh Y, Kawakami M, Matsumoto N, et al. 1998. Permethrin emulsion ingestion: Clinical manifestations and clearance of isomers. Clin Toxicol 36(1\&2):57-61.

*Graillot C, Hoellinger H. 1982. Binding of two pyrethroid isomers, cismethrin and bioresmethrin, to liver proteins. Toxicol Appl Pharmacol 66(313-318):313-318.

*Grant SMB. 1993. An unusual cause of burning mouth sensation. Br Dent J 175:378-380.

*Gray AJ, Connors TA. 1980. Delayed toxicity after intravenous administration of bioresmethrin to rats. Pestic Sci 11:361-366. 
*Gray AJ, Rickard J. 1982. The toxicokinetics of deltamethrin in rats after intravenous administration of a toxic dose. Pestic Biochem Physiol 18:205-215.

*Gray AJ, Soderlund DM. 1985. Mammalian toxicology of pyrethroids. In: Hutson DH, Roberts TR, eds. Insecticides. Vol 5: Progress in pesticide biochemistry and toxicology. New York, NY: John Wiley and Sons Ltd., 193-248.

*Gray AJ, Connors TA, Hoellinger H, et al. 1980a. The relationship between the pharmacokinetics of intravenous cismethrin and bioresmethrin and their mammalian toxicity. Pestic Biochem Physiol 13:281293.

Gray A, Connors TA, Rickard J. 1980b. Mechanism of mammalian toxicity of the pyrethroids. In: Littauer UZ, Silman DI, Teichberg VI, et al., eds. Neurotransmitters and their receptors. New York, NY: John Wiley and Sons Ltd, 565-568.

Grindem CB, Corbett WT, Tomkins MT. 1990. Risk factors for Haemobartonella felis infection in cats. J Am Vet Med Assoc 196(1):96-102.

Grosse G, Thiele T, Heuckendorf E, et al. 2002. Deltamethrin differentially affects neuronal subtypes in hippcampal primary culture. Neuroscience 112(1):233-241.

*Gunderson EL. 1988. FDA total diet study, April 1982-1984, dietary intakes of pesticides, selected elements, and other chemicals. J Assoc Off Anal Chem 71:1200-1209.

*Gunderson EL. 1995a. Dietary intakes of pesticides, selected elements, and other chemicals: FDA total diet study, June 1984-April 1986. J Assoc Off Anal Chem Int 78(4):910-921.

*Gunderson EL. 1995b. FDA Total diet study, July 1986-April 1991, Dietary intakes of pesticides, selected elements, and other chemicals. J Assoc Off Anal Chem Int 78(6):1353-1363.

Gupta A, Agarwal R, Shukla GS. 1999a. Functional impairment of blood-brain barrier following pesticide exposure during early development in rats. Hum Exp Toxicol 18:174-179.

Gupta MK, Jha GJ, Singh KK. 1999b. Effects of chronic cypermethrin toxicity on thyroid function in goats. Indian Vet J 76:340-341.

*Gupta PK. 1990. Teratogenic effects of cypermethrin in rats. J Environ Biol 11(2):121-126.

Gupta PK, Kumar S. 1991. Cumulative toxicity of deltamethrin in mice. J Environ Biol 12(1):45-50.

*Gupta RK, Mehr ZA, Korte DW, et al. 1990. Mutagenic potential of permethrin in the Drosophila melanogaster (diptera: drosophilidae) sex-linked recessive lethal test. J Econ Entomol 83(3):721-724.

*Guzelian PS, Henry CJ, Olin SS, eds. 1992. Similarities and differences between children and adults: Implications for risk assessment. Washington, DC: International Life Sciences Institute Press.

Habazin-Novak V, Pleština R. 1984. The effect of deltamethrin on induction of hepatic microsomal cytochrome P-450 in rats. Period Biol 86(4):315-316. 


\section{REFERENCES}

Habazin-Novak V, Fajdetic T, Kramaric M. 1985. Effects of technical malathion and deltamethrin on hepatic microsomal cytochrome P-450 and antipyrine half-life in rats. Iugosl Physiol Pharmacol Acta 21(2):149-153.

*Haddad LM, Shannon MW, Winchester JR. 1998. Clinical management of poisoning and drug overdose. 3rd ed. Philadelphia, PA: W.B. Saunders Company.

Hadnagy W, Seemayer NH, Kuhn K-H, et al. 1999. Induction of mitotic cell division disturbances and mitotic arrest by pyrethroids in V79 cell cultures. Toxicol Lett 107:81-87.

Haggas RL, Rees L, Thompson HM, et al. 1991. Sexual dimorphism in trans-cypermethrin hydrolysis in the domestic chicken. Biochem Soc Trans 19:303S.

Hagiwara A, Yamada M, Hasegawa R, et al. 1990. Lack of enhancing effects of fenvalerate and esfenvalerate on induction of preneoplastic glutathione $S$-transferase placental form positive liver cell foci in rats. Cancer Lett 54:67-73.

*Haitzer M, Höss S, Traunspurger W, et al. 1998. Effects of dissolved organic matter (DOM) on the bioconcentration of organic chemicals in aquatic organisms-A review. Chemosphere 37(7):1335-1362.

*Haley RW, Kurt TL. 1997. Self-reported exposure to neurotoxic chemical combinations in the Gulf War: A cross-sectional epidemiologic study. JAMA 277:231-237.

*Haley RW, Hom J, Roland PS, et al. 1997a. Evaluation of neurologic function in Gulf War veterans: A blinded case-control study. JAMA 277(3):223-230.

*Haley RW, Kurt TL, Hom J. 1997b. Is there a Gulf War syndrome? Searching for syndromes by factor analysis of symptoms. JAMA 277(3):215-222.

Hall LW, Alden RW. 1997. A review of concurrent ambient water column and sediment toxicity testing in the Chesapeake Bay watershed: 1990-1994. Environ Toxicol Chem 16(8):1606-1617.

Hasan NRA, El-Mahdy MM, Hamouda MA, et al. 1994. Pathological studies on the effect of pyrethroids aerosol on albino rats. Vet Med J Giza 42(1):23-29.

*Hassan AB, Soliman GA, Farag AA, et al. 1993. Effect of the synthetic pyrethroids Sumicidin and S3206 on male rat fertility. Vet Med J Giza 41(2):33-38.

Hassouna I, Wickert H, El-Elaimy I, et al. 1996. Systemic application of pyrethroid insecticides evokes differential expression of c-fos and c-jun proteins in rat brain. Neurotoxicology 17(2):415-432.

*HazDat. 2003. Agency of Toxic Substances and Disease Registry (ATSDR), Atlanta, GA. April 2003.

*He F, Deng H, Ji X, et al. 1991. Changes of nerve excitability and urinary deltamethrin in sprayers. Int Arch Occup Environ Health 62:587-590.

*He F, Sun J, Han K, et al. 1988. Effects of pyrethroid insecticides on subjects engaged in packaging pyrethroids. Br J Ind Med 45:548-551.

*He F, Wang S, Liu L, et al. 1989. Clinical manifestations and diagnosis of acute pyrethroid poisoning. Arch Toxicol 63:54-58. 
Heath J, Leahey JP. 1989. The metabolism of tefluthrin in the goat. Pestic Sci 25:375-389.

Heder AF, Hirsch-Ernst KI, Bauer D, et al. 2001. Induction of cytochrome P450 2B1 by pyrethroids in primary rat hepatocyte cultures. Biochem Pharmacol 62:71-79.

Helson BV, Payne NJ, Sundaram KMS. 1993. Impact assessment of spray drift from silvicultural aerial applications of permethrin on aquatic invertebrates using mosquito bioassays. Environ Toxicol Chem $12: 1635-1642$.

Hemming H, Flodström S, Wärngård L. 1993. Enhancement of altered hepatic foci in rat liver and inhibition of intercellular communication in vitro by the pyrethroid insecticides fenvalerate, flucythrinate and cypermethrin. Carcinogenesis 14(12):2531-3535.

*Hend RW, Gellatly JBM, Fleming DJ. 1979. Toxicity studies on the insecticide WL 41706: A three generation reproduction study (minus histopathology) in rats. Shell Oil Co. OTS0534728.

Henshel DS, Allen CA, Lam Y, et al. 1996. A comparison of the early embryo effects of ethanol, 1,1,1trichloroethane, atrazine, 2,4-D, methyl mercury, lead and 2,3,7,8-TCDD. Toxicologist

$\operatorname{March}(1 \mathrm{pt}): 197$.

*Herrera A, Laborda E. 1988. Mutagenic activity in synthetic pyrethroids in Salmonella typhimurium. Mutagenesis 3(6):509-514.

Heudorf U, Angerer Juergen. 2001. Metabolites of pyrethroid insecticides in urine specimens: Current exposure in an urban population in Germany. Environ Health Perspect 109(3):213-7.

*Hext PM. 1987. PP321: 4-Hour acute inhalation toxicity study in the rat. Imperial Chemical Industries PLC. OTS0545653.

*Hext PM, Brammer A, Chalmers DT, et al. 1986. PP321: 1 Year oral dosing study in dogs. ICI Amers Inc. OTS0545310.

*Hiatzer M, Hoss S, Traunspurger W, et al. 1998. Effects of dissolved organic matter (DOM) on the bioconcentration of organic chemicals in aquatic organisms - a review. Chemosphere 37(7):1335-1362.

Hijzen TH, Slangen JL. 1988. Effect of Type I and Type II pyrethroids on the startle response in rats. Toxicol Lett 40:141-152.

*Hijzen TH, De Beun R, Slangen JL. 1988. Effects of pyrethroids on the acoustic startle reflex in the rat. Toxicology 49:271-276.

*Hill BD. 1983. Persistence of deltamethrin in a Lethbridge sandy clay loam. J Environ Sci Health B18(6):691-703.

*Hill BD, Johnson DL. 1987. Persistence of deltamethrin and its isomers on pasture forage and litter. J Agric Food Chem 35:373-378.

*Hiromori T, Nakanishi T, Kawaguchi S, et al. 1986. Therapeutic effects of methocarbamol on acute intoxication by pyrethroids in rats. J Pestic Sci 11:9-14. 


\section{REFERENCES}

*Hoel DG, Davis DL, Miller AB, et al. 1992. Trends in cancer mortality in 15 industrialized countries, 1969-1986. J Natl Cancer Inst 84(5):313-320.

*Hoellinger H, Lecorsier A, Sonnier M, et al. 1987. Cytotoxicity, cytogenotoxicity and allergenicity tests on certain pyrethroids. Drug Chem Toxicol 10:291-310.

Hoellinger H, Sonnier M, Pichon J, et al. 1983. In vivo covalent binding of cismethrin and bioresmethrin to hepatic proteins. Toxicol Lett 19:179-187.

Holloway SF, Salgado VL, Wu CH, et al. 1989. Kinetic properties of single sodium channels modified by fenvalerate in mouse neuroblastoma cells. Pflugers Arch 414:613-621.

Holmstead RL, Soderlund DM. 1977. Separation and analysis of the pyrethrins by combined gas-liquid chromatography-chemical ionization mass spectrometry. J Assoc Off Anal Chem 60(1):685-689.

Hornychova M, Frantik E, Kubat J, et al. 1995. Neurotoxicity profile of supermethrin, a new pyrethroid insecticide. Cent Eur J Public Health 3(4):210-218.

Hotchkiss SA, Hewitt P, Caldwell J. 1990. Absorption of cypermethrin through rat skin in vitro. Eur J Pharmacol 183:367.

*Hour T-C, Chen L, Lin J-K. 1998. Comparative investigation on the mutagenicities of organophosphate, phthalimide, pyrethroid and carbamate insecticides by the Ames and lactam tests. Mutagenesis 13(2):157-166.

*Howard PH, Meylan WM. 1997. Handbook of physical properties of organic chemicals. Boca Raton, FL: Lewis Publishers.

Hoy JB, Cornell JA, Karlix JL, et al. 2000a. Interactions of pyridostigmine bromide, DEET and permethrin alter locomotor behavior of rats. Vet Hum Toxicol 42(2):65-71.

Hoy JB, Cornell JA, Karlix JL, et al. 2000b. Repeated coadministration of pyridostigmine bromide, DEET, and permethrin alter locomotor behavior of rats. Vet Hum Toxicol 42(2):72-76.

*HSDB. 2001. Pyrethrum: Environmental standards and regulations. Hazardous Substances Data Bank. http://toxnet.nlm.nih.gov/. April 19, 2001.

*Hudson PM, Tilson HA, Chen PH, et al. 1986. Neurobehavioral effects of permethrin are associated with alterations in regional levels of biogenic amine metabolites and amino acid neurotransmitters. Neurotoxicology 7(1):143-154.

Hundley HK, Cairns T, Luke MA, et al. 1988. Pesticide residue findings by the Luke Method in domestic and imported foods and animal feeds for fiscal years 1982-1986. J Assoc Off Anal Chem 71(5):875-892.

*Hunt LM, Gilbert BC. 1977. Distribution and excretion rates of ${ }^{14} \mathrm{C}$-labeled permethrin isomers administered orally to four lactating goats for 10 days. J Agric Food Chem 25(3):673-676.

Hunt LM, Gilbert BN, Lemeilleur CA. 1979. Distribution and depletion of radioactivity in hens treated dermally with ${ }^{14}$ C-labeled permethrin. Poult Sci 58:1197-1201. 
*Husain R, Seth PK. 1991. Neurotoxic effects of deltamethrin, a synthetic pyrethroid during early development in rats. [Abstract]. Int J Toxicol Occup Environ Health 1(1):138.

*Husain R, Gupta A, Khanna VK, et al. 1991. Neurotoxicological effects of a pyrethroid formulation, fenvalerate in rats. Res Commun Chem Pathol Pharmacol 73:111-114.

Husain R, Husain R, Adhami VM, et al. 1996. Behavioral, neurochemical, and neuromorphological effects of deltamethrin in adult rats. J Toxicol Environ Health 48:515-526.

*Hussain M, Perschke H. 1991. A study of factors affecting the persistence of deltamethrin applied to cotton fabric for tsetse fly control. Chemosphere 22(7):677-684.

*Hutson DH. 1979. The metabolic fate of synthetic pyrethroid insecticides in mammals. Prog Drug Metab 5:215-252.

Hutson DH, Casida JE. 1978. Taurine conjugation in metabolism of 3-phenoxybenzoic acid and the pyrethroid insecticide cypermethrin in mouse. Xenobiotica 8(9):565-571.

Hutson DH, Logan CJ. 1986. The metabolic fate in rats of the pyrethroid insecticide WL85871, a mixture of two isomers of cypermethrin. Pestic Sci 17:548-558.

*IARC. 2001. IARC agents and summary evaluations. Lyon, France: International Agency for Research on Cancer. http://monographs.iarc.fr/. April 19, 2001.

Imamura L, Hasegawa H, Kurashina K, et al. 2002. Neonatal exposure of newborn mice to pyrethoid (permethrin) represses activity-dependent $c$-fos mRNA expression in cerebellum. Arch Toxicol 76:392397.

Institóris L, Siroki O, Undeger U, et al. 1999a. Immunotoxicological effects of repeated combined exposure by cypermethrin and the heavy metals lead and cadmium in rats. Int J Immunopharmacol 21:735-743.

Institoris L, Siroki O, Undeger U, et al. 2001. Immunotoxicological investigation of subacute combined exposure by permethrin and the heavy metals arsenic(III) and mercury(II) in rats. Int Immunopharmacol 1:925-933.

Institoris L, Siroki O, Undeger U, et al. 2002. Immunotoxicological investigation i rats dosed repeatedly with combinations of cypermethrin, As (III), and $\mathrm{Hg}(\mathrm{II})$. Toxicology 172:59-67.

*Institóris L, Undeger U, Siroki O, et al. 1999b. Comparison of detection sensitivity of immuno- and genotoxicological effects of subacute cypermethrin and permethrin exposure in rats. Toxicology 137:4755 .

*IRIS. 2003a. Chronic health hazard assessments for noncarcinogenic effects: Cyhalothrin. U.S. Environmental Protection Agency. Integrated Risk Information System.

http://www.epa.gov/iris/subst/0279.htm. May 14, 2003.

*IRIS. 2003b. Chronic health hazard assessments for noncarcinogenic effects: Cypermethrin. U.S. Environmental Protection Agency. Integrated Risk Information System.

http://www.epa.gov/iris/subst/0380.htm. May 14, 2003. 


\section{REFERENCES}

*IRIS. 2003c. Chronic health hazard assessments for noncarcinogenic effects: Danitol. U.S. Environmental Protection Agency. Integrated Risk Information System.

http://www.epa.gov/iris/subst/0034.htm. May 14, 2003.

*IRIS. 2003d. Chronic health hazard assessments for noncarcinogenic effects: Permethrin. U.S. Environmental Protection Agency. Integrated Risk Information System.

http://www.epa.gov/iris/subst/0185.htm. May 14, 2003.

*IRIS. 2003e. Chronic health hazard assessments for noncarcinogenic effects: Resmethrin. U.S. Environmental Protection Agency. Integrated Risk Information System.

http://www.epa.gov/iris/subst/0343.htm. May 14, 2003.

*IRIS. 2003f. U.S. Environmental Protection Agency. Integrated Risk Information System. http://www.epa.gov/iris/subst/index.html. April 3, 2003.

Ishikawa Y, Charalambous P, Matsumura F. 1989. Modification by pyrethroids and DDT of phosphorylation activities of rat brain sodium channel. Biochem Pharmacol 38(15):2449-2457.

*Ishmael J, Litchfield MH. 1988. Chronic toxicity and carcinogenic evaluation of permethrin in rats and mice. Fundam Appl Toxicol 11:308-322.

Isobe N, Kaneko H, Shiba K, et al. 1990. Metabolism of esfenvalerate in rats and mice and effects of its isomers on metabolic fates of esfenvalerate. J Pestic Sci 15:159-168.

Ivie GW, Casida JE. 1971a. Photosensitizers for the accelerated degradation of chlorinated cyclodienes and other insecticide chemicals exposed to sunlight on bean leaves. J Agric Food Chem 19(3):410-416.

Ivie GW, Casida JE. 1971b. Sensitized photodecomposition and photosensitizer activity of pesticide chemicals exposed to sunlight on silica gel chromatoplates. J Agric Food Chem 19(3):405-409.

Izumi T, Kaneko H, Matsuo M, et al. 1984. Comparative metabolism of the six stereoisomers of phenothrin in rats and mice. J Pestic Sci 9:259-267.

Jain RK. 1996. Fenvalerate ( $\alpha$-cyano- $m$-phenoxy-benzyl $\alpha$-isopropyl-p-chlorophenyl acetate) residues in and on okra fruits. Sci Total Environ 187:253-255.

Jao LT, Casida JE. 1974. Esterase inhibitors as synergists for (+)-trans-chrysanthemate insecticide chemicals. Pestic Biochem Physiol 4:456-464.

*Johanson CE. 1980. Permeability and vascularity of the developing brain: Cerebellum vs. cerebral cortex. Brain Res 190:3-16.

Johnstone DR, Cooper JF, Dobson HM. 1987. The availability and fall-out of an insecticidal aerosol dispersed from aircraft during operations for control of tsetse fly in Zimbabwe. Atmos Environ 21(11):2311-2321.

Jokanović M, Maksimović M. 1995. A comparison of trinedoxime, obidoxime, pralidoxime and HI-6 in the treatment of oral organophophorus insecticide poisoning in the rat. Arch Toxicol 70:119-123.

Jordan EG, Kaufman DD. 1986. Degradation of cis- and trans-permethrin in flooded soil. J Agric Food Chem 34:880-884. 
Joy RM, Albertson TE. 1991. Interactions of $\mathrm{GABA}_{\mathrm{A}}$ antagonists with deltamethrin, diazepam, pentobarbital, and SKF100330A in the rat dentate gyrus. Toxicol Appl Pharmacol 109:251-262.

Joy RM, Lister T, Ray DE, et al. 1990. Characteristics of the prolonged inhibition produced by a range of pyrethroids in the rat hippocampus. Toxicol Appl Pharmacol 103:528-538.

Juhler RK, Lauridsen MG, Christensen MR, et al. 1999. Pesticide residues in selected food commodities: Results from the Danish National Pesticide Monitoring Program 1995-1996. J Assoc Off Anal Chem Int 82(2):337-358.

*Junting L, Chuichang F. 1991. Solid phase extraction method for rapid isolation and clean-up of some synthetic pyrethroid insecticides from human urine and plasma. Forensic Sci Int 51:89-93.

Kadota T, Okuno Y, Kohda H, et al. 1976. Mammalian toxicological study of permethrin, 3phenoxybenzyl t-cis, trans-2,2-dimethyl-3-(2,2-dichlorovinyl)-cyclopropane-1-carboxylate. BotyuKagaku 41:143-151.

Kadous A, Matsumura F, Enan E. 1994. High affinity binding of ${ }^{3} \mathrm{H}$-verapamil to rat brain synaptic membrane is antagonized by pyrethroid insecticides. J Environ Sci Health B 29(5):855-871.

Kale M, Rathore N, John S, et al. 1999. Lipid peroxidative damage on pyrethroid exposure and alterations in antioxidant status in rat erythrocytes: A possible involvement of reactive oxygen species. Toxicol Lett 105:197-205.

*Kale PG, Petty BT, Walker S, et al. 1995. Mutagenicity testing of nine herbicides and pesticides currently used in agriculture. Environ Mol Mutagen 25:148-153.

Kallman M, Sylianco-Wu L, Wilson M, et al. 1990. Ability of diazepam (DZ) to block the perinatal neurotoxicity of Type I and Type II pyrethroid formulations. Toxicologist 10(1):172.

Kamei J, Iguchi E, Sasaki M, et al. 2002. Modification of the fenvalerate-induced noiceptive response in mice by diabetes. Brain Res 948:17-23.

Kaneko H, Izumi T, Matsuo M, et al. 1984a. Metabolism of fenvalerate in dogs. J Pestic Sci 9:269-274.

*Kaneko H, Izumi T, Ueda Y, et al. 1984b. Metabolism and placental transfer of stereoisomers of tetramethrin isomers in pregnant rats. J Pestic Sci 9:249-258.

Kaneko H, Matsuo M, Miyamoto J. 1984c. Comparative metabolism of stereoisomers of cyphenothrin and phenothrin isomers in rats. J Pestic Sci 9:237-247.

Kaneko H, Ohkawa H, Miyamoto J. 1981a. Absorption and metabolism of dermally applied phenothrin in rats. J Pestic Sci 6:169-182.

Kaneko H, Ohkawa H, Miyamoto J. 1981b. Comparative metabolism of fenvalerate and the [2S, $\alpha \mathrm{S}]-$ isomer in rats and mice. J Pestic Sci 6:317-326.

Kaneko H, Ohkawa H, Miyamoto J. 1981c. Metabolism of tetramethrin isomers in rats. J Pestic Sci 6:425-435. 


\section{REFERENCES}

Kaneko H, Shiba K, Yoshitake A, et al. 1987. Metabolism of fenpropathrin (S-3206) in rats. J Pestic Sci 12:385-395.

Karen DJ, Li W, Harp PR, et al. 2001. Striatal dopaminergic pathways as a target for the insecticides permethrin and chlorpyrifos. Neurotoxicology 22(6):811-7.

Karmos-Várszegi M, Dési I. 1984. Acute effect of pyrethroid insecticides on the behaviour of mice. Acta Physiol Hung 63:343-344.

*Katagi T. 1991. Photodegradation of the pyrethroid insecticide esfenvalerate on soil, clay minerals, and humic acid surfaces. J Agric Food Chem 39:1351-1356.

Kathren RL. 1994. Toward improved biokinetic models for actinides: the United States Transuranium and Uranium Registries, a twenty-five year report. Radiat Prot Dosim 53(1-4):219-227.

Kathren RL. 1995. The United States Transuranium and Uranium Registries: 1968-1993. Radiat Prot Dosim 60(4):349-354.

*Kaufman DD, Russell BA, Helling CS, et al. 1981. Movement of cypermethrin, decamethrin, permethrin, and their degradation products in soil. J Agric Food Chem 29:239-245.

Kaul PP, Rastogi A, Hans RK, et al. 1996. Fenvalerate-induced alterations in circulatory thyroid hormones and calcium stores in rat brain. Toxicol Lett 89:29-33.

Kaur J, Sandhu HS. 2000. Biochemical alterations induced by repeated dermal toxicity of cypermethrin and deltamethrin in buffalo calves. Indian J Anim Sci 70(7):708-709.

*Kavlock R, Chernoff N, Baron R, et al. 1979. Toxicity studies with decamethrin, a synthetic pyrethroid insecticide. J Environ Pathol Toxicol 2:751-765.

*Khan SU, Behki RM, Tapping RI, et al. 1988. Deltamethrin residues in an organic soil under laboratory conditions and its degradation by a bacterial strain. J Agric Food Chem 36:636-638.

*Khan SU, Kacew S, Akhtar MH. 1986. Bioavailability of bound ${ }^{14} \mathrm{C}$ residues in rats from bean plants treated with ${ }^{14} \mathrm{C}$-deltamethrin. Chemosphere 15(7):923-927.

*Khan SU, Kacew S, Akhtar MH. 1990. Bound ${ }^{14} \mathrm{C}$ residues in stored wheat treated with $\left[{ }^{14} \mathrm{C}\right]$ deltamethrin and their bioavailabilities in rats. J Agric Food Chem 38:1077-1082.

Khan SU, Schnitzer M, Schulten HR. 1993. Fate of deltamethrin after nine years of incubation in an organic soil under laboratory conditions. J Agric Food Chem 41(7):1143-1151.

Khanna RN, Gupta GSD, Anand M. 2002. Kinetics of distribution of cypermethrin in blood, brain, and spinal cord after a single administration to rabbits. Bull Environ Contam Toxicol 69:749-755.

Khurana R, Mahipal SK, Chauhan RS. 1999. Effect of pesticides on delayed type hypersensitivity reaction in sheep. Indian J Anim Sci 69(11):880-881.

Kim SS, Rhee GS, Kim SH, et al. 2002. Permethrin affects reproductive development in rats. Teratology 65(6):333. 


\section{REFERENCES}

Knox JM, Tucker SB. 1983. A new cutaneous sensation caused by synthetic pyrethroids. Clin Res 31(2):586A.

*Knox JM, Tucker SR, Flannigan SA. 1984. Paresthesia from cutaneous exposure to a synthetic pyrethroid insecticide. Arch Dermatol 120:744-746.

*Kolmodin-Hedman B, Swensson Å, Åkerblom M. 1982. Occupational exposure to some synthetic pyrethroids (permethrin and fenvalerate). Arch Toxicol 50:27-33.

*Kolpin DW, Barbash JE, Gilliom RJ. 1998. Occurrence of pesticides in shallow groundwater of the United States: Initial results from the National Water-Quality Assessment Program. Environ Sci Technol 32(5):558-566.

*Kolpin DW, Goolsby DA, Thurman EM. 1995. Pesticides in near-surface aquifers: an assessment using highly sensitive analytical methods and tritium. J Environ Qual 24:1125-1132.

*Komori M, Nishio K, Kitada M, et al. 1990. Fetus-specific expression of a form of cytochrome P-450 in human livers. Biochemistry 29:4430-4433.

Kostka G, Palut D, Kopeć-Szlęzak J, et al. 2000. Early hepatic changes in rats induced by permethrin in comparison with DDT. Toxicology 142:135-143.

Kowalczyk-Bronisz SH, Gieldanowski J, Bubak B. 1990. Immunological profile of animals exposed to pesticide - deltamethrin. Arch Immunol Ther Exp 38:229-238.

*Krapac IG, Roy WR, Smyth CA, et al. 1995. Occurrence and distribution of pesticides in soil at agrichemical facilities in Illinois. J Soil Contam 4(3):209-226.

*Kreuger J, Peterson M, Lundgren E. 1999. Agricultural inputs of pesticide residues to stream and pond sediments in a small catchment in southern Sweden. Bull Environ Contam Toxicol 62:55-62.

*Krishnan K, Andersen ME. 1994. Physiologically based pharmacokinetic modeling in toxicology. In: Hayes AW, ed. Principles and methods of toxicology. New York, NY: Raven Press, Ltd., 149-188.

*Krishnan K, Anderson ME, Clewell HJ III, et al. 1994. Physiologically based pharmacokinetic modeling of chemical mixtures. In: Yang RSH, ed. Toxicology of chemical mixtures. New York, NY: Academic Press, 399-437.

Krishnappa K, Honnegowda, Jayakumar K, et al. 1999a. Effect of lambda cyhalothrin, on non-specific immune response in rats. Indian Vet J 76:1058-1061.

Krishnappa H, Honnegowda, Suresh TP, et al. 1999b. Effect of $\lambda$-cyhalothrin, a synthetic pyrethroid insecticide on certain defense mechanisms and immune response in male rats. Indian Vet J 76:506-510.

Krishnappa H, Honnegowda, Suresh TP, et al. 2000. Acute toxicity study of lambda cyhalothrin, a pyrethroid insecticide in rats. Indian Vet J 77:768-769.

Kühn K-H, Leng G, Bucholski KA, et al. 1996. Determination of pyrethroid metabolites in human urine by capillary gas chromatography-mass spectrometry. Chromatographia 13:285-292. 


\section{REFERENCES}

*Kühn KH, Wieseler B, Leng G, et al. 1999. Toxicokinetics of pyrethroids in humans: consequences for biological monitoring. Bull Environ Contam Toxicol 62:101-108.

Kumar S, Dhanaraj PS, Bhatnagar P. 1989. Bioconcentration and effects of dieldrin, dimethoate, and permethrin on Saccharomyces cerevisiae. Bull Environ Contam Toxicol 43:246-253.

*Kunimatsu T, Yamada T, Keiko O, et al. 2002. Lack of (anti-) androgenic or estrogenic effects of three pyrethroids (esfenvalerate, fenvalerate, and permethrin) in the Hershberger and uterotrophic assays. Regul Toxicol Pharmacol 35:227-237.

*Laughlin J, Newburn K, Gold RE. 1991. Pyrethroid insecticides and formulations as factors in residues remaining in apparel fabrics after laundering. Bull Environ Contam Toxicol 47:355-361.

*Lawrence LL, Casida JE. 1983. Stereospecific action of pyrethroid insecticides on the $\gamma$-aminobutyric acid receptor-ionophore complex. Science 221:1399-1401.

Lazarini CA, Florio JC, Lemonica IP, et al. 2001. Effects of prenatal exposure to deltamethrin on forced swimming behavior, motor activity, and striatal dopamine levels in male and female rats. Neurotoxicol Teratol 23:665-673.

*Lee PW. 1985. Fate of fenvalerate (Pydrin insecticide) in the soil environment. J Agric Food Chem 33:993-998.

Leahey JP, ed. 1985. The pyrethroid insecticides. Philadelphia PA: Taylor and Francis, 263-342.

Lee PW, Stearns SM, Powell WR. 1985. Rat metabolism of fenvalerate (Pydrin insecticide). J Agric Food Chem 33:988-993.

*Leeder JS, Kearns GL. 1997. Pharmacogenetics in pediatrics: Implications for practice. Pediatr Clin North Am 44(1):55-77.

*Leng G, Lewalter J. 1999. Role of individual susceptibility in risk assessment of pesticides. Occup Environ Med 56:449-453.

*Leng G, Kuhn K-H, Idel H. 1996. Biological monitoring of pyrethroid metabolites in urine of pest control operators. Toxicol Lett 88:215-220.

*Leng G, Kühn K-H, Idel H. 1997a. Biological monitoring of pyrethroids in blood and pyrethroid metabolites in urine: Applications and limitations. Sci Total Environ 199:173-181.

*Leng G, Kühn K-H, Wieseler B, et al. 1999a. Metabolism of (S)-bioallethrin and related compounds in humans. Toxicol Lett 107:109-121.

*Leng G, Leng A, Kühn K, et al. 1997b. Human dose-excretion studies with the pyrethroid insecticide cyfluthrin: Urinary metabolite profile following inhalation. Xenobiotica 27(12):1273-1283.

*Leng G, Lewalter J, Röhrig B, et al. 1999b. The influence of individual susceptibility in pyrethroid exposure. Toxicol Lett 107:123-130.

Lenza-Rizos C, Avramides EJ. 1995. Pesticide residues in olive oil. Rev Environ Contam Toxicol 141:111-131. 
*LeQuesne PM, Maxwell IC. 1980. Transient facial sensory symptoms following exposure to synthetic pyrethroids: A clinical and electrophysiological assessment. Neurotoxicology 2:1-11.

*Lessenger JE. 1992. Five office workers inadvertently exposed to cypermethrin. J Toxicol Environ Health 35:261-267.

Lessenger JE. 1995. A rash and chemical burns in a cowboy exposed to permethrin. J Agromed 2(3):2528.

*Leung H-W. 1993. Physiologically-based pharmacokinetic modeling. In: Ballentine B, Marro T, Turner P, eds. General and applied toxicology. New York: Stockton Press, 153-164.

*Lewis RG, Bond AE, Johnson DE, et al. 1988. Measurement of atmospheric concentration of common household pesticides: A pilot study. Environ Monit Assess 10:59-73.

*Litchfield MH. 1985. Toxicity to mammals. In: Leahey JP, ed. The pyrethroid insecticides. London: Taylor \& Francis, 99-150.

*Livingston AL. 1978. Forage plant estrogens. J Toxicol Environ Health 4:301-324.

Llewellyn DM, Brazier A, Brown R, et al. 1996. Occupational exposure to permethrin during its use as a public hygiene insecticide. Ann Occup Hyg 40(5):499-509.

Lock EA, Berry PN. 1980. Biochemical changes in the rat cerebellum following cypermethrin administration. Dev Toxicol Environ Sci 8:623-626.

Lock EA, Berry PN. 1981. Biochemical changes in the rat cerebellum following cypermethrin administration. Toxicol Appl Pharmacol 59:508-514.

*Loeser E, Eiben R. 1983. Multigeneration study on rats. Mobay Chemical Corporation. OTS0555303.

*Lombet A, Mourre C, Lazdunski M. 1988. Interaction of insecticides of the pyrethroid family with specific binding sites on the voltage-dependent sodium channel from mammalian brain. Brain Res 459:44-53.

Lord KA, McKinley M, Walker N. 1982. Degradation of permethrin in soils. Environ Pollut 29(Series A):81-90.

Luke MA, Masumoto HT, Cairns T, et al. 1988. Levels and incidences of pesticide residues in various foods and animal feeds analyzed by the Luke multiresidue methodology for fiscal years 1982-1986. J Assoc Off Anal Chem 71(2):415-420.

*Lukowicz-Ratajczak J, Krechniak J. 1992. Effects of deltamethrin on the immune system in mice. Environ Res 59:467-475.

*Lutnicka H, Bogacka T, Wolska L, et al. 1999. Degradation of pyrethroids in an aquatic ecosystem model. Wat Res 33(16):3441-3446.

Luty S, Latuszyńská J, Halliop J, et al. 1998. Toxicity of dermally applied alpha-cypermethrin in rats. Ann Agric Environ Med 5:109-115. 


\section{REFERENCES}

Luty S, Latuszyńská J, Pbuchowska-Przebirowska D, et al. 2000. Subacute toxicity of orally applied alpha-cypermethrin in Swiss mice. Ann Agric Environ Med 7:33-41.

Lykken L. 1972. Role of photosensitizers in alteration of pesticide residues in sunlight. In: Matsumura F, Boush GM, Misato T, eds. Environmental toxicology of pesticides. New York, NY: Academic Press, 449-469.

MacRae IC. 1989. Microbial metabolism of pesticides and structurally related compounds. Rev Environ Contam Toxicol 109:1-87.

*Madsen C, Claesson MH, Röpke C. 1996. Immunotoxicity of the pyrethroid insecticides deltamethrin and $\alpha$-cypermethrin. Toxicology 107:219-227.

Magnusson B, Blohm SG, Fregert S, et al. 1968. Routine patch testing IV: Supplementary series of test substances for Scandinavian countries. Acta Derm Venereol (Stockh) 48:110-114.

*Maguire RJ. 1990. Chemical and photochemical isomerization of deltamethrin. J Agric Food Chem 38:1613-1617.

Maguire RJ. 1992a. Aquatic environmental fate of deltamethrin. Water Sci Technol 25(11):99-102.

Maguire RJ. 1992b. The importance of pesticide volatilization form the surface microlayer of natural waters after aerial spraying. Water Sci Technol 25(11):111-116.

* Maguire RJ, Carey JH, Hart JH, et al. 1989. Persistence and fate of deltamethrin sprayed on a pond. J Agric Food Chem 37:1153-1159.

* Maiti PK, Kar A. 1998. Is triiodothyronine capable of ameliorating pyrethroid-induced thyroid dysfunction and lipid peroxidation? J Appl Toxicol 18:125-128.

Maity NK, Punia JS. 1991. Effect of fluvalinate, a synthetic pyrethroid on learning and memory traces in rats. Indian J Exp Biol 29:178-179.

Majumder S, Chakraborty AK, Mandal TK, et al. 1994. Subacute toxicity of fenvalerate in broiler chicks: Concentration, cytotoxicity and biochemical profiles. Indian J Exp Biol 32:752-756.

* Malaviya M, Husain R, Seth PK, et al. 1993. Perinatal effect of two pyrethroid insecticides on brain neurotransmitter function in the neonatal rat. Vet Hum Toxicol 35(2):119-122.

*Malley LA, Cagen SZ, Parker CM, et al. 1985. Effect of vitamin E and other amelioratory agents on the fenvalerate-mediated skin sensation. Toxicol Lett 29:51-58.

Malone JC, Brown NC. 1968. Toxicity of various grades of pyrethrum to laboratory animals. Pyrethrum Post 4(3):3-8.

Malpe ND, Phadnaik BS, Sadeker RD, et al. 1996. Acute toxicity studies of deltamethrin in rats. Indian Vet J 73:217-219.

Mandal TK, Bhattacharya A, Chakraborty AK, et al. 1992. Disposition kinetics, cytotoxicity and residues of fenvalerate in tissues following oral administration to goats. Pestic Sci 35:201-207. 


\section{REFERENCES}

*Mandal TK, Chakraborty AK, Bhattacharya A, et al. 1996. The disposition of kinetics and residues of fenvalerate in tissues following a single dermal application to black Bengal goats. Vet Res Commun 20:265-272.

*Mandhane SN, Chopde CT. 1997. Neurobehavioral effects of low level fenvalerate exposure in mice. Indian J Exp Biol 35:623-627.

Marei A, Ruzo LO, Casida JE. 1982. Analysis and persistence of permethrin, cypermethrin, deltamethrin, and fenvalerate in the fat and brain of treated rats. J Agric Food Chem 30:558-562.

Martin CN, Kennelly JC. 1985. Metabolism, mutagenicity, and DNA binding of biphenyl-based azodyes. Drug Metab Rev 16:89-117.

Masri MS, Hendrickson AP, Cox AJ, et al. 1964. Subacute toxicity of two chrysanthemumic acid esters: Barthrin and dimethrin. Toxicol Appl Pharmacol 6:716-725.

*Mayr U, Butsch A, Schneider S. 1992. Validation of two in vitro test systems for estrogenic activities with zearalenone, phytoestrogens and cereal extracts. Toxicology 74:135-149.

*Mbaria JM, Maitho TE, Muchiri DJ. 1993. Median lethal doses, clinical signs and post-mortem changes in acute pyrethrins toxicity in sheep and rabbits. Pyrethrum Post 19(1):26-29.

*McCain WC, Lee R, Johnson MS, et al. 1997. Acute toxicity study of pyridostigmine bromide, permethrin, and DEET in the laboratory rat. J Toxicol Environ Health 50:113-124.

*McCord CP, Kilker CH, Minster DK. 1921. Pyrethrum dermatitis: A record of the occurrence of occupational dermatosis among workers in the pyrethrum industry. JAMA 77(6):448-449.

*McDaniel KL, Moser VC. 1993. Utility of a neurobehavioral screening battery for differentiating the effects of two pyrethroids, permethrin and cypermethrin. Neurotoxicol Teratol 15:71-83.

McKillop CM, Brock JAC, Oliver GJA. 1984. Pyrethroid and aconitine binding sites. Neurotoxicology 5(4):75.

McKillop CM, Brock JAC, Oliver GJA, et al. 1987. A quantitative assessment of pyrethroid-induced paraesthesia in the guinea-pig flank model. Toxicol Lett 36:1-7.

McPhail RC, Gordon WA, Johnston MA. 1981. Behavioral effects of a synthetic pyrethroid insecticide (decamethrin). Fed Proc Fed Am Soc Exp Biol 40(3):678.

*Metcalf RL. 1989. Insect control. In: Elvers B, Hawkins S, Ravenscroft M, et al., eds. Ullmann's encyclopedia of industrial chemistry. Germany: VCH, 263-277.

*Metcalf RL. 1995. Insect control technology. In: Kirk-Othmer encyclopedia of chemical technology. New York: John Wiley and Sons, 533-602.

*Meyer EK. 1999. Toxicosis in cats erroneously treated with 45 to $65 \%$ permethrin products. J Am Vet Med Assoc 215(2):198-203. 


\section{REFERENCES}

* Meylan WM, Howard PH. 1993. Computer estimation of the atmospheric gas-phase reaction rate of organic compounds with hydroxyl radicals and ozone. Chemosphere 26(12):2293-2299.

Miadoková E, Garajová L. 1994. Genotoxicity testing of the technical supercypermethrin in the SOS chromotest. Acta Fac Rerum Nat Univ Comenianae, Form Prot Nat 16:37-43.

Miadoková E, Garajová L, Podstavková S, et al. 1993. Non-mutagenic effect of supercypermethrin forte proved in salmonella typhimurium. Acta Fac Rerum Nat Univ Comenianae, Genet Biol Mol 24-25:9-14.

*Miadoková E, Miklovičová M, Dúhová V, et al. 1991. Effects of the insecticide pyrethroid II in the Ames test, and on Hordeum vulgare and Vicia faba. Biol Plant 33(2):156-162.

*Miadoková E, Vlčková V, Dúhová V, et al. 1992. Effects of supercypermethrin, a synthetic developmental pyrethroid, on four biological test systems. Mutat Res 280:161-168.

Mikula I, Pistl J, Kačmár P. 1992. Immune response of sheep at subchronic intoxication by pyrethroid insecticide supercypermethrine. Acta Vet Brno 61:57-60.

*Millet M, Wortham H, Sanusi A, et al. 1997. Atmospheric contamination by pesticides: Determination in the liquid, gaseous and particulate phases. Environ Sci Pollut Res 4(3) 172-180.

*Milne GWA. 1995. CRC handbook of pesticides. Boca Raton: CRC Press.

Misra S, Sharma CB. 1997. Metabolism and bioaccumulation of fenvalerate and its metabolites in rat organs. Biomed Chromatogr 11:50-53.

*Mitchell JA, Wilson MC, Kallman MJ. 1988. Behavioral effects of pydrin and ambush in male mice. Neurotoxicol Teratol 10:113-119.

Mitchell JC, Dupuid G, Towers GH. 1972. Allergic contact dermatitis from pyrethrum (Chrysanthemum spp.). The roles of pyrethrosin, a sesquiterpene lactone, and of pyrethrin II. Br J Dermatol 86:568-573.

*Mitsche T, Borck H, Horr B, et al. 2000. Pyrethroid syndrome in an animal keeper. Allergy 55:93-94.

*Miyamoto J. 1976. Degradation, metabolism and toxicity of synthetic pyrethroids. Environ Health Perspect 14:15-28.

*Miyamoto J, Kaneko H, Tsuji R, et al. 1995. Pyrethroids, nerve poisons: How their risks to human health should be assessed. Toxicol Lett 82:933-940.

Miyamoto J, Nishida T, Ueda K. 1971. Metabolic fate of resmethrin, 5-benzyl-3-furymethyl dl-transchrysanthemate in the rat. Pestic Biochem Physiol 1:293-306.

Miyamoto J, Sato Y, Yamamoto K, et al. 1968. Biochemical studies on the mode of action of pyrethroidal insecticides. Part I. Metabolic fate of phthalthrin in mammals. Agric Biol Chem 32(5):628640.

Miyamoto J, Suzuki T, Nakae C. 1974. Metabolism of phenothrin or 3-phenoxybenzyl d- transchrysanthemumate in mammals. Pestic Biochem Physiol 4:438-450. 
MMWR. 2000. Illnesses associated with use of automatic insecticide dispenser units-Selected states and United States, 1986-1999. Morbidity and Mortality Weekly Report 49:492-495.

Mohamed OSA, Adam SEI. 1990. Toxicity of Sumicidin (fenvalerate) to Nubian goats. J Comp Pathol 102(1):1-6.

Mohamed OSA, Adam SEI. 1992. Effect of phenobarbitone pretreatment on the toxicity of temik and Sumicidin in Nubian goats. Vet Hum Toxicol 34:138-140.

*Mohan EM, Banupriya CAY, Anitha K, et al. 1998. Effect of sublethal dose of chlorpyrifos $48 \%$ EC and cypermethrin 25\% EC in Wistar rats. Pollut Res 17(1):13-16.

*Moniz AC, Bernardi NM, Souza-Spinosa HS, et al. 1990. Effects of exposure to a pyrethroid insecticide during lactation on the behavior of infant and adult rats. Braz J Med Biol Res 23:45-48.

*Moniz AC, Bernardi MM, Spinosa HS. 1994. Effects of a pyrethroid Type II pesticide on conditioned behaviors of rats. Vet Hum Toxicol 36(2):120-124.

Moniz AC, Cruz-Casallas PE, Oliveira CA, et al. 1999. Perinatal fenvalerate exposure: Behavioral and endocrinology changes in male rats. Neurotoxicol Teratol 21(5):611-618.

Moore JB. 1972. Pyrethrum extract: Part 2. Toxicology and pharmacology of pyrethrum extract. In: Nelson RH, ed. Pyrethrum flowers. Minneapolis, MN: McLaughlin Gormley King Co., 68-82.

*Moore JB. 1975. Pyrethrum extract. In: Nelson RH, ed. Pyrethrum flowers. Minneapolis, MI: McLaughlin Gormley King Co., 68-82.

Moretti M, Villarini M, Scassellati-Sforzolini G, et al. 1997. Applicability of aspecific noninvasive methods for biomonitoring of occupational exposure to deltamethrin: Preliminary study using an animal model. Arch Environ Contam Toxicol 33:323-328.

*Moretto A. 1991. Indoor spraying with the pyrethroid insecticide $\lambda$-cyhalothrin: Effects on spraymen and inhabitants of sprayed houses. Bull WHO 59(5):591-594.

*Moriya M, Ohta T, Watanabe K, et al. 1983. Further mutagenicity studies on pesticides in bacterial reversion assay systems. Mutat Res 116:185-216.

*Morselli PL, Franco-Morselli R, Bossi L. 1980. Clinical pharmacokinetics in newborns and infants: Age-related differences and therapeutic implications. Clin Pharmacokin 5:485-527.

Motomura H, Narahashi T. 2001. Interaction of tetramethrin and deltamethrin at the single sodium channel in rat hippocampal neurons. Neurotoxicology 22(3):329-39.

Mount ME, Moller G, Cook J, et al. 1991. Clinical illness associated with a commercial tick and flea product in dogs and cats. Vet Hum Toxicol 33(1):19-27.

Moussa M, Iskander KG, Gorgy AA. 1989. Scanning electron microscopic investigation of the effect of chronic toxicity on the permethrin on the tongue papillae of albino rats. Egypt Dent J 35(2):107-115.

*Mueller-Beilschmidt D. 1990. Toxicology and environmental fate of synthetic pyrethroids. J Pestic Ref 10(3). http://www.igc.org/panna/resources/_pestis/PESTIS.1996.14.html. February 22, 2001. 


\section{REFERENCES}

*Muir DCG, Rawn GP, Grift NP. 1985. Fate of the pyrethroid insecticide deltamethrin in small ponds: A mass balance study. J Agric Food Chem 33:603-609.

Müller-Mohnssen H. 1999. Chronic sequelae and irreversible injuries following acute pyrethroid intoxication. Toxicol Lett 107:161-175.

Nakamura Y, Tonogai Y, Sekiguchi Y, et al. 1994. Multiresidue analysis of 48 pesticides in agricultural products by capillary gas chromatography. J Agric Food Chem 42:2508-2518.

Nakanishi M, Hamada Y, Izaki K. 1970. Toxicological studies on a new pyrethroid: Kikuthrin (part II). Botyu-Kagaku 35:113-116.

Nakanishi M, Kato Y, Furuta T, et al. 1971. [Metabolic fate of proparthrin. Studies on insecticide. VIII.] Botyu-Kagaku 36:116-121. (Japanese).

*Nakano E, Rabello-Gay MN, Pereira CA. 1996. Evaluation of the genotoxic potential of flumethrin in mouse bone marrow by chromosomal analysis and micronucleus test. Teratog Carcinog Mutagen 16:3748.

*Narahashi T. 1971. Mode of action of pyrethroids. Bull Organ Mond Sante 44:337-345.

*Narahashi T. 1976. Nerve membrane as a target of pyrethroids. Pestic Sci 7:267-272.

Narahashi T. 1982. Cellular and molecular mechanisms of action of insecticides: Neurophysiological approach. Neurobehav Toxicol Teratol 4:753-758.

*Narahashi T. 1985. Nerve membrane ionic channels as the primary target of pyrethroids. Neurotoxicology 6(2):3-22.

*Narahashi T. 1986. Mechanisms of action of pyrethroids on sodium and calcium channel gating. In: Ford MG, Lunt GG, Reay RC, et al., eds. Neuropharmacology and pesticide action. Deerfield Beach, FL: VCH, 267-285.

*Narahashi T. 1996. Neuronal ion channels as the target sites of insecticides. Pharmacol Toxicol 78:114.

Narahashi T, Carter DB, Frey J, et al. 1995. Sodium channels and GABA $\mathrm{A}_{\mathrm{A}}$ receptor-channel complex as targets of environmental toxicants. Toxicol Lett 82/83:239-245.

Narahashi T, Frey JM, Ginsburg KS, et al. 1992. Sodium and GABA-activated channels as the targets of pyrethroids and cyclodienes. Toxicol Lett 64/65:429-436.

Narahashi T, Ginsburg KS, Nagata K, et al. 1998. Ion channels as targets for insecticides. Neurotoxicology 19(4-5):581-590.

Nassif M, Brooke JP, Hutchinson DBA, et al. 1980. Studies with permethrin against body lice in Egypt. Pestic Sci 11:679-684.

*NAS/NRC. 1989. Report of the oversight committee. In: Biologic markers in reproductive toxicology. Washington, DC: National Academy of Sciences, National Research Council, National Academy Press. 


\section{REFERENCES}

*Nehéz M, Lorencz R, Dési I. 2000. Simultaneous action of cypermethrin and two environmental pollutant metals, cadmium and lead, on bone marrow cell chromosomes of rats in subchronic administration. Ecotoxicol Environ Saf 45:55-60.

Neidert E, Saschenbrecker PW. 1996. Occurrence of pesticide residues in selected agricultural food commodities available in Canada. J Assoc Off Anal Chem Int 79(2):549-566.

*NIOSH. 1987. Registry of toxic effects of chemical substances. Vol. 4. 1985-86 ed. Washington, DC U.S. Department of Health and Human Services, Public Health Service, Centers for Disease Control, National Institute for Occupational Safety and Health, 3687.

*NIOSH. 1989. National occupational health survey of mining. Pyrites report. National Institute for Occupational Safety and Health. PB90-180787.

*NIOSH. 2001. Documentation for immediately dangerous to life or health concentrations (IDLHs). National Institute for Occupational Safety and Health. http://www.cdc.gov/niosh/idlh/8003347.html. April 13, 2001.

Nozaki S, Takahashi M, Hashimoto K. 1995. Effect of pyrethroid (allethrin and fenvalerate) on excitability changes following nerve impulse. J Occup Health 37:5-8.

*NRC. 1993. National Research Council. Pesticides in the diets of infants and children. Washington, DC: National Academy Press.

*Ohkawa H, Kaneko H, Tsuji H, et al. 1979. Metabolism of fenvalerate (Sumicidin) in rats. J Pestic Sci 4:143-155.

*Ohsawa K, Casida JE. 1980. Metabolism in rats of the potent knockdown pyrethroid kadethrin. J Agric Food Chem 28:250-255.

Okumura D, Melnicoe R, Jackson T, et al. 1991. Pesticide residues in food crops analyzed by the California Department of Food and Agriculture in 1989. Rev Environ Contam Toxicol 118:87-151.

*Okuno Y, Ito S, Seki T, et al. 1986a. Fenvalerate-induced granulomatous changes in rats and mice. J Toxicol Sci 11:53-66.

Okuno Y, Seki T, Ito S, et al. 1986b. Differential metabolism of fenvalerate and granuloma formation. Toxicol Appl Pharmacol 83:157-169.

* Oraby HA. 1997. Micronuclei formation in bone marrow cells of rats treated with meothrin (synthetic pyrethroid). J Appl Toxicol 17(6):353-356.

Ortiz D, Yáñez L, Gómez H, et al. 1995. Acute toxicological effects in rats treated with a mixture of commercially formulated products containing methyl parathion and permethrin. Ecotoxicol Environ Saf 32:154-158.

*OSHA. 2001a. Limits for air contaminants. U.S. Department of Labor. Occupational Safety and Health Administration. Code of Federal Regulations. 29 CFR 1910.1000, Table Z-1. http://www.oshaslc.gov/OshStddata/19101000TABLEZ-1.html. March 26, 2001. 


\section{REFERENCES}

*OSHA. 2001b. OSHA regulations: Air contaminants. U.S. Department of Labor. Occupational Safety and Health Administration. Code of Federal Regulations. 29 CFR 1915.1000. http://www.oshaslc.gov/OshStddata/19151000.html. March 26, 2001.

*OSHA. 2001c. OSHA Regulations: Gases, vapors, fumes, dusts, and mists. U.S. Department of Labor. Occupational Safety and Health Administration. Code of Federal Regulations. 29 CFR 1926.55. http://www.osha-slc.gov/OshStddata/19260055.html. March 26, 2001.

*Owen GM, Brozek J. 1966. Influence of age, sex and nutrition on body composition during childhood and adolescence. In: Falkner F, ed. Human development. Philadelphia, PA: WB Saunders, 222-238.

Pall HS, Williams AC, Waring R, et al. 1987. Motorneuron disease as manifestation of pesticide toxicity. [Abstract]. Lancet II(8560):685.

Pang G-F, Fan C-L, Chao Y-Z, et al. 1994. Packed-column gas chromatographic method for the simultaneous determination of 10 pyrethroid insecticide residues in fruits, vegetables, and grains. J Assoc Off Anal Chem 77(3):738-747.

*Pang G-F, Cao Y-Z, Fan C-L, et al. 1997. Modification of AOAC multiresidue method for determining synthetic pyrethroid residues in fruits, vegetables, and grains. Part III: Studies of analyte stability and method ruggedness. J Assoc Off Anal Chem Int 80(1):63-73.

* Parihar NS, Gupta A. 1998. Fenvalerate residues in green pods, pod cover, and grain of pigeonpea (Cajanus cajan L.). Bull Environ Contam Toxicol 60:159-163.

*Parker CM, Albert JR, Van Gelder GA, et al. 1985. Neuropharmacologic and neuropathologic effect of fenvalerate in mice and rats. Fundam Appl Toxicol 5:278-286.

*Parker CM, McCullough CB, Gellatly JBM, et al. 1983. Toxicologic and carcinogenic evaluation of fenvalerate in the B6C3F1 mouse. Fundam Appl Toxicol 3:114-120.

*Parker CM, Patterson DR, Van Gelder GA, et al. 1984a. Chronic toxicity and carcinogenicity evaluation of fenvalerate in rats. J Toxicol Environ Health 13:83-97.

*Parker CM, Piccirillo VJ, Kurtz SL, et al. 1984b. Six-month feeding study of fenvalerate in dogs. Fundam Appl Toxicol 4:577-586.

Parker CM, Wimberly HC, Lam AS, et al. 1986. Subchronic feeding study of decarboxyfenvalerate in rats. J Toxicol Environ Health 18:77-90.

*Paterson S, Mackay D, Tam D, et al. 1990. Uptake of organic chemicals by plants: A review of processes, correlations and models. Chemosphere 21(3):297-331.

*Pati PC, Bhunya SP. 1989. Cytogenetic effects of fenvalerate in mammalian in vivo test system. Mutat Res 222:149-154.

Patro N, Mishra SK, Chattopadhyay M, et al. 1997. Neurotoxicological effects of deltamethrin on the postnatal development of cerebellum of rat. J Biosci 22(2):117-130.

Pauluhn J. 1996. Risk assessment of pyrethroids following indoor use. Toxicol Lett 88:339-348. 


\section{REFERENCES}

Pauluhn J, Machemer LH. 1998. Assessment of pyrethroid-induced paraesthesias: Comparison of animal model and human data. Toxicol Lett 96/97:361-368.

*Pauluhn J, Thyssen J. 1982. Study for acute inhalation toxicology (effect of formulating agent on inhalation). Miles Inc. OTS0543768.

Peele DB, Crofton KM. 1987. Pyrethroid effects on schedule-controlled behavior: Time and dosage relationships. Neurotoxicol Teratol 9:387-394.

*Peter JV, John G, Cherian AM. 1996. Pyrethroid poisoning. J Assoc Physicians India 44(5):343-344.

*Pluijmen M, Drevon C, Montesano R, et al. 1984. Lack of mutagenicity of synthetic pyrethroids in Salmonella typhimurium strains and in V79 Chinese hamster cells. Mutat Res 137:7-15.

*Poláková H, Vargová M. 1983. Evaluation of the mutagenic effects of decamethrin: Cytogenetic analysis of bone marrow. Mutat Res 120:167-171.

*Pomorska K. 1999. Determination of alphacypermethrin in the air by capillary gas chromatography. Int J Occup Saf Ergon 5(4):529-536.

Popovic J, Mikov M, Stanulovic M, et al. 2001. Clinical study of permethrin efficacy and toxicity. Toxicol Lett 123:89.

*Poulos L, Athanaselis S, Coutselinis A. 1982. Acute intoxication with cypermethrin (NRDC 149). J Toxicol Clin Toxicol 19(5):519-520.

Pozzi C, Marai P, Ponti R, et al. 1985. Toxicity in man due to stain removers containing 1,2dichloropropane. Br J Ind Med 42:770-772.

Prinsen GH, Van Sittert NJ. 1980. Exposure and medical monitoring study of a new synthetic pyrethroid after one season of spraying on cotton in Ivory Coast. In: Tordoir WF, Van Heemstra-Lequin EAH, eds. Field worker exposure during pesticide application. New York, NY: Elsevier Scientific Publishing Co., 105-120.

*Puig M, Carbonell E, Xamena N, et al. 1989. Analysis of cytogenetic damage induced in cultured human lymphocytes by the pyrethroid insecticides cypermethrin and fenvalerate. Mutagenesis 4(1):7274.

Punareewattana K, Smith BJ, Blaylock BL, et al. 2001. Topical permethrin exposure inhibits antibody production and macrophage function in $\mathrm{C} 57 \mathrm{~B} 1 / 6 \mathrm{~N}$ mice. Food Chem Toxicol 39:133-139.

Queiroz MLS. 1993a. Effects of deltamethrin on the growth and differentiation of bone marrow hematopoietic stem cells. Braz J Med Biol Res 26:525-535.

Queiroz MLS. 1993b. Hematopoietic effects in mice exposed to deltamethrin and hydrocortisone. Int J Immunopharmacol 15(3):301-307.

*Quistad GB, Selim S. 1983. Fluvalinate metabolism by Rhesus monkeys. J Agric Food Chem 31:596599. 


\section{REFERENCES}

*Quistad GB, Staiger LE, Jamieson GC, et al. 1982. Metabolism of fluvalinate by a lactating dairy cow. J Agric Food Chem 30:895-901.

*Quistad GB, Staiger LE, Jamieson GC, et al. 1983. Fluvalinate metabolism by rats. J Agric Food Chem 31:589-596.

Ramon MF, Ballesteros S, Martinez-Arrieta R, et al. 1999. A prospective study of pyrethroids exposures. J Toxicol Clin Toxicol 37:664.

Rangaswamy V, Venkateswarlu K. 1992. Degradation of selected insecticides by bacteria isolated from soil. Bull Environ Contam Toxicol 49:797-804.

Rangoonwala S, Suryawanshi SA, Pandey AK. 1996. Effects of fenvalerate on serum calcium and inorganic phosphate levels, and tissue phophatases of Rattus norvegicus. J Adv Zool 17(1):15-19.

Rani S, Dua KK. 1999. Cypermethrin toxicity induced histological and biochemical changes in the liver of albino rats (Rattus norvegicus). J Ecotoxicol Environ Monit 9(1):41-46.

Rao KSP, Chetty CS, Desaiah D. 1984. In vitro effects of pyrethroids on rat brain and liver ATPase activities. J Toxicol Environ Health 14:257-265.

*Rawn GP, Webster GRB, Muir DCG. 1982. Fate of permethrin in model outdoor ponds. J Environ Sci Health B17(5):463-486.

Ray DE. 1980. An EEG investigation of decamethrin-induced choreoathetosis in the rat. Exp Brain Res 38:221-227.

Ray DE. 1982a. Changes in brain blood flow associated with deltamethrin-induced choreoathetosis in the rat. Exp Brain Res 45:269-276.

Ray DE. 1982b. The contrasting actions of two pyrethroids (deltamethrin and cismethrin) in the rat. Neurobehav Toxicol Teratol 4:801-804.

* Ray DE. 1991. Pesticides derived from plants and other organisms. In: Handbook of Pesticide Toxicology. Vol. 2. Hayes WJ, Laws ER, eds. Academic Press, Inc., 585-636.

* Ray DE, Cremer JE. 1979. The action of decamethrin (a synthetic pyrethroid) on the rat. Pestic Biochem Physiol 10:333-340.

Ray DE, Sutharsan S, Forshaw PJ. 1997. Actions of pyrethroid insecticides on voltage-gated chloride channels in neuroblastoma cells. Neurotoxicology 18(3):755-760.

* Ray DE, Verschoyle, Muhammad BY. 2002. Reproducibility of developmental neurotoxicity produced by pyrethroids and DDT in neonatal mice. Toxicologist 66(1-S):131.

Reddy BN, Reddy KS, Janardhan A. 1991. Effect of dimethoate and fenvalerate on conditioned avoidance and passive avoidance responses. Indian J Exp Biol 29:176-177.

Rekling JC, Theophilidis G. 1995. Effects of the pyrethroid insecticide, deltamethrin, on respiratory modulated hypoglossal motoneurons in a brain stem slice from newborn mice. Neurosci Lett 198:189192. 
Rhodes C, Jones BK, Croucher A, et al. 1984. The bioaccumulation and biotransformation of cis, transcypermethrin in the rat. Pestic Sci 25:471-480.

Rickard J, Brodie ME. 1985. Correlation of blood and brain levels of the neurotoxic pyrethroid deltamethrin with the onset of symptoms in rats. Pestic Biochem Physiol 23:143-156.

Rickett FE, Tyszkiewicz K. 1973. Pyrethrum dermatitis II. The allergenicity of pyrethrum cleoresin and its cross-reactions with the saline extract of pyrethrum flowers. Pestic Sci 4:801-810.

*Ridlen RL, Christopher RJ, Ivie GW, et al. 1984. Distribution and metabolism of cis- and transresmethrin in lactating Jersey cows. J Agric Food Chem 32:1211-1217.

*Rigakis KB, Martin-Scott S, Crown EM, et al. 1987. Limiting pesticide exposure through textile cleaning procedures and selection of clothing. Agric Forestry Bull 10(2):24-27.

*Rivera J, Caixach J, Ventura F, et al. 1985. Herbicide and surfactant spill analysis of an industrial waste dumping at Llobregat River (Spain). Chemosphere 14(5):395-402.

Riviere JE, Baynes RE, Brooks JD, et al. 2003. Percutaneous absorption of topical N,N-diethyl-mtoluamide (DEET): Effects of exposure variables and coadministered toxicants. J Environ Toxicol Environ Health A 66:133-151.

Robertson KE. 1997. Potentially toxic self-treatment of uremic pruritus with topical pyrethroid insecticides. Ann Pharmacother 31:120-121.

*Roinestad KS, Louis JB, Rosen JD. 1993. Determination of pesticides in indoor air and dust. J Assoc Off Anal Chem Int 76(5):1121-1126.

Ronis MJJ, Barger TM, Gandy J, et al. 1995. Anti-androgenic effects of perinatal cypermethrin exposure in the developing rat. Neurotoxicology 16(4):763.

* Rose GP, Dewar AJ. 1983. Intoxication with four synthetic pyrethroids fails to show any correlation between neuromuscular dysfunction and neurobiochemical abnormalities in rats. Arch Toxicol 53:297316.

Rosenberg AM, Semchuk KM, McDuffie HH, et al. 1999. Prevalence of antinuclear antibodies in a rural population. J Toxicol Environ Health 56:225-236.

Ross J, Fong HR, Thonsinthusak T, et al. 1991. Measuring potential dermal transfer of surface pesticide residue generated from indoor fogger use: Using the CDFA roller method interim report II.

Chemosphere 22(9-10):975-984.

*Ross J, Thongsinthusak T, Fong HR, et al. 1990. Measuring potential dermal transfer of surface pesticide residue generated from indoor fogger use: An interim report. Chemosphere 20(3/4):349-360.

Roy RR, Albert RH, Wilson P, et al. 1995. U.S. Food and Drug Administration pesticide program: Incidence/level monitoring of domestic and imported pears and tomatoes. J Assoc Off Anal Chem Int 78(4):930-940. 
Ruzo LO, Casida JE. 1977. Metabolism and toxicology of pyrethroids with dihalovinyl substituents. Environ Health Perspect 21:285-292.

Ruzo LO, Casida JE, Holden I. 1985. Pyrethroid chemistry: Reactive $\alpha, \beta$-unsaturated keto aldehydes from peracid oxidation, oxidative photodecomposition, and metabolism of 5-benzyl-3-furylmethyl derivatives. J Agric Food Chem 33:622-625.

*Ruzo LO, Unai T, Casida JE. 1978. Decamethrin metabolism in rats. J Agric Food Chem 26(4):918925.

*Ryu J-C, Kim K-R, Kim H-J, et al. 1996. Evaluation of the genetic toxicity of synthetic chemicals (II), a pyrethroid insecticide, fenpropathrin. Arch Pharmacal Res 19(4):251-257.

Salawu OA, Iyaniwura TT. 2000. Effects of anticonvulsants on acute cypermethrin poisoning in mice and rats. Vet Hum Toxicol 42(5):303-305.

Saleh MAA, Mohamed ZA, Ahmed FA, et al. 1986. Comparative toxicity of flucythrinate and fenvalerate to albino rats. Egypt J Food Sci 14(1):31-37.

Salem HAH, Al-Busadah KA, Hussein YA, et al. 1999. Effect of supracide and sharkesuper administrations on thyroid, gonadotrophic and female sex hormones in rabbits. Pak Vet J 19(4):188-191.

Salem MH, Abo-Elezz Z, Abd-Allah GA, et al. 1988. Effect of organophosphorous (dimethoate) and pyrethroid (deltamethrin) pesticides on semen characteristics in rabbits. J Environ Sci Health B 23(3):279-290.

*Samsonov YN, Makarov VI. 1996. Kinetics and photophysical mechanism of sunlight photolysis of unstable resmethrin and phenothrin in aerosols and thin films. Bull Environ Contam Toxicol 56:903-910.

*Santoni G, Cantalamessa F, Cavagna R, et al. 1998. Cypermethrin-induced alteration of thymocyte distribution and functions in prenatally-exposed rats. Toxicology 125:67-78.

*Santoni G, Cantalamessa F, Mazzucca L, et al. 1997. Prenatal exposure to cypermethrin modulates rat NK cell cytotoxic functions. Toxicology 120:231-242.

*Santoni G, Cantalamessa F, Spreghini E, et al. 1999. Alterations of T cell distribution and functions in prenatally cypermethrin-exposed rats: Possible involvement of catecholamines. Toxicology 138:175187.

Satpathy SK, Tyagi PK, Das BS, et al. 1997. Evaluation of possible toxic effects of cyfluthrin during short-term, relevant community exposure. Bull Environ Contam Toxicol 59:681-687.

* Sattelle DB, Yamamoto D. 1988. Molecular targets of pyrethroid insecticides. Adv Insect Physiol 20:147-213.

Schattenberg HF, Hsu JP. 1992. Pesticide residue survey of produce from 1989 to 1991. J Assoc Off Anal Chem Int 75(5):925-933.

*Schimmel SC, Garnas RL, Patrick JM, et al. 1983. Acute toxicity, bioconcentration, and persistence of AC 222,705, benthiocarb, chlorpyrifos, fenvalerate, methyl parathion, and permethrin in the estuarine environment. J Agric Food Chem 31:104-114. 
Schmidt S. 1998. Biodegradation of diaryl ether pesticides. In: Wittich RM, ed. Biodegradation of dioxins and furans. R.G. Landes Company, 229-281.

*Schoenig GP. 1995. Mammalian toxicology of pyrethrum extract. In: Casida JE, Quistad GB, eds. Pyrethrum flowers: Production, chemistry, toxicology, and uses. New York: Oxford University Press, 249-257.

Schulz R, Dabrowski JM. 2001. Combined effects of predatory fish and sublethal pesticide contamination on the behavior and mortality of mayfly nymphs. Environ Toxicol Chem 20(11):25372543.

Scott RC, Ramsey JD. 1987. Comparison of the in vivo and in vitro percutaneous absorption of a lipophilic molecule (cypermethrin), a pyrethroid insecticide. J Invest Dermatol 89:142-146.

Sędrowicz L, Wikowska D, Olędzka R. 1996. Effect of chlorfenvinphos, cypermethrin and their mixture on the intestinal transport of leucine and methionine. J Appl Toxicol 16(6):483-489.

*Setchell BP, Waites GMH. 1975. The blood-testis barrier. In: Creep RO, Astwood EB, Geiger SR, eds. Handbook of physiology: Endocrinology V. Washington, DC: American Physiological Society.

*Shah PV, Fisher HL, Sumler MR, et al. 1987. Percutaneous absorption and pharmacokinetics of permethrin in young and adult rats. Toxicology 47:230-231.

Shaker N, Hassan GA, El-Nouty FD, et al. 1988. In vivo chronic effect of dimethoate and deltamethrin on rabbits. J Environ Sci Health B23(4):387-399.

Shakoori A, Ali SS, Saleem MA. 1988. Effects of cypermethrin on the blood and liver of albino rats. J Biochem Toxicol 3:59-71.

* Shakoori AR, Aslam F, Sabir M, et al. 1992a. Effect of prolonged administration of insecticide (cyhalothrin/karate) on the blood and liver of rabbits. Folia Biol 40:91-99.

Shakoori AR, Butt U, Riffat R, et al. 1992b. Toxic effects of short-term oral administration of danitol on the blood and liver of rabbits. Punjab Univ J Zool 7:13-26.

Shan G, Stoutamire DW, Wengatz I, et al. 1999a. Development of an immunoassay for the pyrethroid insecticide esfenvalerate. J Agric Food Chem 47:2145-2155.

Shan G, Wengatz I, Stoutamire DW, et al. 1999b. An enzyme-linked immunosorbent assay for the detection of esfenvalerate metabolites in human urine. Chem Res Toxicol 12(11):1033-1041.

*Sharom MS, Solomon KR. 1981. Adsorption-desorption, degradation, and distribution of permethrin in aqueous systems. J Agric Food Chem 29:1122-1125.

Shawky AS, Gomaa EA, Bakry H, et al. 1984. Mutagenicity and teratogenicity of the synthetic pyrethroid insecticide cypermethrin in albino rats. Genetics 107(3):S98.

Sheets LP. 2000. A consideration of age-dependent differences in susceptibility to organophosphorus and pyrethroid insecticides. Neurotoxicology 2(1-2):57-64. 


\section{REFERENCES}

*Sheets LP, Doherty JD, Law MW, et al. 1994. Age-dependent differences in the susceptibility of rats to deltamethrin. Toxicol Appl Pharmacol 126:186-190.

*Shiba K, Kaneko H, Kakuta N, et al. 1990. Placental transfer of esfenvalerate in pregnant rats. J Pestic Sci 15:169-174.

*Shono T, Ohsawa K, Casida JE. 1979. Metabolism of trans- and cis-permethrin, trans- and ciscypermethrin and decamethrin by microsomal enzymes. J Agric Food Chem 27(2):316-325.

*Shujie W, Qinglang Z, Lan Y, et al. 1988. Health survey among farmers exposed to deltamethrin in the cotton fields. Ecotoxicol Environ Saf 15:1-6.

*Shukla Y, Taneja P. 2000. Mutagenic evaluation of deltamethrin using rodent dominant lethal assay. Mutat Res 467:119-127.

Shukla Y, Arora A, Singh A. 2001. Tumourigenic studies on deltamethrin in Swiss albino mice. Toxicology 163(1):1-9.

Shukla Y, Yadav A, Arora A. 2002. Carcinogenic and cocarcinogenic potential of cypermethrin on mouse skin. Cancer Lett 182:33-41.

Sidon EW, Moody RP, Franklin CA. 1988. Percutaneous absorption of cis- and trans-permethrin in Rhesus monkeys and rats: Anatomic site and interspecies variation. J Toxicol Environ Health 23:207216.

*Siebers J, Mattusch P. 1996. Determination of airborne residues in greenhouses after application of pesticides. Chemosphere 33(8):1597-1607.

*Silver IS, Dauterman WC. 1989a. The pharmacokinetics and metabolism of (1R, cis)- and (1R, trans)tetramethrin in rats. Xenobiotica 19(3):301-314.

*Silver IS, Dauterman WC. 1989b. The toxicokinetics of (1R, cis)- and (1R, trans)-tetramethrin in the isolated perfused rat liver. Xenobiotica 19(5):509-519.

*Simonaitis RA, Cail RS. 1975. Gas-liquid chromatographic determination of resmethrin in corn, cornmeal, flour, and wheat. J Assoc Off Anal Chem Int 58(5):1032-1036.

Singh G, Sharma LD, Ahmad AH, et al. 1999. Fenvalerate induced dermal toxicity in buffalo calves. J Appl Anim Res 16:205-210.

Siroki O, Institóris L, Tatar E, et al. 1994. Immunotoxicological investigation of SCMF, a new pyrethroid pesticide in mice. Hum Exp Toxicol 13:337-343.

*Slameňová D, Dušinská M, Gábelová A, et al. 1992. An evaluation of three pesticides: Piritione, supercypermethrin and metachlor in transformation bioassays of BHK21 and hamster embryo cells. Cell Biol Toxicol 8(4):217-231.

Smith PA, Thompson MJ, Edwards JW. 2002. Estimating occupational exposure to the pyrethroid termiticide bifenthrin by measuring metabolites in urine. J Chromatogr B Analyt Technol Biomed Life Sci 778:113-120. 
Smith S, Willis GH. 1987. Interaction of methyl parathion with permethrin and flucythrinate as related to their mutual persistence in soil. Soil Sci 144(1):67-71.

*Smith S, Willis GH, Cooper CM. 1995. Cyfluthrin persistence in soil as affected by moisture, organic matter, and redox potential. Bull Environ Contam Toxicol 55:142-148.

Smith TJ, Soderlund DM. 1998. Action of pyrethroid insecticide cypermethrin on rat brain IIa sodium channels expressed in Xenopus oocytes. Neurotoxicology 19(6):823-832.

Smith TJ, Soderlund DM. 2001. Potent actions of the pyrethroid insecticides cismethrin and cypermthrin on rat tetrodotoxin-resistant peripheral nerve (SNS/PN3) sodium channels expressed in Xenopus oocytes. Pestic Biochem Physiol 70(1):52-61.

*Soderlund DM. 1995. Mode of action of pyrethrins and pyrethroids. In: Casida JE, Quistad GB, eds. Pyrethrum flowers: Production, chemistry, toxicology, and uses. New York, NY: Oxford University Press, 217-233.

Soderlund DM, Bloomquist JR. 1989. Neurotoxic actions of pyrethroid insecticides. Annu Rev Entomol 34:77-96.

*Soderlund DM, Clark JM, Sheets LP, et al. 2002. Mechanisms of pyrethroid neurotoxicity: implications for cumulative risk assessment. Toxicology 171:3-59.

Soderlund DM, Ghiasuddin SM, Helmuth DW. 1983. Receptor-like stereospecific binding of a pyrethroid insecticide to mouse brain membranes. Life Sci 33:261-267.

Sogorb MA, Vilanova E. 2002. Enzymes involved in the detoxification of organophosphorus, carbamate and pyrethroid insecticides through hydrolysis. Toxicol Lett 128:215-228.

* Song JH, Narahashi T. 1996. Modulation of sodium channels of rat cerebellar purkinje neurons by the pyrethroid tetramethrin. J Pharmacol Exp Ther 277(1):445-453.

*Southwood J. 1984. Acute oral toxicity to the mouse. Imperial Chemical Industries PLC. OTS0545463.

Spencer F, Berhane Z. 1982. Uterine and fetal characteristics in rats following a post-implantational exposure to permethrin. Bull Environ Contam Toxicol 29:84-88.

* Spinosa HDS, Silva YMA, Nicolau AA, et al. 1999. Possible anxiogenic effects of fenvalerate, a Type II pyrethroid pesticide, in rats. Physiol Behav 67(4):611-615.

Spittler TD, Argauer RJ, Lisk DJ, et al. 1984. Gas chromatographic determination of fenvalerate insecticide residues in processed tomato products and by-products. J Assoc Off Anal Chem 67(4):824826.

Springfield AC, Carlson GP, DeFeo JJ. 1973. Liver enlargement and modification of hepatic microsomal drug metabolism in rats by pyrethrum. Toxicol Appl Pharmacol 24:298-308.

*SRI. 2000. Directory of chemical producers. SRI International. 


\section{REFERENCES}

Staatz CG, Bloom AS, Lech JJ. 1980. A pharmacological analysis of mechanisms of permethrin neurotoxicity in mice. Fed Proc Fed Am Soc Exp Biol 39(3):624.

Staatz CG, Bloom AS, Lech JJ. 1982. A pharmacological study of pyrethroid neurotoxicity in mice. Pestic Biochem Physiol 17:287-292.

*Staiger LE, Quistad GB. 1984. Metabolism of [benzyl-U-ring- $\left.{ }^{14} C\right]$ fluvalinate by rats. J Agric Food Chem 32:1130-1133.

Stein EA, Washburn M, Walczak C, et al. 1987. Effects of pyrethroid insecticides on operant responding maintained by food. Neurotoxicol Teratol 9:27-31.

Stelzer KJ, Gordon MA. 1984. Effects of pyrethroids on lymphocyte mitogenic responsiveness. Res Commun Chem Pathol Pharmacol 46:137-150.

*Stockis A, Bitar N, Rougeron C, et al. 1985. Fate of ${ }^{14} \mathrm{C}$-deltamethrin given orally in healthy volunteers. Naunyn-Schmiedebergs Arch Pharmacol 330:R13.

Sukul P. 1995. Dissipation of deltamethrin and fenvalerate residues in green gram (Vigna radiata (L.) Wilczek) under Indian climatic condition. Bull Environ Contam Toxicol 55:562-567.

*Sundaram KMS. 1991. Fate and short-term persistence of permethrin insecticide injected in a Northern Ontario (Canada) headwater stream. Pestic Sci 31:281-294.

*Surrallés J, Cartbonell E, Puig M, et al. 1990. Induction of mitotic micronuclei by the pyrethroid insecticide fenvalerate in cultured human lymphocytes. Toxicol Lett 54:151-155.

*Surrallés J, Xamena N, Creus A, et al. 1995. Induction of micronuclei by five pyrethroid insecticides in whole-blood and isolated human lymphocyte cultures. Mutat Res 341:169-184.

Suzuki T, Miyamoto J. 1974. Metabolism of tetramethrin in houseflies and rats in vitro. Pestic Biochem Physiol 4:86-97.

Sylianco-Wu L, Kallman M, Wilson M, et al. 1990. Behavioral and neurochemical consequences of perinatal exposure to Type I and Type II pyrethroid formulations. Neurotoxicol Teratol 12(1):565-566.

Szépvölgyi J, Nagy K, Bedó M, et al. 1988. Examination of the interaction of decis and dithane in rats. Toxicology 53:107-111.

Tabarean IV, Narahashi T. 2001. Kintetics of modulation of tetrodotoxin-sensitive and tetrodotoxinresistant sodium channels by tetramethrin and deltamethrin. J Pharmacol Exp Ther 299(3):988-97.

Takahashi M, Le Quesne PM. 1982. The effects of the pyrethroids deltamethrin and cismethrin on nerve excitability in rats. J Neurol Neurosurg Psychiatry 45:1005-1011.

*Takahashi N, Mikami N, Matsuda T, et al. 1985a. Hydrolysis of the pyrethroid insecticide cypermethrin in aqueous media. J Pestic Sci 10:643-648.

*Takahashi N, Mikami N, Yamad H, et al. 1985b. Hydrolysis of the pyrethroid insecticide fenpropathrin in aqueous media. Pestic Sci 16:113-118. 


\section{REFERENCES}

*Takahashi N, Mikami N, Yamada H, et al. 1985c. Photodegradation of the pyrethroid insecticide fenpropathrin in water, on soil and on plant foliage. Pestic Sci 16:119-131.

*Talts U, Fredriksson A, Eriksson P. 1998a. Changes in behavior and muscarinic receptor density after neonatal and adult exposure to bioallethrin. Neurobiol Aging 19(6):545-552 .

Talts U, Talts JF, Eriksson P. 1998b. Differential expression of muscarinic subtype mRNAs after exposure to neurotoxic pesticides. Neurobiol Aging 19(6):553-559.

Tamang RK, Gupta G, Chauhan H, et al. 1988. In vivo immunosuppression by synthetic pyrethroid (cypermethrin) pesticide in mice and goats. Vet Immunol Immunopathol 19:299-305.

Tanaka T, Moriwaki SI, Horio T. 1987. Occupational dermatitis with simultaneous immediate and delayed allergy to chrysanthemum. Contact Dermatitis 16:152-154.

Tandon SK, Gupta PK. 1990. Pharmacological basis of cypermethrin neurotoxicity. Indian Vet J 67:2124.

*Tang JX, Siegfried BD. 1996. Bioconcentration and uptake of a pyrethroid and organophosphate insecticide by selected aquatic insects. Bull Environ Contam Toxicol 57:993-998.

Tapase JS, Sharma SN, Singh SP. 1995a. Hematological alterations during experimental oral toxicity of fenvalerate in buffalo calves. Indian Vet Med J 19:239-243.

Tapase JS, Sharma SN, Singh SP. 1995b. Pathology of fenvalerate toxicity in buffalo calves. Indian J Agric Sci 65(5):540-541.

Tateno C, Ito S, Tanaka M, et al. 1993. Effects of pyrethroid insecticides on gap junctional intercellular communications in Balb/c3T3 cells by dye-transfer assay. Cell Biol Toxicol 9(3):215-221.

Taylor P. 1979. Scabies in Zimbabwe Rhodesia: Distribution on the human body and the efficacy of lindane and permethrin as scabicides. Cent Afr J Med 25(8):165-168.

Taylor WG, Vedres DD, Hall TW. 1997. Capillary gas chromatographic determination of permethrin insecticide by transesterification. J Chromatogr B Biomed Sci Appl 690:123-129.

*Thapinta A, Hudak PF. 2000. Pesticide use and residual occurrence in Thailand. Environ Monit Assess 60:103-114.

*Thyssen J. 1980. FCR 1272 subacute inhalational toxicity study on rats. Miles Inc. OTS0543768.

*Tomigahara Y, Mori M, Shiba K, et al. 1994a. Metabolism of tetramethrin isomers in rat. I. Identification of a sulphonic acid type of conjugate and reduced metabolites. Xenobiotica 24(5):473-484.

*Tomigahara Y, Mori M, Shiba K, et al. 1994b. Metabolism of tetramethrin isomers in rat: II. Identification and quantitation of metabolites. Xenobiotica 24(12):1205-1214.

Tomigahara Y, Onogi M, Miki M, et al. 1996. Metabolism of tetramethrin isomers in rat. III. Stereochemistry of reduced metabolites. Xenobiotica 26(2):201-210. 


\section{REFERENCES}

Tomigahara Y, Onogi M, Saito K, et al. 1997. Metabolism of tetramethrin isomers in rat: IV. Tissues responsible for formation of reduced and hydrated metabolites. Xenobiotica 27(9):961-971.

*Tomlin CDS. 1997. The pesticide manual - world compendium. $11^{\text {th }}$ ed. Surrey, England: British Crop Protection Council.

Trainer VL, McPhee JC, Boutelet-Bochan H, et al. 1997. High affinity binding of pyrethroids to the $\alpha$ subunit of brain subunit channels. Mol Pharmacol 51:651-657.

Trainer VL, Moreau E, Guedin D, et al. 1993. Neurotoxin binding and allosteric modulation at receptor sites 2 and 5 on purified and reconstituted rat brain sodium channels. J Biol Chem 268(23):17114-17119.

*TRI99. 2001. TRI explorer: Providing access to EPA's toxics release inventory data. Washington, DC: Office of Information Analysis and Access. Offices of Environmental Information. U.S.

Environmental Protection Agency. Toxic Release Inventory. http:/www.epa.gov/triexplorer/. April 26, 2001.

*Tsuji R, Kobayashi K, Ikeda M, et al. 2002. Lack of changes in brain muscarinic receptor and motor activity of mice after neonatal inhalation exposure to $d$-allethrin. J Appl Toxicol 22:423-429.

Tsuji R, Isobe N, Kawasaki H. 1996. Effect of pyrethroids on pentobarbital-induced sleeping time in relation to the chemical structure. Toxicology 106:131-137.

*Tucker SB, Flannigan SA. 1983. Cutaneous effects from occupational exposure to fenvalerate. Arch Toxicol 54:195-202.

*Tucker SB, Flannigan SA, Ross CE. 1984. Inhibition of cutaneous paresthesia resulting from synthetic pyrethroid exposure. Int J Dermatol 23(10):686-689.

Tulinská J, Kubová J, Janota S, et al. 1995. Investigation of immunotoxicity of supercypermethrin forte in the Wistar rat. Hum Exp Toxicol 14:399-403.

Ueda A, Aoyama K, Manda F, et al. 1994. Delayed-type allergenicity of triforine (Saprol). Contact Dermatitis 31:140-145.

*Ueda K, Gaughan C, Casida JE. 1974. Photodecomposition of resmethrin and related pyrethroids. J Agric Food Chem 22(2):212-220.

*Ueda K, Gaughan C, Casida JE. 1975a. Metabolism of four resmethrin isomers by liver microsomes. Pestic Biochem Physiol 5:280-294.

*Ueda K, Gaughan LC, Casida JE. 1975b. Metabolism of (+)-trans- and (+)-cis-resmethrin in rats. J Agric Food Chem 23(1):106-115.

*USDA. 2001a. ARS Pesticide properties database. U.S. Department of Agriculture. http://wizard.arsusda.gov/acsl/textfiles/PYRETHRINS. February 8, 2001.

*USDA. 2001b. Labeling treated seed. U.S. Department of Agriculture. Code of Federal Regulations. 7 CFR 201.31a. http://www4.law.cornell.edu/cfr/7p201.htm. April 19, 2001. 


\section{REFERENCES}

*USGS. 2001. USGS pesticide national synthesis project. U.S. Geological Survey. http://ca.water.usgs.gov/pnsp/use/92/cyfluthrn.html. March 21, 2001.

Vaccari A, Ruiu S, Mocci I, et al. 1998. Selected pyrethroid insecticides stimulate glutamate uptake in brain synaptic vesicles. NeuroReport 9:3519-3523.

Vais H, Atkinson S, Eldursi N, et al. 2000. A single amino acid change makes a rat neuronal sodium channel highly sensitive to pyrethroid insecticides. FEBS Lett 470:135-138.

*Valentine WM. 1990. Pyrethrin and pyrethroid insecticides. Vet Clin North Am Small Anim Pract 20(2):375-382.

*Vandenplas O, Delwiche JP, Auverdin J, et al. 2000. Asthma to tetramethrin. Allergy 55:418-419.

*van der Rhee HJ, Farquhar JA, Vermeulen NPE. 1989. Efficacy and transdermal absorption of permethrin in scabies patients. Acta Derm Venereol (Stockh) 69:170-182.

Van Haaren F, Cody B, Hoy JB, et al. 2000. The effects of pyridostigmine bromide and permethrin, alone or in combination, on response acquisition in male and female rats. Pharmacol Biochem Behav 66(4):739-746.

*Varshneya C, Singh T, Sharma LD, et al. 1992. Immunotoxic responses of cypermethrin, a synthetic pyrethroid insecticide in rats. Indian J Physiol Pharmacol 36(2):123-126.

Venant A, Belli P, Borrel S, et al. 1990. Excretion of deltamethrin in lactating dairy cows. Food Addit Contam 7(4):535-543.

*Verschoyle RD, Aldridge WN. 1980. Structure-activity relationships of some pyrethroids in rats. Arch Toxicol 45:325-329.

Verschoyle RD, Barnes JM. 1972. Toxicity of natural and synthetic pyrethrins to rats. Pestic Biochem Physiol 2:308-311.

*Viera I, Sonnier M, Cresteil T. 1996. Developmental expression of CYP2E1 in the human liver: Hypermethylation control of gene expression during the neonatal period. Eur J Biochem 238:476-483.

Vijverberg HPM, de Weille JR. 1985. The interaction of pyrethroids with voltage-dependent Na channels. Neurotoxicology 6(2):23-34.

*Vijverberg HPM, van den Bercken J. 1982. Action of pyrethroid insecticides on the vertebrate nervous system. Neuropathol Appl Neurobiol 8:421-440.

*Vijverberg HPM, van den Bercken J. 1990. Neurotoxicological effects and the mode of action of pyrethroid insecticides. Crit Rev Toxicol 21(2):105-126.

*Vijverberg HPM, van der Zalm JM, van Kleef RGD, et al. 1983. Temperature- and structure-dependent interaction of pyrethroids with the sodium channels in frog node of Ranvier. Biochim Biophys Acta 728:73. 


\section{REFERENCES}

*Vijverberg HPM, de Weille JR, Ruigt GSF, et al. 1986. The effect of pyrethroid structure on the interaction with the sodium channel in the nerve membrane. In: Ford MG, Lunt GG, Reay RC, et al., eds. Neuropharmacology and pesticide action. Deerfield Beach, FL: VCH, 267-285.

*Villarini M, Moretti M, Pasquini R, et al. 1998. In vitro genotoxic effects of the insecticide deltamethrin in human peripheral blood leukocytes: DNA damage ('comet' assay) in relation to the induction of sister-chromatid exchanges and micronuclei. Toxicology 130:129-139.

Villarini M, Moretti M, Scassellati-Sforzolini G, et al. 1995. Studies on hepatic xenobiotic-metabolizing enzymes in rats treated with insecticide deltamethrin. J Environ Pathol Toxicol Oncol 14(1):45-52.

*Vlčková V. 1991. Mutagenic activity of supercypermethrin applied to yeast Saccharomyces cerevisiae D7. Acta Fac Rerum Nat Univ Comenianae, Genet Biol Mol 25:25-31.

Wagner SL. 1994. Allergy from pyrethrin of pyrethroid insecticides. J Agromed 1:39-45.

*Wagner SL. 2000. Fatal asthma in a child after use of an animal shampoo containing pyrethrin. West J Med 173:86-87.

Waite DT, Grover R, Westcott ND, et al. 1995. Atmospheric deposition of pesticide in a small southern Saskatchewan watershed. Environ Toxicol Chem 14(7):1171-1175.

Wallace KB. 2002. Mechanisms of pyrethroid neurotoxicity: implications for cumulative risk assessment. Toxicology 171:1.

*Wan H. 1990. Pesticide exposure of applicators working in tea plantations. Bull Environ Contam Toxicol 45:459-462.

Wärngård L, Flodsröm S. 1989. Effects of tetradecanoyl phorbol acetate, pyrethroids and DDT in the V79. Cell Biol Toxicol 5(1):67-75.

*Wax PM, Hoffman RS. 1994. Fatality associated with inhalation of a pyrethrin shampoo. Clin Toxicol 32(4):457-460.

Wax PM, Hoffman RS, Goldfrank LR. 1991. Fatality associated with inhalation of a pyrethrin insecticide [Abstract]. Vet Hum Toxicol 33(4):363.

Wenclawiak B, Otterbach A. 2000. Carbon-based quantitation of pyrethrins by supercritical-fluid chromatography. J Biochem Biophys Meth 43:197-207.

*West JR, Smith HW, Chasi H. 1948. Glomerular filtration rate, effective renal blood flow, and maximal tubular excretory capacity in infancy. J Pediatr 32:10-18.

Wester RC, Bucks DAW, Maibach HI. 1994. Human in vivo percutaneous absorption of pyrethrin and piperonyl butoxide. Food Chem Toxicol 32(1):51-53.

*White INH, Verschoyle RD, Moradian MH, et al. 1976. The relationship between brain levels of cismethrin and bioresmethrin in female rats and neurotoxic effects. Pestic Biochem Physiol 6:491-500.

*Whittem T. 1995. Pyrethrin and pyrethroid insecticide intoxication in cats. Compend Contin Edu Pract Vet 17(4):489-492. 


\section{REFERENCES}

*WHO. 1990a. Cyhalothrin. Environmental Health Criteria 99. Geneva: World Health Organization.

*WHO. 1990b. Fenvalerate. Environmental Health Criteria 95. Geneva: World Health Organization.

*WHO. 1990c. Permethrin. Environmental Health Criteria 94. Geneva: World Health Organization.

*WHO. 2001. Guidelines for drinking water quality. World Health Organization. http://www.who.int/. April 19, 2001.

*Widdowson EM, Dickerson JWT. 1964. Chemical composition of the body. In: Comar CL, Bronner F, eds. Mineral metabolism: An advanced treatise. Volume II: The elements Part A. New York:

Academic Press.

Wieseler B, Kühn K-H, Leng G, et al. 1998. Effects of pyrethroid insecticides on pest control operators. Bull Environ Contam Toxicol 60:837-844.

*Wilkes MF. 2000. Pyrethroid-induced pareasthesia- a central or local toxic effect? Clin Toxicol 38(2):103-105.

Wilkes MF, Woollen BH, Marsh JR, et al. 1993. Biological monitoring for pesticide exposure- the role of human volunteer studies. Int Arch Occup Environ Health 65:S189-S192.

Williams CH. 1973. Tests for possible teratogenic carcinogenic, mutagenic, and allergenic effects of pyrethrum. In: Casida JE, ed. Pyrethrum: The natural insecticide. London, England: Academic Press, 167-176.

Williamson EG, Long SF, Kallman MJ, et al. 1989. A comparative analysis of the acute toxicity of technical-grade pyrethroid insecticides and their commercial formulations. Ecotoxicol Environ Saf 18:27-34.

*Wintersteiger R, Ofner B, Juan H, et al. 1994. Determination of traces of pyrethrins and piperonyl butoxide in biological material by high-performance liquid chromatography. J Chromatogr 660:205-210.

Woodrow JE, Seiber JN. 1997. Correlation techniques for estimating pesticide volatilization flux and downwind concentrations. Environ Sci Technol 31:523-529.

*Woollen BH. 1993. Biological monitoring for pesticide absorption. Ann Occup Hyg 37:525-540.

*Woollen BH, Marsh JR, Laird WJD, et al. 1992. The metabolism of cypermethrin in man: Differences in urinary metabolite profiles following oral and dermal administration. Xenobiotica 22(8):983-991.

*Wright CDP, Forshaw PJ, Ray DE. 1988. Classification of the actions of the ten pyrethroid insecticides in the rat, using the trigeminal reflex and skeletal muscle as test systems. Pestic Biochem Physiol 30:7986.

*Wright CG, Leidy RB, Dupree HE. 1993. Cypermethrin in the ambient air and on surfaces of rooms treated for cockroaches. Bull Environ Contam Toxicol 51:356-360.

*Wright CG, Leidy RB, Dupree HE. 1996. Insecticide residues in the ambient air of commercial pest control buildings, 1993. Bull Environ Contam Toxicol 56:21-28. 


\section{REFERENCES}

*Wszolek PC, Hogue DE, Lisk DJ. 1981a. Accumulation of fenvalerate insecticide in lamb tissues. Bull Environ Contam Toxicol 27:869-871.

*Wszolek PC, LaFaunce NA, Wachs T, et al. 1981b. Studies of possible bovine urinary excretion and rumen decomposition of fenvalerate insecticide and a metabolite. Bull Environ Contam Toxicol 26:262266.

*Wszolek PC, Lein DH, Lisk DJ. 1980. Excretion of fenvalerate insecticide in the milk of dairy cows. Bull Environ Contam Toxicol 24:296-298.

Wu A, Liu Y. 2000. Apoptotic cell death in rat brain following deltamethrin treatment. Neurosci Lett 279:85-88.

$\mathrm{Wu} \mathrm{A}$, Ren T, Hu Q, et al. 2000. Deltamethrin induces altered expression of P53, Bax and Bcl-2 in rat brain. Neurosci Lett 284:29-32.

*Yamamoto D, Yeh JZ, Narahashi T. 1986. Ion permeation and selectivity of squid axon sodium channels modified by tetramethrin. Brain Res 372:193-197.

Yamamoto I, Elliott M, Casida JE. 1971. The metabolic fate of pyrethrin I, pyrethrin II, and allethrin. Bull WHO 44:347-348.

*Yao PP, Li YW, Ding YZ, et al. 1992. Biological monitoring of deltamethrin in sprayers by HPLC method. J Hyg Epidemiol Microbiol Immunol 36(1):31-36.

Yarsan E, Bilgili A, Kanbur M, et al. 2002. Effects of deltamthrin on lipid peroxidation in mice. Vet Hum Toxicol 44(2):73-5.

*Yasin M, Baugh PJ, Bonwick GA, et al. 1996. Analytical method development for the determination of synthetic pyrethroid insecticides in soil by gas chromatography-mass spectrometry operated in negativeion chemical-ionization mode. J Chromatogr 754:235-243.

Yess NJ. 1993. U.S. Food and Drug Administration survey of methyl mercury in canned tuna. J Assoc Off Anal Chem Int 76(1):36-38.

*Yi-Qun W, Xiao-Yen G, Chun-Ling L. 1994. Determination of pyrethroids in human urine by gas chromatography. Biomed Environ Sci 7:216-221.

Yomamoto D, Quandt FN, Narahashi T. 1983. Modification of single sodium channels by the insecticide tetramethrin. Brain Res 274:344-349.

*Yoshida K, Antal A, Fuzesi I, et al. 1990. Characteristics of applicator exposure to synthetic pyrethroid in ULV-handheld and ULV-ULA spray applications. J Environ Sci Health B25(2) 151-167.

Younis HM, Hamid NA, El-Saad MMA, et al. 2000. Alterations by the respiratory protein complexes of rat heart mitochondria induced by the insecticide fenvalerate. Biochem Soc Trans 28(5):A191.

*Zhang L, Khan S, Akhtar M, et al. 1984. Persistence, degradation, and distribution of deltamethrin in an organic soil under laboratory conditions. J Agric Food Chem 32(6):1207-1211. 


\section{REFERENCES}

*Zhang Z, Sun J, Chen S, et al. 1991. Levels of exposure and biological monitoring of pyrethroids in spraymen. Br J Ind Med 48:82-86.

*Ziegler EE, Edwards BB, Jensen RL, et al. 1978. Absorption and retention of lead by infants. Pediatr Res 12:29-34.

Zucker A. 1965. Investigation of purified pyrethrum extracts. Ann Allergy 23:335-339. 



\section{GLOSSARY}

Absorption-The taking up of liquids by solids, or of gases by solids or liquids.

Acute Exposure-Exposure to a chemical for a duration of 14 days or less, as specified in the Toxicological Profiles.

Adsorption-The adhesion in an extremely thin layer of molecules (as of gases, solutes, or liquids) to the surfaces of solid bodies or liquids with which they are in contact.

Adsorption Coefficient $\left(\mathbf{K}_{\mathbf{o c}}\right)$ - The ratio of the amount of a chemical adsorbed per unit weight of organic carbon in the soil or sediment to the concentration of the chemical in solution at equilibrium.

Adsorption Ratio (Kd) - The amount of a chemical adsorbed by a sediment or soil (i.e., the solid phase) divided by the amount of chemical in the solution phase, which is in equilibrium with the solid phase, at a fixed solid/solution ratio. It is generally expressed in micrograms of chemical sorbed per gram of soil or sediment.

Benchmark Dose (BMD) - Usually defined as the lower confidence limit on the dose that produces a specified magnitude of changes in a specified adverse response. For example, a BMD ${ }_{10}$ would be the dose at the $95 \%$ lower confidence limit on a $10 \%$ response, and the benchmark response (BMR) would be $10 \%$. The BMD is determined by modeling the dose response curve in the region of the dose response relationship where biologically observable data are feasible.

Benchmark Dose Model-A statistical dose-response model applied to either experimental toxicological or epidemiological data to calculate a BMD.

Bioconcentration Factor (BCF) - The quotient of the concentration of a chemical in aquatic organisms at a specific time or during a discrete time period of exposure divided by the concentration in the surrounding water at the same time or during the same period.

Biomarkers-Broadly defined as indicators signaling events in biologic systems or samples. They have been classified as markers of exposure, markers of effect, and markers of susceptibility.

Cancer Effect Level (CEL) - The lowest dose of chemical in a study, or group of studies, that produces significant increases in the incidence of cancer (or tumors) between the exposed population and its appropriate control.

Carcinogen-A chemical capable of inducing cancer.

Case-Control Study - A type of epidemiological study which examines the relationship between a particular outcome (disease or condition) and a variety of potential causative agents (such as toxic chemicals). In a case-controlled study, a group of people with a specified and well-defined outcome is identified and compared to a similar group of people without outcome.

Case Report-Describes a single individual with a particular disease or exposure. These may suggest some potential topics for scientific research but are not actual research studies.

Case Series-Describes the experience of a small number of individuals with the same disease or exposure. These may suggest potential topics for scientific research but are not actual research studies. 
Ceiling Value-A concentration of a substance that should not be exceeded, even instantaneously.

Chronic Exposure-Exposure to a chemical for 365 days or more, as specified in the Toxicological Profiles.

Cohort Study - A type of epidemiological study of a specific group or groups of people who have had a common insult (e.g., exposure to an agent suspected of causing disease or a common disease) and are followed forward from exposure to outcome. At least one exposed group is compared to one unexposed group.

Cross-sectional Study - A type of epidemiological study of a group or groups which examines the relationship between exposure and outcome to a chemical or to chemicals at one point in time.

Data Needs - Substance-specific informational needs that if met would reduce the uncertainties of human health assessment.

Developmental Toxicity-The occurrence of adverse effects on the developing organism that may result from exposure to a chemical prior to conception (either parent), during prenatal development, or postnatally to the time of sexual maturation. Adverse developmental effects may be detected at any point in the life span of the organism.

Dose-Response Relationship-The quantitative relationship between the amount of exposure to a toxicant and the incidence of the adverse effects.

Embryotoxicity and Fetotoxicity-Any toxic effect on the conceptus as a result of prenatal exposure to a chemical; the distinguishing feature between the two terms is the stage of development during which the insult occurs. The terms, as used here, include malformations and variations, altered growth, and in utero death.

Environmental Protection Agency (EPA) Health Advisory-An estimate of acceptable drinking water levels for a chemical substance based on health effects information. A health advisory is not a legally enforceable federal standard, but serves as technical guidance to assist federal, state, and local officials.

Epidemiology - Refers to the investigation of factors that determine the frequency and distribution of disease or other health-related conditions within a defined human population during a specified period.

Genotoxicity - A specific adverse effect on the genome of living cells that, upon the duplication of affected cells, can be expressed as a mutagenic, clastogenic or carcinogenic event because of specific alteration of the molecular structure of the genome.

Half-life - A measure of rate for the time required to eliminate one half of a quantity of a chemical from the body or environmental media.

Immediately Dangerous to Life or Health (IDLH) - The maximum environmental concentration of a contaminant from which one could escape within 30 minutes without any escape-impairing symptoms or irreversible health effects.

Incidence - The ratio of individuals in a population who develop a specified condition to the total number of individuals in that population who could have developed that condition in a specified time period. 
Intermediate Exposure-Exposure to a chemical for a duration of 15-364 days, as specified in the Toxicological Profiles.

Immunologic Toxicity-The occurrence of adverse effects on the immune system that may result from exposure to environmental agents such as chemicals.

Immunological Effects - Functional changes in the immune response.

In Vitro-Isolated from the living organism and artificially maintained, as in a test tube.

In Vivo-Occurring within the living organism.

Lethal Concentration $_{(\mathbf{L O})}\left(\mathbf{L C}_{\mathbf{L O}}\right)$-The lowest concentration of a chemical in air which has been reported to have caused death in humans or animals.

Lethal Concentration ${ }_{(50)}\left(\mathbf{L C}_{\mathbf{5 0}}\right)$ - A calculated concentration of a chemical in air to which exposure for a specific length of time is expected to cause death in $50 \%$ of a defined experimental animal population.

Lethal Dose $_{(\mathbf{L O})}\left(\mathbf{L D}_{\mathbf{L O}}\right)$ - The lowest dose of a chemical introduced by a route other than inhalation that has been reported to have caused death in humans or animals.

Lethal Dose $_{(50)}\left(\mathbf{L D}_{\mathbf{5 0}}\right)$ - The dose of a chemical which has been calculated to cause death in $50 \%$ of a defined experimental animal population.

Lethal Time $_{(\mathbf{5 0})}\left(\mathbf{L T}_{\mathbf{5 0}}\right)$-A calculated period of time within which a specific concentration of a chemical is expected to cause death in $50 \%$ of a defined experimental animal population.

Lowest-Observed-Adverse-Effect Level (LOAEL) - The lowest exposure level of chemical in a study, or group of studies, that produces statistically or biologically significant increases in frequency or severity of adverse effects between the exposed population and its appropriate control.

Lymphoreticular Effects-Represent morphological effects involving lymphatic tissues such as the lymph nodes, spleen, and thymus.

Malformations-Permanent structural changes that may adversely affect survival, development, or function.

Minimal Risk Level (MRL) - An estimate of daily human exposure to a hazardous substance that is likely to be without an appreciable risk of adverse noncancer health effects over a specified route and duration of exposure.

Modifying Factor (MF) - A value (greater than zero) that is applied to the derivation of a minimal risk level (MRL) to reflect additional concerns about the database that are not covered by the uncertainty factors. The default value for a MF is 1 .

Morbidity—State of being diseased; morbidity rate is the incidence or prevalence of disease in a specific population.

Mortality - Death; mortality rate is a measure of the number of deaths in a population during a specified interval of time. 
Mutagen-A substance that causes mutations. A mutation is a change in the DNA sequence of a cell's DNA. Mutations can lead to birth defects, miscarriages, or cancer.

Necropsy - The gross examination of the organs and tissues of a dead body to determine the cause of death or pathological conditions.

Neurotoxicity-The occurrence of adverse effects on the nervous system following exposure to a chemical.

No-Observed-Adverse-Effect Level (NOAEL) - The dose of a chemical at which there were no statistically or biologically significant increases in frequency or severity of adverse effects seen between the exposed population and its appropriate control. Effects may be produced at this dose, but they are not considered to be adverse.

Octanol-Water Partition Coefficient $\left(\mathbf{K}_{\mathbf{o w}}\right)$ - The equilibrium ratio of the concentrations of a chemical in $n$-octanol and water, in dilute solution.

Odds Ratio (OR) - A means of measuring the association between an exposure (such as toxic substances and a disease or condition) which represents the best estimate of relative risk (risk as a ratio of the incidence among subjects exposed to a particular risk factor divided by the incidence among subjects who were not exposed to the risk factor). An odds ratio of greater than 1 is considered to indicate greater risk of disease in the exposed group compared to the unexposed.

Organophosphate or Organophosphorus Compound-A phosphorus containing organic compound and especially a pesticide that acts by inhibiting cholinesterase.

Permissible Exposure Limit (PEL) — An Occupational Safety and Health Administration (OSHA) allowable exposure level in workplace air averaged over an 8-hour shift of a 40-hour workweek.

Pesticide - General classification of chemicals specifically developed and produced for use in the control of agricultural and public health pests.

Pharmacokinetics - The science of quantitatively predicting the fate (disposition) of an exogenous substance in an organism. Utilizing computational techniques, it provides the means of studying the absorption, distribution, metabolism and excretion of chemicals by the body.

Pharmacokinetic Model-A set of equations that can be used to describe the time course of a parent chemical or metabolite in an animal system. There are two types of pharmacokinetic models: data-based and physiologically-based. A data-based model divides the animal system into a series of compartments which, in general, do not represent real, identifiable anatomic regions of the body whereby the physiologically-based model compartments represent real anatomic regions of the body.

Physiologically Based Pharmacodynamic (PBPD) Model-A type of physiologically-based doseresponse model which quantitatively describes the relationship between target tissue dose and toxic end points. These models advance the importance of physiologically based models in that they clearly describe the biological effect (response) produced by the system following exposure to an exogenous substance. 
Physiologically Based Pharmacokinetic (PBPK) Model-Comprised of a series of compartments representing organs or tissue groups with realistic weights and blood flows. These models require a variety of physiological information: tissue volumes, blood flow rates to tissues, cardiac output, alveolar ventilation rates and, possibly membrane permeabilities. The models also utilize biochemical information such as air/blood partition coefficients, and metabolic parameters. PBPK models are also called biologically based tissue dosimetry models.

Prevalence - The number of cases of a disease or condition in a population at one point in time.

Prospective Study - A type of cohort study in which the pertinent observations are made on events occurring after the start of the study. A group is followed over time.

$\mathbf{q}_{1}{ }^{*}$ - The upper-bound estimate of the low-dose slope of the dose-response curve as determined by the multistage procedure. The $\mathrm{q}_{1}{ }^{*}$ can be used to calculate an estimate of carcinogenic potency, the incremental excess cancer risk per unit of exposure (usually $\mu \mathrm{g} / \mathrm{L}$ for water, $\mathrm{mg} / \mathrm{kg} /$ day for food, and $\mu \mathrm{g} / \mathrm{m}^{3}$ for air).

Recommended Exposure Limit (REL) - A National Institute for Occupational Safety and Health (NIOSH) time-weighted average (TWA) concentrations for up to a 10-hour workday during a 40-hour workweek.

Reference Concentration (RfC)—An estimate (with uncertainty spanning perhaps an order of magnitude) of a continuous inhalation exposure to the human population (including sensitive subgroups) that is likely to be without an appreciable risk of deleterious noncancer health effects during a lifetime. The inhalation reference concentration is for continuous inhalation exposures and is appropriately expressed in units of $\mathrm{mg} / \mathrm{m}^{3}$ or $\mathrm{ppm}$.

Reference Dose (RfD) — An estimate (with uncertainty spanning perhaps an order of magnitude) of the daily exposure of the human population to a potential hazard that is likely to be without risk of deleterious effects during a lifetime. The RfD is operationally derived from the no-observed-adverse-effect level (NOAEL-from animal and human studies) by a consistent application of uncertainty factors that reflect various types of data used to estimate RfDs and an additional modifying factor, which is based on a professional judgment of the entire database on the chemical. The RfDs are not applicable to nonthreshold effects such as cancer.

Reportable Quantity (RQ) - The quantity of a hazardous substance that is considered reportable under the Comprehensive Environmental Response, Compensation, and Liability Act (CERCLA). Reportable quantities are (1) 1 pound or greater or (2) for selected substances, an amount established by regulation either under CERCLA or under Section 311 of the Clean Water Act. Quantities are measured over a 24hour period.

Reproductive Toxicity-The occurrence of adverse effects on the reproductive system that may result from exposure to a chemical. The toxicity may be directed to the reproductive organs and/or the related endocrine system. The manifestation of such toxicity may be noted as alterations in sexual behavior, fertility, pregnancy outcomes, or modifications in other functions that are dependent on the integrity of this system. 
Retrospective Study - A type of cohort study based on a group of persons known to have been exposed at some time in the past. Data are collected from routinely recorded events, up to the time the study is undertaken. Retrospective studies are limited to causal factors that can be ascertained from existing records and/or examining survivors of the cohort.

Risk-The possibility or chance that some adverse effect will result from a given exposure to a chemical.

Risk Factor-An aspect of personal behavior or lifestyle, an environmental exposure, or an inborn or inherited characteristic, that is associated with an increased occurrence of disease or other health-related event or condition.

Risk Ratio - The ratio of the risk among persons with specific risk factors compared to the risk among persons without risk factors. A risk ratio greater than 1 indicates greater risk of disease in the exposed group compared to the unexposed.

Short-Term Exposure Limit (STEL) - The American Conference of Governmental Industrial Hygienists (ACGIH) maximum concentration to which workers can be exposed for up to 15 minutes continually. No more than four excursions are allowed per day, and there must be at least 60 minutes between exposure periods. The daily Threshold Limit Value - Time Weighted Average (TLV-TWA) may not be exceeded.

Standardized Mortality Ratio (SMR) - A ratio of the observed number of deaths and the expected number of deaths in a specific standard population.

Target Organ Toxicity-This term covers a broad range of adverse effects on target organs or physiological systems (e.g., renal, cardiovascular) extending from those arising through a single limited exposure to those assumed over a lifetime of exposure to a chemical.

Teratogen-A chemical that causes structural defects that affect the development of an organism.

Threshold Limit Value (TLV)—An American Conference of Governmental Industrial Hygienists (ACGIH) concentration of a substance to which most workers can be exposed without adverse effect. The TLV may be expressed as a Time Weighted Average (TWA), as a Short-Term Exposure Limit (STEL), or as a ceiling limit (CL).

Time-Weighted Average (TWA) - An allowable exposure concentration averaged over a normal 8-hour workday or 40-hour workweek.

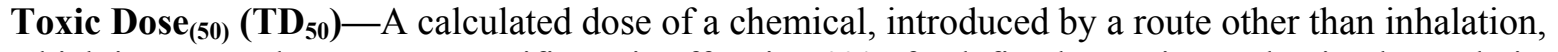
which is expected to cause a specific toxic effect in $50 \%$ of a defined experimental animal population.

Toxicokinetics - The study of the absorption, distribution and elimination of toxic compounds in the living organism. 
Uncertainty Factor (UF) - A factor used in operationally deriving the Minimal Risk Level (MRL) or Reference Dose (RfD) or Reference Concentration (RfC) from experimental data. UFs are intended to account for (1) the variation in sensitivity among the members of the human population, (2) the uncertainty in extrapolating animal data to the case of human, (3) the uncertainty in extrapolating from data obtained in a study that is of less than lifetime exposure, and (4) the uncertainty in using lowestobserved-adverse-effect level (LOAEL) data rather than no-observed-adverse-effect level (NOAEL) data. A default for each individual UF is 10; if complete certainty in data exists, a value of one can be used; however a reduced UF of three may be used on a case-by-case basis, three being the approximate logarithmic average of 10 and 1.

Xenobiotic - Any chemical that is foreign to the biological system. 


\section{APPENDIX A. ATSDR MINIMAL RISK LEVELS AND WORKSHEETS}

The Comprehensive Environmental Response, Compensation, and Liability Act (CERCLA) [42 U.S.C. 9601 et seq.], as amended by the Superfund Amendments and Reauthorization Act (SARA) [Pub. L. 99499], requires that the Agency for Toxic Substances and Disease Registry (ATSDR) develop jointly with the U.S. Environmental Protection Agency (EPA), in order of priority, a list of hazardous substances most commonly found at facilities on the CERCLA National Priorities List (NPL); prepare toxicological profiles for each substance included on the priority list of hazardous substances; and assure the initiation of a research program to fill identified data needs associated with the substances.

The toxicological profiles include an examination, summary, and interpretation of available toxicological information and epidemiologic evaluations of a hazardous substance. During the development of toxicological profiles, Minimal Risk Levels (MRLs) are derived when reliable and sufficient data exist to identify the target organ(s) of effect or the most sensitive health effect(s) for a specific duration for a given route of exposure. An MRL is an estimate of the daily human exposure to a hazardous substance that is likely to be without appreciable risk of adverse noncancer health effects over a specified duration of exposure. MRLs are based on noncancer health effects only and are not based on a consideration of cancer effects. These substance-specific estimates, which are intended to serve as screening levels, are used by ATSDR health assessors to identify contaminants and potential health effects that may be of concern at hazardous waste sites. It is important to note that MRLs are not intended to define clean-up or action levels.

MRLs are derived for hazardous substances using the no-observed-adverse-effect level/uncertainty factor approach. They are below levels that might cause adverse health effects in the people most sensitive to such chemical-induced effects. MRLs are derived for acute (1-14 days), intermediate (15-364 days), and chronic (365 days and longer) durations and for the oral and inhalation routes of exposure. Currently, MRLs for the dermal route of exposure are not derived because ATSDR has not yet identified a method suitable for this route of exposure. MRLs are generally based on the most sensitive chemical-induced end point considered to be of relevance to humans. Serious health effects (such as irreparable damage to the liver or kidneys, or birth defects) are not used as a basis for establishing MRLs. Exposure to a level above the MRL does not mean that adverse health effects will occur. 
MRLs are intended only to serve as a screening tool to help public health professionals decide where to look more closely. They may also be viewed as a mechanism to identify those hazardous waste sites that are not expected to cause adverse health effects. Most MRLs contain a degree of uncertainty because of the lack of precise toxicological information on the people who might be most sensitive (e.g., infants, elderly, nutritionally or immunologically compromised) to the effects of hazardous substances. ATSDR uses a conservative (i.e., protective) approach to address this uncertainty consistent with the public health principle of prevention. Although human data are preferred, MRLs often must be based on animal studies because relevant human studies are lacking. In the absence of evidence to the contrary, ATSDR assumes that humans are more sensitive to the effects of hazardous substance than animals and that certain persons may be particularly sensitive. Thus, the resulting MRL may be as much as a hundredfold below levels that have been shown to be nontoxic in laboratory animals.

Proposed MRLs undergo a rigorous review process: Health Effects/MRL Workgroup reviews within the Division of Toxicology, expert panel peer reviews, and agency wide MRL Workgroup reviews, with participation from other federal agencies and comments from the public. They are subject to change as new information becomes available concomitant with updating the toxicological profiles. Thus, MRLs in the most recent toxicological profiles supersede previously published levels. For additional information regarding MRLs, please contact the Division of Toxicology, Agency for Toxic Substances and Disease Registry, 1600 Clifton Road NE, Mailstop E-29, Atlanta, Georgia 30333. 


\section{MINIMAL RISK LEVEL (MRL) WORKSHEET}

Chemical Name: Permethrin

CAS Number: $\quad$ 52645-53-1

Date: $\quad$ August 25, 2003

Profile Status: Third Draft Post Public

Route: [ ] Inhalation [X] Oral

Duration: [X] Acute [ ] Intermediate [ ] Chronic

Graph Key: $\quad 20$

Species: Rat

Minimal Risk Level: $0.3 \quad[\mathrm{X}] \mathrm{mg} / \mathrm{kg} /$ day $\quad[$ ] ppm

Reference: McDaniel KL, Moser VC. 1993. Utility of a neurobehavioral screening battery for differentiating the effects of two pyrethroids, permethrin and cypermethrin. Neurotoxicol Teratol 15:7183.

Experimental design and effects noted: The acute-duration oral MRL is based on the results of a study in which the critical effect was neurological impairment in rats. Groups of Long-Evans rats (8/sex/dose) were administered permethrin (95\% purity; 50/50 cis/trans; in corn oil vehicle) in single gavage doses of $0,25,75$, or $150 \mathrm{mg} / \mathrm{kg}$. Selected rats from each dose group were subjected to FOB and motor activity assessment at 2 and 4 hours following dosing. A LOAEL of $75 \mathrm{mg} / \mathrm{kg}$ was identified for neurological impairment that included increased excitability and aggressiveness, abnormal motor movement, and decreased grip strength and motor activity. The NOAEL was $25 \mathrm{mg} / \mathrm{kg}$.

Dose and end point used for MRL derivation: $25 \mathrm{mg} / \mathrm{kg}$; multiple neurological effects.

[X] NOAEL [ ] LOAEL

Uncertainty Factors used in MRL derivation:

[ ] 10 for use of a LOAEL

[X] 10 for extrapolation from animals to humans

[X] 10 for human variability

Was a conversion factor used from $\mathrm{ppm}$ in food or water to a $\mathrm{mg} /$ body weight dose? No

If an inhalation study in animals, list conversion factors used in determining human equivalent dose: NA

Was a conversion used from intermittent to continuous exposure? No

Agency Contact (Chemical Manager): G. Daniel Todd, Ph.D. 


\section{MINIMAL RISK LEVEL (MRL) WORKSHEET}

Chemical Name: Cypermethrin

CAS Number: $\quad$ 52315-07-8

Date: $\quad$ August 25, 2003

Profile Status: Third Draft Post Public

Route: [ ] Inhalation [X] Oral

Duration: [X] Acute [ ] Intermediate [ ] Chronic

Graph Key: 21

Species: Rat

Minimal Risk Level: $0.02 \quad[\mathrm{X}] \mathrm{mg} / \mathrm{kg} / \mathrm{day} \quad[$ ] ppm

Reference: McDaniel KL, Moser VC. 1993. Utility of a neurobehavioral screening battery for differentiating the effects of two pyrethroids, permethrin and cypermethrin. Neurotoxicol Teratol 15:7183.

Experimental design and effects noted: The acute-duration oral MRL is based on the results of a study in which the critical effect was neurological impairment in rats. Groups of Long-Evans rats (8/sex/dose) were administered cypermethrin (97\% purity; $50 / 50$ cis/trans; in corn oil vehicle) in single gavage doses of $0,20,60$, or $120 \mathrm{mg} / \mathrm{kg}$. Selected rats from each dose group were subjected to FOB and motor activity assessment at 2 and 4 hours following dosing. A LOAEL of $20 \mathrm{mg} / \mathrm{kg}$ was identified for neurological impairment that included statistically significantly altered gait and decreased motor activity. A NOAEL was not established.

Dose and end point used for MRL derivation: $20 \mathrm{mg} / \mathrm{kg}$; neurological effects.

\section{[ ] NOAEL [X] LOAEL}

\section{Uncertainty Factors used in MRL derivation:}

[X] 10 for use of a LOAEL

[X] 10 for extrapolation from animals to humans

[X] 10 for human variability

Was a conversion factor used from $\mathrm{ppm}$ in food or water to a $\mathrm{mg} /$ body weight dose? No

If an inhalation study in animals, list conversion factors used in determining human equivalent dose: NA

Was a conversion used from intermittent to continuous exposure? No

Agency Contact (Chemical Manager): G. Daniel Todd, Ph.D. 


\section{MINIMAL RISK LEVEL (MRL) WORKSHEET}

Chemical Name: Cyhalothrin

CAS Number: $\quad 68085-85-8$

Date: $\quad$ August 25, 2003

Profile Status: Third Draft Post Public

Route: [ ] Inhalation [X] Oral

Duration: [X] Acute [ ] Intermediate [ ] Chronic

Graph Key: $\quad 38$

Species: Dog

Minimal Risk Level: $0.01 \quad[\mathrm{X}] \mathrm{mg} / \mathrm{kg} / \mathrm{day} \quad[$ ] ppm

Reference: EPA. 1981. Data evaluation record: Chronic toxicity (dog). Tox review 005100 (excerpt).

Experimental design and effects noted: The acute-duration oral MRL is based on the results of a study in which the critical effect was increased fluid feces (diarrhea) in dogs. Groups of 4-5-month-old male and female beagle dogs $(6 / \mathrm{sex} / \mathrm{dose})$ were administered cyhalothrin (in corn oil vehicle) in gelatin capsules at doses of $0,1.0,2.5$, or $10.0 \mathrm{mg} / \mathrm{kg} /$ day for 26 weeks. The dosing volume was $0.1 \mathrm{~mL} / \mathrm{kg}$ body weight. A dose-related increase in diarrhea was observed throughout the study, including the first week of treatment $(7,26$, and $39 \%$ greater incidences of diarrhea in low-, mid-, and high-dose dogs, respectively, relative to controls). The $7 \%$ increased incidence of diarrhea at the $1.0 \mathrm{mg} / \mathrm{kg} /$ day dose level may not be clear indication of an adverse treatment-related effect. However, the $26 \%$ increased incidence of diarrhea at $2.5 \mathrm{mg} / \mathrm{kg} /$ day is considered to represent a definitive adverse effect. Thus, $1.0 \mathrm{mg} / \mathrm{kg} /$ day is interpreted as a NOAEL and $2.5 \mathrm{mg} / \mathrm{kg} /$ day is considered a LOAEL for gastrointestinal effects. A detailed description of the test substance was not provided in the study. The acute-duration oral MRL is based on the assumption that the test substance consisted of technical-grade cyhalothrin with a purity of approximately $90 \%$.

Dose and end point used for MRL derivation: $1.0 \mathrm{mg} / \mathrm{kg} /$ day; gastrointestinal effects (diarrhea).

[X] NOAEL [ ] LOAEL

\section{Uncertainty Factors used in MRL derivation:}

[ ] 10 for use of a LOAEL

[X] 10 for extrapolation from animals to humans

[X] 10 for human variability

Was a conversion factor used from $\mathrm{ppm}$ in food or water to a $\mathrm{mg} /$ body weight dose? No

If an inhalation study in animals, list conversion factors used in determining human equivalent dose: NA

Was a conversion used from intermittent to continuous exposure? No

Agency Contact (Chemical Manager): G. Daniel Todd, Ph.D. 


\section{MINIMAL RISK LEVEL (MRL) WORKSHEET}

Chemical Name: Permethrin

CAS Number: 52645-53-1

Date: $\quad$ August 25, 2003

Profile Status: Third Draft Post Public

Route: [ ] Inhalation [X] Oral

Duration: [ ] Acute [X] Intermediate [ ] Chronic

Graph Key: $\quad 41$

Species: Rat

Minimal Risk Level: $0.2 \quad[\mathrm{X}] \mathrm{mg} / \mathrm{kg} / \mathrm{day} \quad[$ ] ppm

Reference: EPA. 1994b. Memorandum: Permethrin: Review of series 81-8ss and 82-7ss acute and subchronic neurotoxicity screen studies and a literature publication on the neurotoxicity and commentary on a special positive control study with acrylamide. U.S. Environmental Protection Agency. Office of Pesticides and Toxic Substances.

Experimental design and effects noted: The intermediate-duration oral MRL is based on the results of a study in which the critical effect was neurological impairment (tremors, impaired gait, hindlimb splay) in rats. Groups of Sprague-Dawley rats (10/sex/dose) were administered permethrin (technical grade; 50/50 cis/trans) in the diet for 13 weeks at concentrations of $0,250,1,500$, or 2,500 ppm (time-weighted average doses of $0,15.5,91.5$, or $150.4 \mathrm{mg} / \mathrm{kg} /$ day for males and $0,18.7,111.4$, or $189.7 \mathrm{mg} / \mathrm{kg} /$ day for females). Hindlimb splay was observed as early as days 38 and 18 in some 1,500-ppm males and females, respectively. Other signs of neurotoxicity in the 1,500-ppm rats first appeared between treatment days 35 and 68. Signs of neurotoxicity appeared earlier and were more prevalent in rats of the 2,500-ppm treatment group. There were no signs of neurotoxicity in rats of the 250-ppm treatment group. This study identified a LOAEL of 1,500 ppm (91.5 and $111.4 \mathrm{mg} / \mathrm{kg} /$ day in males and females, respectively) for neurotoxicity and a NOAEL of $250 \mathrm{ppm}$ (15.5 and 18.7 for males and females, respectively).

Dose and end point used for MRL derivation: $15.5 \mathrm{mg} / \mathrm{kg} /$ day; neurological effects (tremors, impaired gait, hindlimb splay).

[X] NOAEL [ ] LOAEL

Uncertainty Factors used in MRL derivation:

[ ] 10 for use of a LOAEL

[X] 10 for extrapolation from animals to humans

[X] 10 for human variability

Was a conversion factor used from $\mathrm{ppm}$ in food or water to a $\mathrm{mg} /$ body weight dose? Yes, conversion was performed by the study authors.

If an inhalation study in animals, list conversion factors used in determining human equivalent dose: NA

Was a conversion used from intermittent to continuous exposure? No

Agency Contact (Chemical Manager): G. Daniel Todd, Ph.D. 


\section{MINIMAL RISK LEVEL (MRL) WORKSHEET}

Chemical Name: Cyhalothrin

CAS Number: $\quad$ 68085-85-8

Date: $\quad$ August 25, 2003

Profile Status: Third Draft Post Public

Route: [ ] Inhalation [X] Oral

Duration: [ ] Acute $[\mathrm{X}]$ Intermediate [ ] Chronic

Graph Key: $\quad 38$

Species: Dog

\section{Minimal Risk Level: $0.01 \quad[\mathrm{X}] \mathrm{mg} / \mathrm{kg} /$ day $\quad[\mathrm{j}$ ppm}

Reference: EPA. 1981. Data evaluation record: Chronic toxicity (dog). Tox review 005100 (excerpt).

Experimental design and effects noted: The intermediate-duration oral MRL is based on the results of a study in which the critical effect was increased fluid feces (diarrhea) in dogs. Groups of 4-5-month-old male and female beagle dogs $(6 / \mathrm{sex} /$ dose) were administered cyhalothrin (in corn oil vehicle) in gelatin capsules at doses of $0,1.0,2.5$, or $10.0 \mathrm{mg} / \mathrm{kg} /$ day for 26 weeks. The dosing volume was $0.1 \mathrm{~mL} / \mathrm{kg}$ body weight. A dose-related increase in diarrhea was observed throughout the study $(7,26$, and $39 \%$ greater incidences of diarrhea in low-, mid-, and high-dose dogs, respectively, relative to controls). The 7\% increased incidence of diarrhea at the $1.0 \mathrm{mg} / \mathrm{kg} /$ day dose level may not be clear indication of an adverse treatment-related effect. However, the $26 \%$ increased incidence of diarrhea at $2.5 \mathrm{mg} / \mathrm{kg} / \mathrm{day}$ is considered to represent a definitive adverse effect. Thus, $1.0 \mathrm{mg} / \mathrm{kg} / \mathrm{day}$ is interpreted as a NOAEL and $2.5 \mathrm{mg} / \mathrm{kg} /$ day is considered a LOAEL for gastrointestinal effects. A detailed description of the test substance was not provided in the study. The intermediate-duration oral MRL is based on the assumption that the test substance consisted of technical-grade cyhalothrin with a purity of approximately $90 \%$.

Dose and end point used for MRL derivation: $1.0 \mathrm{mg} / \mathrm{kg} /$ day; gastrointestinal effects (diarrhea).

[X] NOAEL [ ] LOAEL

Uncertainty Factors used in MRL derivation:

[ ] 10 for use of a LOAEL

[X] 10 for extrapolation from animals to humans

[X] 10 for human variability

Was a conversion factor used from $\mathrm{ppm}$ in food or water to a $\mathrm{mg} /$ body weight dose? No

If an inhalation study in animals, list conversion factors used in determining human equivalent dose: NA

Was a conversion used from intermittent to continuous exposure? No

Agency Contact (Chemical Manager): G. Daniel Todd, Ph.D. 


\section{APPENDIX B. USER'S GUIDE}

\section{Chapter 1}

\section{Public Health Statement}

This chapter of the profile is a health effects summary written in non-technical language. Its intended audience is the general public especially people living in the vicinity of a hazardous waste site or chemical release. If the Public Health Statement were removed from the rest of the document, it would still communicate to the lay public essential information about the chemical.

The major headings in the Public Health Statement are useful to find specific topics of concern. The topics are written in a question and answer format. The answer to each question includes a sentence that will direct the reader to chapters in the profile that will provide more information on the given topic.

\section{Chapter 2}

\section{Relevance to Public Health}

This chapter provides a health effects summary based on evaluations of existing toxicologic, epidemiologic, and toxicokinetic information. This summary is designed to present interpretive, weightof-evidence discussions for human health end points by addressing the following questions.

1. What effects are known to occur in humans?

2. What effects observed in animals are likely to be of concern to humans?

3. What exposure conditions are likely to be of concern to humans, especially around hazardous waste sites?

The chapter covers end points in the same order they appear within the Discussion of Health Effects by Route of Exposure section, by route (inhalation, oral, dermal) and within route by effect. Human data are presented first, then animal data. Both are organized by duration (acute, intermediate, chronic). In vitro data and data from parenteral routes (intramuscular, intravenous, subcutaneous, etc.) are also considered in this chapter. If data are located in the scientific literature, a table of genotoxicity information is included.

The carcinogenic potential of the profiled substance is qualitatively evaluated, when appropriate, using existing toxicokinetic, genotoxic, and carcinogenic data. ATSDR does not currently assess cancer potency or perform cancer risk assessments. Minimal risk levels (MRLs) for noncancer end points (if derived) and the end points from which they were derived are indicated and discussed.

Limitations to existing scientific literature that prevent a satisfactory evaluation of the relevance to public health are identified in the Chapter 3 Data Needs section. 


\section{Interpretation of Minimal Risk Levels}

Where sufficient toxicologic information is available, we have derived minimal risk levels (MRLs) for inhalation and oral routes of entry at each duration of exposure (acute, intermediate, and chronic). These MRLs are not meant to support regulatory action; but to acquaint health professionals with exposure levels at which adverse health effects are not expected to occur in humans.

They should help physicians and public health officials determine the safety of a community living near a chemical emission, given the concentration of a contaminant in air or the estimated daily dose in water. MRLs are based largely on toxicological studies in animals and on reports of human occupational exposure.

MRL users should be familiar with the toxicologic information on which the number is based. Chapter 2, "Relevance to Public Health," contains basic information known about the substance. Other sections such as Chapter 3 Section 3.9, "Interactions with Other Substances," and Section 3.10, "Populations that are Unusually Susceptible" provide important supplemental information.

MRL users should also understand the MRL derivation methodology. MRLs are derived using a modified version of the risk assessment methodology the Environmental Protection Agency (EPA) provides (Barnes and Dourson 1988) to determine reference doses for lifetime exposure (RfDs).

To derive an MRL, ATSDR generally selects the most sensitive end point which, in its best judgement, represents the most sensitive human health effect for a given exposure route and duration. ATSDR cannot make this judgement or derive an MRL unless information (quantitative or qualitative) is available for all potential systemic, neurological, and developmental effects. If this information and reliable quantitative data on the chosen end point are available, ATSDR derives an MRL using the most sensitive species (when information from multiple species is available) with the highest NOAEL that does not exceed any adverse effect levels. When a NOAEL is not available, a lowest-observed-adverse-effect level (LOAEL) can be used to derive an MRL, and an uncertainty factor (UF) of 10 must be employed. Additional uncertainty factors of 10 must be used both for human variability to protect sensitive subpopulations (people who are most susceptible to the health effects caused by the substance) and for interspecies variability (extrapolation from animals to humans). In deriving an MRL, these individual uncertainty factors are multiplied together. The product is then divided into the inhalation concentration or oral dosage selected from the study. Uncertainty factors used in developing a substance-specific MRL are provided in the footnotes of the LSE Tables.

\section{Chapter 3}

\section{Health Effects}

\section{Tables and Figures for Levels of Significant Exposure (LSE)}

Tables (3-1, 3-2, and 3-3) and figures (3-1 and 3-2) are used to summarize health effects and illustrate graphically levels of exposure associated with those effects. These levels cover health effects observed at increasing dose concentrations and durations, differences in response by species, minimal risk levels (MRLs) to humans for noncancer end points, and EPA's estimated range associated with an upper- bound individual lifetime cancer risk of 1 in 10,000 to 1 in 10,000,000. Use the LSE tables and figures for a quick review of the health effects and to locate data for a specific exposure scenario. The LSE tables and figures should always be used in conjunction with the text. All entries in these tables and figures represent studies that provide reliable, quantitative estimates of No-Observed-Adverse-Effect Levels (NOAELs), Lowest-Observed-Adverse-Effect Levels (LOAELs), or Cancer Effect Levels (CELs). 
The legends presented below demonstrate the application of these tables and figures. Representative examples of LSE Table 3-1 and Figure 3-1 are shown. The numbers in the left column of the legends correspond to the numbers in the example table and figure.

\section{LEGEND}

\section{See LSE Table 3-1}

(1) Route of Exposure One of the first considerations when reviewing the toxicity of a substance using these tables and figures should be the relevant and appropriate route of exposure. When sufficient data exists, three LSE tables and two LSE figures are presented in the document. The three LSE tables present data on the three principal routes of exposure, i.e., inhalation, oral, and dermal (LSE Table 3-1, 3-2, and 3-3, respectively). LSE figures are limited to the inhalation (LSE Figure 3-1) and oral (LSE Figure 3-2) routes. Not all substances will have data on each route of exposure and will not therefore have all five of the tables and figures.

(2) Exposure Period Three exposure periods - acute (less than 15 days), intermediate (15-364 days), and chronic (365 days or more) are presented within each relevant route of exposure. In this example, an inhalation study of intermediate exposure duration is reported. For quick reference to health effects occurring from a known length of exposure, locate the applicable exposure period within the LSE table and figure.

(3) Health Effect The major categories of health effects included in LSE tables and figures are death, systemic, immunological, neurological, developmental, reproductive, and cancer. NOAELs and LOAELs can be reported in the tables and figures for all effects but cancer. Systemic effects are further defined in the "System" column of the LSE table (see key number 18).

(4) Key to Figure Each key number in the LSE table links study information to one or more data points using the same key number in the corresponding LSE figure. In this example, the study represented by key number 18 has been used to derive a NOAEL and a Less Serious LOAEL (also see the 2 "18r" data points in Figure 3-1).

(5) Species The test species, whether animal or human, are identified in this column. Chapter 2, "Relevance to Public Health," covers the relevance of animal data to human toxicity and Section 3.4, "Toxicokinetics," contains any available information on comparative toxicokinetics. Although NOAELs and LOAELs are species specific, the levels are extrapolated to equivalent human doses to derive an MRL.

(6) Exposure Frequency/Duration The duration of the study and the weekly and daily exposure regimen are provided in this column. This permits comparison of NOAELs and LOAELs from different studies. In this case (key number 18), rats were exposed to 1,1,2,2-tetrachloroethane via inhalation for 6 hours per day, 5 days per week, for 3 weeks. For a more complete review of the dosing regimen refer to the appropriate sections of the text or the original reference paper, i.e., Nitschke et al. 1981.

(7) System This column further defines the systemic effects. These systems include: respiratory, cardiovascular, gastrointestinal, hematological, musculoskeletal, hepatic, renal, and dermal/ocular. "Other" refers to any systemic effect (e.g., a decrease in body weight) not covered in these systems. In the example of key number 18, 1 systemic effect (respiratory) was investigated. 
(8) NOAEL A No-Observed-Adverse-Effect Level (NOAEL) is the highest exposure level at which no harmful effects were seen in the organ system studied. Key number 18 reports a NOAEL of $3 \mathrm{ppm}$ for the respiratory system which was used to derive an intermediate exposure, inhalation MRL of $0.005 \mathrm{ppm}$ (see footnote "b").

(9) LOAEL A Lowest-Observed-Adverse-Effect Level (LOAEL) is the lowest dose used in the study that caused a harmful health effect. LOAELs have been classified into "Less Serious" and "Serious" effects. These distinctions help readers identify the levels of exposure at which adverse health effects first appear and the gradation of effects with increasing dose. A brief description of the specific end point used to quantify the adverse effect accompanies the LOAEL. The respiratory effect reported in key number 18 (hyperplasia) is a Less serious LOAEL of $10 \mathrm{ppm}$. MRLs are not derived from Serious LOAELs.

(10) Reference The complete reference citation is given in Chapter 9 of the profile.

(11) CEL A Cancer Effect Level (CEL) is the lowest exposure level associated with the onset of carcinogenesis in experimental or epidemiologic studies. CELs are always considered serious effects. The LSE tables and figures do not contain NOAELs for cancer, but the text may report doses not causing measurable cancer increases.

(12) Footnotes Explanations of abbreviations or reference notes for data in the LSE tables are found in the footnotes. Footnote "b" indicates the NOAEL of 3 ppm in key number 18 was used to derive an MRL of $0.005 \mathrm{ppm}$.

\section{LEGEND}

\section{See Figure 3-1}

LSE figures graphically illustrate the data presented in the corresponding LSE tables. Figures help the reader quickly compare health effects according to exposure concentrations for particular exposure periods.

(13) Exposure Period The same exposure periods appear as in the LSE table. In this example, health effects observed within the intermediate and chronic exposure periods are illustrated.

(14) Health Effect These are the categories of health effects for which reliable quantitative data exists. The same health effects appear in the LSE table.

(15) Levels of Exposure concentrations or doses for each health effect in the LSE tables are graphically displayed in the LSE figures. Exposure concentration or dose is measured on the log scale "y" axis. Inhalation exposure is reported in $\mathrm{mg} / \mathrm{m}^{3}$ or $\mathrm{ppm}$ and oral exposure is reported in $\mathrm{mg} / \mathrm{kg} / \mathrm{day}$.

(16) NOAEL In this example, the open circle designated 18r identifies a NOAEL critical end point in the rat upon which an intermediate inhalation exposure MRL is based. The key number 18 corresponds to the entry in the LSE table. The dashed descending arrow indicates the extrapolation from the exposure level of $3 \mathrm{ppm}$ (see entry 18 in the Table) to the MRL of $0.005 \mathrm{ppm}$ (see footnote "b" in the LSE table).

(17) CEL Key number 38r is 1 of 3 studies for which Cancer Effect Levels were derived. The diamond symbol refers to a Cancer Effect Level for the test species-mouse. The number 38 corresponds to the entry in the LSE table. 
(18) Estimated Upper-Bound Human Cancer Risk Levels This is the range associated with the upperbound for lifetime cancer risk of 1 in 10,000 to 1 in 10,000,000. These risk levels are derived from the EPA's Human Health Assessment Group's upper-bound estimates of the slope of the cancer dose response curve at low dose levels $\left(\mathrm{q}_{1}{ }^{*}\right)$.

(19) Key to LSE Figure The Key explains the abbreviations and symbols used in the figure. 


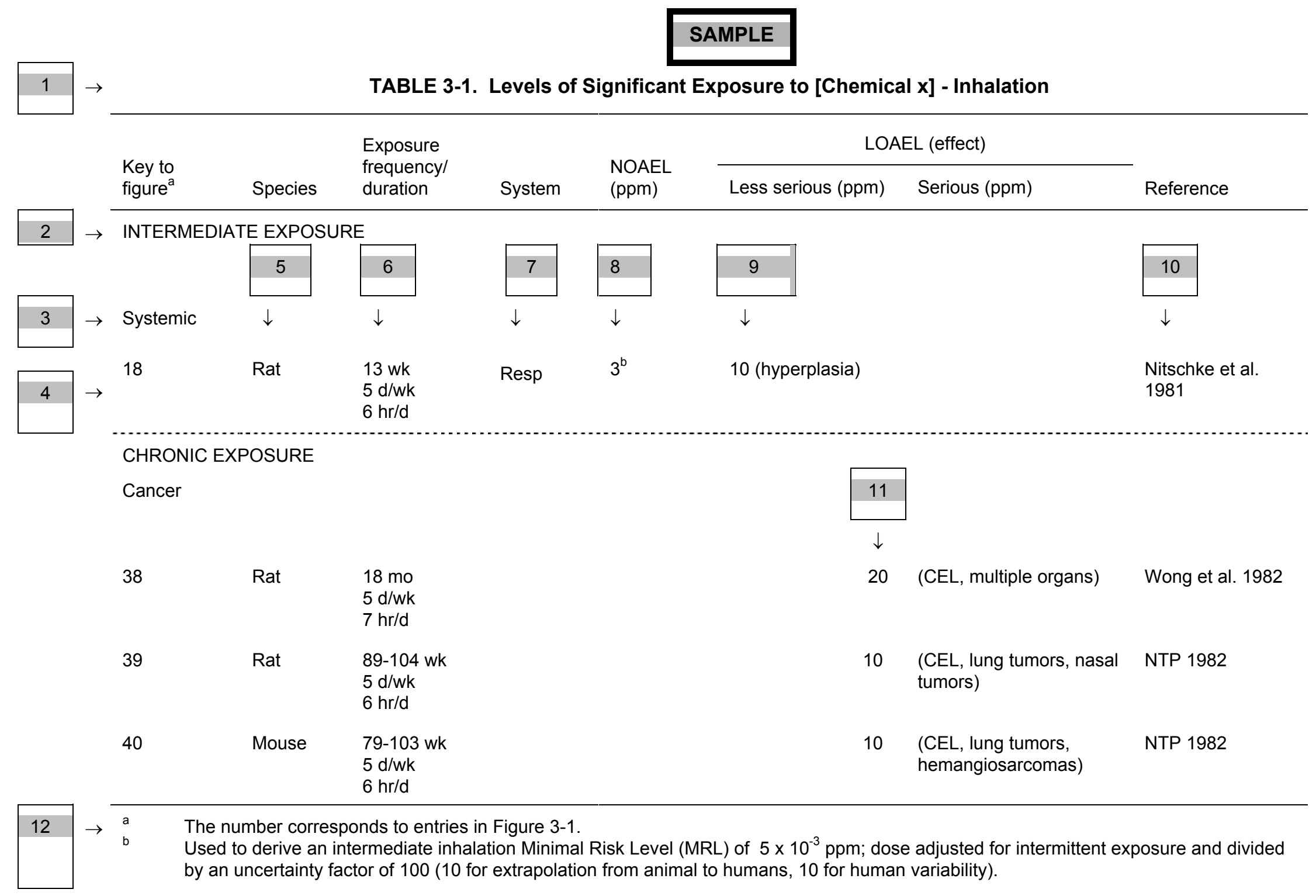




\section{SAMPLE}

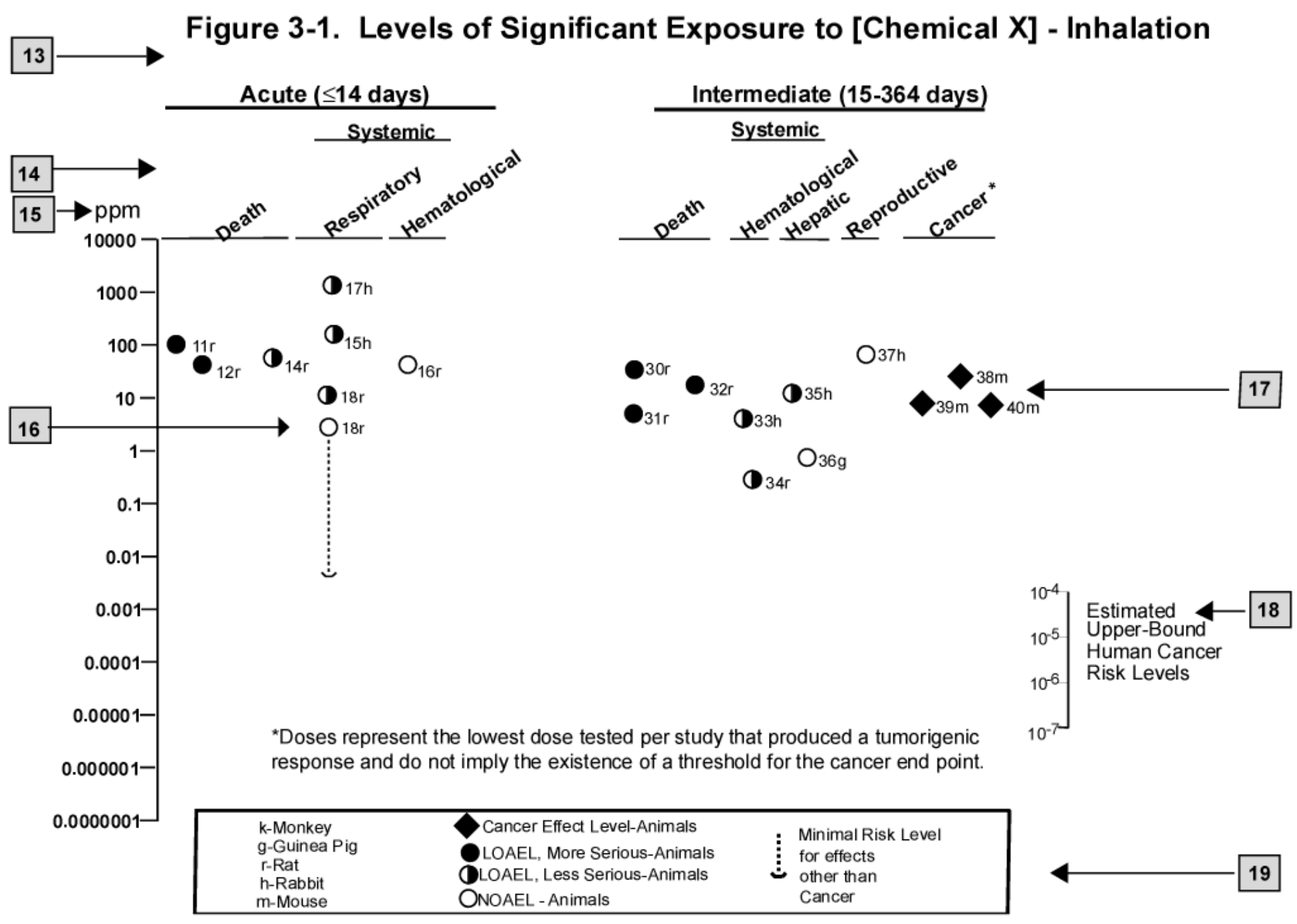




\section{APPENDIX C. ACRONYMS, ABBREVIATIONS, AND SYMBOLS}

\begin{tabular}{|c|c|}
\hline ACOEM & American College of Occupational and Environmental Medicine \\
\hline ACGIH & American Conference of Governmental Industrial Hygienists \\
\hline ADI & acceptable daily intake \\
\hline ADME & absorption, distribution, metabolism, and excretion \\
\hline AED & atomic emission detection \\
\hline AOEC & Association of Occupational and Environmental Clinics \\
\hline AFID & alkali flame ionization detector \\
\hline AFOSH & Air Force Office of Safety and Health \\
\hline ALT & alanine aminotransferase \\
\hline AML & acute myeloid leukemia \\
\hline $\mathrm{AOAC}$ & Association of Official Analytical Chemists \\
\hline AP & alkaline phosphatase \\
\hline APHA & American Public Health Association \\
\hline AST & aspartate aminotransferase \\
\hline atm & atmosphere \\
\hline ATSDR & Agency for Toxic Substances and Disease Registry \\
\hline AVDI & average daily intake \\
\hline AWQC & Ambient Water Quality Criteria \\
\hline BAT & best available technology \\
\hline $\mathrm{BCF}$ & bioconcentration factor \\
\hline BEI & Biological Exposure Index \\
\hline BSC & Board of Scientific Counselors \\
\hline $\mathrm{C}$ & centigrade \\
\hline CAA & Clean Air Act \\
\hline $\mathrm{CAG}$ & Cancer Assessment Group of the U.S. Environmental Protection Agency \\
\hline CAS & Chemical Abstract Services \\
\hline $\mathrm{CDC}$ & Centers for Disease Control and Prevention \\
\hline CEL & cancer effect level \\
\hline CELDS & Computer-Environmental Legislative Data System \\
\hline CERCLA & Comprehensive Environmental Response, Compensation, and Liability Act \\
\hline CFR & Code of Federal Regulations \\
\hline $\mathrm{Ci}$ & curie \\
\hline $\mathrm{CI}$ & confidence interval \\
\hline $\mathrm{CL}$ & ceiling limit value \\
\hline CLP & Contract Laboratory Program \\
\hline $\mathrm{cm}$ & centimeter \\
\hline CML & chronic myeloid leukemia \\
\hline CPSC & Consumer Products Safety Commission \\
\hline CWA & Clean Water Act \\
\hline $\mathrm{d}$ & day \\
\hline DCCA & cis-/trans-3-(2,2-dichlorovinyl)-2,2-dimethylcyclopropane carboxylic acid \\
\hline Derm & dermal \\
\hline DHEW & Department of Health, Education, and Welfare \\
\hline DHHS & Department of Health and Human Services \\
\hline DNA & deoxyribonucleic acid \\
\hline DOD & Department of Defense \\
\hline DOE & Department of Energy \\
\hline DOL & Department of Labor \\
\hline
\end{tabular}




\begin{tabular}{|c|c|}
\hline DOT & Department of Transportation \\
\hline DOT/UN/ & Department of Transportation/United Nations/ \\
\hline NA/IMCO & North America/International Maritime Dangerous Goods Code \\
\hline DWEL & drinking water exposure level \\
\hline ECD & electron capture detection \\
\hline ECG/EKG & electrocardiogram \\
\hline EEG & electroencephalogram \\
\hline EEGL & Emergency Exposure Guidance Level \\
\hline EPA & Environmental Protection Agency \\
\hline $\mathrm{F}$ & Fahrenheit \\
\hline $\mathrm{F}_{1}$ & first-filial generation \\
\hline FAO & Food and Agricultural Organization of the United Nations \\
\hline FDA & Food and Drug Administration \\
\hline FEMA & Federal Emergency Management Agency \\
\hline FIFRA & Federal Insecticide, Fungicide, and Rodenticide Act \\
\hline FPBA & 4-fluoro-3-phenoxybenzoic acid \\
\hline FPD & flame photometric detection \\
\hline fpm & feet per minute \\
\hline FR & Federal Register \\
\hline FSH & follicle stimulating hormone \\
\hline $\mathrm{ft}$ & foot \\
\hline $\mathrm{g}$ & gram \\
\hline GC & gas chromatography \\
\hline $\operatorname{gd}$ & gestational day \\
\hline gen & generation \\
\hline GLC & gas liquid chromatography \\
\hline GPC & gel permeation chromatography \\
\hline HPLC & high-performance liquid chromatography \\
\hline $\mathrm{hr}$ & 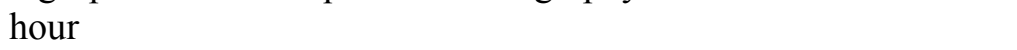 \\
\hline HRGC & high resolution gas chromatography \\
\hline HSDB & Hazardous Substance Data Bank \\
\hline IARC & International Agency for Research on Cancer \\
\hline IDLH & immediately dangerous to life and health \\
\hline ILO & International Labor Organization \\
\hline in & inch \\
\hline IRIS & Integrated Risk Information System \\
\hline $\mathrm{Kd}$ & adsorption ratio \\
\hline $\mathrm{kg}$ & kilogram \\
\hline $\mathrm{kkg}$ & metric ton \\
\hline $\mathrm{K}_{\mathrm{oc}}$ & organic carbon partition coefficient \\
\hline $\mathrm{K}_{\mathrm{ow}}$ & octanol-water partition coefficient \\
\hline $\mathrm{L}$ & liter \\
\hline $\mathrm{LC}$ & liquid chromatography \\
\hline $\mathrm{LC}_{\mathrm{Lo}}$ & lethal concentration, low \\
\hline $\mathrm{LC}_{50}$ & lethal concentration, $50 \%$ kill \\
\hline $\mathrm{LD}_{\mathrm{Lo}}$ & lethal dose, low \\
\hline $\mathrm{LD}_{50}$ & lethal dose, $50 \%$ kill \\
\hline LDH & lactic dehydrogenase \\
\hline LH & luteinizing hormone \\
\hline $\mathrm{LT}_{50}$ & lethal time, $50 \%$ kill \\
\hline LOAEL & lowest-observed-adverse-effect level \\
\hline
\end{tabular}




\begin{tabular}{|c|c|}
\hline $\begin{array}{l}\text { LSE } \\
\mathrm{m}\end{array}$ & $\begin{array}{l}\text { Levels of Significant Exposure } \\
\text { meter }\end{array}$ \\
\hline MA & trans,trans-muconic acid \\
\hline MACh & muscarinic acetylcholine \\
\hline MAL & maximum allowable level \\
\hline $\mathrm{mCi}$ & millicurie \\
\hline MCL & maximum contaminant level \\
\hline MCLG & maximum contaminant level goal \\
\hline MFO & mixed function oxidase \\
\hline $\mathrm{mg}$ & milligram \\
\hline $\min$ & minute \\
\hline $\mathrm{mL}$ & milliliter \\
\hline $\mathrm{mm}$ & millimeter \\
\hline $\mathrm{mmHg}$ & millimeters of mercury \\
\hline mmol & millimole \\
\hline mo & month \\
\hline mppcf & millions of particles per cubic foot \\
\hline MRL & Minimal Risk Level \\
\hline MS & mass spectrometry \\
\hline NAAQS & National Ambient Air Quality Standard \\
\hline NAS & National Academy of Science \\
\hline NATICH & National Air Toxics Information Clearinghouse \\
\hline NATO & North Atlantic Treaty Organization \\
\hline NCE & normochromatic erythrocytes \\
\hline $\mathrm{NCEH}$ & National Center for Environmental Health \\
\hline NCI & National Cancer Institute \\
\hline ND & not detected \\
\hline NFPA & National Fire Protection Association \\
\hline ng & nanogram \\
\hline NIEHS & National Institute of Environmental Health Sciences \\
\hline NIOSH & National Institute for Occupational Safety and Health \\
\hline NIOSHTIC & NIOSH's Computerized Information Retrieval System \\
\hline NLM & National Library of Medicine \\
\hline $\mathrm{nm}$ & nanometer \\
\hline $\begin{array}{l}\text { NHANES } \\
\text { nmol }\end{array}$ & $\begin{array}{l}\text { National Health and Nutrition Examination Survey } \\
\text { nanomole }\end{array}$ \\
\hline NOAEL & no-observed-adverse-effect level \\
\hline NOES & National Occupational Exposure Survey \\
\hline NOHS & National Occupational Hazard Survey \\
\hline NPD & nitrogen phosphorus detection \\
\hline NPDES & National Pollutant Discharge Elimination System \\
\hline NPL & National Priorities List \\
\hline NR & not reported \\
\hline NRC & National Research Council \\
\hline NS & not specified \\
\hline NSPS & New Source Performance Standards \\
\hline NTIS & National Technical Information Service \\
\hline NTP & National Toxicology Program \\
\hline ODW & Office of Drinking Water, EPA \\
\hline OERR & Office of Emergency and Remedial Response, EPA \\
\hline $\mathrm{OHM} / \mathrm{TADS}$ & Oil and Hazardous Materials/Technical Assistance Dat \\
\hline
\end{tabular}




\begin{tabular}{|c|c|}
\hline OPP & Office of Pesticide Programs, EPA \\
\hline OPPTS & Office of Prevention, Pesticides and Toxic Substances, EPA \\
\hline OPPT & Office of Pollution Prevention and Toxics, EPA \\
\hline OR & odds ratio \\
\hline OSHA & Occupational Safety and Health Administration \\
\hline OSW & Office of Solid Waste, EPA \\
\hline OTS & Office of Toxic Substances \\
\hline OW & Office of Water \\
\hline OWRS & Office of Water Regulations and Standards, EPA \\
\hline PAH & polycyclic aromatic hydrocarbon \\
\hline PBPD & physiologically based pharmacodynamic \\
\hline PBPK & physiologically based pharmacokinetic \\
\hline PCE & polychromatic erythrocytes \\
\hline PEL & permissible exposure limit \\
\hline pg & picogram \\
\hline PHS & Public Health Service \\
\hline PID & photo ionization detector \\
\hline pmol & picomole \\
\hline PMR & proportionate mortality ratio \\
\hline $\mathrm{ppb}$ & parts per billion \\
\hline ppm & parts per million \\
\hline ppt & parts per trillion \\
\hline PSNS & pretreatment standards for new sources \\
\hline $\mathrm{RBC}$ & red blood cell \\
\hline REL & recommended exposure level/limit \\
\hline $\mathrm{RfC}$ & reference concentration \\
\hline RfD & reference dose \\
\hline RNA & ribonucleic acid \\
\hline RTECS & Registry of Toxic Effects of Chemical Substances \\
\hline RQ & reportable quantity \\
\hline SARA & Superfund Amendments and Reauthorization Act \\
\hline SCE & sister chromatid exchange \\
\hline $\sec$ & second \\
\hline SGOT & serum glutamic oxaloacetic transaminase \\
\hline SGPT & serum glutamic pyruvic transaminase \\
\hline SIC & standard industrial classification \\
\hline SIM & selected ion monitoring \\
\hline SMCL & secondary maximum contaminant level \\
\hline SMR & standardized mortality ratio \\
\hline SNARL & suggested no adverse response level \\
\hline SPEGL & Short-Term Public Emergency Guidance Level \\
\hline STEL & short term exposure limit \\
\hline STORET & Storage and Retrieval \\
\hline $\mathrm{TD}_{50}$ & toxic dose, $50 \%$ specific toxic effect \\
\hline TLV & threshold limit value \\
\hline TOC & total organic carbon \\
\hline TPQ & threshold planning quantity \\
\hline TRI & Toxics Release Inventory \\
\hline TSCA & Toxic Substances Control Act \\
\hline TWA & time-weighted average \\
\hline UF & uncertainty factor \\
\hline
\end{tabular}




\begin{tabular}{ll} 
U.S. & United States \\
USDA & United States Department of Agriculture \\
USGS & United States Geological Survey \\
VOC & volatile organic compound \\
WBC & white blood cell \\
wk & week \\
WHO & World Health Organization \\
yr & year \\
& \\
$>$ & greater than \\
$\geq$ & greater than or equal to \\
$=$ & equal to \\
$<$ & less than \\
$\leq$ & less than or equal to \\
$\%$ & percent \\
$\alpha$ & alpha \\
$\beta$ & beta \\
$\gamma$ & gamma \\
$\delta$ & delta \\
$\mu \mathrm{m}$ & micrometer \\
$\mu \mathrm{g}$ & microgram \\
$\mathrm{q}_{1}{ }^{*}$ & cancer slope factor \\
- & negative \\
+ & positive \\
$(+)$ & weakly positive result \\
$(-)$ & weakly negative result \\
\hline &
\end{tabular}



